\author{
UNIVERSIDADE DE SÃO PAULO \\ ESCOLA DE ENGENHARIA DE SÃO CARLOS \\ Departamento de Engenharia de Estruturas
}

JONAS BENEDETT DORR

\title{
MODELOS NUMÉRICOS DE PILARES DE AÇO EM SITUAÇÃO DE INCÊNDIO CONSIDERANDO A INFLUÊNCIA DA RESTRIÇÃO AXIAL
}

São Carlos - SP

2010 



\section{JONAS BENEDETT DORR}

Modelos numéricos de pilares de aço em situação de incêndio considerando a influência da restrição axial

Dissertação apresentada à Escola de Engenharia de São Carlos como parte dos requisitos necessários para obtenção do Título de Mestre em Engenharia de Estruturas.

Área de concentração: Estruturas Metálicas Orientador: Prof. Dr. Jorge Munaiar Neto 
AUTORIZO A REPRODUÇÃO E DIVULGAÇÃO TOTAL OU PARCIAL DESTE TRABALHO, POR QUALQUER MEIO CONVENCIONAL OU ELETRÔNICO, PARA FINS DE ESTUDO E PESQUISA, DESDE QUE CITADA A FONTE.

Ficha catalográfica preparada pela Seção de Tratamento da Informação do Serviço de Biblioteca - EESC/USP

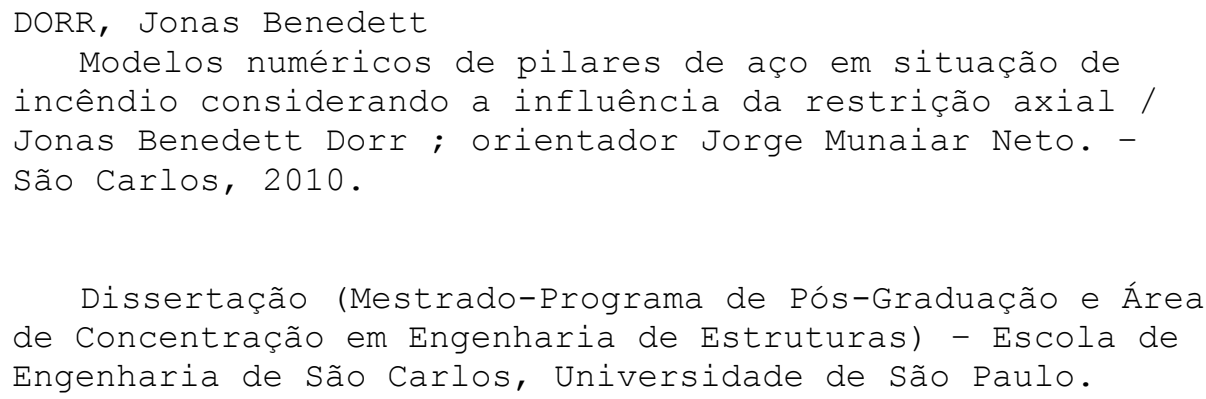

Dissertação (Mestrado-Programa de Pós-Graduação e Área de Concentração em Engenharia de Estruturas) - Escola de Engenharia de São Carlos, Universidade de São Paulo.

1. Pilar de Aço. 2.Incêndio. 3. Restrição Axial. 4. Modelagem Numérica. 5. ANSYS. 
FOLHA DE JULGAMENTO

Candidato: Engenheiro JONAS BENEDETT DORR.

Dissertação defendida e julgada em 11.11.2010 perante a Comissão Julgadora:

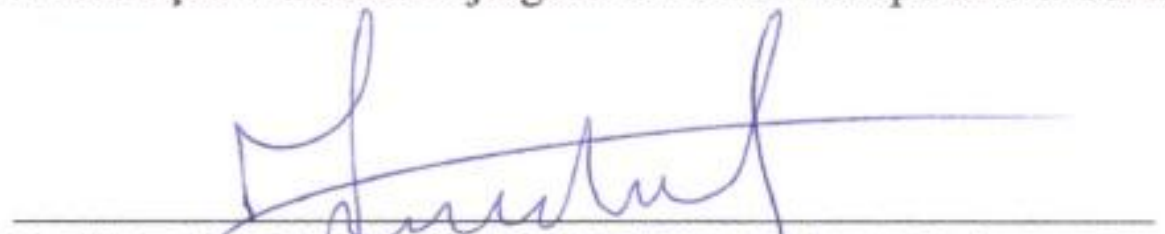

Prof. Dr. JORGE MUNAIAR NETO - (Orientador)

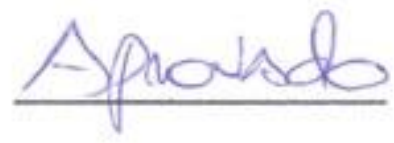

(Escola de Engentaria de São Carlos/USP)

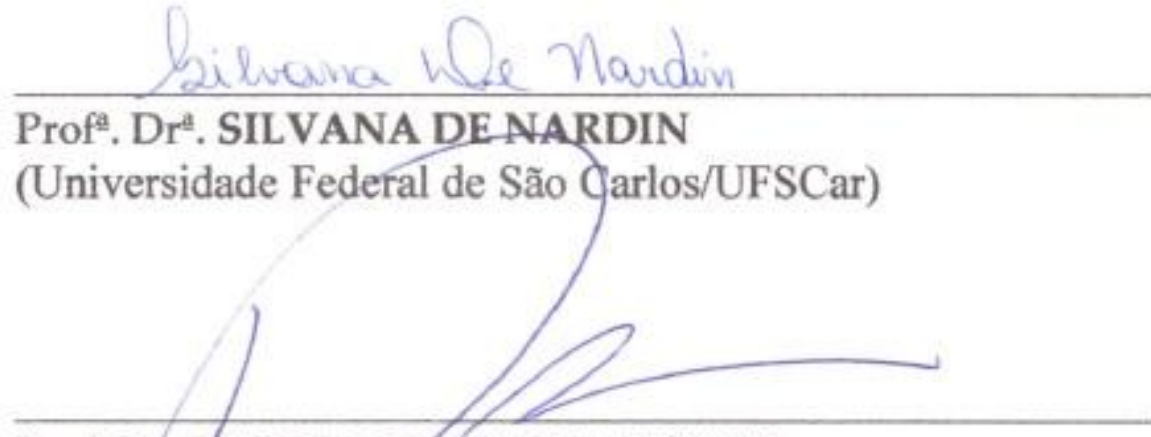

Prof. Dr. VALDIR PIGNATTA E SILVA

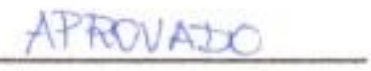

(Escola PolitécnicaUSP)
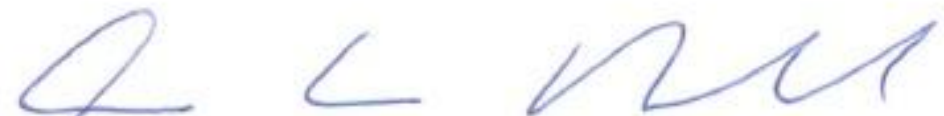

Pyof. Associado MARCIO ANTONIO RAMALHO

Coordenador do Programa de Pós-Graduação em

Engenharia Civil (Engenharia de Estruturas)

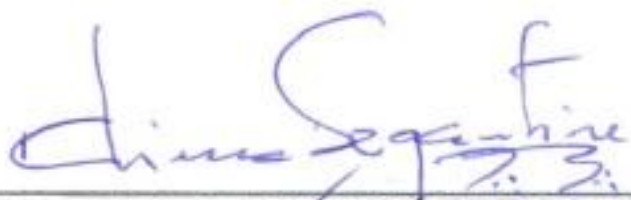

Prof. Associado PAU LO CESAR LIMA SEGANTINE

Suplente do Presidente da Comissão de Pós-Graduação 

Aos meus pais Ivori e Sandra e ao meu irmão Jéfer dedico esse trabalho com muito carinho e gratidão. 



\section{AGRADECIMENTOS}

Aos meus pais Ivori e Sandra e ao meu irmão Jéfer pela paciência, compreensão, apoio e privação de minha presença e distância de casa por tanto tempo.

Ao Professor Jorge Munaiar Neto pela confiança, paciência, incentivo e por todos os conhecimentos transmitidos na realização desse trabalho.

Aos professores José Jairo de Sáles e Valdir Pignatta e Silva pelas importantes contribuições no exame de qualificação e ao longo do desenvolvimento desse trabalho.

Ao Departamento de Engenharia de Estruturas (SET) pela estrutura, aos professores pelos conhecimentos passados durante esses meses (anos) de mestrado e aos funcionários pela disposição.

À CAPES - Coordenação de Aperfeiçoamento de Pessoal de Nível Superior, pela bolsa concedida por 24 meses, cujo financiamento foi de primordial importância para a realização desta pós-graduação.

Ao Conselho Nacional de Pesquisa e Desenvolvimento Científico, CNPq e ao Departamento de Engenharia de Estruturas SET - EESC - USP.

Aos professores e às escolas do ensino fundamental pelo bom encaminhamento e aos professores e escola (La Salle-Too) de ensino médio, onde tive ótima formação escolar e pessoal.

Aos meus amigos de graduação na Universidade Estadual de Maringá.

À Universidade Estadual de Maringá, ao Departamento de Engenharia Civil e todos os seus professores.

Aos amigos de Pós-Graduação que deram todo o apoio necessário nos momentos difíceis e nas horas de descontração. Àqueles ingressantes comigo em 2008, aos anteriores e posteriores, enfim, todos que compartilharam o mesmo ambiente de trabalho e estudo. 
À Cátia Costa e Silva, pela amizade verdadeira e pelas ajudas nas traduções de artigos, convites ao cinema, e tantos outros.

Ao Francisco Quim, companheiro de sala no mestrado, baladas e no novo emprego.

À Érica Kimura, por estar sempre disposta a ajudar a todos, pelos ensinamentos no ANSYS, ajuda na elaboração da pesquisa e construção deste texto e inúmeras outras ajudas.

Ao Dênis Delázari, pela ajuda em todos os momentos difíceis e auxílio incondicional nos momentos de necessidade.

Ao Dr. Jony e Dra. Simone.

Aos engenheiros Luiz Aurélio e Nelson Covas da TQS Informática, por acolherem em meu primeiro emprego na melhor empresa que poderia imaginar iniciar carreira. 
"Dificuldades e obstáculos são fontes valiosas de saúde e força para qualquer sociedade."

"Penso noventa e nove vezes e nada descubro; deixo de pensar, mergulho em profundo silêncio - e eis que a verdade me é revelada."

Albert Einstein 

DORR, J. B. Modelos numéricos de pilares de aço em situação de incêndio considerando a influência da restrição axial. 2010. 210p. Dissertação (mestrado) Departamento de Engenharia de Estruturas, Escola de Engenharia de São Carlos, Universidade de São Paulo, São Carlos, São Paulo. 2010.

Dentro do conjunto de aspectos relacionados à elaboração de projetos em estruturas de aço e mistas de aço e concreto, destaca-se como de grande importância e interesse, para fins de dimensionamento, a consideração de elementos estruturais submetidos a temperaturas elevadas. Nesse sentido, o presente trabalho tem como objetivo principal propor a construção de modelos numéricos tridimensionais de pilares de aço pertencentes a sistemas estruturais correntes da construção civil, para análise em situação de incêndio, com vistas a simular numericamente a evolução dos níveis de temperatura ao longo do tempo com posterior acoplamento termoestrutural. Considera-se uma análise paramétrica com vista a variar as restrições axiais totais e parciais da barra, no referente aos deslocamentos axiais, contemplando desde a situação de extremidade livre até a restrição completa em resposta à consideração de apoio do tipo fixo, por exemplo. Os resultados numéricos são comparados a ensaios experimentais de outros autores, bem como com outros trabalhos numéricos já publicados. São obtidas respostas de deslocamentos axiais e laterais do modelo termoestrutural para diversas disposições de paredes em relação ao perfil, bem como gráficos do acréscimo de força axial introduzido no sistema pela restrição axial. Os estudos aqui realizados poderão servir como base para novas pesquisas tanto no campo numérico quanto experimental, assim como para futuras revisões da ABNT NBR 14323:1999, buscando contemplar situações de interesse não abordadas neste documento normativo. Os resultados da pesquisa apontam que a consideração do campo térmico com a inclusão da alvenaria no modelo termoestrutural pode melhorar consideravelmente o desempenho do elemento estrutural em situação de incêndio.

Palavras-chave: Pilar de aço. Restrição axial. Incêndio. Análise térmica. Análise numérica. 



\section{ABSTRACT}

\section{DORR, J. B. Numerical models of steel columns under fire condition considering}

the axial restraint. 2010. 210p. Dissertation (master) - Structural Engineering Department, Engineering School of São Carlos, University of Sao Paulo, Sao Carlos, Sao Paulo, Brazil. 2010.

Within the set of aspects related to the development of researches in steel and composite steel and concrete structures, stands out with great importance and interest, aiming to dimension, the consideration of structural elements subjected to high temperatures. In this way, the present work has as main objective to propose the construction of three-dimensional numerical models of steel columns that belong to current structural systems of civil construction, for examination in fire situation, aiming to simulate numerically the evolution of temperature levels throughout of time with later termoestrutural coupling. It will be considered a parametric analysis in order to vary the total and partial axial restraint in respect to the axial displacements, since the free end situation until the complete restriction in response to the consideration of support for the fixed type, for example. The numerical results are compared to experimental tests made by other authors, as well as with others numerical works already published. Answers are obtained from axial and lateral displacements of the thermo structural model to many displacement of wall related to the profile, also charts of adding axial force introduced into the system by the axial restraint. The results of the current research could serve as a basis for further research in both the numerical field or experimental, also for future revisions of ABNT NBR 14323:1999, aiming to see situations of interest not studied in the same normative document. The results of this work show that consideration of thermal field with the inclusion of masonry in the thermo structural model can, significantly, improve the performance of the structural element in a fire situation.

Key-words: Steel column. Axial restraint. Fire. Thermal analysis. Numerical analysis. 



\section{LISTA DE TABELAS}

Tabela 3.1 - Tempo requerido de resistência ao fogo..........................................................51

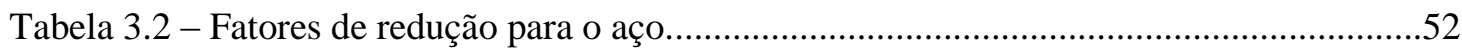

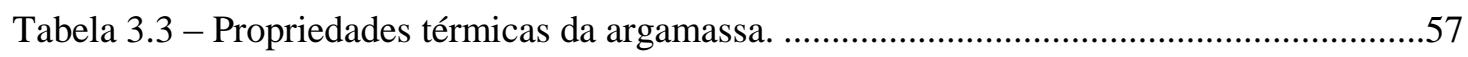

Tabela 4.1 - Coeficiente de instabilidade K para barras isoladas. ...........................................63

Tabela 5.1 - Tipo de elementos compatíveis para análises acopladas. ......................................87

Tabela 5.2 - Configuração relevante do computador utilizado................................................92

Tabela 5.3 - Parâmetros para as seções analisadas. .............................................................92

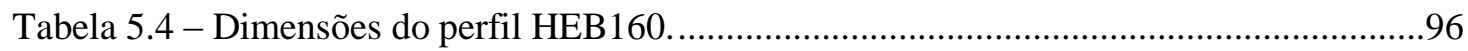

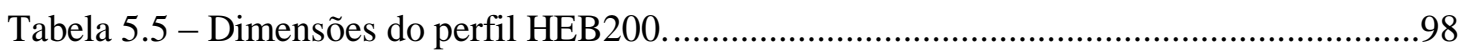

Tabela 5.6 - Parâmetros do polinômio curva tipo 1................................................................101

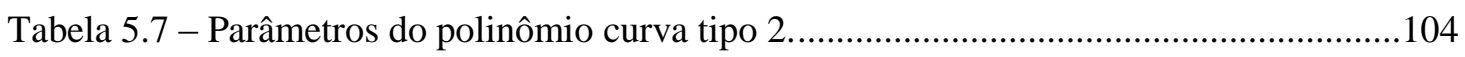

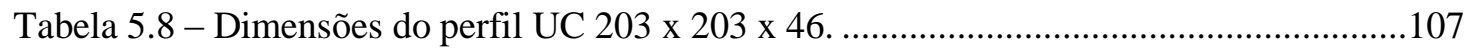

Tabela 5.9 - Resultados experimentais e numéricos............................................................113

Tabela 5.10 - Detalhes dimensionais dos elementos e nós para diferentes malhas testadas no modelo com paredes nas mesas. 116

Tabela 6.1 - Dimensões do perfil UC 203 x 203 x 46. 123

Tabela 6.2 - Grau de restrição e constantes elásticas adotadas na restrição axial. .134

Tabela 6.3 - Grau de restrição e constantes elásticas adotadas na restrição axial em Rodrigues (2000) para o perfil 50x8 $\mathrm{mm}^{2}$.

Tabela 6.4 - Resultados experimentais e numéricos........................................................... 141

Tabela 6.5 - Dimensões do perfil HEA100.

Tabela 6.6 - Resultados de tempo crítico e temperaturas críticas das análises numéricas do modelo de pilar isolado.

Tabela 6.7 - Resultados de tempo e temperaturas críticas das análises numéricas do modelo com paredes nas mesas.

Tabela 6.8 - Resultados de tempo e temperaturas críticas das análises numéricas do modelo com paredes na alma. 


\section{SUMÁRIO}

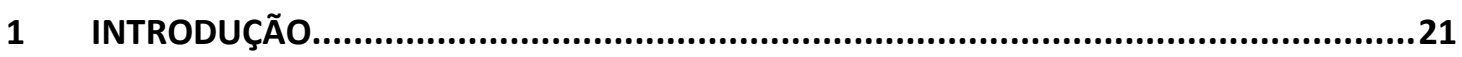

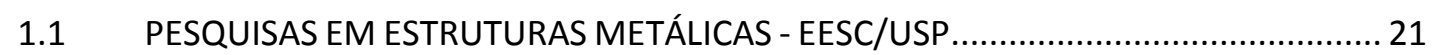

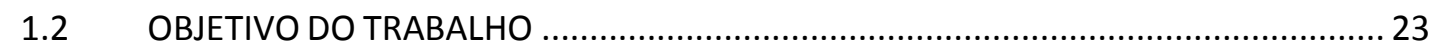

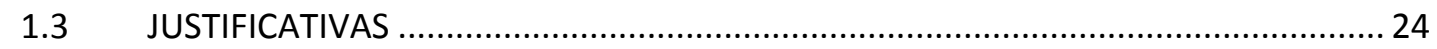

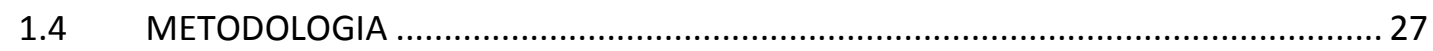

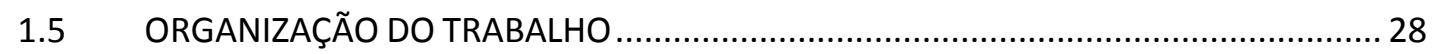

2 SOBRE A AÇÃO TÉRMICA EM ESTRUTURAS METÁLICAS ..........................................31

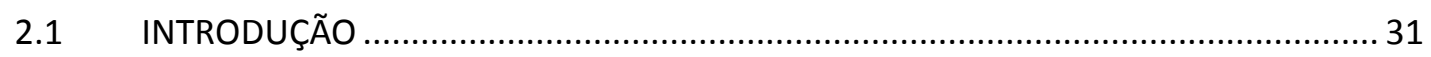

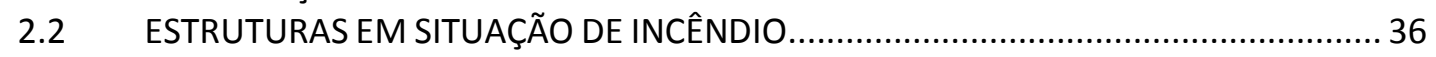

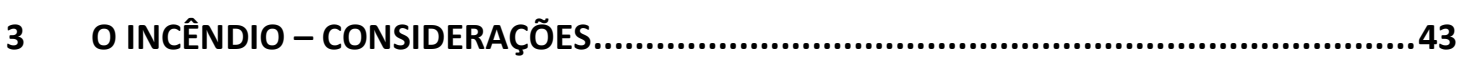

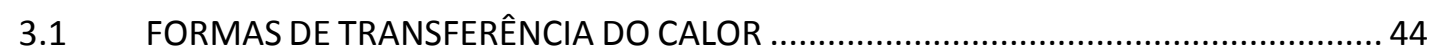

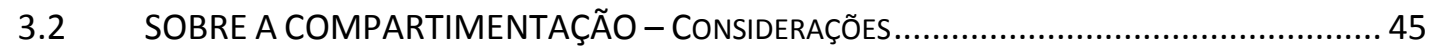

3.3 MODELOS DE INCÊNDIO - CURVAS TEMPO X TEMPERATURA .......................................... 46

3.4 TEMPO REQUERIDO DE RESISTÊNCIA AO FOGO - TRRF .......................................... 51

3.5 PROPRIEDADES MECÂNICAS E FÍSICAS DO AÇO SOB TEMPERATURAS ELEVADAS .. 52

3.5.1 Resistência ao escoamento e módulo de elasticidade ........................................5 52

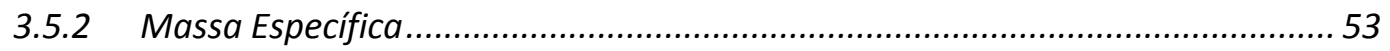

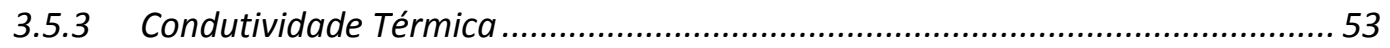

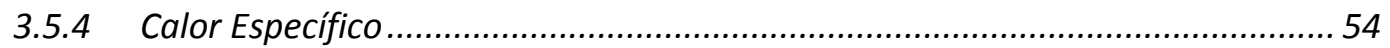

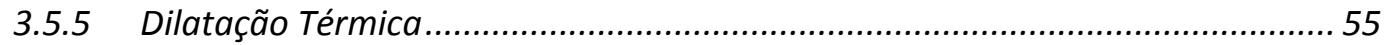

3.6 ARGAMASSA PARA REVESTIMENTO - PROPRIEDADES ........................................... 57

4 RESTRIÇÃO AXIAL E DEFORMAÇÕES TÉRMICAS - CONSIDERAÇÕES.............................59

4.1 COMENTÁRIOS PRELIMINARES ……….............................................................. 59

4.2 ANÁLISE DA DILATAÇÃO TÉRMICA CONSIDERANDO EXTREMIDADES EM APOIOS INDESLOCÁVEIS

4.3 ANÁLISE DA DILATAÇÃO TÉRMICA CONSIDERANDO EXTREMIDADES EM APOIOS

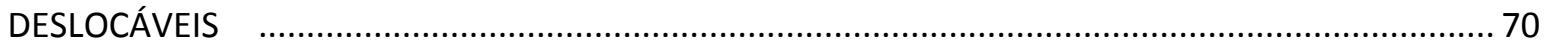

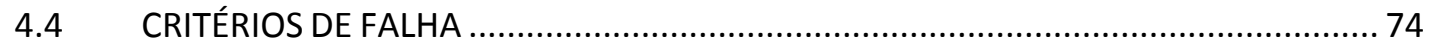

5 ANÁLISE TÉRMICA - MODELOS PROPOSTOS, VALIDAÇÃO E RESULTADOS ...................81

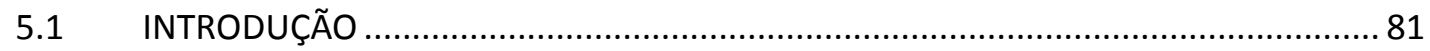

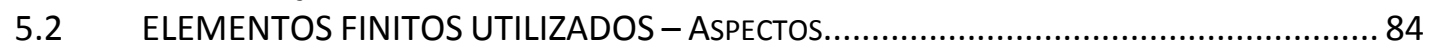

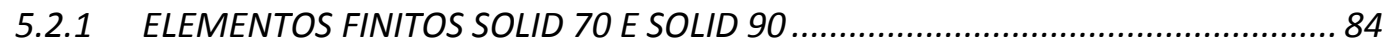

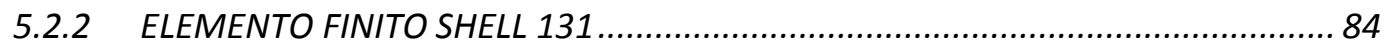

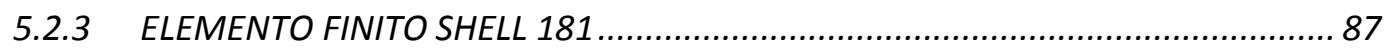

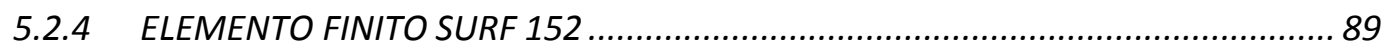

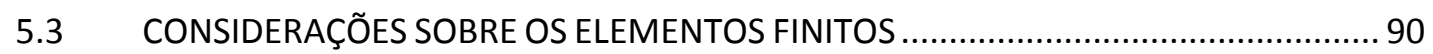

5.4 MICROCOMPUTADOR UTILIZADO - CONFIGURAÇÃO …........................................ 91

5.5 VALIDAÇÃO DE RESULTADOS TÉRMICOS - "EXPERIMENTAL X SUPERTEMPCALC X

ANSYS"

5.5.1 Perfil HEB160 - paredes em contato com as mesas........................................ 96

5.5.2 Perfil HEB200 - paredes em contato com as mesas....................................... 97

5.5.3 Perfil HEB200 - paredes em contato com a alma ............................................ 104

5.6 COMPARAÇÃO DE RESULTADOS TÉRMICOS OBTIDOS VIA STC E ANSYS ................ 107

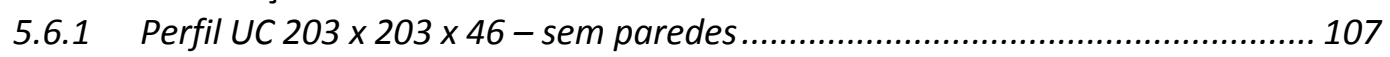

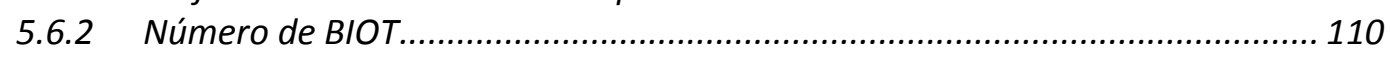


5.6.3 Comparações complementares .............................................................. 113

5.7 RESULTADOS DA ANÁLISE TÉRMICA REALIZADA PARA O PERFIL UC 203 X 203 X 46....

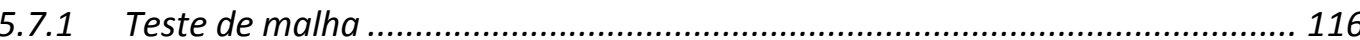

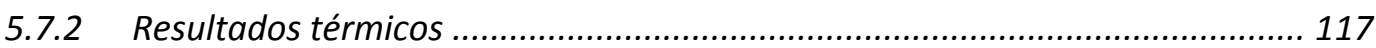

6 ANÁLISE TERMOESTRUTURAL - MODELOS PROPOSTOS, VALIDAÇÃO E RESULTADOS ...

6.1 ANÁLISE E VALIDAÇÃO EM TEMPERATURA AMBIENTE ......................................... 119

6.2 ANÁLISE E VALIDAÇÃO TERMOESTRUTURAL “SEM" RESTRIÇÃO AXIAL ................. 122

6.2.1 Pilar isolado com emissividade 0,5 .......................................................... 125

6.2.2 Pilar com paredes nas mesas e emissividade 0,5 ......................................... 127

6.2.3 Pilar com paredes na alma e emissividade 0,5............................................ 131

6.3 ANÁLISE E VALIDAÇÃO TERMOESTRUTURAL “COM” RESTRIÇÃO AXIAL ................ 133

6.3.1 Restrição axial com base em Rodrigues (2000).............................................. 134

6.3.2 Restrição axial com base em Franssen (2000)............................................ 141

6.4 RESULTADOS DOS MODELOS TERMOESTRUTURAIS: EMISSIVIDADE IGUAL A 0,7 146

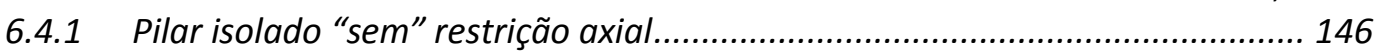

6.4.2 Pilar isolado "com" restrição axial .................................................................. 149

6.4.3 Pilar com paredes em contato com as mesas "sem" restrição axial................. 154

6.4.4 Pilar com paredes em contato com as mesas "com" restrição axial................. 158

6.4.5 Pilar com paredes em contato com a alma "sem" restrição axial .................... 164

6.4.6 Pilar com paredes em contato com a alma "com" restrição axial ................... 170

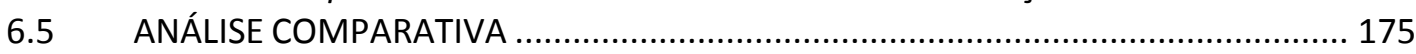

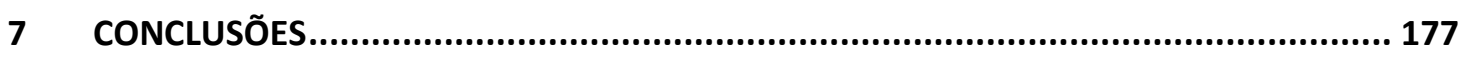

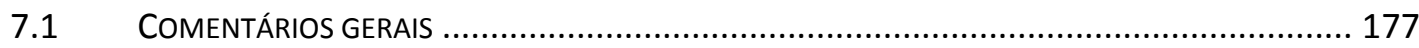

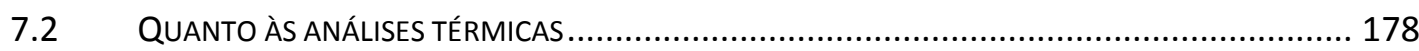

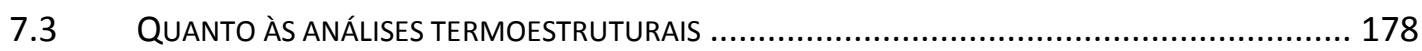

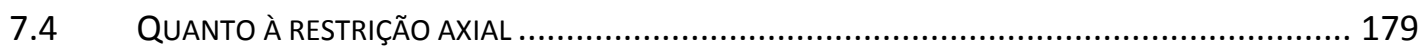

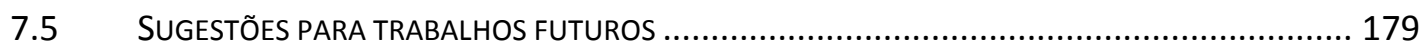

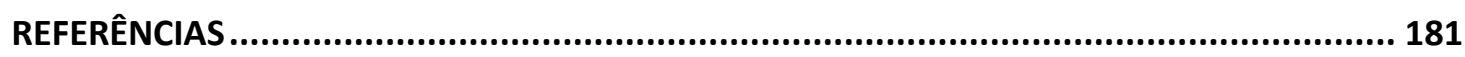

APÊNDICE A - GRÁFICOS DO MODELO SEM PAREDES EM CONTATO COM O PERFIL COM

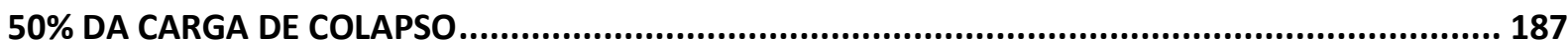

APÊNDICE B - GRÁFICOS DO MODELO SEM PAREDES EM CONTATO COM O PERFIL COM

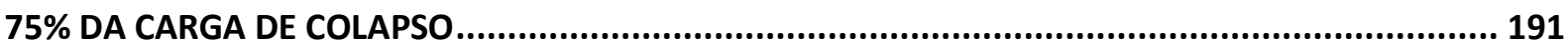

APÊNDICE C - GRÁFICOS DO MODELO COM PAREDES NAS MESAS COM 50\% DA CARGA DE COLAPSO 195

APÊNDICE D - GRÁFICOS DO MODELO COM PAREDES NAS MESAS COM 75\% DA CARGA DE COLAPSO 199

APÊNDICE E - GRÁFICOS DO MODELO COM PAREDES NA ALMA COM 50\% DA CARGA DE COLAPSO 203

APÊNDICE F - GRÁFICOS DO MODELO COM PAREDES NA ALMA COM 75\% DA CARGA DE COLAPSO 



\section{INTRODUÇÃO}

\subsection{PESQUISAS EM ESTRUTURAS METÁLICAS - EESC/USP}

A Escola de Engenharia de São Carlos da Universidade de São Paulo, desde a sua fundação em 1953, sempre se destacou no campo das Estruturas Metálicas com vistas principalmente à formação de seus alunos de graduação e de pós-graduação, com dissertações e teses concluídas, bem como trabalhos publicados em eventos nacionais e internacionais. Passou, a partir de meados de 2000, a incluir em seu acervo trabalhos inseridos no tema voltado ao estudo de estruturas em situação de incêndio. Nesse mesmo sentido, a área de conhecimento em destaque tem por objetivo dar continuidade às pesquisas em estruturas de aço em situação de incêndio, somando-a àquelas já existentes e com trabalhos em andamento.

Atualmente, no Departamento de Engenharia de Estruturas da EESC/USP, se encontram inseridos trabalhos já concluídos e em andamento, em níveis de mestrado e doutorado, como consequência da participação de docentes da EESC/USP, e a colaboração de pesquisadores de outras instituições. No contexto das estruturas de aço em situação de incêndio, foram abordados temas referentes aos perfis formados a frio, às barras mistas de aço e concreto e análise térmica de seções transversais e de elementos estruturais, dentro do campo da modelagem numérica considerando a elevação de temperatura, tais como:

a-) Kirchhof (2004): Trabalho de mestrado intitulado "Uma contribuição ao estudo de vigas mistas aço-concreto simplesmente apoiadas em temperatura ambiente e em situação de incêndio", o qual abordou estudos sobre o comportamento de vigas mistas, em temperatura ambiente e em situação de incêndio, por meio da elaboração de modelos numéricos construídos no ABAQUS 6.3.1;

b-) Mendes (2004): Trabalho de mestrado intitulado "Estudo teórico sobre perfis formados a frio em situação de incêndio", fez breve histórico sobre estruturas de aço em situação de 
incêndio, sobre perfis formados a frio em temperatura ambiente e em situação de incêndio, além de apresentar tipos de revestimentos térmicos e suas aplicações. No mesmo trabalho, foi sugerida uma proposta, ainda que preliminar, para o dimensionamento de perfis formados a frio em situação de incêndio, por meio de adaptações referentes às prescrições da ABNT NBR 14762:2001;

c-) Regobello (2007): Trabalho de mestrado intitulado "Análise numérica de seções transversais e de elementos estruturais de aço e mistos de aço e concreto em situação de incêndio", com financiamento FAPESP, no qual foram construidos modelos numéricos de seções transversais de elementos estruturais de aço, mistos de aço e concreto, e de madeira, para análise em situação de incêndio;

d-) Santos (2009): Trabalho de mestrado intitulado "Modelos numéricos de pilares mistos curtos de seções circulares de aço preenchidos com concreto em situação de incêndio", em que foi realizado estudo numérico com a utilização da mesma ferramenta computacional utilizada em Regobello (2007) e de onde serão seguidas estratégias para a criação do modelo como, por exemplo, o acoplamento de nós, com o objetivo de garantir a transferência de calor entre a parede de aço e o interior de concreto;

e-) Kimura (2009): Trabalho de mestrado intitulado "Análise termo-estrutural de pilares de aço em situação de incêndio", em que a compartimentação do incêndio e o efeito do aquecimento não uniforme da seção de pilares de aço foram estudados, bem como o efeito da não linearidade geométrica global inicial e o sentido desta em relação à fonte de calor como mostra a Figura 1.1.

A pesquisa realizada e apresentada em Kimura (2009) merece destaque, uma vez que o presente trabalho consiste de continuidade das análises desenvolvidas na última referência. $\mathrm{O}$ trabalho citado realiza uma série de testes no intuito de validar o código computacional ANSYS. Posteriormente procederam-se as análises estruturais em temperatura ambiente e análises térmicas acopladas com o objetivo de representar o comportamento dos elementos sob diversas situações e configurações, verificando se as prescrições normativas prevêm, com segurança, esse comportamento. 

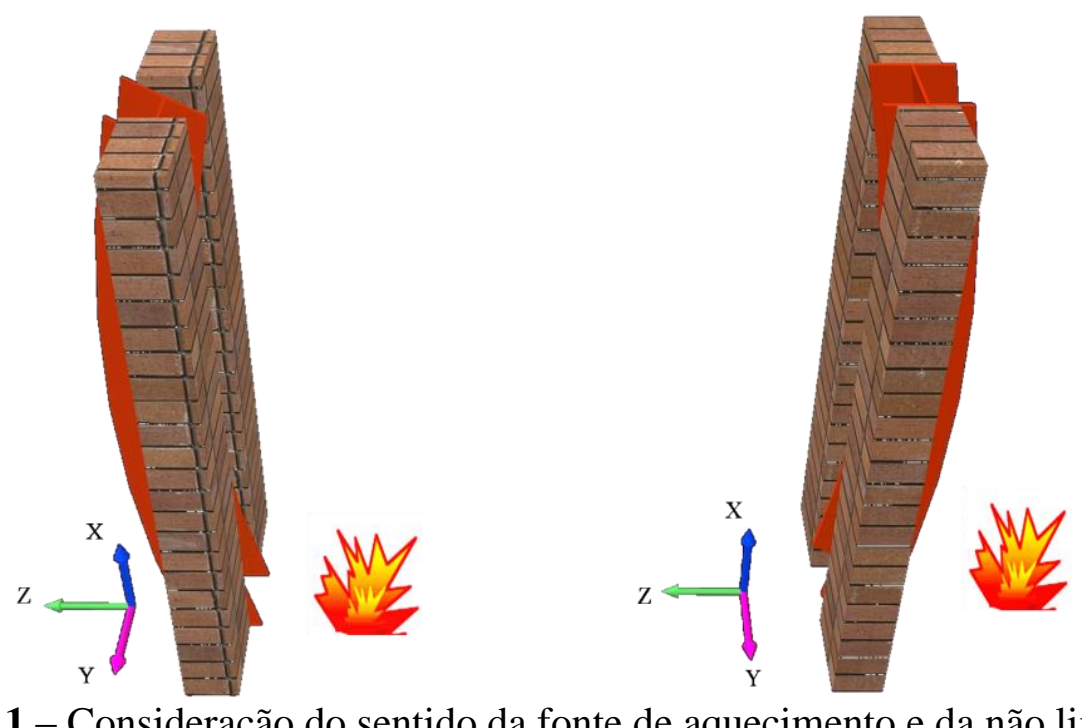

Figura 1.1 - Consideração do sentido da fonte de aquecimento e da não linearidade geométrica global inicial. FONTE: Kimura (2009)

\subsection{OBJETIVO DO TRABALHO}

A presente pesquisa tem como objetivo principal construir modelos numéricos tridimensionais de pilares de aço, com dimensões usualmente empregadas na prática da construção civil, com vistas à análise em situação de incêndio. Será simulado numericamente a evolução dos níveis de temperatura ao longo do tempo para, em seguida, estabelecer o acoplamento termoestrutural, considerando o pilar restringido axialmente de forma que a dilatação térmica acrescente esforço solicitante ao elemento.

O objetivo é analisar elementos estruturais isolados acrescentando restrições axiais às deformações térmicas de forma que essa possa representar o comportamento do restante da estrutura, geralmente menos aquecida, e também a consideração dos diferentes gradientes térmicos impostos pela presença das alvenarias.

Os modelos para a obtenção do campo de temperatura serão elaborados em campo tridimensional, cujas informações referentes às temperaturas serão levadas para modelos estruturais por meio de análise acoplada, considerando a temperatura evoluindo conforme análise térmica anteriormente realizada, carregamento estático e restrição axial, possibilitando avaliação das equações propostas pela ABNT NBR 14323:1999 e comparações a resultados de pesquisas anteriores, tanto numéricas quanto experimentais. 


\subsection{JUSTIFICATIVAS}

A verificação estrutural em situação de incêndio é necessária devido ao fato de as propriedades mecânicas dos materiais (aço, madeira e concreto, por exemplo) resultarem reduzidas quando expostas a elevada temperatura, provocando o colapso estrutural do elemento afetado em intervalo de tempo que pode não ser suficiente para garantir a desocupação da edificação. A influência da temperatura na resistência ao escoamento e módulo de elasticidade do aço pode ser observada na Figura 1.2.

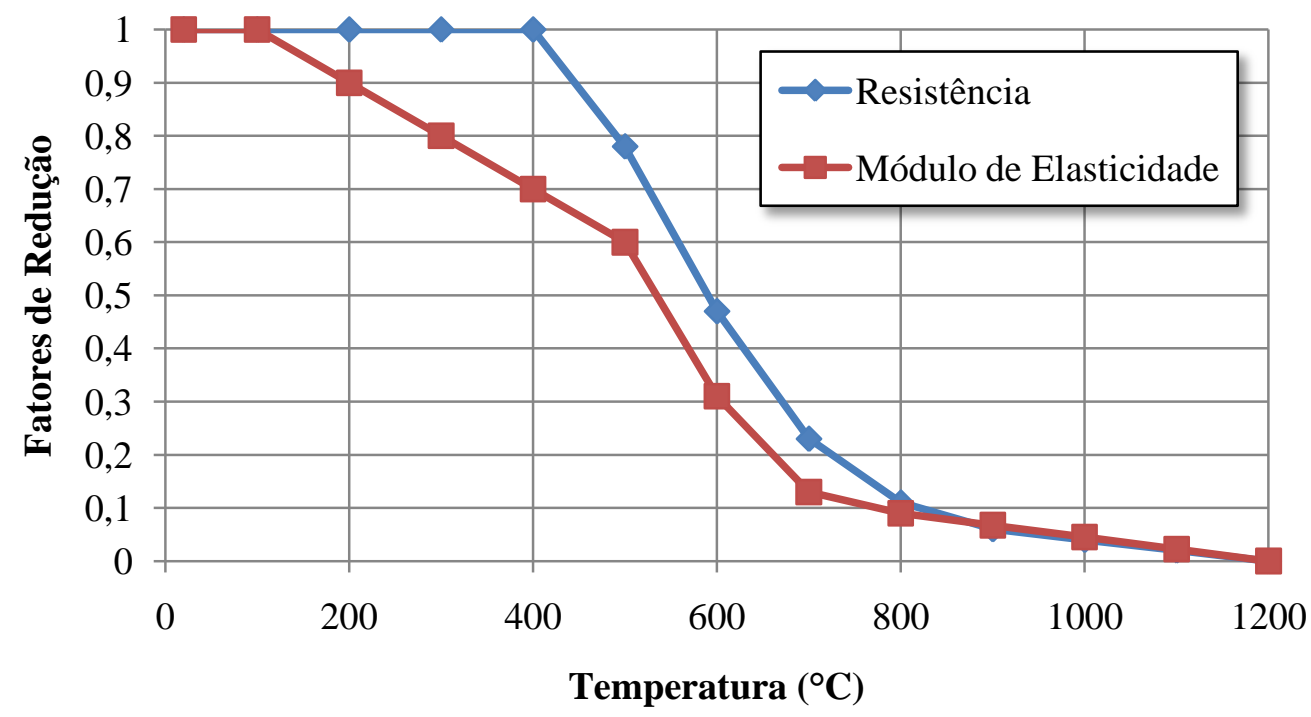

Figura 1.2 - Influência da temperatura na resistência e rigidez do aço.

O estudo aqui proposto se faz necessário uma vez que os conhecimentos do comportamento de estruturas de aço e mistas são, em geral, baseados nas respostas obtidas de elementos isolados experimentados em fornos, os quais, apesar da ampla aceitação entre os engenheiros estruturais, resultam em abordagem conservadora. Portanto, o presente estudo visa analisar a resposta estrutural de um elemento isolado em aço no âmbito das ações térmicas cujas condições de contorno possam representar a estrutura circundante.

Trata-se de garantir a continuidade dos estudos iniciados em Regobello (2007) e, mais especificamente, uma continuidade da pesquisa realizada em Kimura (2009), assim como nos demais citados, focando em uma das situações que lá foram identificadas como de interesse para fins de contribuições com a ABNT NBR 14323:1999, que é a consideração da restrição axial. 
A Figura 1.3 esquematiza algumas das situações de interesse para estudos, extraídas de Regobello (2007), e não abordadas pela ABNT NBR 14323:1999. A Figura 1.4 apresenta resultados de temperaturas da referência anterior para o caso (c) da Figura 1.3.

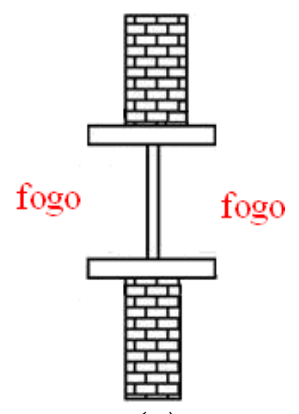

(a)

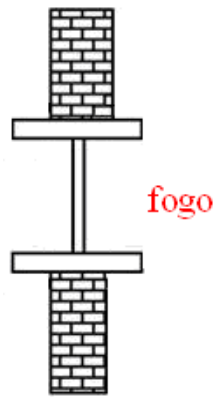

(b)

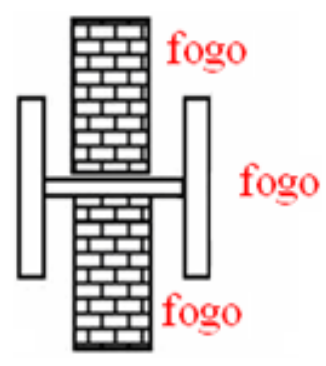

(c)

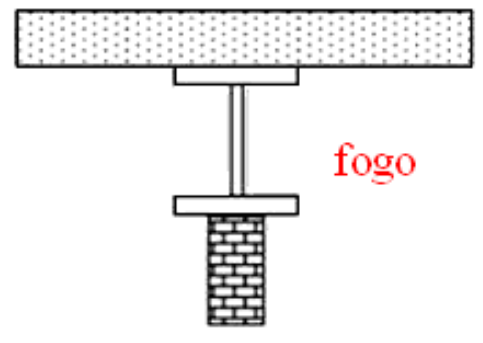

(d)

Figura 1.3 - Alguns casos de interesse, considerando a influência da compartimentação. FONTE: Regobello (2007)
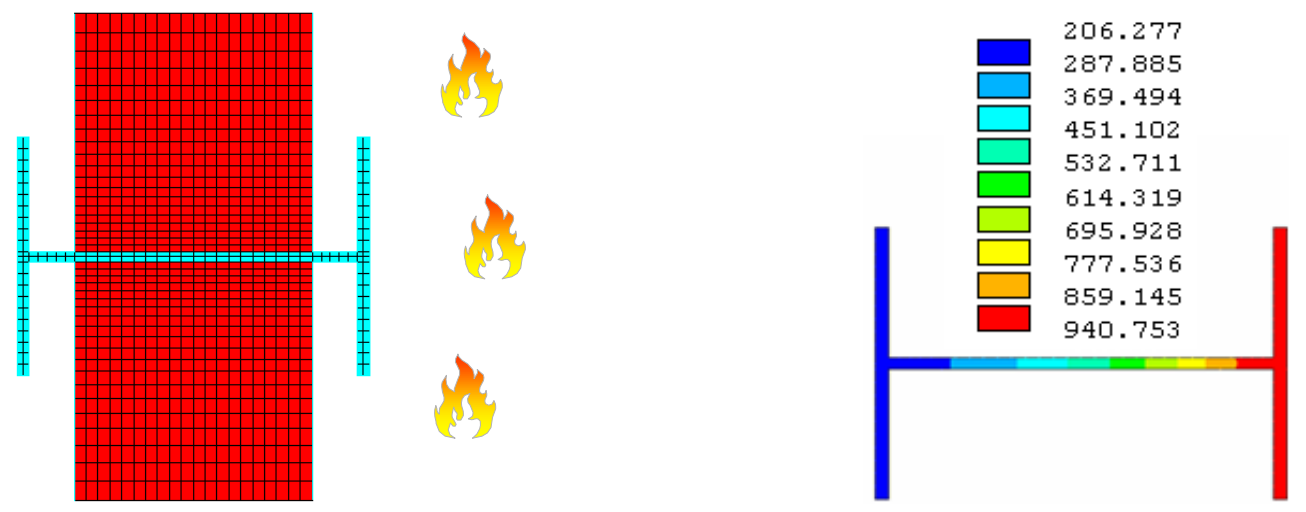

Figura 1.4 - Caso (c): Malha de elementos finitos e campo de temperaturas correspondente a um tempo de exposição ao incêndio-padrão de 60 minutos. FONTE: Kimura (2009)

A consideração da restrição axial na extremidade do elemento representa um passo à frente na expansão da esfera do conhecimento no sentido de compreender como a estrutura global pode atuar quando um elemento isolado está sob a ação térmica. Os modelos que permitem obter a evolução da temperatura no elemento estrutural e, consequentemente, a redução da resistência e rigidez, dividem-se basicamente em: modelos simplificados de cálculo e modelos avançados de cálculo.

Os modelos simplificados de cálculo permitem obter a elevação de temperatura de modo homogêneo para toda a seção transversal e ao longo do comprimento do elemento de interesse, por meio de simples equações analíticas. É o caso adotado pelas normas como a ABNT NBR 14323:1999, que traz a Equação 1.1, em que a elevação da temperatura do aço sem proteção (não envolvido por material de proteção contra incêndio, capazes de reduzir os 
efeitos da ação do incêndio no aço) está diretamente relacionada com o fator de massividade da seção transversal do elemento.

$$
\Delta \theta_{a}=\frac{(u / A)}{c_{a} \rho_{a}} \varphi \Delta t
$$

Na Equação 1.1, aplicada aos casos de elementos não revestidos, $\Delta \theta_{\mathrm{a}, \mathrm{t}}$ é a elevação da temperatura do aço, em ${ }^{\circ} \mathrm{C}$; u/A é o fator de massividade para elementos estruturais de aço sem proteção contra incêndio, em $\mathrm{m}^{-1} ; \rho_{\mathrm{a}}$ é a massa específica do aço, em $\mathrm{kg} / \mathrm{m}^{3} ; \mathrm{c}_{\mathrm{a}}$ é o calor específico do aço, $\mathrm{em} J / \mathrm{kg}^{\circ} \mathrm{C} ; \varphi$ é o valor do fluxo de calor por unidade de área, em W/m ${ }^{2}$ e $\Delta \mathrm{t}$ o intervalo de tempo, em s. O parâmetro de fluxo de calor $(\varphi)$ envolve as parcelas de convecção e radiação da fonte de calor e seu significado e contribuição de cada parcela pode ser visto em Mendes (2004), assim como em Regobello (2007) e em Kimura (2009).

Para barras prismáticas, o fator de massividade (u/A) é dado pela razão entre a área da face exposta ao fogo e o volume do elemento ou, se for considerado um comprimento longitudinal unitário, será a relação entre o perímetro exposto ao fogo (u) e a área total da seção transversal $\left(\mathrm{A}_{\mathrm{g}}\right)$. Esse modelo simplificado permite determinar de modo bastante satisfatório a temperatura máxima atingida pelos elementos estruturais de aço para situações que contemplem casos em que ocorra aquecimento uniforme e igual por todas as faces da seção, como representados no caso (a) da Figura 1.3.

Esse modelo simplificado, no entanto, é geralmente aplicável a um número limitado de casos e pode, eventualmente, conduzir a resultados antieconômicos, pelo fato de o modelo simplificado considerar temperatura uniforme no elemento, a qual, na maioria das vezes, resulta bastante próxima ou mesmo superior à temperatura máxima da seção, avaliada numericamente em Regobello (2007).

A importância de estudos direcionados à análise da variação da temperatura ao longo do tempo (análise transiente) em seções transversais de aço (e mistas de aço e concreto) está relacionada ao fato de que para situação em que não ocorra aquecimento uniforme e igual por todos os lados, como, por exemplo, os casos (b), (c) e (d) da Figura 1.3. Também a consideração de seção com revestimento contra fogo, a relação $u / A$ consiste de uma simplificação normativa para fins de dimensionamento e para as situações em que não haja 
uniformidade ou simetria na variação do campo térmico, podendo, eventualmente, o método analítico de resolução conduzir a valores, conforme enfatizado em Kimura (2009), que não estejam em concordância com aquelas que de fato venham a ocorrer na prática.

Para uma melhor representação do fenômeno são usados métodos avançados de cálculo, que têm base nos métodos numéricos como o Método dos Elementos Finitos (MEF), que será utilizado neste trabalho. Esses métodos permitem obter o campo de temperatura e demais grandezas de interesse durante o aquecimento dos elementos estruturais em situação de incêndio.

Sendo assim, o método simplificado de calculo é aplicável a um número limitado de casos. Por outro lado, o método avançado de dimensionamento, conforme será investigado no presente trabalho, proporciona uma análise dos elementos estruturais e a consideração dos efeitos da estrutura do entorno mais condizente com a realidade observada em temperaturas elevadas. A modelagem numérica consiste, portanto, de ferramenta de interesse para uma análise mais precisa dos pilares de aço em situação de incêndio, devendo essa estar, sempre que possível, associada a resultados de análises experimentais.

\subsection{METODOLOGIA}

Os modelos numéricos serão construídos por meio do pacote ANSYS, o qual disponibiliza ao pesquisador ferramentas necessárias para a obtenção dos resultados de interesse para análises térmicas. Com esse código é possível considerar os três modos primários de transferência de calor: condução, convecção e radiação. A análise de interesse será do tipo análise térmica transiente, a qual considera a evolução da temperatura ao longo do tempo que permite determinar a distribuição de temperatura e outras grandezas térmicas com variação num período de tempo.

Após realizada a análise térmica para definição da distribuição do campo térmico na seção do pilar para cada configuração da disposição entre pilares e de paredes, simulando a compartimentação do incêndio, será realizada a análise estrutural em temperatura ambiente. Essa análise servirá para determinar a carga última da capacidade resistente da barra. Por fim, proceder-se-á a análise termoestrutural transiente com aplicação de parcelas da carga última, variando-se então o nível de restrição axial para cada uma das cargas. 
A estratégia a ser adotada na construção dos modelos numéricos da análise térmica, bem como na construção dos modelos estruturais para a análise acoplada termoestrutural, será a mesma considerada em Regobello (2007) e em Kimura (2009). Na ocasião foram utilizados os elementos finitos SOLID70 e SOLID90 disponibilizados pelo ANSYS, para cada uma das finalidades, enquanto que o presente trabalho irá utilizar os elementos finitos SHELL131 e SHELL181, respectivamente para análise térmica e estrutural.

Os resultados obtidos por meio das simulações numéricas serão comparados a diversos resultados apresentados por outras referências bibliográficas, frutos de artigos publicados por pesquisadores da área.

\subsection{ORGANIZAÇÃO DO TRABALHO}

No capítulo 1 (presente) faz-se a apresentação do trabalho proposto, documentos normativos, objetivos, justificativa e metodologia. O capitulo 2 apresenta alguns comentários a respeito das estruturas em situação de incêndio, casos históricos e desafios enfrentados nas análises térmicas, documentos normativos e uma introdução ao assunto de restrição axial.

O capitulo 3 apresenta os principais conceitos que envolvem o incêndio, como curvas de aquecimento dos gases e formas de transferência de calor dos gases para os elementos estruturais, também aborda a influência da elevação de temperatura nas propriedades mecânicas do aço como a resistência ao escoamento e o módulo de elasticidade. Mostra propriedades térmicas como a condutividade, calor específico e dilatação térmica do aço.

O capitulo 4 apresenta uma descrição teórica de como age o fenômeno da dilatação térmica com a resposta das condições de contorno do elemento estrutural.

No capitulo 5, faz-se a comparação aos resultados térmicos obtidos, via ANSYS, com os resultados de outros pesquisadores, sejam experimentais ou numéricos (ANSYS e STC). São citados e comentados os elementos finitos utilizados, todas as hipóteses consideradas e as etapas de construção do modelo de análise térmica. Serão apresentadas de forma objetiva as estratégias usadas na construção dos modelos numéricos e as respostas de validação do modelo térmico e resultados encontrados. 
O capítulo 6 traz detalhes da construção do modelo termoestrutural incluindo validações numéricas e com resultados experimentais de outros pesquisadores. Algumas estratégias adotadas são comentadas bem como os resultados finais obtidos tanto de modelos sem restrição axial quanto dos modelos com restrição.

Para finalizar, o capítulo 7 traz todas as conclusões referentes ao presente trabalho e a pesquisa realizada para sua elaboração. Na forma de Apêndices podem ser encontrados todos os resultados que não fizeram parte do corpo do texto principal e os scripts dos modelos produzidos pela pesquisa em si. 
Dissertação de Mestrado 


\section{SOBRE A AÇÃO TÉRMICA EM ESTRUTURAS METÁLICAS}

\subsection{INTRODUÇ̃̃O}

O fogo é um dos fenômenos naturais que, se não considerado apropriadamente no dimensionamento de estruturas, pode provocar consequências devastadoras. Quando ocorre de forma descontrolada, o incêndio pode constituir um risco considerável à propriedade e à segurança humana. De acordo com Silva (2000), no passado se imaginava o incêndio como obra do acaso e a vítima uma infortunada. No entanto, sabe-se, atualmente, que o incêndio é uma ação que pode e deve ser evitada, uma vez que as vítimas resultam como consequência de ignorância ou ato criminoso, quer por morte ou por perda do patrimônio.

Segundo Wang (2002), até recentemente, medidas para prevenir incêndios em edifícios têm sido tomadas anos após a ocorrência de desastres. Tais medidas foram consagradas em diversos códigos e regulamentos sobre incêndios, porém, reconhecidamente como diretrizes aproximadas. Para os profissionais, o cumprimento dessas regras prescritas torna os projetos inflexíveis e antieconômicos. Com o desejo de mudar esse cenário acabou surgindo o campo da Engenharia de Segurança contra Incêndio.

Como outras medidas para fins de segurança contra o incêndio, também podem ser considerados revestimentos contra fogo, tais como pintura intumescente, recobrimento com placas de gesso, aplicação de argamassas a base de vermiculita ou gesso, de modo a garantir que o aço necessite um tempo maior de exposição ao fogo até atingir temperaturas idênticas àquelas que seriam alcançadas sem o uso da proteção. Em Ferreira, Claret e Santolin (2007) se menciona que a utilização de revestimento contra fogo é a forma mais simples de garantir a estabilidade estrutural, contudo, seu elevado custo causa um significativo impacto sobre a competitividade da estrutura metálica nas edificações frente a outros materiais estruturais. Em 
Costa (2001) e em Claret (2000a), por exemplo, se menciona que o custo de revestimento contra fogo de estruturas metálicas é um fator restritivo ao desenvolvimento do mercado do aço para a construção civil podendo chegar a valores da ordem de 15 a $30 \%$ do custo total da estrutura.

De acordo com Usmani et al. (2001) diversos pesquisadores concordam com o fato de as prescrições normativas trazerem aproximações para se projetar estruturas, sendo elas conservadoras e nem sempre baseadas em princípios racionais, focando sempre em elementos isolados. Sendo assim, é possível construir uma mesma estrutura de uma edificação de forma muito mais econômica, com pouca perda da resistência da estrutura global frente a uma situação de incêndio compartimentado, em vez de considerar apenas elementos isolados, por meio da remoção ou grande redução da proteção contra incêndios nos elementos de aço. Para explorar plenamente as consideráveis reservas de capacidade portante da estrutura global, é imprescindível que a mecânica do comportamento da estrutura de aço em situação de incêndio seja bem entendida. A consideração da restrição axial no presente trabalho é uma forma, ainda que bastante simplificada, de considerar o efeito da estrutura atuando sobre um elemento isolado.

Com avanços no conhecimento científico do comportamento do incêndio e seu impacto nas estruturas de aço, é possível planejar métodos que façam o projeto e a construção de estruturas em aço mais seguras e econômicas. Com relação às exigências de resistência ao fogo de elementos estruturais de aço e mistos de aço e concreto em situação de incêndio, a maioria dos regulamentos e principais códigos normativos do mundo ainda têm por base ensaios de elementos isolados em fornos. Isso se deve à dificuldade, tanto econômica quanto técnica, de realizar ensaios em estruturas complexas, os quais representam melhor o comportamento real das estruturas.

Atualmente é reconhecido o fato de as prescrições normativas conduzirem, em alguns casos, a projetos antieconômicos, tendo em vista que as mesmas normas necessitam de ajustes constantes e, consequentemente, de estudos mais detalhados com relação ao comportamento global dos elementos. Por essa razão, no contexto internacional, a regulamentação de segurança contra incêndio em edificações tem evoluído no sentido de se libertar progressivamente das exigências de caráter prescritivo, passando a basear-se mais no desempenho dos elementos construtivos expostos a situações de incêndios reais. Os avanços 
ocorridos no contexto mundial com relação ao entendimento do desempenho de estruturas submetidas a elevadas temperaturas, juntamente com as exigências quanto à segurança em situação de incêndio por parte do Corpo de Bombeiros nos grandes centros, têm estimulado, no Brasil, estudos relacionados ao tema "Segurança contra incêndio" com destaque ao desempenho de estruturas em situações de incêndio.

$\mathrm{Na}$ década de 90 foram realizados experimentos em estruturas em escala real em Cardington, como mostra a Figura 2.2 no sentido de conhecer melhor o comportamento da estrutura global em situação de incêndio considerando a discrepância entre resultados de estudos de elementos isolados e a ausência de histórico de colapso total de edifícios de múltiplos andares com estruturas mistas após grandes desastres.

Em Usmani et al. (2001) se apresenta uma descrição teórica-analítica do fenômeno que governa o comportamento de estruturas de aço e mistas em situação de incêndio. Esses estudos foram desenvolvidos em paralelo com modelagem numérica via análise computacional do comportamento estrutural dos experimentos em escala real de Cardington (UK). O comportamento de estruturas mistas em situação de incêndio há muito tem sido entendido como dominada pelos efeitos de perda de resistência dos materiais estruturais causada pela elevação de temperatura e as grandes deformações pela carga imposta à estrutura.

A última referência menciona que são os esforços e as deformações termicamente induzidas que governam a resposta estrutural em situação de incêndio, e não a degradação do material, uma vez que o acréscimo de esforço axial pode levar a barra a atingir instabilidades em temperaturas da ordem de 150 ou $200^{\circ} \mathrm{C}$, muito inferiores àquelas em que o material começa a ter sua resistência reduzida (a partir do $400^{\circ} \mathrm{C}$ ). A Figura 2.1, apresentada em Usmani et al. (2001), esquematiza a temperatura crítica encontrada analiticamente, em que os elementos estruturais com diversos índices de esbeltez perdem a estabilidade inicial em resposta ao aquecimento e à consequente dilatação térmica, considerando as extremidades da barra com apoios fixos rígidos ou com restrição parcial da ordem de rigidez da barra. 


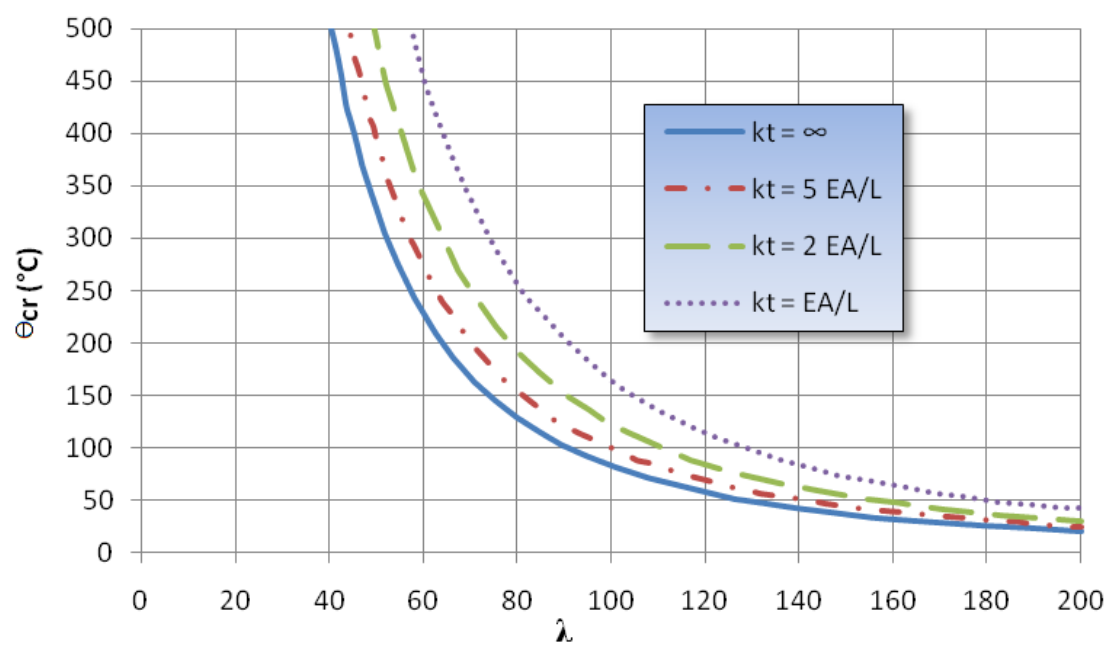

Figura 2.1 - Temperatura crítica de instabilidade por dilatação térmica de pilares de aço restringidos axialmente. Fonte: Usmani et al. (2001)

Assim, capacidade portante e carregamento são, geralmente, fatores determinantes na resposta estrutural (fundamentalmente, nada diferente do comportamento à temperatura ambiente). O novo entendimento produzido por recentes estudos e aqui discutido é de que estruturas mistas de aço e concreto como as ensaiadas possuem enormes reservas de resistência quando consideradas no seu comportamento global. Essas reservas são manifestadas por meio de novas configurações da estrutura, cujas deformações excessivas causam uma redistribuição dos esforços na direção dos elementos circundantes, geralmente com temperaturas menores.

Vale destacar que elemento isolado deixa de resistir às ações de serviço após a degradação de suas propriedades a elevadas temperaturas. A degradação do módulo de elasticidade do material com a elevação da temperatura pode causar grandes deslocamentos e conduzir a modos seguros de carregamento em virtude da redistribuição dos esforços para os demais elementos estruturais. Isso só é verdade até pouco antes do colapso estrutural, quando o carregamento e a degradação do material passam a dominar o comportamento do elemento estrutural novamente.

No entanto, segundo Usmani et al. (2001), no mundo nenhum colapso total de edifícios de múltiplos pavimentos composto por estruturas mistas de aço e concreto ocorreu somente pela ação de um incêndio, sendo que essa informação se confirma até os dias atuais, como pode ser visto em: http://911research.wtc7.net/wtc/analysis/compare/fires.html e http://www.thetruthseeker.co.uk/article.asp?ID=2796. Por esse motivo, experimentos como os 
realizados em estruturas em escala real são importante no sentido de esclarecer o quão distantes essas estruturas estão do colapso quando submetidas a uma situação de incêndio.

Tais questões foram levantadas após as investigações do incêndio de Broadgate, em 1990. O Edifício Broadgate da Figura 2.3, conforme citado em Drysdale (2001), de 14 andares, com estrutura mista de aço e lajes de concreto, incendiou-se em Londres no ano de 1990 ainda na fase de construção e, por isso, ainda não havia proteção nos elementos estruturais e nem o sistema de sprinklers estava operando. O incêndio durou 4,5 horas sendo que a temperatura ultrapassou os $1000^{\circ} \mathrm{C}$ por pelo menos 2 horas, contudo nenhum pilar, laje ou viga veio ao colapso, conforme informado na tese de $\mathrm{PhD}$ de Susan Lamont, conforme http://911research.wtc7.net/mirrors/guardian2/fire/cardington.htm. Diferentemente do que se acreditava baseado no conhecimento sobre o comportamento de elementos isolados, a estrutura global foi capaz de resistir ao incêndio compartimentado, fato que incentivou a realização de experimentos em edifícios em escala real poucos anos após, em Cardington.

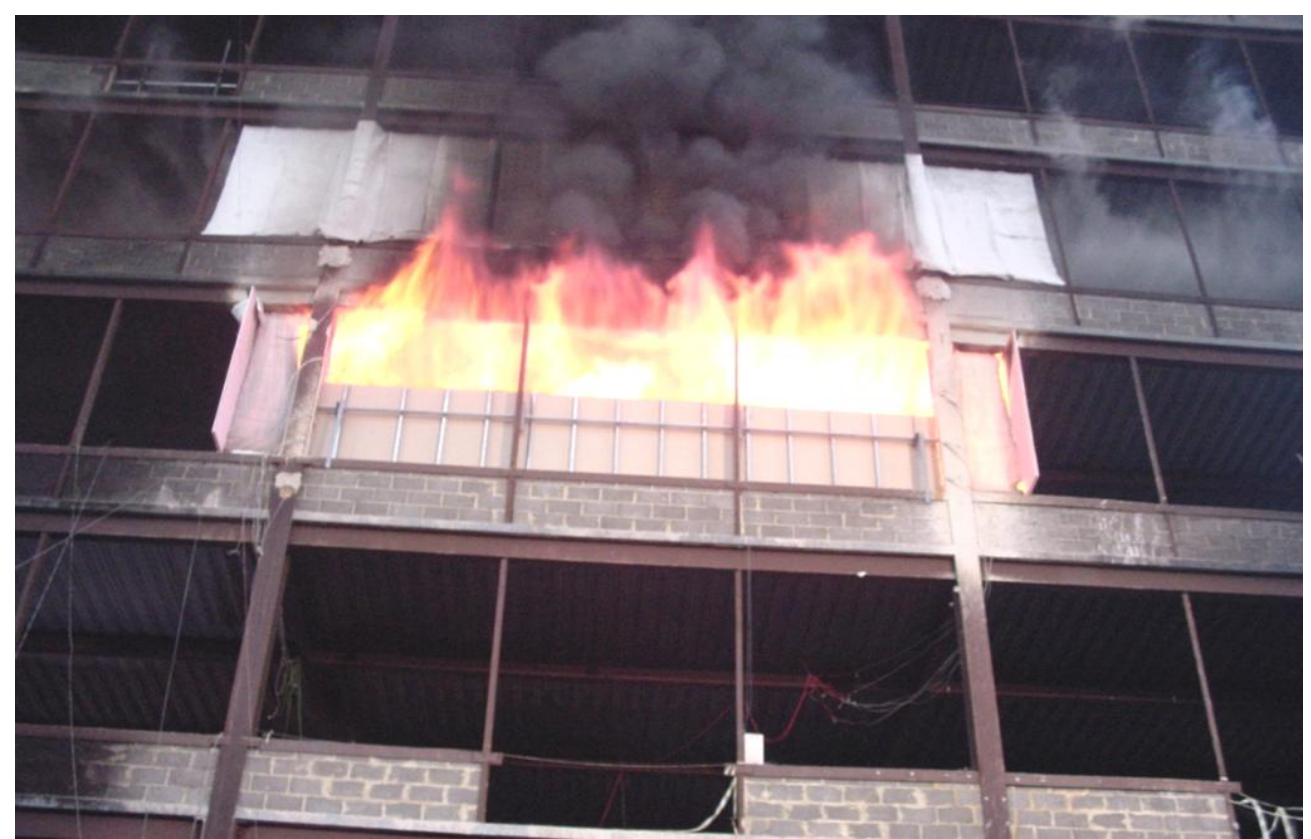

Figura 2.2 - Edifício de estrutura mista em escala real no Laboratório de Cardington para experimentos com incêndio em escala real. 


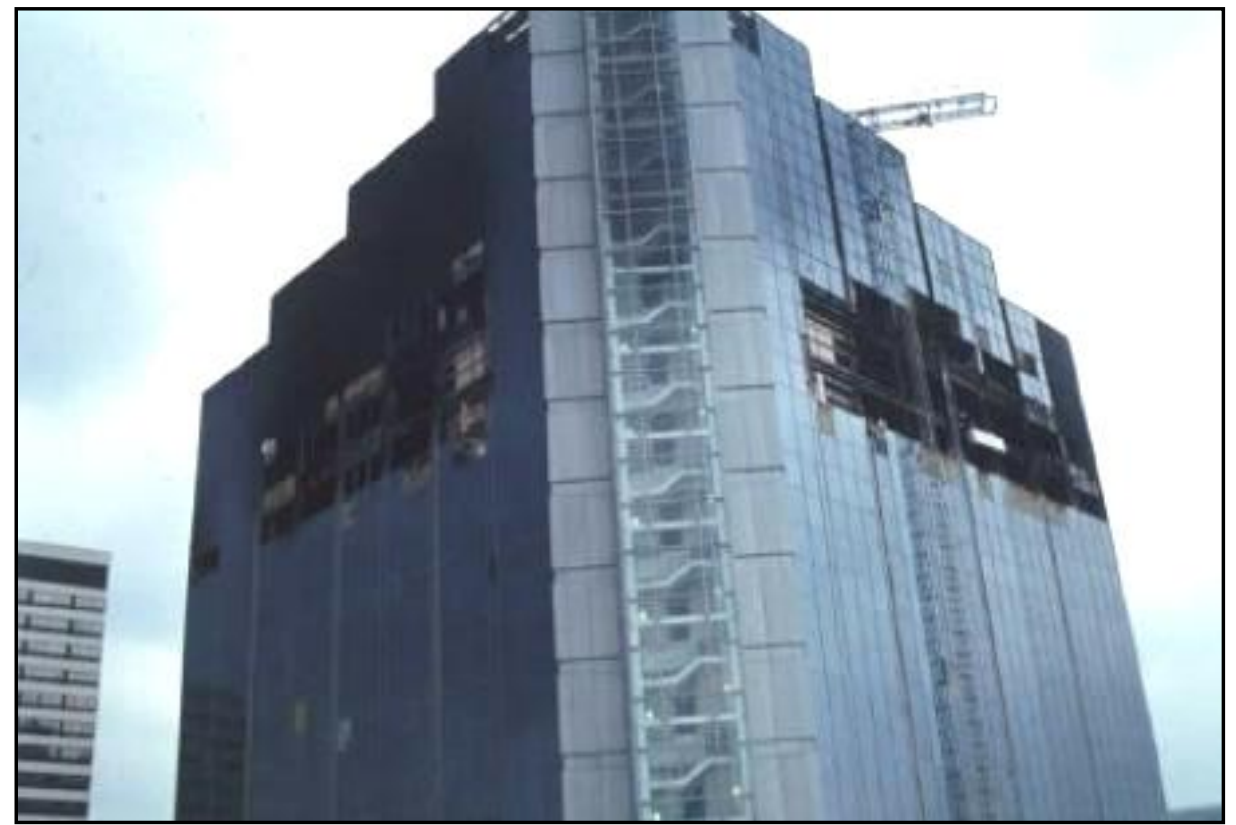

Figura 2.3 - Edifício Broadgate, em Londres, cujo incêndio incentivou experimentos em escala real.

Na busca de uma ferramenta matemática de fácil utilização, que possa descrever o comportamento dessas estruturas e que possa auxiliar o aprimoramento das normas técnicas, uma série de princípios fundamentais do comportamento estrutural sob diferentes formas de ação térmica foram discutidos em Rotter et al. (1999) e em Rotter e Usmani (2000) com o objetivo de determinar o comportamento global da estrutura. Esses princípios podem ser muito úteis na interpretação dos resultados de modelagens numéricas e análises computacionais mais complexas, além de ajudar a esclarecer, de forma mais coerente, o comportamento estrutural.

\subsection{ESTRUTURAS EM SITUAÇÃO DE INCÊNDIO}

As primeiras exigências de proteção contra incêndio surgiram por volta de 1666, com a ocorrência de um grande incêndio na cidade de Londres. Porém, este tema só começou a ser realmente estudado em meados do século XIX e início do século XX. Conforme mencionado em Claret (2000b) e Kirchhof (2004), o estabelecimento das primeiras normas para testes de resistência ao fogo deve-se à ASTM - American Society for Testing and Materials que, em 1911, estabeleceu a norma "Standard tests for fireproof constructions". Em 1932, a British Standard Institution (BSI) publicou a norma BS 476, intitulada "Fire tests on buildings materials and structures", a qual, com as devidas revisões e ampliações, ainda hoje é bastante utilizada e tem por base ensaios de elementos isolados em fornos. 
Até os dias atuais, as exigências de resistência ao fogo de elementos estruturais de aço e mistos de aço e concreto em situação de incêndio, da maioria dos regulamentos e códigos normativos, ainda tem por base ensaios de elementos isolados em fornos, fato que pode conduzir, eventualmente, a projetos antieconômicos que inviabilizam a construção em aço. No Brasil, até a década de 70 as corporações de bombeiros conviviam com a possibilidade de ocorrência de incêndio no seu cotidiano, porém, sem a ferramenta principal, ou seja, o regulamento compulsório de segurança contra incêndio. Historicamente, as tragédias, acidentes ou situações adversas, impulsionam a sociedade na busca por soluções para diferentes tipos de problemas ou ameaças.

Foram ocorrências como aquelas registradas nos Edifícios Andraus (1972), com 31 andares, Joelma (1974), de 25, e da Caixa Econômica do Rio de Janeiro (1974), que demarcaram um novo período de preocupação com a segurança contra incêndios nas edificações, o que motivou (ou mesmo obrigou) as autoridades municipais a sancionarem Decreto sobre a proteção contra incêndio em edificações. A partir dessa década, surgem regulamentos no Brasil, os quais basicamente consistem de adaptação de legislação estrangeira realizada por meio de Instituto de Resseguros, cujo objetivo principal era a contratação de seguros, segundo Ferreira, Correia e Azevedo (2006). A Figura 2.4 ilustra alguns dos incêndios citados.

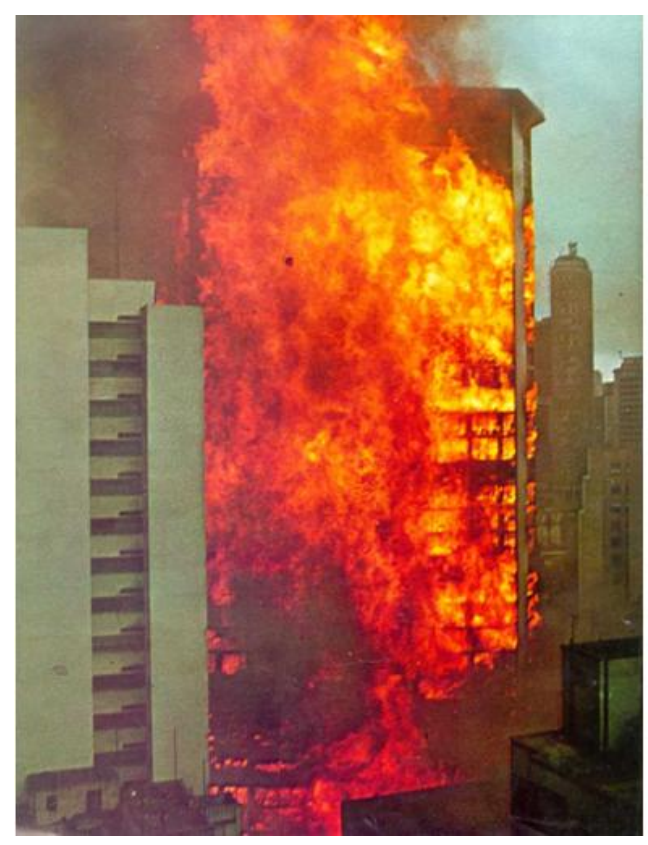

(a)

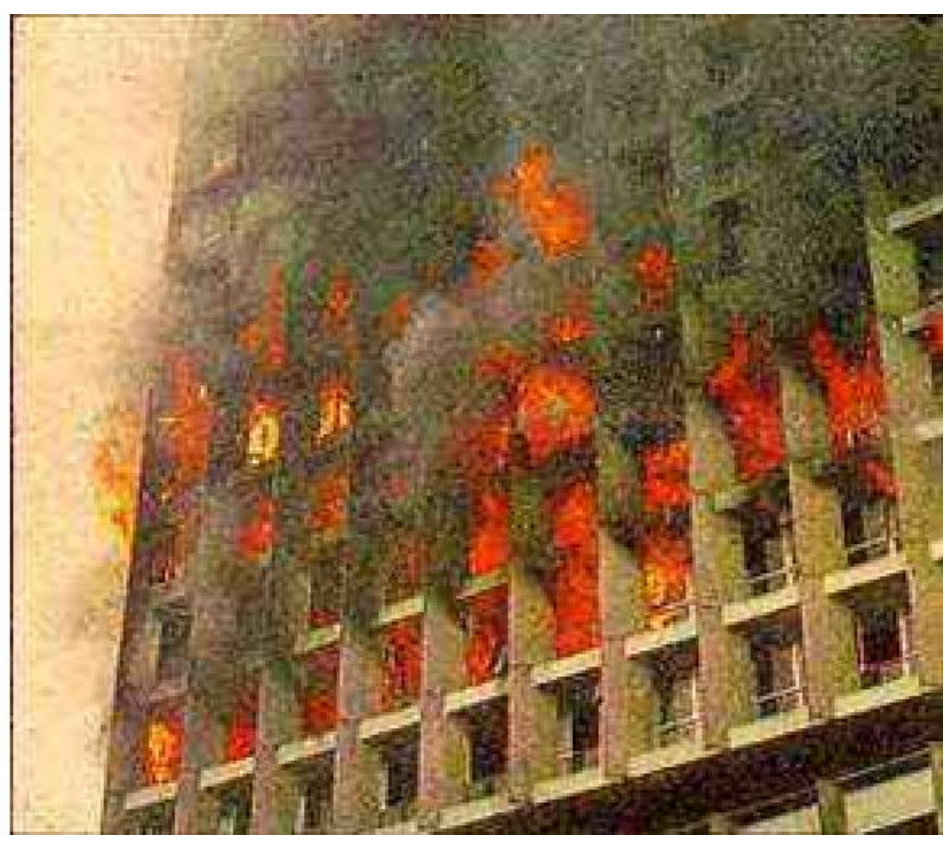

(b)

Figura 2.4 - Incêndios ocorridos nos edifícios: (a) Andraus (1972) e (b) Joelma (1974). 
Assim como sempre ocorreu no passado, tais acontecimentos levaram à criação de códigos normativos e, agora, com um maior conhecimento do comportamento termoestrutural dos materiais e o crescente número de pesquisas e estudos sobre prevenção de incêndio tem por objetivo a melhoria das legislações de segurança contra incêndio, tornando as edificações mais eficientes e econômicas.

Em 1994, o Corpo de Bombeiros de São Paulo publicou uma Instrução Técnica (IT) com diretrizes para o projeto de estruturas metálicas. Na época já existia norma para estruturas de concreto em situação de incêndio, a ABNT NBR 5627:1980, cujas exigências foram consideradas excessivas e inflexíveis, mas incentivou o interesse pelo assunto nos meios técnicos, acadêmicos e industriais.

Em 1996 a Associação Brasileira de Normas Técnicas (ABNT) instala uma comissão de estudos com representantes do meio universitário e do meio técnico. Após 3 anos de trabalho, juntamente com o Corpo de Bombeiros de São Paulo, fabricantes do setor, o Instituto de Pesquisas Tecnológicas, profissionais e siderúrgicas, elaboraram as normas brasileiras ABNT NBR 14323:1999 intitulada "Dimensionamento de estruturas de aço de edifícios em situação de incêndio" e ABNT NBR 14432:2000, intitulada "Exigências de resistência ao fogo de elementos construtivos das edificações”. Nelas são apresentados critérios para dimensionamento de elementos isolados e a determinação do tempo que as estruturas devem resistir para garantir a desocupação da edificação, a segurança das operações de combate a incêndio e a minimização de danos às edificações adjacentes (Tempo Requerido de Resistência ao Fogo - TRRF), respectivamente. Vale destacar que a ABNT NBR 14323:1999 e a ABNT NBR 14432:2000 se encontram, atualmente, em processo de revisão, como forma de adequar os procedimentos normativos face aos novos conhecimentos obtidos na área, inclusive pelas pesquisas de mestrado e doutorado citados anteriormente.

Os códigos atuais, como o BS 5950 Parte 8 e o EUROCODE 3 parte 1.2 (EC3 parte 1.2), trazem aos projetistas o que há de mais recente no campo do conhecimento tratando a ação de incêndio da mesma forma como os outros estados limites. Os avanços na compreensão do comportamento estrutural em situação de incêndio adquiridos nos últimos anos têm sido consideráveis, graças ao grande número de grupos em toda a Europa empreendendo extensos projetos de pesquisa e concentrando em diferentes aspectos do comportamento estrutural em situação de incêndio. Um desses projetos, desenvolvidos pela 
Universidade de Edimburgo, o DETR-PIT (2000) apud Usmani et al. (2001), consiste de relatório técnico que traz uma série de informações sobre o comportamento de estruturas de aço em situação de incêndio.

Estes avanços, combinados com as conclusões do projeto DETR-PIT (2000) apud Usmani et al. (2001), tornam possível aos engenheiros tratarem projetos para estruturas em situação de incêndio de forma integrada com o projeto estrutural como se faz com as outras formas de carregamento, fato que poderá ser feito por meio de ferramentas de análise numérica.

No entanto, o uso de tais ferramentas, indispensáveis na área de pesquisa, não é prático para o uso em escritórios de projeto. A exploração dos novos conhecimentos só se torna viável na prática, se o entendimento gerado vier acompanhado de expressões analíticas simples, permitindo aos engenheiros consultores e projetistas desenvolverem seus projetos baseados no desempenho da estrutura de aço, sem precisar recorrer a recursos computacionais avançados. Os princípios aqui apresentados constituem um passo no sentido de gerar o instrumento analítico necessário para tal uso.

Muitos autores propuseram expressões analíticas para descrever o fenômeno da dilatação térmica de elementos estruturais de maneira simples e analítica, sem precisar recorrer a métodos avançados de cálculo. Em Wong (2005) é proposto um método modificado para cálculo da temperatura limite de falha em barras de edificações de múltiplos andares. Seu método leva em conta o acréscimo de força axial imposta pela restrição axial promovida pelos demais elementos estruturais durante a dilatação térmica. Esse efeito é modelado por meio de um sistema de molas de rigidez equivalente à conexão semi rígida da extremidade da barra.

Adaptações da clássica expressão de Rankine, utilizada para determinar a capacidade resistente em pilares de aço à temperatura ambiente e expressa pela Equação 1.2, foram propostas em Huang e Tan (2003) ao levar em consideração os efeitos da elevação de temperatura sob o material e processos iterativos. Em Toh, Tan e Fung (2003) foi analisada a fórmula de Rankine para uso em temperaturas elevadas, comparando-a a modelos numéricos em elementos finitos e resultados experimentais, chegando à conclusão de que os resultados obtidos se apresentam contra a segurança mas, com algumas considerações, pode ser utilizada como ferramenta para análises expeditas. 


$$
\frac{1}{\mathrm{~F}_{\mathrm{R}}^{\mathrm{n}}}=\frac{1}{\mathrm{~F}_{\mathrm{E}}^{\mathrm{n}}}+\frac{1}{\mathrm{~F}_{\mathrm{P}}^{\mathrm{n}}}
$$

$\mathrm{Na}$ última equação, $\mathrm{F}_{\mathrm{R}}$ é a carga resistente $(\mathrm{em} \mathrm{kN})$ da barra de Rankine, $\mathrm{F}_{\mathrm{E}}$ é a carga de instabilidade (em kN) de Euler, considerada idealmente retilínea, dada pela Equação 1.3, $\mathrm{F}_{\mathrm{P}}$ é a carga (em kN) de plastificação do material, dado pela Equação 1.4 e n é o índice de imperfeição da barra que, na prática pode assumir valores entre 1,0 e 3,0 e podem ser vistos na Figura 2.5.

$$
\begin{aligned}
& F_{E}=\frac{\pi^{2} E_{20} I}{L_{e}^{2}} \\
& F_{P}=f_{y, 20} A
\end{aligned}
$$

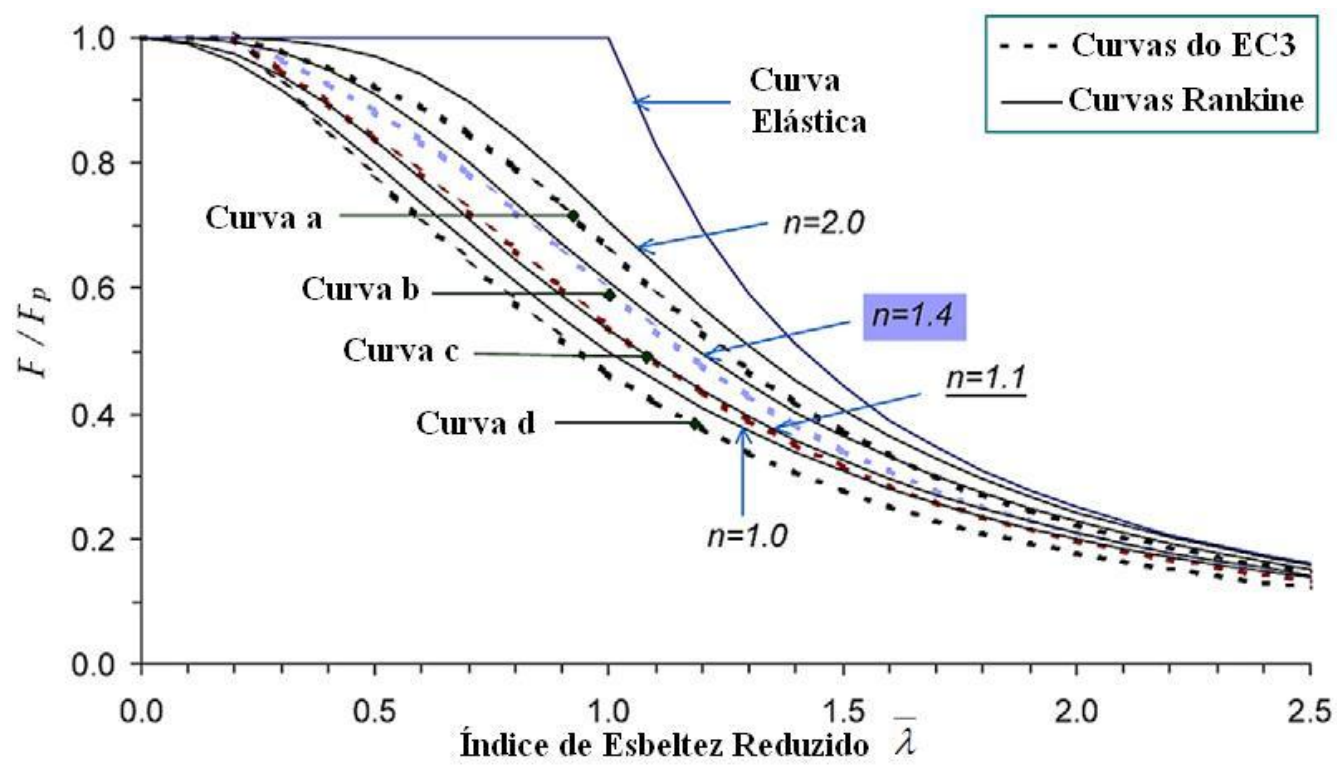

Figura 2.5 - Curvas de índices de imperfeição de barras para a Fórmula de Rankine e EC3. FONTE: Huang e Tan (2003)

$\mathrm{Na}$ Equação $1.3 \mathrm{E}_{20}$ é o valor inicial do módulo de elasticidade do aço a $20^{\circ} \mathrm{C} \mathrm{em} \mathrm{MPa}$, I a inércia, em $\mathrm{m}^{4}$, da seção no eixo sendo considerado e $\mathrm{L}_{\mathrm{e}} \mathrm{o}$ comprimento, em $\mathrm{m}$, efetivo do pilar. Na Equação 1.4, A é a área, $\mathrm{m}^{2}$, da seção transversal e $\mathrm{f}_{\mathrm{y}, 20}$ a resistência ao escoamento, em $\mathrm{MPa}$, do material a $20^{\circ} \mathrm{C}$. Os autores que tentaram utilizar essa expressão para consideração à temperatura elevadas fizeram, principalmente, alterações no módulo de elasticidade e na resistência, atualizando seus valores com a temperatura atual, além de suas próprias considerações de modelo mecânico e matemáticas. 
Considerando as inúmeras pesquisas no campo da engenharia de segurança contra incêndio, com análises utilizando métodos complexos de cálculo ou experimentais, em Usmani et al. (2001) se enfatiza que todo o conhecimento obtido em pesquisas só poderá vir a fazer parte de uma norma técnica e ser efetivamente utilizado pelos projetistas se esse vier acompanhado de expressões matemáticas de fácil utilização. Na última referência foram deduzidas expressões analíticas para descrever o comportamento de barras restringidas axialmente com base na mecânica fundamental das estruturas. $O$ relacionamento mais fundamental que rege o comportamento das estruturas quando sujeito a efeitos térmicos é o descrito na Equação 1.5 .

$$
\varepsilon_{\text {total }}=\varepsilon_{\text {mecânica }}+\varepsilon_{\text {térmico }}
$$

Quando as deformações térmicas são totalmente restringidas sem cargas externas, as tensões térmicas e a plastificação resultam da Equação 1.6, sendo que a deformação mecânica implica em tensões internas. A deformação mecânica ( $\left.\varepsilon_{\text {mecânica }}\right)$ implica em tensão $(\sigma)$, e a deformação total $\left(\varepsilon_{\text {total }}\right)$ causa uma flecha $(\delta)$ no centro da barra. A deformação total determina a deformada da estrutura (flecha) através da cinemática ou considerações de compatibilidade. Em contrapartida, o estado de tensão na estrutura (elástica ou plástica) depende somente das deformações mecânicas.

$$
0=\varepsilon_{\text {mecânica }}+\varepsilon_{\text {térmico }}^{\text {ou }} \quad-\varepsilon_{\text {mecânica }}=\varepsilon_{\text {térmico }}
$$

A maioria das situações em estruturas reais sob ação de fogo tem uma complexa mistura de deformações mecânicas devido à carga aplicada e às deformações mecânicas devido à dilatação térmica restringida. Essas combinações de deformações mecânicas geralmente excedem aos valores de elasticidade, resultando em ampla plastificação. 


\section{O INCÊENIO - Considerações}

Desde o início da humanidade já se sabia, ainda que intuitivamente, que para se obter fogo são necessários três fatores: uma fonte de ignição, um combustível e um material comburente (oxigênio), conforme esquematiza a Figura 3.1.

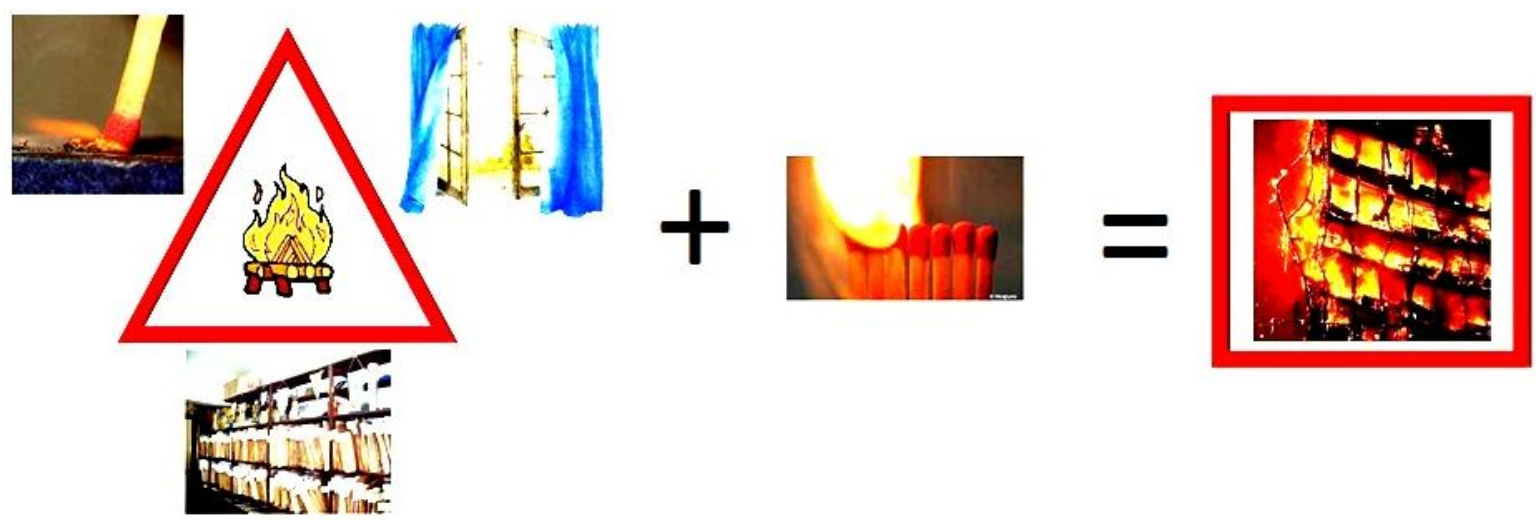

Figura 3.1 - Combinações necessárias para a ocorrência de Fogo e Incêndio.

Para situações em que o material combustível seja abundante (papéis e móveis, no caso de edificações correntes) e a chama inicialmente instalada puder ser fonte de ignição da chama seguinte com o fogo crescendo descontroladamente, então se tem um princípio de incêndio.

A capacidade resistente e os esforços solicitantes em uma estrutura dependem, direta ou indiretamente, da temperatura dos materiais e, por isso, se faz necessário conhecer a temperatura dos gases no ambiente em chamas, assim como as formas de transferência do calor. O aumento da temperatura dos elementos estruturais se deve ao fluxo de calor, por convecção e por radiação, provocado pela diferença de temperatura entre os gases quentes do ambiente em chamas e os componentes da estrutura. 


\subsection{FORMAS DE TRANSFERÊNCIA DO CALOR}

Uma forma de transferência de calor a ser considerada é do tipo “convecção”. O fluxo de calor por convecção é gerado pela diferença de densidade entre os gases do ambiente em chamas, de forma que é necessário sempre um meio fluido (líquido ou gás, por exemplo) para sua ocorrência. Os gases quentes são menos densos e tendem a ocupar a atmosfera superior, enquanto os gases frios, de densidade maior, tendem a se movimentar para a atmosfera inferior do ambiente. Esse movimento gera o contato entre os gases quentes e as estruturas, ocorrendo transferência de calor. Vale aqui ressaltar que para os modelos numéricos a serem aqui estudados será utilizado o valor para o coeficiente de transferência de calor por convecção $\alpha_{c}$ igual a $\mathbf{2 5} \mathbf{~ W / \mathbf { m } ^ { 2 }}{ }^{\circ} \mathbf{C}$, conforme item 8.5.1.1.2 da ABNT NBR 14323:1999.

Outra forma de transferência de calor a ser considerada é do tipo "radiação". A radiação é o processo pelo qual o calor flui na forma de propagação de ondas, de um corpo a elevadas temperaturas para a superfície de outro, normalmente com temperatura mais baixa. Essa forma de transferência de calor não necessita de meio físico, assim como a luz do Sol, a qual fornece fonte de calor que se irradia para nosso planeta. Dentre os parâmetros a serem considerados nos modelos numéricos aqui propostos no referente à radiação, serão atribuídos: coeficiente de emissividade igual a $\mathbf{0 , 5}$ (para validações de resultados numéricos) e constante de Stefan-Boltzmann igual a $\mathbf{5 , 6 7 x 1 0 ^ { - 8 }} \mathbf{W} / \mathbf{m}^{2} \cdot \mathbf{K}^{\mathbf{4}}$ (ambos segundo item 8.5.1.1.2 da ABNT NBR 14323:1999), bem como fator de configuração com valor igual a 1,0, conforme Regobello (2007).

O valor da emissividade entre a chama e o aço tem, nos últimos anos, recebido atenção especial dos pesquisadores sendo que seu valor vem sendo aferido com maior precisão. $\mathrm{O}$ EUROCODE 3 parte 1.2, no seu item 2.2, já sugere o valor de $\mathbf{0 , 7}$, mas ressaltando a necessidade de considerar o efeito shadow (descrito no Capítulo 5), enquanto a ABNT NBR 14323:1999 (em processo de revisão) prescreve 0,5, sujeito a alteração na versão revisada. Antevendo essa mudança, e amparado pelo EUROCODE 3 parte 1.2, o valor de $\mathbf{0 , 7}$ será utilizado nas análises térmicas cujo campo térmico servirá posteriormente para as análises termoestruturais. $\mathrm{O}$ valor $\mathbf{0 , 5}$ será utilizado apenas em análises preliminares com o único objetivo de comparação aos resultados de Kimura (2009) e também para análise comparativa entre os resultados de emissividade $\mathbf{0 , 5}$ e $\mathbf{0 , 7}$, conforme Capítulo 5. 
A terceira forma de propagação do calor a ser considerada é denominada "condução". A condução faz com que o interior do elemento estrutural (pontos ao longo do seu comprimento e da seção transversal) seja aquecido em resposta a um fluxo de calor gerado na sua superfície, por convecção e radiação. Tal mecanismo de transferência vale não só para considerar a propagação do calor de uma extremidade a outra de um mesmo elemento estrutural, mas também para elementos estruturais que estejam em contato físico entre si, fato que permite considerar a condução como forma de transferência de calor que necessita de um meio físico qualquer para se propagar. Os coeficientes de interesse utilizados nos modelos numéricos propostos no presente trabalho serão devidamente descritos nos itens seguintes sobre as propriedades térmicas do aço.

No caso de sistemas estruturais e de seus elementos, as formas de transferência de calor anteriormente citadas, esquematizadas na Figura 3.2, são aquelas normalmente envolvidas na transferência do calor dos gases aquecidos de um dado ambiente em incêndio, sendo a última forma atuante no interior do material. Maiores esclarecimentos sobre as questões físicas e matemáticas que envolvem os fenômenos citados podem ser encontrados em diversas bibliografias especializadas, inclusive nos trabalhos de mestrado da mesma linha de pesquisa como Kimura (2009) e Regobello (2007).

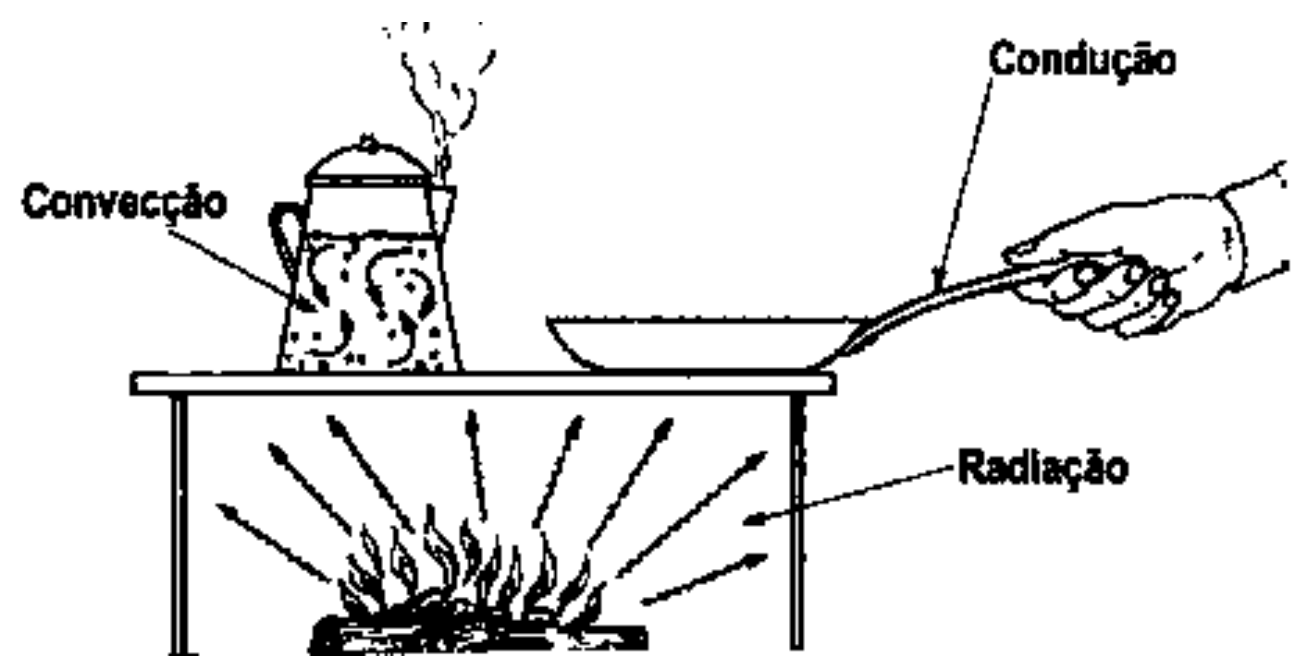

Figura 3.2 - Formas de transferência de calor: condução, convecção e radiação.

\subsection{SOBRE A COMPARTIMENTAÇÃO-CONSIDERAÇÕES}

De acordo com Silva et al. (2008), a compartimentação da edificação é uma medida de proteção passiva fundamental para evitar a propagação do calor e das chamas, minimizando 
assim as consequências inerentes ao incêndio. A área máxima de compartimento é, geralmente, estabelecida em códigos ou normas. De acordo com a última referência, resistência ao fogo é a propriedade de um elemento de construção de resistir à ação do fogo por determinado período de tempo, mantendo sua segurança estrutural (estabilidade e integridade), estanqueidade a gases e chamas, e isolamento térmico. A Figura 3.3 esquematiza uma situação de ambiente compartimentado com chamas contidas no mesmo.

Conforme citado em Ono, Venezia e Valentin (2008), tanto a compartimentação horizontal como a vertical tem como objetivo impedir a propagação do fogo entre ambientes e pavimentos adjacentes. Tradicionalmente, a compartimentação é realizada por componentes e sistemas construtivos fixos nas edificações, tais como paredes de alvenaria, lajes de concreto, portas e janelas. No entanto, também é possível obter a compartimentação de grandes ambientes (como salões, pavilhões e átrios) somente em situação de emergência, por meio de elementos móveis, como cortinas móveis, por exemplo, resistentes ao fogo e que se fecham por acionamento manual ou automático.

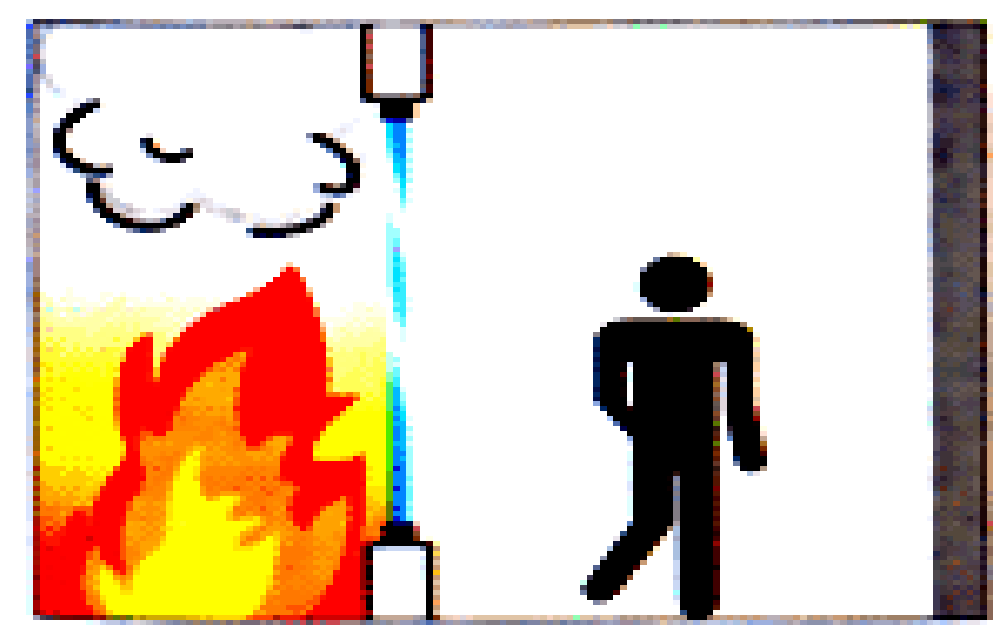

Figura 3.3 - Compartimentação de um dado ambiente em chamas, impedindo ou retardando sua propagação para os demais ambientes por um tempo mínimo definido em norma.

\subsection{MODELOS DE INCÊEDIO - CURVAS TEMPO X TEMPERATURA}

Segundo Vargas e Silva (2003), quando se trata do estudo de estruturas em situação de incêndio, a principal característica de um incêndio é a curva que fornece a temperatura dos gases em função do tempo. Essa curva pode apresentar 3 fases distintas, conforme esquematiza a Figura 3.4 para uma situação de incêndio denominada "real". 


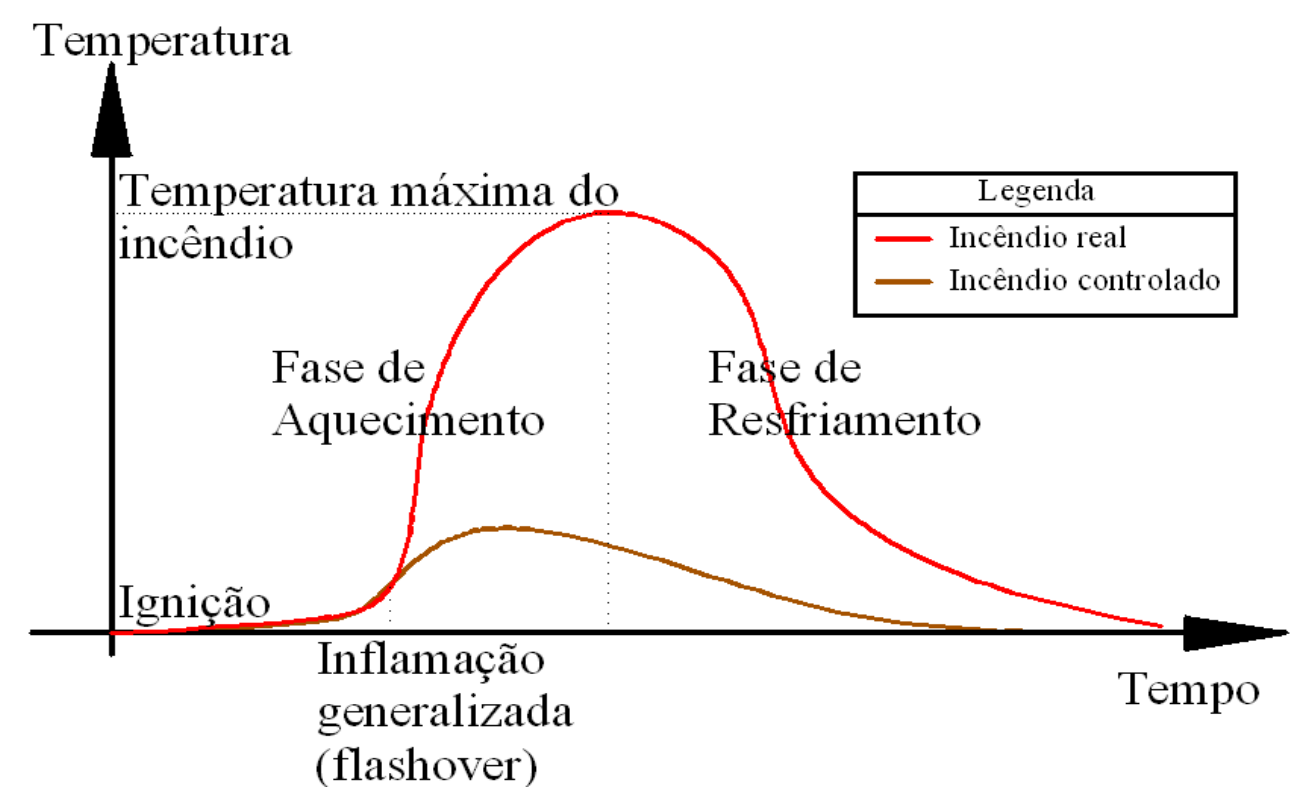

Figura 3.4 - Curva de evolução de temperatura de um incêndio real e incêndio controlado.

A primeira fase começa com a "ignição", a qual consiste do desenvolvimento das chamas, porém, com o incêndio ainda sob controle. Nessa fase, a combustão dos materiais produz muita fumaça e sua inalação pode causar o maior número de vítimas fatais, cerca de $70 \%$ do total de óbitos segundo Mitidieri (2008). A estrutura não sofre danos severos tendo em vista que a temperatura é considerada com valores não elevados para fins estruturais.

Em seguida, há um momento iniciado pela “inflamação generalizada”, também denominada flashover, sendo que se o incêndio for controlado nesse momento não haverá danos estruturais significativos. É caracterizado por um aumento rápido da temperatura e ocorre quando todo o material combustível presente no ambiente entra em ignição. A partir desse instante, segundo Vargas e Silva (2003), o incêndio torna-se de grandes proporções, tomando todo o compartimento. A temperatura dos gases se eleva rapidamente até que, decorrido certo intervalo de tempo, todo o material combustível começa a se extinguir. Sua duração, segundo DRYSDALE (1994), dependerá da disponibilidade de material combustível no ambiente e de sua taxa de queima, fortemente dependente da quantidade de ar que entra no compartimento do ambiente em chamas pelas aberturas de portas e janelas, por exemplo.

Após o consumo do material combustível, o fogo começará a diminuir, provocando redução gradativa da temperatura dos gases, quando então se tem a terceira fase do incêndio caracterizada pelo "resfriamento" do ambiente, a qual não oferece risco à estrutura se for considerada apenas a degradação das propriedades do material, os quais poderão ser, 
eventualmente, recuperados após avaliação de perícia técnica. Vale destacar que, no caso de vigas e lajes, poderão ocorrer esforços de tração devido ao efeito de catenária.

A curva de incêndio real, conforme Figura 3.4, é de difícil determinação, uma vez que fatores como temperatura máxima atingida e velocidade de aquecimento dependerão de inúmeros fatores e será diferente para cada edificação, projeto, compartimento, material combustível, grau de ventilação, entre outros. Por razões descritas, tal curva é comumente substituída por curvas denominadas "incêndio natural" ou "parametrizadas", conforme esquematiza a Figura 3.5, com a fase de resfriamento linearizada e ignorando a fase inicial, que não oferece risco estrutural. Por meio de considerações matemáticas a respeito de todos os parâmetros envolvidos no incêndio, é possível construir essa curva, porém, de forma diferenciada para cada caso a ser analisado.

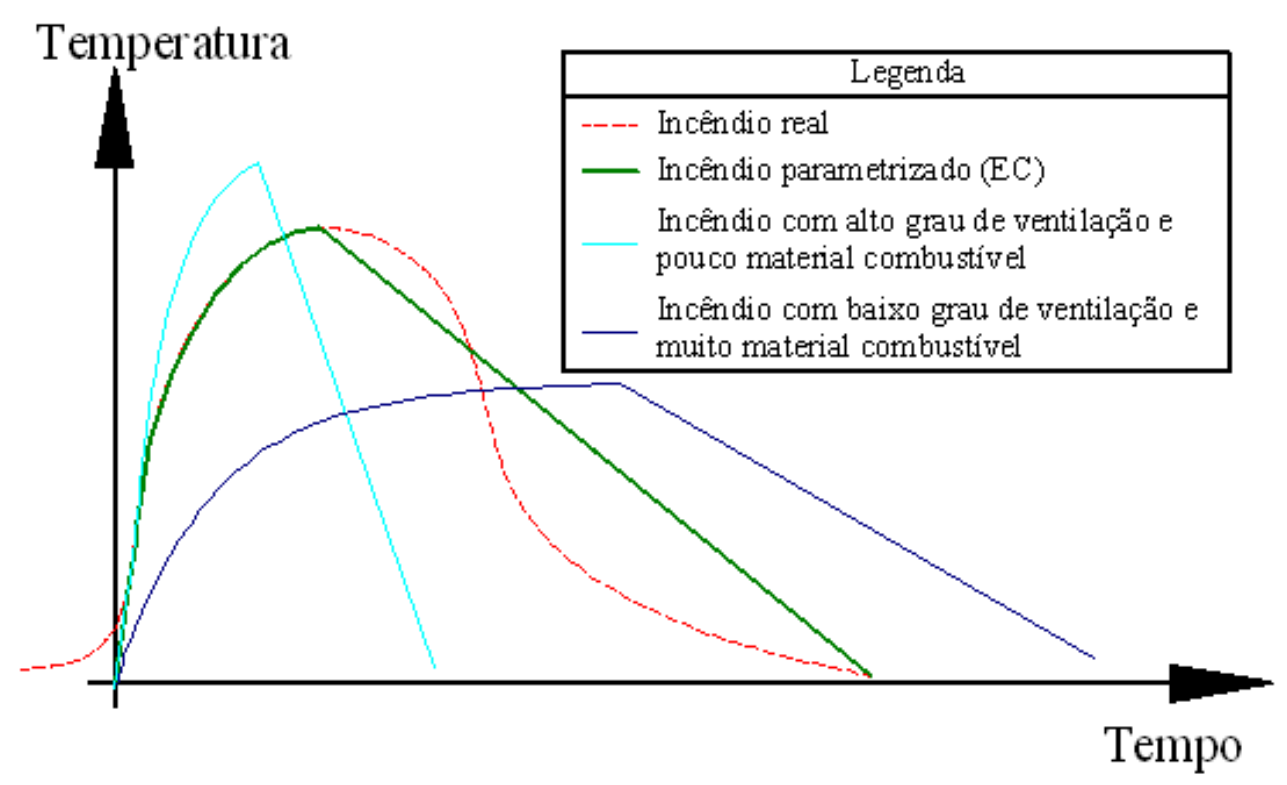

Figura 3.5 - Curvas tempo x temperatura de incêndios sob condições distintas de ventilação e disponibilidade de material combustível.

Em Seito (2008), é apresentada uma série de equações de desenvolvimento do incêndio em relação, principalmente, à carga de incêndio e ao grau de ventilação para todas as suas fases. Para o momento pós flashover, a Equação 3.1 descreve a razão de desenvolvimento do calor $Q_{f 0}$, em $\mathrm{kW}$, sendo que as variáveis envolvidas são $A_{t}$ como a área total do compartimento, em $\mathrm{m}^{2}, A_{v}$ a área da abertura de ventilação, em $\mathrm{m}^{2}, h_{w}$ a altura da abertura de ventilação, em m, e $h_{k}$ o coeficiente de transferência efetiva de calor, em $\mathrm{kW} / \mathrm{m}^{2} \mathrm{~K}$. 


$$
\mathrm{Q}_{\mathrm{fo}}=750 \cdot\left(\mathrm{h}_{\mathrm{k}} \cdot \mathrm{A}_{\mathrm{t}} \cdot \mathrm{A}_{\mathrm{v}} \cdot \sqrt{\mathrm{h}_{\mathrm{w}}}\right)
$$

Pode-se concluir, por meio da Equação 3.1 que, quanto maior o grau de ventilação mais rápido será o aquecimento do ambiente. Ainda, segundo Seito (2008), a duração do incêndio está ligada à carga de incêndio, que passa dos 80\% para 30\% do seu valor inicial entre o fim do primeiro estágio e início do terceiro. $\mathrm{O}$ desenvolvimento do incêndio nesse estágio é controlado por dois mecanismos: ventilação e carga de incêndio.

O primeiro trabalho que apresenta estudos para a duração do incêndio, relacionando-o com a carga de incêndio, foi de Ingberg apud Seito (2008), em 1928, chegando à relação apresentada na Equação 3.2, em que $t$ é o tempo de duração do incêndio em minutos e $w$ a carga de incêndio.

$$
\mathrm{t}=1,2 \cdot \mathrm{w}
$$

Posteriormente, na década de 70, em Kawagoe e Sekine apud Seito (2008) fez-se a proposta de relação da duração do incêndio com a ventilação do ambiente confinado, chegando à Equação 3.3, em que $t$ é o tempo de duração do incêndio em horas, $w$ a carga de incêndio, $A_{p}$ é a área do piso do ambiente em chamas, $A_{v}$ a área da abertura de ventilação e $H$ sua altura. Da Equação 3.3 pode-se concluir que quanto maior a carga de incêndio maior a sua duração, enquanto que, quanto maior a ventilação, menor a duração do incêndio.

$$
t=\frac{w \cdot A_{p}}{5,5 \cdot A_{v} \sqrt{H}}
$$

Tendo em vista, portanto, que a curva tempo x temperatura do incêndio natural se altera para cada situação estudada, na intenção de padronizar as análises de estruturas em situação de incêndio no que diz respeito à curva de aquecimento dos gases, tanto em contexto experimental quanto numérico, com o objetivo de sempre gerar dados possíveis de serem comparados em pesquisas realizadas em qualquer lugar do mundo, convencionou-se adotar uma curva padronizada proposta pela norma ISO 834-1:1999, conhecida como modelo de incêndio-padrão, descrita por meio da Equação 3.4 em que $\theta_{\mathrm{g}}$ é a temperatura dos gases do ambiente em chamas $\left(\mathrm{em}^{\circ} \mathrm{C}\right)$ e $t$ representa o tempo em minutos. 


$$
\theta_{\mathrm{g}}=345 \log _{10}(8 \mathrm{t}+1)+20^{\circ} \mathrm{C}
$$

De acordo com Silva et al. (2008) a curva de incêndio-padrão é empregada para incêndio em ambientes com material combustível formado, predominantemente, de materiais celulósicos (papéis e madeira). Vale ressaltar que a curva de incêndio-padrão é de fácil aplicação, porém, quaisquer conclusões com base em resultados obtidos por meio da aplicação da mesma devem ser analisadas com cuidado, pois o incêndio-padrão não corresponde às reais condições de um incêndio real.

Além da curva ISO 834-1:1999, outras curvas padronizadas internacionalmente e também recomendadas são aquelas propostas pela ASTM E 119 (2000), pela norma sueca SBN 67, pela BS 476 (1987), entre outras. Dada a similaridade entre as curvas propostas e também pela prescrição da norma ABNT NBR 5628:2001 utilizar-se-á a curva ISO 8341:1999, da Equação 3.4 e ilustrada na Figura 3.6.

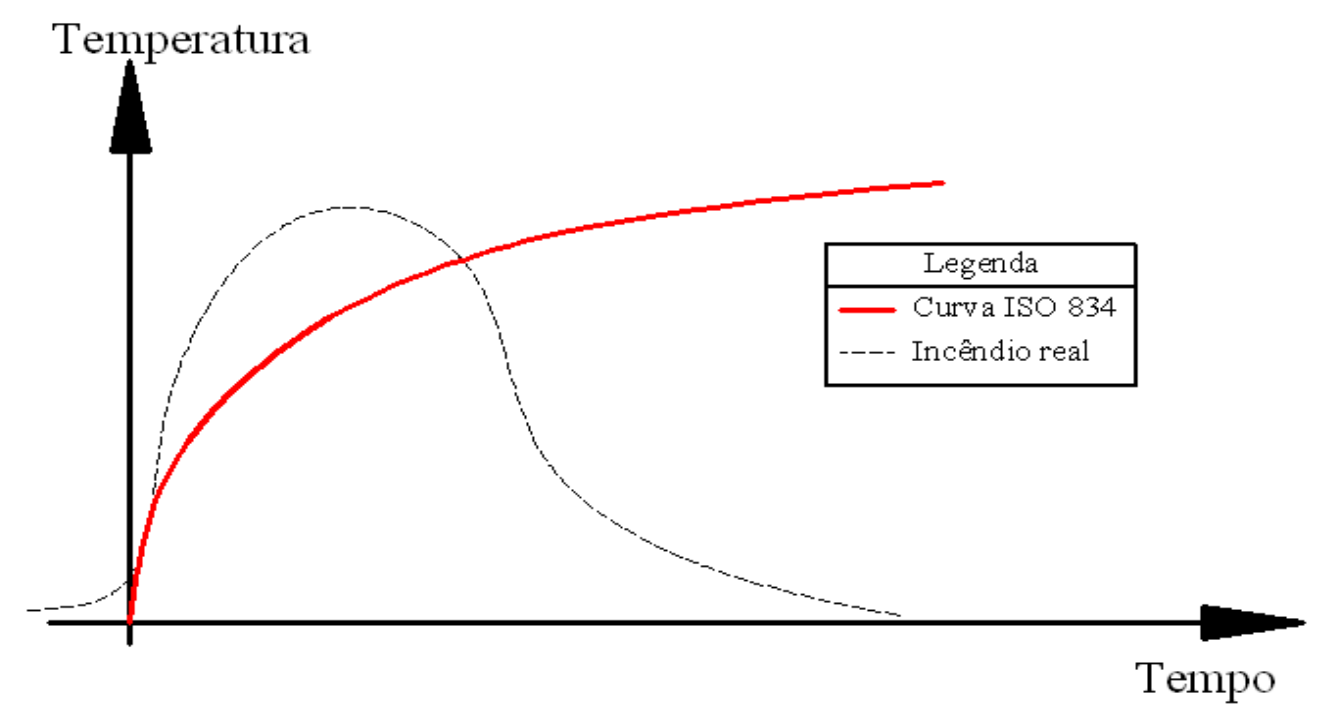

Figura 3.6 - Curva de Incêndio-padrão proposta pela ISO 834-1:1999.

Como a curva ISO 834-1:1999 não apresenta um ponto de máxima temperatura, mas sim um trecho somente ascendente, é necessário fixar um tempo de referência para obtenção da máxima temperatura à qual a estrutura estará submetida, e para a qual deverá apresentar capacidade portante suficiente para garantir a desocupação de seus ocupantes em tempo e com segurança, o qual é denominado Tempo Requerido de Resistência ao Fogo (TRRF) e devidamente apresentado no item que segue. 


\subsection{TEMPO REQUERIDO DE RESISTENNCIA AO FOGO-TRRF}

O TRRF (Tempo Requerido de Resistência ao Fogo) é um tempo fictício que, associado à curva de incêndio-padrão, permitirá conduzir à máxima temperatura no elemento de aço. Trata-se de tempo mínimo que os elementos construtivos devem resistir a uma ação térmica padronizada, em um ensaio de laboratório ou modelagem numérica. Esse tempo é descrito em minutos e seus limites foram estabelecidos como fruto do consenso do meio técnico para cada tipo de edificação, tendo seus valores expostos na Tabela 3.1.

A respeito da resistência ao fogo dos elementos construtivos, esses devem manter-se estanques à infiltração das chamas, devem permanecer íntegros para cumprirem sua função estrutural, e prover isolamento térmico, evitando o aumento excessivo da temperatura nos ambientes vizinhos à ocorrência do incêndio. A variável "tempo" é utilizada, em códigos e regulamentos, como uma medida para a definição do desempenho em incêndio.

Tabela 3.1 - Tempo requerido de resistência ao fogo.

\begin{tabular}{lccccc}
\hline \multirow{2}{*}{ OCUPAÇÃO/USO } & \multicolumn{5}{c}{ ALTURA DA EDIFICAÇÃO } \\
& $\mathbf{h} \leq \mathbf{6 m}$ & $\mathbf{6 m} \leq \mathbf{h} \leq \mathbf{1 2} \mathbf{m}$ & $\mathbf{1 2} \mathbf{m} \leq \mathbf{h} \leq \mathbf{2 3} \mathbf{m}$ & $\mathbf{2 3} \mathbf{m} \leq \mathbf{h} \leq \mathbf{3 0 m}$ & $\mathbf{h}>\mathbf{3 0 m}$ \\
\hline Residência & 30 & 30 & 60 & 90 & 120 \\
Hotel & 30 & 60 & 60 & 90 & 120 \\
Supermercado & 60 & 60 & 60 & 90 & 120 \\
Escritório & 30 & 60 & 60 & 90 & 120 \\
Shopping & 60 & 60 & 60 & 90 & 120 \\
Escola & 30 & 30 & 60 & 90 & 120 \\
Hospital & 30 & 60 & 60 & 90 & 120 \\
Igreja & 60 & 60 & 60 & 90 & 120 \\
\hline
\end{tabular}

FONTE: ABNT NBR 14432:2000 
Tabela 3.2 - Fatores de redução para o aço.

Fator de redução para a Fator de redução para o módulo

Temperatura do aço resistência ao escoamento dos de elasticidade ao escoamento dos

\begin{tabular}{ccc}
$\boldsymbol{\theta}_{\mathbf{a}}\left({ }^{\mathbf{0}} \mathbf{C}\right)$ & $\begin{array}{c}\mathbf{a c ̧ o s ~} \mathbf{l a m i n a d o s}_{\mathbf{k}_{\mathbf{y}, \boldsymbol{\theta}}} \\
\mathbf{k}_{\mathbf{E}, \boldsymbol{\theta}}\end{array}$ \\
\hline 20 & 1,00 & $\begin{array}{c}\text { aços laminados } \\
100\end{array}$ \\
200 & 1,00 & 1,0000 \\
300 & 1,00 & 0,9000 \\
400 & 1,00 & 0,8000 \\
500 & 1,00 & 0,7000 \\
600 & 0,78 & 0,6000 \\
700 & 0,47 & 0,3100 \\
800 & 0,23 & 0,1300 \\
900 & 0,11 & 0,0900 \\
1000 & 0,06 & 0,0675 \\
1100 & 0,04 & 0,0450 \\
1200 & 0,02 & 0,0225 \\
\hline
\end{tabular}

Nota: Para valores intermediários da temperatura do aço pode ser feita interpolação linear.

FONTE: ABNT NBR 14323:1999

\subsection{PROPRIEDADES MECÂNICAS E FÍSICAS DO AÇO SOB}

\section{TEMPERATURAS ELEVADAS}

\subsubsection{Resistência ao escoamento e módulo de elasticidade}

Para taxas de aquecimento entre $2^{\circ} \mathrm{C} / \mathrm{min}$ e $50^{\circ} \mathrm{C} / \mathrm{min}$, a Tabela 3.2 extraída da ABNT NBR 14323:1999 traz fatores de redução para o aço que correspondem à relação entre a resistência ao escoamento e o módulo de elasticidade em uma dada temperatura $\theta_{\mathrm{a}}$ em relação aos correspondentes valores em temperatura ambiente $\left(20^{\circ} \mathrm{C}\right)$, aplicáveis aos aços laminados ou soldados, representados respectivamente pelos parâmetros $\mathrm{k}_{\mathrm{y}, \theta}, \mathrm{k}_{\mathrm{E}, \theta}$. Os valores dos fatores de redução $\mathrm{k}_{\mathrm{y}, \theta}$ e $\mathrm{k}_{\mathrm{E}, \theta}$ e resposta à variação da temperatura, apresentados na Tabela 3.2, são esquematizados na forma gráfica conforme ilustrado na Figura 3.7. 


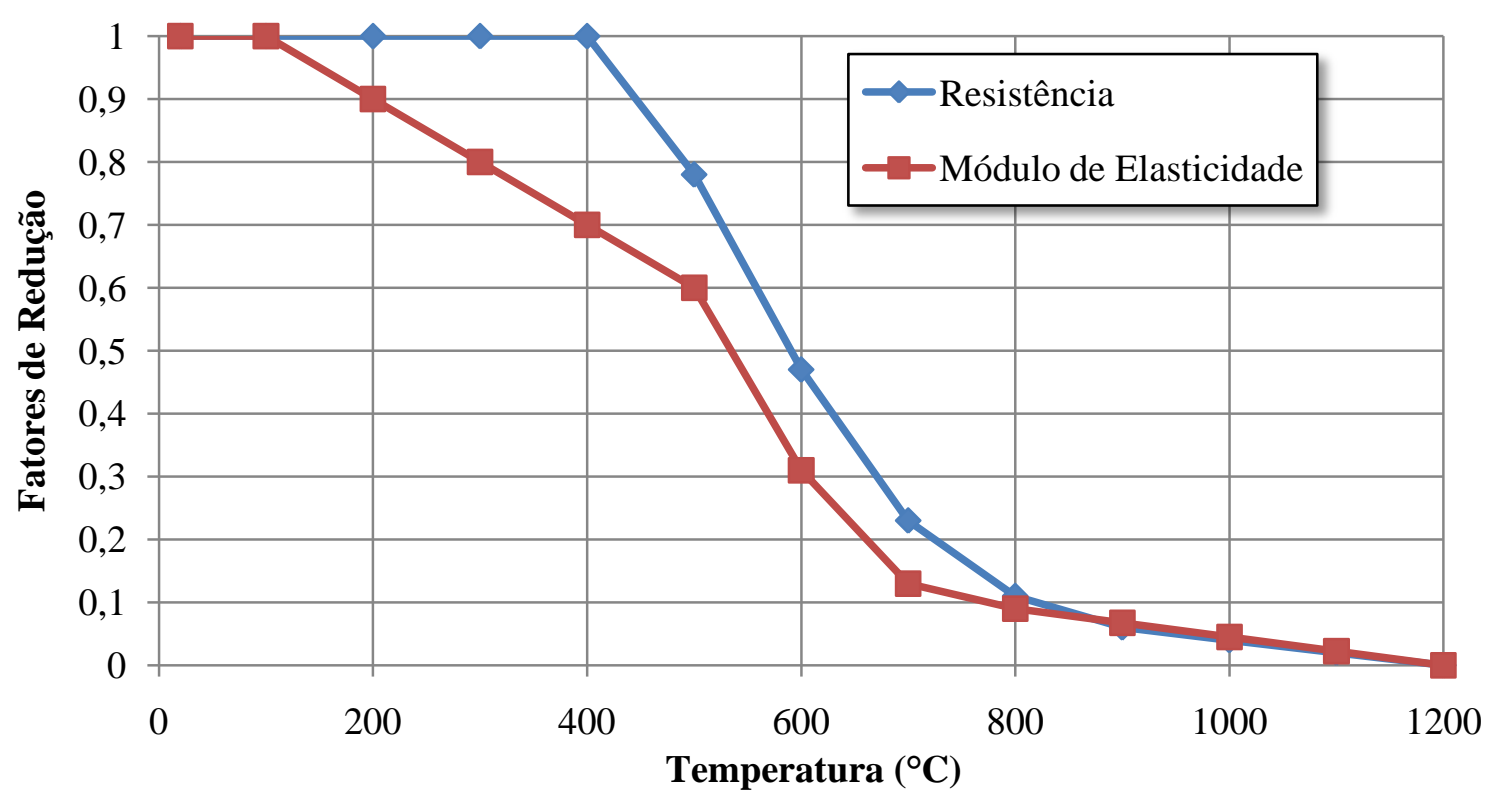

Figura 3.7 - Variação dos fatores de redução para a resistência ao escoamento e o módulo de elasticidade dos aços com a temperatura.

\subsubsection{Massa Específica}

O valor a ser adotado para massa específica do aço $\left(\rho_{\mathrm{a}}\right)$ pode ser considerado independente da variação da temperatura, e será aqui admitido igual $7.850 \mathbf{~ k g} / \mathbf{m}^{3}$, conforme ABNT NBR 14323:1999.

\subsubsection{Condutividade Térmica}

A condutividade térmica do aço apresenta variação com a temperatura de acordo com o conjunto da Equação 3.5, com base no EUROCODE 3 parte 1.2 e com unidade em $\mathrm{W} / \mathrm{m}^{\circ} \mathrm{C}$, devidamente esquematizada na forma gráfica conforme Figura 3.8, na qual se faz também comparações com o valor proposto pela norma brasileira ABNT NBR 14323:1999 para fins de aplicação de procedimento simplificado de dimensionamento proposto pela mesma.

$$
\lambda_{a}\left(\theta_{a}\right)=\left\{\begin{array}{cc}
54-3,33 \times 10^{-2} \theta_{a} & \rightarrow 20^{\circ} \mathrm{C} \leq \theta_{a}<800^{\circ} \mathrm{C} \\
27,3 & \rightarrow 800^{\circ} \mathrm{C} \leq \theta_{a}<1200^{\circ} \mathrm{C}
\end{array}\right.
$$




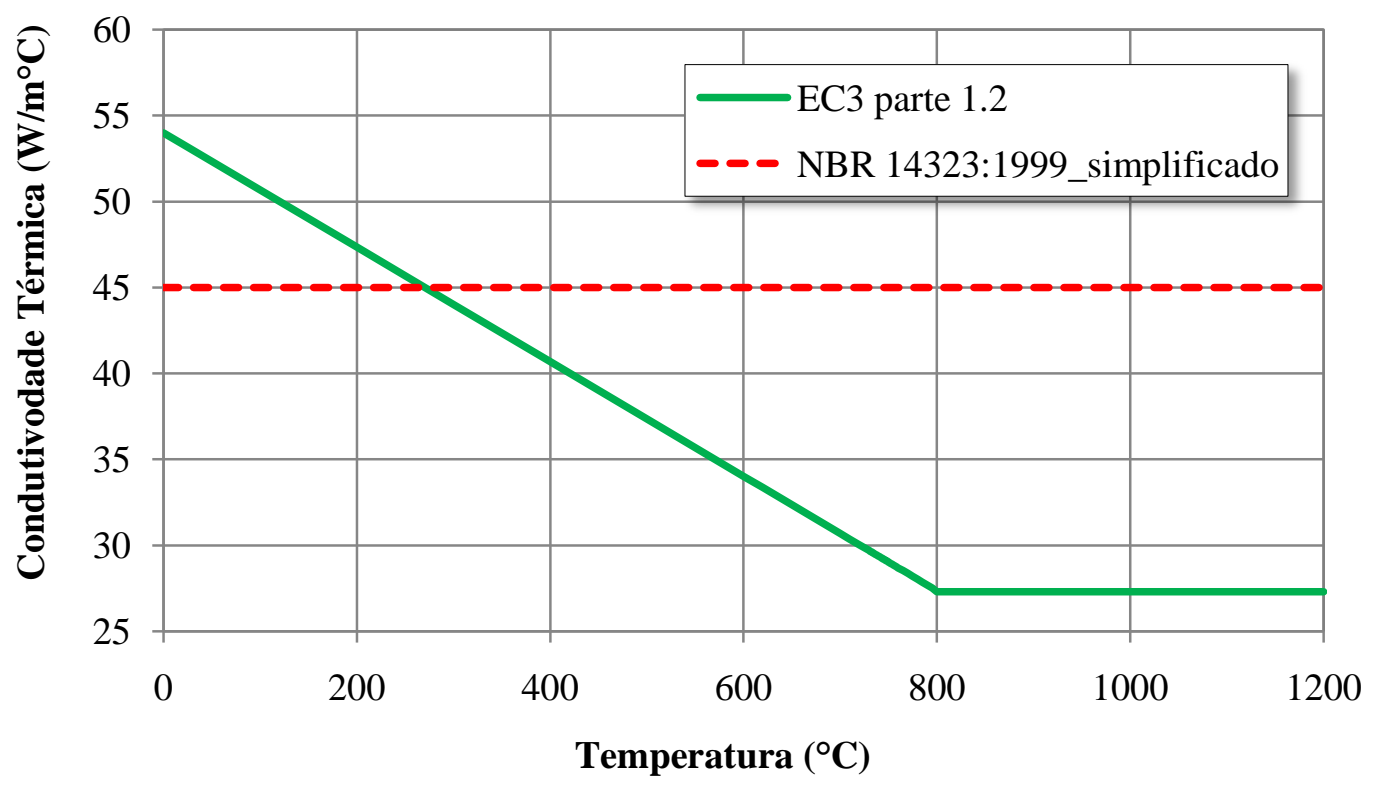

Figura 3.8 - Valores referentes à condutividade térmica para os aços estruturais.

A ABNT NBR 14323:1999 sugere as mesmas equações do EUROCODE 3 parte 1.2, mas para análises simplificadas, permite adotar $\lambda_{\mathrm{a}}=45 \mathrm{~W} / \mathrm{m}^{\circ} \mathrm{C}$.

\subsubsection{Calor Específico}

O calor específico adotado para os aços estruturais pode ser determinado por meio do conjunto de Equações 3.6, cuja unidade se apresenta em $\mathrm{J} / \mathrm{kg}^{\circ} \mathrm{C}$, as quais também são apresentadas na forma gráfica conforme apresenta a Figura 3.9.

$c_{a}\left(\theta_{a}\right)= \begin{cases}425+7,73 \times 10^{-1} \theta_{a}-1,69 \times 10^{-3} \theta_{a}{ }^{2}+2,22 \times 10^{-6} \theta_{a}^{3} & \rightarrow 20^{\circ} \mathrm{C} \leq \theta_{a}<600^{\circ} \mathrm{C} \\ 666+\frac{13002}{738-\theta_{a}} & \rightarrow 600^{\circ} \mathrm{C} \leq \theta_{a}<735^{\circ} \mathrm{C} \\ 545+\frac{17820}{\theta_{a}-731} & \rightarrow 735^{\circ} \mathrm{C} \leq \theta_{a}<900^{\circ} \mathrm{C} \\ 650 & \rightarrow 900^{\circ} \mathrm{C} \leq \theta_{a}<1200^{\circ} \mathrm{C}\end{cases}$ 


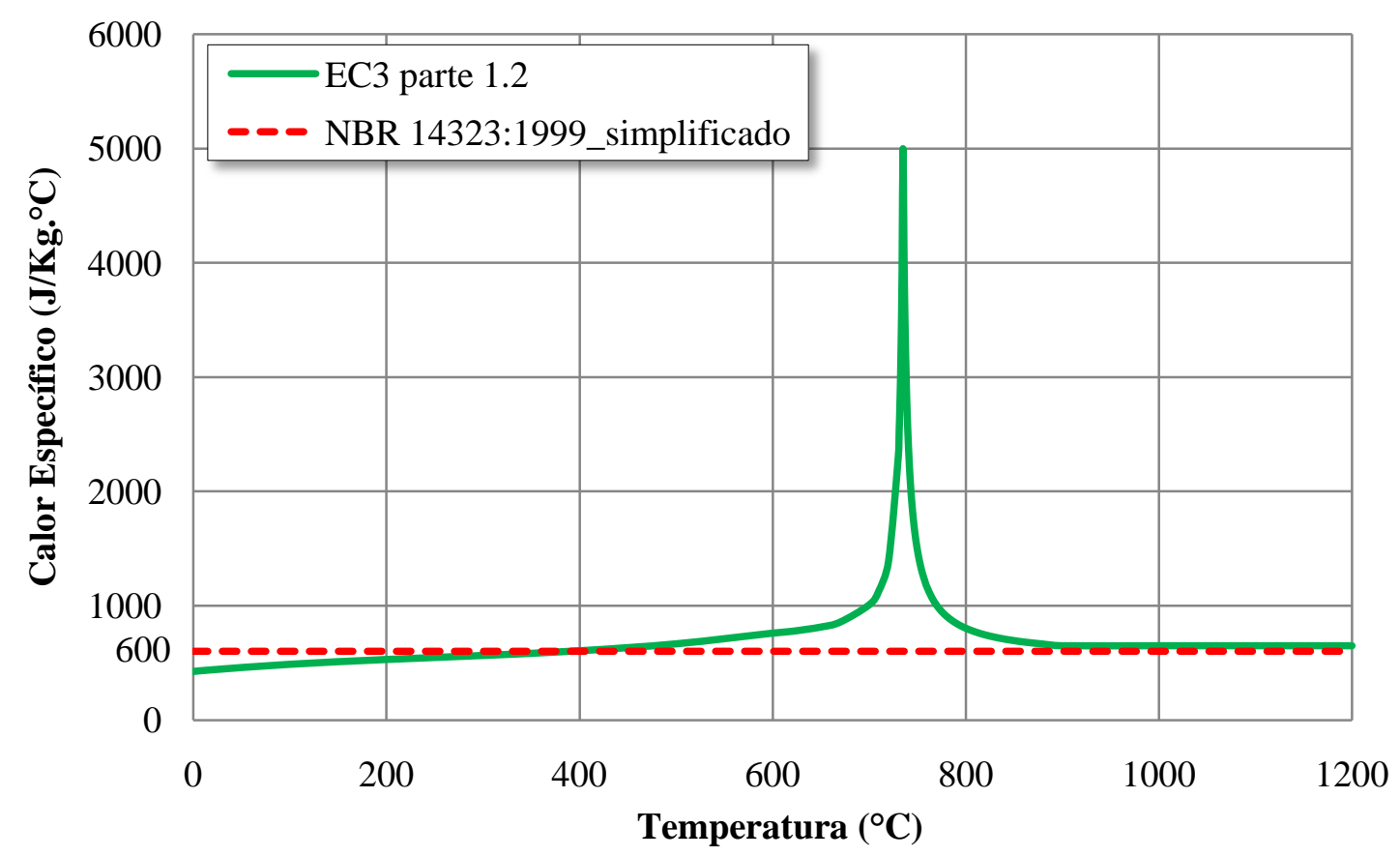

Figura 3.9 - Valores referentes ao calor específico para aços estruturais.

A ABNT NBR 14323:1999 sugere as mesmas equações do EUROCODE 3 parte 1.2, mas, para análises simplificadas permite adotar $\mathrm{c}_{\mathrm{a}}=600 \mathrm{~J} / \mathrm{kg}^{\circ} \mathrm{C}$.

\subsubsection{Dilatação Térmica}

O alongamento dos aços estruturais pode ser determinado pelas equações que seguem, em que $\ell$ é o comprimento a $20^{\circ} \mathrm{C}, \Delta \ell$ é o alongamento térmico, $\theta_{\mathrm{a}}$ a temperatura do aço e $\Delta \ell / \ell$ o valor adimensional do alongamento térmico.

$$
\frac{\Delta \ell}{\ell}\left(\theta_{a}\right)= \begin{cases}1,2 \times 10^{-5} \theta_{a}+0,4 \times 10^{-8} \theta_{a}^{2}-2,416 \times 10^{-4} & \rightarrow 20^{\circ} C \leq \theta_{a}<750^{\circ} C \\ 1,1 \times 10^{-2} & \rightarrow 750^{\circ} C \leq \theta_{a}<860^{\circ} C \\ 2 \times 10^{-5} \theta_{a}-6,2 \times 10^{-3} & \rightarrow 860^{\circ} C \leq \theta_{a}<1200^{\circ} C \\ 1,4 \times 10^{-5}\left(\theta_{a}-20\right) & \rightarrow N B R 14323: 1999\end{cases}
$$

A Figura 3.10 demonstra graficamente essas equações com o valor adimensional do alongamento térmico em função da temperatura, bem como o valor sugerido pela ABNT NBR 14323:1999 para análises simplificadas, apesar de também prescrever as mesmas equações do EUROCODE 3 parte 1.2. 


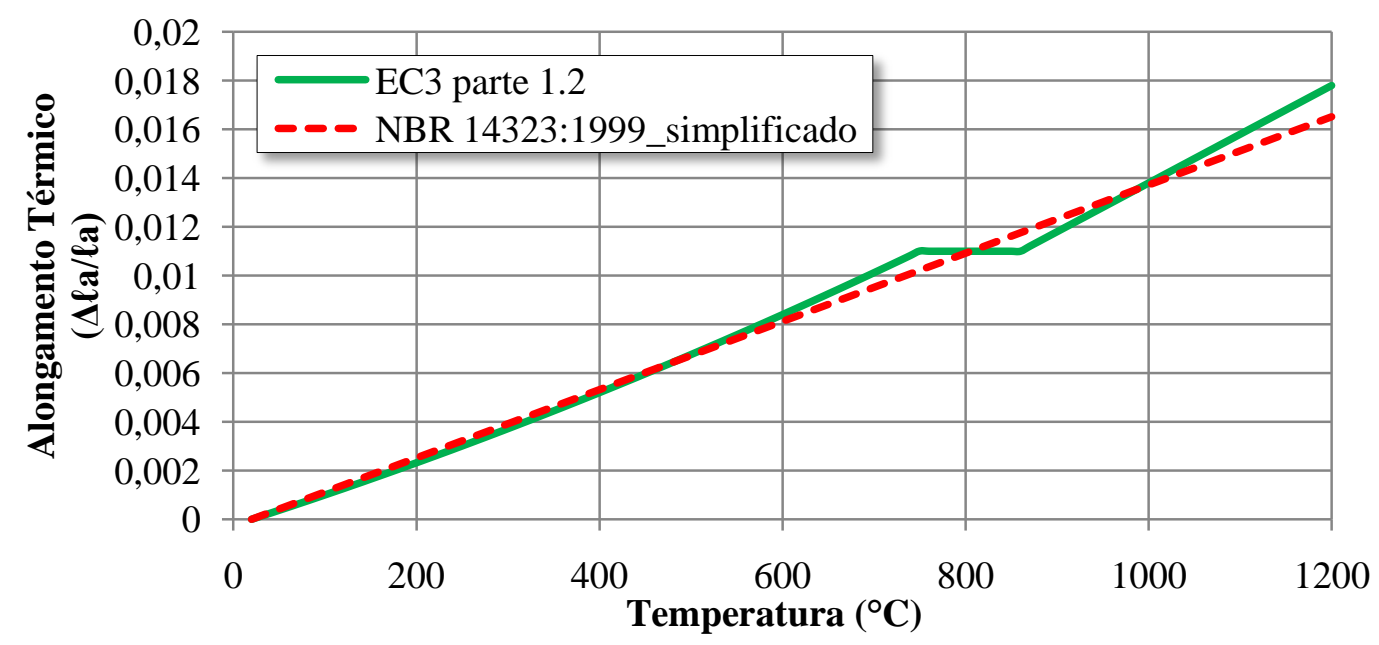

Figura 3.10 - Valores referentes ao alongamento térmico para os aços estruturais.

Em Silva et al. (2008) e em diversas outras bibliografias que trazem informações sobre as propriedades térmicas do aço (ou de outros materiais), o coeficiente de dilatação térmica $\alpha$ é apresentado conforme a Equação 3.8 e exibida graficamente na Figura 3.11. Seu conjunto de equações é correspondente à mesma Equação 3.7, porém com todos os seus termos divididos pela variável da temperatura, indicando a dimensão ${ }^{\circ} \mathrm{C}^{-1}$ para o parâmetro $\alpha$. Seu valor simplificado sugerido pela ABNT NBR 14323:1999 é a constante $1,4 \times 10-5^{\circ} \mathrm{C}^{-1}$.

$$
\alpha\left(\theta_{a}\right)= \begin{cases}\frac{1,2 \times 10^{-5}+0,4 \times 10^{-8} \theta_{a}-\frac{2,416 \times 10^{-4}}{\theta_{a}}}{\theta_{a}} & \rightarrow 20^{\circ} \mathrm{C} \leq \theta_{a}<750^{\circ} \mathrm{C} \\ 2 \times 10^{-5}-\frac{6,2 \times 10^{-3}}{\theta_{a}} & \rightarrow 750^{\circ} \mathrm{C} \leq \theta_{a}<860^{\circ} \mathrm{C} \\ 1,4 \times 10^{-5}\left(1-\frac{20}{\theta_{a}}\right) & \rightarrow N B 0^{\circ} \mathrm{C} \leq \theta_{a}<1200^{\circ} \mathrm{C} 14323: 1999\end{cases}
$$

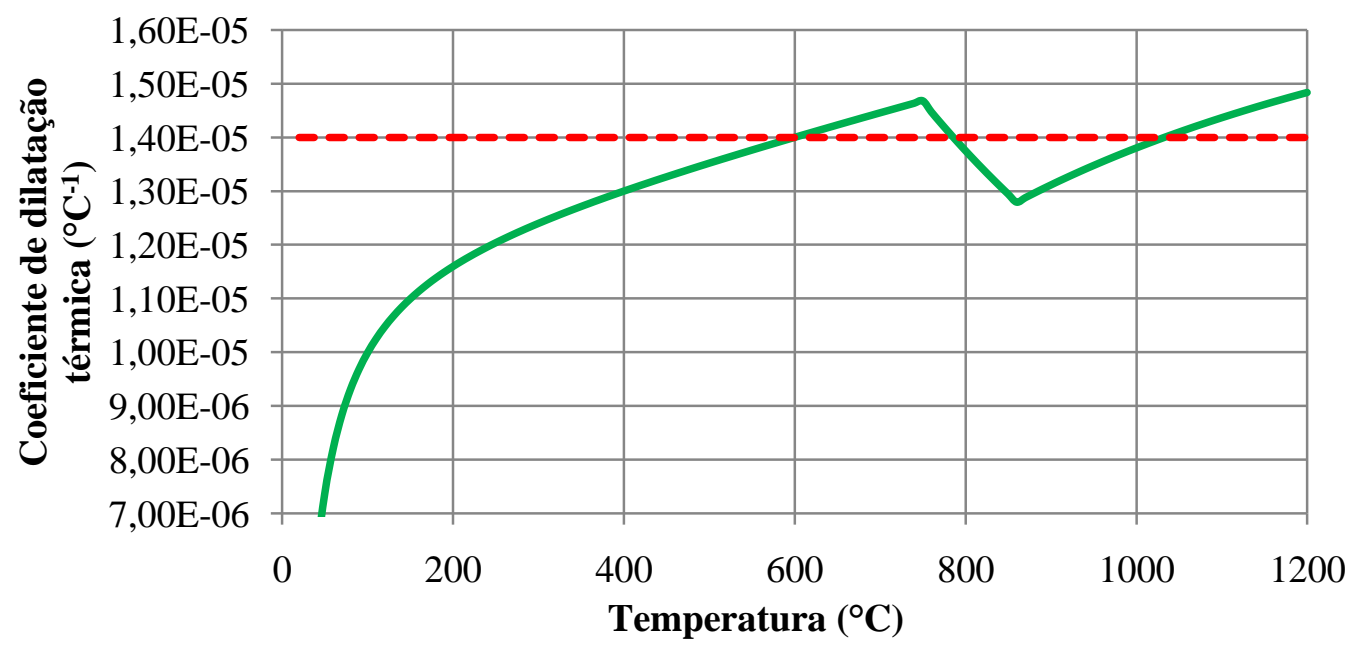

Figura 3.11 - Coeficiente de dilatação térmica dos aços. 


\subsection{ARGAMASSA PARA REVESTIMENTO - PROPRIEDADES}

Para tornar possível a comparação dos resultados com Silva, Correia e Rodrigues (2008), a Tabela 3.3 apresenta as propriedades térmicas da argamassa utilizada no revestimento das paredes que compõem o modelo experimental e numérico, juntamente com o pilar metálico. Será possível observar nos capítulos seguintes a forma como a argamassa foi introduzida no modelo.

Tabela 3.3 - Propriedades térmicas da argamassa.

\begin{tabular}{cccc}
\hline \multirow{2}{*}{$\begin{array}{c}\text { Temperatura } \\
\left({ }^{\circ} \mathrm{C}\right)\end{array}$} & \multicolumn{3}{c}{ Concreto/argamassa de cimento e areia } \\
\cline { 2 - 4 } & $\begin{array}{c}\text { Calor específico (umid. }=1,5 \%) \\
\left(\mathrm{J} / \mathrm{kg}^{\circ} \mathrm{C}\right)\end{array}$ & $\begin{array}{c}\text { Massa específica } \\
\left(\mathrm{kg} / \mathrm{m}^{3}\right)\end{array}$ & $\begin{array}{c}\text { Condutividade Térmica } \\
\left(\mathrm{W} / \mathrm{m}^{\circ} \mathrm{C}\right)\end{array}$ \\
\hline 20 & 900 & 2400 & 1,33 \\
100 & 900 & 2400 & 1,23 \\
115 & 1470 & 2400 & 1,21 \\
200 & 1000 & 2352 & 1,11 \\
300 & 900 & 2316 & 1,00 \\
400 & 1100 & 2280 & 0,91 \\
500 & 1100 & 2280 & 0,82 \\
600 & 1100 & 2280 & 0,75 \\
700 & 1100 & 2280 & 0,69 \\
735 & 1100 & 2280 & 0,67 \\
736 & 1100 & 2280 & 0,67 \\
800 & 1100 & 2280 & 0,64 \\
900 & 1100 & 2280 & 0,60 \\
1000 & 1100 & 2280 & 0,57 \\
1100 & 1100 & 2280 & 0,55 \\
1200 & 1100 & 2280 & 0,55 \\
1500 & 1100 & 2280 & 0,60 \\
\hline
\end{tabular}

FONTE: Silva, Correia e Rodrigues (2008) 
Dissertação de Mestrado 


\section{RESTRIÇÃO AXIAL E DEFORMAÇÕES TÉRMICAS - Considerações}

\subsection{COMENTÁRIOS PRELIMINARES}

Um elemento estrutural quando submetido a uma elevação de temperatura tende a se expandir em todas as direções. Os elementos lineares (barras, por exemplo), possuem dilatação predominante na direção axial, fenômeno este denominado dilatação térmica, conforme representado pela Equação 4.1.

$$
\varepsilon_{\text {térmica }}=\alpha \Delta \theta
$$

Quando as dilatações térmicas são livres para se desenvolverem não introduzem esforços axiais adicionais em resposta ao aumento do comprimento da barra, sendo a deformação total exclusivamente devida à dilatação térmica. Em contrapartida, quando as deformações térmicas são restringidas (total ou parcialmente), a dilatação térmica provoca deformações mecânicas e, consequentemente, introduzem tensões internas adicionais. No contexto do presente trabalho, a consideração da restrição axial corresponde à reação da estrutura sobre um elemento isolado submetido ao aquecimento.

Formas de avaliar os efeitos térmicos em elementos estruturais consistem em análises experimentais, analíticas e numéricas. Os ensaios em elementos isolados possuem geralmente custos elevados, pois são realizados em escala real, como, por exemplo, aqueles realizados no laboratório britânico "Cardington Laboratory of the Building Research Establishment $(B R E)$ ". O objetivo dos ensaios em escala real é compreender melhor o comportamento global da estrutura e fornecer dados para fins de comparação com testes em elementos isolados e, consequentemente, para as estratégias numéricas propostas por diversos 
pesquisadores, com vistas a simular o comportamento de estruturas ou de elementos isolados em situação de incêndio.

Outra forma de analisar estruturas em elevadas temperaturas com restrição (axial e rotacional) consiste de análises numéricas. Em Valente e Neves (1999) se estudou numericamente, por meio do código FINEFIRE, desenvolvido com base no método dos elementos finitos, a influência das restrições à deformação e à rotação (decorrentes da interação com outras partes do sistema estrutural) em pilares metálicos solicitados axialmente em situação de incêndio, conforme esquematiza a Figura 4.1. De acordo com a última referência, a rigidez da ligação com outros elementos da estrutura restringe as deformações e distorções provocadas pela ação térmica no pilar.
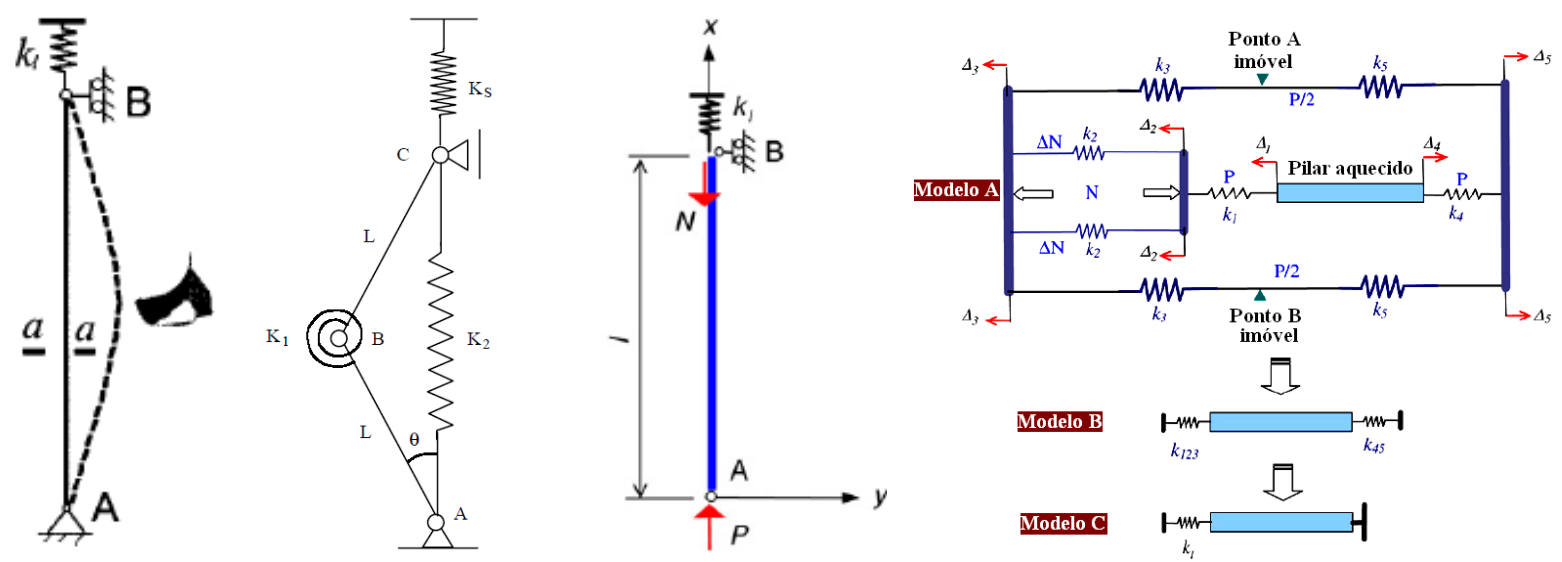

Figura 4.1 - Estratégia de modelagem para a consideração da restrição axial.

Os resultados e análises, tanto em contexto experimental quanto numérico, servem de base para revisão e complementação de códigos normativos, como aqueles prescritos pelo EUROCODE ou pela norma brasileira, por exemplo. Em Valente e Neves (1999) afirma-se que pelo EUROCODE 3 parte 1.2, na sua versão de 1995, os projetos em situação de incêndio consideravam apenas as situações limite de extremidade livre ou apoios fixos, e que os cálculos só eram aceitáveis para pilares robustos ou quando o pórtico proporcionava considerável rigidez rotacional para o pilar, ou seja, para restrição axial elevada e rigidez rotacional suficientemente baixa a temperatura crítica real dos pilares de aço pode ser muito inferior àquela calculada de acordo com as simplificações propostas pela norma.

A versão atual do EUROCODE 3 parte 1.2, de 2005, permite três formas de análise: elementos isolados, partes da estrutura ou análise global; sendo que para todas elas o modelo 
adotado para análise em situação de incêndio deverá refletir o comportamento esperado da estrutura global.

Para a análise de elementos isolados pode ser feita a simplificação da ação do incêndio ao considerar a resistência do elemento estrutural igual à resistência de projeto em temperatura ambiente reduzida por um fator tomado, por simplificação, igual a 0,65. Considera também que apenas os efeitos das deformações térmicas resultantes de gradientes térmicos da seção transversal precisam ser considerados e os efeitos da deformação térmica axial podem ser desprezados, bem como as condições de contorno podem ser assumidas inalteradas com a exposição ao incêndio.

Ao analisar partes da estrutura, o EUROCODE 3 parte 1.2 diz que as reações de apoio, forças internas e momentos no contorno podem ser obtidos de uma análise em temperatura ambiente. A interação da parte da estrutura a ser analisada com o restante da estrutura poderá ser aproximada como invariável durante a exposição ao fogo. As propriedades do material, rigidez dos elementos e efeitos da expansão e deformação térmica poderão ser levados em conta, porém as condições de contorno da parte da estrutura analisada com o restante da estrutura podem ser assumidas como invariável com a exposição ao fogo.

Quando proceder à análise global da estrutura, segundo o EUROCODE 3 parte 1.2, todos os parâmetros que influenciam o colapso da estrutura em situação de incêndio podem ser levados em conta, como as propriedades do material dependentes da temperatura, a rigidez dos elementos e efeitos da deformação térmica.

A partir daqui, todas as definições que serão dadas são válidas tanto para vigas quanto para pilares, lembrando que a diferença entre esses dois elementos estruturais é a direção do esforço predominante: se transversal ao eixo da barra será uma viga e, se axial, um pilar. Portanto, os esforços termicamente induzidos com a restrição axial serão predominantemente axiais e, por não apresentarem forças transversais ao seu eixo, as ilustrações a seguir representarão pilares, independente de sua orientação ser horizontal ou vertical.

Se a estrutura apresentar uma restrição axial insuficiente para impedir a dilatação térmica, as deformações se manifestarão na forma de deslocamento das extremidades, produzindo uma resposta predominantemente de deslocamento, como mostra a Figura 4.2. Gradientes térmicos induzem uma curvatura no elemento cujas extremidades estejam livres 
para girar, apresentando grandes flechas. As propriedades térmicas do material e rigidez do elemento, efeitos da expansão térmica e deformação poderão ser levadas em conta.

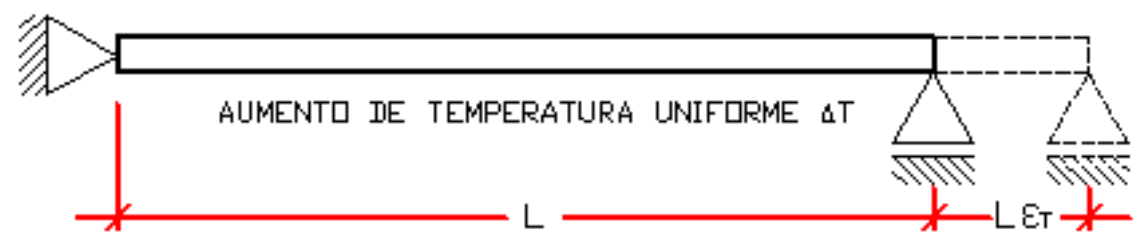

Figura 4.2 - Aquecimento uniforme em uma barra simplesmente apoiada.

\subsection{ANÁLISE DA DILATAÇÃO TÉRMICA CONSIDERANDO}

\section{EXTREMIDADES EM APOIOS INDESLOCÁVEIS}

Quando os deslocamentos são restritos em suas extremidades de modo que as translações estejam impedidas, são produzidas deformações mecânicas opostas às deformações da dilatação térmica, impondo reações axiais contrárias à tendência de expansão, conforme observado na Equação 4.2 e esquematizado na Figura 4.3.

$$
0=\varepsilon_{\text {mecânica }}+\varepsilon_{\text {térmico }} \quad \text { ou } \quad-\varepsilon_{\text {mecânica }}=\varepsilon_{\text {térmico }}
$$

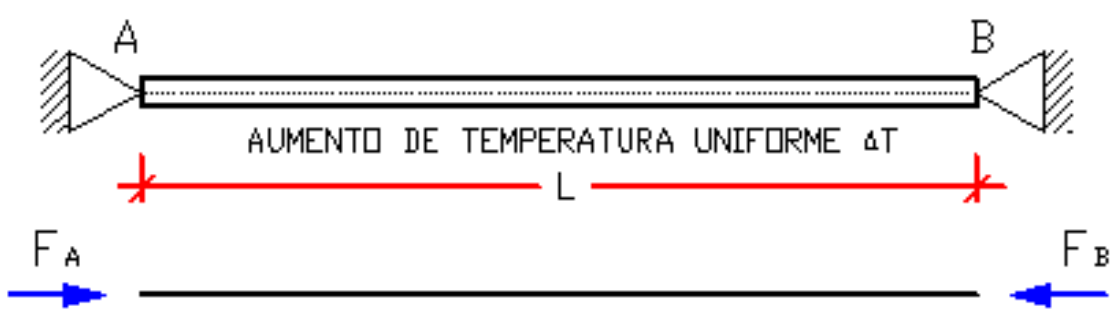

Figura 4.3 - Diagrama de Corpo Livre de barra axialmente restringida sob ação de aquecimento uniforme.

Fica claro que, nesse caso, a deformação total resulta nula (sem deslocamentos), uma vez que a dilatação térmica é cancelada por contração igual e oposta causada pela força $\mathrm{F}$. Tal força pode ser compreendida como uma tensão axial uniforme $(\sigma)$ na barra igual a $E \varepsilon_{\text {mecânica. }}$. A magnitude da força F é dada pela Equação 4.3.

$$
\mathrm{F}=\mathrm{EA} \varepsilon_{\text {mecânica }}=-\mathrm{EA} \varepsilon_{\text {térmica }}=-\mathrm{EA} \alpha \Delta \theta
$$


Para o caso relatado na Figura 4.3, caso a temperatura aumente indefinidamente, duas possíveis respostas básicas, consideradas como casos de referência, poderão ocorrer e serão diretamente dependentes da esbeltez da barra em análise:

a-) Se a barra for suficientemente compacta, então a tensão axial irá, cedo ou tarde, atingir o valor da resistência ao escoamento $\left(f_{y}\right)$ do material. A temperatura fará com que o material venha a atingir o escoamento, dado pela Equação 4.4;

$$
\Delta \theta_{y}=\frac{f_{y}}{E \alpha}
$$

b-) Se a barra for esbelta, então ela irá perder a estabilidade inicial antes de o material atingir a resistência ao escoamento. A carga $F_{c r}$ (Euler) para a barra é dada na forma:

$$
F_{c r}=\frac{\pi^{2} E I}{L^{2}}
$$

A Equação 4.5 é válida para outras condições de restrição se L for interpretado como o comprimento efetivo de instabilidade (KL). Os valores de $\mathrm{K}$ para as principais condições de contorno de barras recomendados pela ABNT NBR 8800:2008, são dados na Tabela 4.1.

\begin{tabular}{|c|c|c|c|c|c|c|}
\hline $\begin{array}{l}\text { A linha tracejada indica a } \\
\text { linha elástica de flambagem }\end{array}$ & (a) & 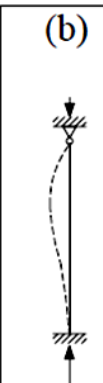 & (c) & (d) & $\begin{array}{l}\text { (e) } \\
b \\
\vdots \\
;\end{array}$ & (f) \\
\hline Valores teóricos de $\mathrm{K}$ & 0,5 & 0,7 & 1,0 & 1,0 & 2,0 & 2,0 \\
\hline Valores recomendados & 0,65 & 0,80 & 1,2 & 1,0 & 2,1 & 2,0 \\
\hline $\begin{array}{l}\text { Código para condição de } \\
\text { apoio }\end{array}$ & 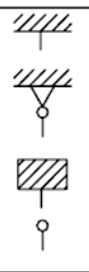 & \multicolumn{5}{|c|}{$\begin{array}{l}\text { Rotação e translação impedidas } \\
\text { Rotação livre, translação impedida } \\
\text { Rotação impedida, translação livre } \\
\text { Rotação e translação livres }\end{array}$} \\
\hline
\end{tabular}

Tabela 4.1 - Coeficiente de instabilidade K para barras isoladas.

FONTE: ABNT NBR 8800:2008 
Ao se igualar as últimas equações pode-se encontrar um procedimento matemático para a determinação da temperatura crítica da instabilidade de Euler, em que $\lambda$ é o índice de esbeltez e $\alpha$ o coeficiente de dilatação térmica, conforme Equação 4.6.

$$
\Delta \theta_{c r}=\frac{\pi^{2}}{\alpha \lambda^{2}}
$$

Hipoteticamente, após atingir a força crítica de instabilidade, se a temperatura continuar a aumentar, então a força de reação da restrição axial total permanecerá constante, supondo um material elástico e sem degradação das propriedades físicas do material pela ação térmica. As deformações de dilatação térmica continuarão a ser acomodadas pela flecha da barra $(\delta)$ como mostrado na Figura 4.4 e na Figura 4.8a. O principal motivo para a ocorrência de grandes flechas é que, ao se impedir a dilatação longitudinal pela restrição do apoio, o elemento estrutural tenta acomodar esse comprimento adicional gerado pela dilatação térmica com o arqueamento da barra.

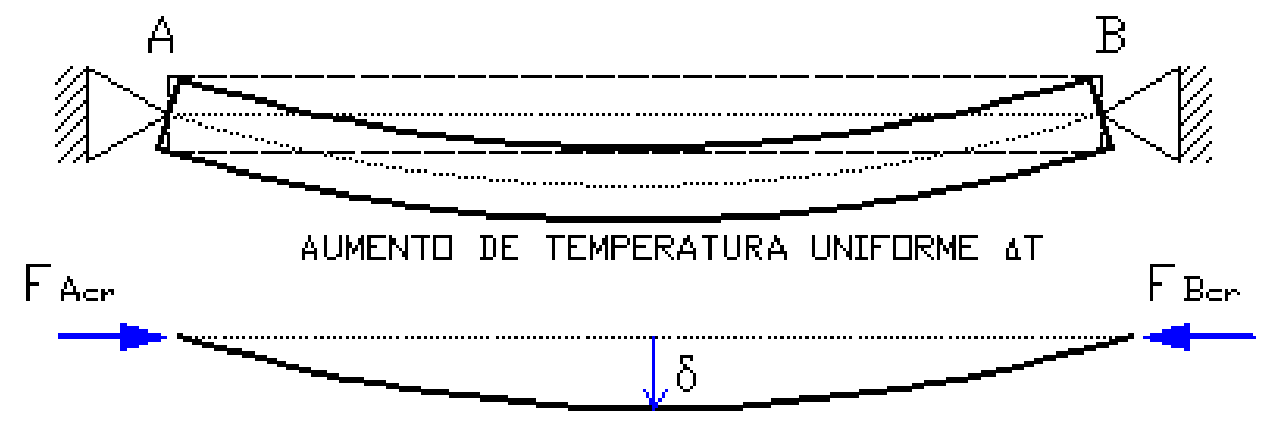

Figura 4.4 - Diagrama de Corpo Livre da força crítica de instabilidade da barra.

Os casos em análise representam duas respostas fundamentais em barras submetidas à dilatação térmica restringida. Qualquer uma das situações destacadas (escoamento ou instabilidade) pode ocorrer por si só (dependendo da esbeltez da barra) ou uma resposta mais complexa também pode ocorrer, consistindo em uma combinação de escoamento e instabilidade.

Segundo Usmani et al. (2001), o fator determinante na resposta real da estrutura ao aquecimento é o modo como ele ocorre, ocasionando diferenças na forma da deformação térmica por meio do aquecimento. Caso haja uma elevação na temperatura média, $\Delta \theta$, da linha de centro da barra de um elemento simplesmente apoiado, estas deformações são puramente de dilatação térmica, ou aumento do comprimento, conforme Figura 4.2. Assim, a deformação 
total é igual à dilatação térmica e não há esforços mecânicos, o que significa que nenhuma tensão se desenvolve.

Caso a temperatura na seção se eleve apresentando um gradiente de temperatura $\left(\nabla \theta_{\mathrm{y}}\right)$ ao longo da altura da seção da barra, entre os lados opostos da seção, a dilatação térmica ocorrerá em níveis diferentes nos lados opostos, gerando uma curvatura na barra, como mostrado na Figura 4.5.

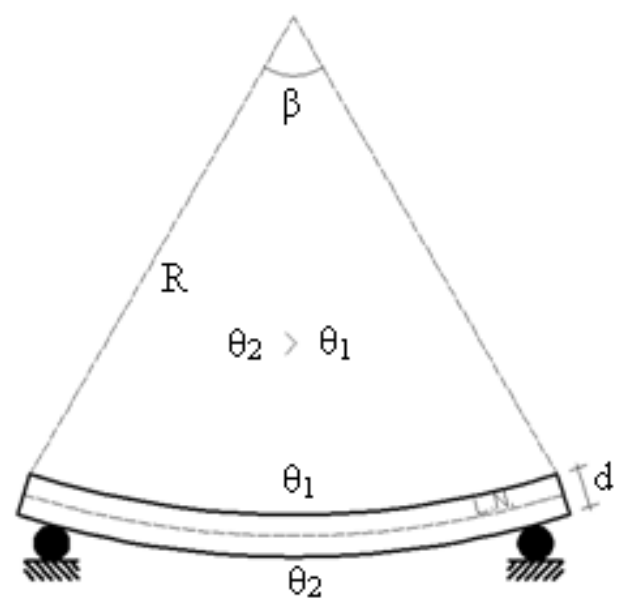

Figura 4.5 - Barra biapoiada sujeita a um dado gradiente térmico.

Em compartimento de dimensões reduzidas ou mesmo moderadas, com um formato regular, pode-se supor que a temperatura do compartimento resultará aproximadamente uniforme a partir de um dado momento. A temperatura dos elementos estruturais no compartimento dependerá do material combustível, da geometria, do projeto (como o isolamento, por exemplo), entre outros. Vigas e lajes próximas ao teto do compartimento poderão estar submetidas a elevados gradientes de temperaturas devido ao baixo coeficiente de transferência de calor do concreto. Por conseguinte, as superfícies expostas ao fogo estarão a uma temperatura muito mais elevada do que as superfícies do lado de fora do compartimento. Isso faz com que as camadas do lado do compartimento expandam muito mais do que as do exterior induzindo flexão no elemento.

Se um gradiente térmico uniforme $\nabla \theta_{\mathrm{y}}$, sem aumento da temperatura média, é aplicado a essa barra, como esquematizado na Figura 4.6, o resultado é uma tração termicamente induzida na barra e correspondentes reações no apoio, ao contrário do que ocorre quando há somente a dilatação térmica uniforme, como discutido anteriormente. $\mathrm{O}$ aparecimento da curvatura irá consumir o comprimento retilíneo para compor o novo trajeto curvo da barra, de 
forma a reduzir a distância entre os apoios. Caso esses sejam fixos, aparecerão esforços de tração no elemento.

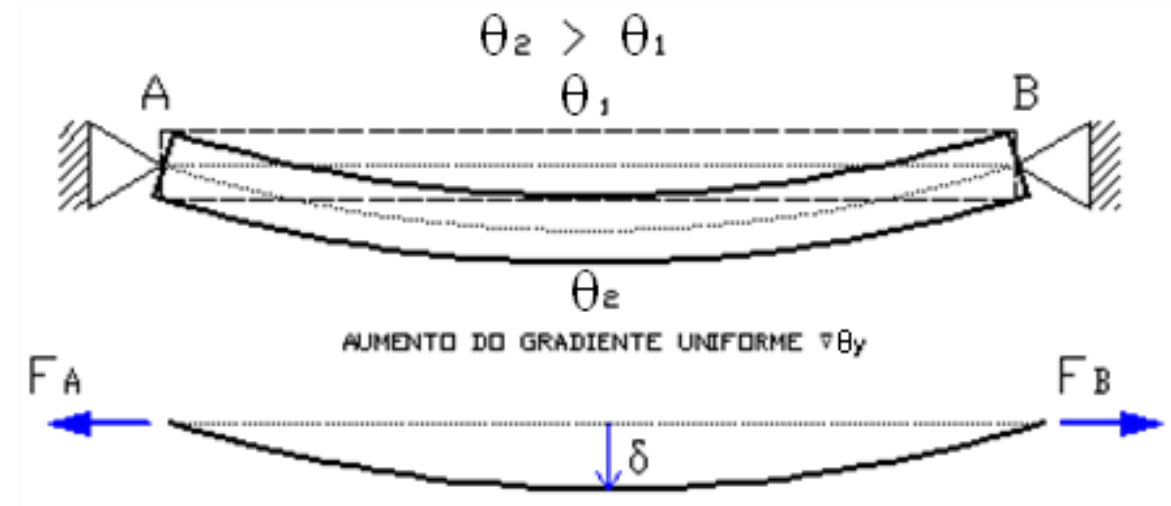

Figura 4.6 - Diagrama de Corpo Livre de uma barra biapoiada axialmente restringida submetida a gradiente de temperatura.

Essa situação de curvatura provocada por gradiente térmico foi observada por Kimura (2009) por meio de modelos matemáticos mais complexos. Na última referência, o sentido da imperfeição geométrica global inicial em relação à fonte de calor mostrava influência no tempo resistente de exposição à ação de incêndio do elemento em questão de duas formas distintas, conforme Figura 4.7.

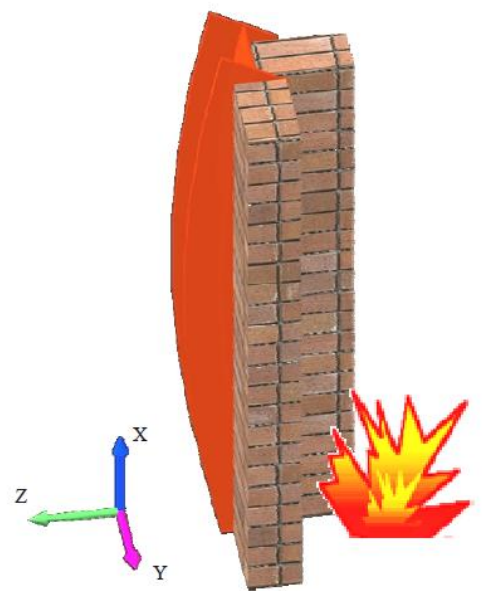

(a)

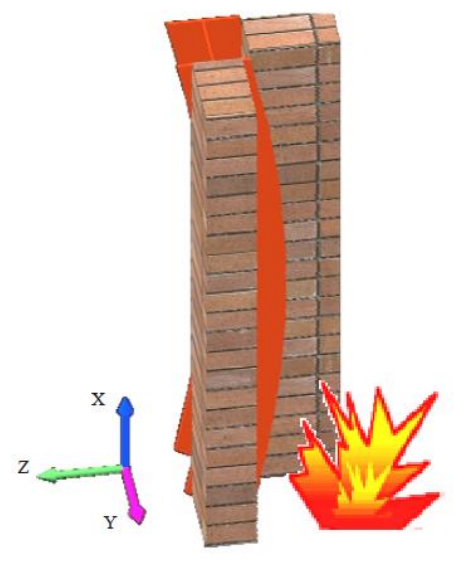

(b)

Figura 4.7 - Sentido da imperfeição geométrica inicial global em relação à fonte de calor em que é (a) positiva quando a concavidade está voltada para a fonte de calor e (b) negativa com a concavidade oposta à fonte de calor. FONTE: Kimura (2009)

Caso a concavidade estivesse voltada para a face do aquecimento, conforme Figura 4.7a, a curvatura provocada pelo gradiente térmico e sua consequente dilatação não uniforme “corrige” momentaneamente a imperfeição, tornando o elemento mais retilíneo inicialmente, 
reduzindo os esforços do momento $\mathbf{F}-\boldsymbol{\delta}$ provocados pela excentricidade da linha de ação da carga axial em relação a linha média do perfil, como na Figura 4.4. A segunda possibilidade ocorre quando a concavidade está voltada para o lado oposto à face de aquecimento como na Figura 4.7b, ocorrendo uma curvatura sempre crescente e consequente aumento contínuo do momento $\mathrm{F}-\delta$.

O padrão de desenvolvimento das flechas de uma única barra e a formato dessa curva para diferentes valores de esbeltez, assim como o desenvolvimento de esforço axial, são mostradas na Figura 4.8a e na Figura 4.8b, extraídas de Rotter et al. (1999).

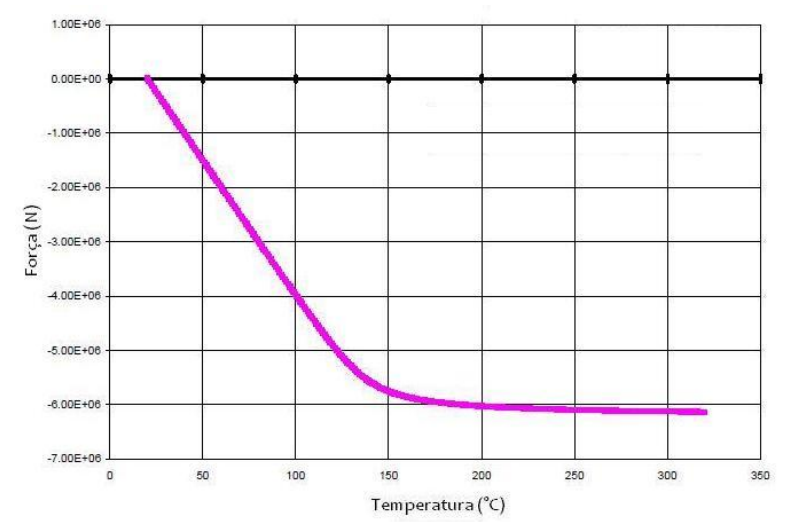

(a)

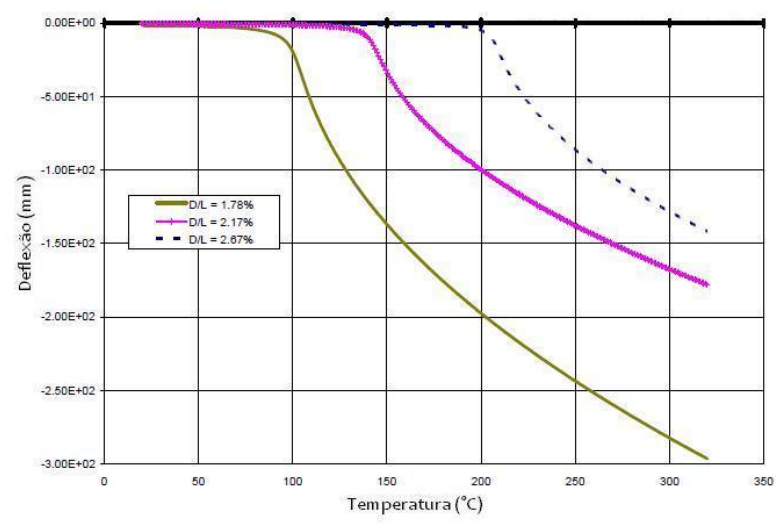

(b)

Figura 4.8 - (a) Força axial e (b) flecha em barras elásticas de diferentes esbeltezes. FONTE: Rotter et al. (1999)

A trajetória da curva da força axial na Figura 4.8a e as de deslocamento no centro do vão da barra da Figura 4.8b mostram uma resposta estrutural com um comportamento diferenciado nos instantes antes e após a perda da estabilidade inicial. A bifurcação do equilíbrio não é observada quando existe um carregamento transversal ao eixo (como em uma viga), pois um deslocamento inicial já é imposto pela carga. O momento fletor no meio do vão continua a aumentar após a perda da estabilidade inicial, o qual consiste principalmente do momento $\mathrm{F}-\delta$. 


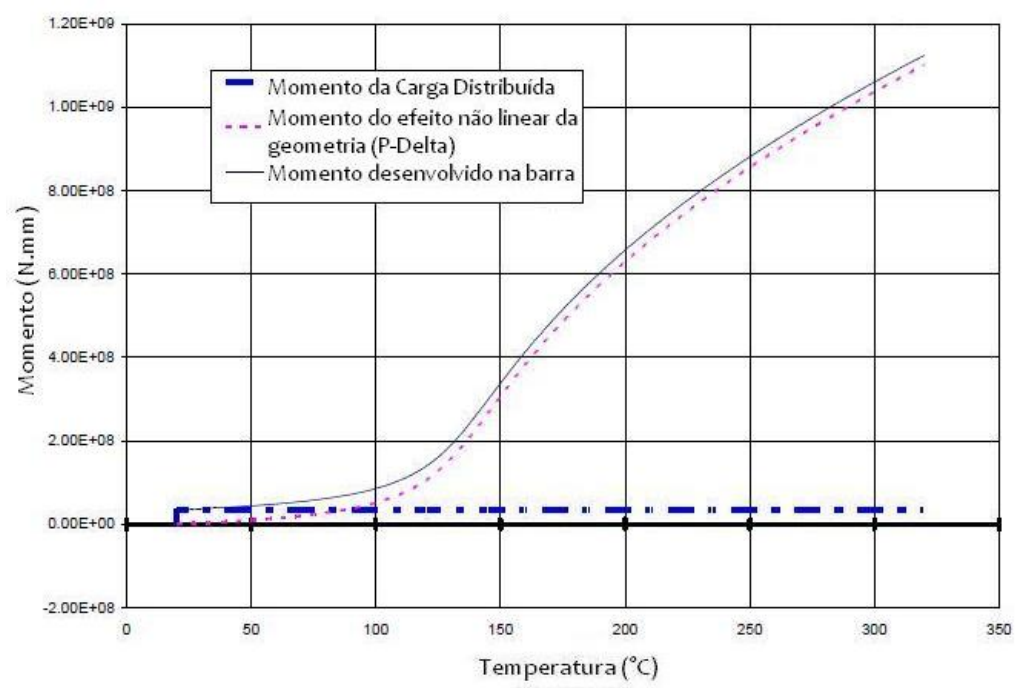

Figura 4.9 - Momento no meio do vão de barra elástica. FONTE: Rotter et al. (1999)

Propriedades elásticas ideais foram assumidas na discussão do caso de instabilidade anteriormente analisada. Se as propriedades do material continuam elásticas, embora com uma degradação uniforme das propriedades físicas com o aumento da temperatura, o padrão de deformação e compressão axial na barra assume a forma das curvas apresentadas na Figura 4.10a e Figura 4.10b, extraídas de Rotter et al. (1999). A redução de rigidez pelo aquecimento reduz a magnitude da força de compressão axial na barra restringida, e quando o material da barra atinge seu limite elástico, uma redução muito mais rápida na força restritiva ocorre com um aumento correspondente na flecha.

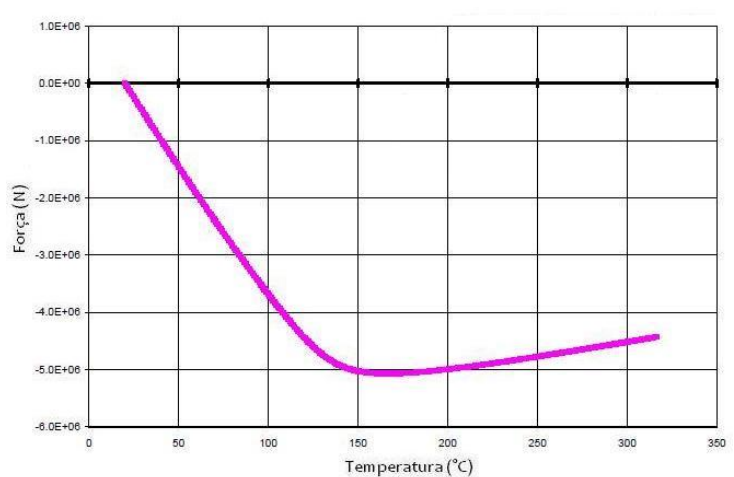

(a)

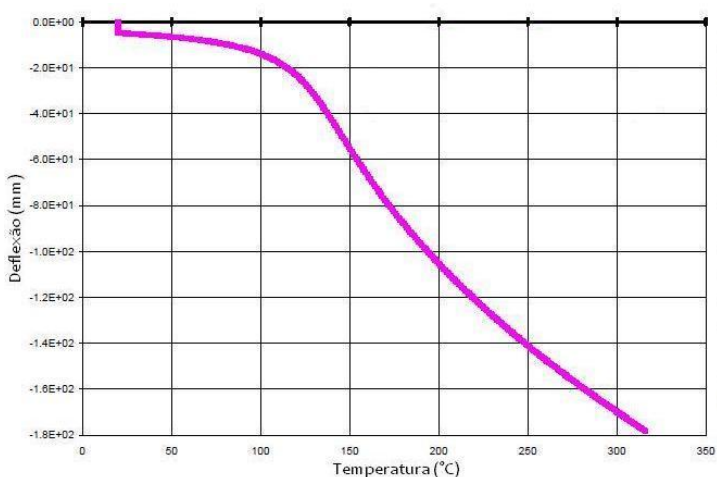

(b)

Figura 4.10 - (a) Força axial e (b) flecha na barra restringida com degradação do material pelo aquecimento. FONTE: Rotter et al. (1999)

Por outro lado, conforme mostra a Figura 4.11, com um gradiente térmico atuando e caso a rotação esteja restringida, haverá o aparecimento de momentos fletores ao longo do comprimento da barra sem que, segundo Rotter et al. (1999), haja a formação de flechas. 


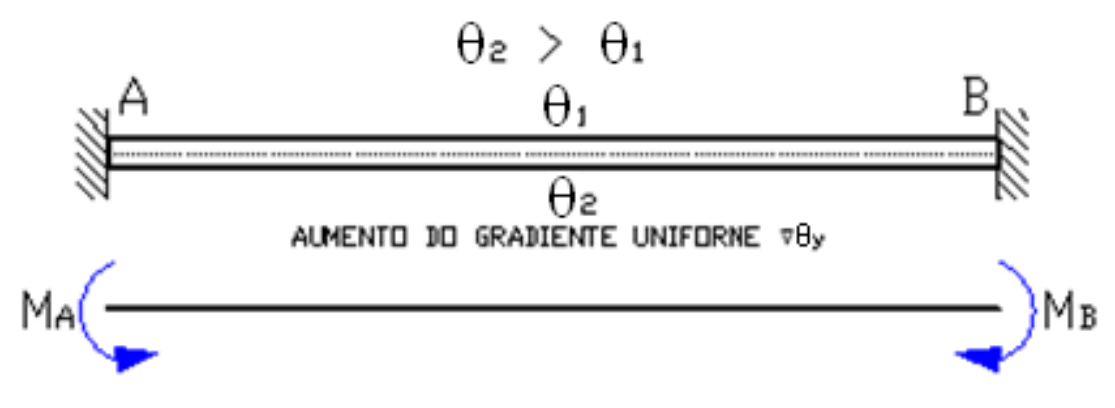

Figura 4.11 - Diagrama de Corpo Livre de uma barra biengastada rotacionalmente restringida submetida a gradiente de temperatura.

Claramente, a resposta de barras reais sujeitas à dilatação térmica restringida consistirá de uma combinação das respostas anteriormente mostradas (aquecimento uniforme e gradiente térmico).

Segundo Usmani et al. (2001), para um mesmo estado de deformação de um elemento pode haver uma grande variedade de estados de tensões, conforme Figura 4.12, considerando a possibilidade de elevadas tensões de compressão quando a dilatação térmica é restringida, bem como reduzidas tensões quando a dilatação e o efeito de curvatura compensam um ao outro. Para casos em que a curvatura provocada pela ação térmica é dominante, ocorre uma tração em elementos restringidos axialmente e livres para girar, enquanto que a restrição rotacional causa o aparecimento de momentos fletores.

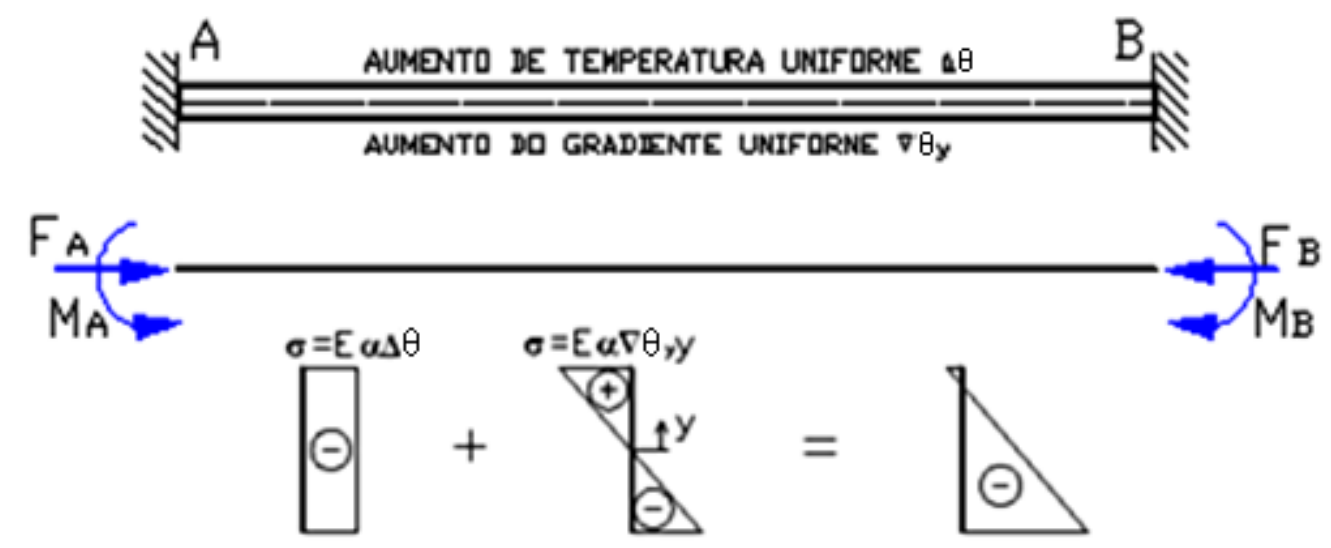

Figura 4.12 - Diagrama de Corpo Livre de uma barra biengastada com ação combinada de dilatação térmica uniforme e gradiente térmico, com rotações restringidas. 


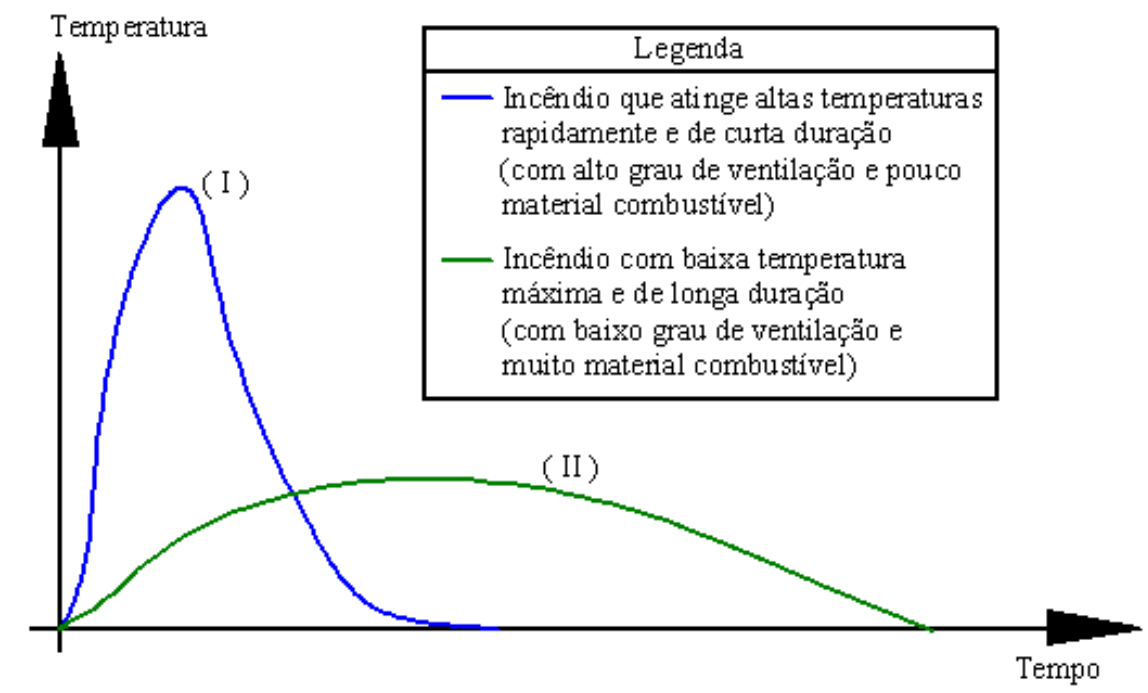

Figura 4.13 - Curvas de elevação de temperatura dos gases de dois incêndios distintos que podem causar elevado gradiente térmico nos elementos estruturais, com baixa temperatura média no elemento (I) ou baixo gradiente com alta temperatura média (II).

Situações em que o aquecimento dos gases do incêndio atinge elevadas temperaturas em poucos minutos e, em seguida se extingue, como o ilustrado pela curva I da Figura 4.13, podem causar gradientes térmicos elevados na estrutura (em pilares mistos, por exemplo, em que o aço resulta mais aquecido se comparado ao núcleo de concreto) com uma temperatura média muito baixa. Por outro lado, situações em que a elevação de temperatura dos gases ocorre em um intervalo de tempo maior, e que atinge apenas temperaturas médias, mas com maior duração até sua extinção, como representado pela curva II da Figura 4.13, pode produzir temperaturas médias consideravelmente altas com baixo gradiente térmico.

\subsection{ANÁLISE DA DILATAÇÃO TÉRMICA CONSIDERANDO}

\section{EXTREMIDADES EM APOIOS DESLOCÁVEIS}

$\mathrm{Na}$ discussão apresentada no item 4.2 foram assumidas restrições axiais perfeitamente rígidas, ou seja, restrições com rigidez infinita, situação essa praticamente impossível de ocorrer em estruturas reais, as quais oferecem apenas restrições parciais. A Figura 4.14 esquematiza uma barra com a configuração mais próxima da realidade, axialmente restringida por uma mola translacional de rigidez $\mathrm{k}_{\mathrm{t}}$, enquanto a Figura 4.15 esquematiza $\mathrm{o}$ comportamento da barra após a força axial atingir a carga crítica de instabilidade. 


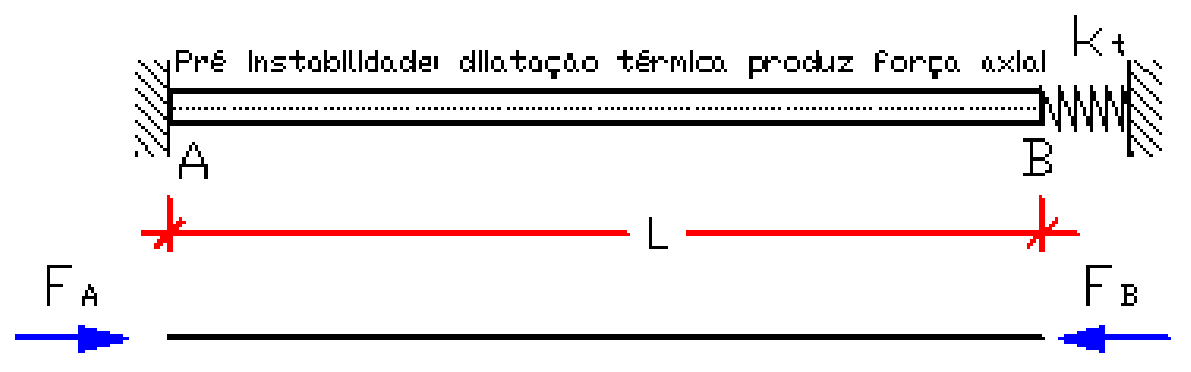

Figura 4.14 - Diagrama de Corpo Livre de uma barra aquecida com restrição axial parcial.

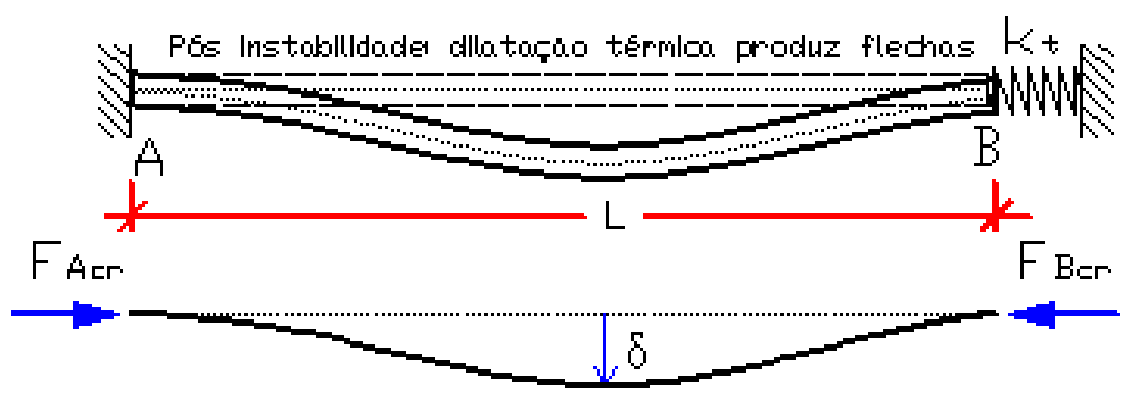

Figura 4.15 - Diagrama de Corpo Livre de uma barra com o desenvolvimento de flecha após a carga crítica de instabilidade.

Segundo Usmani et al. (2001), a tensão de compressão axial desenvolvida pela dilatação térmica passa a ser dada pela Equação 4.7, enquanto a temperatura crítica de instabilidade é dada pela Equação 4.8. Por meio da Equação 4.8 e pela Figura 1.1, no capítulo 1, pode-se observar que a ocorrência de perda da estabilidade pode ser verificada inicialmente para temperaturas baixas (em termos de incêndio) em estruturas cujos apoios exercem uma restrição translacional $\left(\mathrm{k}_{\mathrm{t}}\right)$ da ordem de grandeza da rigidez axial do elemento (EA/L).

$$
\begin{aligned}
& \left.\sigma=\frac{E \alpha \Delta T}{\left(1+E A / k_{t} L\right.}\right) \\
& \Delta \theta_{c r}=\frac{\pi^{2}}{\alpha \lambda^{2}}\left(1+\frac{E A}{k_{t} L}\right)
\end{aligned}
$$

A restrição axial de rigidez infinita representa um apoio fixo, como visto anteriormente. Os resultados analíticos encontrados em Usmani et al. (2001) mostram claramente que a restrição axial reduz a temperatura crítica de instabilidade, especialmente para seções muito esbeltas. Para elementos estruturais de dimensões usuais, com esbeltez próxima a 80 , por exemplo, a temperatura crítica de instabilidade pode resultar da ordem de 
130 a $250^{\circ} \mathrm{C}$, muito abaixo da temperatura onde se inicia a degradação do material (a partir $\operatorname{dos} 400^{\circ} \mathrm{C}$ no caso do aço).

Segundo Rotter et al. (1999) esse limite de temperatura crítica pode ocorrer entre 100 e $200^{\circ} \mathrm{C}$ com apoios fixos e chegar a $300^{\circ} \mathrm{C}$ quando a restrição axial é da ordem da rigidez do elemento de interesse. Segundo a última referência, o comportamento pós instabilidade devido ao acréscimo de esforço axial pela expansão térmica tem um comportamento muito diferente da observada em temperatura ambiente, cujo valor da força axial estática aplicada ao pilar não é afetada pela resposta do elemento já deformado.

Por outro lado, ainda segundo a última referência, devido ao aquecimento, o esforço axial adicional desenvolvido apenas pelo deslocamento axial restringido e o aumento da flecha na fase de pós instabilidade fazem com que haja o encurtamento axial devido à curvatura, reduzindo o esforço adicional e não conduzindo a uma condição instável. A força axial se estabiliza próximo à força crítica de instabilidade e toda a expansão térmica adicional é absorvida pela flecha ao invés de causar aumento de tensão. Rotter et al. (1999) ainda conclui que, para um incêndio compartimentado, esse efeito de deformação lateral pode ser benéfico no sentido em que limita a força adicional gerada, evitando que outros elementos estruturais recebam esta força na forma de reação.

Em Usmani et al. (2001) também é citada a função benéfica do aparecimento das flechas, as quais são normalmente associadas à perda de capacidade resistente nas estruturas sob condições ambientais. No caso de incêndio, essa simples interpretação pode ser discutível. Ambos os mecanismos térmicos discutidos anteriormente (dilatação térmica e encurvamento térmico) resultam em grandes flechas, porém, o estado de tensão que pode ser associado a um elemento estrutural submetido a diferentes proporções desses dois mecanismos não é único para uma determinada flecha observada, uma grande variedade de possibilidades de estados de tensões pode existir.

As possibilidades vão desde grande compressão até tração, ou tensões muito baixas, dependendo da distribuição da temperatura no elemento e das propriedades do material, assim como das condições de restrição. Essas relações, que indicam que as maiores flechas podem reduzir os danos do material e corresponder à maior rigidez do elemento, podem produzir situações estruturais as quais parecem ser contraditórias se vistas de uma perspectiva convencional (temperatura ambiente) de engenharia estrutural. 
A partir da discussão anteriormente apresentada, fica evidente que o efeito das condições de contorno, como o tipo de apoio das extremidades, é de fundamental importância na determinação da resposta dos elementos estruturais às ações térmicas. As principais conclusões indicam que as deformações térmicas se manifestarão como deslocamentos se as extremidades não estiverem restringidas, ou como esforços adicionais se restringidas, sendo força axial (a princípio) para deslocamentos restringidos e momentos fletores para rotações restringidas.

Conforme aspectos discutidos sobre a restrição axial, as restrições rotacionais perfeitas também não podem ser facilmente alcançadas por estruturas reais (exceto em caso de carregamento simétrico em barras contínuas, sem a formação de rótula plástica pela degradação do material). A Figura 4.16 mostra uma barra restringida rotacionalmente nas extremidades por molas, cuja rigidez rotacional é dada por $\mathrm{k}_{\mathrm{r}}$. Neste caso, o momento fletor restritivo aplicado pelas molas dependerá da rotação da barra e vice-versa.

Segundo estudos numéricos realizados e apresentados em Huang, Tan e Ting (2006), até mesmo a mais fraca restrição rotacional poderá aumentar o valor da temperatura crítica devido ao efeito restaurador da forma da barra, ou seja, mantém a barra próxima da forma retilínea por mais tempo. Restrições rotacionais resultam em um aumento dos momentos de rotação até que se forme uma rótula plástica por degradação do material e/ou instabilidade local.

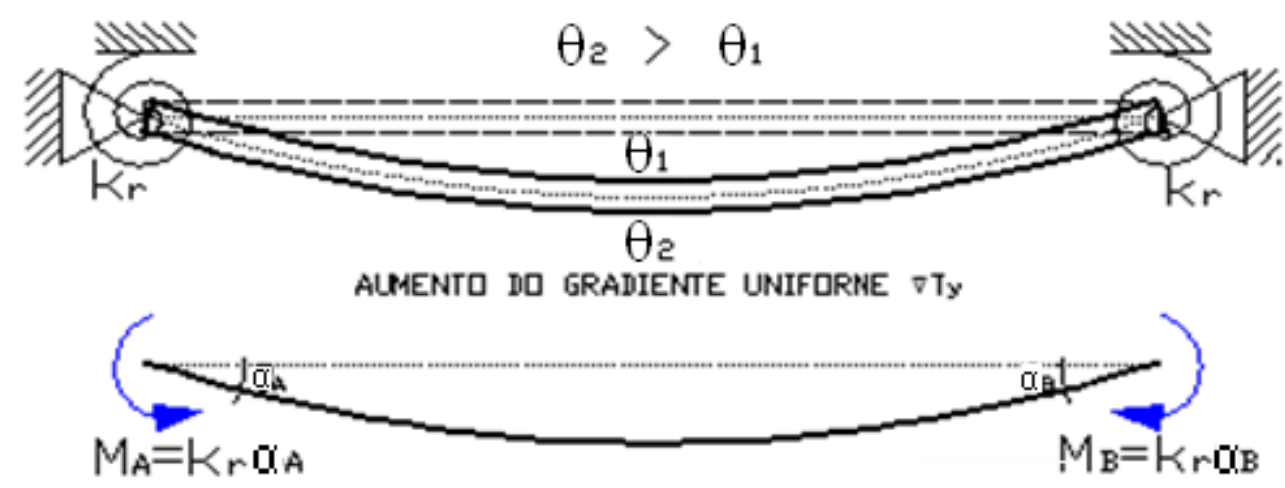

Figura 4.16 - Barra com restrição rotacional finita com gradiente uniforme de temperatura.

Portanto, com relação à restrição axial é possível sintetizar que dilatação térmica restrita introduz esforços de compressão, enquanto que o gradiente térmico (com sua respectiva curvatura) pode introduzir esforços de tração, essa última ocorrendo mais 
especificamente em vigas, uma vez que quando se fala em pilares essa "tração" corresponde, na verdade, a uma redução da força inicial aplicada.

Contudo, pouco foi falado a respeito do comportamento estrutural frente à degradação do material, mais especificamente da resistência e da rigidez. Condições de restrição podem certamente ter um efeito maior sobre a distribuição das forças internas e deslocamentos, do que como foi ilustrado pela análise teórica simples e, possivelmente, mais cedo (sob ação de incêndio) que a ocorrência da degradação das propriedades do material.

\subsection{CRITÉRIOS DE FALHA}

De acordo com Neves, Valente e Rodrigues (2002), em um pilar real de uma estrutura aquecida, o alongamento térmico será elasticamente restringido pela estrutura e, nesse caso, forças de restrição serão desenvolvidas. $\mathrm{O}$ aumento da temperatura irá afetar as propriedades mecânicas que, por sua vez, afetarão o desenvolvimento das forças de restrição. Ignorando por um momento a dependência das propriedades mecânicas à elevação da temperatura, podese afirmar que a evolução dos esforços internos entre o pilar e a estrutura será qualitativamente idêntica à evolução das forças em um ensaio com controle de deslocamentos, como mostrado na Figura 4.17.

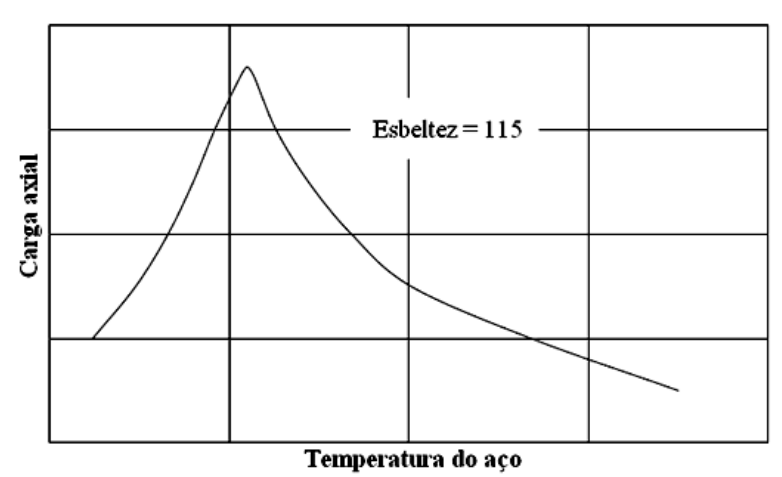

(a)

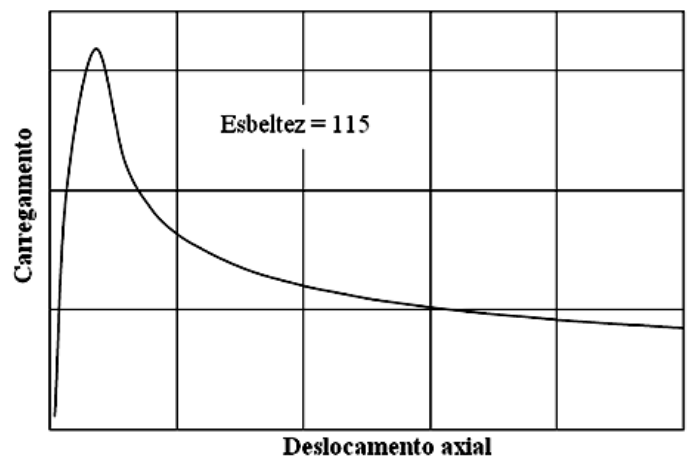

(b)

Figura 4.17 - Desenvolvimento de esforços axial: $(\boldsymbol{a})$ pela elevação da temperatura e $(\boldsymbol{b})$ pelo controle de deslocamento em temperatura ambiente. FONTE: Neves, Valente e Rodrigues (2002)

Ainda em Neves, Valente e Rodrigues (2002) é mostrado um estudo numérico com o código computacional FINEFIRE e experimental realizado no Instituto Superior Técnico de Lisboa onde se variou os níveis de restrição axial para uma barra de esbeltez igual a 133, obtendo um espectro da variação do esforço axial como mostra a Figura 4.18. Para uma 
esbeltez elevada pode-se observar que a falha ocorreu, em todas as situações, por instabilidade do elemento.

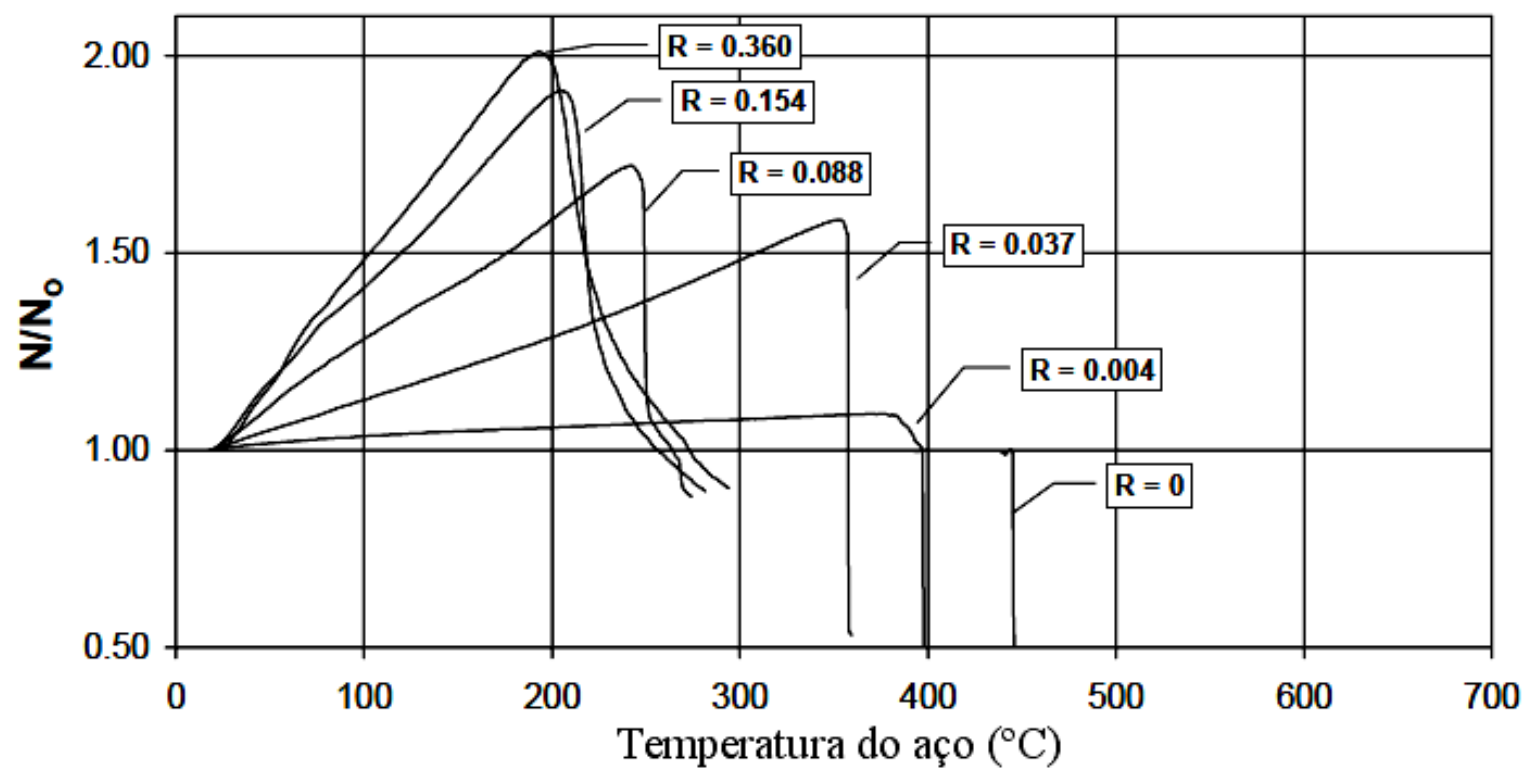

Figura 4.18 - Evolução do esforço axial em barras de aço restringidas axialmente em diferentes níveis. FONTE: Neves, Valente e Rodrigues (2002)

Por meio de análises numéricas e analíticas, utilizando a fórmula de Rankine modificada, vista em Huang e Tan (2003), assim como análises mais complexas com a utilização do MEF, é possível tecer alguns comentários a respeito do critério de falha de um pilar quando analisado numericamente. Na Figura 4.19 são descrito dois possíveis caminhos da resposta estrutural para a relação de força pela temperatura do elemento.

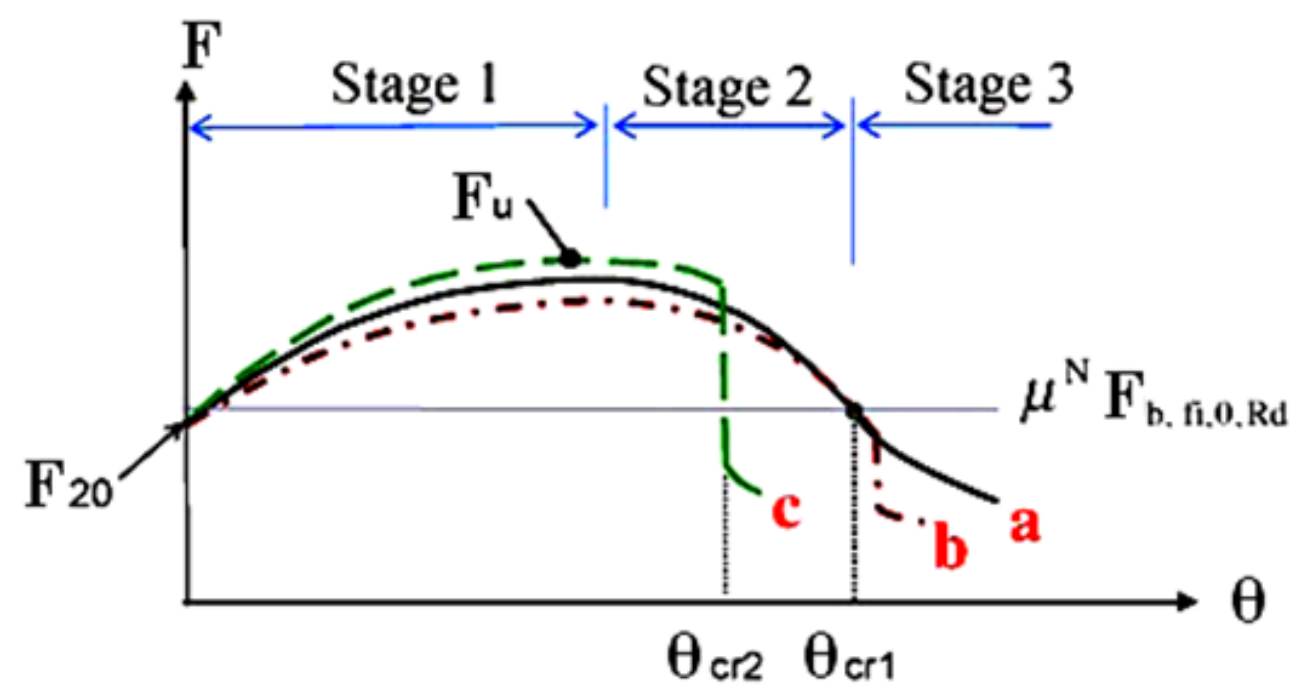

Figura 4.19 - Desenvolvimento de forças internas em um pilar restringido axialmente. FONTE: Huang e Tan (2004) 
Considera-se um carregamento inicial à temperatura ambiente dada por $\mathrm{F}_{20}$. Com a elevação da temperatura ocorre o fenômeno da dilatação térmica e, considerando a restrição axial, ocorrerá um acréscimo da força aplicada. Essa relação será linear para o aço-carbono, salvo possíveis influências da complexidade da ligação viga-pilar, até o limite de $100^{\circ} \mathrm{C}$, a partir daí assumirá a forma parabólica em virtude da degradação da rigidez do material.

Para as barras que seguirem o caminho a da Figura 4.19, a temperatura em que for atingida a força última de escoamento do material será considerada a temperatura crítica, já que não houve instabilidade global. Esse caminho será preferencialmente seguido por barras curtas, lembrando que o valor de $\mathrm{F}_{\mathrm{u}}$ também será variável com a temperatura, como ilustrado na Figura 1.2 e reproduzido na Figura 4.20 e Figura 4.21. Porém, com base nos resultados numéricos encontrados em Kimura (2009), sem a consideração da restrição axial, nenhuma das barras estudadas atingiu a resistência ao escoamento do material, sendo que todas elas perderam a estabilidade inicial, com o deslocamento do topo da barra descrevendo trajeto análogo ao caminho b ou c da Figura 4.19, porém, sem mudança na força aplicada.

Na Figura 4.20 possíveis trajetos da força aplicada estão ilustrados, os quais podem ser descritos pelas barras, sendo que as diferenças entre as curvas ocorrem por fatores intrínsecos ao modelo estrutural como a esbeltez da barra e, principalmente, a rigidez axial da restrição. Caso a barra esteja livre para se expandir a força não varia, seguindo a linha horizontal desde a carga inicial $F_{20}$, como pode ser observado na Figura 4.20, Figura 4.21 e Figura 4.22 que se seguem. 


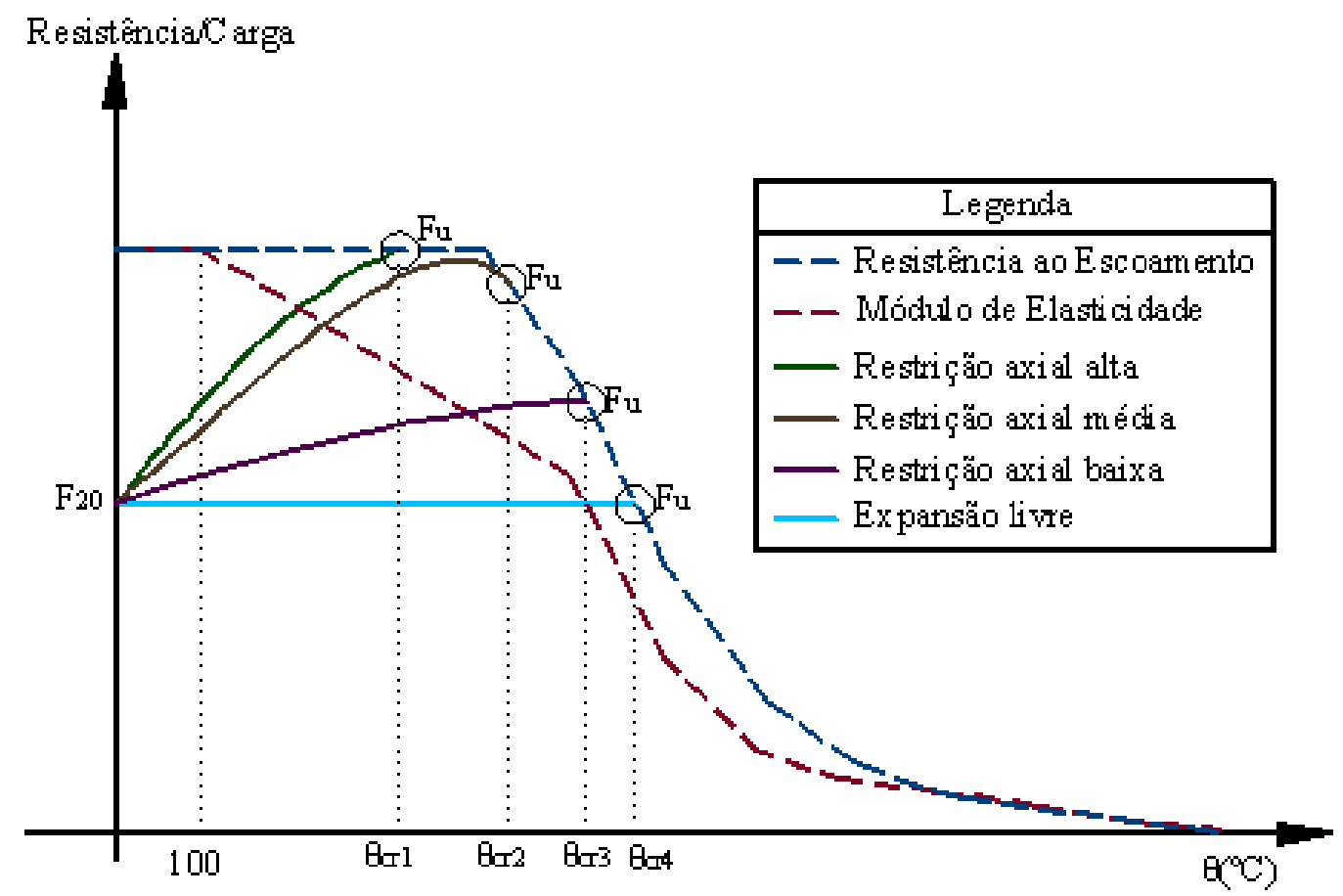

Figura 4.20 - Limite de resistência de elementos estruturais com restrição axial ao aquecimento considerando o caminho (a).

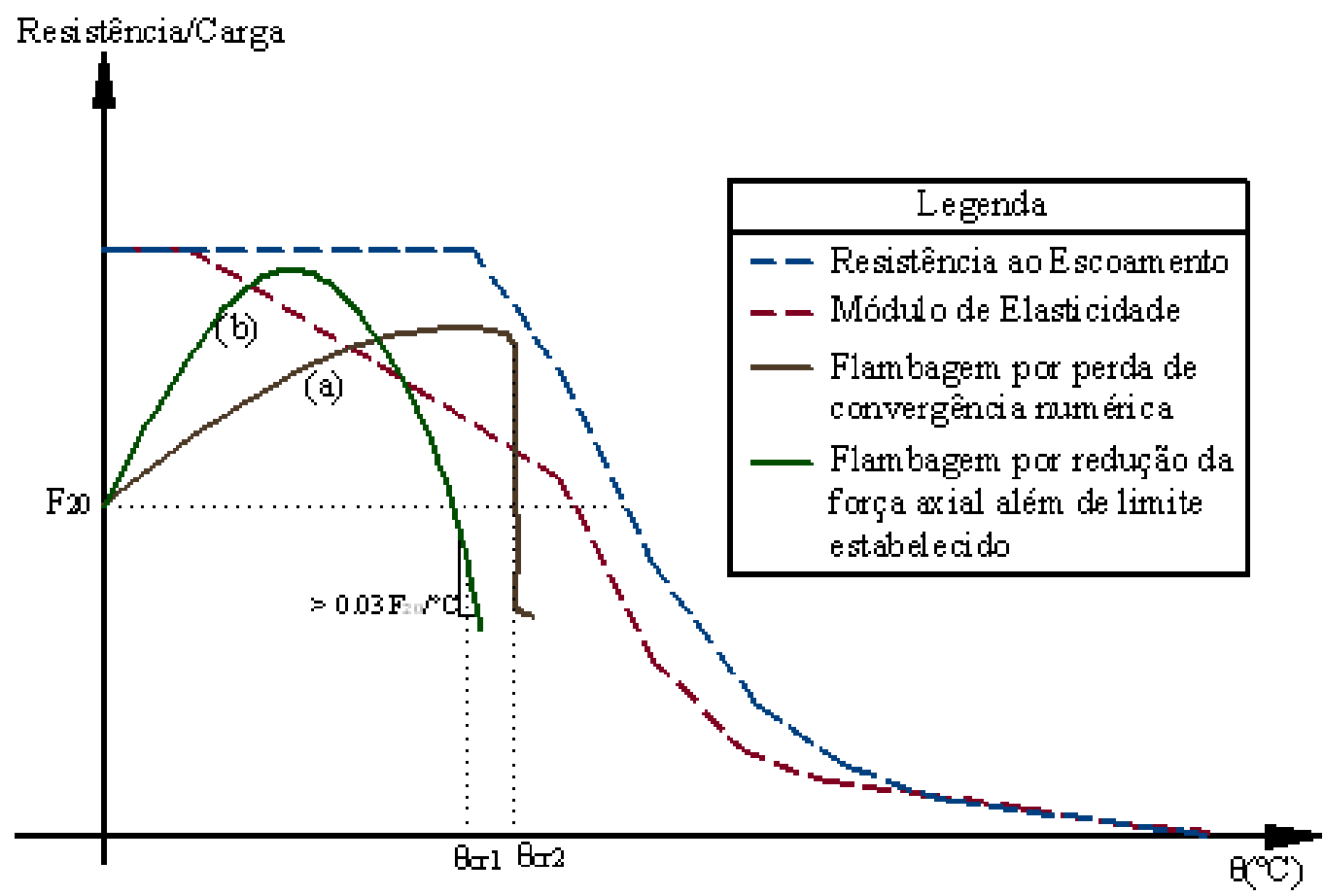

Figura 4.21 - Perda de estabilidade inicial por rápido declínio da força axial interna ou por perda de convergência numérica considerando o caminho (b). 


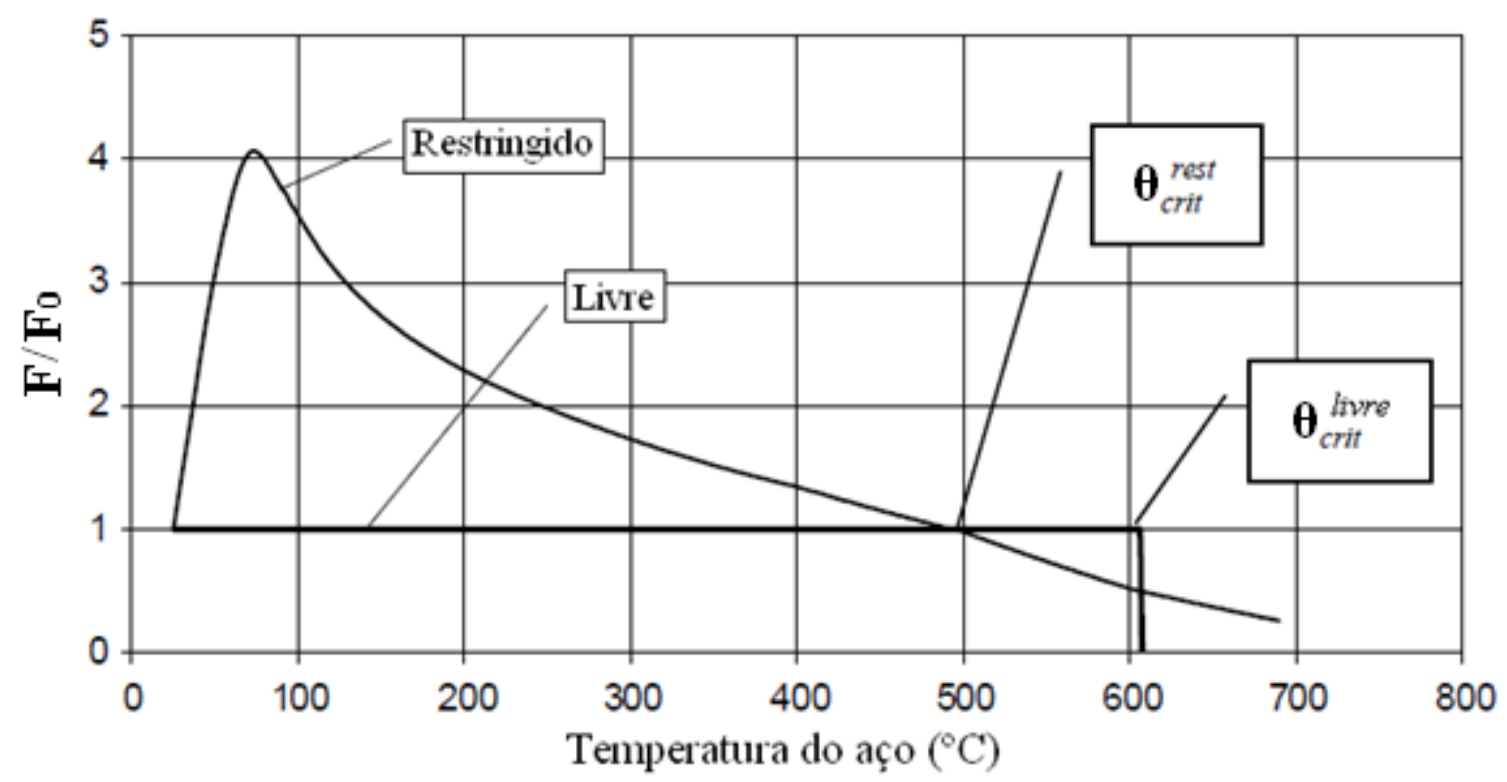

Figura 4.22 - Evolução do esforço axial calculado, com expansão livre ou totalmente restringida. FONTE: Neves, Valente e Rodrigues (2002)

Ainda de acordo com Huang e Tan (2003), a barra que segue o caminho b ou $c$ da Figura 4.19 sofre a perda de sua estabilidade inicial, sem que o esforço tenha atingido a resistência ao escoamento do material, como anteriormente. Isso é percebido numericamente de duas formas; quando a análise é feita via MEF e a resposta perde a convergência, ilustrado pela curva (a) da Figura 4.21. O caminho $b$ da Figura 4.19, mostra que apesar de a barra ter perdido a estabilidade inicial, a temperatura crítica será considerada aquela quando a carga axial aplicada retorna ao valor inicial por motivos explicados a seguir. Outra possibilidade para se concluir numericamente que a barra perdeu sua estabilidade inicial, segundo Huang e Tan (2003) através de inúmeros modelos estudados, é que a taxa de decréscimo da força interna axial exceda o valor de $0,03 \mathrm{~F}_{20} /{ }^{\circ} \mathrm{C}$, ilustrado na Figura 4.21 pela curva $(b)$.

Ao observar a Figura 4.21, se percebe que a força aplicada pode ser inferior à carga inicial. Como foi discutido anteriormente, isso é possível porque parte da carga pode ser redistribuída para os demais elementos estruturais. Porém, esse fenômeno ainda não é totalmente esclarecido e, como dito em Huang, Tan e Ting (2006), a definiçãa de temperatura crítica nesse caso será quando a carga suportada se tornar inferior à carga inicial $F_{20}$ aplicada, ou seja, quando atinge o limite de serviço da barra.

$\mathrm{Na}$ consideração do modelo adotado nesta atual pesquisa, o carregamento nunca será considerado inferior ao inicial, ou seja, a restrição axial apenas acrescentará força de compressão, fato que está de acordo com o exposto em Neves, Valente e Rodrigues (2002), 
onde se demonstra essa condição na Figura 4.22, após estudo numérico com o código computacional FINEFIRE. Essa condição também foi considerada em outros trabalhos como Neves (1995), Valente e Neves (1999), Franssen (2000), Wang (2004), Huang, Tan e Ting (2006), entre outros. Tal consideração conduz a resultados sempre a favor da segurança, e ainda $\mathrm{o}$ fato de o modelo matemático, para pequenas tensões aplicadas, resultar excessivamente demorado computacionalmente para a obtenção da solução desejada. A hipótese de que a força retorna ao valor inicialmente aplicado também significa que os esforços aplicados não mais se equilibram aos que podem ser resistidos pela barra no dado instante.

A Figura 4.23 a seguir ilustra como poderá evoluir a força axial, sendo que a instabilidade da barra em resposta às situações discutidas anteriormente (esmagamento do material ou perda de estabilidade inicial) poderá ocorrer em qualquer fase, com força axial em ascendência, máxima, descendente ou constante, após retornar ao valor inicialmente aplicado.

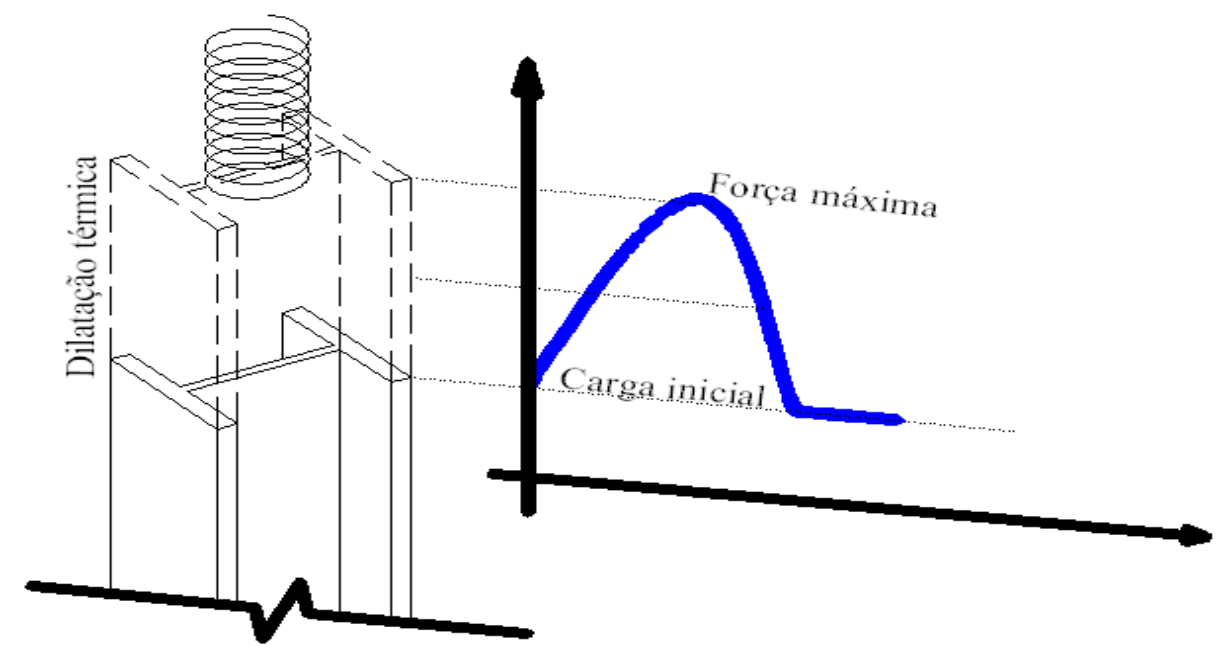

Figura 4.23 - Desenvolvimento de esforço axial aplicado, nunca inferior à carga inicial.

Segundo Valente e Neves (1999), considerando que o pilar deve resistir a uma força axial inicial de projeto, e mais uma força adicional proveniente da expansão térmica restringida axialmente e, então, quando a soma dessas forças reduzir para o nível daquela inicialmente aplicada será considerado que o pilar já não cumpre mais a sua função. $\mathrm{Na}$ prática, desse momento em diante a força axial aplicada no pilar continuará a diminuir, como na Figura 4.22, sendo que essa crescente diferença será continuamente transferida para a estrutura menos aquecida no seu entorno. Em outras palavras, o tempo de resistência ao fogo do pilar é definido pelo momento em que a carga axial no pilar, depois de ter aumentado, diminui para o nível da carga inicial. Essa situação também já foi descrita em Neves (1995) 
Dissertação de Mestrado

sendo, portanto, a temperatura correspondente à do aço, nesse instante, a temperatura crítica $\left(\theta_{\text {cr }}\right)$ e seu correspondente tempo crítico ( $\left.t_{\text {crit }}\right)$. 


\section{ANÁLISE TÉRMICA - MODELOS PROPOSTOS, VALIDAÇÃO E RESULTADOS}

\subsection{INTRODUÇÃO}

Pilares de aço podem apresentar distribuição não uniforme de aquecimento, tanto na seção transversal quanto ao longo do comprimento. Exemplos de aquecimento não uniformes na seção transversal incluem pilares com revestimento contra fogo, exposição parcial por compartimentação, entre outros aspectos. Uma distribuição não uniforme na direção longitudinal do pilar pode ser causada pela exposição ao incêndio localizado, por exemplo. Seguindo as prescrições normativas, e por questões de simplificação nas análises aqui propostas, a elevação da temperatura será considerada uniforme na direção longitudinal.

A proposta de modelagem numérica a ser adotada no presente trabalho seguirá procedimento análogo àquele utilizado na Figura 5.1, extraída de Regobello (2007), a qual esquematiza a discretização adotada para um modelo de viga mista de aço e concreto, a forma adotada para a aplicação do carregamento estático, bem como a condição de exposição ao fogo. Na mesma figura é apresentada a evolução da temperatura para o "Ponto 1" da seção, bem como comparação dos resultados térmicos entre os códigos computacionais ANSYS e SuperTempCalc (STC).

Dentro da proposta do presente trabalho, as Figura 5.2a e Figura 5.2b mostram malhas utilizadas em modelos para análise térmica, considerando diferentes níveis de refinamento em elementos finitos, com vistas a otimizar o procedimento adotado em Kimura (2009). As diferentes abordagens para níveis de discretização da malha de elementos finitos resultaram em grandes diferenças no tempo de processamento. A modelo com a malha mostrada na Figura 5.2a foi processado em um tempo total de cerca de 10 segundos, enquanto que a malha da Figura 5.2b levou cerca de 10 minutos. Mesmo com essa grande diferença em tempo de 
processamento não foi observada nenhuma divergência significativa nos resultados. Em Kimura (2009) foi utilizado o elemento finito do tipo sólido que necessitava de um tempo de processamento do modelo térmico de cerca de 2 horas, sendo que um dos objetivos do presente trabalho é otimizar esse tempo de processamento com a utilização do elemento finito do tipo casca, mais apropriado para representar elementos constituídos por chapas.

(a)
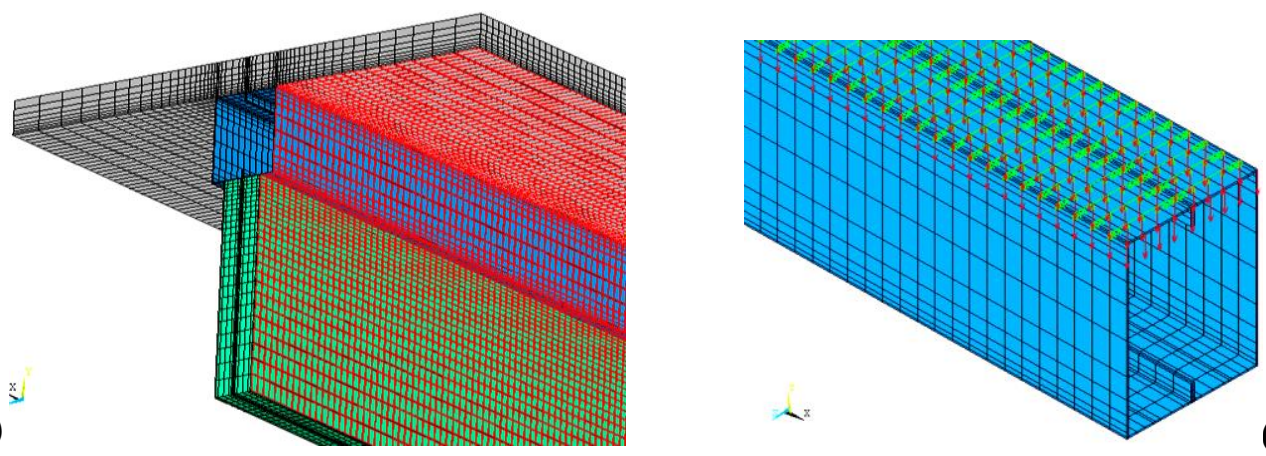

(b)

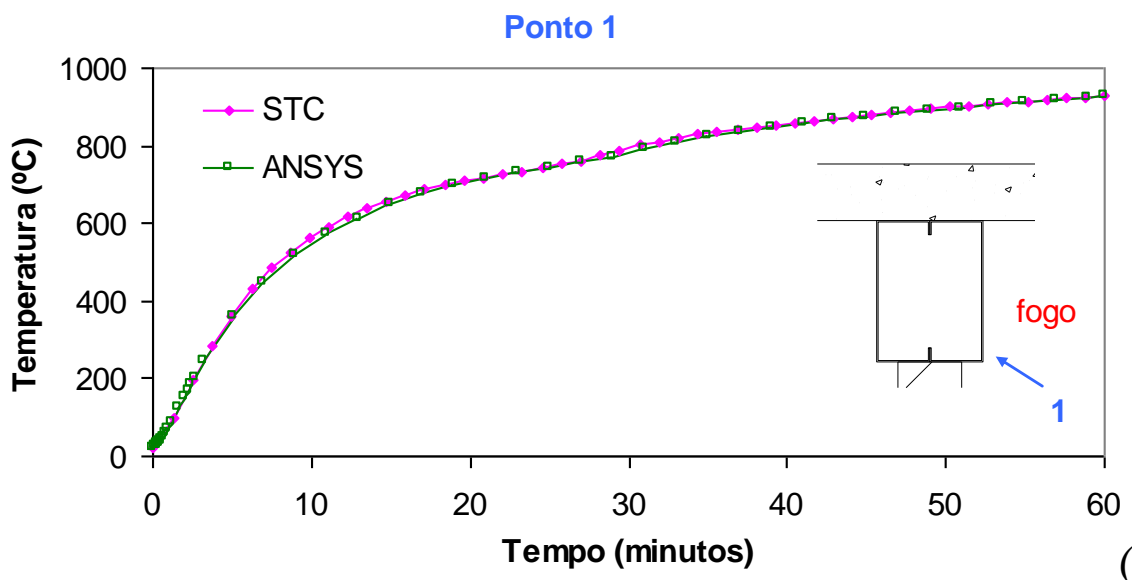

Figura 5.1 - $(a)$ Modelo para análise térmica, $(b)$ aplicação do carregamento no modelo e $(c)$ variação da temperatura no ponto 1 ao longo do tempo (ANSYS x STC). FONTE:

Regobello (2007)

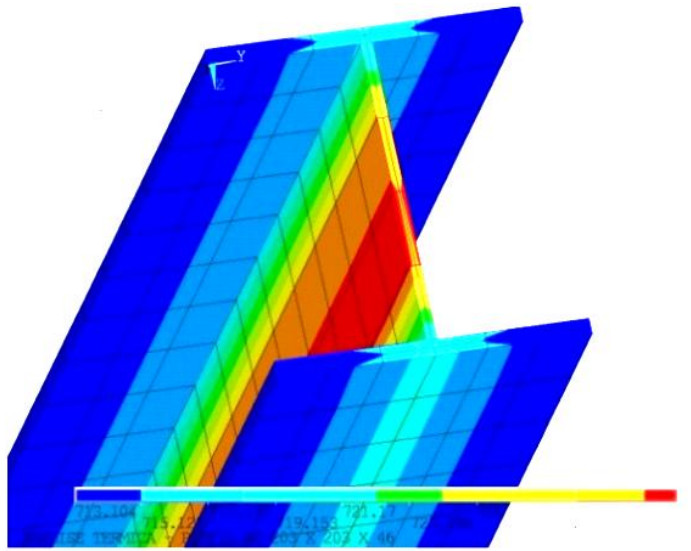

(a)

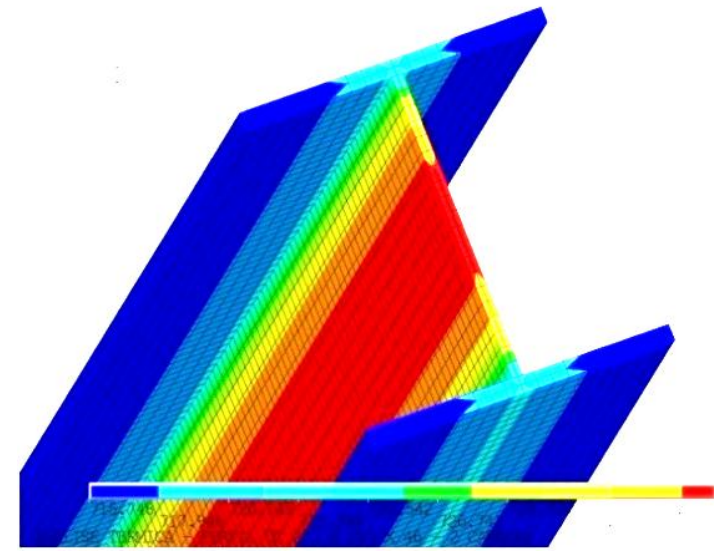

(b)

Figura 5.2 - Exemplo de diferentes níveis de discretização de malhas para análise térmica, casos $(a)$ e $(b)$, referente a um tempo de exposição igual a 20 minutos. 
O elemento finito do tipo casca a ser aqui utilizado também permite considerar diversas camadas na espessura que podem, inclusive, ser atribuídas às propriedades de diferentes materiais, como uma chapa de madeira laminada colada, conforme Figura 5.3. No entanto, esse recurso foi aqui utilizado com vistas a se obter maior número de dados de temperatura ao longo da espessura da chapa de aço que compõe o perfil.

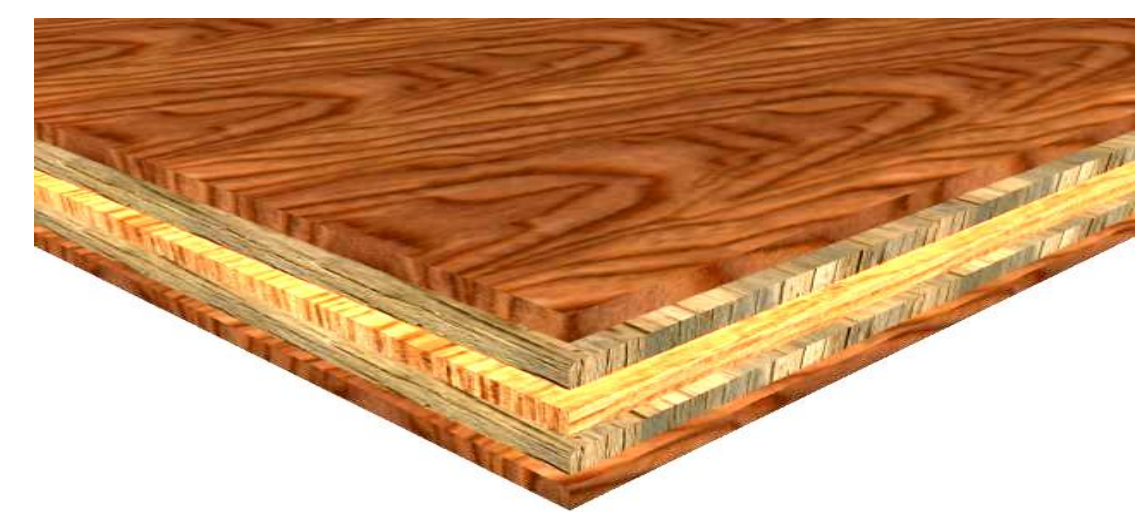

Figura 5.3 - Exemplo de material composto por diversas camadas de materiais com propriedades diferenciadas.

A consideração de um maior número de camadas também aumenta o tempo de processamento, embora de forma pouco significativa, e a diferença nos valores numéricos de temperatura da linha do esqueleto para diversas quantidades de camadas não mostraram diferenças significativas, conforme será analisado no item 5.6.2 e mostrado na Figura 5.33 e Figura 5.36. Para perfis metálicos, cujas espessuras de seus elementos são reduzidas e a condutividade térmica elevada se comparada ao concreto, sabe-se que a variação da temperatura no interior da espessura é desprezível, porém, a intenção de realizar testes se faz com vistas a consolidar o conhecimento sobre a utilização deste elemento para que, em pesquisas futuras, possa ser utilizado na modelagem de lajes de concreto.

O modelo para análise térmica foi desenvolvido utilizando o elemento finito do tipo casca, no caso o SHELL131 para a análise térmica, disponível na biblioteca interna do ANSYS, com o objetivo de transferir o campo térmico para o elemento SHELL181, também disponível na biblioteca interna do ANSYS, aplicado na análise estrutural, compatíveis para fins de análises acopladas, cujos resultados obtidos são considerados carregamentos nodais para a análise estrutural. Para a modelagem das paredes, para fins de compartimentação, por simplificação, se optou pelo elemento SOLID70, tendo em vista que eles não serão necessários quando da análise acoplada. Os elementos mencionados serão devidamente apresentados nos itens que seguem. 
Vale aqui ressaltar que a não utilização apenas de elementos do tipo casca se deveu ao fato de o elemento SHELL131 possuir apenas um nó na espessura, o que poderia dificultar o acoplamento dos nós do perfil metálico em contato com a parede, cuja geometria de planos concorrentes disponibilizaria apenas um nó compartilhado para acoplar. A solução encontrada foi manter a parede com o elemento SOLID70, que disponibiliza um nó em cada canto do elemento, sendo possível a compatibilização do número de nós na interface com a SHELL131 do perfil e seu acoplamento.

Tal escolha, no entanto, trouxe um novo problema a ser resolvido uma vez que o ANSYS traz a nomenclatura dos graus de liberdade do elemento SHELL131 de acordo com sua posição na seção (TBOT, TE2, TE3, ... , TTOP), enquanto que o elemento SOLID70 possui apenas um grau de liberdade (TEMP). Apesar do mesmo significado físico (temperatura), o código não reconhece como idênticos por possuírem nomes distintos, impedindo a compatibilização dos graus de liberdade entre os diferentes elementos. A solução encontrada é dada pelo próprio elemento SHELL131, uma vez que dentre suas opções de personalização inclui uma opção denominada "Paint Application”, cuja única função é alterar o nome do grau de liberdade do elemento SHELL131 de TBOT para TEMP, possibilitando o acoplamento adequado com o elemento SOLID70.

\subsection{ELEMENTOS FINITOS UTILIZADOS - ASPECTOS}

\subsubsection{ELEMENTOS FINITOS SOLID 70 E SOLID 90}

O SOLID70, apresentado na Figura 5.4a, é um elemento finito sólido que possui oito nós, com um grau de liberdade em cada nó, no caso, a temperatura (TEMP). Apresenta como principal vantagem a de adaptar-se a qualquer geometria volumétrica regular, para geometrias irregulares existe o SOLID90, Figura 5.4b, com nós intermediários nas faces.

\subsubsection{ELEMENTO FINITO SHELL 131}

O elemento SHELL131 é do tipo casca e térmico tridimensional, o qual permite a decomposição em camadas (layers) e informa o campo de temperaturas através do seu plano e da seção transversal. É definido por quatro nós, uma espessura por camada, um ângulo de disposição do material para cada camada e as propriedades do material (que pode ser diferente 
para cada camada), constantes reais não são necessárias para este elemento. A Figura 5.5 esquematiza o elemento SHELL 131 , o qual possui quatro nós com até 32 graus de liberdade por nó, todos unicamente de temperatura, diferenciando-se entre si pela posição relativa na espessura, como indicado na Figura 5.6.

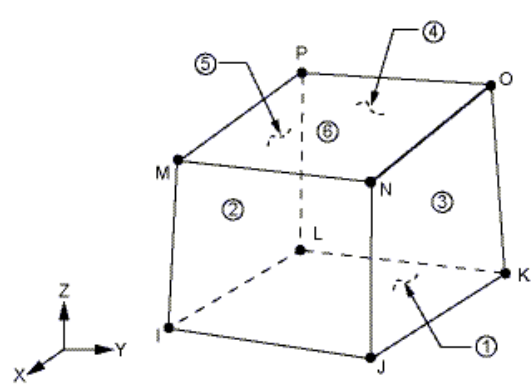

(a)

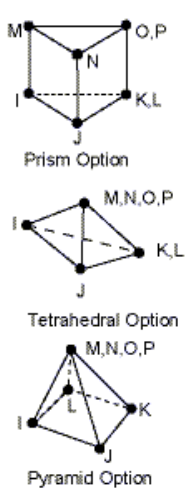

Pranid option

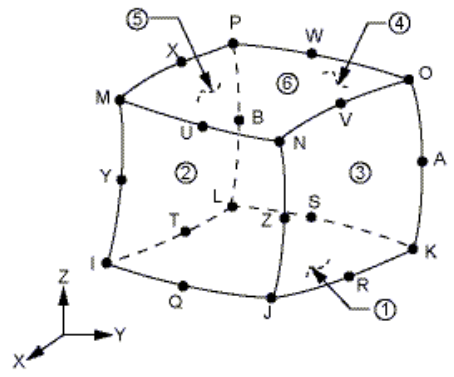

(b)

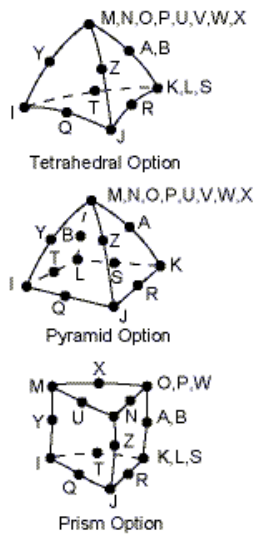

Figura 5.4 - Elementos finitos térmicos sólidos utilizados: (a) SOLID70 e (b) SOLID90.

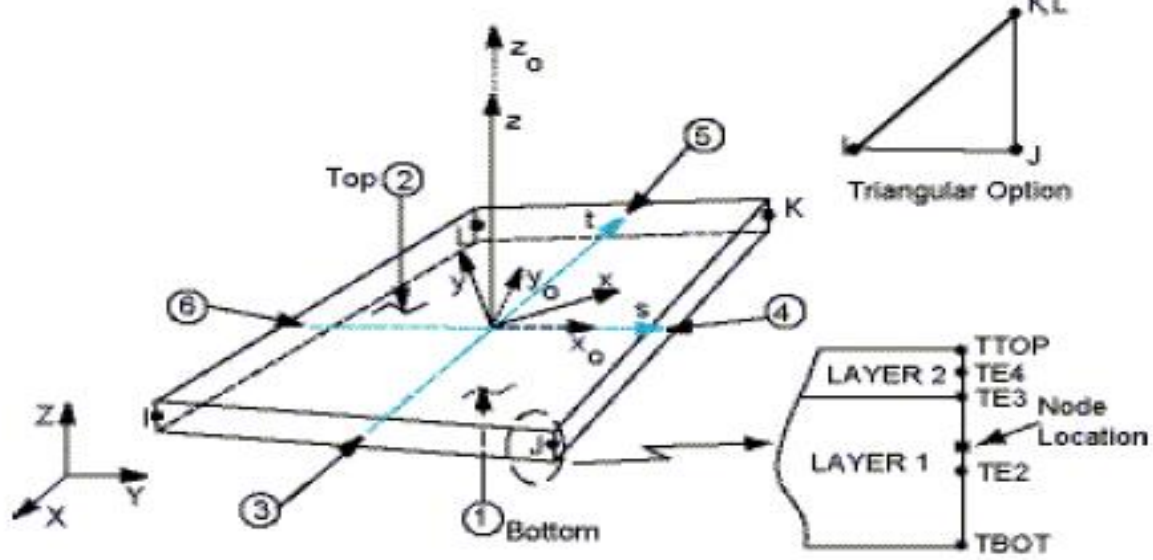

Figura 5.5 - Elemento finito térmico do tipo casca: SHELL131.
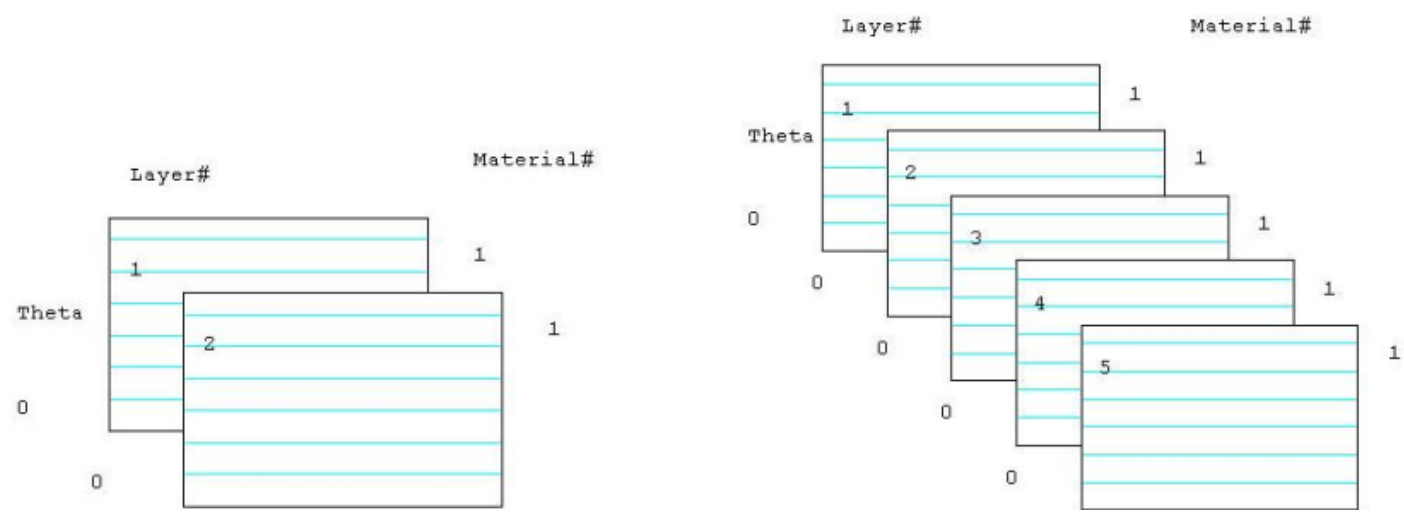

Figura 5.6 - Forma como se apresentam as camadas para simples conferência do material e orientação atribuída a cada uma. 
As propriedades a serem informadas para os materiais são: condutividade térmica nas três direções principais, densidade e condutividade. O elemento finito térmico do tipo casca é aplicável em análises térmicas tridimensionais, estáticas ou transientes. O número máximo de camadas do elemento é igual a 15 quando considerada variação quadrática da temperatura ao longo da seção transversal da chapa, ou igual a 31 quando a variação for considerada linear. Se o material for homogêneo (não composto) e a análise térmica não for transiente, apenas uma camada se faz necessária com variação linear de temperatura.

Geralmente, a variação quadrática da temperatura através de cada camada é utilizada para análises transientes ou com materiais fortemente dependentes da variação de temperatura, enquanto que a variação linear é utilizada para análises estáticas com materiais que não dependem da variação da temperatura ou são fracamente dependentes. As camadas (ou layers) podem ser utilizadas para representar mudanças físicas das propriedades do material ao longo da espessura, ou a análise dos efeitos transientes com um maior detalhamento. A geometria do elemento, a localização dos nós, o sistema de coordenadas e a composição de camadas também são mostrados na Figura 5.5, enfatizando-se os pontos onde é possível conhecer os valores escalares de temperatura em cada nó, sendo até três por camada, conhecidos no código como grau de liberdade e recebendo o nome de TBOT, TE2, TE3, ... , TTOP, a depender de sua posição nas camadas da seção.

O campo de temperaturas gerado pode ser transferido para um elemento de casca do tipo estrutural na intenção de modelar o comportamento termoestrutural de uma dada estrutura de interesse. Se o modelo construído com este elemento térmico for posteriormente analisado quanto ao seu comportamento estrutural com base na resposta ao campo térmico do material, este pode ser facilmente substituído por um elemento equivalente estrutural, como o SHELL181. Os elementos compatíveis para análise acoplada termoestrutural são citados na Tabela 5.1. Vale aqui ressaltar que no trabalho desenvolvido e apresentado em Kimura (2009) foram utilizados os elementos SOLID45 e SOLID70 para análise tridimensional, bem como o elemento PLANE77 para análise bidimensional e validação do código computacional ANSYS em comparação ao SuperTempCalc (STC).

A construção da seção transversal do elemento, assim como toda a modelagem, definição de propriedade dos materiais, dos elementos, forças, restrições de graus de liberdade, podem ser feitas tanto via comandos específicos (script), quanto pela interface 
gráfica $(G U I)$. Para a construção da seção transversal, processos devidamente detalhados são encontrados no guia do programa no capítulo Shell Analysis and Cross Sections em ANSYS Structural Analysis Guide, mais especificamente em How to Create Cross Sections. Basicamente será informado ao código ANSYS a quantidade de camadas da seção transversal, a espessura de cada uma delas, o material que a compõe, a orientação do material, o número de pontos de integração e o sentido de extrusão da espessura em relação à posição dos nós, definida pela geometria de base do modelo.

Tabela 5.1 - Tipos de elementos compatíveis para análises acopladas.

\begin{tabular}{ll}
\hline ESTRUTURAL & TÉRMICO \\
\hline SOLID45 & SOLID70 \\
SOLID92 & SOLID87 \\
SOLID95 & SOLID90 \\
PLANE42 & PLANE55 \\
PLANE2 & PLANE35 \\
PLANE82 & PLANE77 \\
SHELL63, & SHELL57, \\
SHELL181 & SHELL131 \\
SHELL91, & SHELL132 \\
SHELL93 & LINK33 \\
LINK8 & \multicolumn{2}{c}{ FONTE: ANSYS guide }
\end{tabular}

\subsubsection{ELEMENTO FINITO SHELL 181}

O elemento SHELL181 é do tipo casca e é utilizado para análises estruturais tridimensionais. É um elemento finito composto por 4 nós, como pode ser visto na Figura 5.7, e apresenta 6 graus de liberdade em cada nó, translações nas direções X, Y e Z (UX, UY e UZ) e rotações em torno dos eixos X, Y e Z (ROTX, ROTY e ROTZ). É preferencialmente utilizado para modelar estruturas finas até moderadamente espessas. Pode ser utilizado com a opção de membrana que faz com que o elemento possua apenas os graus de liberdade de translações. O elemento $\mathbf{S H E L L 1 8 1}$ aceita aplicações lineares, grandes rotações, grandes deformações e aplicações não lineares. 


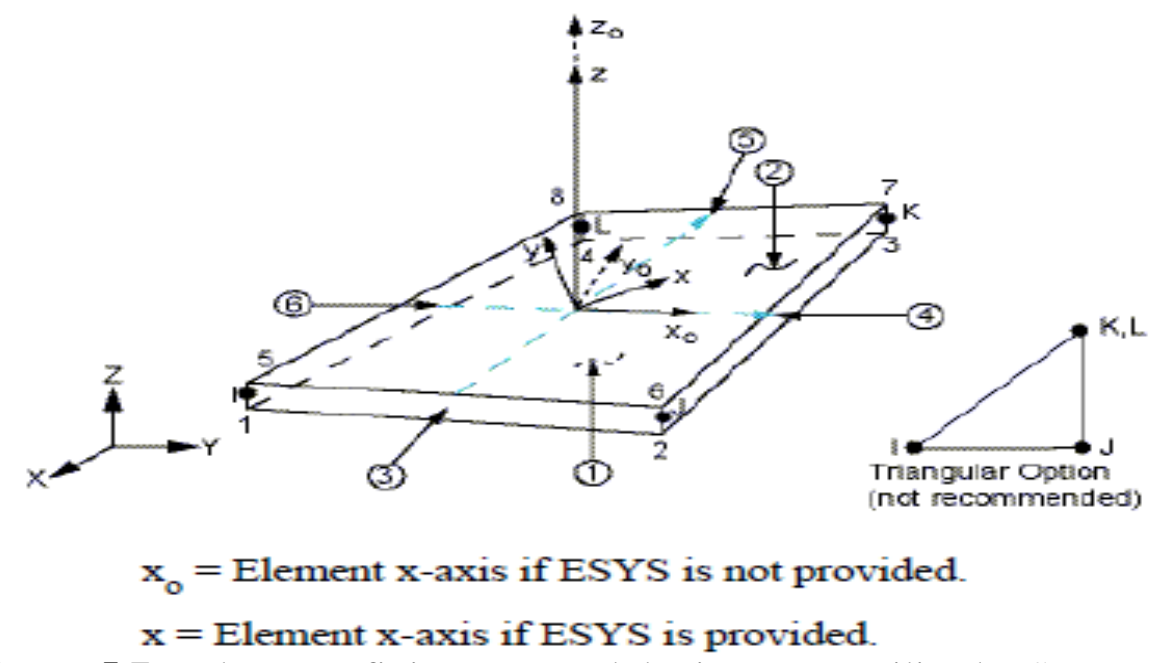

Figura 5.7 - Elemento finito estrutural do tipo casca utilizado: SHELL181.

Ele pode ser utilizado em aplicações que necessitem modelar estruturas compósitas laminadas do tipo casca. As definições de espessura podem ser inseridas como real constante ou com a definição de uma seção (section type). No segundo caso podem ser incluídas mais de uma camada (até o limite de 250) de espessuras variáveis, cada uma composta por materiais distintos e o número de pontos de integração ao longo da espessura.

Quanto aos carregamentos, pressões podem ser inseridas em todas as faces com um número circulado conforme visto na Figura 5.7; forças concentradas são inseridas diretamente nos nós do elemento. Temperaturas podem ser inseridas em cada um dos nós e para cada uma das interfaces entre as camadas. Os resultados provenientes de uma análise térmica (SHELL131) são importados na forma de carregamento para uma análise termoestrutural (SHELL181). Os graus de liberdade do elemento SHELL131 TBOT, TE2, TE3, ... , TTOP são então nomeados para T1, T5, T9, ... no primeiro nó, T2, T6, T10,... no segundo nó respectivamente.

O elemento permite a utilização de integração completa ou reduzida, sendo essa última a opção padrão e que garante melhor performance computacional. A integração reduzida é recomendada quando o elemento sofrerá flexão no seu plano, como mostra a Figura 5.8, enquanto que a integração completa é recomendada para quando o elemento poderá sofrer flexão fora do seu plano. Quando a análise incluir os dois modos de flexão é recomendado a utilização da integração completa. 


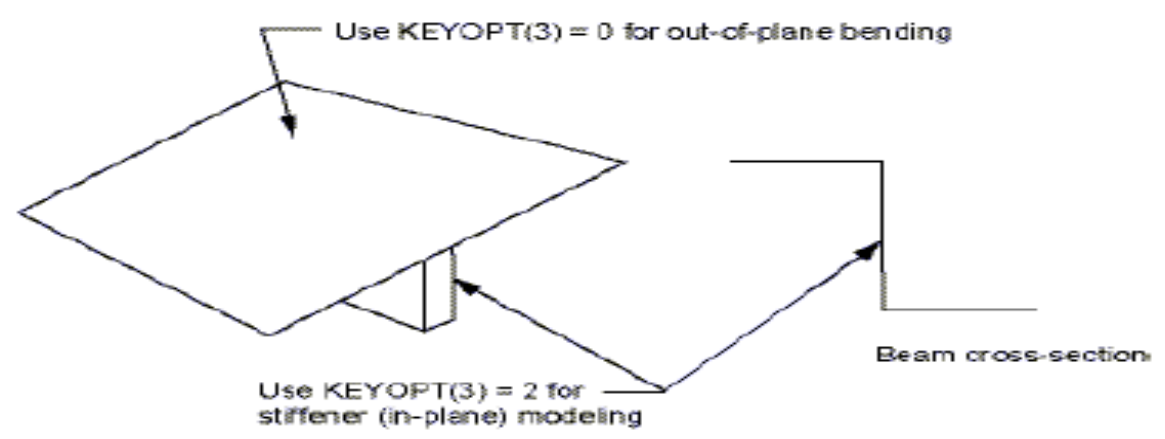

Figura 5.8 - Elemento com flexão no plano e fora dele.

O elemento pode ser associado a materiais elástico lineares, elastoplásticos, viscoplástico ou hiperelástico. Para a elasticidade apenas propriedades isotrópicas, anisotrópicas e ortotrópicas lineares podem ser inseridas. O coeficiente de Poisson é usado para especificar a compressibilidade do material. O coeficiente de expansão térmica pode ser inserido tanto de forma isotrópica quanto ortotrópica.

\subsubsection{ELEMENTO FINITO SURF 152}

O elemento $\boldsymbol{S U R F 1 5 2}$ pode ser utilizado para aplicação de diversos carregamentos e efeitos de superfície, neste caso, efeitos térmicos de convecção e radiação do incêndio em modelos de três dimensões.

O elemento possui uma forma plana definida por quatro a nove nós, sendo eles dispostos apenas nos cantos, adicionais no centro de suas linhas laterais para melhor ajuste em geometrias irregulares e, opcionalmente, um nó extra que representa a temperatura do ambiente, conforme esquematizado na Figura 5.9. Seu único grau de liberdade é a temperatura (TEMP). As propriedades do material atribuídas ao elemento incluem fator de emissividade, constante de Stefan-Boltzmann e filme de convecção, sendo que esse último pode ser definido no momento de aplicação do carregamento de superfície.
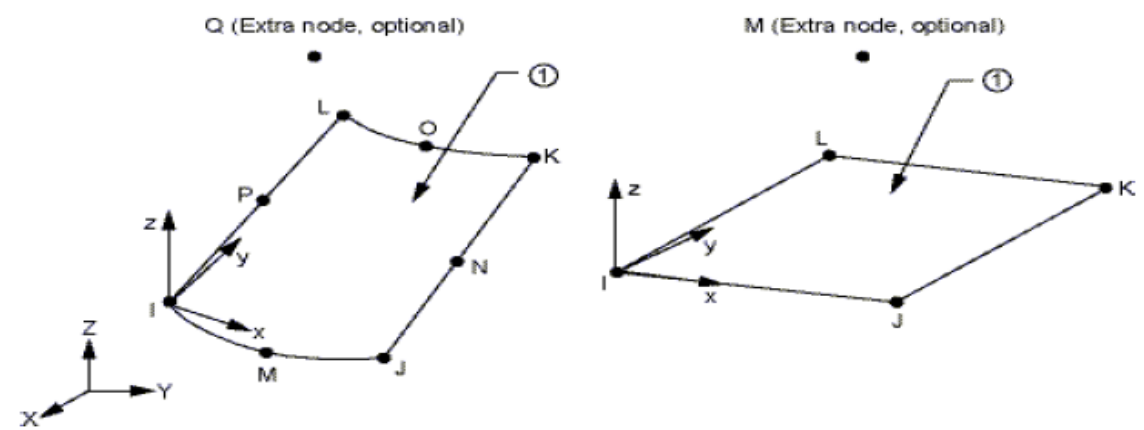

Figura 5.9 - Elemento finito de aplicação de efeitos de superfície SURF152. 
Um nó extra, fora da geometria do elemento, pode ser utilizado para prescrever a temperatura do "ambiente"; no caso do incêndio, a temperatura dos gases. Com base nas temperaturas dos gases e daquela referente à superfície do aço, cumpre-se a função de transferir pelos efeitos de radiação e convecção a temperatura dos gases para a superfície do perfil, conforme as relações matemáticas de cada um dos efeitos, conforme Kimura (2009). Fluxos de calor por radiação ou por convecção podem ser especificados em um modelo numérico, porém, é permitido apenas um tipo de ação térmica no elemento finito de interesse. Para contornar essa restrição, utilizam-se dois elementos finitos de efeitos térmicos de superfície sobrepostos, sendo que cada um receberá o carregamento de ação térmica por radiação ou por convecção, respectivamente.

\subsection{CONSIDERAÇÕES SOBRE OS ELEMENTOS FINITOS}

$\mathrm{Na}$ tentativa de eliminar a dependência de uma série de elementos de superfície sobrepostos, e aproveitando uma opção do Ansys de aplicar carregamento superficial diretamente sobre o elemento finito SHELL131 em cada uma de suas faces (assinaladas na Figura 5.5 por um número circulado) de forma isolada, foi pesquisada tal forma de aplicação de carregamento térmico. O mesmo código, em seu guia, enfatiza que apenas um efeito poderia ser considerado para cada face, sendo que um dos efeitos térmicos deveria ser obrigatoriamente aplicado com o elemento SURF152. Contudo, a utilização desse método para a convecção (com a radiação no elemento de superfície) não trouxe bons resultados e optou-se por continuar com a metodologia das referências anteriores com a utilização de um elemento finito do tipo $\boldsymbol{S U R \boldsymbol { R }} 152$ para cada efeito térmico. Maiores detalhes sobre a forma de aplicação dos efeitos térmicos utilizando elementos de superfície são encontrados em Regobello (2007) e Kimura (2009).

Essa solução foi motivada por causa de uma limitação do código que impedia o uso do elemento de casca em substituição ao elemento sólido, uma vez que em versões anteriores do código computacional ANSYS o elemento finito SURF152 possuía apenas o grau de liberdade (TEMP), o que causava dificuldade na aplicação da temperatura no elemento SHELL131, pois os graus de liberdade eram denominados diferentemente. Esse problema não acontecia com o elemento SOLID70 utilizado anteriormente em que o grau de liberdade também se chama TEMP, o que favorece sua aplicação. 
As versões mais recentes do código trazem o elemento SURF152 com a opção de alterar o nome de seu grau de liberdade de TEMP para TTOP ou TBOT, compatibilizando com a SHELL131 ou com o SOLID70, conforme a situação. Dessa forma, foi possível contornar o problema dos diferentes nomes dos graus de liberdade do elemento que representa o perfil metálico, do elemento que aplica a ação térmica e do elemento utilizado na modelagem das paredes. Contudo, será necessária agora a utilização de quatro elementos de superfície em cada chapa do perfil, dois para a convecção (TEMP e TTOP) e dois para a radiação (TEMP e TTOP). Vale lembrar novamente que a utilização da Paint option no elemento SHELL131 muda o nome de seu grau de liberdade de TBOT para TEMP, possibilitando o acoplamento com o SOLID70 das paredes.

A geometria, localização dos nós e sistema de coordenadas do elemento são exibidos na Figura 5.9. Se o nó extra for utilizado, ele representará a temperatura do ambiente. O elemento pode manter sua forma retangular ou degenerar-se para formas triangulares para melhor ajustar-se à geometria do modelo. Efeitos de convecção podem ser inseridos como carregamento de superfície no elemento SHELL, no entanto isto não trouxe resultados coerentes.

O cálculo da matriz de condutividade da superfície de convecção utiliza o coeficiente de filme, que é inserido sobre esse elemento. No caso da radiação entre o nó extra e a superfície, é utilizado o valor de emissividade, inserido como propriedade do material atribuído ao elemento, para a montagem da matriz de condutividade da superfície de radiação, bem como o fator de forma e a constante de Stefan-Boltzmann, estas inseridas com constantes reais. O fator de forma padrão é 1, como sugerido em Regobello (2007), mantendo a opção chave número 9 do elemento com seu valor igual a 1. Esse valor, com outro parâmetro nessa opção chave permite que o próprio programa calcule o valor do fator de forma considerando a posição relativa das superfícies e sua distância, o que não é o caso desta modelagem, já que é considerado o contato entre os gases aquecidos e o perfil.

\subsection{MICROCOMPUTADOR UTILIZADO-CONFIGURAÇÃO}

O computador utilizado traz a configuração descrita na Tabela 5.2 a seguir. Esta é uma configuração considerada atualizada e de grande capacidade para a época em que as análises foram realizadas. 
Tabela 5.2 - Configuração relevante do computador utilizado.

\begin{tabular}{ll}
\hline Item & Descrição \\
\hline Placa Mãe & MSI P35 Neo (MS-7360) \\
CPU & Intel® Core ${ }^{\mathrm{TM}} 2$ Duo E8500 3.16GHz (2 núcleos) \\
Memória & 4GB DDR2-800 (400MHz) (3,25GB endereçados pelo S.O.) \\
Vídeo & NVIDIA GeForce 9400 GT (512 MB DDR2) \\
Sist. Operacional & Microsoft® Windows ${ }^{\mathrm{TM}}$ XP Professional SP3 (32 bits) \\
Disco Rígido C: & 195 GB (155 GB livres) \\
Disco Rígido D: & 270 GB (262 GB livres) \\
Discos Remotos & 750 GB (418 GB livres) $+250 \mathrm{~GB}$ (232 GB livres) \\
\hline
\end{tabular}

\subsection{VALIDAÇÃO DE RESULTADOS TÉRMICOS -}

\section{“EXPERIMENTAL X SUPERTEMPCALC X ANSYS"}

Para todas as seções transversais a serem analisadas, valem os seguintes parâmetros, conforme descrito na Tabela 5.3 e esquematizado na Figura 5.10.

Tabela 5.3 - Parâmetros para as seções analisadas.

\begin{tabular}{ll}
\hline Dimensão & Descrição \\
\hline $\mathrm{L}$ & Comprimento do pilar \\
$\mathrm{h}_{\mathrm{w}}$ & Altura do perfil I, sem as mesas \\
$\mathrm{h}_{\mathrm{d}}$ & Altura do perfil l, com as mesas \\
$\mathrm{t}_{\mathrm{w}}$ & Espessura da alma \\
$\mathrm{b}_{\mathrm{f}}$ & Largura da mesa \\
$\mathrm{t}_{\mathrm{f}}$ & Espessura da mesa \\
$\mathrm{A}_{\mathrm{g}}$ & Área bruta da seção transversal \\
\hline
\end{tabular}

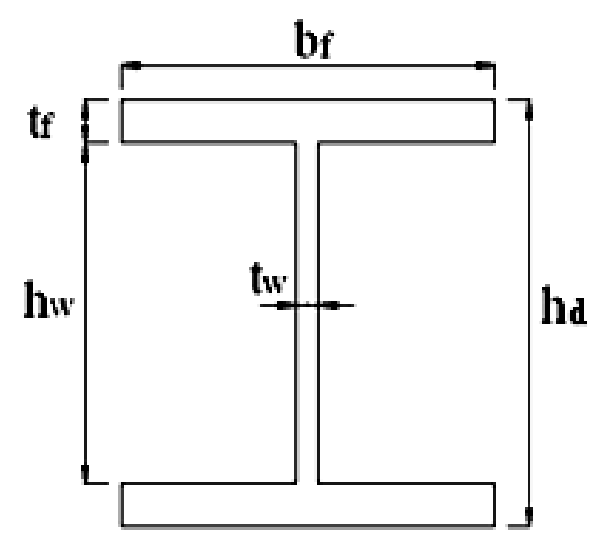

Figura 5.10 - Parâmetros envolvidos na descrição da geometria da seção transversal. 
Os modelos a seguir, descritos e estudados tanto numérica quanto experimentalmente em Silva, Correia e Rodrigues (2008), se referem ao perfil HEB160 mostrado na Figura 5.129a, e ao perfil HEB200 mostrado na Figura 5.129b. Para validação do modelo da presente pesquisa foram comparados os resultados com a análise experimental realizada no Laboratório de Ensaio de Materiais e Estruturas (LEME) do Departamento de Engenharia Civil da Faculdade de Ciências e Tecnologia da Universidade de Coimbra bem como com os resultados do STC encontrados em Silva, Correia e Rodrigues (2008).

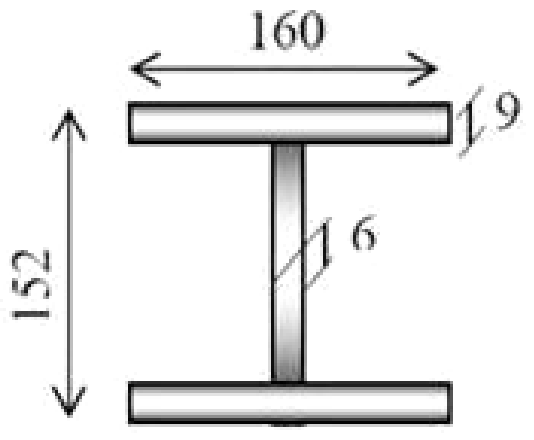

\section{Tipos 2 e 3}

(a)

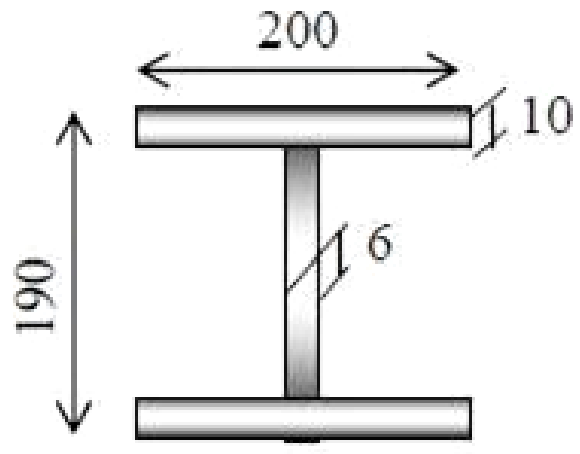

\section{Tipos 1 e 4}

(b)

Figura 5.11 - Perfis considerados: (a) perfil HEB160 e (b) perfil HEB200. FONTE: Silva, Correia e Rodrigues (2008).

As dimensões consideradas para o modelo são as dimensões do perfil, tal como são mostradas, e comprimento longitudinal igual a $294 \mathrm{~cm}$. Para a parede foi considerada uma espessura igual a $15 \mathrm{~cm}$, sem argamassa a princípio, comprimento para cada um dos lados de $100 \mathrm{~cm}$ e a aplicação da ação térmica nos $94 \mathrm{~cm}$ centrais do modelo, conforme esquematizado pela Figura 5.12. A modelagem via MEF realizada por meio do código computacional ANSYS é mostrada na Figura 5.13b, cujos elementos em destaque são SHELL131 para o perfil, SOLID70 para a parede e $\boldsymbol{S U R F 1 5 2}$ para aplicação da ação térmica. 


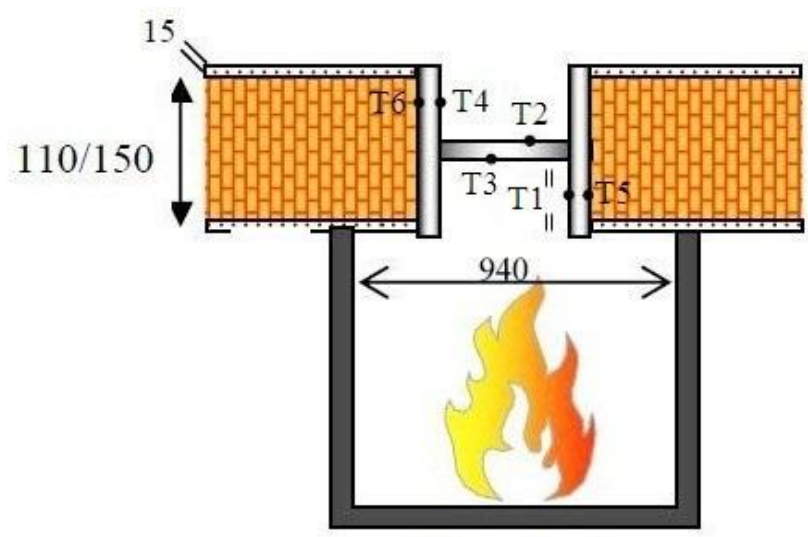

Tipos 1 e 3

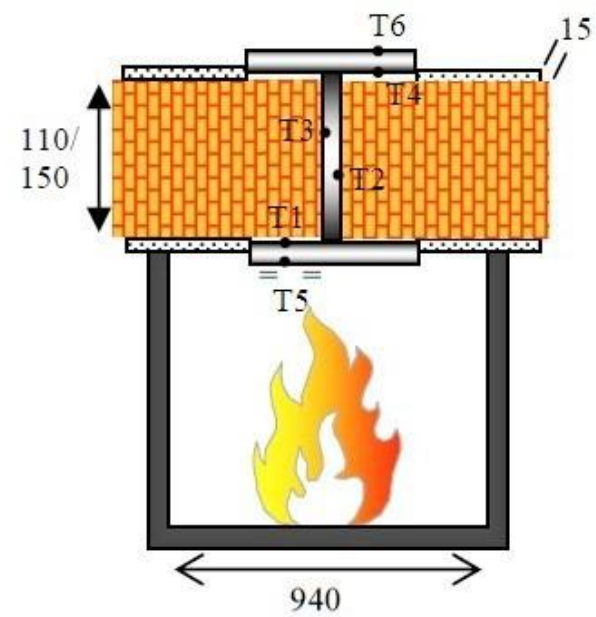

Tipos 2 e 4

(a)

(b)

Figura 5.12 -Esquema da disposição do aquecimento experimental e teórico com: $(a)$ parede encontrando as mesas e $(b)$ paredes encontrando a alma do perfil. FONTE: Silva, Correia e Rodrigues (2008).

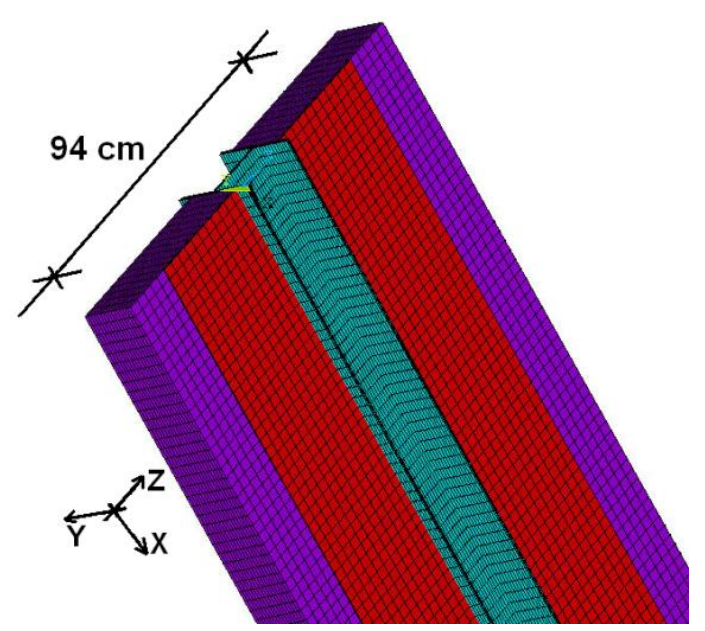

(a)

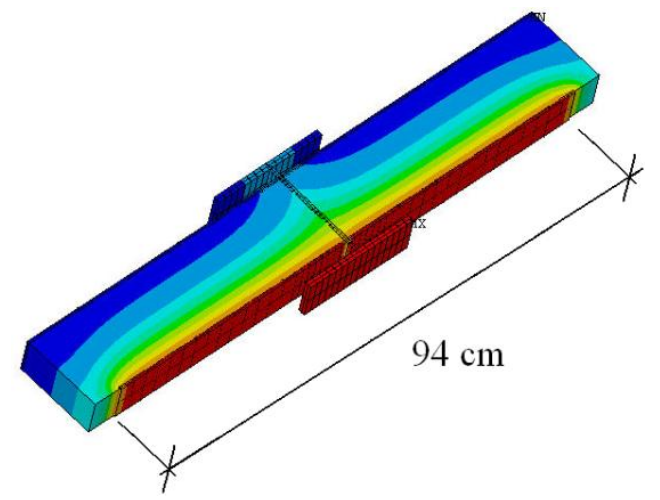

(b)

Figura 5.13 - Região considerada para aplicação da ação térmica: (a) perfil com paredes nas mesas e $(b)$ perfil com paredes na alma.

Os resultados encontrados foram comparados aos resultados disponíveis em Silva, Correia e Rodrigues (2008) sendo vistos na Figura 5.14 e na Figura 5.15, assim como nos gráficos comparativos da Figura 5.16. 


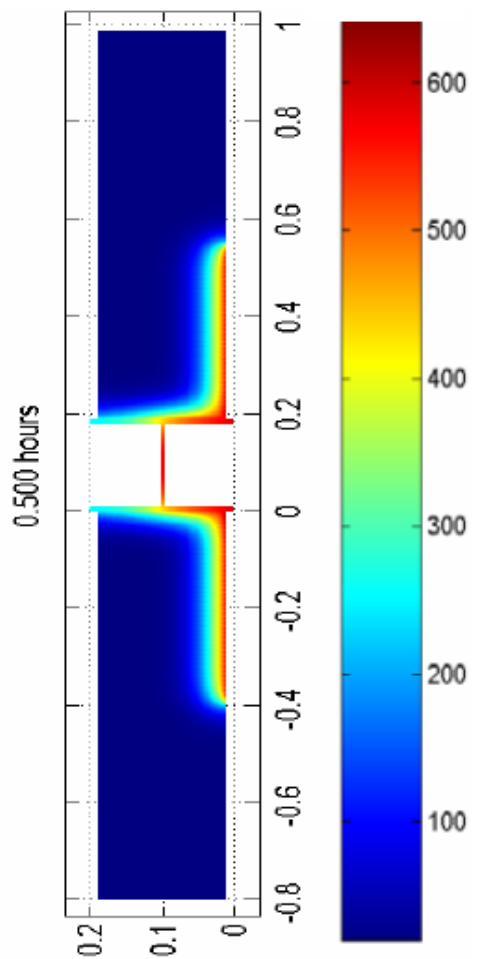

(a)

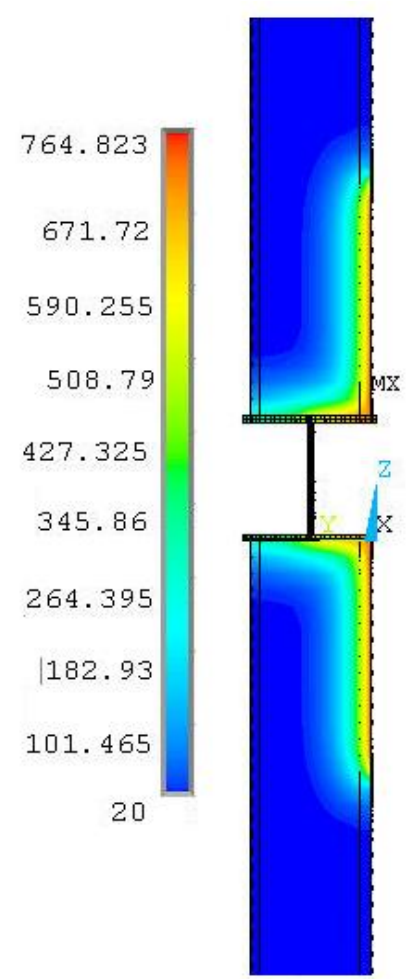

(b)

Figura 5.14 - Comparativo para 30 minutos de ação do incêndio com a consideração da superfície de perda de calor: (a) STC para perfil HEB200 (SILVA et al. 2008) e (b) via ANSYS no presente trabalho.

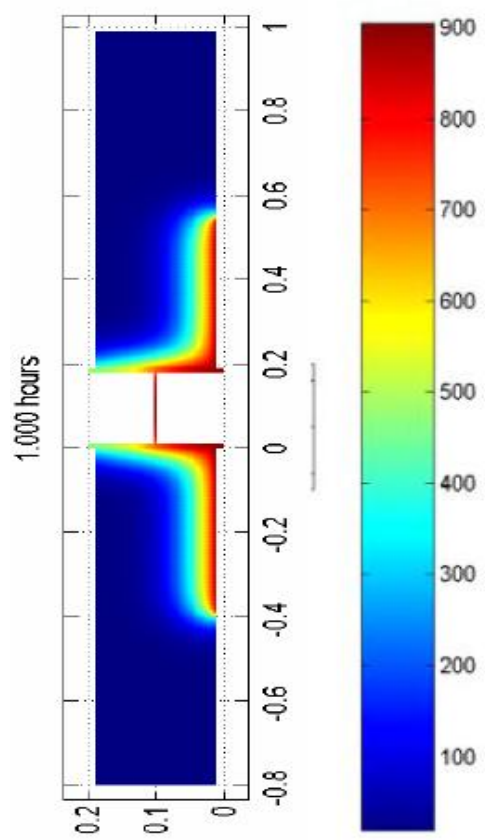

(a)

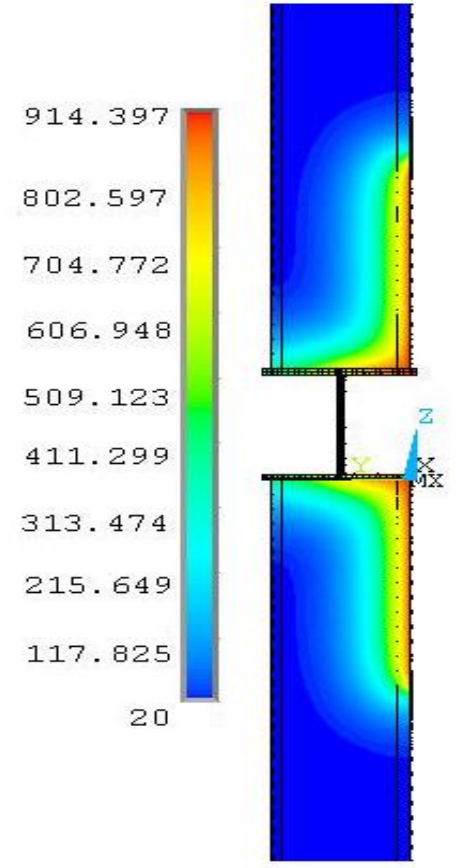

(b)

Figura 5.15 - Comparativo para 60 minutos de ação do incêndio com a consideração da superfície de perda de calor: (a) STC para perfil HEB200 (SILVA et al. 2008) e (b) via ANSYS do presente trabalho. 


\subsubsection{Perfil HEB160 - paredes em contato com as mesas}

Para o perfil HEB160, os pontos de interesse T1 e T5, conforme indicados na Figura 5.12a, apresentaram boa concordância com os resultados numéricos realizados no STC, Silva et al. (2008), e coerência com os resultados experimentais como visto na Figura 5.16.

Tabela 5.4 - Dimensões do perfil HEB160.

\begin{tabular}{lr}
\hline Dimensão & Valor \\
\hline$h_{w}$ & $134 \mathrm{~mm}$ \\
$h_{d}$ & $152 \mathrm{~mm}$ \\
$t_{w}$ & $6 \mathrm{~mm}$ \\
$b_{f}$ & $160 \mathrm{~mm}$ \\
$t_{f}$ & $9 \mathrm{~mm}$ \\
Parede & $110 \mathrm{~mm}$ \\
\hline
\end{tabular}

T1

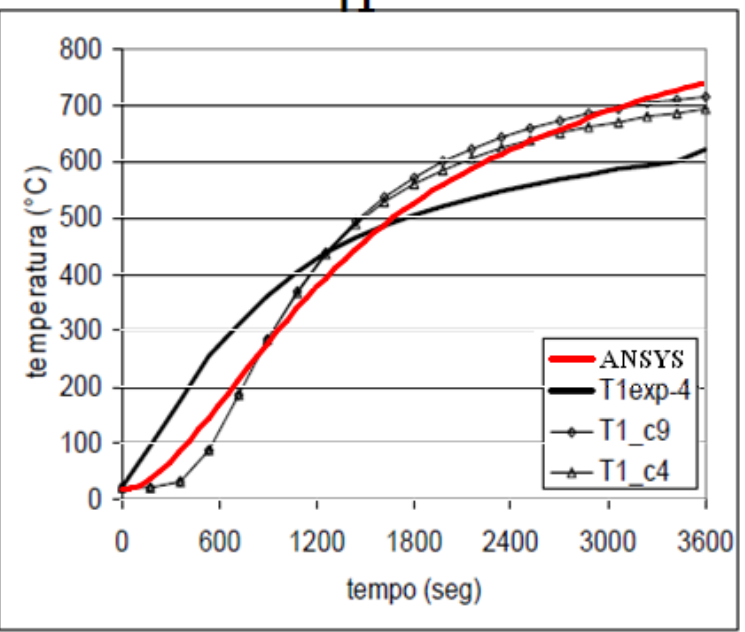

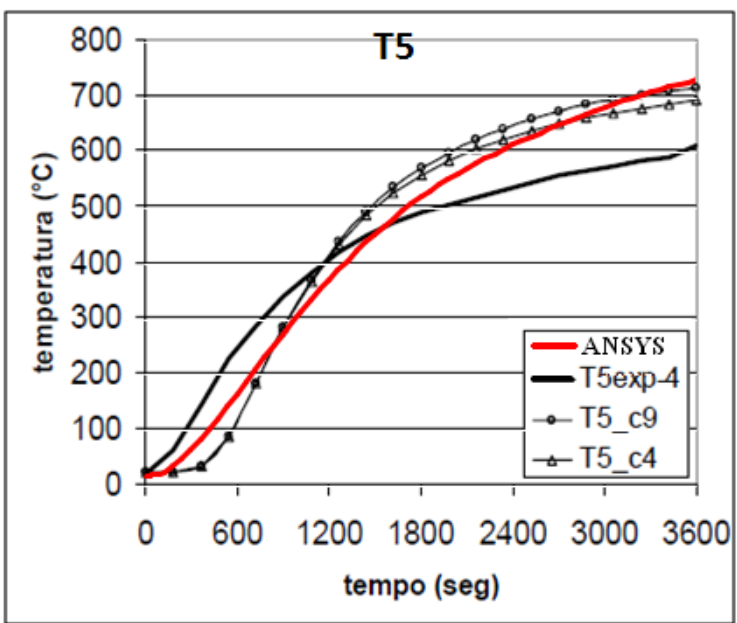

Figura 5.16 - Comparação de resultados para os pontos T1 e T5 para o perfil HEB160 com emissividade 0,5 sem perda de calor na face oposta.

Essa coerência será melhor estudada posteriormente, pois a consideração do fator de emissividade foi diferente, sendo $\mathbf{0 , 5}$ nesta pesquisa e $\mathbf{0 , 7}$ para aquela realizada com o STC. Contudo, na última referência se salienta em suas conclusões que para o uso do valor $\mathbf{0 , 7}$ o efeito shadow deve ser melhor estudado e compreendido.

O valor maior de emissividade induz mais calor para a superfície, no entanto a superfície oposta perde calor, situação não considerada nesse modelo, podendo ser esse o motivo de as curvas resultarem próximas. Também não foi incluída a argamassa com espessura de $15 \mathrm{~mm}$ de cada lado, sendo que no modelo seguinte será considerada para melhor adequar as comparações aos resultados experimentais e do STC. 
Os resultados dos pontos $T 2$ e $T 3$, por outro lado, não convergiram de forma semelhante aos resultados anteriores, se comparados à última referência, como pode ser visto na Figura 5.17. Isso se deve ao fato de a última referência considerar a superfície não exposta ao incêndio com perda de calor por convecção e por radiação, o que não ocorreu nesse primeiro modelo, e os pontos estarem localizados na alma do perfil, de espessura muito fina e considerada a perda de calor.
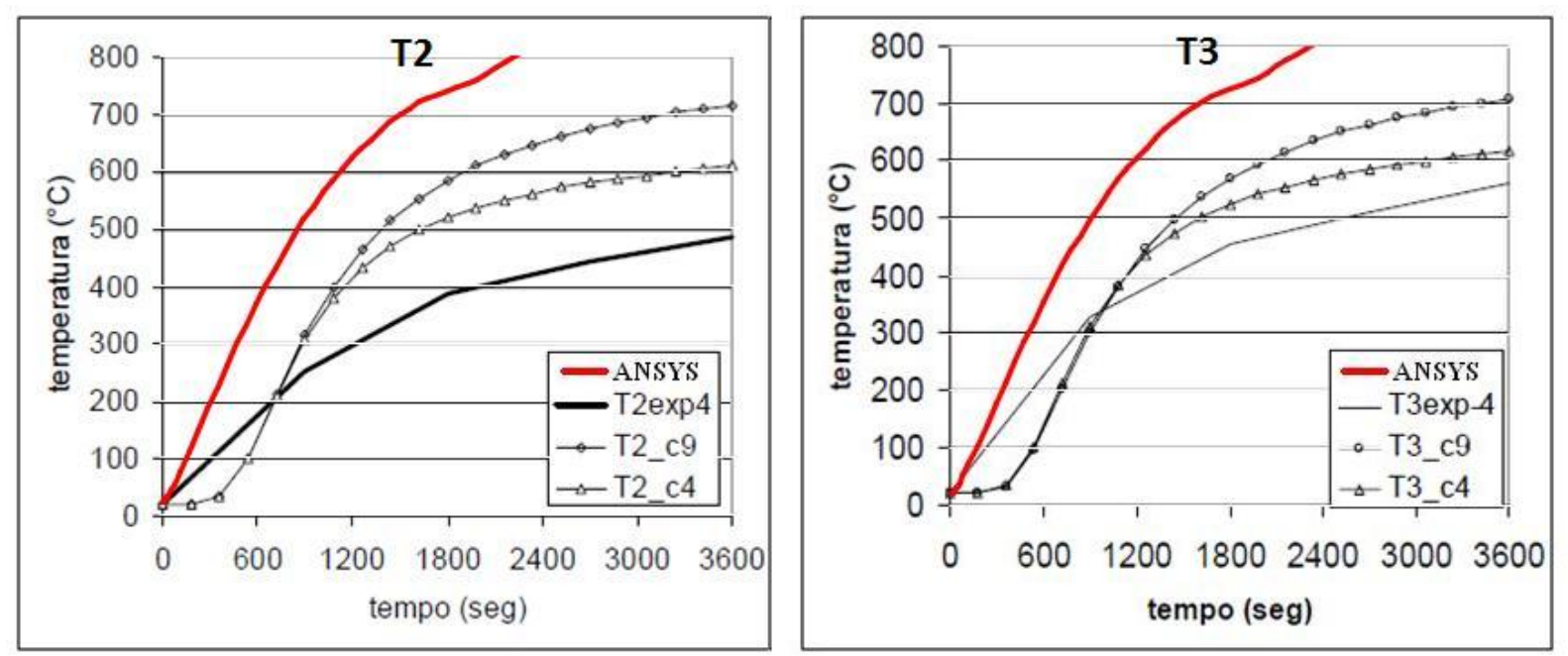

Figura 5.17 - Comparação dos resultados dos pontos T2 e T3 para o perfil HEB160 com emissividade 0,5 sem perda de calor na face oposta.

A não consideração de perda de calor na superfície se deveu ao fato de Kimura (2009) ter considerado tais superfícies adiabáticas e, por se tratar de uma continuação daquele, o presente trabalho inicialmente seguiria a mesma proposta, possibilitando a comparação de dados. Porém, considerando a necessidade de evolução do modelo numérico que está sendo construído e a necessidade de o modelo representar da maneira mais próxima possível a realidade, será considerada superfície com perda de calor na face oposta ao aquecimento nos modelos definitivos.

\subsubsection{Perfil HEB200 - paredes em contato com as mesas}

Na modelagem do perfil HEB200 foi considerada superfície com perda de calor na face oposta àquela referente à ação térmica, $15 \mathrm{~mm}$ de argamassa revestindo a parede de ambos os lados com as propriedades térmicas citadas em Silva, Correia e Rodrigues (2008) e vistas no item 3.6 através da Tabela 3.3, bem como parede com $15 \mathrm{~cm}$ de espessura por $80 \mathrm{~cm}$ de largura. A Figura 5.18 mostra os pontos de onde os resultados foram coletados para fins de comparação aos resultados de outros autores. 


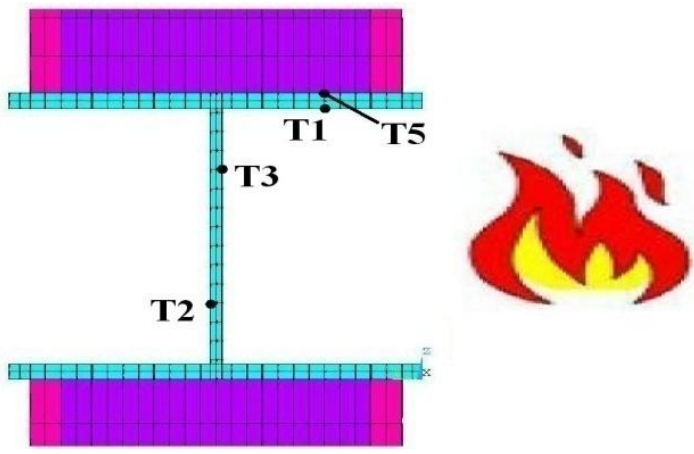

Figura 5.18 - Disposição dos pontos com dados coletados e malha de elementos finitos.

Tabela 5.5 - Dimensões do perfil HEB200.

\begin{tabular}{lr}
\hline Dimensão & Valor \\
\hline$h_{w}$ & $170 \mathrm{~mm}$ \\
$h_{d}$ & $190 \mathrm{~mm}$ \\
$t_{w}$ & $6 \mathrm{~mm}$ \\
$b_{f}$ & $200 \mathrm{~mm}$ \\
$t_{f}$ & $10 \mathrm{~mm}$ \\
Parede & $150 \mathrm{~mm}$ \\
Argamassa & $15 \mathrm{~mm}$ \\
\hline
\end{tabular}

Variou-se a emissividade em $\mathbf{0 , 5}$ e $\mathbf{0 , 7}$ para observar a diferença dos resultados na consideração de cada um desses valores, bem como a perda de calor pelo efeito de radiação (com emissividade $\mathbf{0 , 5}$ ou $\mathbf{0 , 7}$ e temperatura do ambiente externo constante em $20{ }^{\circ} \mathrm{C}$ ) e convecção $\left(4 \mathbf{W} / \mathbf{m}^{20} \mathbf{C}\right)$. Também foi considerada a hipótese de ambos os efeitos de perda de calor (radiação e convecção) combinados em um coeficiente de convecção equivalente (9 $\mathbf{W} / \mathbf{m}^{\mathbf{2}_{\mathbf{o}}} \mathbf{C}$ ), conforme Figura 5.19, ambos sugeridos em Silva, Correia e Rodrigues (2008) e recomendado pelo EUROCODE 1 parte 1.2.

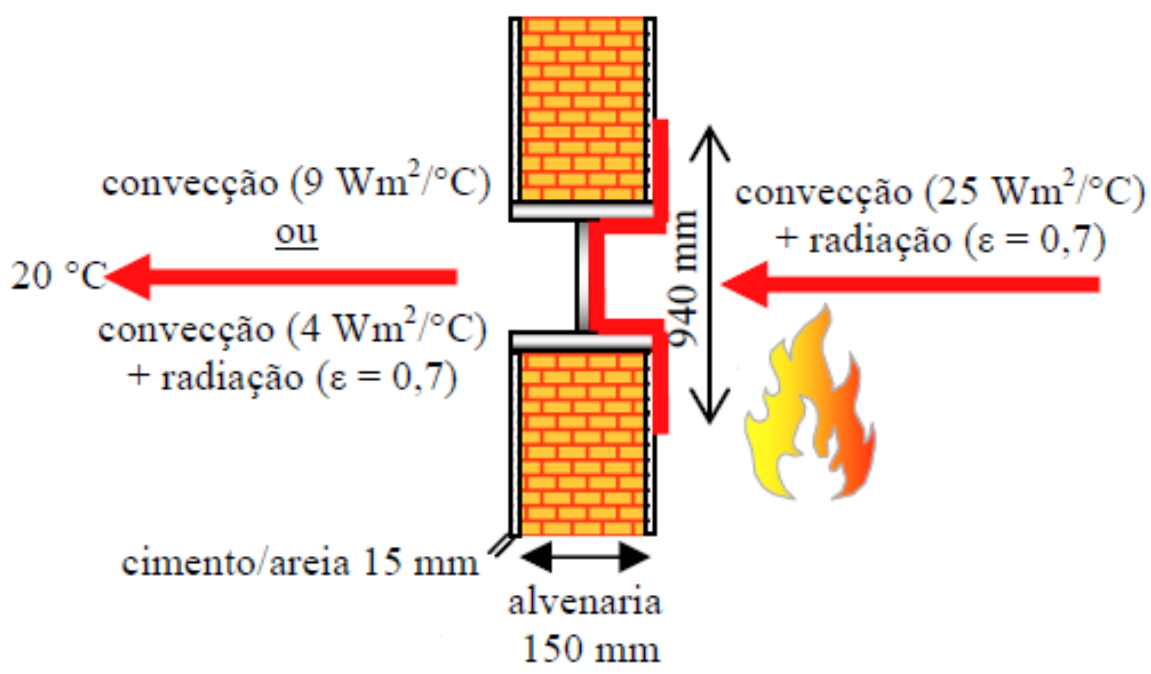

Figura 5.19 - Esquema da fonte de calor e da perda com paredes as mesas. FONTE: Silva, Correia e Rodrigues (2008) 
Inicialmente fora utilizada a curva de incêndio-padrão ISO 834-1:1999 para o aquecimento dos gases e, consequentemente, do modelo numérico. Os resultados com a variação na emissividade, tanto para o fornecimento de calor quanto para a perda pela face oposta, e com a variação do modo de perda de calor, conforme citado anteriormente, e utilizada em Silva, Correia e Rodrigues (2008), são exibidos na Figura 5.20.
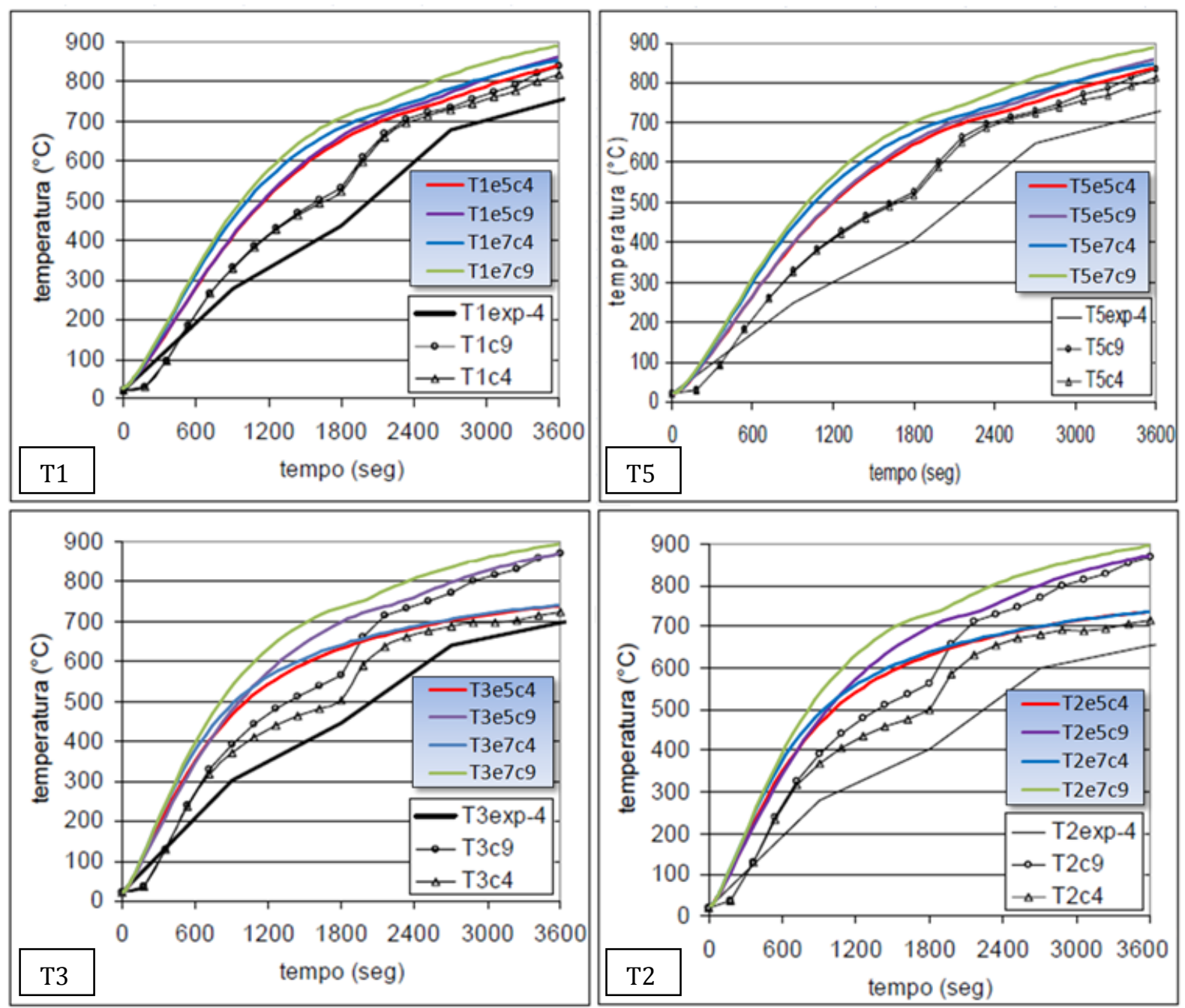

Figura 5.20 - Curvas de aquecimento de quatro pontos de interesse do perfil HEB200 para diferentes situações de emissividade, superfície de perda de calor e curva de incêndio ISO 834-1:1999.

Com relação à última figura, vale lembrar que os pontos $T 1, T 2, T 3$ e T5 estão esquematizados na Figura 5.18, destacando que os valores de emissividade e a forma utilizada para a perda de calor são vistos na legenda da figura a seguir, da seguinte forma: Tle $5 c 4$ indica o ponto $T 1$ com emissividade 0,5 e perda de calor por convecção de $4 \mathbf{W} / \mathbf{m}^{20} \mathrm{C}$ e por radiação, enquanto $T l e 7 c 9$ indica o ponto $T 1$ com emissividade $\mathbf{0 , 7}$ e perda com ambos 
efeitos combinados considerados pela convecção de $9 \mathbf{W} / \mathbf{m}^{20} \mathbf{C}$. Os resultados encontrados são comparados aos obtidos em Silva, Correia e Rodrigues (2008).

Apesar de as curvas não apresentarem boa concordância entre si é interessante observar que a mudança do fator de emissividade pouco altera a resposta térmica do perfil. Por outro lado, a forma que se considera a perda de calor muda consideravelmente o resultado. Em Staggs e Phylaktou (2008) resultados numéricos e experimentais mostram que o valor considerado para a emissividade pouco influencia nos resultados, como mostra a Figura 5.21, e sugere para a convecção valores próximos a $28 \mathbf{W} / \mathbf{m}^{\mathbf{2}^{\circ}} \mathbf{C}$ como mais apropriados. Posteriormente em Stagss (2009), concluiu-se que um valor satisfatório da convecção para a superfície de perda de calor resultaria em algo entre 2 e $4 \mathrm{~W} / \mathbf{m}^{2_{0}} \mathbf{C}$.

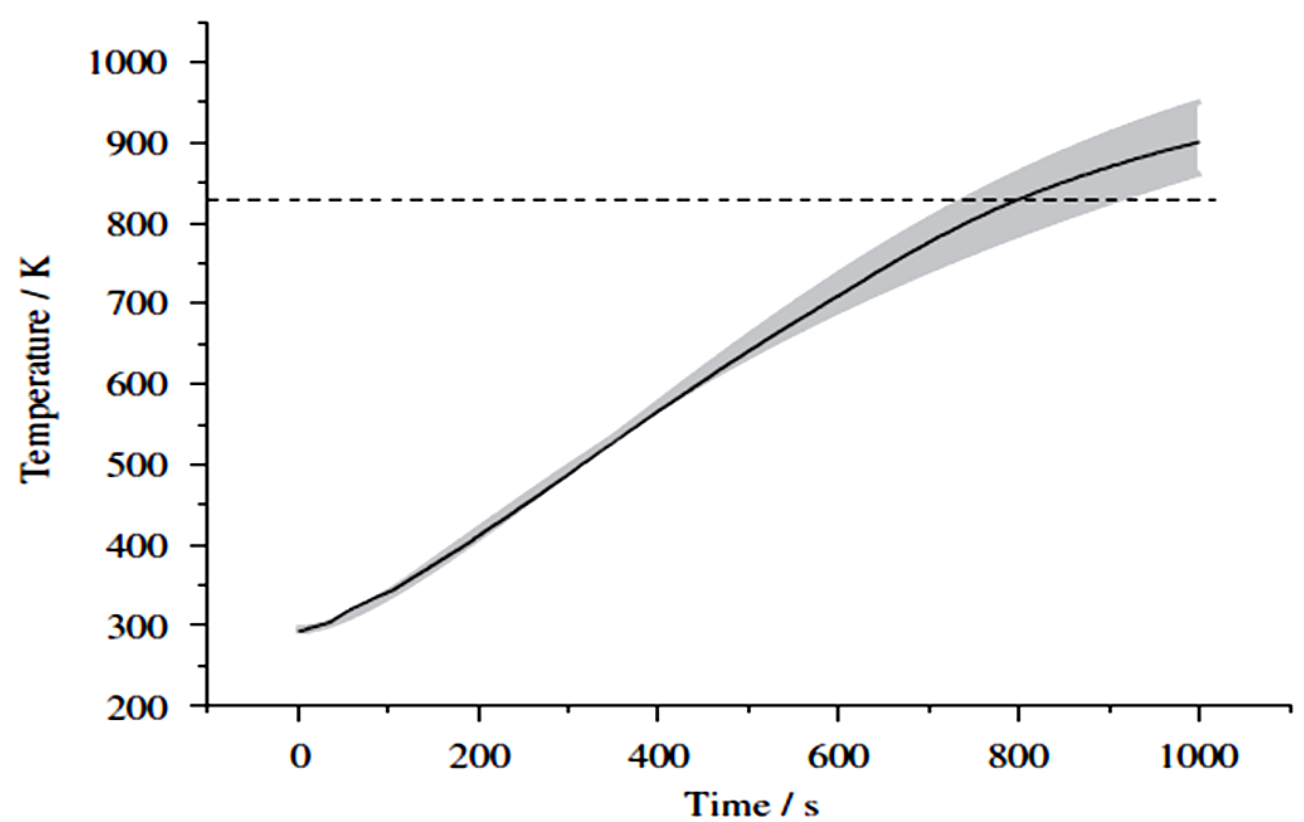

Figura 5.21 - Efeitos máximo e mínimo na temperatura do aço devido a variação da emissividade $(0<\varepsilon<1)$ comparado ao experimento de uma viga de aço sem proteção.

FONTE: Stagss (2009)

Uma vez que os valores térmicos obtidos pelos modelos numéricos aqui propostos resultaram sempre superiores em relação à última referência citada, buscou-se melhorar os dados de entrada com vistas a uma melhor convergência dos resultados comparativos. Em Silva, Correia e Rodrigues (2008) é apresentada uma série de curvas de tomada de temperatura do forno (como na Figura 5.22a) no modelo experimental, quatro ao total, uma para cada situação e perfil estudado, as quais resultaram sempre abaixo da curva de incêndiopadrão ISO 834-1:1999 adotada nos modelos numéricos desta atual pesquisa, sendo esse um possível motivo para o "superaquecimento". 
A curva de temperaturas do tipo 1, reproduzida na Figura 5.22, representa a situação que se pretende comparar, nesse caso, perfil HEB200 com paredes em contato com as almas. A curva de tipo 3 considera a mesma configuração da curva tipo 1, porém, considera a utilização do perfil HEB160. Para facilitar a entrada dos dados no código computacional ANSYS e para que os pontos discretos de temperatura obtidos no forno pudessem ser extrapolados para qualquer tempo dentro do intervalo de 0 a 3600 segundos, foi realizada uma regressão linear dos pontos e encontrada uma expressão polinomial do quinto grau, com coeficiente de correlação $\mathrm{r}^{2}$ igual a 0,9982524 ) para representar a curva do tipo 1 .

Os gráficos citados estão na Figura 5.22, e o polinômio é apresentado na Equação 5.1, em que o tempo (t) é dado em segundos e a temperatura $(\theta)$ em graus Celsius, cujos coeficientes são apresentados na Tabela 5.6.

$$
\theta\left({ }^{\circ} \mathrm{C}\right)=\mathrm{A}+\mathrm{Bt}+\mathrm{Ct}^{2}+\mathrm{Dt}^{3}+\mathrm{Et}^{4}+\mathrm{Ft}^{5}
$$

Tabela 5.6 - Parâmetros do polinômio curva tipo 1 .

\begin{tabular}{lr}
\hline Termo & Valor \\
\hline A & $-57,760123$ \\
B & 2,3154003 \\
C & $-0,003090188$ \\
D & $1,9316895 \times 10^{-6}$ \\
E & $-5,3937487 \times 10^{-10}$ \\
F & $5,4839927 \times 10^{-14}$ \\
\hline
\end{tabular}

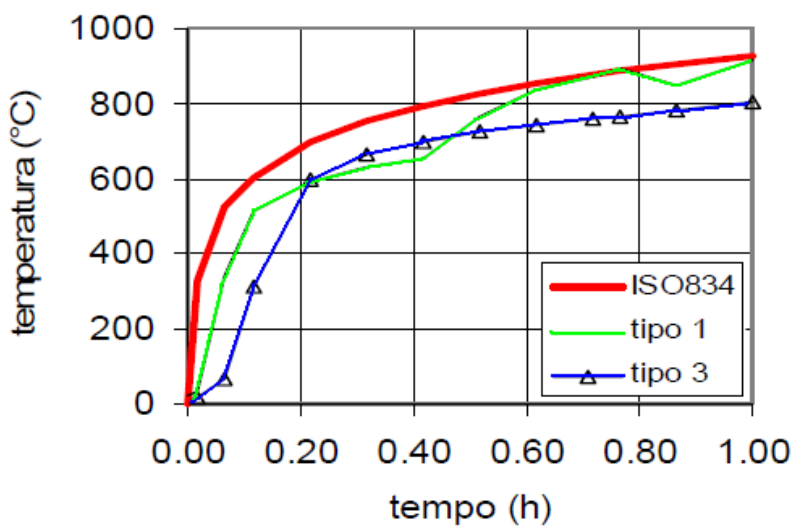

(a)

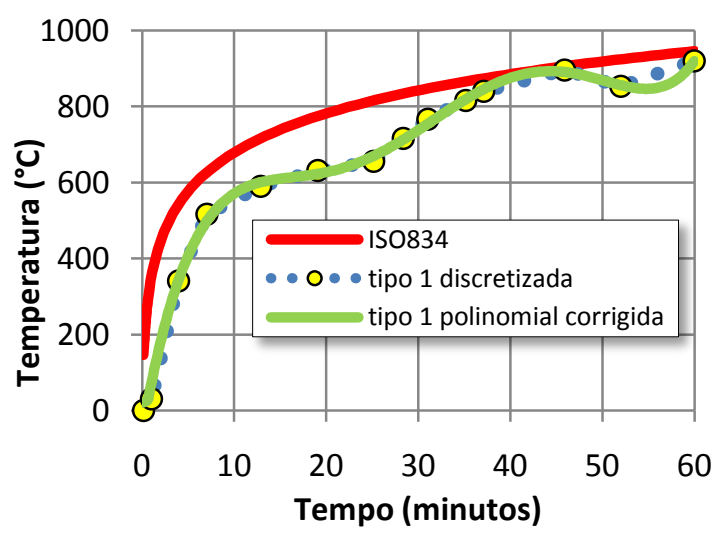

(b)

Figura 5.22 - Curvas (a) ISO 834-1:1999, tipo 1 e tipo 3 consideradas na referência citada e (b) curva tipo 1 discretizada e polinômio equivalente.

Como o polinômio de aproximação da Equação 5.1 apresenta valores negativos no trecho inicial, considerou-se essa equação apenas para o trecho da curva após o primeiro 
ponto (60 segundos; $\left.29,7^{\circ} \mathrm{C}\right)$ da curva, sendo antes desse considerada uma equação linear (Equação 5.2) para corrigir os valores negativos e inferiores à temperatura ambiente. Foi então considerada a nova curva de aquecimento dos gases, coerente com o observado experimentalmente e, portanto, com maior confiabilidade na comparação dos resultados. Foram encontradas curvas de aquecimento dos pontos de interesse T1, T2, T3 e T5 para uma emissividade de $\mathbf{0 , 7}$ e perda de calor na face oposta apenas por convecção $\left(\mathbf{9} \mathbf{W} / \mathbf{m}^{2^{\circ}} \mathbf{C}\right)$ conforme esquematiza a Figura 5.23.

$$
\theta\left({ }^{\circ} \mathrm{C}\right)=20+\frac{\mathrm{t}}{6,2}
$$
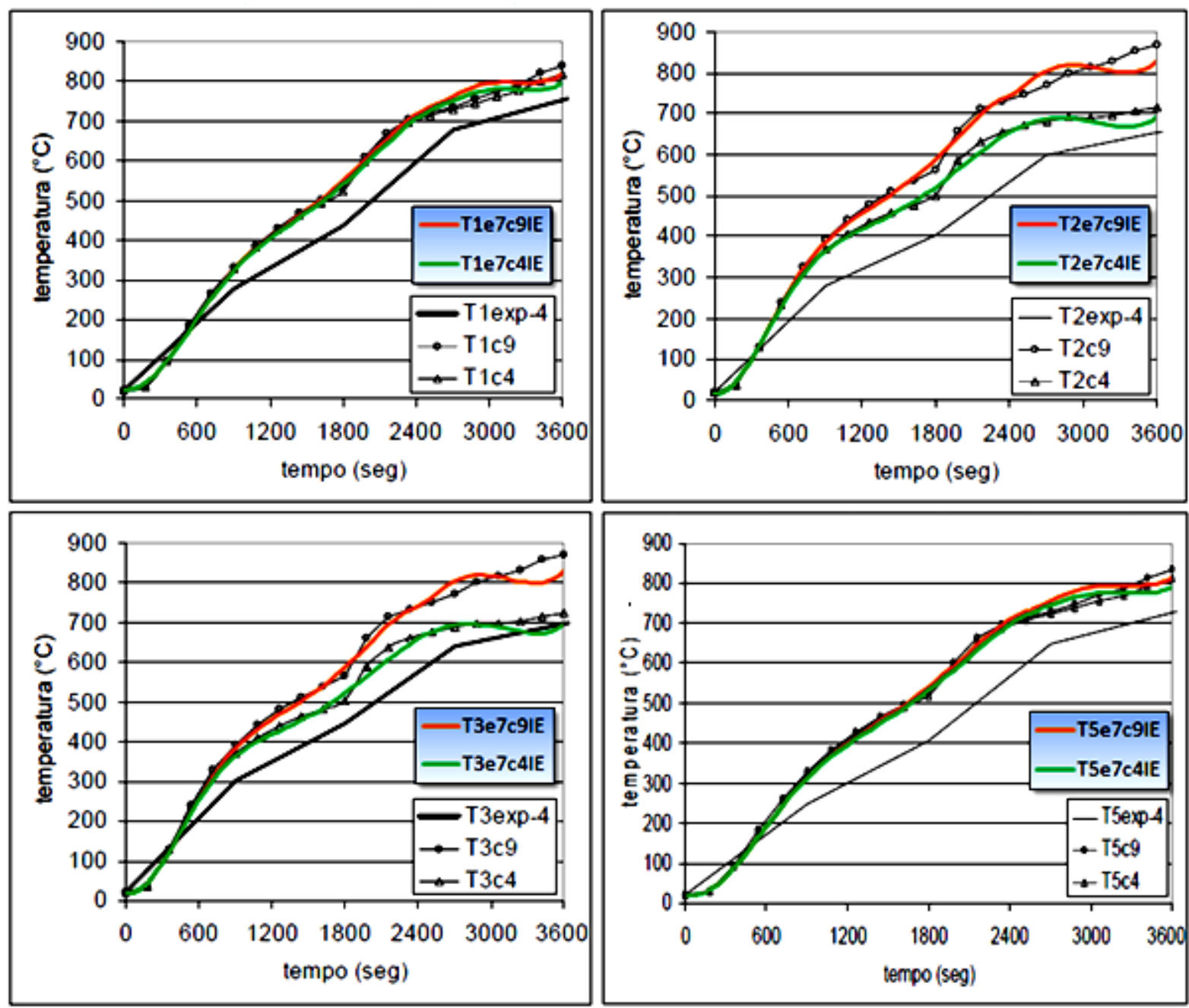

Figura 5.23 - Curvas de aquecimento de quatro pontos de interesse do perfil HEB200 para emissividade 0,7 , superfície de perda de calor, paredes nas mesas e curva de incêndio experimental tipo 1 .

A nomenclatura das legendas segue o padrão das figuras anteriores, ou seja, Tle $7 c 9 I E$ indica o ponto de interesse $T 1$ com emissividade considerada com o valor $\mathbf{0 , 7}$ e perda de calor 
somente por convecção com o valor de $9 \mathrm{~W} / \mathrm{m}^{2 \circ} \mathrm{C}$. A indicação de $T l e 7 c 4 I E$ representa o mesmo ponto $T 1$, porém, com perda de calor por convecção $\left(4 \mathbf{W} / \mathbf{m}^{\mathbf{2}_{\mathbf{o}}} \mathrm{C}\right)$ e por radiação. As letras $I E$ ao final significam Incêndio Experimental, indicando que fora utilizada a mesma curva de aquecimento dos gases registrada no interior do forno.

Apesar da boa convergência em relação aos resultados numéricos apresentados em Silva, Correia e Rodrigues (2008), esses obtidos com o código computacional STC, os resultados experimentais ainda resultam pouco coincidentes. Um dos motivos "possíveis" para tal fato é a não caracterização das propriedades físico térmicas da alvenaria, que desempenha papel importante nas trocas de calor com o perfil de aço. Os valores utilizados em diversas referências encontradas (inclusive na presente pesquisa) são os sugeridos pelo código computacional Ozone, desenvolvido pela Universidade de Liège. Os valores das propriedades para a alvenaria são: $0,7 \mathrm{~W} / \mathrm{m}^{2 \mathbf{o}} \mathrm{C}$ para a condutividade térmica, $840 \mathrm{~J} / \mathbf{k g}^{\mathbf{0}} \mathrm{C}$ o calor específico e densidade de $1600 \mathbf{~ k g} / \mathbf{m}^{3}$, ambos considerados constantes com a variação da temperatura.

Também podem ser citados outros fatores que "possivelmente" interferem na comparação entre os resultados experimentais e numéricos, a exemplo do valor correto da emissividade de radiação a ser utilizada. A ABNT NBR 14323:1999 considera um valor de 0,5 para a emissividade, enquanto que o EUROCODE 3 - Parte 1.2 adota o valor de $\mathbf{0 , 7}$, o qual é ponderado por um fator de correção para consideração do efeito shadow (o qual sugere estudos mais detalhados). Os resultados apresentados na Figura 5.20 sugerem que as duas formas de considerar a perda de calor na face oposta ao aquecimento interferem com maior evidência se comparados à emissividade adotada.

Um terceiro fator que merece destaque é o fato de, na análise experimental, ser observado o descolamento da alvenaria do perfil de aço em dado momento. Esse descolamento interfere na transferência de calor por condução na região afetada e passa a atuar, então, uma transferência por radiação, além da perda de calor pela fresta entre as superfícies do interior do forno para o ambiente sem passar pelo modelo experimental.

Vale destacar que além dos aspectos mencionados anteriormente, podem existir outros fatores, muitas vezes de difícil determinação, que influenciam eventualmente na resposta do modelo experimental e, consequentemente, nas estratégias adotadas nos modelos numéricos 
para estudo de estruturas em situação de incêndio. O objetivo de ambos, porém, sempre será de encontrar formas mais precisas e confiáveis de predizer o comportamento nessas situações.

\subsubsection{Perfil HEB200 - paredes em contato com a alma}

Seguindo metodologia semelhante àquela adotada no item 5.5.2, faz-se agora a construção de modelo com o perfil HEB200 em que as paredes estão em contato com a alma do perfil. O esquema utilizado pode ser visto na Figura 5.24

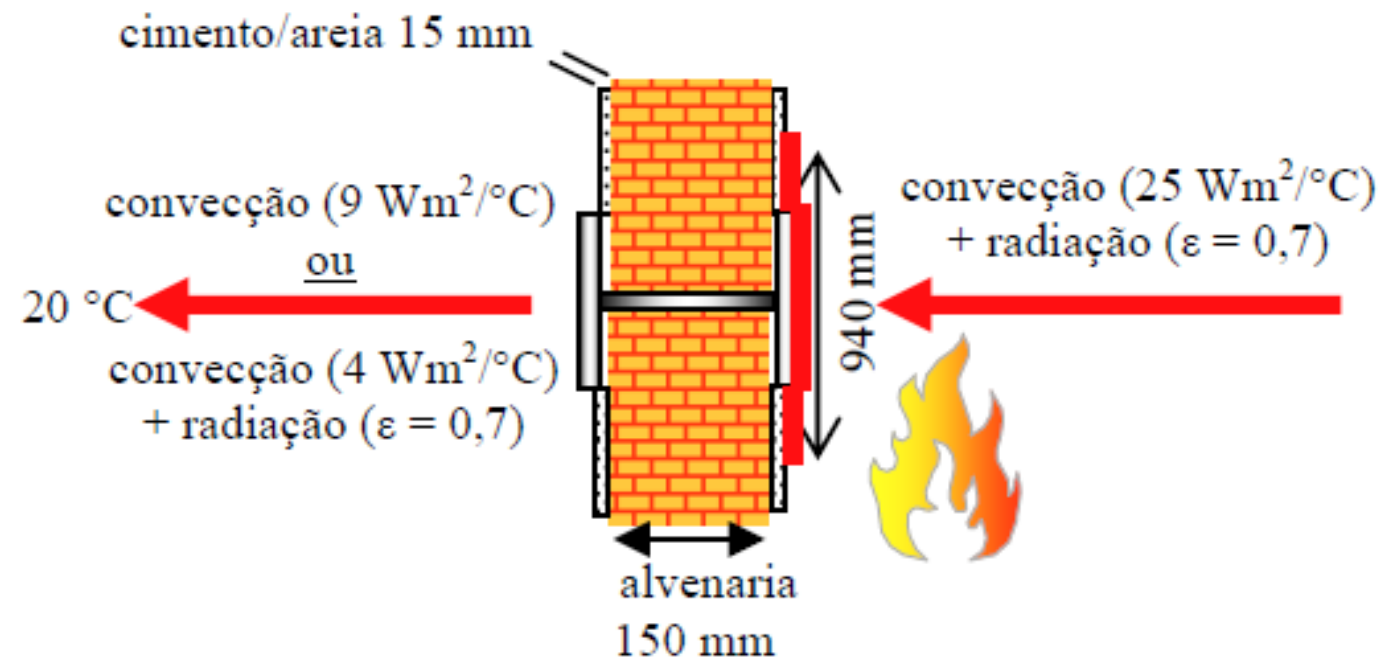

Figura 5.24 - Esquema da fonte de calor e da perda com paredes na alma. FONTE: Silva, Correia e Rodrigues (2008)

Novamente, foi realizada uma regressão linear dos pontos e encontrada uma expressão polinomial do quinto grau, cujo coeficiente de correlação $\mathrm{r}^{2}$ igual a 0,99790219 para representar a curva do tipo 2. Os gráficos citados estão na Figura 5.25 e o polinômio é demonstrado na Equação 5.3, em que o tempo (t) é dado em segundo e a temperatura $(\theta)$ em graus Celsius, cujos coeficientes são apresentados na Tabela 5.7.

$$
\theta\left({ }^{\circ} \mathrm{C}\right)=\mathrm{A}+\mathrm{Bt}+\mathrm{Ct}^{2}+\mathrm{Dt}^{3}+\mathrm{Et}^{4}+\mathrm{Ft}^{5}
$$

Tabela 5.7 - Parâmetros do polinômio curva tipo 2 .

\begin{tabular}{lr}
\hline Termo & Valor \\
\hline A & $-67,7454381$ \\
B & 2,0849816 \\
C & $-2,5939436 \times 10^{-6}$ \\
D & $1,5417454 \times 10^{-6}$ \\
E & $-4,1240012 \times 10^{-10}$ \\
F & $4,0453053 \times 10^{-14}$ \\
\hline
\end{tabular}




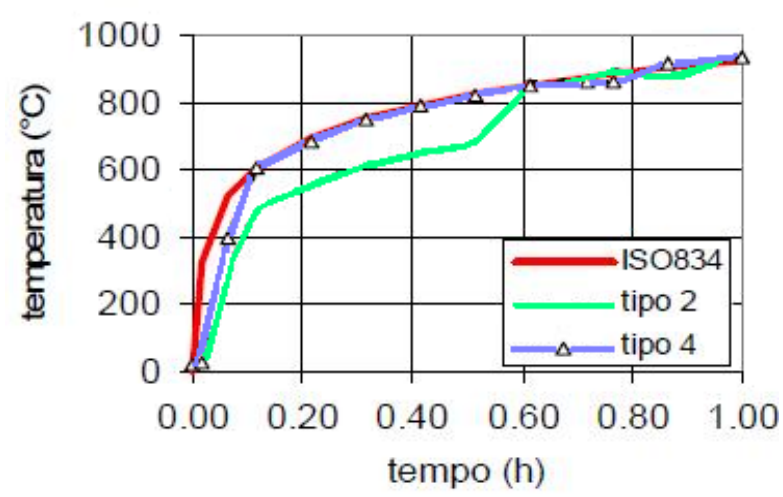

(a)

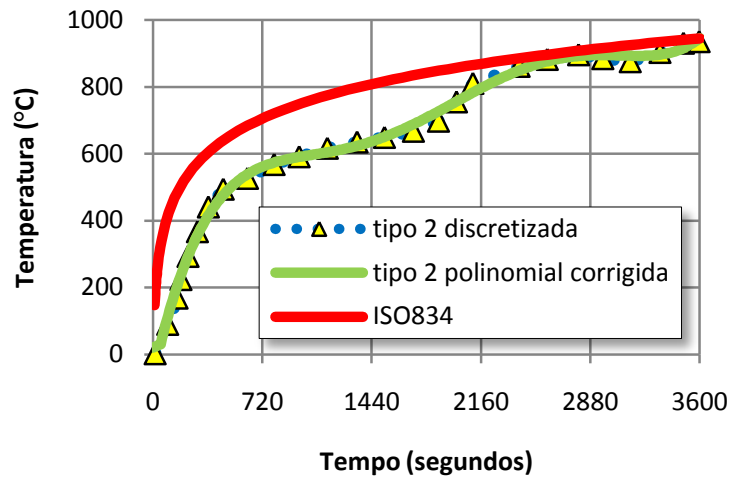

(b)

Figura 5.25 - Curvas: (a) ISO 834-1:1999, tipo 2 e tipo 4 consideradas na referência citada, e (b) tipo 2 discretizada e polinômio equivalente.

Como visto anteriormente, o polinômio de aproximação da Equação 5.3 também apresenta valores negativos no trecho inicial. Por esse motivo considerou-se essa equação apenas após o polinômio superar o valor da temperatura ambiente $\left(20^{\circ} \mathrm{C}\right)$, ou seja, após o ponto (50 segundos; $30,5^{\circ} \mathrm{C}$ ). Desde o tempo inicial até o ponto citado, foi considerada uma equação linear (Equação 5.4), corrigindo os valores negativos e inferiores à temperatura ambiente. Foram então obtidos os resultados do aquecimento em pontos de interesse marcados na Figura 5.26 considerando uma emissividade de $\mathbf{0 , 7}$ e perda de calor na face oposta apenas por convecção $\left(9 \mathrm{~W} / \mathbf{m}^{2_{0}} \mathbf{C}\right)$.

$$
\theta\left({ }^{\circ} \mathrm{C}\right)=20+0,21 \times \mathrm{t}
$$

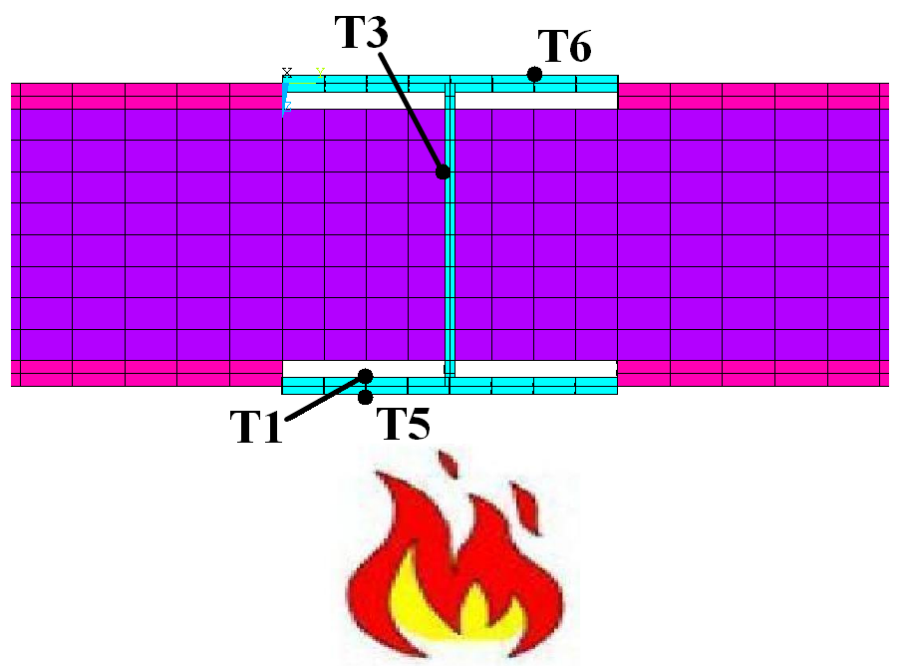

Figura 5.26 - Malha de elementos finitos e disposição dos pontos com dados coletados. 
Nesse modelo a nomenclatura dos pontos nas legendas não foram variados como anteriormente, uma vez que a curva de aquecimento dos gases utilizada foi somente a experimental, como explicado anteriormente, e com emissividade igual a $\mathbf{0 , 7}$. A forma de perda de calor considerada foi apenas uma, a que considera emissividade de radiação igual a 0 e coeficiente de convecção equivalente igual a $\mathbf{9} \mathbf{W} / \mathbf{m}^{\mathbf{2}^{\circ}} \mathbf{C}$. Se fosse utilizada a mesma nomenclatura do modelo anterior, resultaria algo como $T 1 e 7 c 9 I E$ para representar o ponto $T 1$.

Novamente, a convergência com os resultados numéricos de Silva, Correia e Rodrigues (2008) foi satisfatória, no entanto, ambos ficaram abaixo dos resultados experimentais, por motivos anteriormente expostos. Os resultados obtidos nos pontos T1, T3, T5 e T6 podem ser vistos em comparação com os de Silva, Correia e Rodrigues (2008) na Figura 5.27.
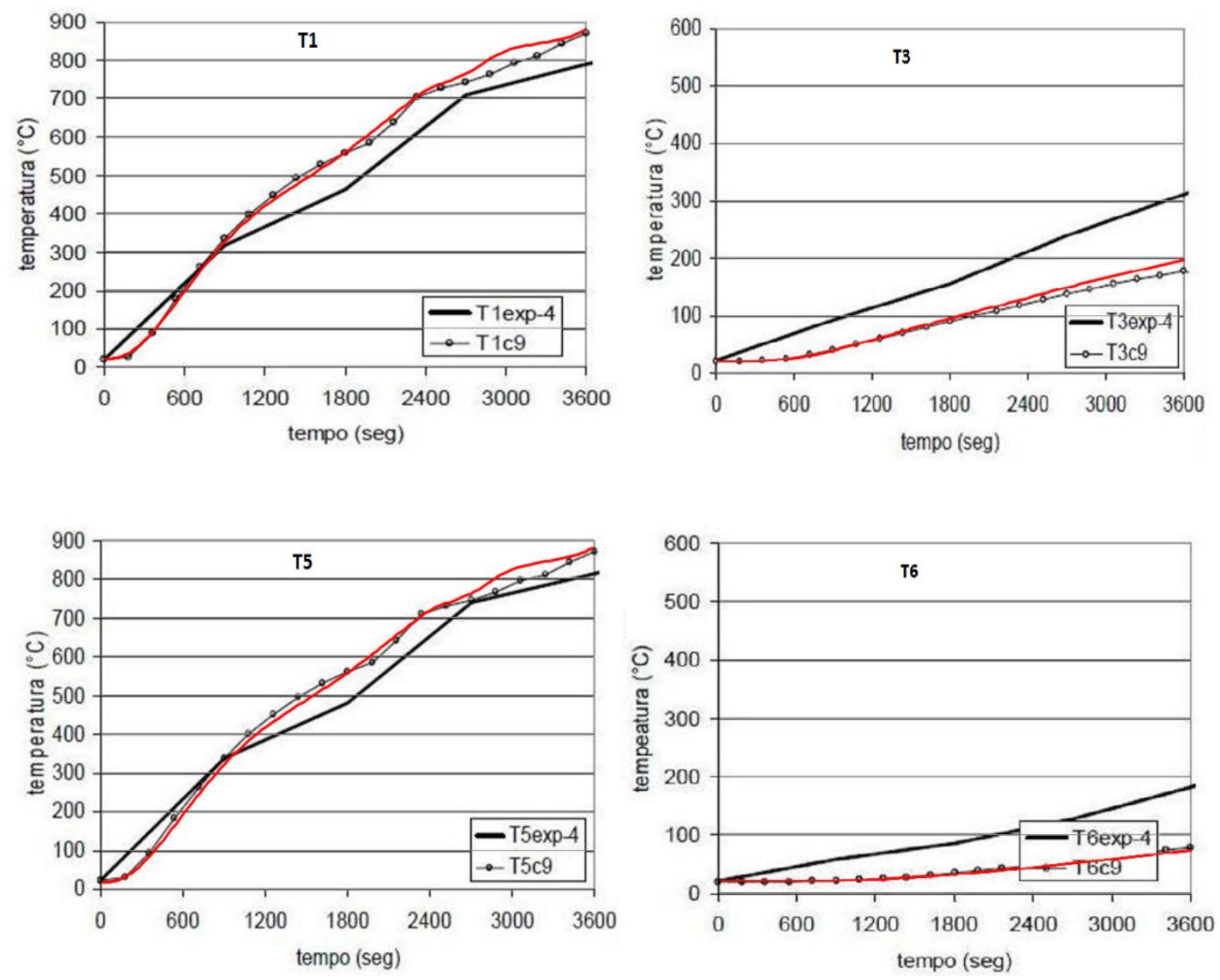

Figura 5.27 - Curvas de aquecimento dos quatro pontos de interesse referentes ao perfil HEB200 para emissividade 0,7, superfície com perda de calor, paredes na alma e curva de incêndio experimental tipo 2 . 


\subsection{COMPARAÇÃO DE RESULTADOS TÉRMICOS OBTIDOS}

\section{VIA STC E ANSYS}

Lembrando que a presente proposta é dar continuidade aos estudos realizados e apresentados em Kimura (2009), serão validados os resultados dos modelos aqui propostos, agora considerando elementos do tipo casca, por meio de comparação àqueles propostos na última referência, em que foram empregados elementos finitos do tipo sólido.

\subsubsection{Perfil UC $203 \times 203 \times 46$ - sem paredes}

A ilustração da malha de elementos finitos tipo casca, aqui proposta, é comparada à malha do tipo sólido, conforme Kimura (2009), por meio da Figura 5.28, sendo que ambas foram submetidos a um campo de temperatura uniforme por todos os lados.

Tabela 5.8 - Dimensões do perfil UC 203 x 203 x 46 .

\begin{tabular}{lr}
\hline Dimensão & Valor \\
\hline$h_{w}$ & $181,2 \mathrm{~mm}$ \\
$t_{w}$ & $7,2 \mathrm{~mm}$ \\
$b_{f}$ & $203,6 \mathrm{~mm}$ \\
$t_{f}$ & $11 \mathrm{~mm}$ \\
$d$ & $203,2 \mathrm{~mm}$ \\
$A_{g}$ & $5870 \mathrm{~mm}^{2}$ \\
Parede & $140 \mathrm{~mm}$ \\
\hline
\end{tabular}

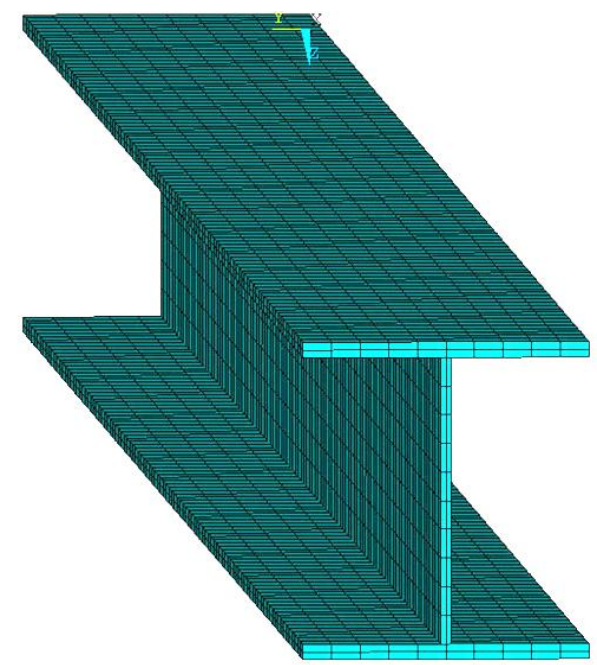

(a)

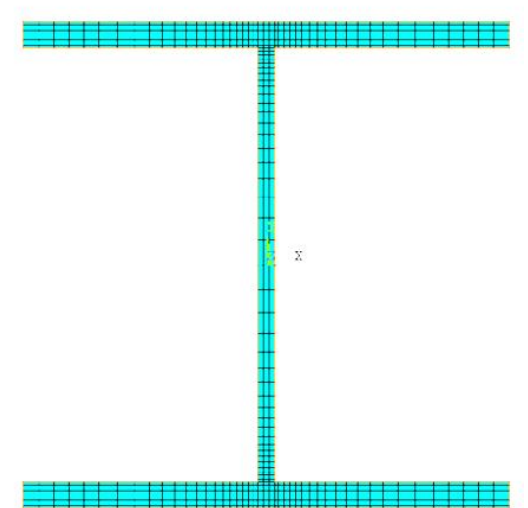

(b)

Figura 5.28 - Geometria e malha de elementos finitos do perfil UC 203 x 203 x 46 com: (a) elementos tipo casca da atual pesquisa e $(b)$ elementos SOLID conforme Kimura (2009). 
A Figura 5.29 ilustra a distribuição de temperatura ao final de um intervalo de tempo correspondente a 60 minutos, na qual se comparam os resultados térmicos, enquanto desempenho, obtidos entre os elementos tipo casca (presente trabalho) e tipo sólido obtidos em Kimura (2009).

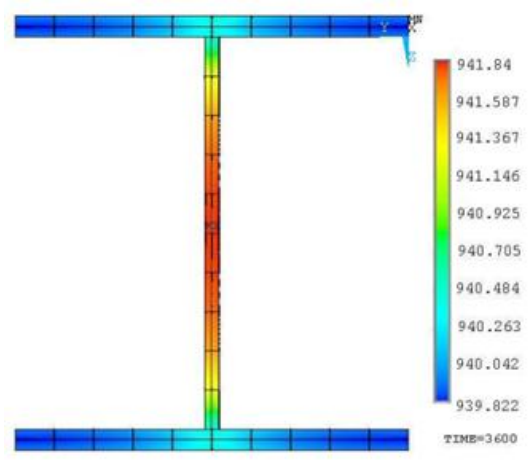

(a)

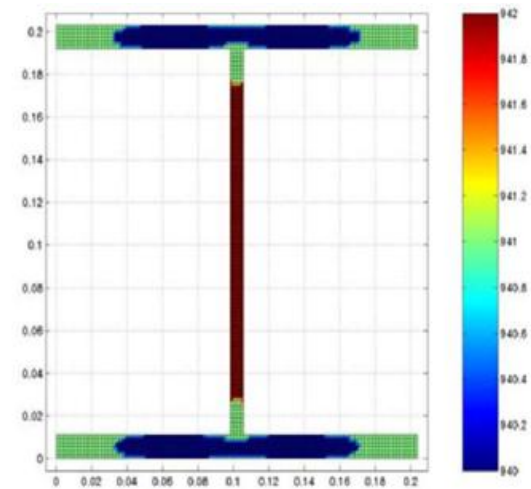

(b)

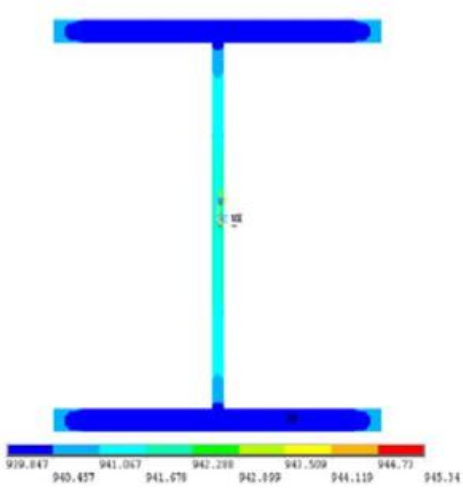

(c)

Figura 5.29 - Campos térmicos obtidos para perfil UC 203 × 203 x 46 aos 60 minutos de exposição ao incêndio-padrão ISO 834-1:1999: (a) elementos tipo casca da atual pesquisa, (b) via STC (Kimura 2009) e (c) via ANSYS com elemento sólido (Kimura 2009).

A Figura 5.30 apresenta a variação da temperatura ao longo do tempo, no ponto central da alma e na extremidade da mesa, comparando aos valores obtidos em Kimura (2009) tanto pelo código computacional STC como pelo ANSYS.

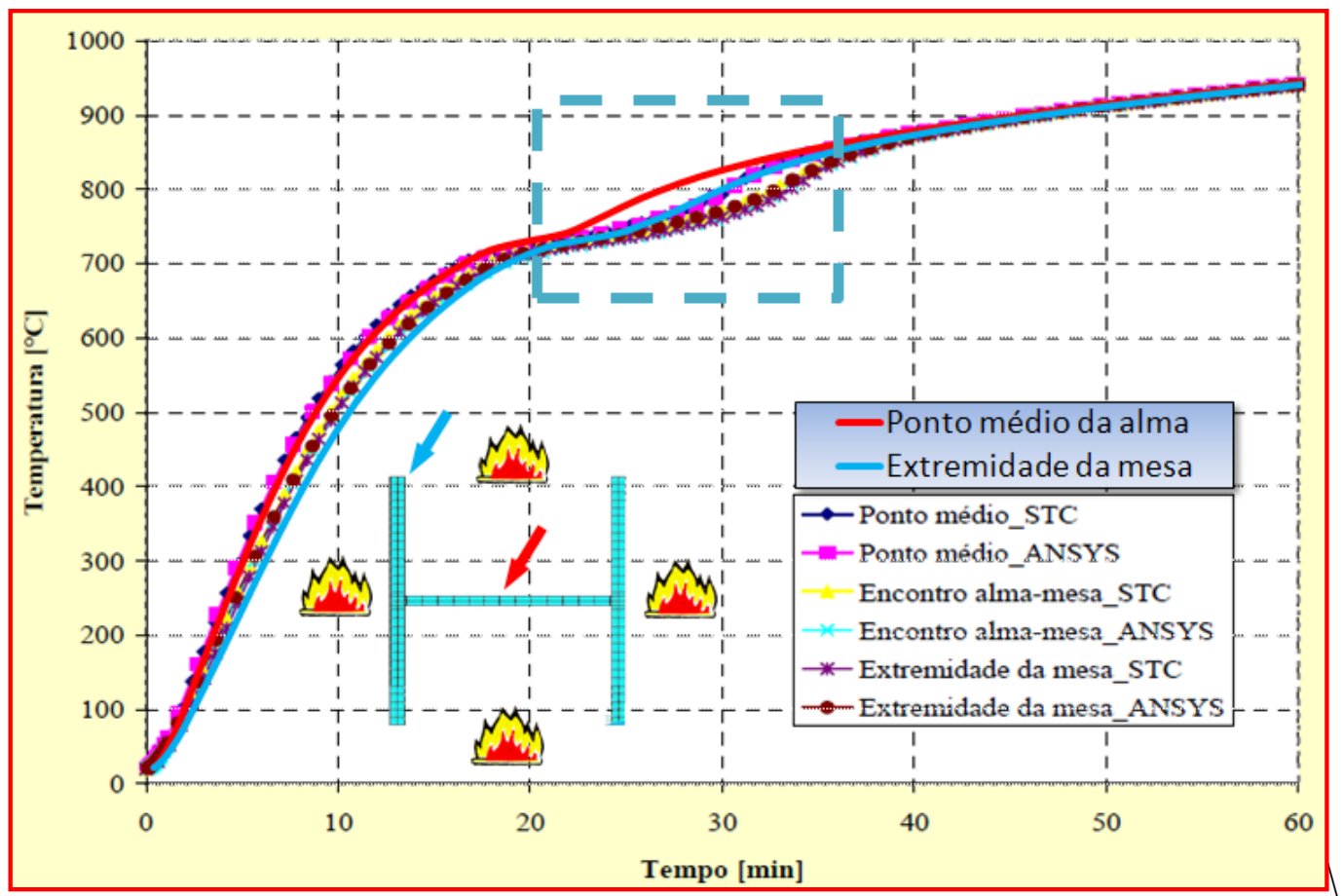

Figura 5.30 - Gráfico da evolução térmica obtida via STC e ANSYS em Kimura (2009) e via ANSYS nesta pesquisa com elemento do tipo casca. 
Pode ser observado na Figura 5.30 que as curvas mantêm-se coincidentes na fase inicial, havendo pequena divergência em um pequeno trecho entre os 25 e 30 minutos, voltando a convergir após esse período. Esse trecho corresponde a uma temperatura do aço próxima aos $735^{\circ} \mathrm{C}$, região de acentuada não linearidade do calor específico do material. A divergência das curvas na proximidade dos 30 minutos (ou $735^{\circ} \mathrm{C}$ ) ocorreu em virtude do maior refinamento na entrada dos dados do calor específico no código computacional ANSYS nesta pesquisa em comparação à pesquisa de Kimura (2009).

Na Figura 5.31 é mostrada graficamente a diferença da entrada de dados com apenas 15 pontos discretos e o maior refinamento da curva obtido com 60 pontos discretos na entrada dos dados. Para valores intermediários entre um ponto e outro é feita uma interpolação linear. O maior refinamento dessa propriedade térmica do aço, assim como de outras propriedades que sejam não lineares, segue um dos objetivos principais desta pesquisa, constantes nas sugestões de trabalhos futuros de Kimura (2009), que consiste em aprimorar e otimizar os modelos numéricos lá propostos, além de acrescentar a restrição axial ao modelo.

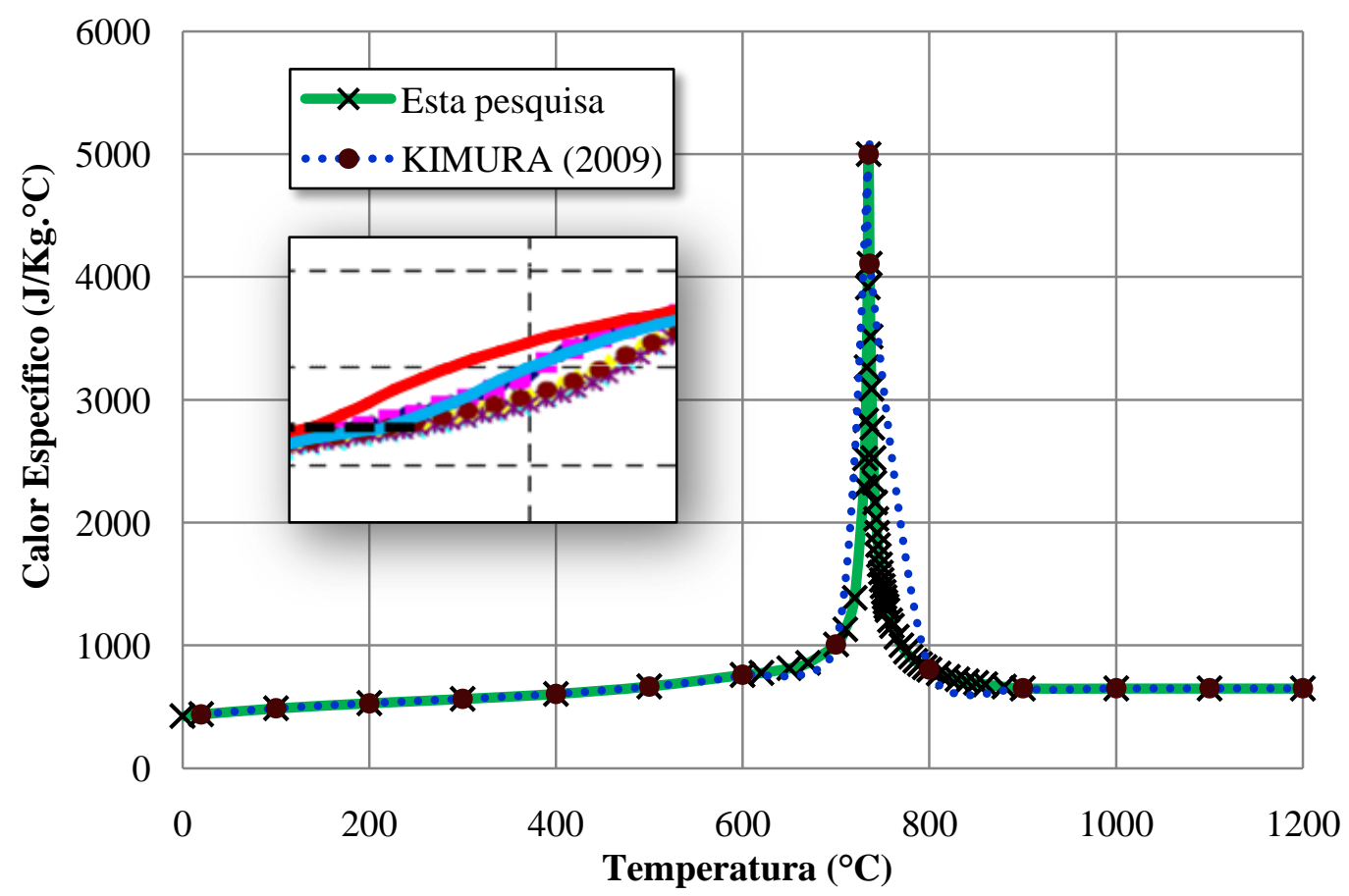

Figura 5.31 - Refinamento dos dados de entrada para o calor específico do aço considerados nas pesquisas e divergência vista na Figura 5.30.

A diferença gráfica parece ser bastante sutil, porém, como visto anteriormente na Figura 5.30, apresenta pequena divergência. Essa sutil diferença, porém, não deverá afetar os resultados da pesquisa já que em Kimura (2009) a temperatura de colapso para carregamentos 
reduzidos, da ordem de $30 \%$ da máxima resistente, ocorrendo para cerca de $730{ }^{\circ} \mathrm{C}$ sem a consideração da restrição axial, como é o caso desta pesquisa, o que reduzirá esse valor de temperatura crítica.

\subsubsection{Número de BIOT}

Segundo Lewis, Nithiarasu e Seetharamu (2004), em uma análise transiente, a temperatura de um corpo pode ser assumida constante em qualquer ponto do corpo em um dado instante, dependendo de suas dimensões. Isso quer dizer que a temperatura do corpo varia uniformemente com o tempo. Essa condição será válida para corpos com pequena dimensão, para material com condutividade térmica elevada ou ambas as situações. Para as pequenas espessuras das chapas de aço que formam os perfis metálicos essas duas condições são satisfeitas, conforme Figura 5.32.

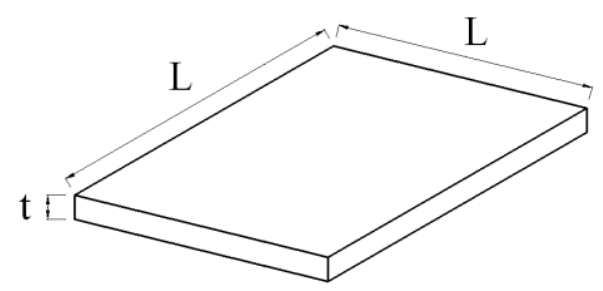

Figura 5.32 - Chapa finita.

Em Carslaw e Jaeguer (1959) apud Wang (2002) menciona-se que, se o número de Biot $\left(\mathrm{B}_{\mathrm{i}}\right)$ for inferior a 0,1 então a placa pode ser assumida com distribuição uniforme de temperatura. De acordo com as definições mais precisas encontradas em Regobello (2007), para a condição de uma placa de aço em situação de incêndio, a necessidade de conhecer a variação da temperatura ao longo da espessura só seria necessária com o material aço caso a espessura fosse superior a $83 \mathrm{~mm}$, não encontrada em perfis comerciais.

O modelo proposto nesta pesquisa será constituído de duas camadas, como descrito anteriormente. A Figura 5.34 demonstra a diferença percentual de temperatura encontrada no modelo, na linha do esqueleto da alma, comparando valores numéricos para: alma com camada única (grau de liberdade da posição central TE2) e alma com quatro camadas (grau de liberdade da posição central TE5). Também foi realizada a verificação ao se considerar duas camadas (grau de liberdade da posição central TE3) com as mesmas quatro camadas propostas. 


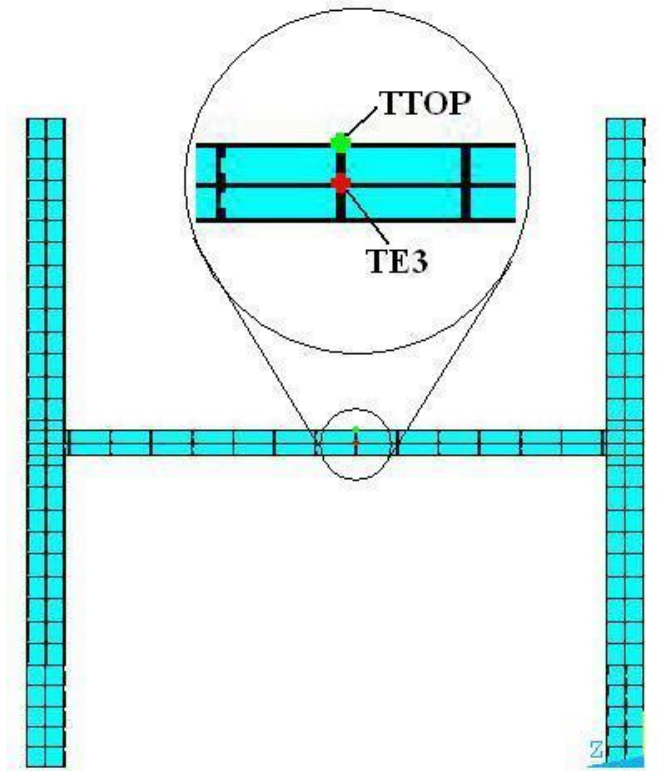

(a)

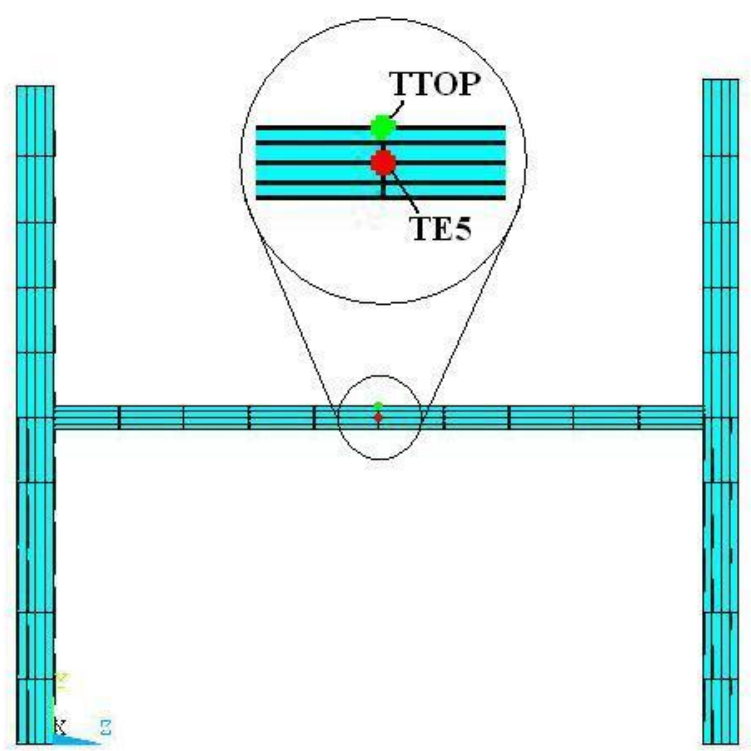

(b)

Figura 5.33 - Localização dos graus de liberdade no modelo numérico: (a) TE3 e TTOP com duas camadas (layers) e (b) TE5 e TTOP com quatro camadas.

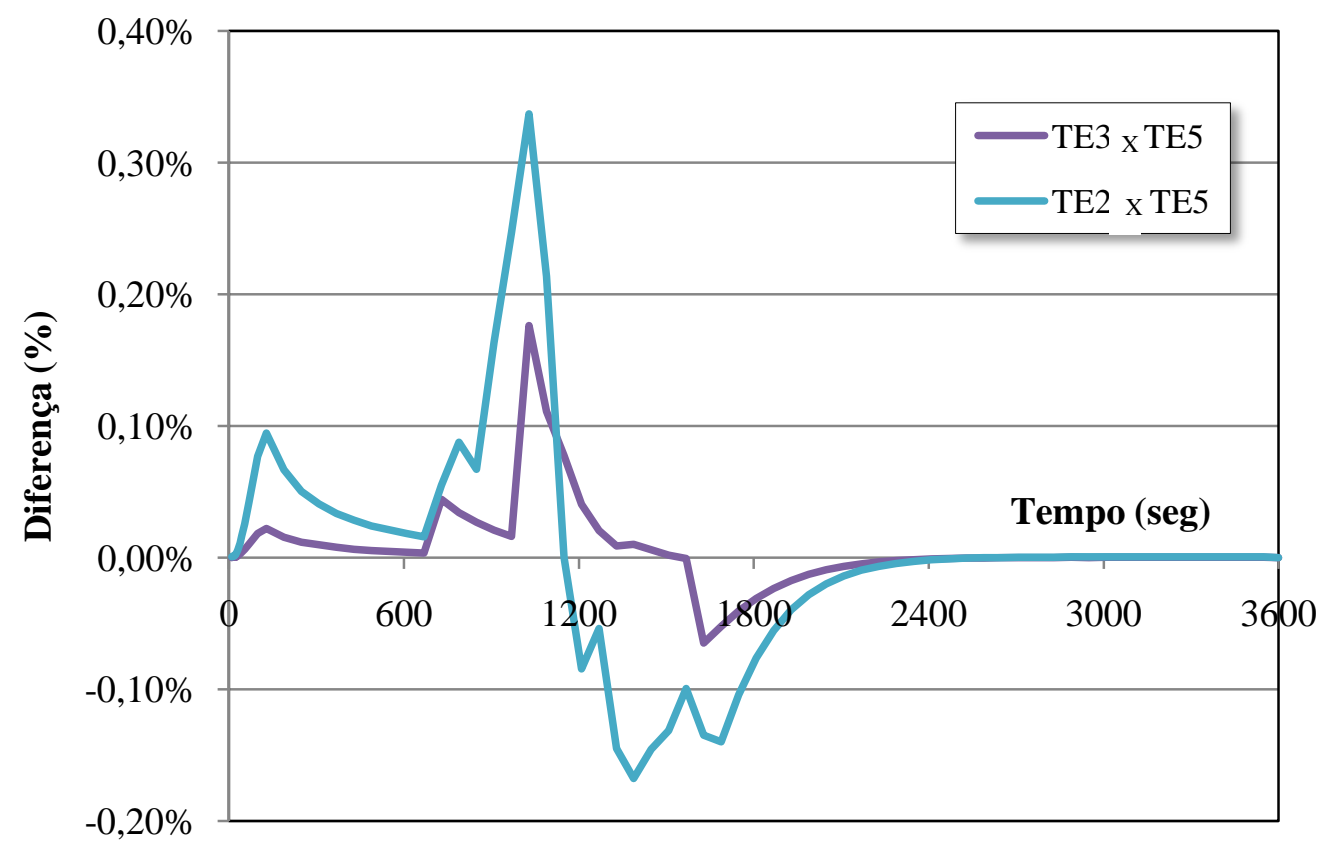

Figura 5.34 - Diferença da temperatura na linha do esqueleto do ponto médio da alma entre duas e quatro camadas e entre uma e quatro camadas.

Outra verificação também foi realizada com vistas a pesquisar a diferença entre o valor numérico da temperatura na linha do esqueleto no ponto médio da alma em comparação ao valor da temperatura na face da mesma (TTOP), considerando uma, três, quatro e até dez camadas (grau de liberdade da posição central TE11), ilustrada na Figura 5.35. 


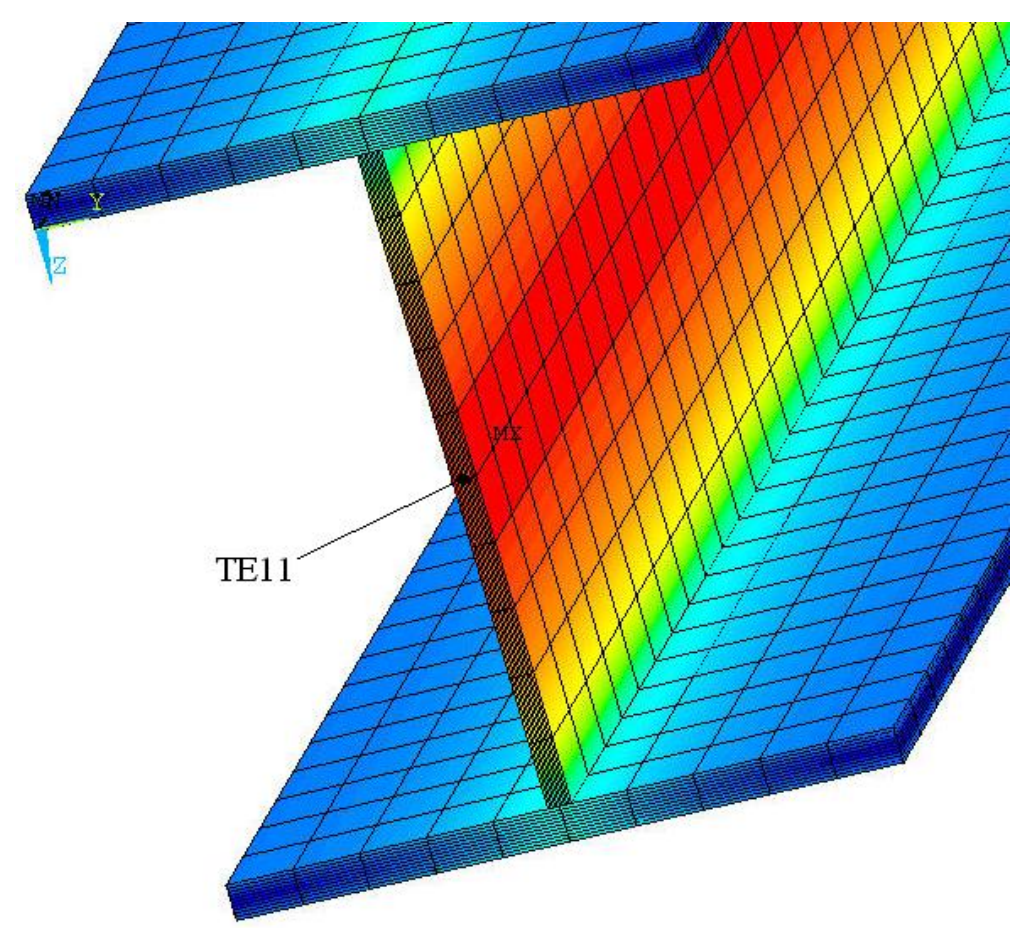

Figura 5.35 - Modelo com 10 camadas ao longo da espessura dos elementos.

Conforme mostra a Figura 5.36, não ocorre diferença significativa na temperatura entre a face e o centro da espessura da chapa, mesmo considerando um número maior de camadas, chegando a uma diferença máxima de $0,8 \%$ apenas nos segundos iniciais. No modelo proposto serão consideradas duas camadas.

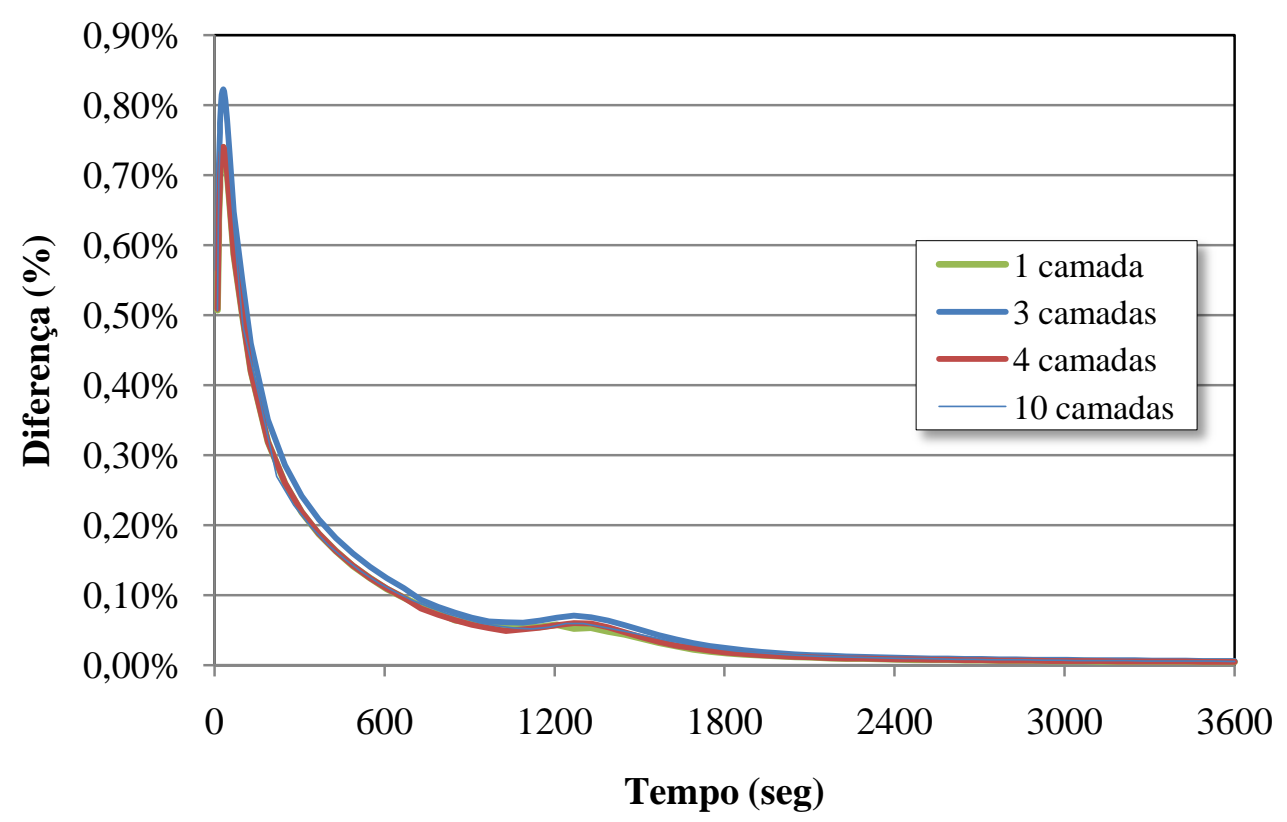

Figura 5.36 - Diferença da temperatura entre linha do esqueleto e a face da chapa no nó central da alma. 
Esse modelo, com a configuração do computador apresentada no item 5.4, levou cerca de cinco minutos para ser processado, sabendo-se que a maior quantidade de camadas na seção aumenta o tempo necessário de processamento.

\subsubsection{Comparações complementares}

Com o objetivo de validar não somente os modelos térmicos, mas também os modelos termoestruturais foram realizadas validações do campo térmico com os experimentos realizados no doutorado do Professor Doutor João Paulo C. Rodrigues, da Universidade de Coimbra, Portugal. Em Rodrigues (2000), foram realizados estudos experimentais com chapas metálicos retangulares sujeitos a uma carga inicial constante e uma restrição axial aos deslocamentos ocorridos devido à dilatação térmica.

Nos experimentos realizados em Rodrigues (2000) não foram utilizadas nenhuma das curvas de aquecimento dos gases do incêndio internacionais como a ISO ou ASTM. O aquecimento do forno objetivou uma taxa de crescimento constante de $5^{\circ} \mathrm{C} / \mathrm{min}$. No entanto, em testes preliminares de aferição do forno foi constatado um aquecimento médio de $5,1^{\circ} \mathrm{C} / \mathrm{min}$ com base em tomadas de temperatura em três pontos distintos do seu interior. Alguns resultados referentes à temperatura máxima crítica são apresentados na Tabela 5.9, bem como dados experimentais relevantes. O perfil utilizado nas comparações foi a chapa retangular de seção 50x8 ( $\mathrm{mm}$ x mm) com $465 \mathrm{~mm}$ de comprimento perfeitamente retilíneo e com excentricidade na aplicação da carga de $1 \mathrm{~mm}$.

Tabela 5.9 - Resultados experimentais e numéricos.

\begin{tabular}{|c|c|c|c|c|c|}
\hline \multirow{2}{*}{$\begin{array}{c}\text { Rigidez K } \\
(\mathrm{kN} / \mathrm{mm})\end{array}$} & \multirow{2}{*}{$\begin{array}{c}\text { Teste } \\
\mathrm{n}^{\circ} .\end{array}$} & $\begin{array}{c}\text { Teste } \\
\text { Experimental } \\
\end{array}$ & $\begin{array}{l}\text { Software } \\
\text { ZWAN }\end{array}$ & $\begin{array}{c}\text { Software } \\
\text { FINEFIRE }\end{array}$ & ANSYS \\
\hline & & $\theta_{\mathrm{s}, \text { máx - crit. }}\left({ }^{\circ} \mathrm{C}\right)$ & $\theta_{\mathrm{s}, \text { máx - crit. }}\left({ }^{\circ} \mathrm{C}\right)$ & $\theta_{\mathrm{s}, \text { máx - crit. }}\left({ }^{\circ} \mathrm{C}\right)$ & $\begin{array}{c}\theta_{\mathrm{s}, \text { máx - crit. }} \\
\left({ }^{\circ} \mathrm{C}\right)\end{array}$ \\
\hline 0 & 166 & 578 & 526 & 545 & 545 \\
\hline 1 & 48 & 551 & 439 & 473 & 496 \\
\hline 10 & 86 & 387 & 432 & 420 & 416 \\
\hline 24 & 100 & 376 & 430 & 454 & 416 \\
\hline 42 & 135 & 382 & 434 & 433 & 415 \\
\hline 98 & 158 & 382 & 438 & 441 & 415 \\
\hline
\end{tabular}

FONTE: Rodrigues (2000) - ADAPTADO

Em Rodrigues (2000) são apresentados os resultados de temperatura do modelo experimental ao longo do tempo em diversas posições do comprimento do perfil. O modelo 
construído no ANSYS para validar os resultados desta pesquisa com o uso da restrição axial deveria obter os mesmo valores (ou valores muito próximos) dos resultados térmicos nas posições definidas. A Figura 5.37 mostra o gráfico de tempo por temperatura nos diversos pontos coletados experimentalmente, cujos termopares estão localizados nas posições indicadas, e confrontados com os resultados encontrados no modelo do ANSYS.

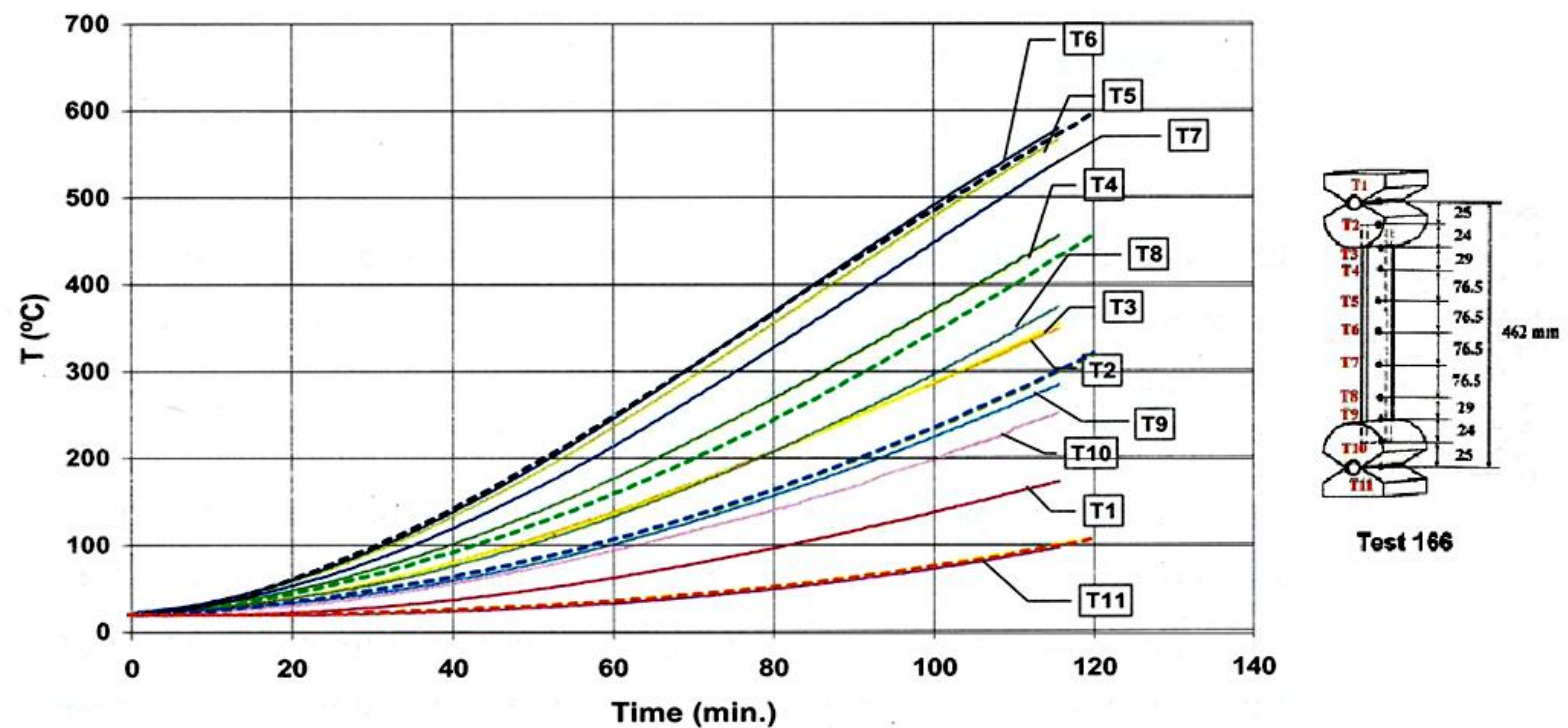

Figura 5.37 - Resultados térmicos experimentais apresentados em Rodrigues (2000) e obtidos pelo ANSYS.

Para que fossem obtidos esses valores de temperatura próximos aos obtidos experimentalmente foram introduzidos volumes nas extremidades com propriedades térmicas estimadas e perda de calor. Os valores de condutividade térmica, volume e densidade foram variados até que se obtivessem os resultados mais próximos possíveis dos experimentais. Comparações do modelo termoestrutural serão vistas no capítulo seguinte.

\subsection{RESULTADOS DA ANÁLISE TÉRMICA REALIZADA PARA}

\section{O PERFIL UC 203 X $203 X 46$}

A análise térmica é feita, preliminarmente, para obter campos de temperatura para instantes de tempo determinados, variando de $\mathrm{t}=0$ a 9000 segundos $(2,5$ horas $* 60$ minutos * 60 segundos) ou 150 minutos, com respostas a cada segundo. Posteriormente, para a análise termoestrutural, os resultados serão tomados como dados de entrada a cada 60 segundos, ou seja, cada passo de carga do modelo termoestrutural representará um minuto inteiro. 
A consideração de alvenaria tem como funções absorver o calor do perfil metálico e isolar o ambiente em chamas e, portanto, não possui função estrutural sendo desconsiderada na análise estrutural. Tanto a alvenaria quanto o perfil metálico permitem a perda de calor na face oposta ao incêndio, razão pela qual, por motivos de melhor acoplamento da parede ao perfil metálico em diversas disposições, a alvenaria foi modelada com elemento térmico SOLID70, enquanto o perfil metálico foi modelado com o elemento térmico SHELL131. Para o aquecimento dos gases do ambiente em chamas foi adotada a curva de incêndio-padrão proposta pela ISO 834-1:1999.

Quanto ao fluxo de calor por convecção (gerado pela diferença de densidade entre os gases do ambiente em chamas), para os modelos numéricos é adotado o coeficiente de transferência de calor por convecção $\boldsymbol{\alpha}_{\mathbf{c}}$ igual a $25 \mathrm{~W} / \mathbf{m}^{2}{ }^{\circ} \mathbf{C}$, conforme item 8.5.1.1.2 da norma brasileira ABNT NBR 14323 (1999). Quanto ao fluxo de calor por radiação (processo pelo qual o calor flui na forma de propagação de ondas), são considerados nos modelos numéricos aqui propostos: coeficiente de emissividade com valor igual a $\mathbf{0 , 5}$ (inicialmente), constante de Stefan-Boltzmann com valor igual a $\mathbf{5 , 6 7 \times 1 0 ^ { - 8 }} \mathbf{W} / \mathbf{m}^{\mathbf{2}} \cdot \mathbf{K}^{\mathbf{4}}$, ambos conforme ABNT NBR 14323 (1999) e fator de configuração com valor igual a 1,0 conforme Regobello (2007). Os efeitos de radiação e de convecção, tanto para ganho quanto para perda de calor, será aplicado no modelo com o elemento SURF152 conforme mostra a Figura 5.38.

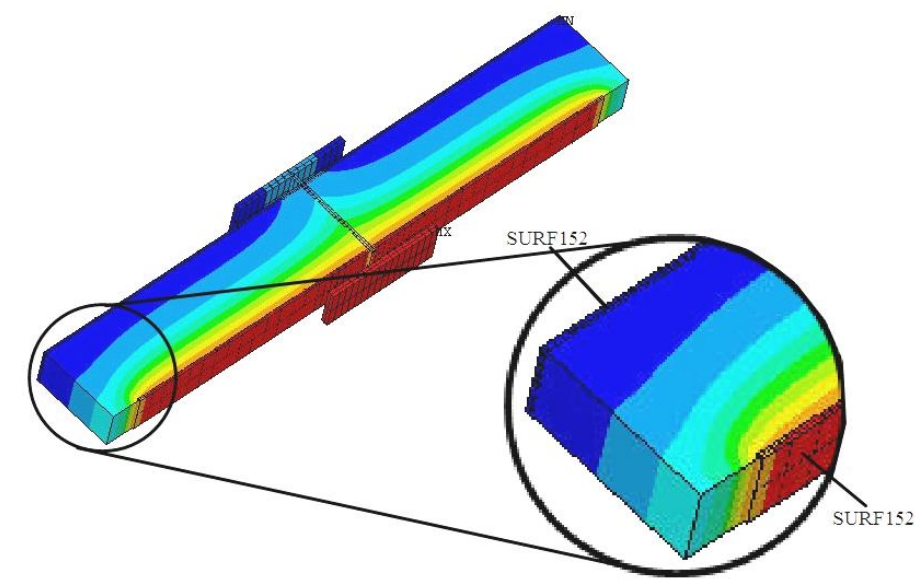

Figura 5.38 - Aplicação do elemento SURF152 para ganho e perda de calor.

Para a emissividade de radiação, o EUROCODE 3 parte 1-2 (2005), no seu item 2.2, sugere o valor de $\mathbf{0 , 7}$, mas ressalta a necessidade de considerar o efeito shadow. No entanto, por motivos de comparação a outros trabalhos (KIMURA 2009), o valor 0,5 será por ora utilizado. Porém, serão apresentados posteriormente resultados com o valor $\mathbf{0 , 7}$ e a perda de calor na face oposta ao incêndio com os efeitos de radiação e convecção, de acordo com o 
Eurocódigo, considerando emissividade de radiação nula e coeficiente de convecção equivalente de $9 \mathrm{~W} / \mathbf{m}^{2}{ }^{\circ} \mathbf{C}$, além da restrição axial na barra.

Os resultados do modelo termoestrutural, quando comparados à Kimura (2009), utilizaram os dados de temperatura obtidos na análise térmica considerando estratégia adotada à época. Para a radiação fora utilizada emissividade $\mathbf{0 , 5}$ sem perda de calor na face oposta. Para obter a elevação da temperatura dos gases ao longo do tempo a curva de incêndio-padrão ISO 834-1:1999 foi utilizada. Após essas comparações, os modelos finais utilizaram as prescrições normativas mais recentes, como emissividade $\mathbf{0 , 7}$, perda de calor na face não exposta com efeitos combinados em um coeficiente de convecção equivalente e curva de incêndio-padrão ISO 834-1:1999.

\subsubsection{Teste de malha}

Para o modelo com paredes em contato com as mesas do perfil foram realizados testes de eficiência com três malhas com diferentes graus de discretização como visto na Figura 5.39. Os números de elementos finitos utilizados em cada malha estão apresentados na Tabela 5.10, bem como o número de nós e as dimensões aproximadas dos elementos. Resultados de eficiência e tempo de processamento de cada malha serão abordados no capítulo seguinte.

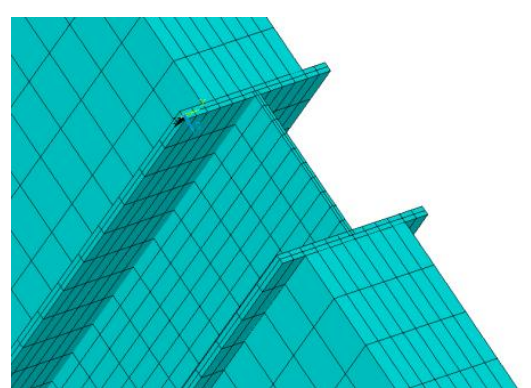

(a)

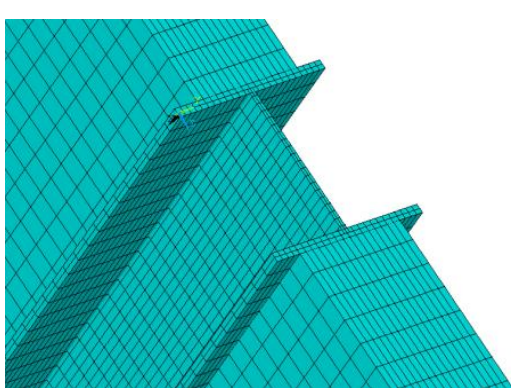

(b)

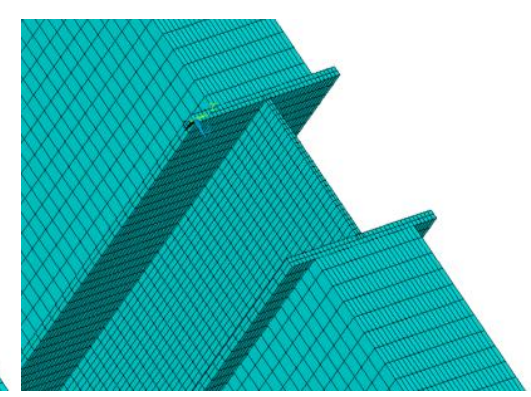

(c)

Figura 5.39 - Malhas de elementos finitos testadas $(a)$ ref1, $(b)$ ref2 e $(c)$ ref3.

Tabela 5.10 - Detalhes dimensionais dos elementos e nós para diferentes malhas testadas no modelo com paredes nas mesas.

\begin{tabular}{lccc}
\hline & ref1 & ref2 & ref3 \\
\hline Elementos no perfil - shell & 2040 & 8160 & 18360 \\
Nós - shell & 2135 & 8349 & 18643 \\
Largura x altura (mm x mm) - shell & $17 \times 53$ & $8,5 \times 26,5$ & $5,6 \times 17,6$ \\
Elementos na chapa de topo - shell & 240 & 960 & 2160 \\
Elementos na alvenaria - solid & 3840 & 7680 & 11520 \\
Largura x altura x espessura (mm x mm x mm)-solid & $62,5 \times 53,0 \times 17,5$ & $31,3 \times 26,5 \times 8,8$ & $20,8 \times 17,6 \times 5,8$ \\
\hline
\end{tabular}




\subsubsection{Resultados térmicos}

Após as análises realizadas para validação do modelo numérico construído no ANSYS, Kimura (2009), foram aqui realizadas novas análises utilizando emissividade $\mathbf{0 , 7}$ e considerada a perda de calor na face não exposta ao incêndio com coeficiente de convecção equivalente. Os valores de temperatura do aço para os modelos de perfil isolado, com paredes em contato com as mesas e com a alma são apresentados graficamente nas Figura 5.40, Figura 5.41 e Figura 5.42, respectivamente.

Nas figuras mencionadas é possível observar que o perfil com paredes na alma possui dados de temperatura até os 150 minutos. Isso porque os dados foram obtidos do modelo com menor carga aplicada (10\%) em todos os casos e, portanto, até o tempo máximo de exposição ao incêndio que cada modelo resistiu. Com isso já é possível concluir que essa disposição das paredes promove uma melhor proteção térmica ao perfil, como veremos no capítulo seguinte.

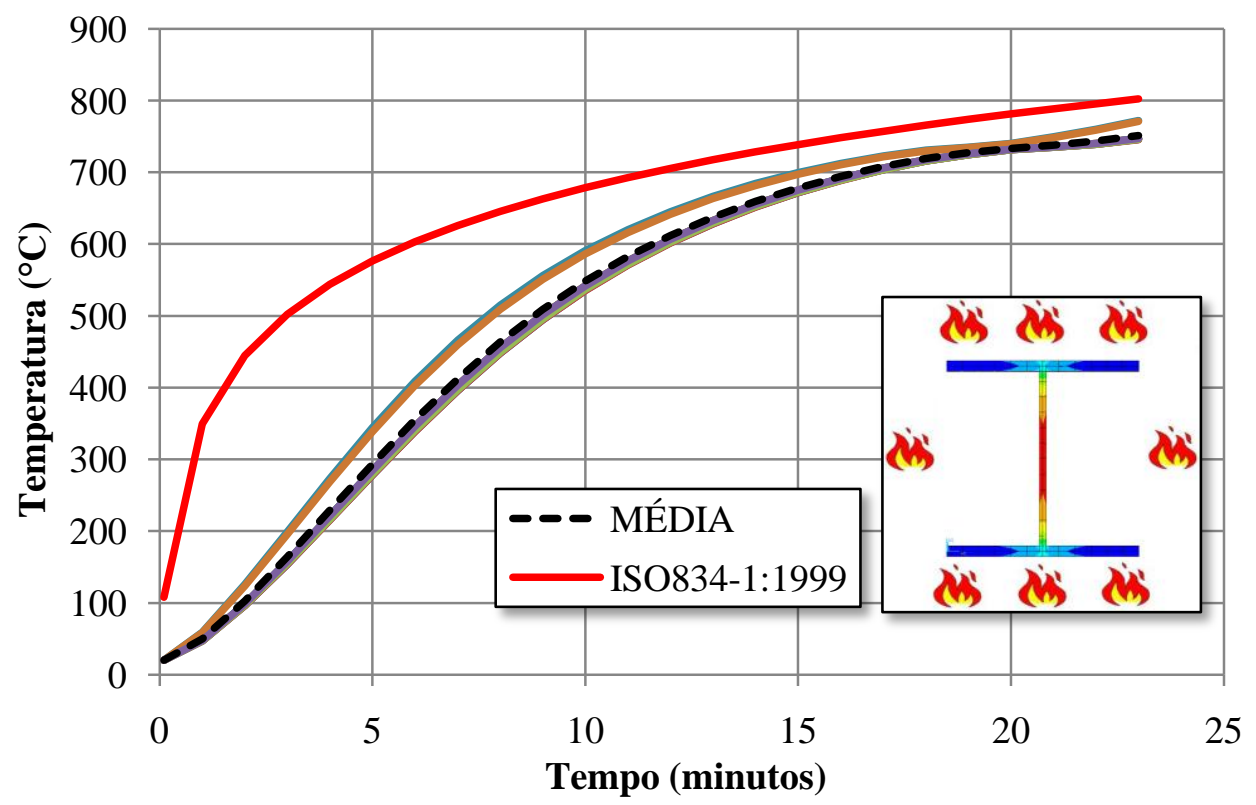

Figura 5.40 - Temperatura no aço para o perfil isolado. 


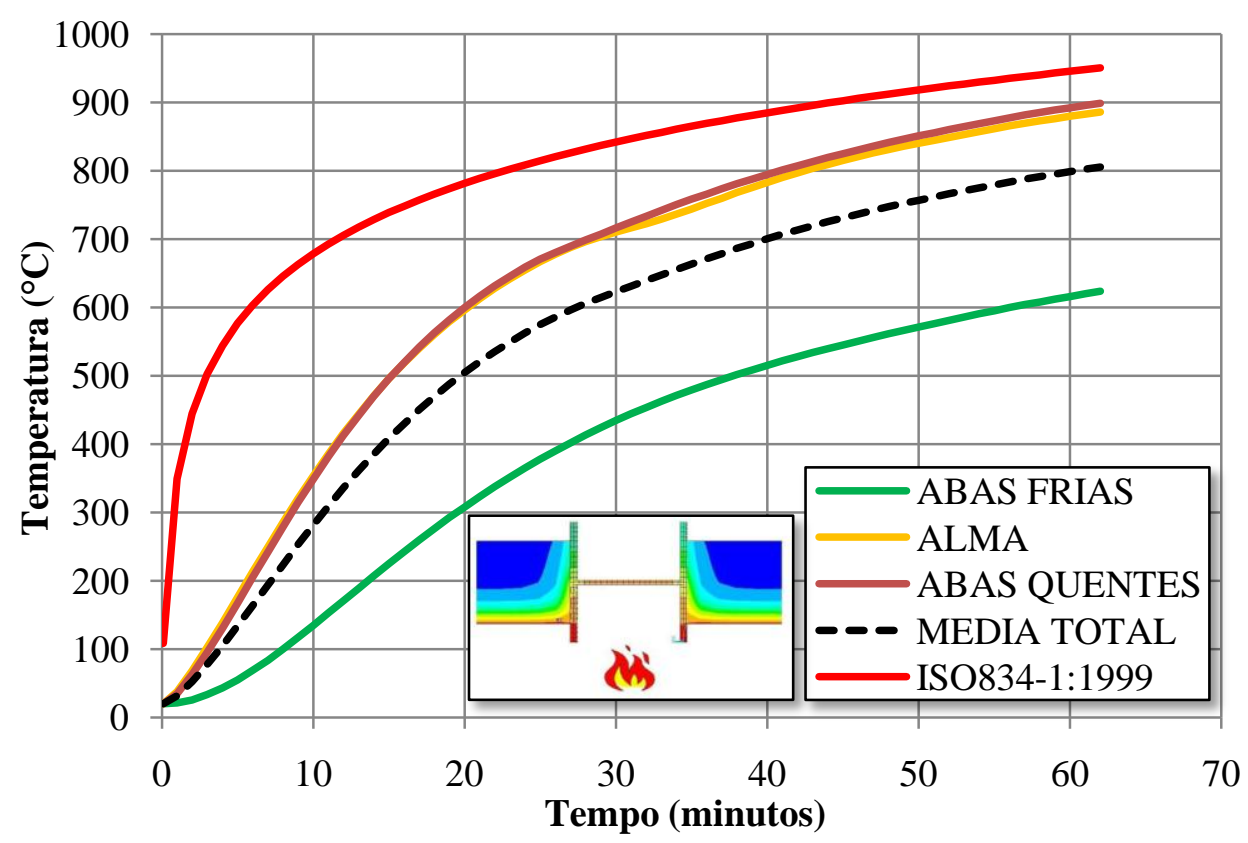

Figura 5.41 - Temperatura no aço para perfil com paredes em contato com as mesas.

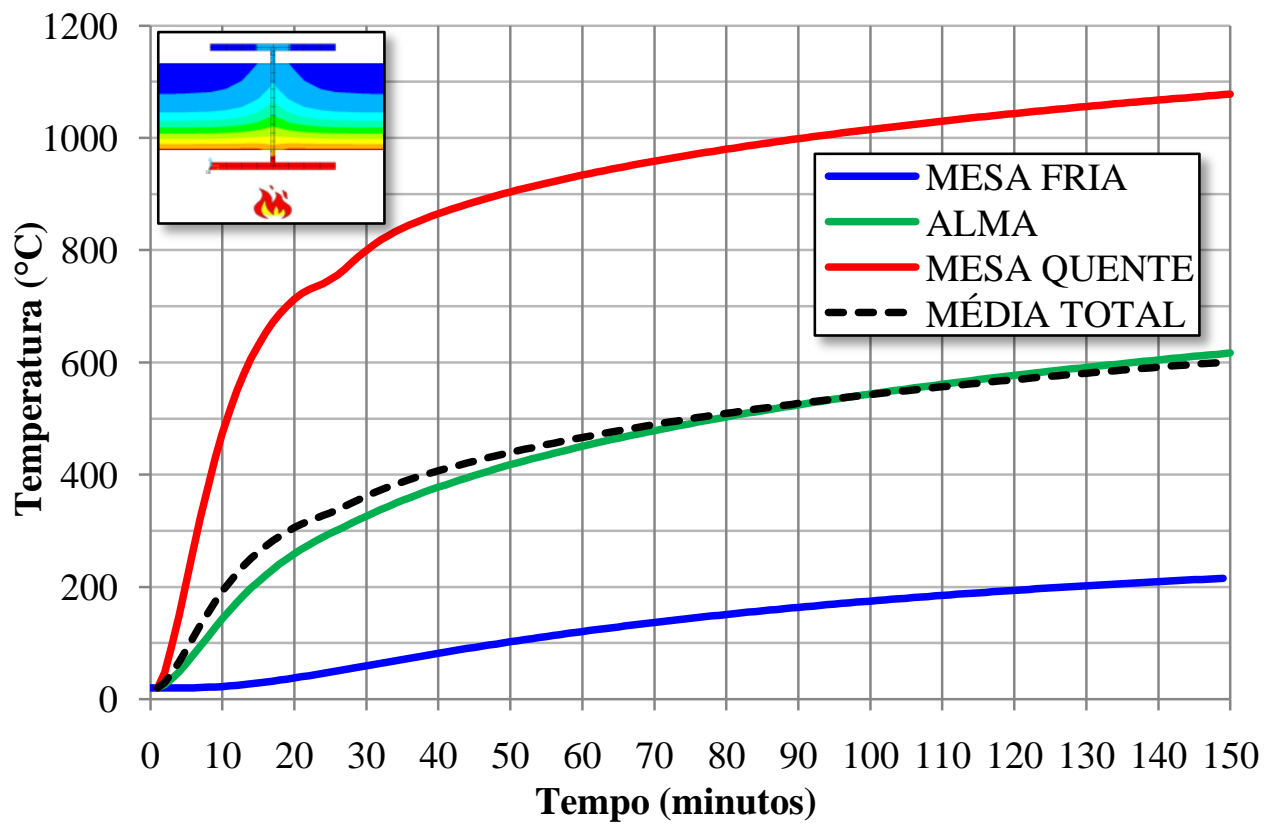

Figura 5.42 - Temperatura no aço para o perfil com paredes na alma.

No capítulo seguinte serão mostradas todas as validações dos modelos termoestruturais que foram realizadas antes de se construírem os modelos definitivos desta pesquisa. Serão comentados aspectos da construção dos modelos numéricos ao que cabem as condições de contorno do modelo estrutural, imperfeições geométricas iniciais globais, níveis de força aplicados e de restrição axial. 


\section{ANÁLISE TERMOESTRUTURAL - MODELOS PROPOSTOS, VALIDAÇÃO E RESULTADOS}

\subsection{ANÁLISE E VALIDAÇÃO EM TEMPERATURA AMBIENTE}

No presente capítulo, são apresentados os passos para elaborar modelos para análise estrutural dos pilares metálicos, constituídos por perfis comumente encontrados na prática da construção civil. Os modelos de análise estrutural serão divididos em três fases. A primeira consistirá de análise de autovalor para a definição da imperfeição geométrica inicial global. A segunda fase será a análise à temperatura ambiente para que seja encontrada a força máxima resistente e, posteriormente, na terceira fase, utilizar parcelas dessa força na análise acoplada termoestrutural com a restrição axial no topo da barra.

Para os modelos numéricos com vistas à análise estrutural à temperatura ambiente, cujos resultados serão posteriormente usados para fins de comparação, foram adotadas as seguintes propriedades mecânicas: resistência ao escoamento igual a $275 \mathrm{MPa}$ e módulo de elasticidade longitudinal igual a $210.000 \mathrm{MPa}$, buscando coerência quando da comparação a resultados de outros trabalhos. No entanto, vale destacar que os modelos definitivos adotarão o módulo de elasticidade igual a 200.000 MPa, conforme ABNT NBR 8800:2008.

Com o intuito de saber qual a carga de colapso do perfil em estudo, se constrói um modelo à temperatura ambiente que simula um ensaio experimental com controle de deslocamento. Em Kimura (2009) foram construídos esses modelos em temperatura ambiente utilizando o elemento finito SHELL181, o mesmo dessa atual pesquisa, e também com o elemento finito SOLID45. Em ambos os casos os resultados de força última e deslocamentos foram muito semelhantes. No entanto, as condições de contorno hora utilizadas incluíam uma restrição aos graus de liberdade em todos os nós da chapa de topo, vista em detalhes na Figura 
6.1. Os graus de liberdade restringidos correspondiam à rotação em torno do eixo Y (ROTY), de maior inércia, e deslocamento na direção Z (UZ), direção das mesas.

Para a presente pesquisa foram restringidos esses mesmos graus de liberdade apenas na linha que passa pela alma, formando uma rótula cilíndrica (e não mais em toda a chapa de topo) como é demonstrado na Figura 6.2. A restrição dos graus de liberdade em todos os nós da chapa de topo é desnecessária, já que ela trabalha como um corpo rígido.

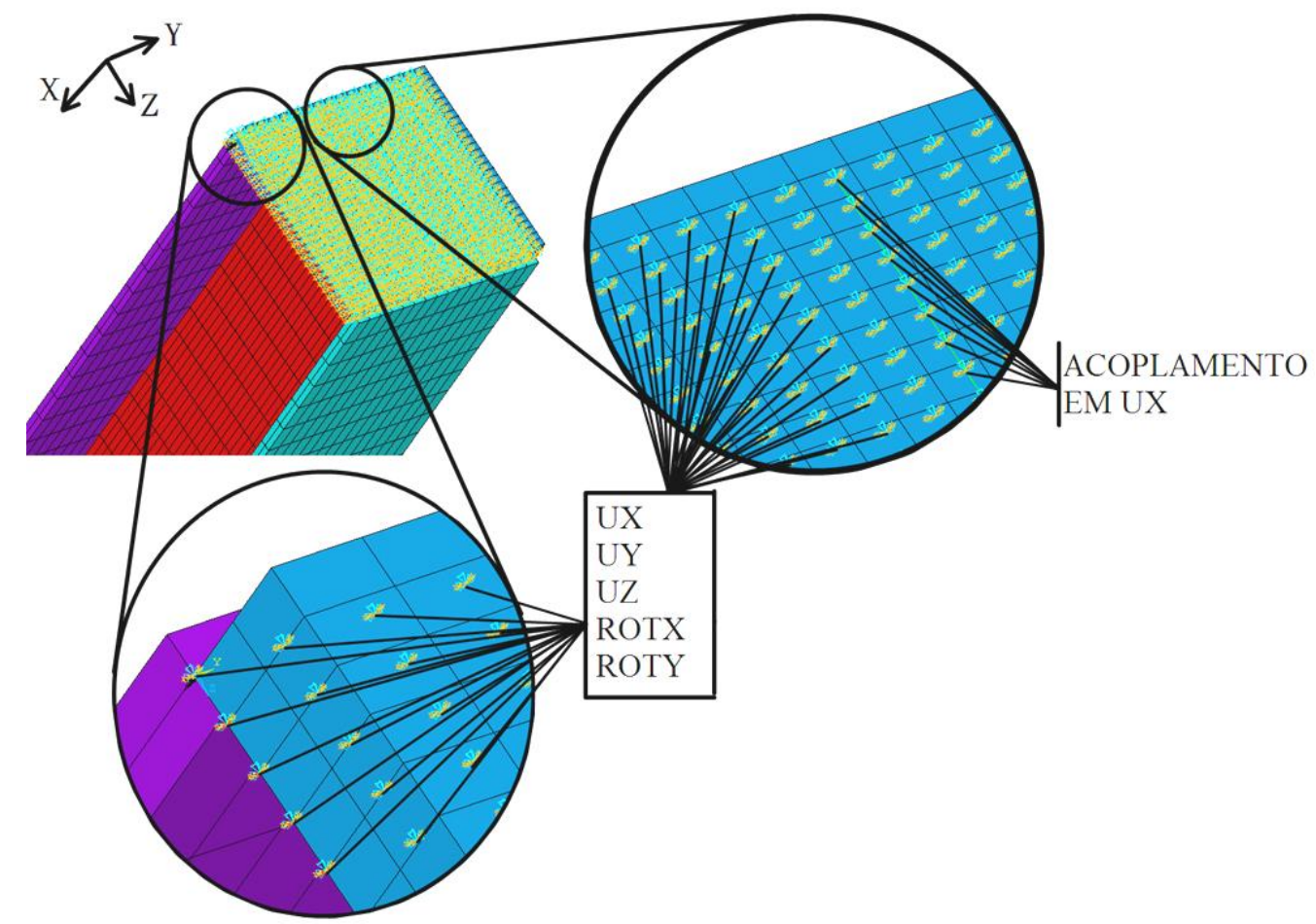

Figura 6.1 - Detalhes dos graus de liberdade restringidos em toda a chapa de topo para o modelo à temperatura ambiente e termoestrutural.

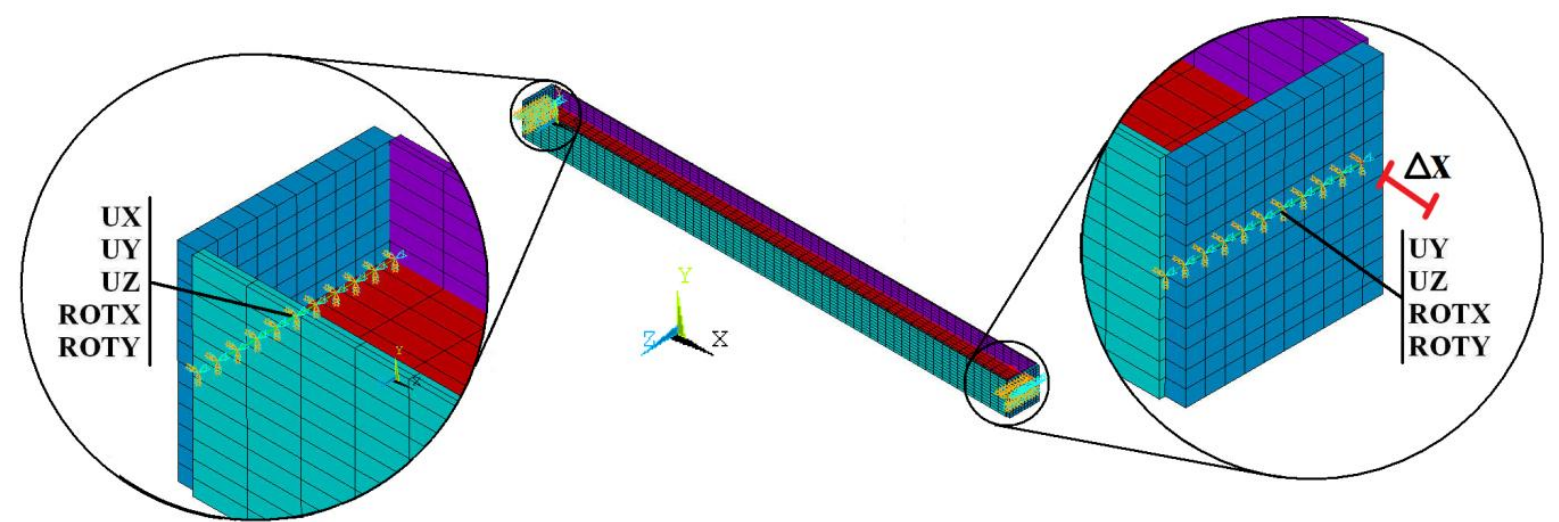

Figura 6.2 - Detalhes dos graus de liberdade restringidos para o modelo à temperatura ambiente do tipo rótula cilíndrica e deslocamento prescrito. 
Os resultados obtidos e a curva que relaciona força com deslocamento do perfil UC 203 x 203 x 46 com um comprimento de $3170 \mathrm{~mm}$ podem ser vistos na Figura 6.3. A coerência das curvas mostra que a restrição aos graus de liberdade ROTY e UZ pode ser considerada de modo mais simples apenas na linha da alma (curva preta), sendo desnecessário considerar restrições em toda a chapa de topo (curva verde). A concordância entre as curvas mostra que é possível aplicar as restrições aos graus de liberdade somente na linha que passa pela alma, condição de contorno que torna o modelo numérico mais semelhante à montagem de um modelo experimental, eliminando possíveis discordâncias entre os mesmos.

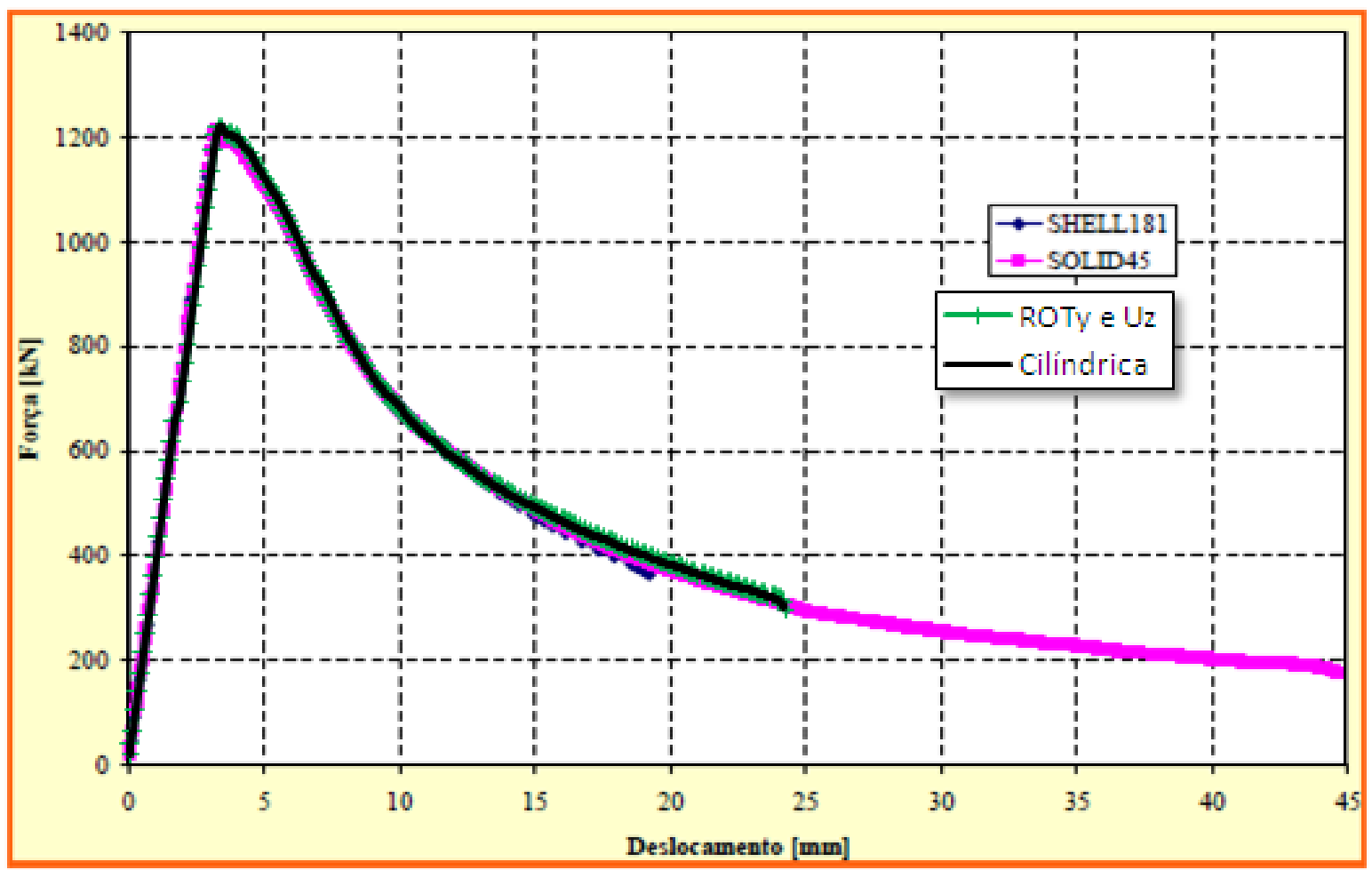

Figura 6.3 - Curvas força por deslocamento do modelo à temperatura ambiente comparando estratégias de modelagem.

Para atender à ABNT NBR 8800:2008, esse modelo foi novamente processado com o módulo de elasticidade igual a 200.000 MPa. As curvas não apresentaram grandes diferenças, mas a força máxima resistida resultou ligeiramente maior, igual a $1223 \mathrm{kN}$. O valor de força máxima encontrado em Kimura (2009) para módulo de elasticidade igual a 210.000 MPa foi de $1214 \mathrm{kN}$, representando menos de $1 \%$ de diferença. 


\subsection{ANÁLISE E VALIDAÇÃO TERMOESTRUTURAL "SEM" RESTRIÇÃO AXIAL}

Para os modelos definitivos dessa pesquisa, que consideram emissividade de radiação 0,7 e perda de calor na face não exposta, o valor do módulo de elasticidade foi de 200.000 MPa, conforme ABNT NBR 8800:2008.

$\mathrm{Na}$ análise termoestrutural realizada com o código ANSYS, considerando temperaturas elevadas, foi adotada a relação constitutiva proposta pelo EUROCODE 3 parte 1-2 (2005), que leva em conta a penalização da resistência ao escoamento e do módulo de elasticidade longitudinal, conforme mostra a Figura 6.4, extraída do ANSYS. Na análise termoestrutural, assim como na análise de autovalor, o elemento térmico SHELL131 foi substituído pelo elemento estrutural SHELL181, o qual permite representar as deformações elastoplásticas inerentes ao modelo numérico.

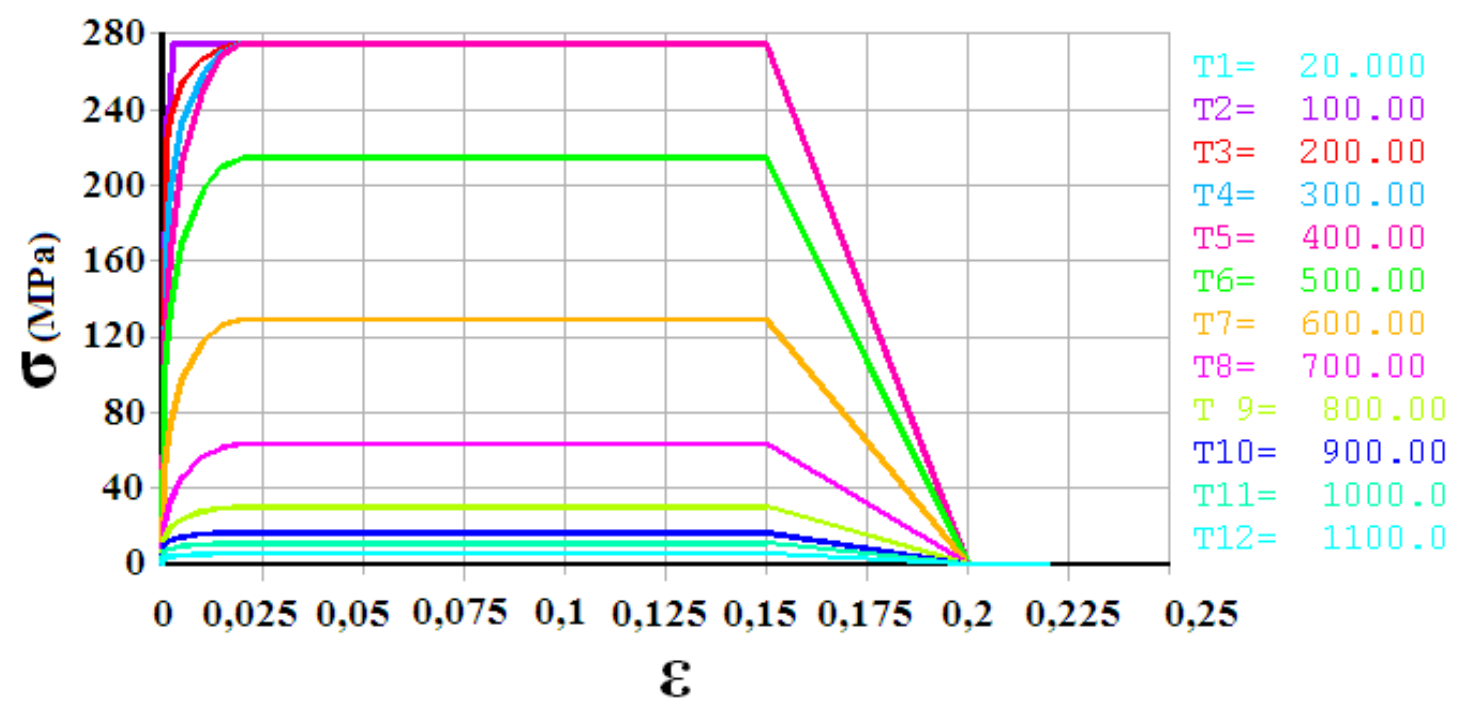

Figura 6.4 - Relação constitutiva do aço em altas temperaturas.

É possível atribuir ao elemento finito SHELL181 materiais com propriedades não lineares, tanto no que diz respeito às deformações quanto ao comportamento sob elevadas temperaturas. As densidades das malhas referentes aos modelos da análise térmica, de autovalor e termoestrutural devem ser idênticas, possibilitando que informações de interesse, referentes ao campo térmico e às imperfeições geométricas, sejam transferidas corretamente de uma análise à outra. Também foram testadas as 3 densidades de malhas já descritas 
anteriormente, quanto à eficiência computacional e precisão dos resultados, cujas diferenças são apresentadas nos itens que seguem.

Assim como em Kimura (2009), a análise termoestrutural foi realizada com relação a um perfil de seção transversal aberta, do tipo I laminado submetido aos efeitos de imperfeições geométricas iniciais do tipo global. A seção transversal utilizada nos modelos foi do tipo UC 203 × 203 x 46 (série inglesa). Suas características geométricas encontram-se apresentadas na Tabela 6.1. Seguindo orientações vistas em Kimura (2009), os modos de instabilidade dos tipos local e distorcional, cuja evidência é mais comum em perfis formados a frio, não serão aqui abordados por se tratar de perfil cuja esbeltez local não é preponderante.

As extremidades dos pilares foram consideradas rotuladas com chapas de topo de 20 mm de espessura e módulo de elasticidade da ordem de 1000 vezes o valor adotado para o perfil metálico, buscando evitar efeitos localizados nas mesmas. Na concepção das extremidades rotuladas do modelo numérico foram consideradas condições específicas de restrição de modo a permitir considerar rótulas cilíndricas, conforme mostra a Figura 6.5, bem como a possibilidade de aplicação do carregamento inicial apenas em um nó.

Tabela 6.1 - Dimensões do perfil UC 203 x 203 x 46.

\begin{tabular}{|c|c|c|c|c|}
\hline Dimensão & Valor $(\mathrm{mm})$ & \multicolumn{3}{|c|}{ Figura } \\
\hline $\mathrm{h}_{\mathrm{w}}$ & 181,2 & \multicolumn{3}{|c|}{$b_{f}$} \\
\hline$h_{d}$ & 203,2 & tf & & t \\
\hline$t_{w}$ & 7,2 & & & \\
\hline$b_{f}$ & 203,6 & & & \\
\hline$t_{f}$ & 11,0 & $h_{w}$ & tw & hd \\
\hline $\mathrm{L}$ & 3170,0 & & & \\
\hline $\begin{array}{l}\text { Espessura } \\
\text { da parede }\end{array}$ & 140,0 & & & \\
\hline
\end{tabular}

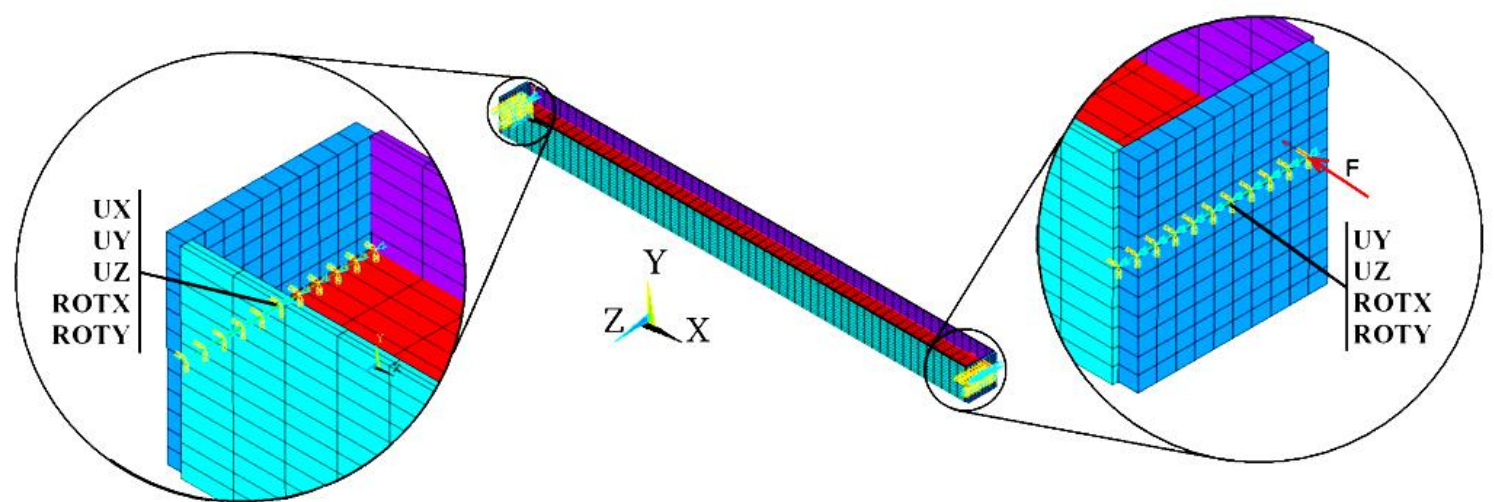

Figura 6.5 - Detalhe das vinculações do pilar, aplicação da força axial e graus de liberdade restringidos em cada extremidade. 
A aplicação da carga pode ser feita integralmente apenas em um nó (geralmente o de menor numeração) devido ao acoplamento dos graus de liberdade. Os nós da chapa de topo que passam na linha da alma estão ligados entre si de forma que todos apresentem o mesmo deslocamento em X (longitudinal).

A análise termoestrutural é realizada aplicando-se cargas estáticas correspondentes a uma parcela da carga de colapso a temperatura ambiente (10 a 90\% sem restrição axial; 25, 50 e 75\% com restrição). O modelo considera a imperfeição geométrica global inicial obtida por meio de análise de autovalor da ordem de L/1000, em concordância com Almeida (2007). Em seguida, o campo de temperaturas é aplicado em cada nó e para cada passo de carga, na forma de carregamento de volume (bodyload), com os resultados da análise térmica transiente prévia.

O tempo crítico ( $\mathrm{t}_{\text {crit }}$ ) é avaliado no instante em que a barra perde a estabilidade em resposta à elevação da temperatura, numericamente representado pela perda de convergência. Outra possibilidade de determinação do tempo crítico considera que o valor da força axial retorne ao valor inicialmente aplicado, no caso de um pilar isolado os esforços externos aplicado não mais se equilibrariam com os esforços resistentes, em uma pilar inserido em uma estrutura ele passaria a transferir parte da força atuante para outros elementos, perdendo sua função estrutural. Existe ainda a possibilidade de o processamento do modelo termoestrutural ocorrer até o final dos 150 minutos considerados na análise térmica. Nesses casos o tempo crítico não será explicitamente determinado, apenas saber-se-á que, para aquela força axial inicial aplicada o modelo é capaz de resistir por duas horas e meia.

A utilização da opção line search (LNSRCH), disponível no ANSYS, facilita a convergência numérica do método Newton-Raphson e, apesar de ter sido testada, não será utilizada, uma vez que, para todos os casos analisados, o tempo crítico do modelo foi atingido rapidamente. No entanto, no passo de carga em que o modelo perderia a convergência, os subpassos eram variados para mais e para menos em busca do seu valor exato. Contudo, a busca do valor exato levava o mesmo tempo de processamento que o necessário até chegar a ele. Ainda, o conhecimento do valor exato do subpasso de carga não é necessário, já que os resultados são dados pelo ANSYS apenas para passos de carga inteiros.

O tempo máximo analisado será de 150 minutos, ou duas horas e meia, suficiente para ser comparado às tabelas normativas. As análises foram realizadas tanto com o pilar com ação 
térmica por todos os lados, Figura 6.6a, quanto com a alvenaria nas mesas, Figura 6.6b, sendo a ação térmica aplicada em apenas um dos lados e a imperfeição geométrica inicial voltada para o lado do incêndio (e-) ou para o sentido contrário (e+). O terceiro modelo estudado, Figura 6.6c, possui a alvenaria de encontro com a alma e a imperfeição será considerada apenas positiva devido à simetria do modelo.

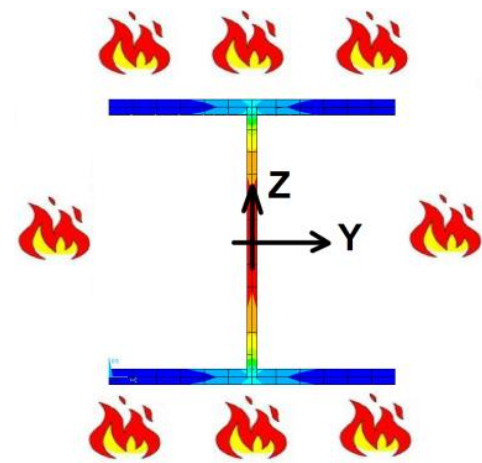

(a)

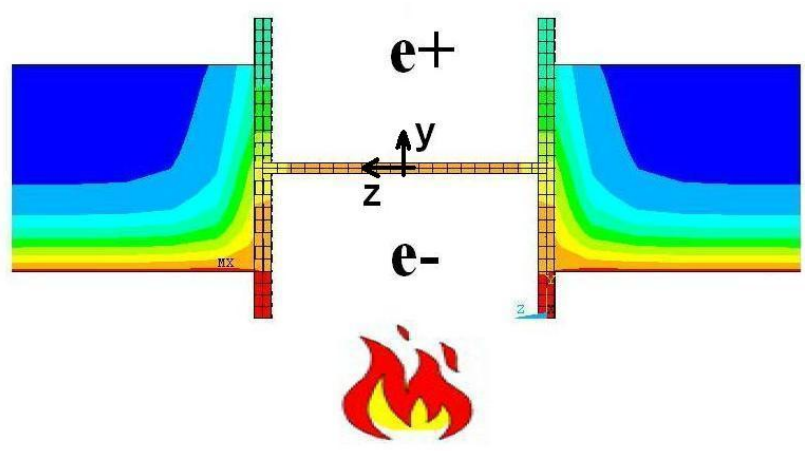

(b)

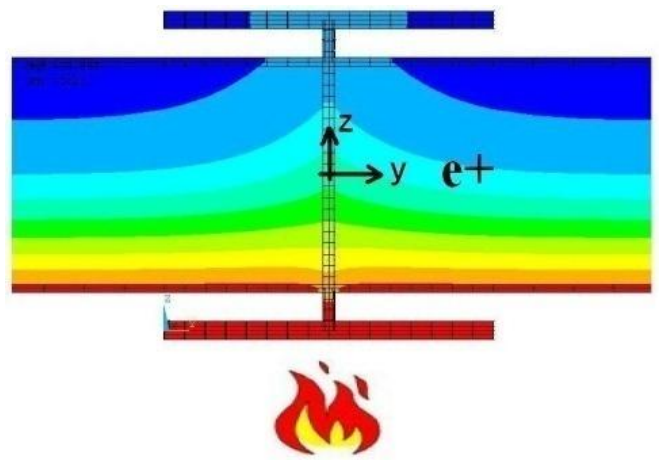

(c)

Figura 6.6 - (a) Pilar isolado com ação térmica por todos os lados, (b) pilar com paredes nas mesas e sentido da imperfeição geométrica global inicial e (c) pilar com paredes na alma.

\subsubsection{Pilar isolado com emissividade 0,5}

Os resultados dos deslocamentos, axial (no topo) e lateral (no meio do vão), apresentaram boa concordância com aqueles vistos em Kimura (2009). A Figura 6.7 e Figura 6.8 apresentam, em linha cheia, os resultados anteriores com elementos SOLID e, em curva tracejada, os resultados aqui obtidos com elementos SHELL.

Foram identificadas diferenças significativas no tempo de processamento entre os elementos finitos utilizados: para elementos tipo SHELL a análise termoestrutural levou de 1,1 a 2,8 horas com uma malha de 8160 elementos, dependendo da parcela da carga de colapso aplicada considerando a configuração do microcomputador conforme Tabela 5.2, 
enquanto que para elementos tipo SOLID o tempo de processamento foi de aproximadamente 24 horas para concluir a análise.

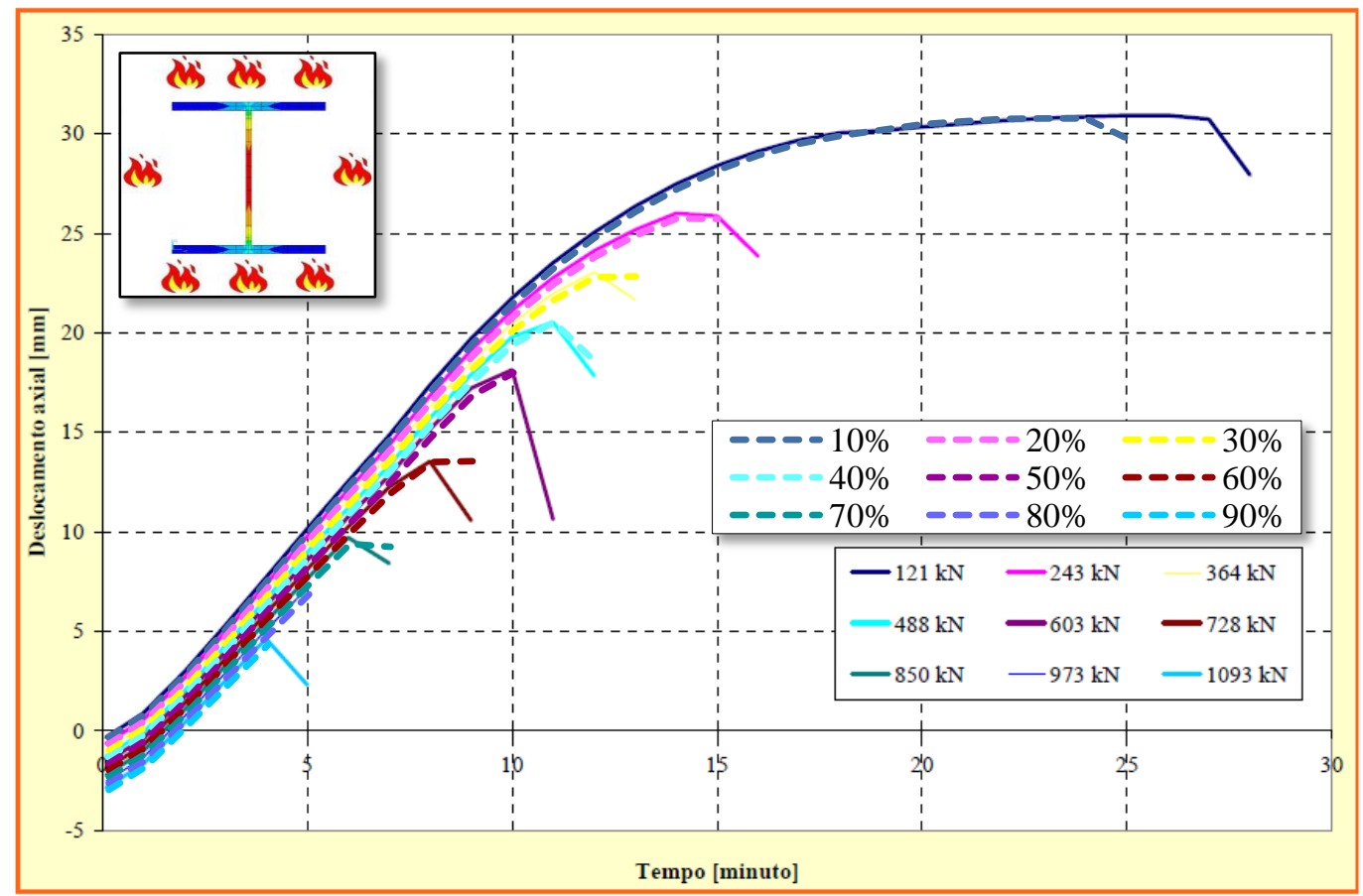

Figura 6.7 - Resultados de deslocamento axial do pilar sem paredes e fonte de calor em todas as direções: com elemento SOLID (traço cheio) e SHELL (tracejadas).

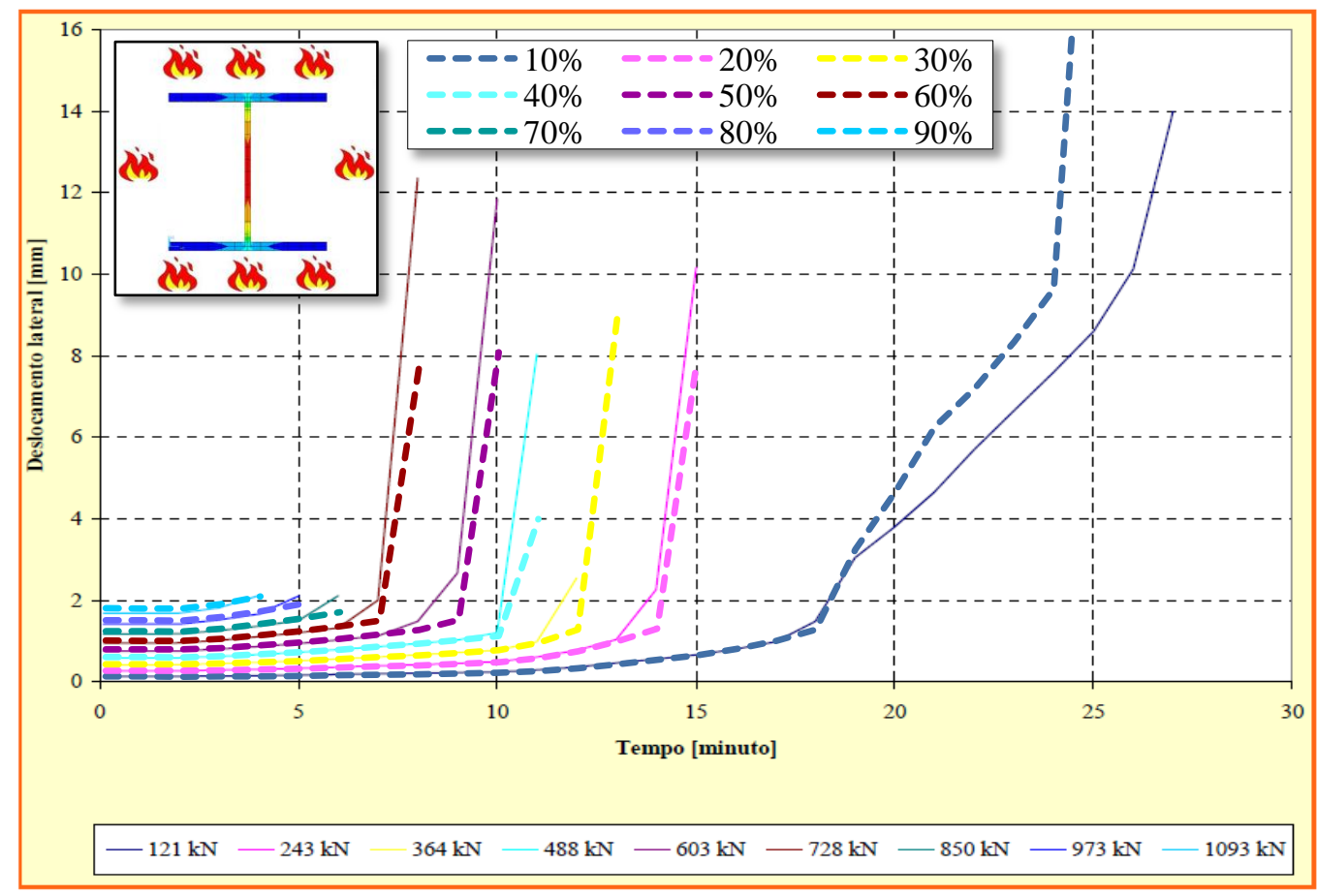

Figura 6.8 - Resultados de deslocamento lateral no meio do vão do pilar sem paredes e fonte de calor em todas as direções: com elemento SOLID (traço cheio) e SHELL (tracejadas). 


\subsubsection{Pilar com paredes nas mesas e emissividade 0,5}

Para o modelo com alvenaria em contato com as mesas o tempo de processamento foi maior se comparado àquele identificado para o pilar isolado. Provavelmente, isso se deve ao fato de as paredes compartimentarem o incêndio em um único ambiente, de forma que a ação térmica ocorre apenas em um dos lados do perfil. Tal aspecto, juntamente com o fato de as paredes absorverem calor do aço, faz com que a temperatura média do pilar seja inferior àquelas identificadas para pilares sem paredes. Com temperatura média menor, passa a ser necessário um maior número de passos de carga, ou seja, minutos de incêndio. Além disso, o gradiente térmico promoverá um arqueamento da barra, aumentando os deslocamentos laterais no meio do vão em relação ao pilar isolado. Esse arqueamento traz como aspecto positivo o não colapso instantâneo, mas sim de forma gradativa e com deformações mais perceptíveis.

Os resultados obtidos nessa pesquisa, comparados aos resultados vistos em Kimura (2009) são mostrados na Figura 6.9 e Figura 6.10, no referente aos deslocamentos axiais no topo da barra e deslocamentos laterais no meio do vão, considerando imperfeição inicial global positiva (ver Figura 6.6b). A Figura 6.12 e a Figura 6.13 mostram o deslocamento axial e lateral, respectivamente, considerando a imperfeição inicial global negativa (ver Figura 6.6b). Vale ressaltar que em todas as figuras de validação de resultados que seguem, as curvas de traço cheio foram extraídas de Kimura (2009), em que se utiliza os elementos do tipo SOLID, enquanto que as curvas tracejadas representam as respostas do elemento SHELL aqui utilizado.

Observa-se boa concordância entre o modelo construído com SHELL e aquele construído com SOLID para o deslocamento axial. O deslocamento lateral no meio do vão, no entanto, foi maior em todos os casos com o elemento SHELL. Acredita-se que isso se deve ao fato de tais elementos possuírem também graus de liberdade referentes às rotações e permitirem grandes deslocamentos, características não presentes no elemento SOLID.

Os tempos críticos para modelos com elemento SHELL foram ligeiramente inferiores àqueles construídos com SOLID, provavelmente associado ao fato de o maior deslocamento no meio do vão aumentar a distância entre a linha de ação da carga e o eixo longitudinal da barra, aumentando e concentrando esforços internos. Os tempos totais de processamento para a malha nomeada ref2 (ver Figura 5.39 e Tabela 5.10) resultaram aproximadamente de 6 a 12 
vezes menores até que concluído o processamento em relação ao modelo em SOLID, que processava entre 48 e 72 horas.

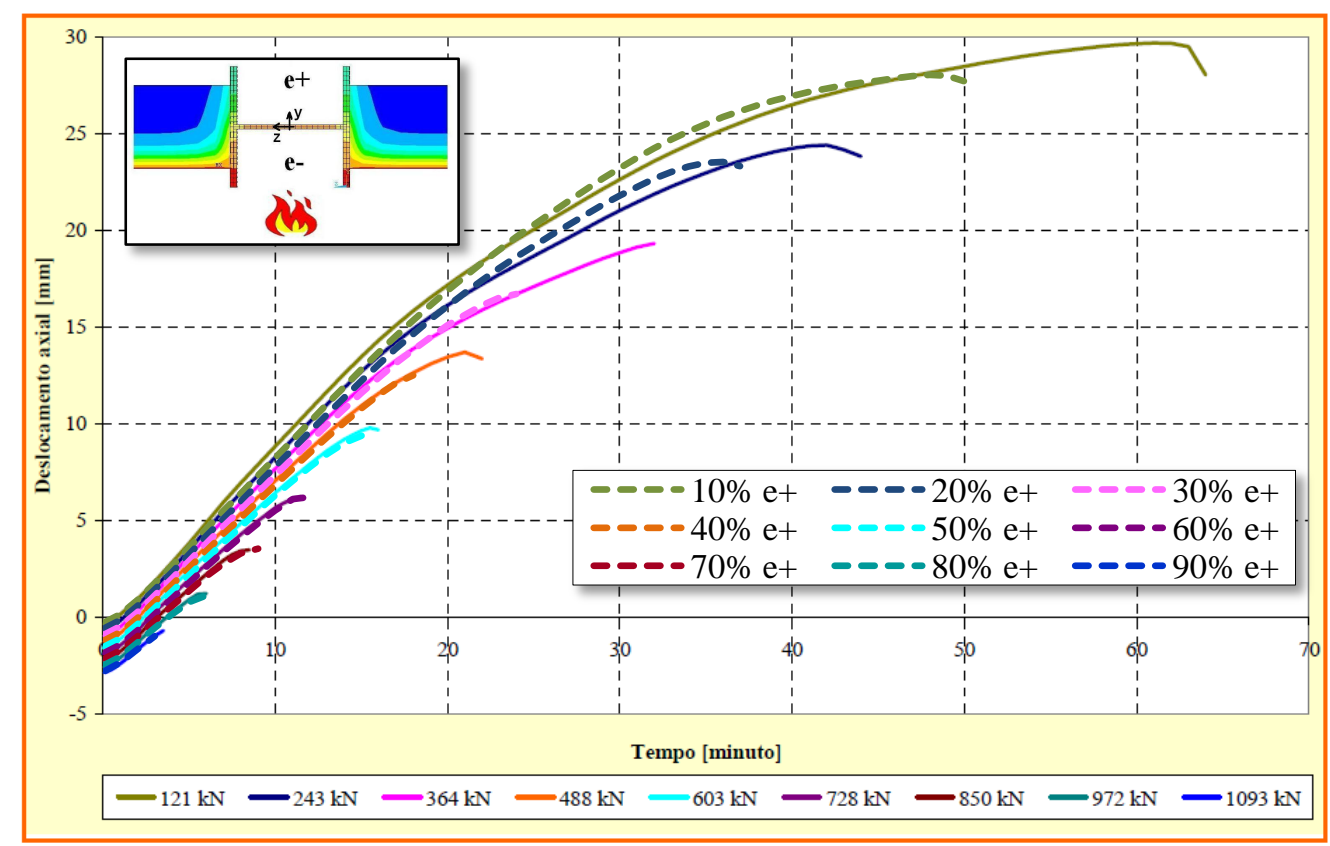

Figura 6.9 - Deslocamento axial no topo com imperfeição geométrica global inicial positiva em relação à fonte de calor comparando elementos SOLID com elementos SHELL.

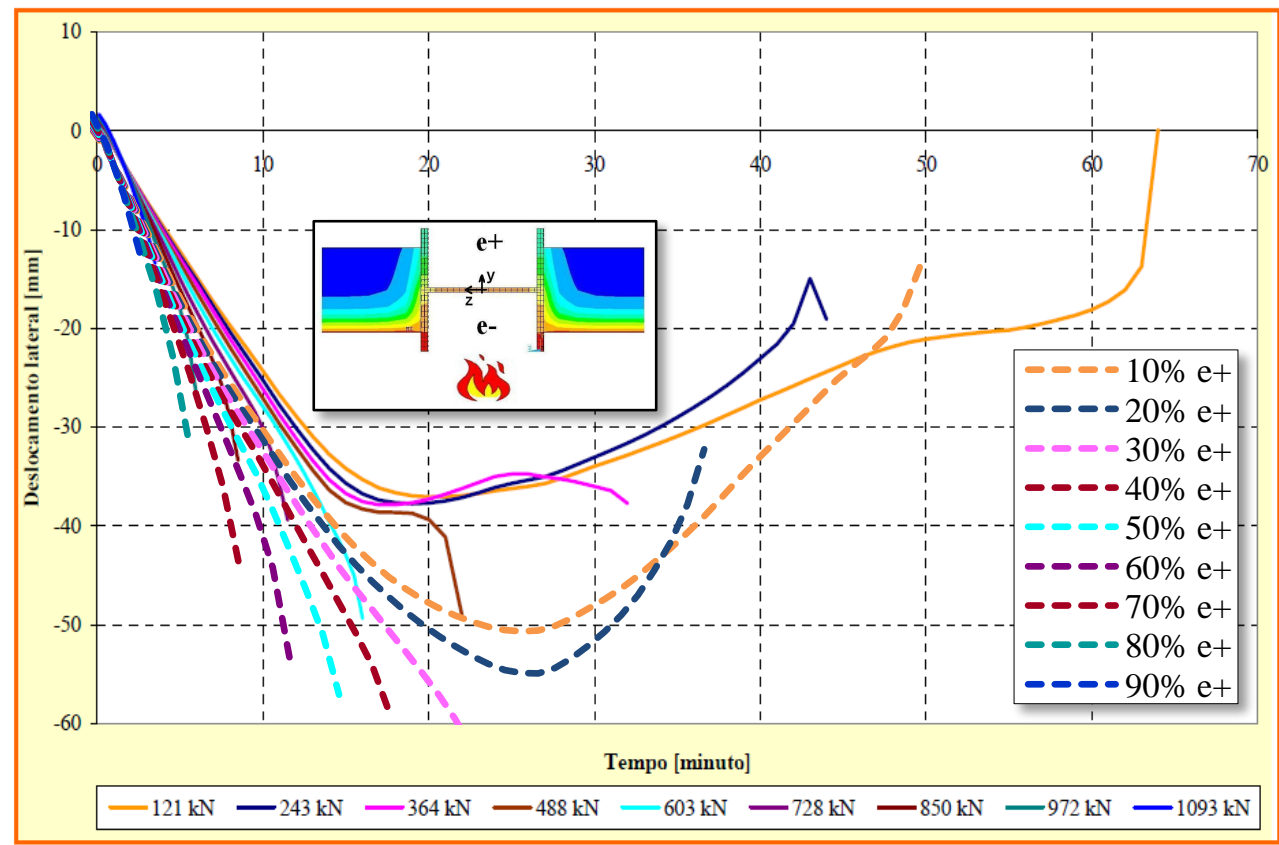

Figura 6.10 - Deslocamento lateral no meio do vão com imperfeição geométrica global inicial positiva em relação à fonte de calor comparando elementos SOLID com elementos SHELL. 
Nos testes das três malhas foram medidos os tempos de processamento e colocados em forma de gráfico, conforme Figura 6.11. As malhas ref2 e ref3 tiveram resultados próximos entre si e também das curvas de referência, em elemento SOLID. Os resultados da malha ref1 resultaram ligeiramente abaixo da curva de referência. Tendo em vista a grande diferença no tempo de processamento e a boa qualidade dos resultados, optou-se por utilizar a malha nomeada ref2.

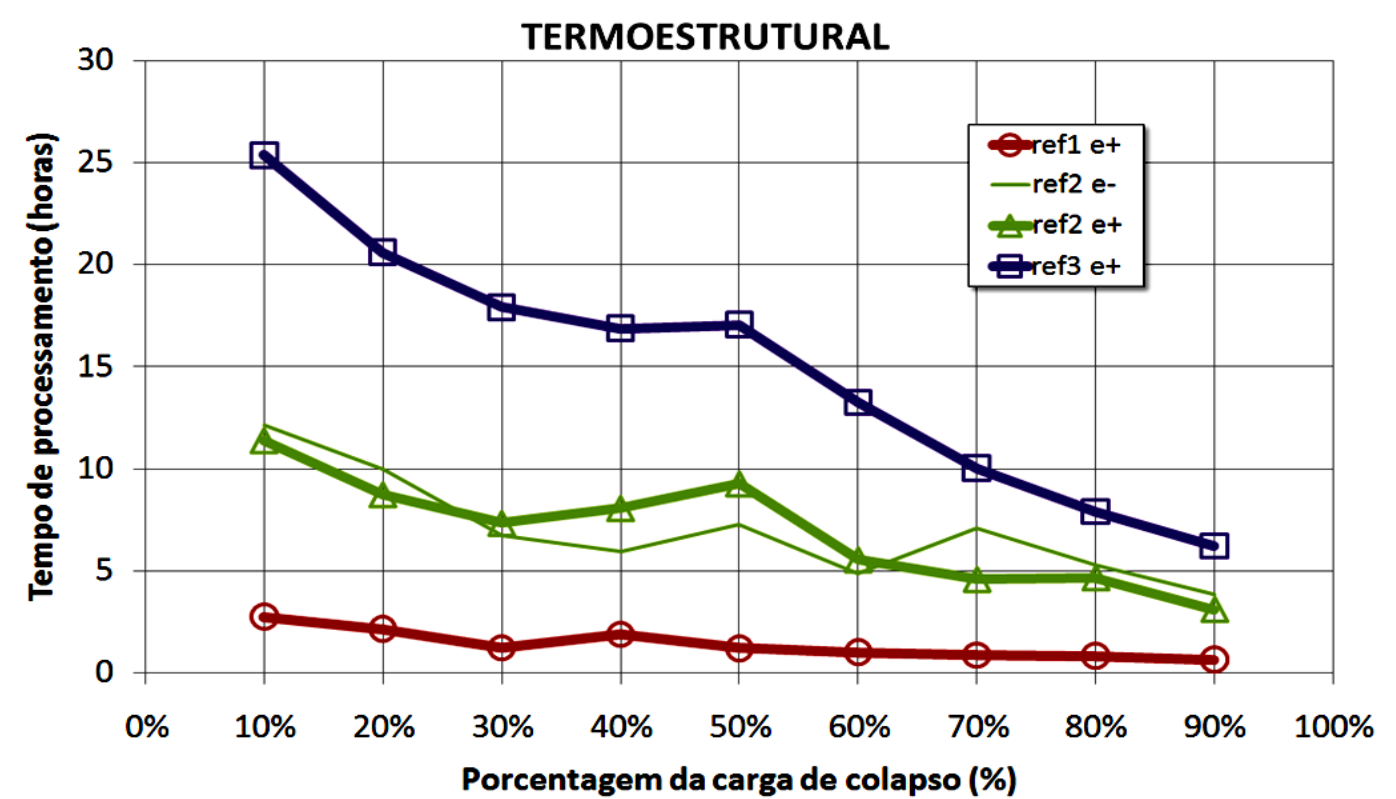

Figura 6.11 - Teste de malha e tempos de processamento do modelo com paredes nas mesas.

O tempo total de processamento, assim como o tempo crítico, acaba resultando maior sempre que a parcela da força axial de colapso resulta baixa. Os resultados dos deslocamentos axiais no topo do pilar considerando a imperfeição geométrica global inicial negativa, obtidos na presente pesquisa (tracejado), são comparados aos resultados de Kimura (2009), em traço cheio, e podem ser vistos na Figura 6.12, bem como os deslocamentos laterais no meio do vão, os quais podem ser vistos na Figura 6.13.

Durante o processamento do modelo termoestrutural, cada passo de carga térmica recebe pequenos incrementos, e cada subpasso necessita convergência numérica. A perda da convergência numérica ocorrerá no passo de carga em que deverá haver um grande deslocamento em um intervalo de tempo muito reduzido. Vale ressaltar que devido às grandes distorções nos elementos, a resposta numérica pode resultar em formas muitas vezes incoerentes com a realidade. No entanto, muitas das vezes a barra poderá apresentar configurações de instabilidade global e local como se imagina que ocorreria em uma situação real. 


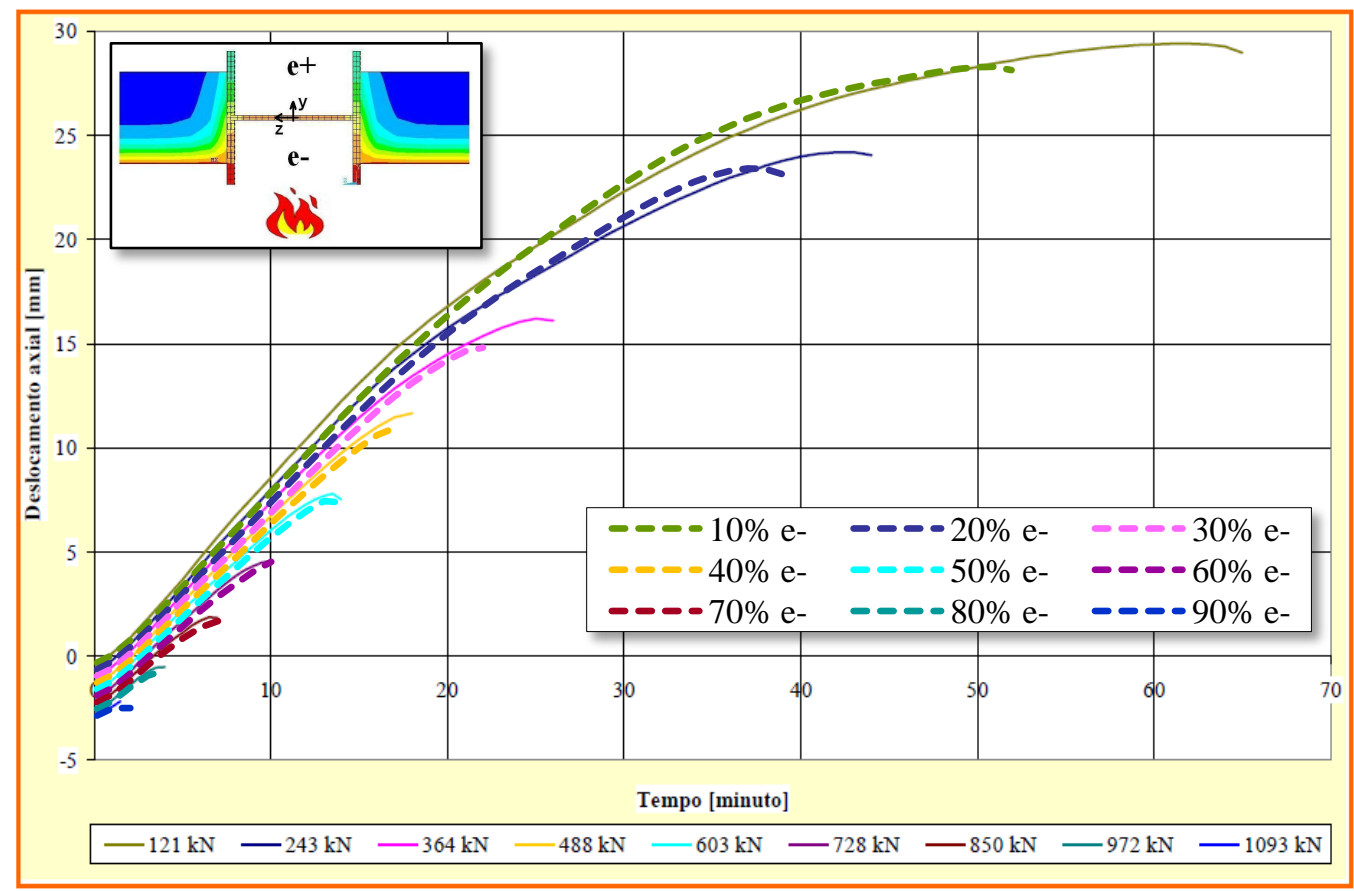

Figura 6.12 - Deslocamento axial no topo com imperfeição geométrica global inicial negativa em relação à fonte de calor.

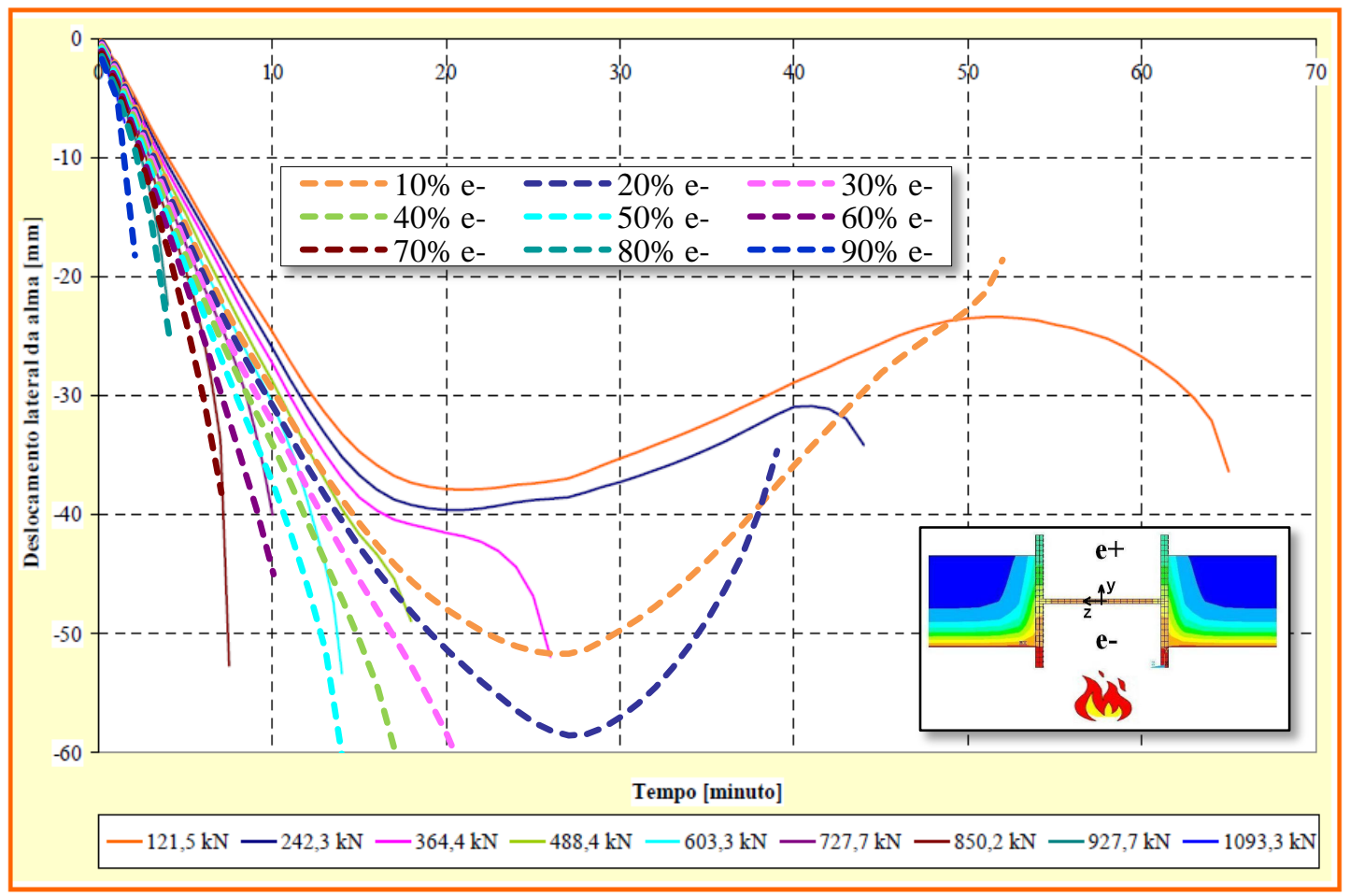

Figura 6.13 - Deslocamento lateral no meio do vão com imperfeição geométrica global inicial negativa em relação à fonte de calor.

A Figura 6.14 apresenta algumas dessas configurações, mas lembrando que tal fenômeno ocorre apenas quando da perda da convergência, sendo uma resposta numérica 
muitas vezes incoerente. A qualidade dos resultados não é afetada, uma vez que se deseja o comportamento do elemento estrutural em todos os passos de carga anteriores até o instante da perda de convergência, bem como o passo de carga térmica em que ela ocorre, sendo esse o tempo crítico.
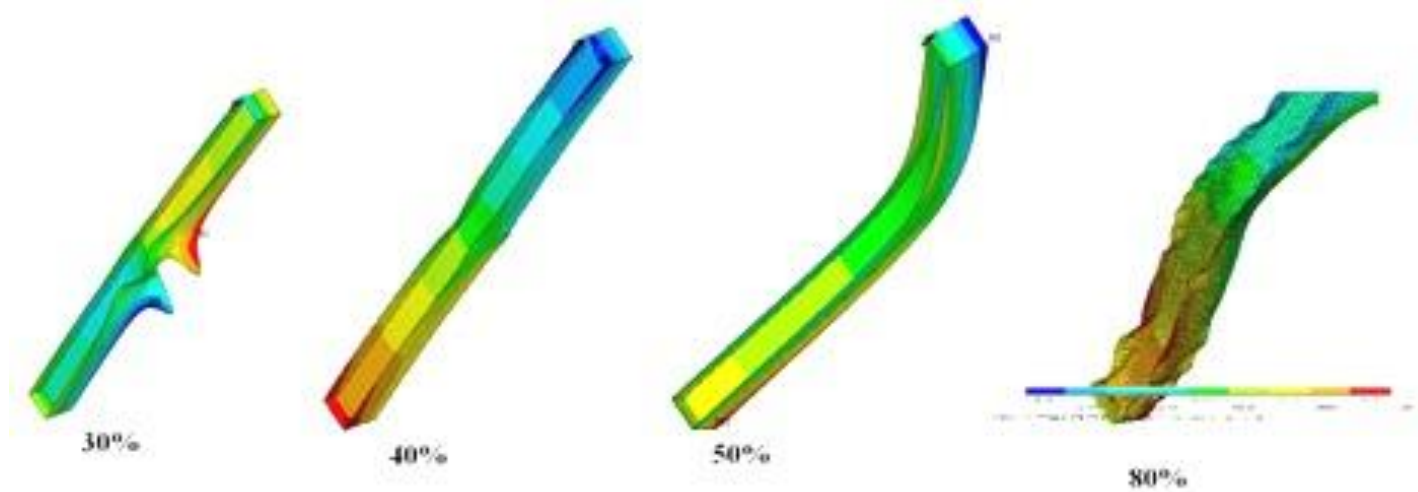

Figura 6.14 - Instabilidade do elemento estrutural durante a perda de convergência numérica dos modelos com paredes nas mesas para algumas das porcentagens de carga de colapso.

\subsubsection{Pilar com paredes na alma e emissividade 0,5}

Da mesma foram que feito anteriormente, serão validados os resultados obtidos nesta pesquisa, com o elemento SHELL181, a partir dos resultados de Kimura (2009) em que foi utilizado o elemento SOLID45, agora para o modelo termoestrutural com paredes encontrando a alma. As figuras a seguir ilustram os resultados de Kimura (2009) nas curvas de traço cheio, enquanto que os resultados da atual pesquisa são exibidos em linhas tracejadas.

O deslocamento axial no topo do pilar, Figura 6.15, apresenta boa concordância apenas no início do incêndio, nos primeiros 5 minutos para cargas de $10 \%$ a $40 \%$ e até cerca de 10 minutos para cargas de 50\% a 90\%. É observado um distanciamento das três primeiras curvas $(10 \%, 20 \%$ e $30 \%$ da carga de colapso) após cerca de 10 minutos. Após o afastamento, as curvas voltam a apresentar trecho ascendente e paralelo às curvas de referência. As curvas de $40 \%$ e $50 \%$ também apresentam o afastamento, mais discretos, ressaltando que as curvas de referência não apresentam o trecho ascendente. As curvas de 50\% até $90 \%$ são praticamente coincidentes e se confundem com as de referência. 


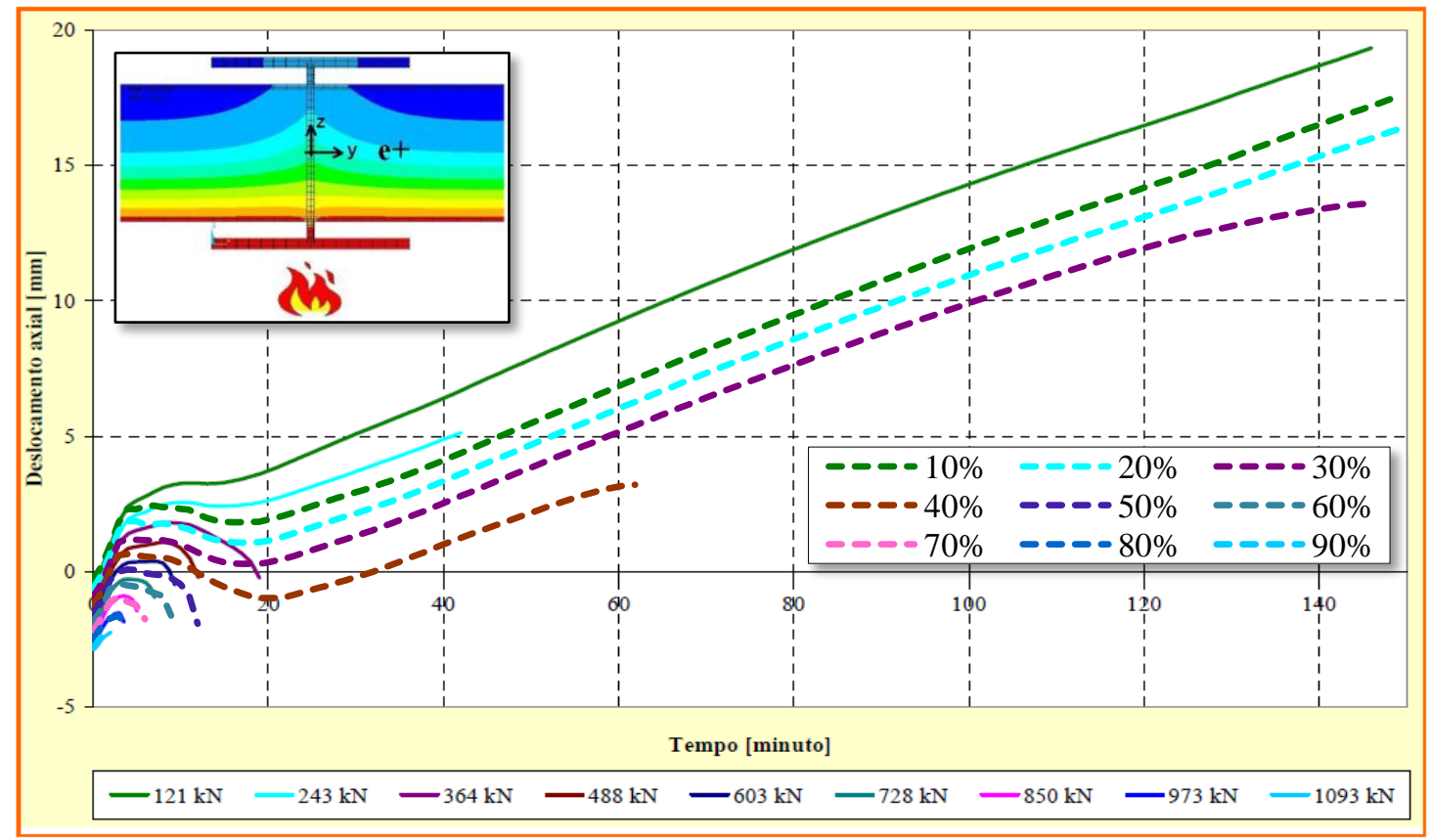

Figura 6.15 - Deslocamento axial no topo do modelo com parede na alma comparando elementos SOLID com elementos SHELL.

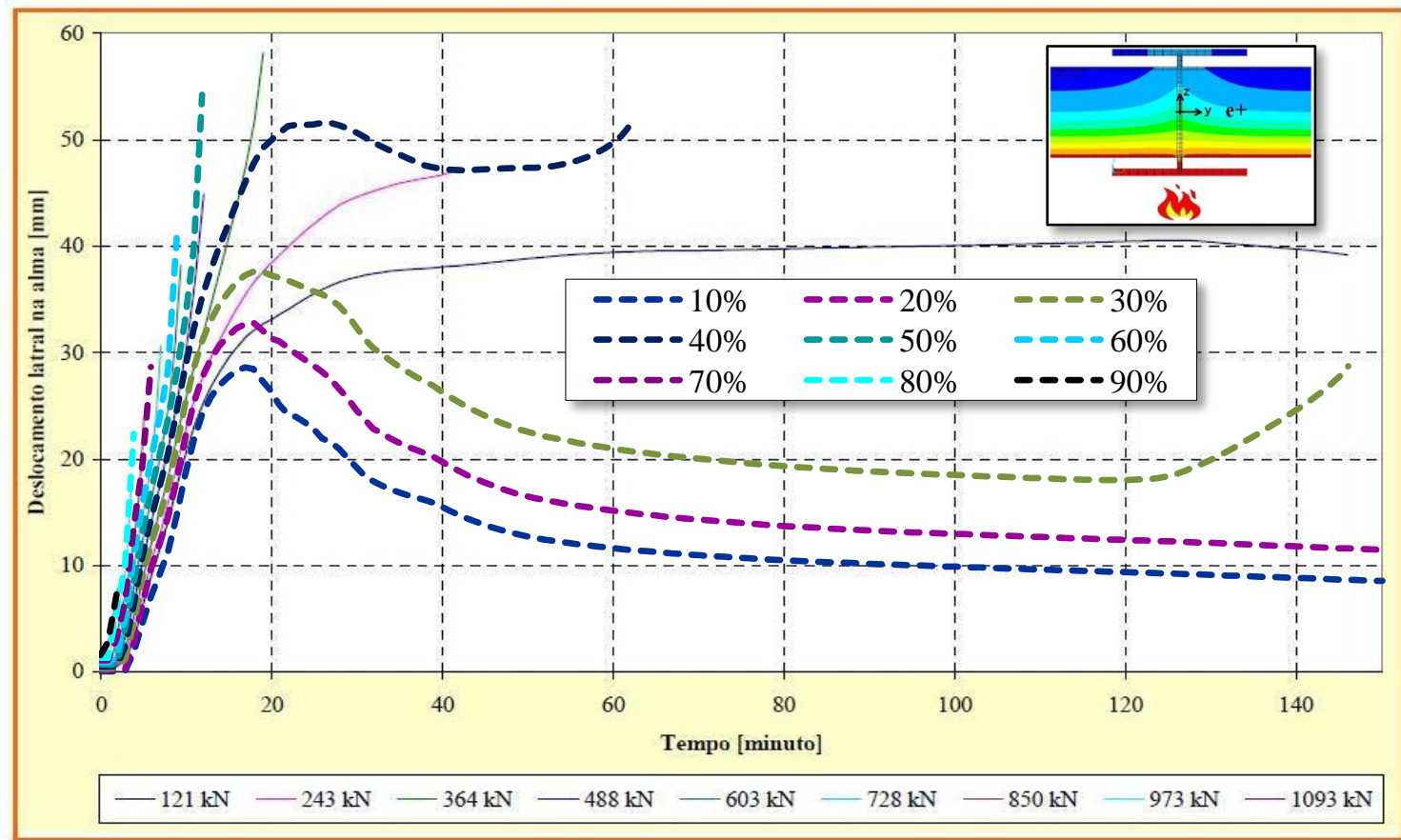

Figura 6.16 - Deslocamento lateral no meio do vão na direção da imperfeição inicial do modelo com paredes na alma comparando elementos SOLID com elementos SHELL.

A Figura 6.16 apresenta a comparação entre os resultados de deslocamento lateral no meio do vão do pilar das duas pesquisas. Assim como no deslocamento axial, com as forças 
axiais iniciais de $10 \%$ a $30 \%$ tem-se afastamento da curva de referência a partir de cerca de 10 minutos. Isso mostra que o elemento SHELL181 apresenta maior deslocabilidade, além da capacidade de rotação dos nós, grau de liberdade que o elemento SOLID45 não possui. Nas três primeiras curvas (10\% a 30\%) observa-se que o deslocamento lateral é crescente e após os 10 minutos retorna alguns milímetros. Isso também ocorre, mas em menor escala, com a curva de $40 \%$.

\subsection{ANÁLISE E VALIDAÇÃO TERMOESTRUTURAL “COM” RESTRIÇÃO AXIAL}

A restrição axial aos deslocamentos causadas pela dilatação térmica foi modelada utilizando o elemento finito LINK10. Trata-se de elemento de barra uniaxial com dois nós que possibilita sua utilização atuando somente com tração, como um cabo, ou somente compressão, como uma escora, sendo essa última opção aqui utilizada. Dentre as opções do elemento e do material atribuídos a ele, são citados: a área da seção e o módulo de elasticidade. Seu comprimento é definido pela distância entre seus dois nós, o qual, no caso dos modelos, foi restringido em $0,10 \mathrm{~m}$, por questões explicadas a seguir. A aplicação do elemento de restrição está esquematizada na Figura 6.17. Também aparecem detalhes dos graus de liberdade restringidos na linha da alma, formando uma rótula cilíndrica em cada extremidade, e o deslocamento em $\mathrm{X}$ na restrição axial, além do nó mestre em que se aplica a força axial inicial.

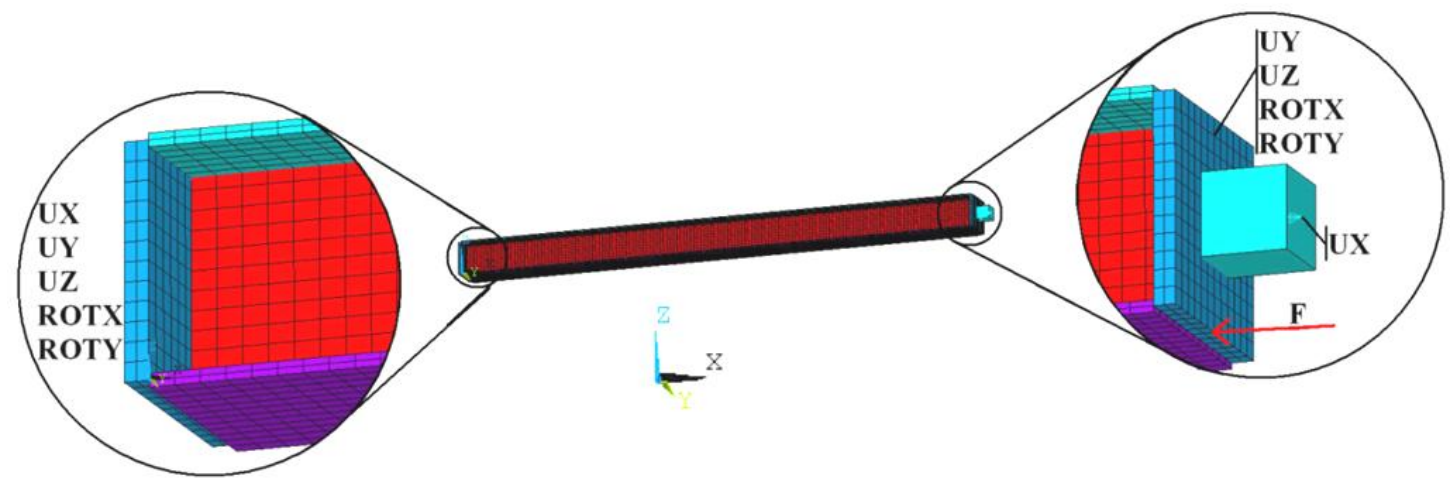

Figura 6.17 - Detalhe da posição da restrição axial com elemento LINK10, força aplicada e graus de liberdade restringidos.

A discretização da malha do elemento LINK10 foi testada e avaliada, ou seja, a restrição axial foi dividida em 1 (um), 4 e 8 elementos. No entanto, nenhuma diferença nos 
resultados de evolução da força axial foi observada e optou-se por manter a restrição axial representada por apenas 1 (um) elemento do tipo LINK10. O valor da restrição segue proporção com base na constante elástica do pilar em estudo conforme Equação 6.1, em que R é a constante elástica da mola de restrição em N/m (elemento LINK10), $\mathrm{k}_{\mathrm{r}}$ é o coeficiente de proporção, E é o módulo de elasticidade do aço $\left(\mathrm{N} / \mathrm{m}^{2}\right)$, A é a área da seção do pilar $\left(\mathrm{m}^{2}\right)$ e $\mathrm{L}$ o comprimento do pilar (m).

$$
R=k_{r} \frac{E A}{L}
$$

Para que o elemento da restrição possua a constante elástica desejada, atribui-se a ele a mesma área da seção do pilar e, a princípio, o mesmo comprimento. O módulo de elasticidade atribuído a ele fica sendo $\mathrm{k}_{\mathrm{r}} \mathrm{E}$. Porém, como o comprimento do elemento de restrição foi, posteriormente, limitado a $0,10 \mathrm{~m}$, o módulo de elasticidade do material atribuído a ele foi ponderado de forma que tivesse rigidez equivalente se possuísse o mesmo comprimento do pilar. O novo módulo de elasticidade passa a valer então $\mathrm{k}_{\mathrm{r}} \mathrm{E} /\left(\mathrm{L} / \mathrm{L}_{\mathrm{s}}\right)$, onde $\mathrm{L}$ é o comprimento do pilar e $L_{s}$ o comprimento da restrição. Os valores de $k_{r}$ utilizados são apresentados na Tabela 6.2, bem como os valores correspondentes da constante elástica $\mathrm{R}$ adotada para a restrição. As proporções $\mathrm{k}_{\mathrm{r}}$ escolhidas foram da mesma ordem de grandeza daquelas adotadas em Franssen (2000) e em Rodrigues (2000).

Tabela 6.2 - Grau de restrição e constantes elásticas adotadas na restrição axial.

\begin{tabular}{ccc}
\hline $\mathbf{k}_{\mathbf{r}}$ & $\mathbf{R}(\mathbf{N} / \mathbf{m})$ & $\mathbf{R}(\mathbf{k N} / \mathbf{m m})$ \\
\hline 0,00 & 0,00 & 0,000 \\
0,03 & $10,95 \times 10^{6}$ & 10,947 \\
0,06 & $21,89 \times 10^{6}$ & 21,895 \\
0,10 & $36,49 \times 10^{6}$ & 36,491 \\
0,20 & $72,98 \times 10^{6}$ & 72,982 \\
50,00 & $\infty$ & $\infty$ \\
\hline
\end{tabular}

\subsubsection{Restrição axial com base em Rodrigues (2000)}

No presente item serão apresentados os resultados obtidos das análises térmicas e termoestruturais, os quais foram comparados com resultados de outros pesquisadores como Rodrigues (2000) e, posteriormente, com Franssen (2000), para fins de validação dos modelos termoestruturais com restrição axial. 
Em Rodrigues (2000) foram realizados experimentos com chapas metálicas retangulares de diversas dimensões. Foram testados experimentalmente modelos com as extremidades rotuladas e engastadas, bem como com o uso de excentricidade na aplicação das cargas. A Figura 6.18a esquematiza o modelo experimental construído, a Figura 6.18b mostra o detalhe da aplicação da excentricidade e a Figura 6.18c mostra o modelo numérico construído no ambiente do código ANSYS.

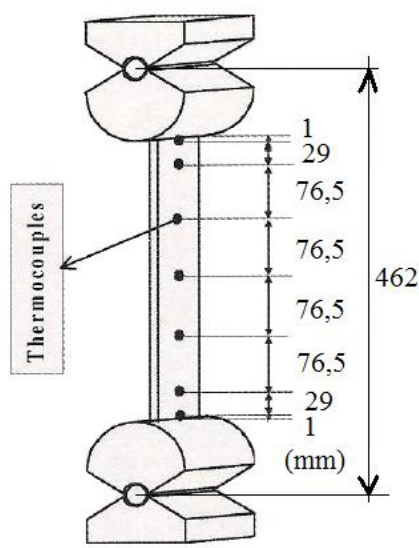

(a)

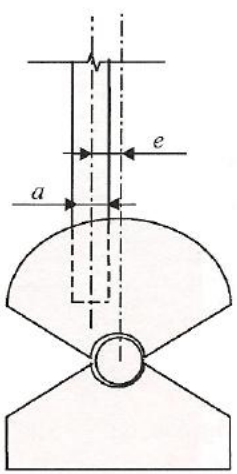

(b)

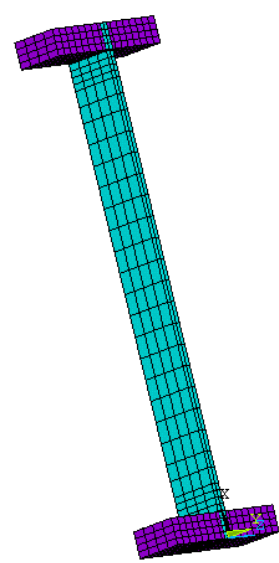

(c)

Figura 6.18 - Esquema: (a) modelo experimental de chapa bi rotulada de Rodrigues (2000), (b) detalhe da excentricidade e (c) modelo numérico do ANSYS.

Estudou-se a influência da excentricidade da carga aplicada, sendo considerados dois valores: $1 \mathrm{~mm}$ e um valor igual à espessura da chapa, sendo portanto diferente para cada perfil estudado. Para realizar as comparações entre essas duas pesquisas foi escolhido apenas o modelo de 50x $8 \mathrm{~mm}^{2}$ com excentricidade de $1 \mathrm{~mm}$. Para ilustrar o instante final do modelo numérico do ANSYS com a restrição axial, a Figura 6.19 mostra algumas das possíveis configurações do perfil ao final da análise.
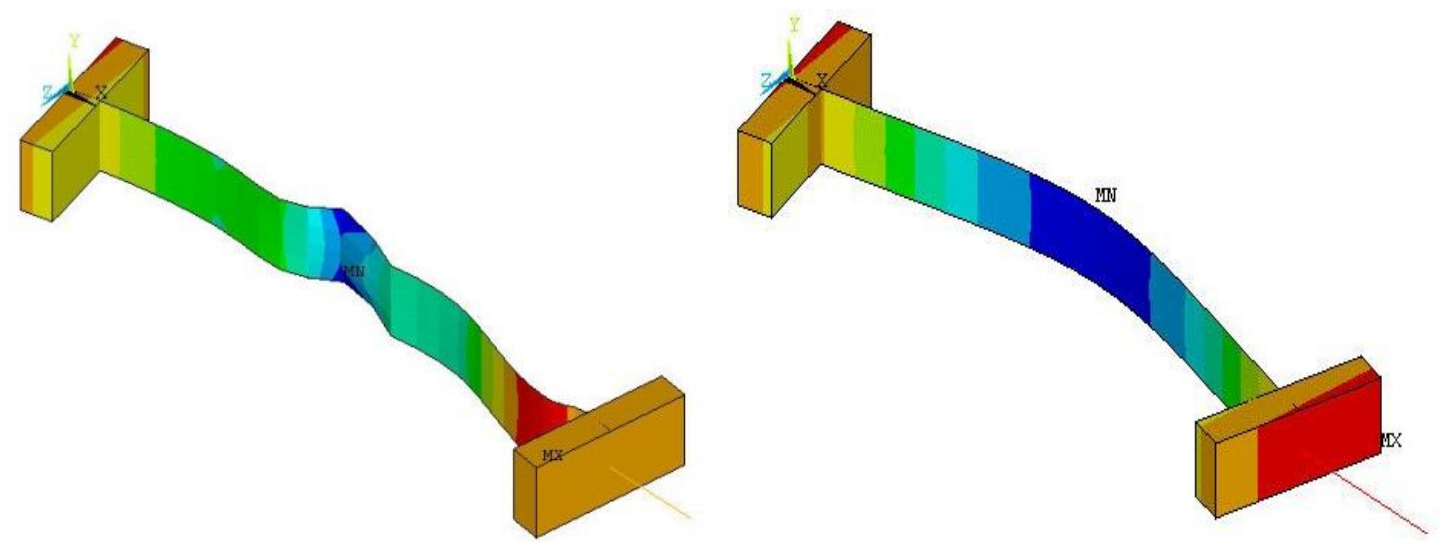

Figura 6.19 - Exemplo da configuração da barra após a perda de convergência numérica. 
Na Figura 6.20 são confrontados os resultados experimentais do acréscimo da força axial aplicada pela restrição com diversas constantes elásticas, obtidos por Rodrigues (2000), conforme Tabela 6.3 .

Tabela 6.3 - Grau de restrição e constantes elásticas adotadas na restrição axial em Rodrigues (2000) para o perfil 50x8 $\mathrm{mm}^{2}$.

\begin{tabular}{ccc}
\hline $\boldsymbol{\alpha}_{\mathbf{K}}$ & $\mathbf{K}_{\mathbf{s}} \mathbf{( N / \mathbf { m } )}$ & $\mathbf{K}_{\mathbf{s}}(\mathbf{k N} / \mathbf{m m})$ \\
\hline 0,0000 & 0 & 0 \\
0,0055 & $1 \times 10^{6}$ & 1 \\
0,0550 & $10 \times 10^{6}$ & 10 \\
0,1320 & $24 \times 10^{6}$ & 24 \\
0,2310 & $42 \times 10^{6}$ & 42 \\
0,5390 & $98 \times 10^{6}$ & 98 \\
\hline
\end{tabular}

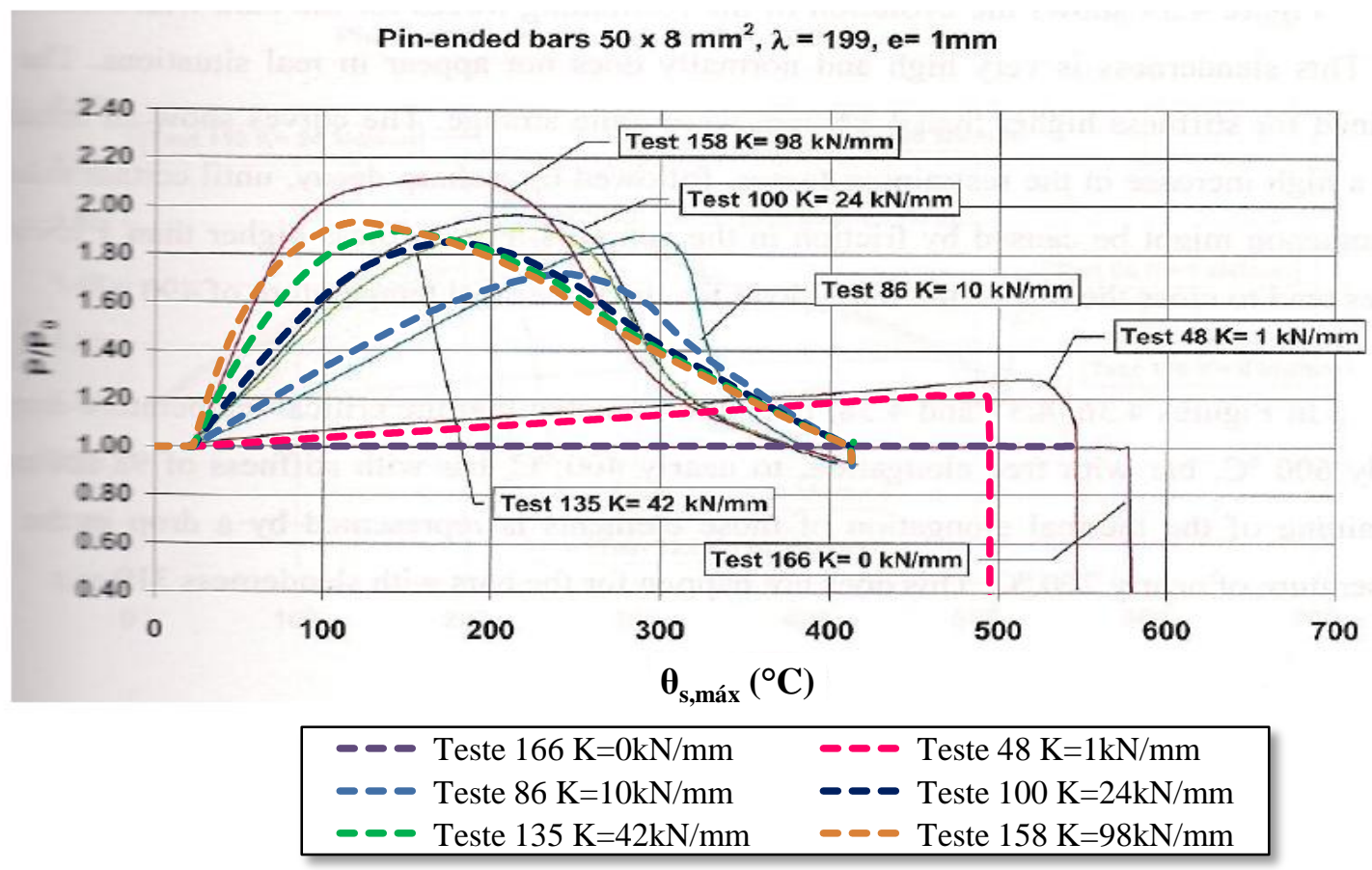

Figura 6.20 - Resultados experimentais de Rodrigues (2000) e numéricos do ANSYS para o perfil $50 \times 8 \mathrm{~mm}^{2}$.

Uma primeira impressão do gráfico apresentado anteriormente mostra boa concordância nos comportamento das curvas, apesar de não ficarem muito próximas. Modelos numéricos e experimentais dentro do contexto da área de incêndio sempre terão alguma divergência por motivos já citados. No entanto, cada um desses testes experimentais apresentados em Rodrigues (2000) foram simulados numericamente na mesma pesquisa. Foram utilizados dois códigos diferentes na modelagem, ZWAN e FINEFIRE, sendo que este 
último utilizando dados de entrada da temperatura de duas formas: temperatura homogênea e gradiente térmico longitudinal tal como medido experimentalmente.

A partir da Figura 6.21 até a Figura 6.26 são mostradas, separadamente, cada uma dessas curvas experimentais com os resultados numéricos obtidos em Rodrigues (2000) com os códigos ZWAN e FINEFIRE, bem como os obtidos na atual pesquisa por meio do código ANSYS. Como pode ser observado em cada um dos gráficos, os resultados do ANSYS ficaram sempre muito próximos dos resultados numéricos de Rodrigues (2000).

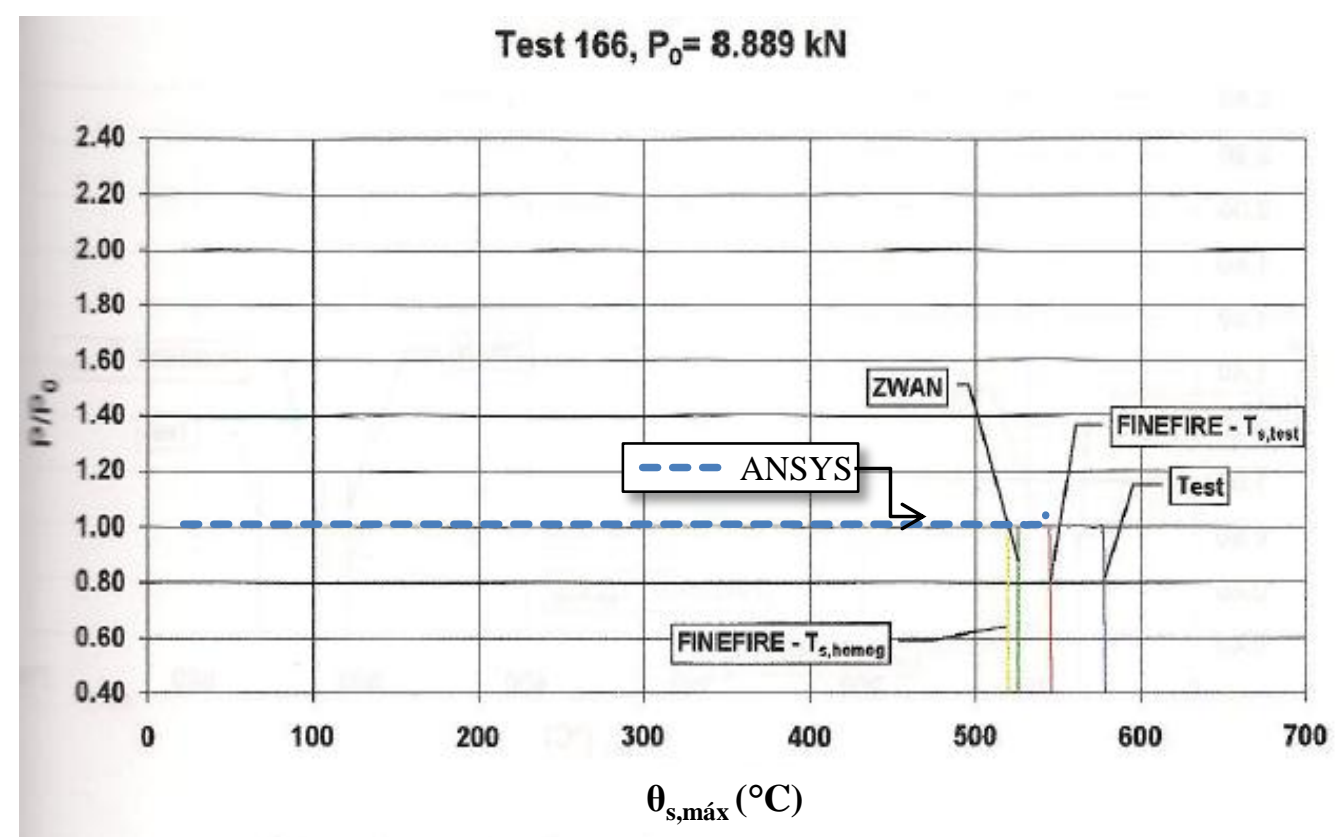

Fig. A 15.2 Pin-ended bar $50 \times 8 \mathrm{~mm}^{2}$, e $=1 \mathrm{~mm}, \mathrm{~K}=0 \mathrm{kN} / \mathrm{mm}$

Figura 6.21 - Resultados experimentais e numéricos do Teste 166 do perfil 50x8mm². 


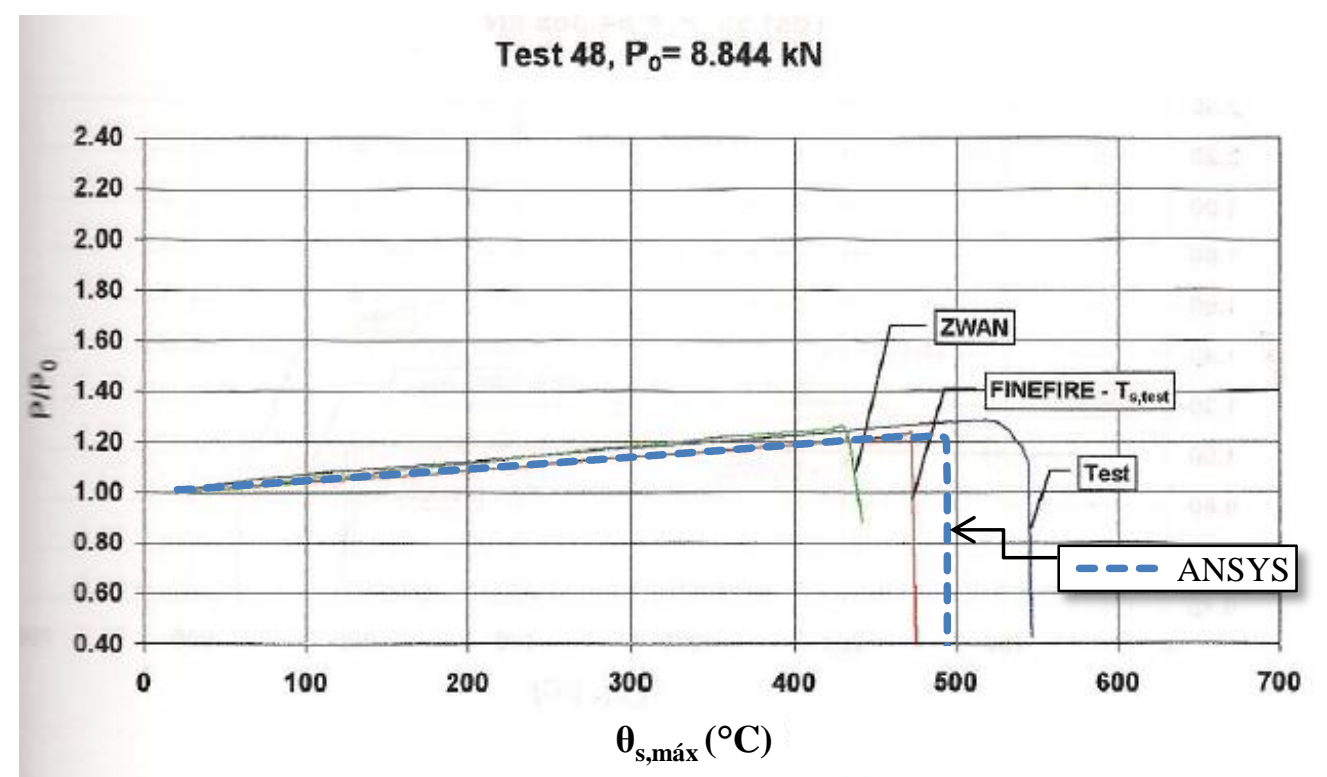

Fig. A 15.10 Pin-ended bar $50 \times 8 \mathrm{~mm}^{2}, \mathrm{e}=1 \mathrm{~mm}, \mathrm{~K}=1 \mathrm{kN} / \mathrm{mm}$

Figura 6.22 - Resultados experimentais e numéricos do Teste 48 do perfil 50x8mm².

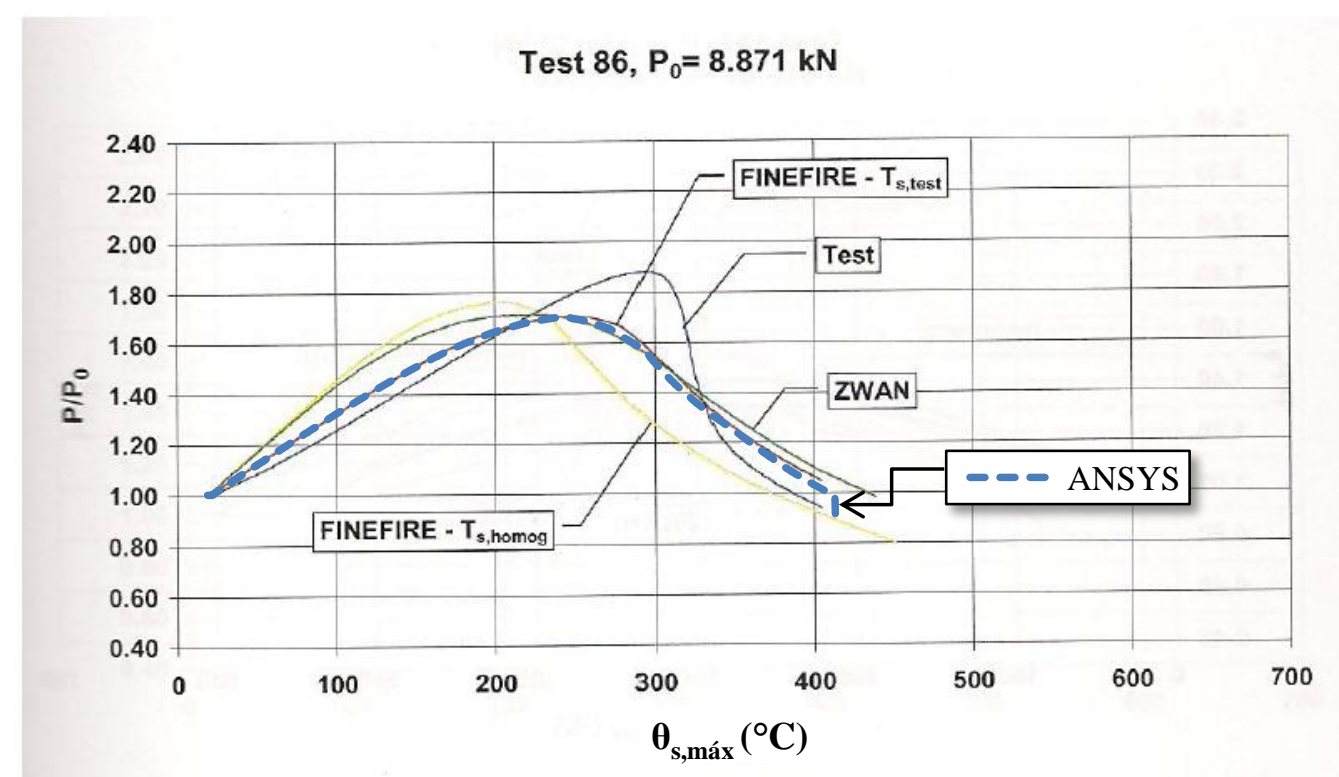

Fig. 5.12 Numerical simulations, $50 \times 8 \mathrm{~mm}^{2}$ pin-ended bars, $\mathrm{e}=1 \mathrm{~mm}, \mathrm{~K}=10 \mathrm{kN} / \mathrm{mm}$

Figura 6.23 - Resultados experimentais e numéricos do Teste 86 do perfil 50x8mm². 


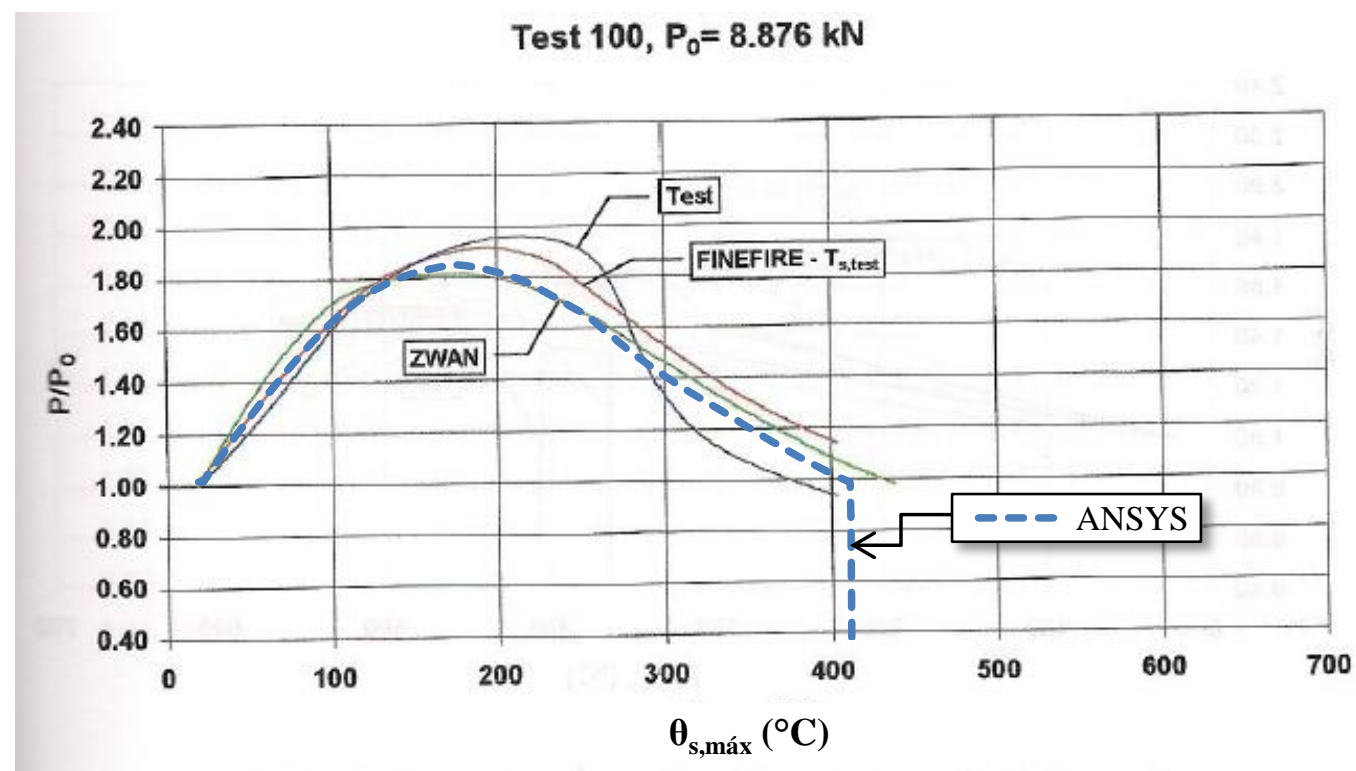

Fig. A 15.26 Pin-ended bar $50 \times 8 \mathrm{~mm}^{2}$, e= 1mm, K= $24 \mathrm{kN} / \mathrm{mm}$

Figura 6.24 - Resultados experimentais e numéricos do Teste 100 do perfil 50x8mm².

Test 135, $\mathrm{P}_{0}=\mathbf{8 . 8 9 2} \mathrm{kN}$

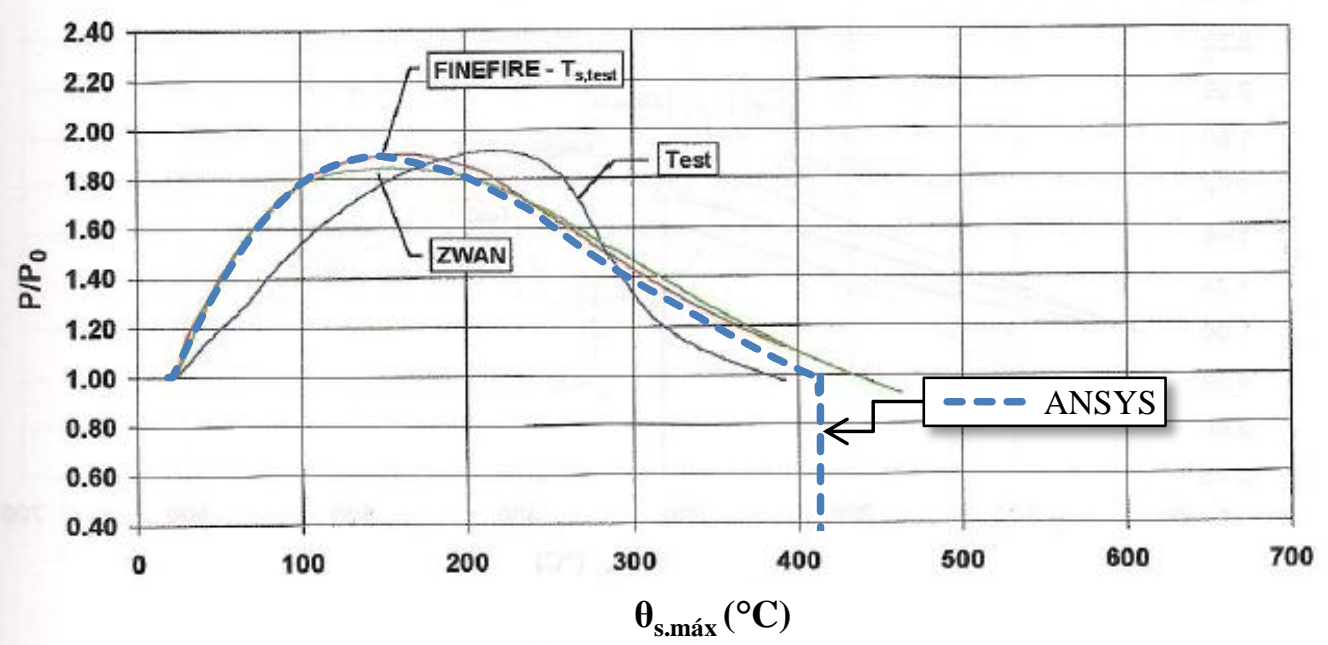

Fig. A 15.34 Pin-ended bar $50 \times 8 \mathrm{~mm}^{2}$, e=1mm, $\mathrm{K}=42 \mathrm{kN} / \mathrm{mm}$

Figura 6.25 - Resultados experimentais e numéricos do Teste 135 do perfil 50x $8 \mathrm{~mm}^{2}$. 


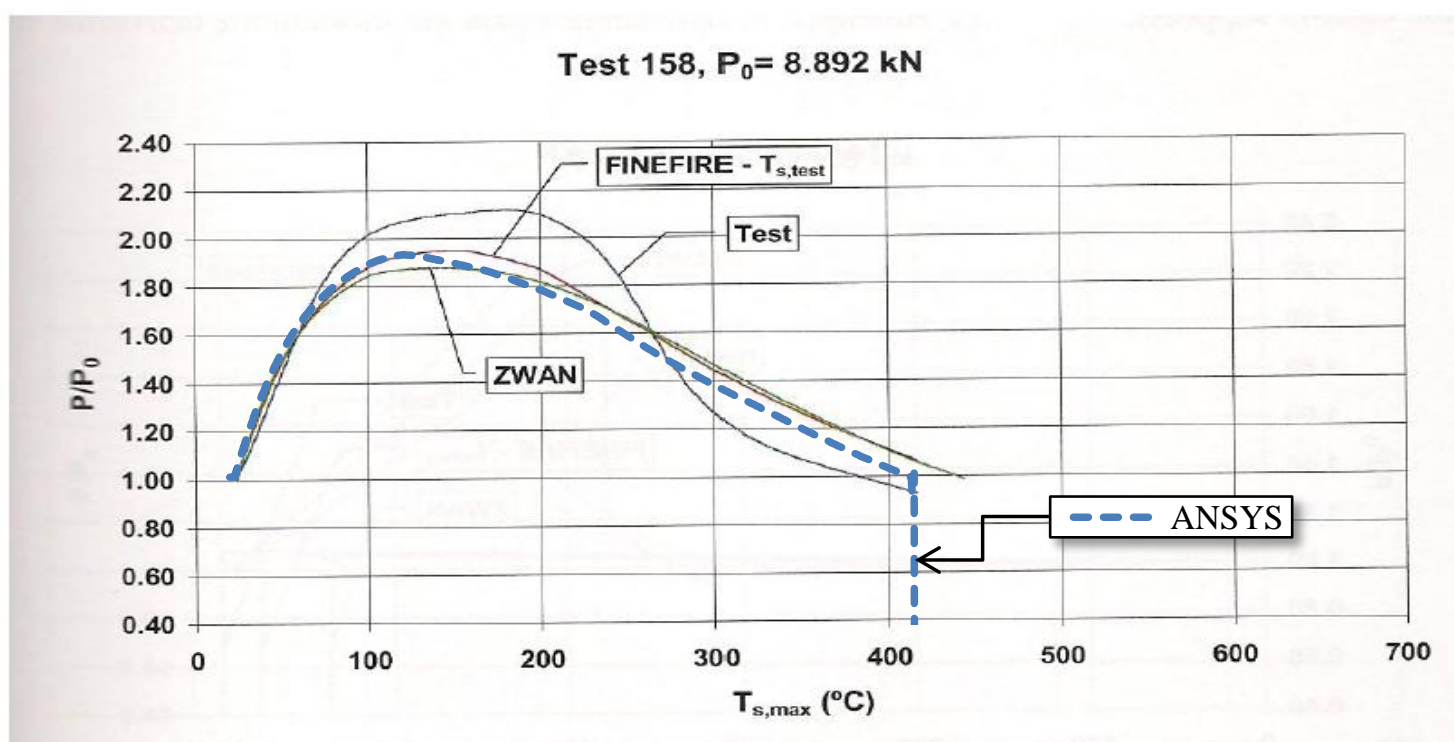

Fig. 5.17 Numerical simulations, $50 \times 8 \mathrm{~mm}^{2}$ pin-ended bars, $\mathrm{e}=1 \mathrm{~mm}, \mathrm{~K}=98 \mathrm{kN} / \mathrm{mm}$

Figura 6.26 - Resultados experimentais e numéricos do Teste 158 do perfil 50x8mm².

Além dos resultados da evolução da força axial também foram comparados os resultados do deslocamento lateral. Na Figura 6.27 os valores dos deslocamentos laterais no meio do vão estão confrontando as respostas experimentais de Rodrigues (2000) àquelas obtidas por meio do código ANSYS.

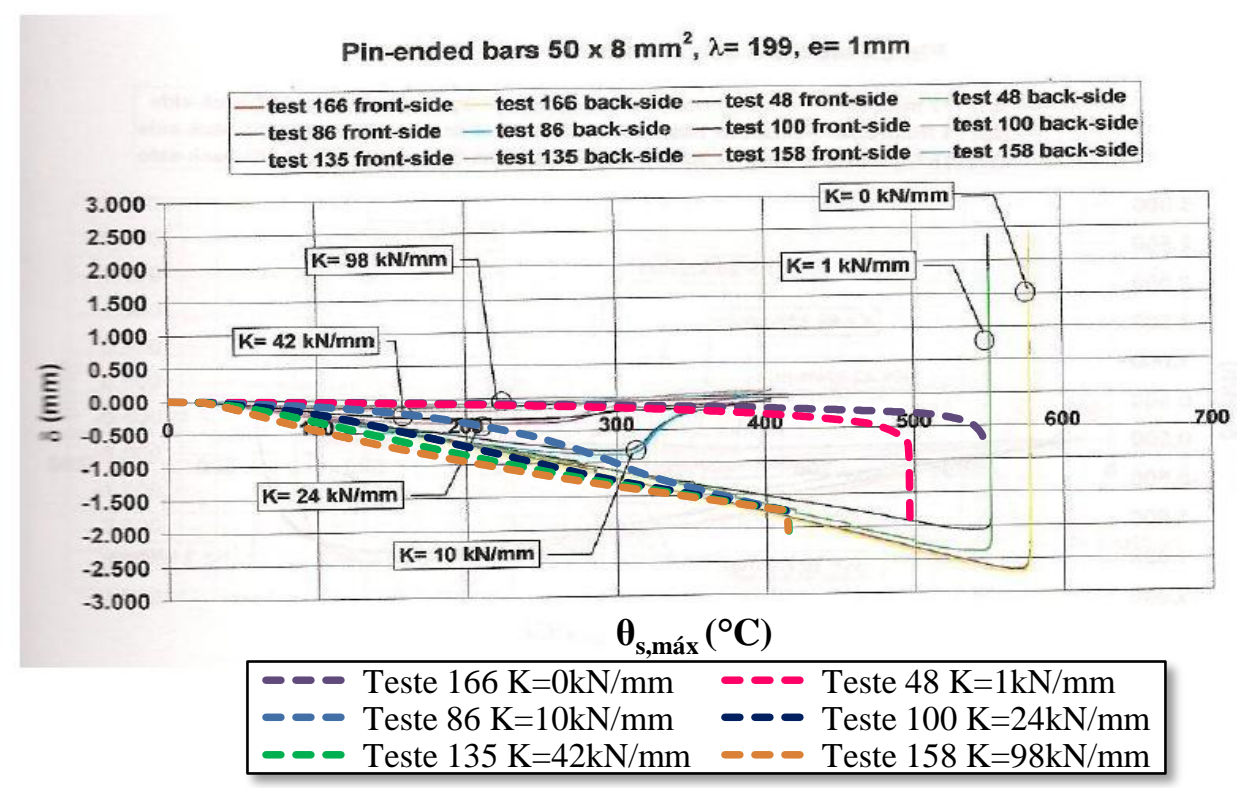

Figura 6.27 - Resultados experimentais e numéricos do deslocamento lateral do perfil $50 \times 8 \mathrm{~mm}^{2}$. 
A Tabela 6.4 apresenta um resumo dos principais resultados experimentais e numéricos de Rodrigues (2000), bem como aqueles obtidos pelo ANSYS com a finalidade de validar o modelo numérico construído para esta pesquisa.

Tabela 6.4 - Resultados experimentais e numéricos.

\begin{tabular}{|c|c|c|c|c|c|c|c|c|c|c|}
\hline \multirow{2}{*}{$\begin{array}{l}\text { Rigidez } K_{\mathrm{s}} \\
(\mathrm{kN} / \mathrm{mm})\end{array}$} & \multirow{2}{*}{$\begin{array}{l}\text { Teste } \\
\mathrm{n}^{\circ} .\end{array}$} & \multirow{2}{*}{$\begin{array}{c}\mathrm{F}_{0} \\
(\mathrm{kN})\end{array}$} & \multicolumn{2}{|c|}{$\begin{array}{c}\text { Teste } \\
\text { Experimental }\end{array}$} & \multicolumn{2}{|c|}{ Software ZWAN } & \multicolumn{2}{|c|}{$\begin{array}{l}\text { Software } \\
\text { FINEFIRE }\end{array}$} & \multicolumn{2}{|c|}{ ANSYS } \\
\hline & & & $\begin{array}{l}\mathrm{F}_{\max } \\
(\mathrm{kN})\end{array}$ & $\begin{array}{c}\theta_{\mathrm{s}, \text { máx - crit. }} \\
\left({ }^{\circ} \mathrm{C}\right)\end{array}$ & $\begin{array}{l}\mathrm{F}_{\max } \\
(\mathrm{kN})\end{array}$ & $\begin{array}{c}\theta_{\mathrm{s}, \mathrm{máx}} \text { - crit. } \\
\left({ }^{\circ} \mathrm{C}\right)\end{array}$ & $\begin{array}{l}\mathrm{F}_{\max } \\
(\mathrm{kN})\end{array}$ & $\begin{array}{c}\theta_{\mathrm{s}, \text { máx - crit. }} \\
\left({ }^{\circ} \mathrm{C}\right)\end{array}$ & $\begin{array}{l}\mathrm{F}_{\max } \\
(\mathrm{kN})\end{array}$ & $\begin{array}{c}\theta_{\mathrm{s}, \text { máx - crit. }} \\
\left({ }^{\circ} \mathrm{C}\right)\end{array}$ \\
\hline 0 & 166 & 8,89 & 8,89 & 578 & 8,89 & 526 & 8,89 & 545 & 8,89 & 545 \\
\hline 1 & 48 & 8,86 & 11,27 & 551 & 11,05 & 439 & 10,89 & 473 & 10,73 & 496 \\
\hline 10 & 86 & 8,87 & 16,65 & 387 & 15,19 & 432 & 15,13 & 420 & 15,21 & 416 \\
\hline 24 & 100 & 8,88 & 17,4 & 376 & 16,11 & 430 & 17,03 & 454 & 16,40 & 416 \\
\hline 42 & 135 & 8,89 & 16,97 & 382 & 16,41 & 434 & 16,91 & 433 & 16,82 & 415 \\
\hline 98 & 158 & 8,89 & 18,83 & 382 & 16,69 & 438 & 17,38 & 441 & 17,15 & 415 \\
\hline
\end{tabular}

FONTE: Rodrigues (2000) - ADAPTADO

\subsubsection{Restrição axial com base em Franssen (2000)}

Segundo Franssen (2000), estimar o grau de restrição axial a que está submetido um pilar inserido em uma estrutura é tarefa bastante complexa. Em Wang e Moore (1994) apud Franssen (2000) é dito que a ordem de magnitude dessa restrição nas estruturas usuais fica em torno de 0,02 a 0,03. Em Franssen (2000) é apresentado um exemplo de cálculo de pilar restringido axialmente em que esse grau é variado desde totalmente livre até totalmente restrito, passando por níveis de restrição axial ( $\alpha$ ou R) com os seguintes valores: 0,01, 0,02, 0,05 e 0,10 , sendo $\mathrm{R}\left(\right.$ ou $\alpha$ ) a razão entre a rigidez da estrutura, a restrição axial $\left(\mathrm{K}_{\mathrm{s}}\right)$, e a rigidez do pilar em temperatura ambiente $\left(\mathrm{K}_{\mathrm{c}}\right.$ ou $\left.\mathrm{K}_{\mathrm{co}}\right)$.

$\mathrm{Na}$ última referência é apresentado um método numérico capaz de simular o comportamento de um elemento estrutural antes e após a instabilidade inicial, como ocorre em um ensaio de barra comprimida com controle de deslocamento. O método em questão é chamado de arc-length ou comprimento de arco, e possibilita a obtenção de resultados de elementos com grandes deformações sem a perda de convergência numérica como ocorreria em métodos numéricos mais tradicionais ou em ensaios de compressão com controle de força. O método foi implementado no código SAFIR, desenvolvido pelo autor da última referência, e alguns exemplos de seu uso e eficiência foram demonstrados em modelos numéricos considerando elevadas temperaturas. 
Conforme Figura 6.28, em Franssen (2000) é apresentada a evolução das cargas axiais de uma barra comprimida, com 4 metros de comprimento e perfil HEA100 (dimensões na Tabela 6.5). Apresenta resistência ao escoamento igual a $235 \mathrm{MPa}$, módulo de elasticidade igual a 210.000 MPa e propriedades térmicas conforme Eurocode 3 parte 1-2 (2005).

Tabela 6.5 - Dimensões do perfil HEA100.

\begin{tabular}{lr}
\hline Dimensão & Valor \\
\hline$h_{w}$ & $80 \mathrm{~mm}$ \\
$t_{w}$ & $5 \mathrm{~mm}$ \\
$b_{f}$ & $100 \mathrm{~mm}$ \\
$t_{f}$ & $8 \mathrm{~mm}$ \\
$d$ & $96 \mathrm{~mm}$ \\
Área & $21,2 \mathrm{~cm}^{2}$ \\
$\mathrm{l}_{x}$ & $349 \mathrm{~cm}^{4}$ \\
$r_{x}$ & $4,05 \mathrm{~cm}$ \\
$l_{y}$ & $134 \mathrm{~cm}^{4}$ \\
$r_{y}$ & $2,51 \mathrm{~cm}$ \\
\hline
\end{tabular}

Como o exemplo considera a instabilidade em torno do eixo de maior inércia, o índice de esbeltez para um comprimento de 4 metros resulta aproximadamente igual a 100 . O objetivo desse exemplo é mostrar a capacidade de o método numérico predizer o comportamento do elemento antes e após a instabilidade inicial, ou seja, é necessária uma barra bastante esbelta. A referência não cita o valor para a imperfeição geométrica global inicial, no entanto, o valor de L/1000 foi utilizado e trouxe resultados satisfatórios.

Na Figura 6.28 observa-se que uma restrição axial com rigidez maior que uma vez a rigidez do pilar já pode ser considerada como rigidez infinita para a mola. A rigidez de duas vezes a constante elástica do pilar concorda ainda melhor com a restrição infinita de Franssen (2000).

Para a rigidez da restrição axial igual a duas vezes a rigidez do pilar pode-se observar que a consideração do passo de carga igual a um minuto inteiro pode não representar corretamente a curva $(R=2,00 \mathrm{c} / 60 \mathrm{seg})$. Como o intervalo de tempo total é muito curto, de apenas alguns minutos, algum comportamento de pico da curva pode ser perdido por esta ser expressa com poucos pontos. 


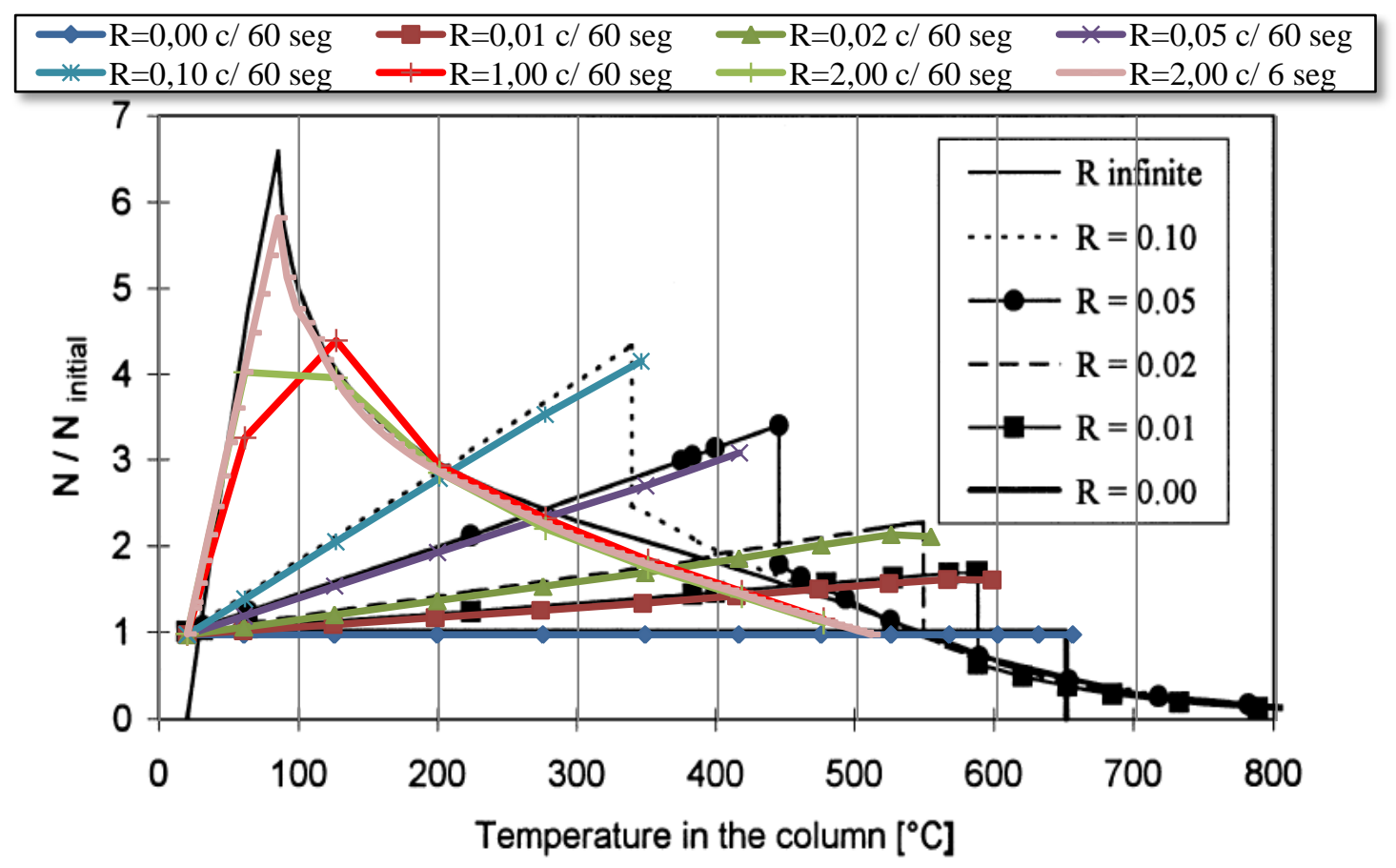

Figura 6.28 - Comparativo da evolução da força da restrição axial entre exemplo numérico de Franssen (2000) e modelo similar construído no ANSYS.

Para contornar essa deficiência, o intervalo do passo de carga foi reduzido a um décimo de seu valor, ou seja, a cada 6 segundos. A curva $R=2,00 \mathrm{c} / 6 \mathrm{seg}$ segue a mesma citada no parágrafo anterior, mas representando melhor o comportamento de pico. Essa estratégia será adotada nos modelos seguintes para que todas as curvas sejam bem representadas.

A Figura 6.29 mostra a diferença entre uma curva representando os resultados dos deslocamentos laterais do modelo que será apresentado posteriormente no item 6.4 .6 com restrição axial em que os passos de carga foram considerados a cada 60 segundos e outra curva em que foi considerada a cada 6 segundos. O número maior de passos de carga faz com que a curva apresente mais pontos a fim de descrevê-la melhor no gráfico. 


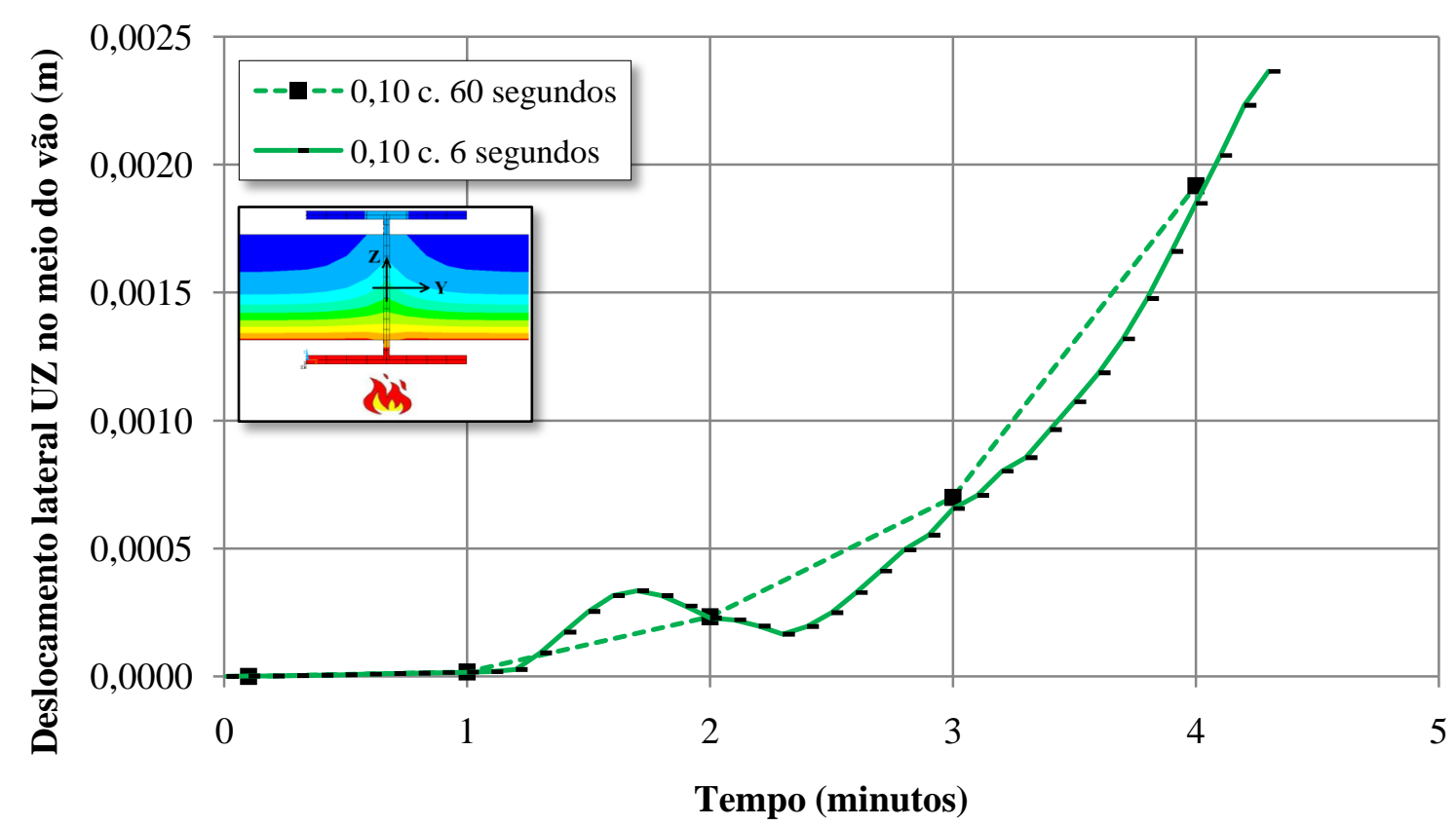

Figura 6.29 - Modelo mostrando a diferença no traçado da curva de deslocamento lateral entre os passos de carga de 60 e de 6 segundos do modelo com paredes na alma, $75 \%$ de carga inicial e restrição axial de 0,10 .

Conforme a montagem do modelo visto em Franssen (2000), a carga axial inicial aplicada irá mobilizar o pilar à compressão e também a restrição à tração. Ou seja, a deformação inicial do pilar devido à carga aplicada irá deformar também a mola da restrição, absorvendo parte da força de forma proporcional ao valor de restrição. Para contornar esse problema, a última referência utiliza a seguinte estratégia: compensar a carga absorvida pela mola com um acréscimo da carga inicial proporcional ao grau de restrição, garantindo a carga inicial desejada aplicada ao pilar. Em outras palavras, para uma carga inicial de $50 \mathrm{kN}$ e uma restrição de 0,10 , será aplicada uma carga de $55 \mathrm{kN}$, sendo $5 \mathrm{kN}$ absorvido pela mola e garantindo os $50 \mathrm{kN}$ para o pilar, conforme descrito na última referência.

Os modelos construídos no ANSYS, tanto para validar a estratégia numérica quanto os modelo definitivos, contornaram essa questão de forma diferente e mais próxima de uma situação realística, considerando o processo construtivo. Como esquematizado na Figura 6.30, o nó superior do elemento LINK10 foi restringido ao deslocamento em X, no entanto, foi dado a ele um deslocamento inicial igual à deformação inicial da barra devido à força aplicada. Ou seja, conforme mostra Equação 6.2, o valor da deformação inicial foi inicialmente calculada e utilizada como "recalque" inicial do nó superior da restrição. Dessa forma, a expansão térmica do pilar irá solicitar a restrição axial à compressão desde o início, 
não apenas quando o topo do pilar retornar ao ponto inicial (sem deformação devido à força axial), o que em alguns modelos nunca ocorrerá.

$$
\varepsilon_{\text {inicial }}=F \frac{L}{E A}
$$

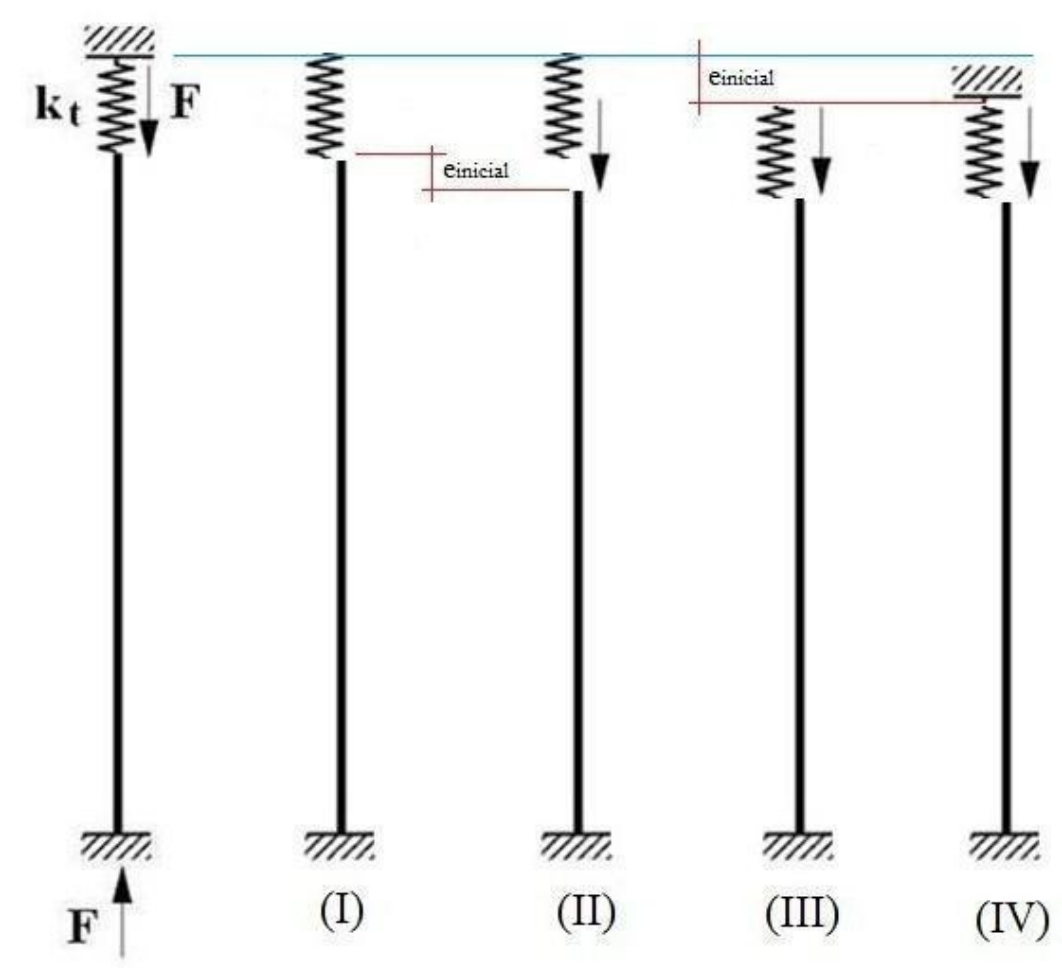

Figura 6.30 - Etapas da consideração da deformação inicial do pilar em relação à posição inicial da restrição axial.

Em Franssen (2000) se observa que a temperatura crítica, para uma determinada carga inicial, em diversos níveis de restrição é praticamente o mesmo. A temperatura crítica seria mais dependente da carga inicial aplicada do que do grau de restrição propriamente. Segundo Franssen (2000), não seria necessário conhecer a priori o valor do grau da restrição. Com isso o autor sugere uma simplificação da análise termoestrutural em que se aplica uma restrição axial infinita sem carga inicial alguma. Como demonstra a Figura 6.31, a temperatura crítica seria aquela que, ao traçar uma reta a partir da carga inicial desejada, encontra a curva da análise realizada sem carga alguma e restrição axial infinita. 


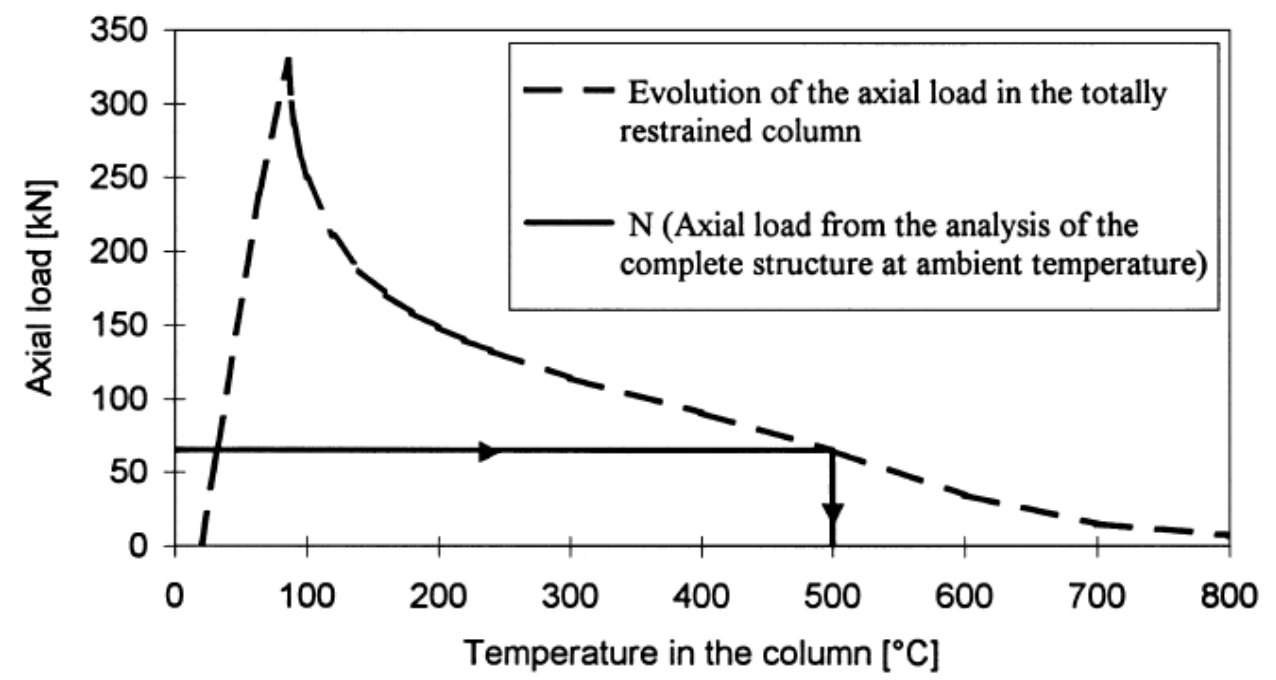

Figura 6.31 - Evolução da carga pelo método simplificado, restrição axial infinita, carga inicial nula. Fonte: Franssen (2000)

Os resultados dos modelos desta pesquisa serão confrontados com esse método simplificado, proposto em Franssen (2000), com o fim de validar sua eficiência, inclusive quando os modelos apresentarem compartimentação do incêndio e gradientes térmicos na seção. Caso os resultados sejam satisfatórios, passa a ser possível elaborar ábacos de dimensionamento e projetos de estruturas metálicas em situação de incêndio. Essa possibilidade será testada e comentada juntamente com os resultados desta pesquisa.

\subsection{RESULTADOS DOS MODELOS TERMOESTRUTURAIS:}

\section{EMISSIVIDADE IGUAL A 0,7}

Após as validações dos modelos vistos anteriormente, parâmetros normativos mais atuais foram considerados e os resultados discutidos. Tais parâmetros incluem: emissividade de radiação com valor $\mathbf{0 , 7}$, perda de calor na face não exposta ao incêndio tanto pelo perfil quanto pela alvenaria, restrição axial, módulo de elasticidade igual a 200.000 MPa e curva de incêndio-padrão segundo a ISO 834-1:1999.

\subsubsection{Pilar isolado "sem" restrição axial}

Os resultados mostrados na Figura 6.32 se referem aos deslocamentos axiais no topo do pilar, enquanto que os deslocamentos laterais no meio do vão do pilar isolado são mostrados na Figura 6.33. 


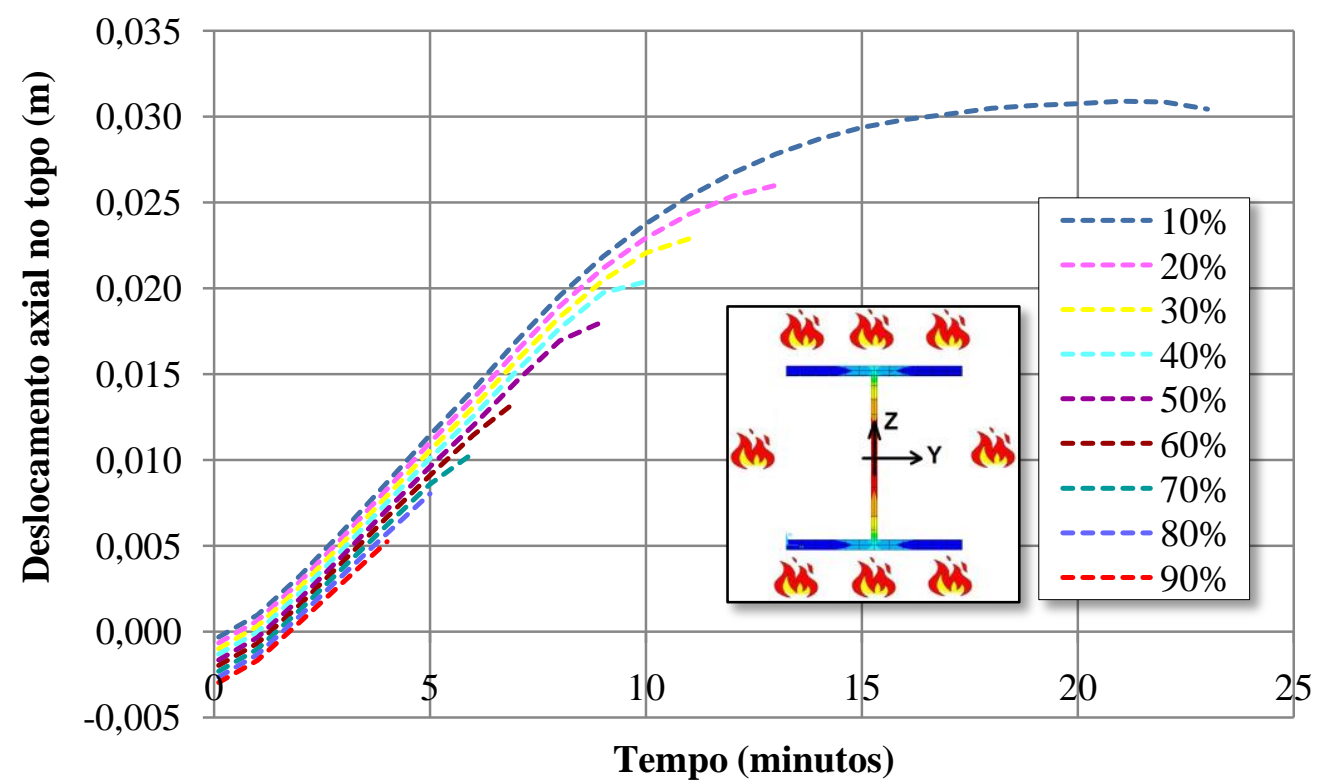

Figura 6.32 - Deslocamento axial no topo do pilar isolado para diversos níveis de carregamento.

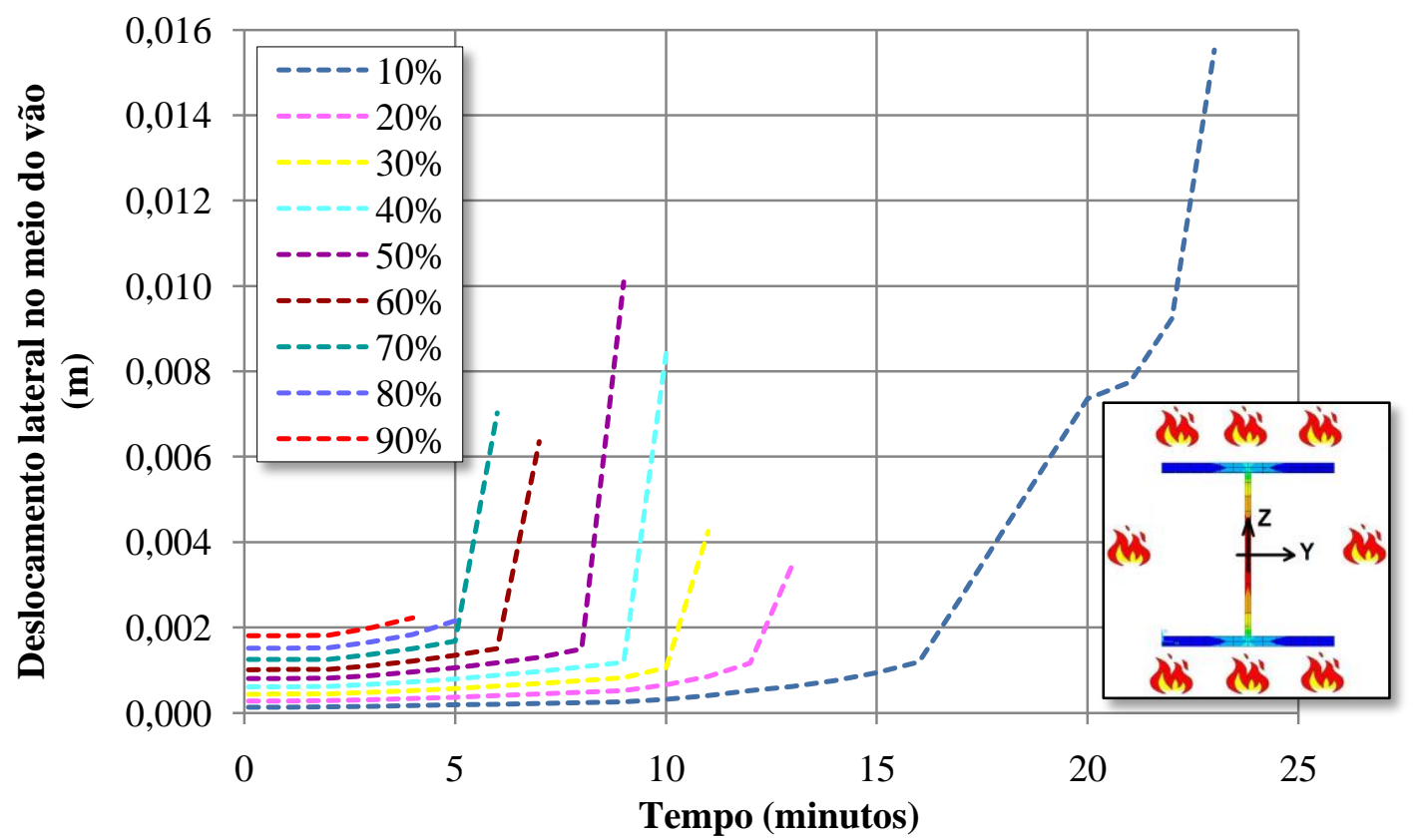

Figura 6.33 - Deslocamento lateral no meio do vão do pilar isolado na direção da imperfeição inicial para diversos níveis de carregamento.

É possível observar, pelos deslocamentos axiais, Figura 6.32, que para os diversos níveis de carregamento o comportamento do elemento estrutural é semelhante, atingindo valores maiores de tempo crítico tanto quanto menor for o carregamento inicial. Também se observa que os deslocamentos laterais iniciais, Figura 6.33, são tão maiores quanto maior for o carregamento inicial, como esperado, devido à imperfeição geométrica global inicial. 
Observa-se que, com a evolução da temperatura do aço, o deslocamento lateral pouco se altera, provavelmente, em resposta à uniformidade do campo térmico. O deslocamento lateral, como esperado, aumenta bruscamente ao atingir o tempo crítico, caracterizando a instabilidade do elemento estrutural. Esse modelo demonstra o comportamento do elemento estrutural sob elevação das temperaturas do aço juntamente com a ação de um carregamento axial estático, sem elemento que represente a interação deste com a estrutura circundante, bem como paredes de vedação e compartimentação das chamas.

Além dos deslocamentos na direção da imperfeição inicial, foram coletados resultados de deslocamentos na direção perpendicular a essa mesma imperfeição, mostrados na Figura 6.34. A princípio, imagina-se que esse deslocamento não ocorrerá, pois o aquecimento é uniforme.

No entanto, a combinação de deformações mecânicas e térmicas se mostrou bastante complexa. O elemento estrutural apresenta rotações do seu eixo longitudinal, Figura 6.35, mesmo com valores muito próximos a zero, provocando deslocamento na direção $\mathrm{Z}$ igualmente pequenos. Na Figura 6.36 é possível observar o deslocamento no plano da seção Y-Z , mostrando a diferença de magnitude dos deslocamentos concorrentes da ordem de 1000 vezes.

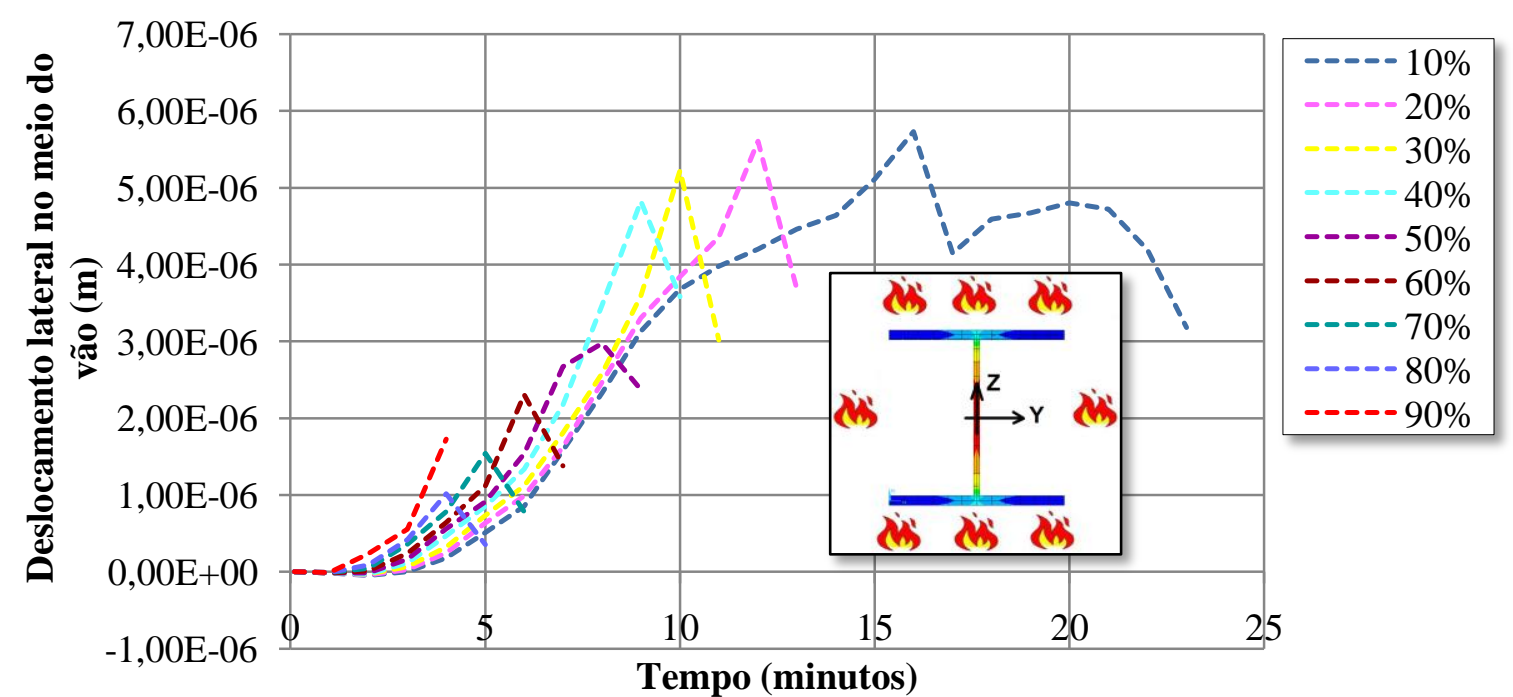

Figura 6.34 - Deslocamento lateral no meio do vão na direção perpendicular à imperfeição inicial. 


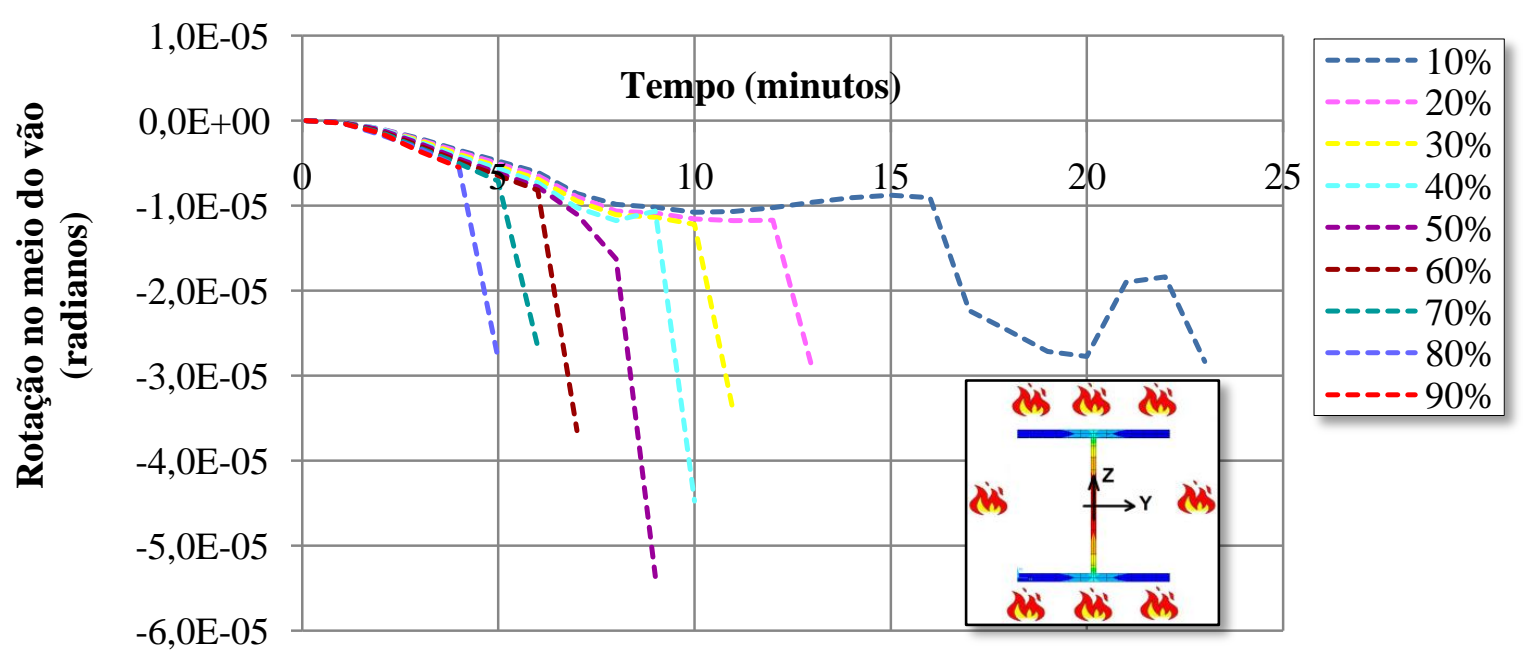

Figura 6.35 - Rotação do eixo longitudinal no meio do vão.

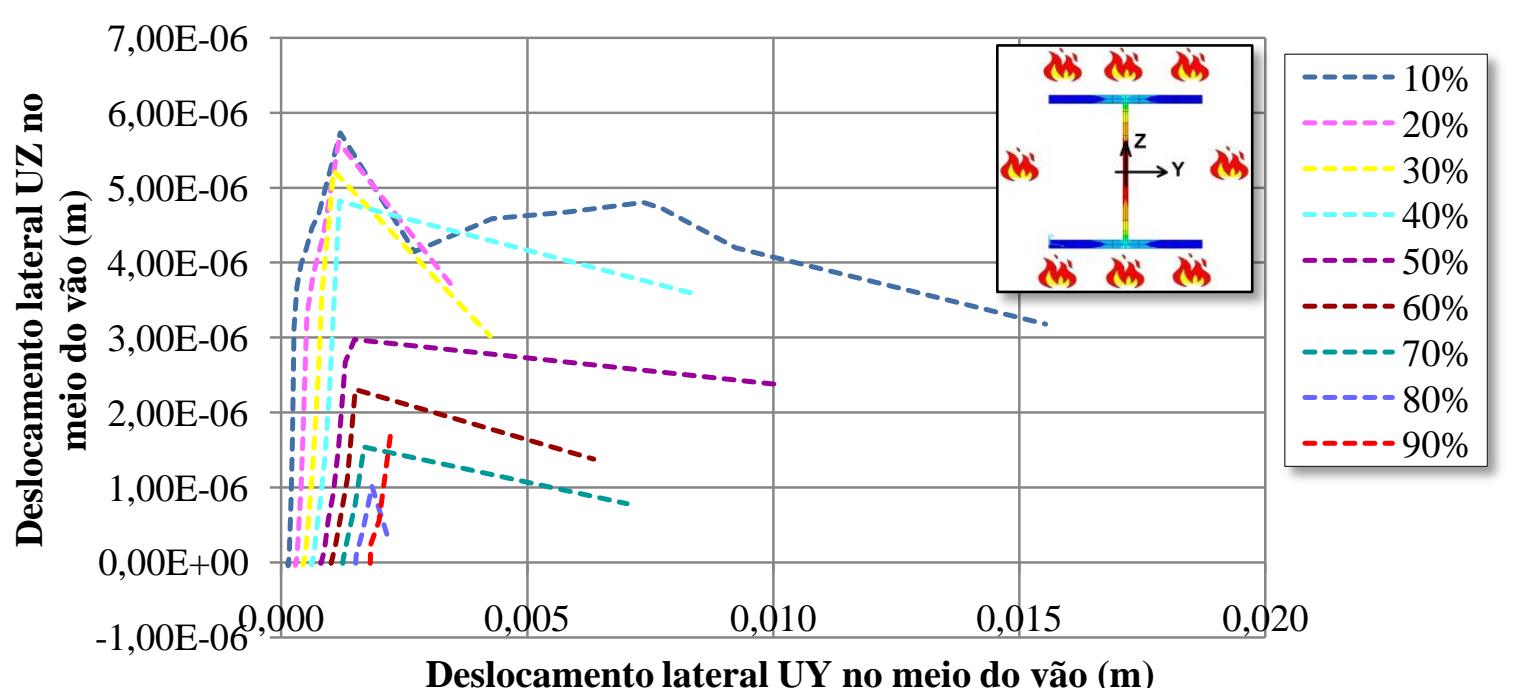

Figura 6.36 - Deslocamento lateral no meio do vão nas direções Y e Z do plano da seção.

\subsubsection{Pilar isolado "com" restrição axial}

A Figura 6.37 apresenta o resultado da evolução da carga inicial aplicada somada àquela introduzida pela restrição axial devido ao impedimento da expansão térmica. Para desempenhar essa função de restrição axial foi introduzido um elemento de barra (LINK10). Os graus de restrição são impostos pelo parâmetro $\mathrm{k}_{\mathrm{r}}$ (constante elástica do elemento de restrição) variam de 0 a infinito, incluindo outros quatro valores intermediários $(0,03 ; 0,06$; 0,10; e 0,20). Quanto maior for o grau de restrição, maior será o valor máximo de força reativa atingindo, na maioria das vezes, um valor próximo ao do colapso em temperatura ambiente encontrado numericamente $(1223 \mathrm{kN})$. 
Poderá ser também observado que, para graus de restrição elevados ocorre um trecho descendente suave da curva, sem ser interrompida. A interrupção da curva antes de a mesma retornar ao valor da força inicial ocorre quando há perda de convergência numérica. Pela Figura 6.37, observa-se que tal aspecto ocorre para os menores graus de restrição, da mesma forma que para os modelos sem restrição.

Na Figura 6.38, os deslocamentos axiais no topo são apresentados para cada um dos graus de restrição $\left(\mathrm{k}_{\mathrm{r}}\right)$ e carga estática inicial de $25 \%(305,75 \mathrm{kN})$ da carga de colapso, observando que a restrição dita infinita, igual a 50 vezes a constante elástica do pilar, não demonstra deslocamento no topo além daquele que ocorre em resposta à compressão devido ao carregamento inicial.

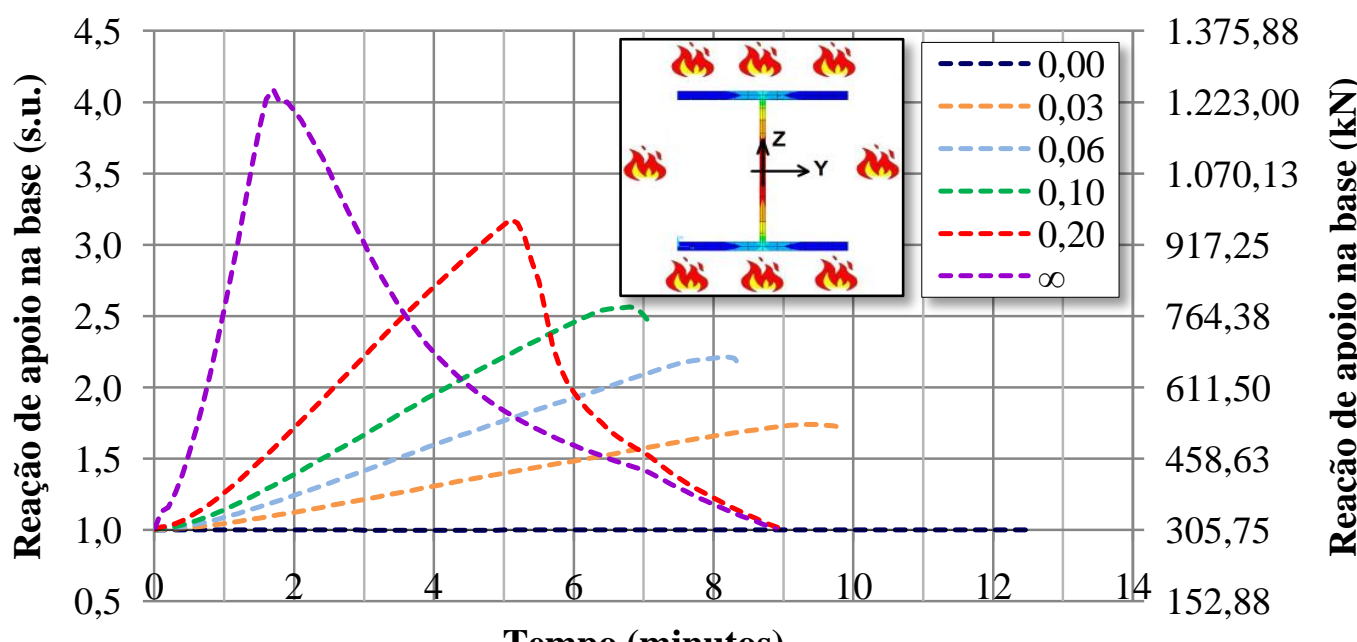

Tempo (minutos)

Figura 6.37 - Carregamento total aplicado para diversos níveis de restrição axial e carga estática inicial de $25 \%$ da carga de colapso à temperatura ambiente.

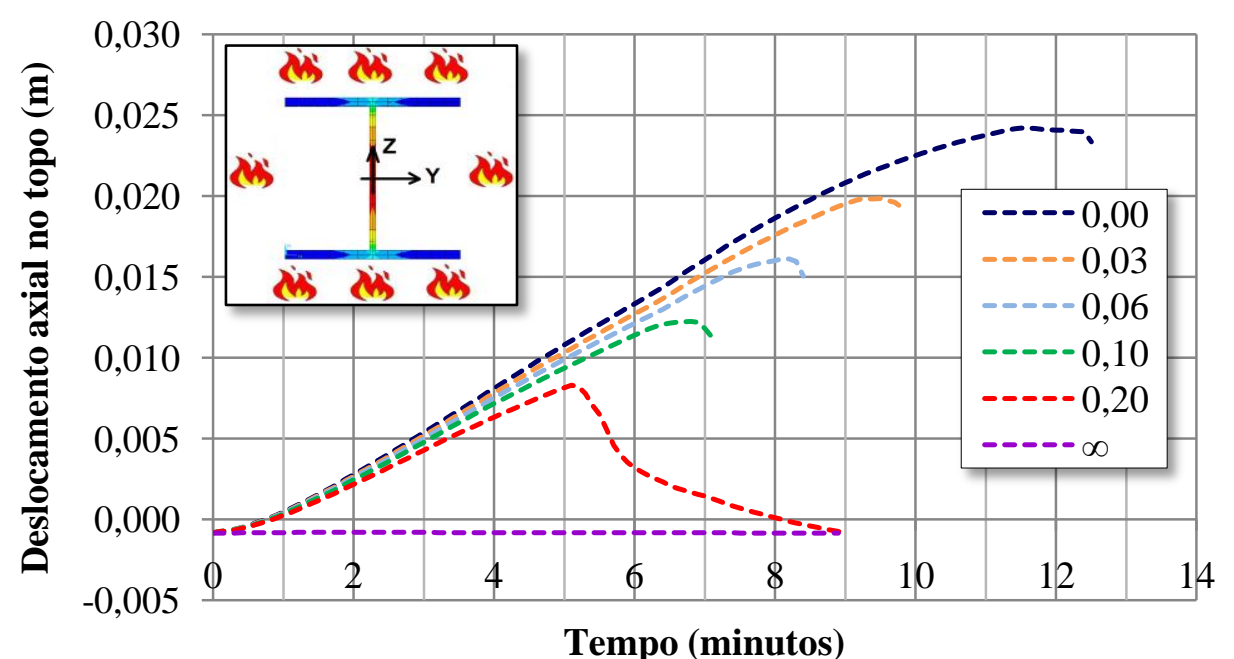

Figura 6.38 - Deslocamento axial no topo do pilar para diversos níveis de restrição axial e carga estática inicial de $25 \%$ da carga de colapso a temperatura ambiente. 
O gráfico do deslocamento axial, para a restrição axial igual a 0,20 apresenta uma curva suavemente ascendente e ligeiramente descendente, enquanto as outras restrições apresentam apenas o trecho ascendente e patamar curto. Acredita-se que tal fato, descrito anteriormente, para grau mais elevado da restrição promova grande deformação na configuração da barra desde o início da evolução da temperatura. Caso contrário, tal mudança de configuração se torna brusca, com ponto limite de estabilidade (snap through buckling), levando o processamento à perda de convergência numérica.

A Figura 6.39 mostra de forma clara como o deslocamento lateral no meio do vão pode ser muito pequeno, devido à uniformidade do aquecimento, e apresentar um grande desvio próximo ao instante da perda de estabilidade do elemento estrutural, ficando mais evidenciado para restrições elevadas.

Assim como visto nos modelos sem restrição axial, novamente é observado que há deslocamento lateral no meio do vão na direção perpendicular à imperfeição geométrica global inicial, como mostra a Figura 6.40. Para restrições iguais a 0,20 e infinita, houve deslocamentos da ordem de grandeza dez vezes superior ao das demais restrições e no sentido contrário. Para se ter uma melhor ideia da trajetória descrita pelo nó central da alma no meio do vão a Figura 6.41 apresenta os deslocamentos $\mathrm{Y}$ e Z em um mesmo gráfico. É importante observar que a escala do eixo dos deslocamentos em $\mathrm{Z}$ resulta cerca de $10^{4}$ vezes menor que os deslocamentos em Y, na direção da imperfeição inicial.

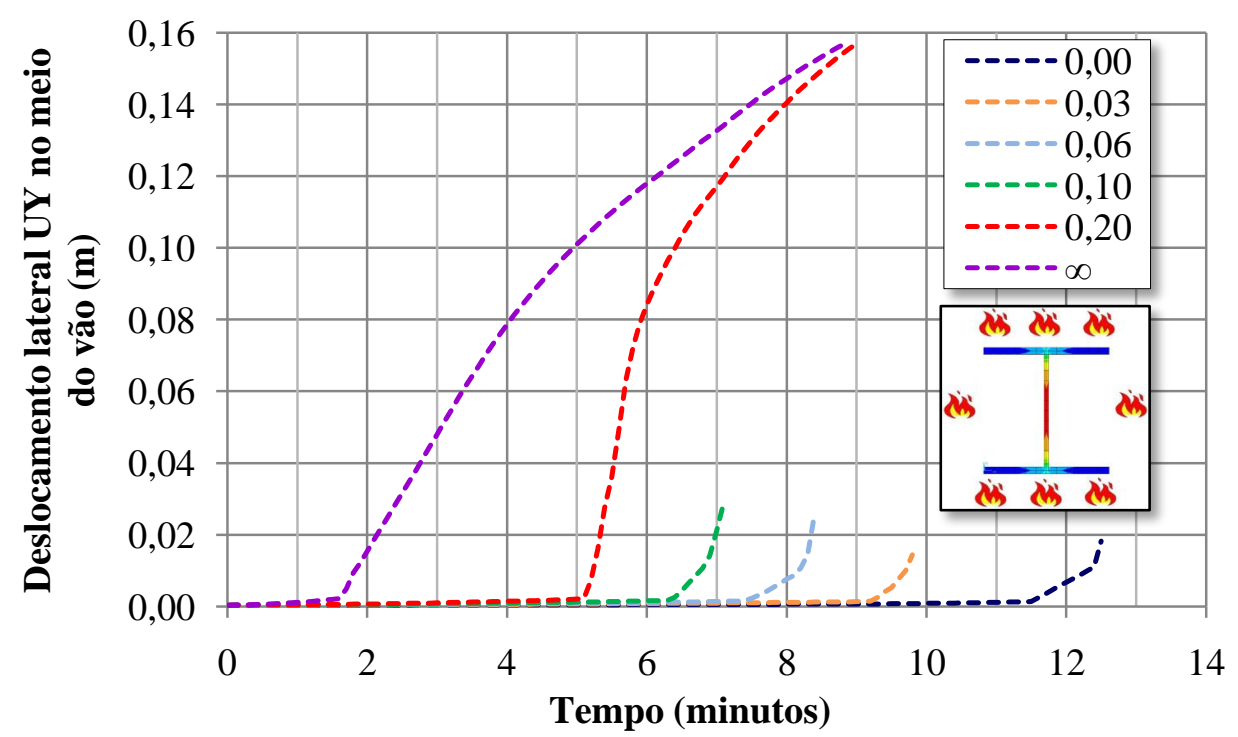

Figura 6.39 - Deslocamento lateral no meio do vão na direção da imperfeição inicial para diversos níveis de restrição axial e carga estática inicial de $25 \%$ da carga de colapso à temperatura ambiente. 


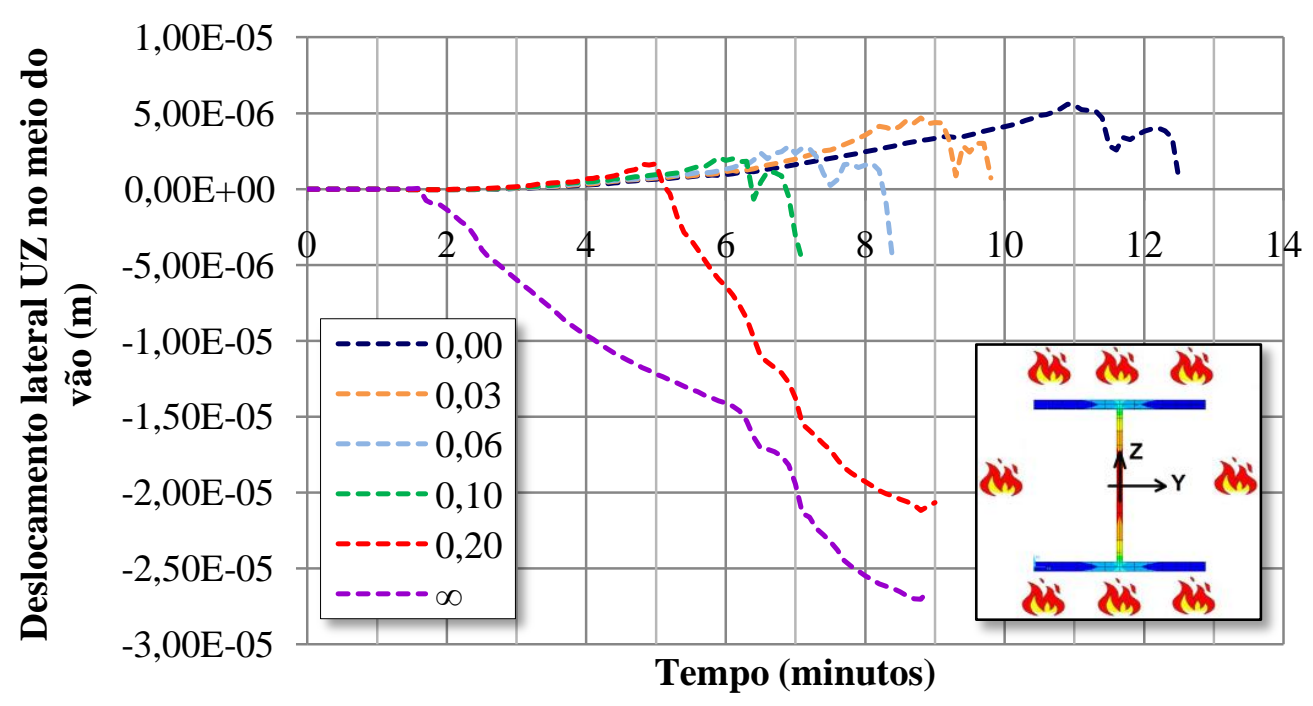

Figura 6.40 - Deslocamento lateral no meio do vão na direção perpendicular à imperfeição inicial com $25 \%$ de carga inicial.

Tais deslocamentos na direção perpendicular à imperfeição inicial, em parte, são explicados pela ocorrência de rotações do eixo longitudinal, cujos valores são apresentados na Figura 6.42. A rotação longitudinal do modelo com restrição axial, assim como o deslocamento perpendicular à imperfeição, resulta maior do que sem a restrição axial, e ocorre antecipadamente, ou seja, para níveis reduzidos de temperatura.

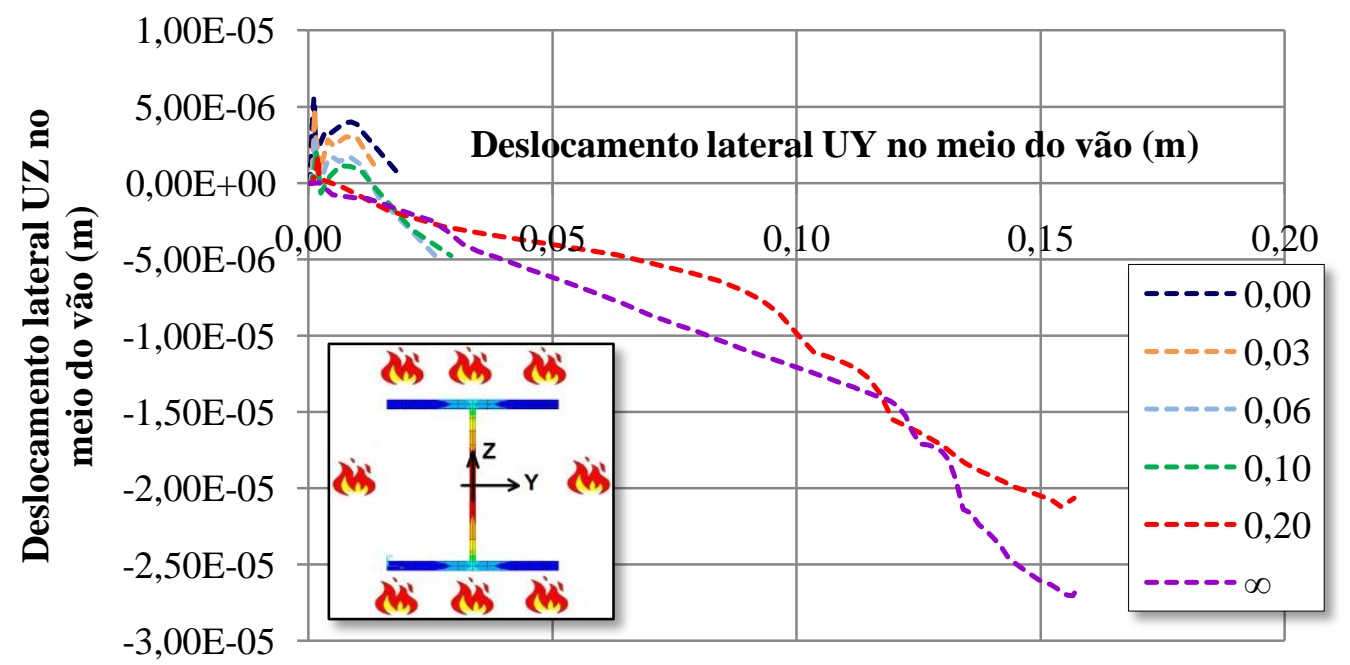

Figura 6.41 - Deslocamento lateral no meio do vão nas direções Y e Z do plano da seção com $25 \%$ carga inicial. 


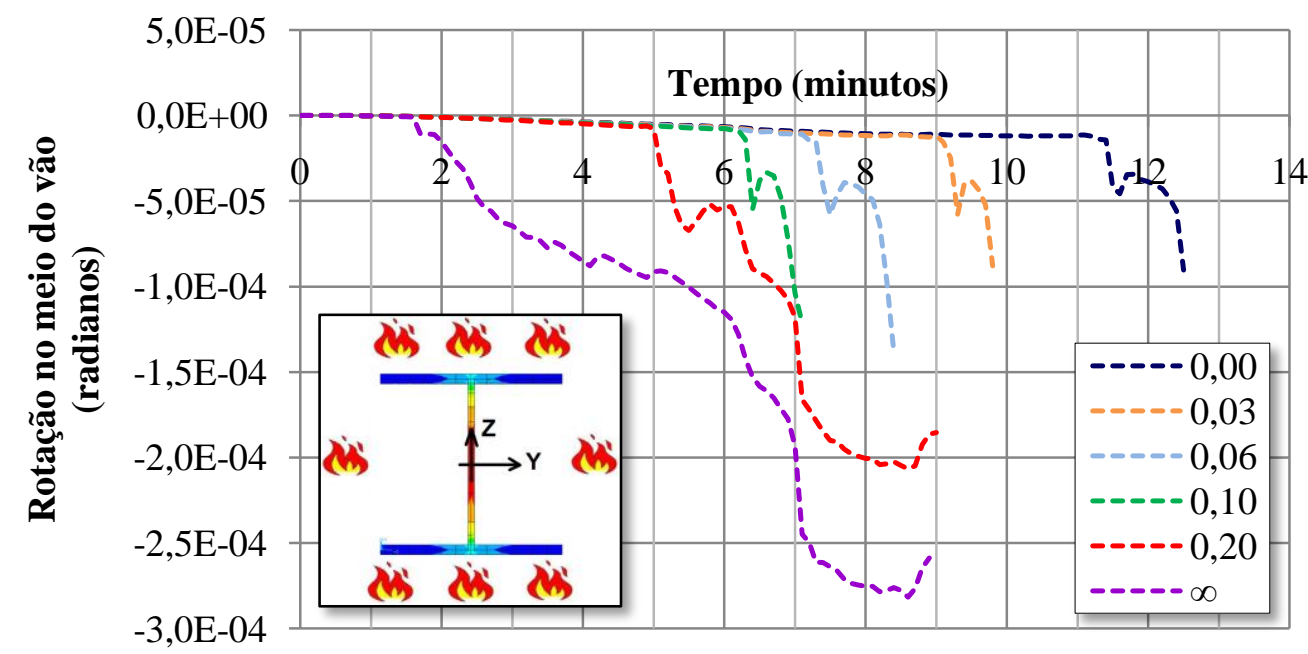

Figura 6.42 - Rotação do eixo longitudinal no meio do vão com $25 \%$ de carga inicial.

Nas seções anteriores foi apresentado o método simplificado proposto em Franssen (2000). Com o intuito de validar (ou não) sua aplicabilidade, foram feitas comparações sob as condições previstas aos resultados das análises contempladas no presente trabalho.

A Figura 6.43 apresenta a evolução da força axial promovida unicamente pelo elemento de restrição axial, sem aplicação de carga inicial alguma. Com essa curva construída, o método indica que seja traçada uma reta horizontal a partir da carga inicial que se deseja e, então, obter o tempo crítico no ponto onde as linhas se cruzarem.

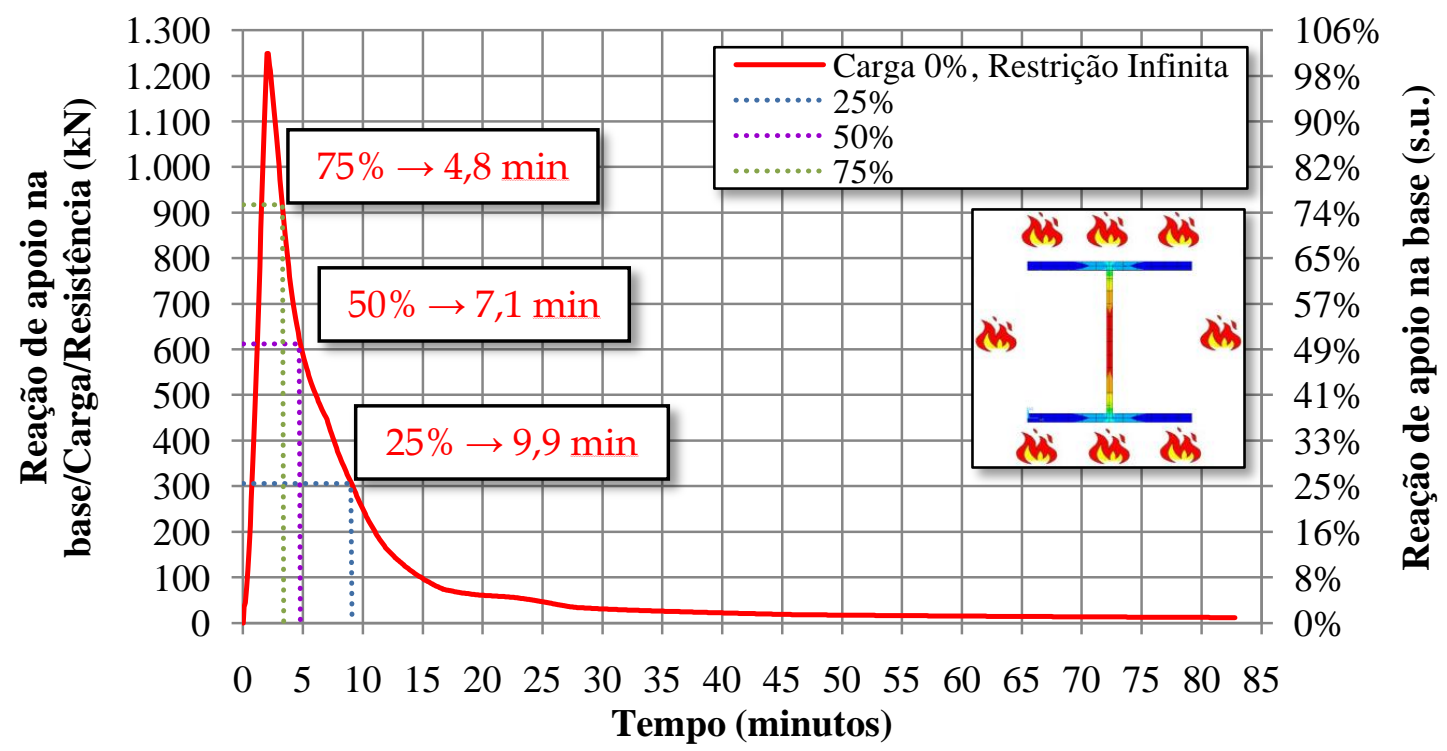

Figura 6.43 - Reação de apoio do modelo com restrição axial infinita sem carga inicial aplicada.

A Tabela 6.6 apresenta os resultados de todas as análises complexas executadas com o modelo de pilar sem paredes e os compara aos valores obtidos pela análise simplificada. 
Observa-se que apesar de a análise ser bem mais simples, os resultados são bastante aproximados e, considerando $\mathrm{k}_{\mathrm{r}}$ igual a 0,03, sempre a favor da segurança. A principal diferença consiste no fato de que seria necessário apenas uma análise numérica para conhecer o tempo crítico para qualquer intensidade de força, enquanto que, para a análise complexa se faz necessário introduzir a carga inicial desejada e proceder uma análise para cada grau de restrição axial, nesse caso 6 análises apenas para a carga de $25 \%$.

Os gráficos de evolução da força axial e deslocamentos considerando as cargas iniciais de 50 e $75 \%$ podem ser vistas no APÊNDICE A e APÊNDICE B.

Tabela 6.6 - Resultados de tempo crítico e temperaturas críticas das análises numéricas do modelo de pilar isolado.

\begin{tabular}{|c|c|c|c|c|c|c|c|c|c|c|}
\hline \multirow{2}{*}{ Rigidez $\mathrm{k}_{\mathrm{r}}$} & \multirow{2}{*}{$\begin{array}{c}\mathrm{R} \\
(\mathrm{kN} / \mathrm{mm})\end{array}$} & \multicolumn{3}{|c|}{$\begin{array}{l}\text { Força axial inicial } \\
25 \%\end{array}$} & \multicolumn{3}{|c|}{$\begin{array}{l}\text { Força axial inicial } \\
50 \%\end{array}$} & \multicolumn{3}{|c|}{$\begin{array}{l}\text { Força axial inicial } \\
75 \%\end{array}$} \\
\hline & & $\mathrm{F}_{\max (\mathrm{kN})}$ & $\begin{array}{c}\theta_{\mathrm{s}, \text { máx - crit. }} \\
\left({ }^{\circ} \mathrm{C}\right) \\
\end{array}$ & $\mathrm{t}_{\text {crit (min.) }}$ & $\mathrm{F}_{\max (\mathrm{kN})}$ & $\theta_{\mathrm{s}, \operatorname{máx} \text { - crit. }}$ & $\mathrm{t}_{\text {crit (min.) }}$ & $\mathrm{F}_{\max (\mathrm{kN})}$ & $\theta_{\mathrm{s}, \operatorname{máx}}{ }_{\left({ }^{\circ} \mathrm{C}\right)}$ crit. & $\mathrm{t}_{\text {crit (min.) }}$ \\
\hline 0,00 & 0,000 & 305,75 & 627,27 & 12,6 & 611,50 & 548,82 & 10,0 & 917,25 & 330,44 & 5,6 \\
\hline 0,03 & 10,947 & 531,88 & 544,87 & 9,9 & 768,91 & 417,56 & 7,1 & 1021,04 & 280,48 & 4,8 \\
\hline 0,06 & 21,895 & 676,57 & 486,67 & 8,5 & 870,51 & 360,89 & 6,1 & 1099,08 & 254,70 & 4,4 \\
\hline 0,10 & 36,491 & 783,64 & 422,72 & 7,2 & 973,16 & 311,91 & 5,3 & 1169,48 & 222,46 & 3,9 \\
\hline 0,20 & 72,982 & 971,53 & 513,31 & 9,1 & 1123,30 & 241,26 & 4,2 & 1235,98 & 158,13 & 2,9 \\
\hline 50,00 & $\infty$ & 1250,14 & 509,37 & 9,0 & 1247,59 & 248,26 & 4,3 & 1249,46 & 133,54 & 2,5 \\
\hline $\begin{array}{c}\text { Método } \\
\text { simplificado } \\
\text { proposto por } \\
\text { Franssen (2000) }\end{array}$ & $\infty$ & - & 511,34 & 9,05 & - & 280,48 & 4,8 & - & 183,67 & 3,3 \\
\hline
\end{tabular}

\subsubsection{Pilar com paredes em contato com as mesas "sem" restrição axial}

O modelo aqui apresentado possui paredes em contato com as mesas e considera emissividade de radiação do incêndio igual a 0,7, conforme Eurocode 3 parte 1-2. Também foi considerado, diferentemente dos exemplos anteriores para fins de validação, perda de calor na face não exposta às chamas, fato que certamente reduz a temperatura média do perfil em relação ao modelo adiabático e também ao perfil isolado. A Figura 6.44 mostra os resultados do deslocamento axial no topo do pilar do modelo com paredes em contato com as mesas. 


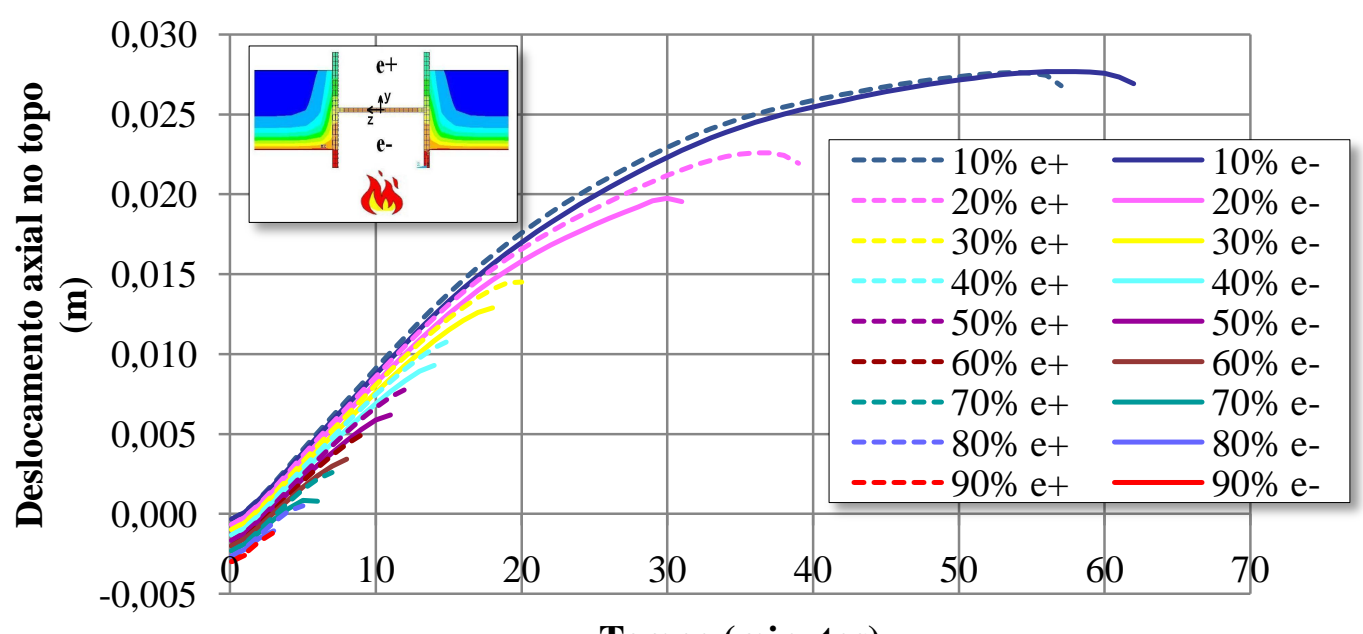

Tempo (minutos)

Figura 6.44 - Deslocamento axial no topo do pilar com paredes nas mesas para diversos níveis de carregamento sem restrição axial.

Ao analisar a Figura 6.44 é possível observar que para os mesmos níveis de carregamento e tempo de exposição que o pilar isolado (Figura 6.32), os deslocamentos axiais do modelo com paredes em contato com as mesas resultam cerca da metade dos deslocamentos axiais do modelo sem paredes. O tempo crítico, instante em que se identifica a perda de estabilidade do pilar, também é sempre maior se comparado ao pilar isolado para uma mesma carga axial inicial. Isso se deve ao fato de a compartimentação das chamas promovida pelas paredes, bem como a perda de calor na face não exposta resultar em temperaturas médias do aço inferiores àquelas para o pilar isolado, fazendo com que o mesmo resista por mais tempo.

A Figura 6.45 traz resultados dos deslocamentos laterais no meio do vão para o modelo em análise, os quais são consideravelmente maiores se comparados aos deslocamentos do perfil isolado da Figura 6.33. Isso se deve ao fato que no modelo de perfil com paredes ocorre um aquecimento não uniforme da seção (apresenta um gradiente térmico) com um lado mais aquecido que o outro. Isso pode ser visto claramente no gráfico da Figura 5.41 do capítulo anterior que apresenta as temperaturas médias da seção em cada trecho desse modelo. Esse aquecimento não uniforme provoca dilatação térmica diferencial da seção transversal, mais expressiva nas abas que primeiro se aquecem. 


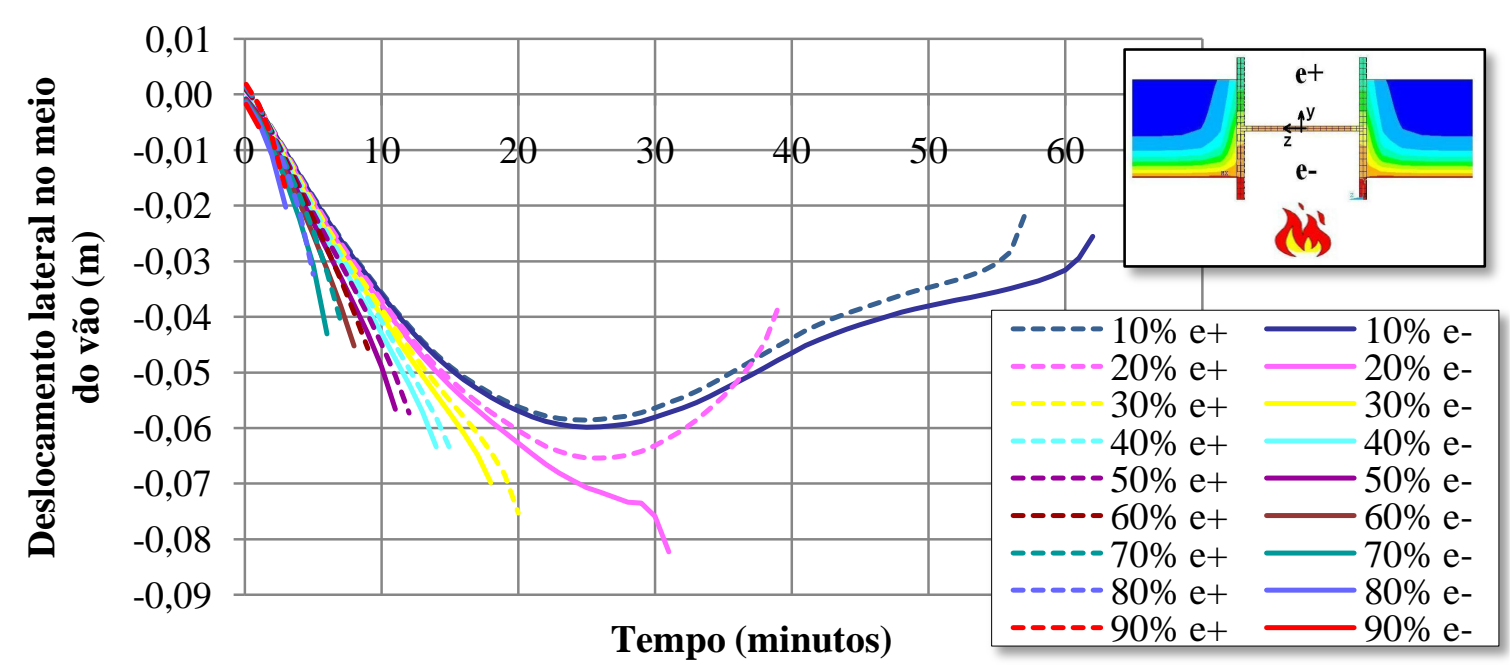

Figura 6.45 - Deslocamento lateral no meio do vão na direção da imperfeição inicial do modelo com parede nas mesas sem restrição axial.

Tal fato pode ser interpretado mais facilmente ao se considerar a fonte de calor “atraindo" a barra. No entanto, o aquecimento maior em partes específicas da seção também provoca a redução do módulo de elasticidade primeiramente nesses pontos, fato que, provavelmente explica o retorno dos deslocamentos laterais a partir de aproximadamente 15 minutos, em que as partes mais quentes da seção estão a $500^{\circ} \mathrm{C}$. A partir dessa temperatura o módulo de elasticidade já está bastante penalizado e continua reduzindo.

Assim como o modelo anterior, a Figura 6.46 mostra os deslocamentos da seção no meio do vão na direção perpendicular à imperfeição inicial. Devido à direção de incidência da ação térmica, esses deslocamentos são muito pequenos, da ordem de $10^{-5} \mathrm{~m}$. Analogamente ao pilar isolado, esse deslocamento na direção perpendicular à fonte de aquecimento (UZ) pode ser explicada pela rotação longitudinal do elemento estrutural. Os resultados do grau de liberdade ROTX do nó central da alma na seção no meio do vão são apresentados na Figura 6.47. Esses valores, em radianos, são muito pequenos e ao serem convertidos para graus resultam em menos de um décimo de grau. 


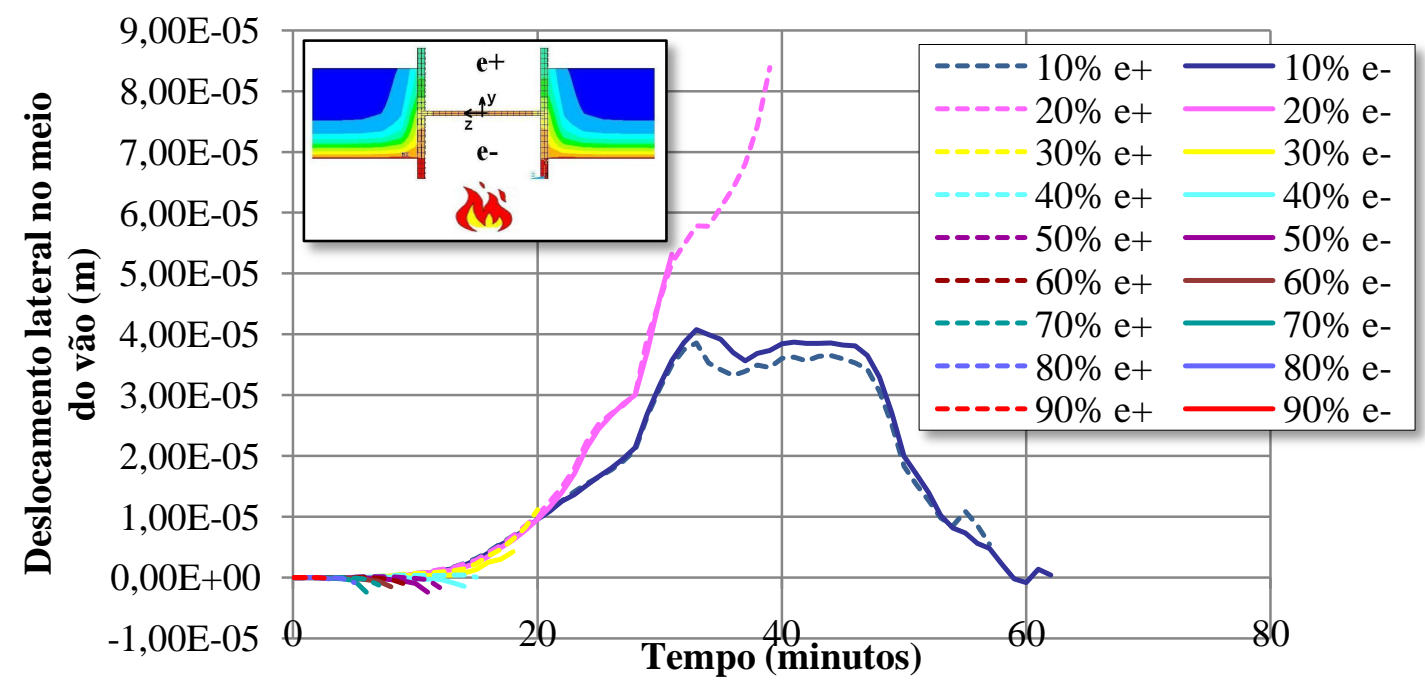

Figura 6.46 - Deslocamento lateral no meio do vão na direção perpendicular à imperfeição inicial.

Da mesma forma, o deslocamento imposto pela rotação também resulta muito pequeno. A Figura 6.48 confronta os resultados dos deslocamentos nos eixos Y e Z, de forma a visualizar o movimento da seção e a diferença na ordem de grandeza de cerca de 1000 vezes.

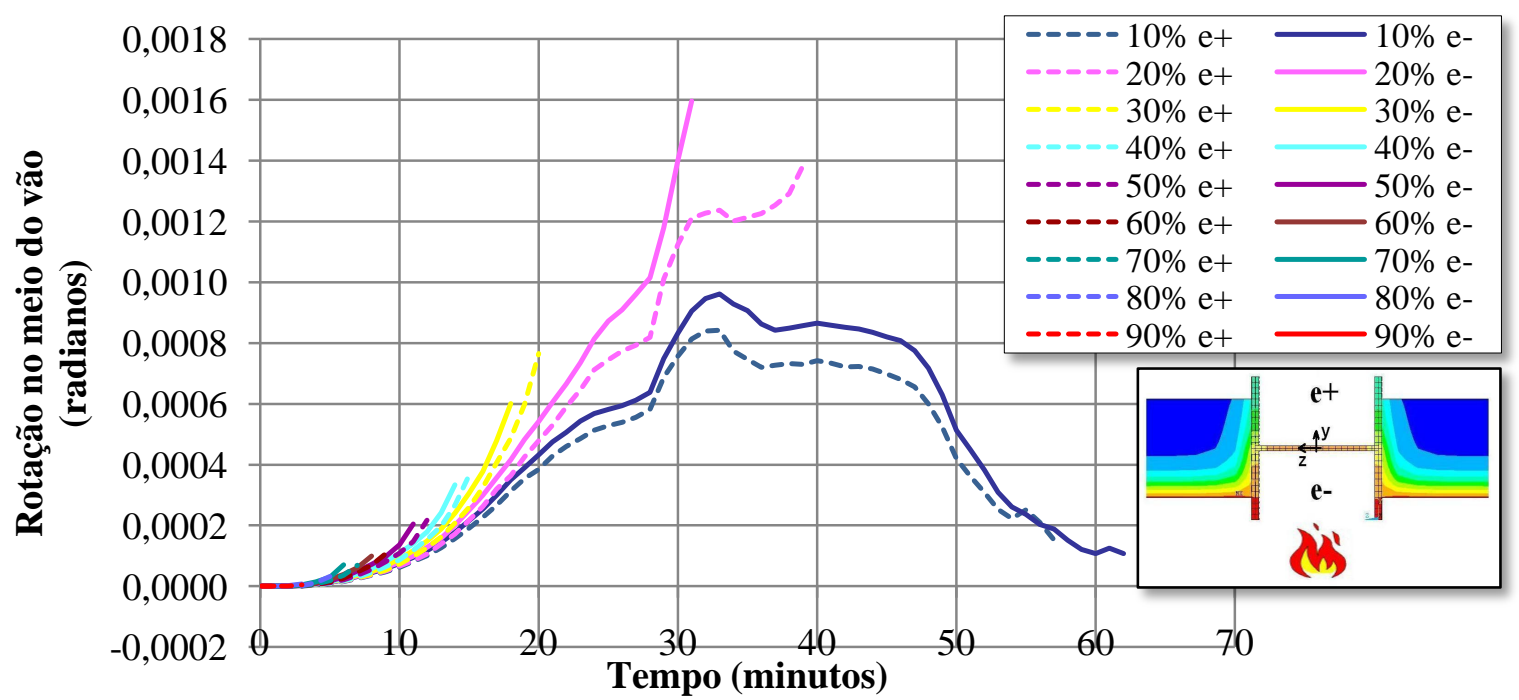

Figura 6.47 - Rotação do eixo longitudinal no meio do vão.

Para que fossem demonstrados esses gráficos do modelo de pilar com paredes nas mesas e sem restrição axial foram necessárias 18 análises de cerca de 8 horas de duração, em média, cada uma. Foram 9 níveis de carregamento considerados e 2 sentidos de imperfeição geométrica global inicial. 


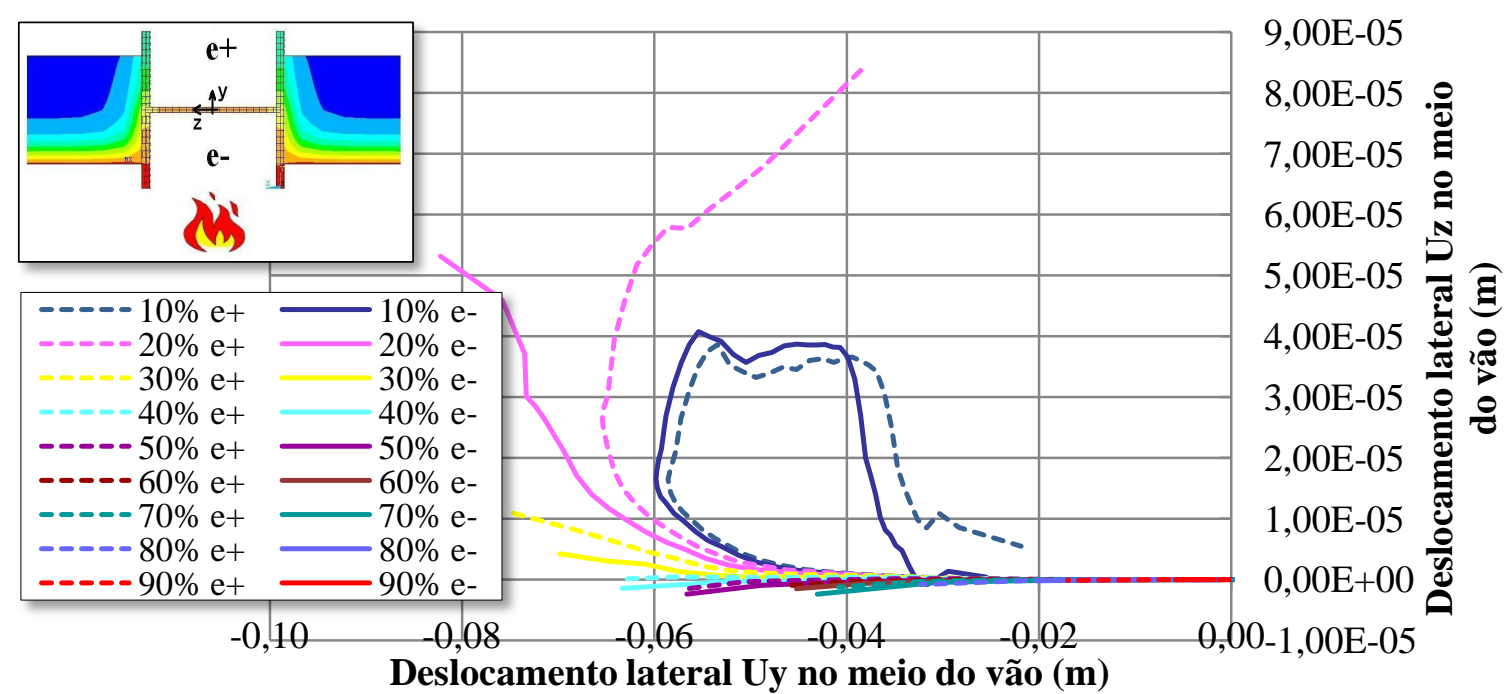

Figura 6.48 - Deslocamento lateral no meio do vão nas direções Y e Z do plano da seção.

\subsubsection{Pilar com paredes em contato com as mesas "com" restrição axial}

Quando introduzido o elemento para fins de restrição axial (LINK10) no modelo com paredes em contato com as mesas, a força aplicada no pilar evolui conforme mostrado na Figura 6.49. Os graus de restrição foram os mesmos do pilar isolado e podem ser vistos na Tabela 6.2 exibida anteriormente. Esse modelo considera emissividade de radiação igual a $\mathbf{0 , 7}$ e perda de calor na face não exposta às chamas.

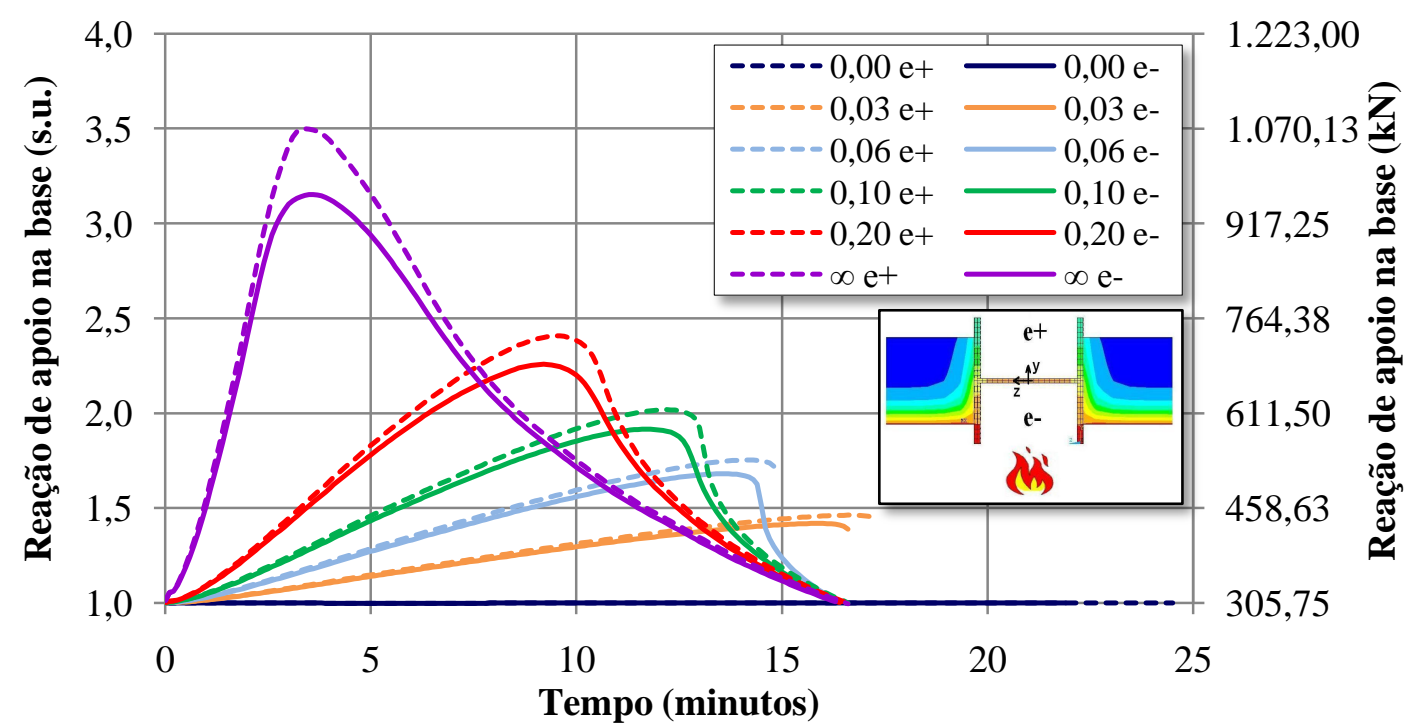

Figura 6.49 - Carregamento total aplicado para diversos níveis de restrição axial e carga estática inicial de $25 \%$ da carga de colapso em temperatura ambiente.

O modelo com paredes nas mesas, diferentemente do modelo sem paredes, foi processado considerando a imperfeição global positiva e negativa. A imperfeição geométrica 
global inicial é uma curvatura inicial dada ao pilar no sentido da fonte de calor (negativa) ou no sentido contrário (positiva), conforme anteriormente visto na Figura 6.6b. É importante observar que, para a maioria dos graus de restrição, o tempo crítico de exposição ao incêndiopadrão ISO 834-1:1999 foi sempre muito próximo. Tal fato, aparentemente, sugere que o valor da restrição axial não precisa ser conhecido a priori. Essa possibilidade será investigada posteriormente. Observa-se, pela intensidade da força reativa causada pela restrição axial que para a imperfeição geométrica global inicial positiva seu valor é sempre maior do que a negativa para um mesmo grau de restrição. Isso porque, como as chamas "atraem" a barra e a imperfeição positiva está direcionada para o lado contrário delas, haverá um instante em que a barra passará por uma configuração próxima ao formato retilíneo.

O aquecimento do aço causa a expansão térmica. Com a presença da restrição axial, essa expansão divide-se em deslocamento e deformação do aço. A deformação está diretamente ligada à força adicional, enquanto que a parcela restante é o deslocamento axial no topo da barra, que pode ser visto na Figura 6.50. O grau de restrição 0,06 mostra um comportamento importante do modelo numérico, em que para a imperfeição geométrica inicial global negativa houve uma descida suave da curva até tempo crítico final, instante em que se retorna ao valor da força axial inicial.

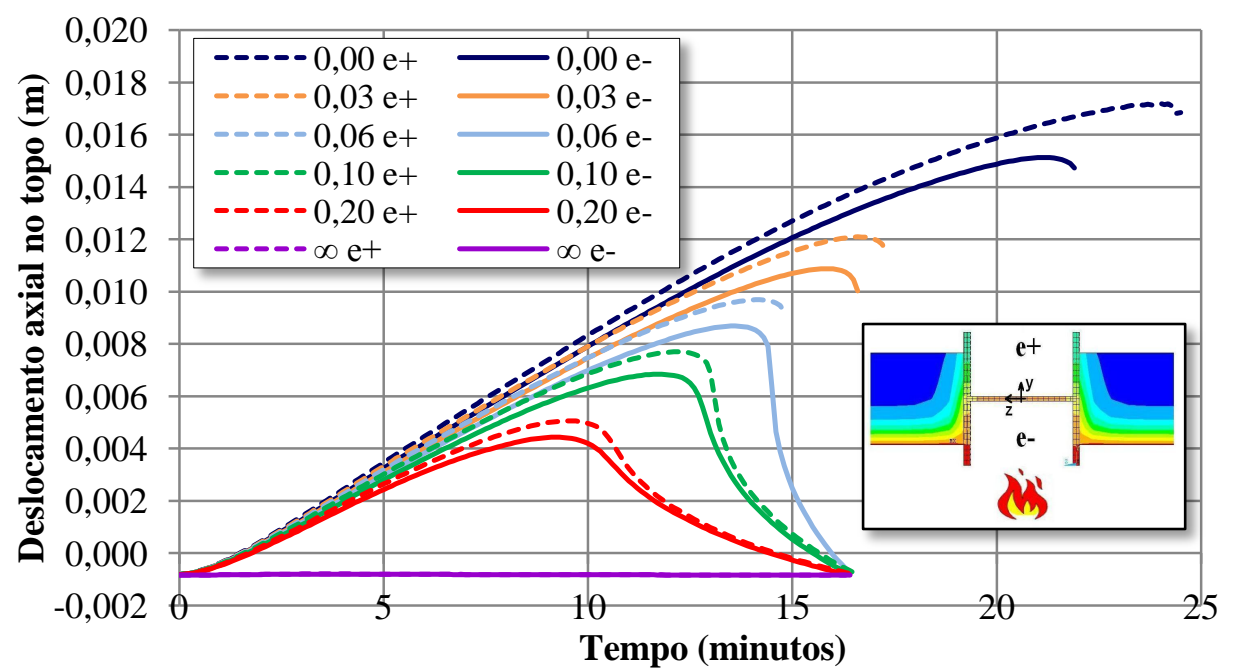

Figura 6.50 - Deslocamento axial no topo do pilar para diversos níveis de restrição axial e carga estática inicial de $25 \%$ da carga de colapso em temperatura ambiente.

Se forem observadas todas as curvas de uma forma geral, é possível notar que o trecho descendente apresenta inclinação cada vez mais acentuada, tendo o grau de restrição 0,06 como limite entre o processamento completo (e-) e a perda de convergência de forma precoce $(\mathrm{e}+)$. 
Na Figura 6.51 são apresentadas as curvas dos deslocamentos laterais na direção da imperfeição geométrica global inicial do modelo com paredes nas mesas e com restrição axial para a força axial inicial de $25 \%$ da carga de colapso em temperatura ambiente. Novamente, é possível observar que, para graus de restrição elevados, ocorrem grandes deslocamentos quando o modelo está entre 10 e 15 minutos de exposição ao incêndio.

Observa-se ainda que o ponto de convergência final desses deslocamentos é sempre muito próximo, como também ocorre para os deslocamentos axiais, laterais perpendiculares à imperfeição e rotação longitudinal. Isso mostra que a configuração final da barra é sempre semelhante para a maioria dos graus de restrição axial, enquanto que para a imperfeição positiva o modelo perde a convergência numérica antes de apresentar o trecho descendente.

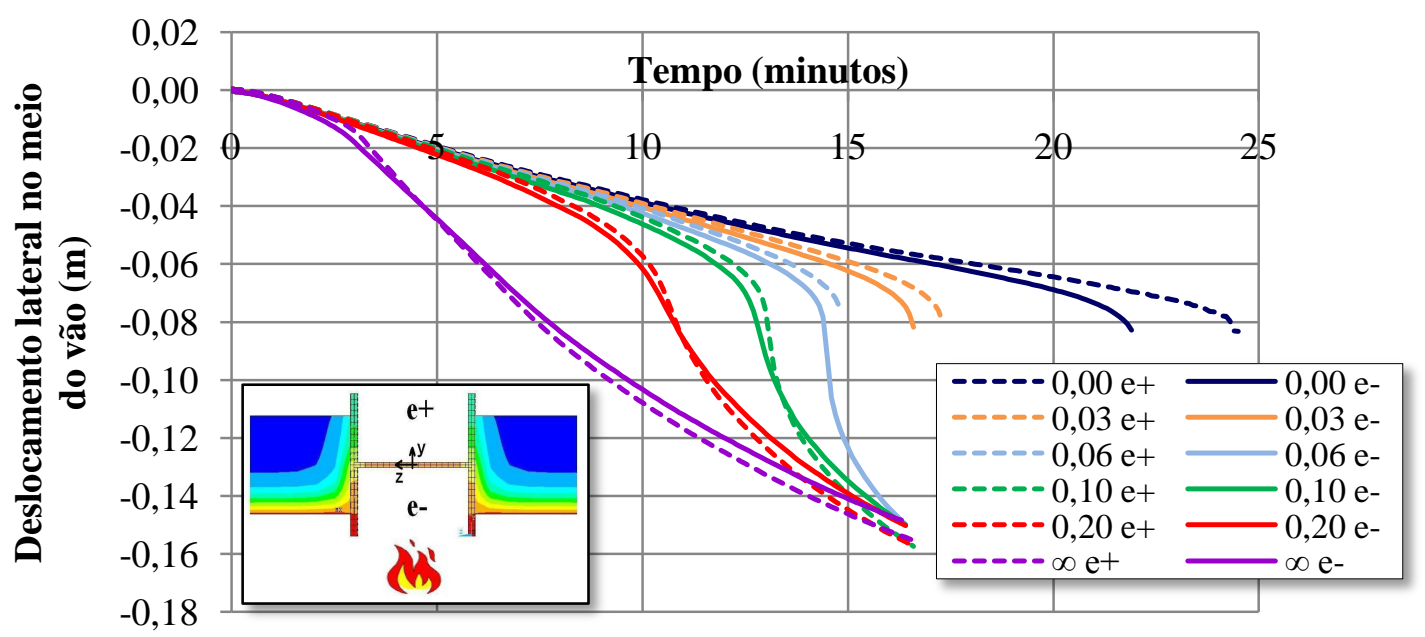

Figura 6.51 - Deslocamento lateral no meio do vão na direção da imperfeição inicial para diversos níveis de restrição axial e carga estática inicial de $25 \%$ da carga de colapso em temperatura ambiente.

Assim como visto anteriormente, a Figura 6.52 apresenta os valores dos deslocamentos na direção perpendicular à imperfeição inicial. Tal como visto nos gráficos anteriores, percebe-se que os valores apresentados são muito inferiores aos deslocamentos na direção da imperfeição inicial. Nesse modelo, devido à orientação das paredes e da fonte de calor, já é esperado que os deslocamentos na direção $\mathrm{Y}$ sejam muito maiores àqueles ocorridos na direção Z. O modelo apresenta rotação em torno do eixo X (torção da barra) assim como visto no modelo sem paredes. Ainda que muito pequenos, pode-se observar que os valores são da mesma ordem de grandeza para ambos os modelos. 


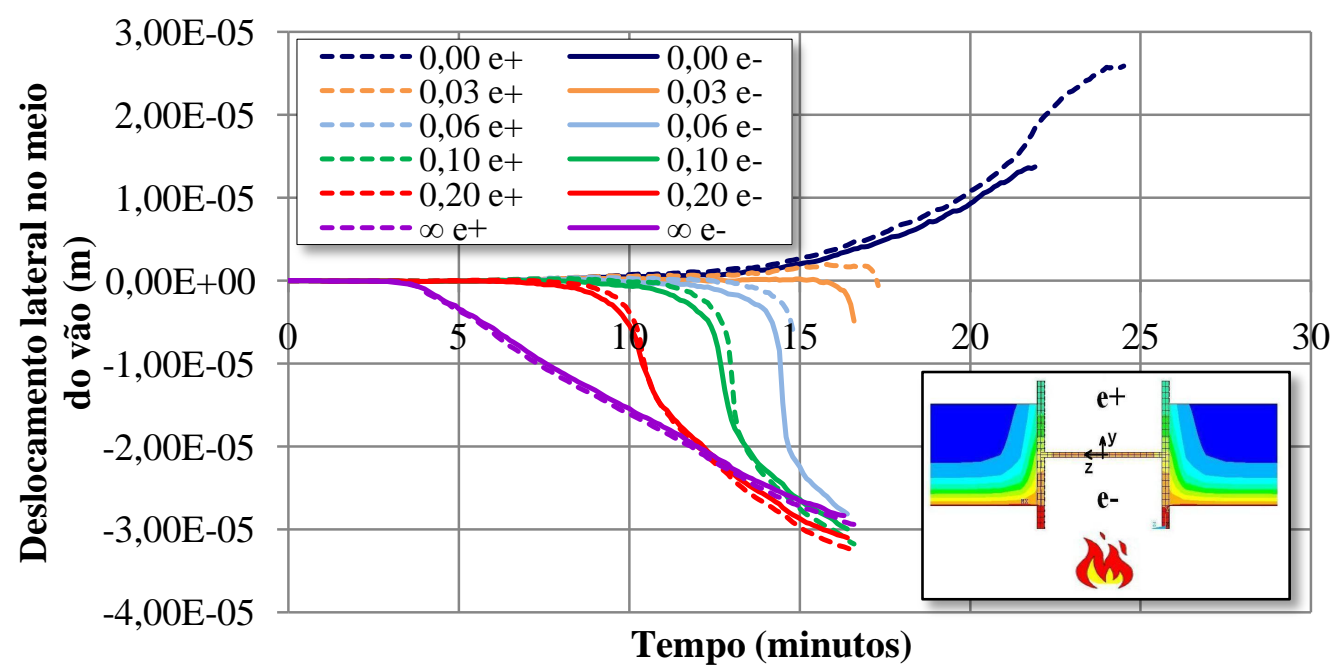

Figura 6.52 - Deslocamento lateral no meio do vão na direção perpendicular à imperfeição inicial para diversos níveis de restrição axial e carga estática inicial de $25 \%$ da carga de colapso em temperatura ambiente.

A Figura 6.53 mostra as curvas descritas de rotação em torno do eixo X para cada caso de restrição axial considerado. Enquanto isso, a Figura 6.54 confronta os valores dos deslocamentos nas direções $\mathrm{Y}$ e $\mathrm{Z}$ do plano da seção, de modo a observar o trajeto por ela descrito com a evolução da temperatura, bem como a diferença de grandeza entre os dois valores.

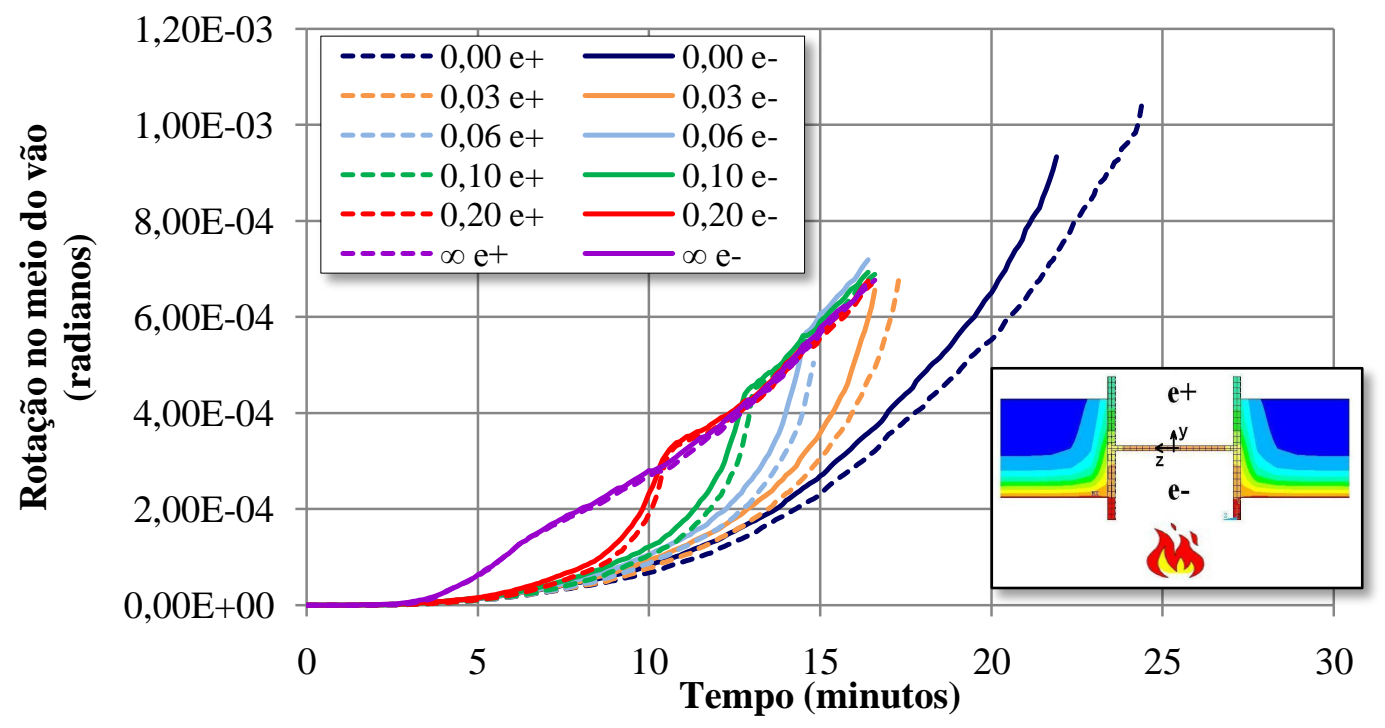

Figura 6.53 - Rotação do eixo longitudinal no meio do vão para diversos níveis de restrição axial e carga estática inicial de $25 \%$ da carga de colapso em temperatura ambiente. 


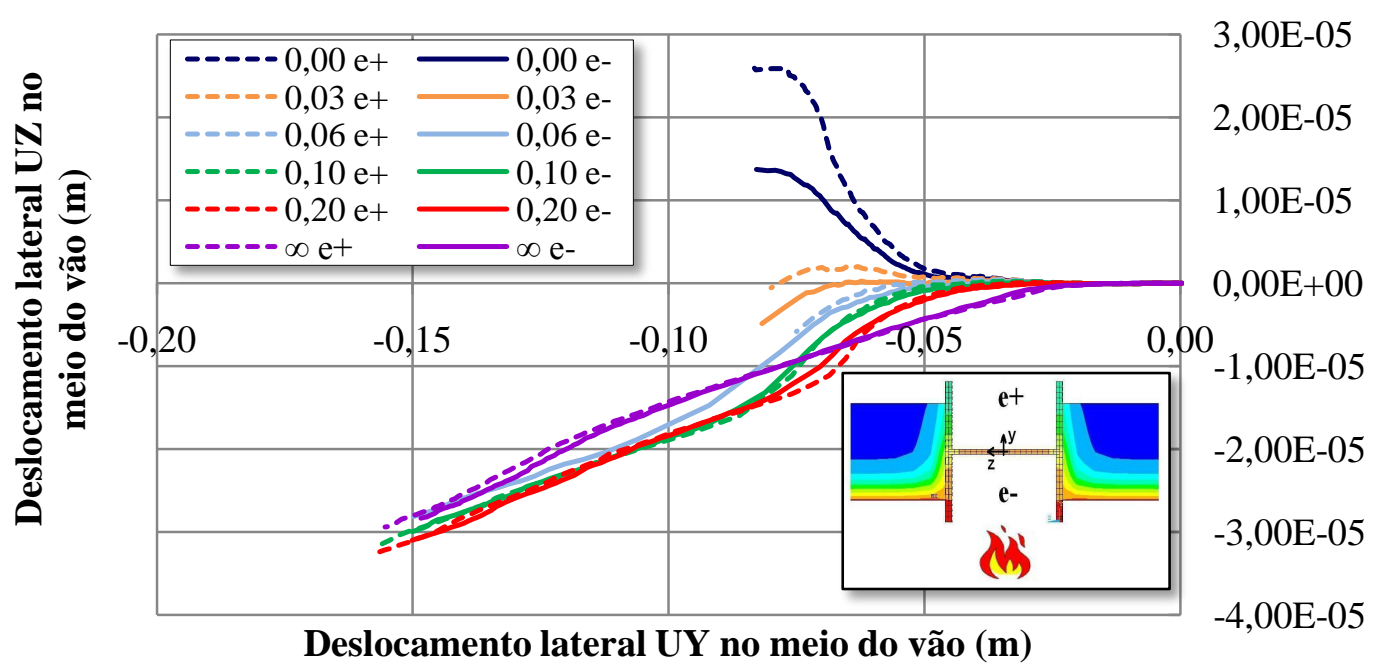

Figura 6.54 - Deslocamento nas direções Y e Z do plano da seção para diversos níveis de restrição axial e carga estática inicial de $25 \%$ da carga de colapso em temperatura ambiente.

O método de análise simplificada vista em Franssen (2000) e descrita anteriormente, propõe realizar apenas uma análise do modelo com restrição axial infinita e nenhuma força axial inicial. O método proposto diz que, ao traçarmos uma reta a partir da carga inicial, teremos uma previsão do tempo crítico sem a necessidade de conhecer o valor exato da restrição axial e sem a necessidade de realizar uma série de análises complexas e dispendiosas. As previsões de resultados com a análise feita sob essas condições podem ser vistas na Figura 6.55 e comparadas com os valores obtidos pelas análises complexas na Tabela 6.7.

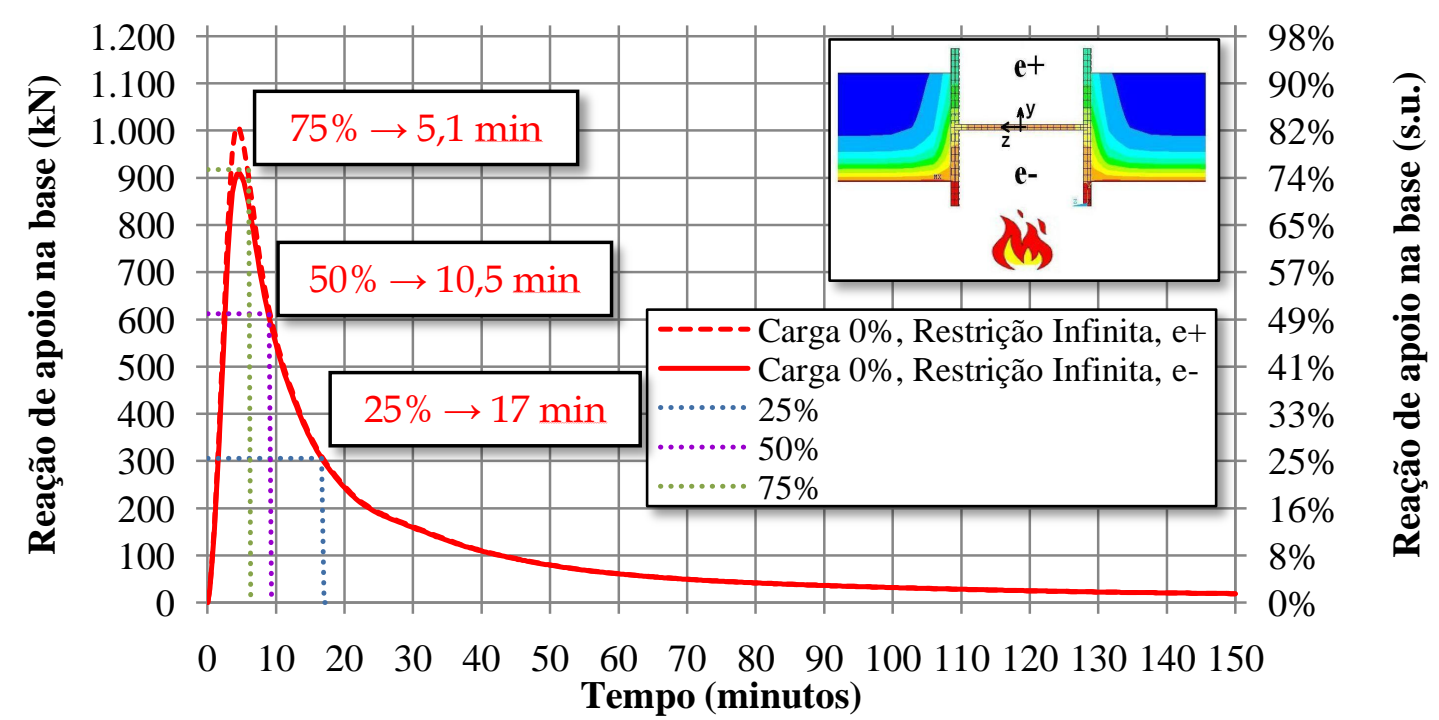

Figura 6.55 - Reação de apoio do modelo com restrição axial infinita sem carga inicial aplicada. 
Tabela 6.7 - Resultados de tempo e temperaturas críticas das análises numéricas do modelo com paredes nas mesas.

\begin{tabular}{|c|c|c|c|c|c|c|c|c|c|c|}
\hline \multirow{2}{*}{ Rigidez $\mathrm{k}_{\mathrm{r}}$} & \multirow{2}{*}{$\mathrm{R}(\mathrm{kN} / \mathrm{mm})$} & \multicolumn{3}{|c|}{$\begin{array}{c}\text { Força axial inicial } \\
25 \%\end{array}$} & \multicolumn{3}{|c|}{$\begin{array}{c}\text { Força axial inicial } \\
50 \%\end{array}$} & \multicolumn{3}{|c|}{$\begin{array}{c}\text { Força axial inicial } \\
75 \%\end{array}$} \\
\hline & & $\mathrm{F}_{\max (\mathrm{kN})}$ & $\begin{array}{c}\theta_{\mathrm{s}, \text { máx - crit. }} \\
\left({ }^{\circ} \mathrm{C}\right)\end{array}$ & $\mathrm{t}_{\text {crit (min.) }}$ & $\mathrm{F}_{\max (\mathrm{kN})}$ & $\theta_{\mathrm{s}, \text { máx - crit. }}$ & $\mathrm{t}_{\text {crit (min.) }}$ & $\mathrm{F}_{\max (\mathrm{kN})}$ & $\theta_{\mathrm{s}, \text { máx - crit. }}$ & $\mathrm{t}_{\text {crit (min.) }}$ \\
\hline \multirow{2}{*}{0,00} & $0,000 \mathrm{e}+$ & 305,75 & 665,64 & 24,6 & 611,50 & 412,77 & 12,0 & 917,25 & 215,75 & 6,3 \\
\hline & $0,000 \mathrm{e}-$ & 305,75 & 631,56 & 22,0 & 611,50 & 412,77 & 12,0 & 917,25 & 163,47 & 4,9 \\
\hline \multirow{2}{*}{0,03} & $10,947 \mathrm{e}+$ & 447,19 & 549,87 & 17,4 & 694,53 & 378,33 & 10,9 & 954,02 & 193,34 & 5,7 \\
\hline & $10,947 \mathrm{e}-$ & 433,88 & 534,89 & 16,7 & 680,24 & 348,73 & 10,0 & 939,48 & 148,73 & 4,5 \\
\hline \multirow{2}{*}{0,06} & $21,895 \mathrm{e}+$ & 536,11 & 492,79 & 14,9 & 751,51 & 341,85 & 9,8 & 981,98 & 178,38 & 5,3 \\
\hline & $21,895 \mathrm{e}-$ & 514,00 & 530,43 & 16,5 & 727,15 & 314,31 & 9,0 & 956,92 & 141,36 & 4,3 \\
\hline \multirow{2}{*}{0,10} & $36,491 \mathrm{e}+$ & 617,10 & 534,89 & 16,7 & 804,85 & 307,17 & 8,8 & 1009,89 & 163,47 & 4,9 \\
\hline & $36,491 \mathrm{e}-$ & 585,72 & 530,43 & 16,5 & 770,14 & 285,73 & 8,2 & 974,17 & 133,99 & 4,1 \\
\hline \multirow{2}{*}{0,20} & $72,982 \mathrm{e}+$ & 735,91 & 532,66 & 16,6 & 884,69 & 285,73 & 8,2 & 1055,28 & 152,41 & 4,6 \\
\hline & $72,982 \mathrm{e}-$ & 690,18 & 530,43 & 16,5 & 835,20 & 274,92 & 7,9 & 1001,84 & 133,99 & 4,1 \\
\hline \multirow{2}{*}{50,00} & $\infty$ e+ & 1069,60 & 534,89 & 16,7 & 1150,01 & 285,73 & 8,2 & 1247,81 & 152,41 & 4,6 \\
\hline & $\infty$ e- & 963,76 & 528,21 & 16,4 & 1026,84 & 274,92 & 7,9 & 1111,94 & 133,99 & 4,1 \\
\hline \multirow{2}{*}{$\begin{array}{l}\text { Método } \\
\text { simplificado } \\
\text { proposto por } \\
\text { Franssen } \\
(2000)\end{array}$} & $\infty \mathrm{e}+$ & - & 534,22 & 16,67 & - & 314,31 & 9,00 & - & 204,56 & 6,00 \\
\hline & $\infty$ e- & - & 534,89 & 16,70 & - & 314,31 & 9,00 & - & 154,99 & 4,67 \\
\hline
\end{tabular}

Apesar de o método simplificado ter sido idealizado para modelos com temperatura homogênea tanto na seção quanto longitudinalmente, as previsões foram muito próximas dos valores obtidos pelas análises mais complexas. A análise simplificada, para esse modelo com paredes nas mesas, poderia até ser aplicada em projeto, visto que os valores de tempo crítico para o grau de restrição da ordem de 0,03 foram muito próximos aos das análises complexas.

Apenas para finalizar essa seção, é apresentada a Figura 6.56 para mostrar que é possível obter o comportamento pós crítico, para alguns casos, sem grandes alterações no modelo. A única alteração realizada foi a consideração do passo de carga a cada 1 segundo. Como os scripts foram construídos de forma parametrizada, todas as considerações necessárias ao modelo são automaticamente atualizadas. 


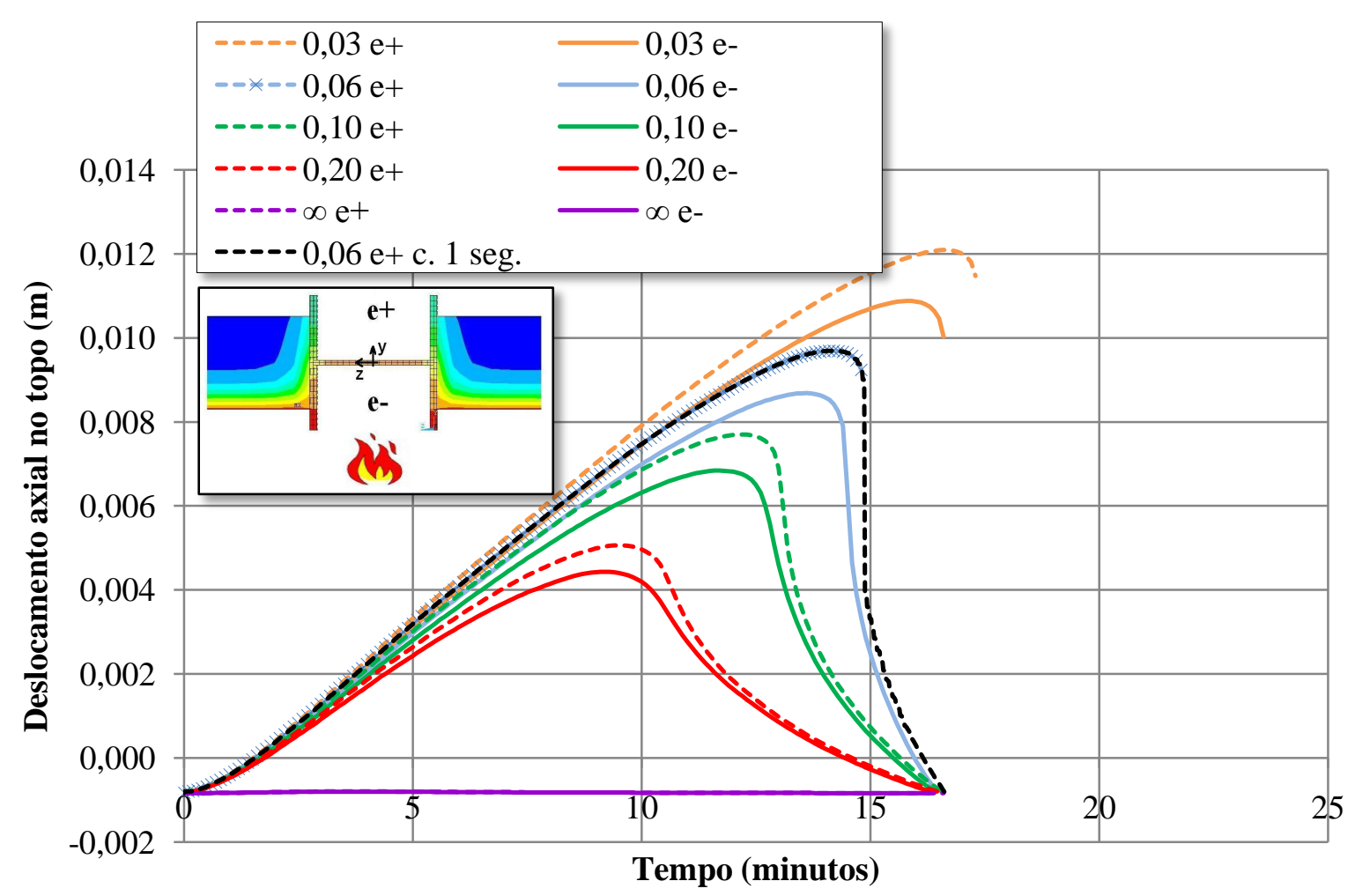

Figura 6.56 - Deslocamento axial no topo do modelo com paredes na alma e restrição axial apresentando a curva com processamento com passo de carga a cada 1 segundo e as demais com passo de 6 segundos.

A curva com restrição axial de grau 0,06 com imperfeição inicial global positiva foi reprocessada considerando, ao invés dos 6 segundos anteriores, o passo de carga de 1 segundo. A desvantagem dessa modificação está no tempo de processamento e no volume de dados gerados, cerca de 6 dias e mais de 50 GB de memória consumidos.

De forma geral, esse modelo com paredes encontrando as mesas do perfil mostrou melhor desempenho estrutural que o perfil isolado, sem alvenaria. Os gráficos de forças e deslocamentos das análises que consideraram força axial inicial de 50 e $75 \%$ podem ser vistos no APÊNDICE C e APÊNDICE D.

\subsubsection{Pilar com paredes em contato com a alma "sem" restrição axial}

O modelo apresentado possui paredes em contato com a alma do perfil conforme visto anteriormente na Figura 6.6c. Assim como para o modelo anterior, foi considerado emissividade de radiação do incêndio igual a $\mathbf{0 , 7}$ e perda de calor na face não exposta às chamas. Primeiramente será apresentado o modelo sem restrição axial. 
Inicialmente, seguindo as prescrições e os modelos apresentados em Kimura (2009), cada passo de carga inteiro era considerado com um minuto inteiro (60 segundos) de ação térmica. Após estas análises preliminares e alguns dos modelos com restrição axial, optou-se por reduzir esse passo para um décimo de seu valor (6 segundos), tendo em vista que alguns modelos (perfil isolado e com paredes nas mesas) apresentaram um tempo crítico de poucos minutos, gerando curvas pouco representativas do fenômeno de interesse. Assim procedeu-se para todos os modelos anteriores (sem paredes e parede em encontro com as mesas).

No entanto, especificamente o modelo de paredes na alma do perfil com e sem restrição axial, manteve-se o minuto inteiro (60 segundos) como unidade do passo de carga. Essa estratégia se deve ao fato de este modelo, para cargas baixas, atingir o tempo máximo analisado de 150 minutos, ou 1500 passos de carga. No entanto, o ANSYS tem por padrão um limite de 1000 resultados a serem armazenados, o que pode ser alterado pelo usuário. Porém, tendo em vista que o armazenamento de cada passo de carga demanda uma grande capacidade de memória (cerca de $80 \mathrm{MB}$ cada passo para esse modelo) a aplicação desse valor de incremento (6 segundos) se torna inviável.

O modelo do perfil com parede na alma sem restrição axial foi considerado com cada passo de carga (de temperatura) igual a um minuto inteiro, diferentemente dos anteriores. Em Kimura (2009), para passos de carga de um minuto, os subpassos foram considerados respectivamente inicial, mínimo e máximo como sendo 0,01;0,001 e 0,02. Nesta atual pesquisa, como os passos de carga foram reduzidos para um décimo (6 segundos), entendeuse ser conveniente que os subpassos fossem maiores, preservando a precisão dos resultados e mantendo um bom desempenho computacional.

Para que pudessem ser adotados subpassos de carga com valores maiores, de 0,25; 0,10 e 0,50 com o passo em 6 segundos, foram realizados testes de precisão e desempenho. O passo de carga foi mantido em um minuto inteiro para a realização dos testes. Como se observa na Figura 6.57, para uma carga inicial de 50\% da carga de colapso as diferenças entre os deslocamentos axiais foram mínimos e restritos a um pequeno trecho. 


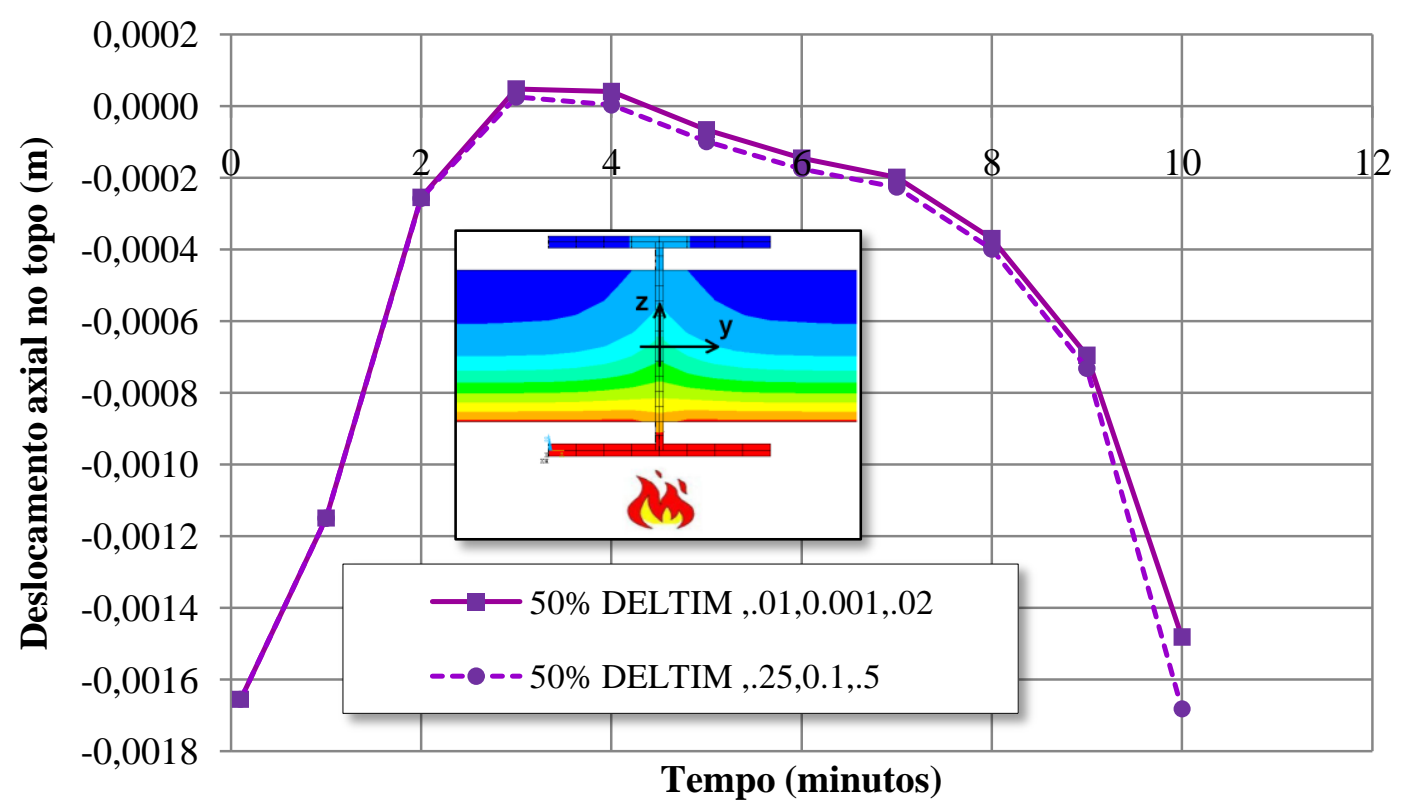

Figura 6.57 - Deslocamento axial com consideração de diferentes tamanhos nos incrementos dos subpassos de carga para carga inicial de $50 \%$.

Utilizando o passo de carga de um minuto inteiro, a Figura 6.58 mostra os resultados do deslocamento axial no topo do pilar com paredes na alma. O deslocamento axial apresenta um comportamento bastante diferenciado em relação ao pilar isolado e ao pilar com parede nas mesas. Para as três menores forças axiais aplicadas (10, 20 e 30\%), o modelo resistiu pelo tempo total analisado, que foi de duas horas e meia de ação térmica.

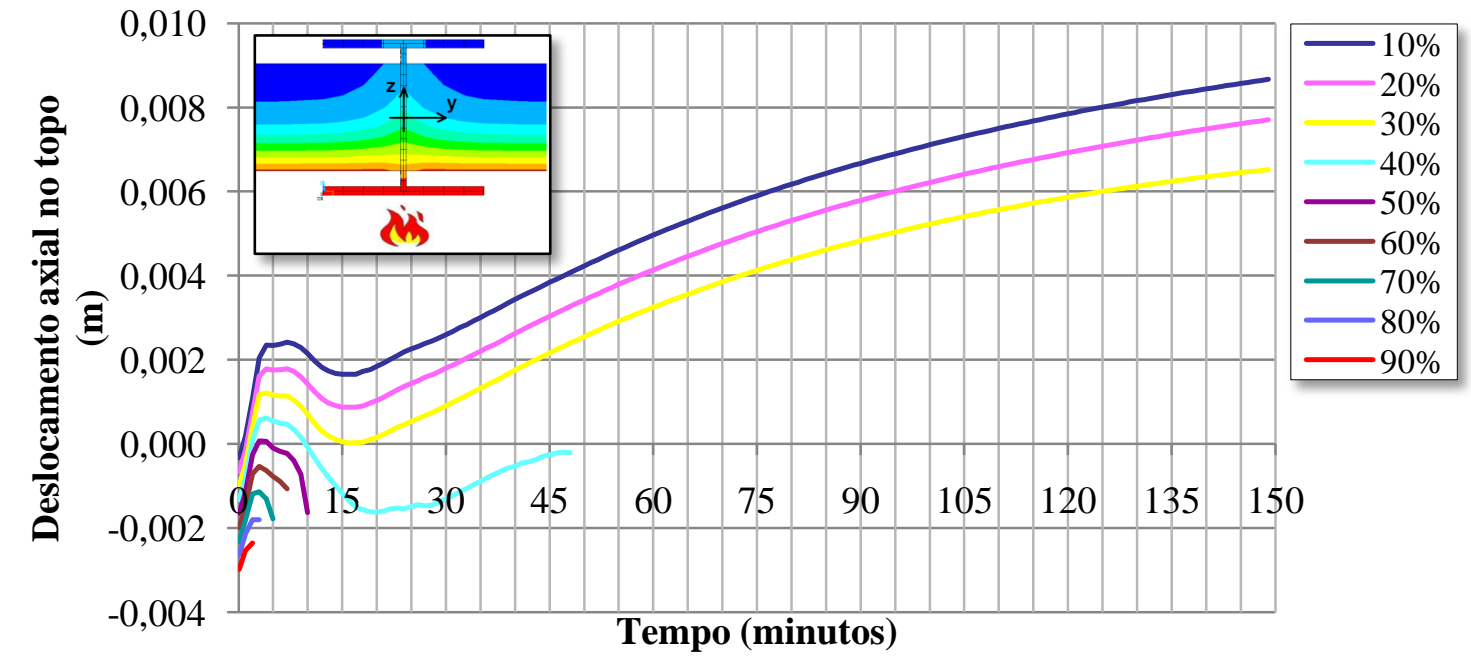

Figura 6.58 - Deslocamento axial no topo do pilar com paredes na alma para diversos níveis de carregamento sem restrição axial.

As curvas de deslocamento axial das quatro menores forças (10, 20, 30 e 40\%) apresentam trechos bem definidos: um ascendente, uma leve decaída e um segundo trecho 
ascendente até o final de cada processamento. Ao observarmos o gráfico de deslocamento axial da Figura 6.58 juntamente com o gráfico de temperatura desse modelo, exibido na Figura 5.42 do capítulo anterior, e também a relação constitutiva do aço da Figura 6.4 é possível estabelecer algumas considerações, ainda que preliminares:

a-) O pico das curvas do deslocamento axial ocorre pouco antes dos 5 minutos, instante de tempo em que a mesa mais aquecida ultrapassa os $200^{\circ} \mathrm{C}$, temperatura em que se inicia a penalização do módulo de elasticidade. Enquanto isso, a mesa não exposta às chamas permanece com temperatura praticamente constante. A partir de cerca de 10 ou 15 minutos inicia-se a elevação da temperatura na mesa não exposta, o que pode explicar a retomada do crescimento dos deslocamentos axiais de forma praticamente constante, sendo que esta quase não ultrapassa os $200^{\circ} \mathrm{C}$ ao final dos 150 minutos;

b-) O tempo crítico desse modelo resulta sempre maior que o correspondente ao pilar isolado quando submetido à mesma carga axial. Isso se deve ao fato de a compartimentação do ambiente em chamas promovida pelas paredes, bem como a perda de calor na face oposta, resultam em temperatura média do aço inferior à do pilar isolado, fazendo com que este resista por mais tempo.

O deslocamento lateral no meio do vão na direção Y, conforme Figura 6.59, se refere ao modelo com paredes na alma e sem restrição axial, enquanto a Figura 6.60 apresenta os deslocamentos laterais no meio do vão na direção Z, perpendicular à imperfeição geométrica global inicial.

Já é possível observar no modelo em questão que, diferentemente dos anteriores, os deslocamentos laterais no meio do vão nos dois eixos se aproximam em ordem de grandeza. A diferença de apenas 10 vezes pode ser explicada pela direção em que ocorre a ação térmica. Nesse modelo o aquecimento ocorre de tal forma que a dilatação térmica de uma das mesas é maior que na mesa oposta. Dessa foram, é como se o pilar fosse "atraído" na direção da fonte de calor, perpendicular à imperfeição geométrica global inicial. 


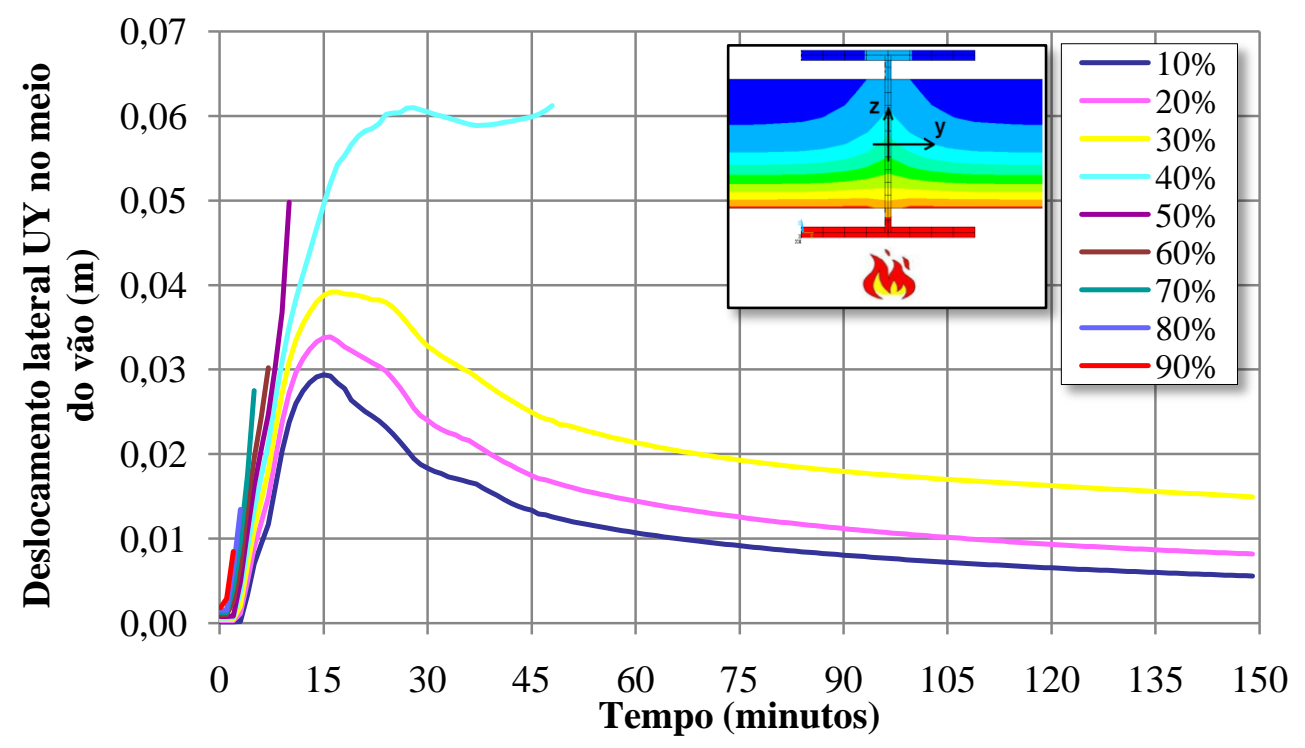

Figura 6.59 - Deslocamento lateral no meio do vão na direção da imperfeição inicial do modelo com parede na alma sem restrição axial.

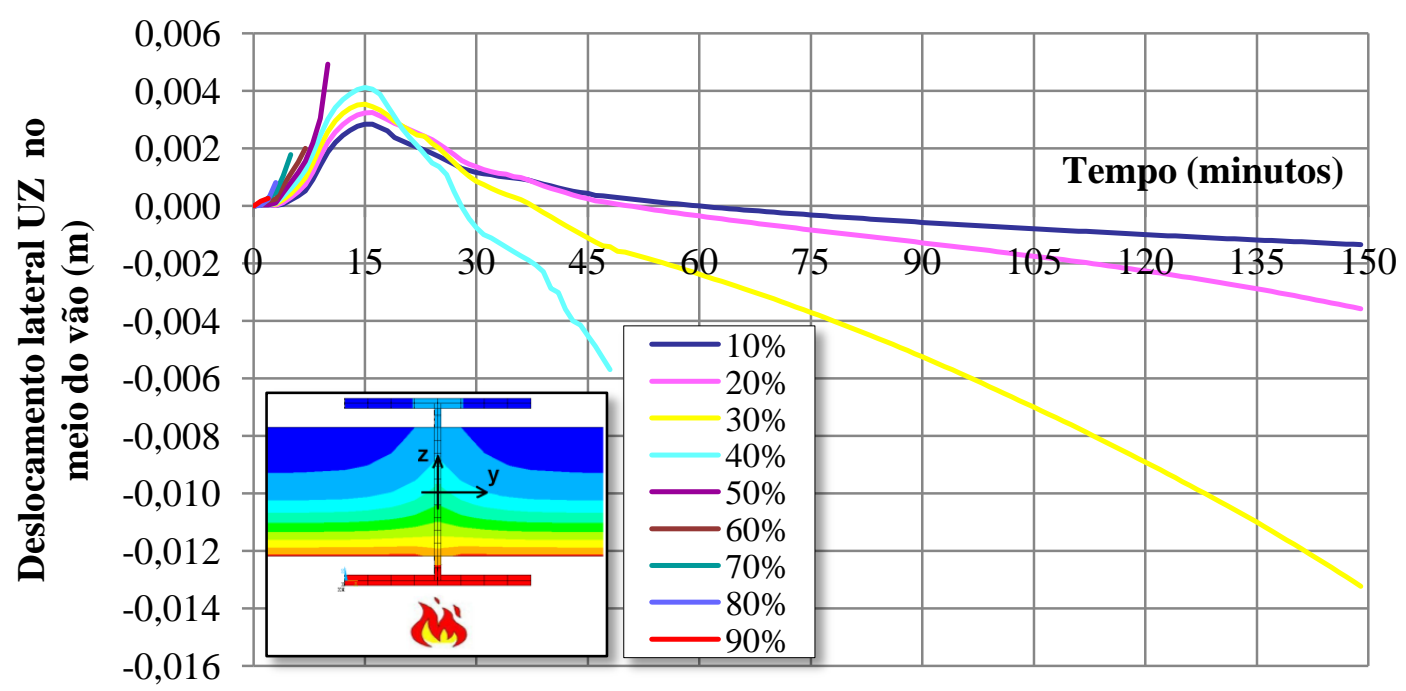

Figura 6.60 - Deslocamento lateral no meio do vão na direção perpendicular à imperfeição inicial do modelo com parede na alma sem restrição axial.

Essa pequena diferença pode ser melhor vista na Figura 6.61, que relaciona os deslocamentos laterais nas duas direções da seção (Z e Y), descrevendo o movimento da seção para cada carga considerada. Por fim, a Figura 6.62 mostra a rotação do eixo longitudinal da barra no nó central do modelo. Essa rotação agora pode atingir valores tão grandes como $20^{\circ}$. Isso porque enquanto a imperfeição geométrica global inicial e a força axial aplicadas agem em uma direção, o aquecimento não uniforme age na direção perpendicular, de forma que essa combinação provoca um giro maior do pilar. 


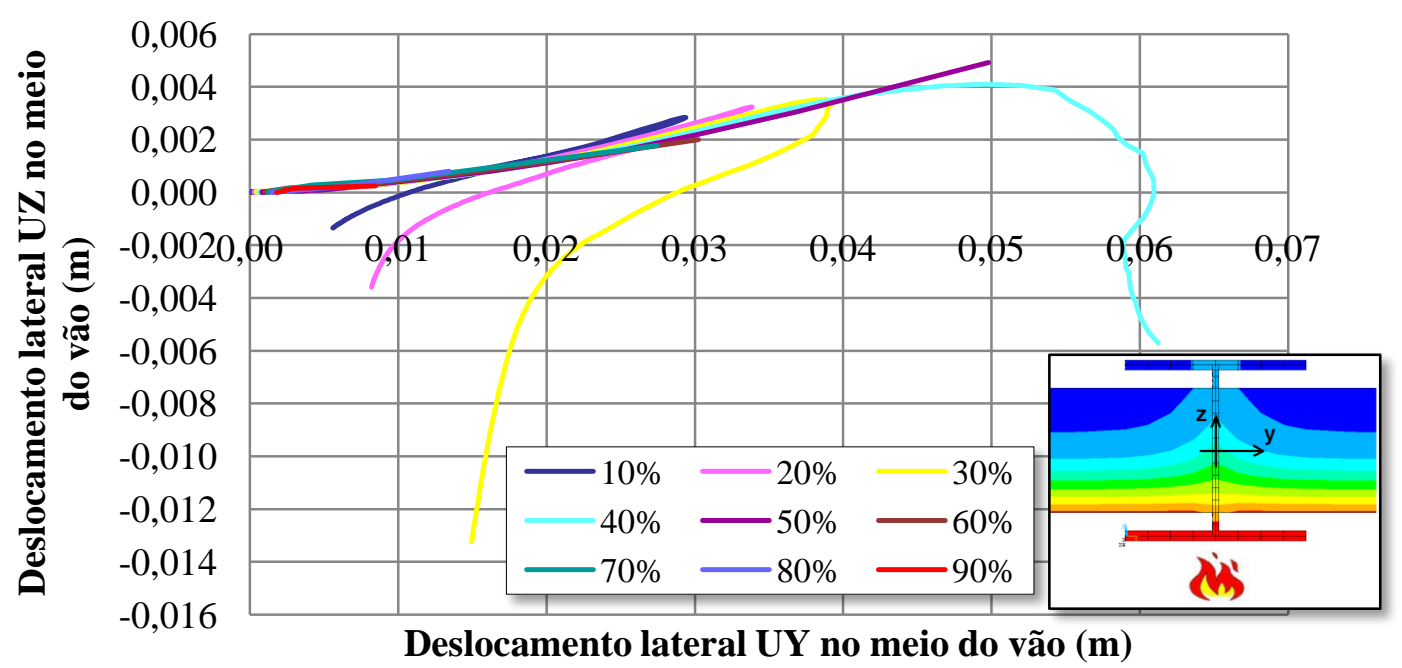

Figura 6.61 - Deslocamento lateral no meio do vão nas direções Y e Z do plano da seção do modelo com parede na alma sem restrição axial.

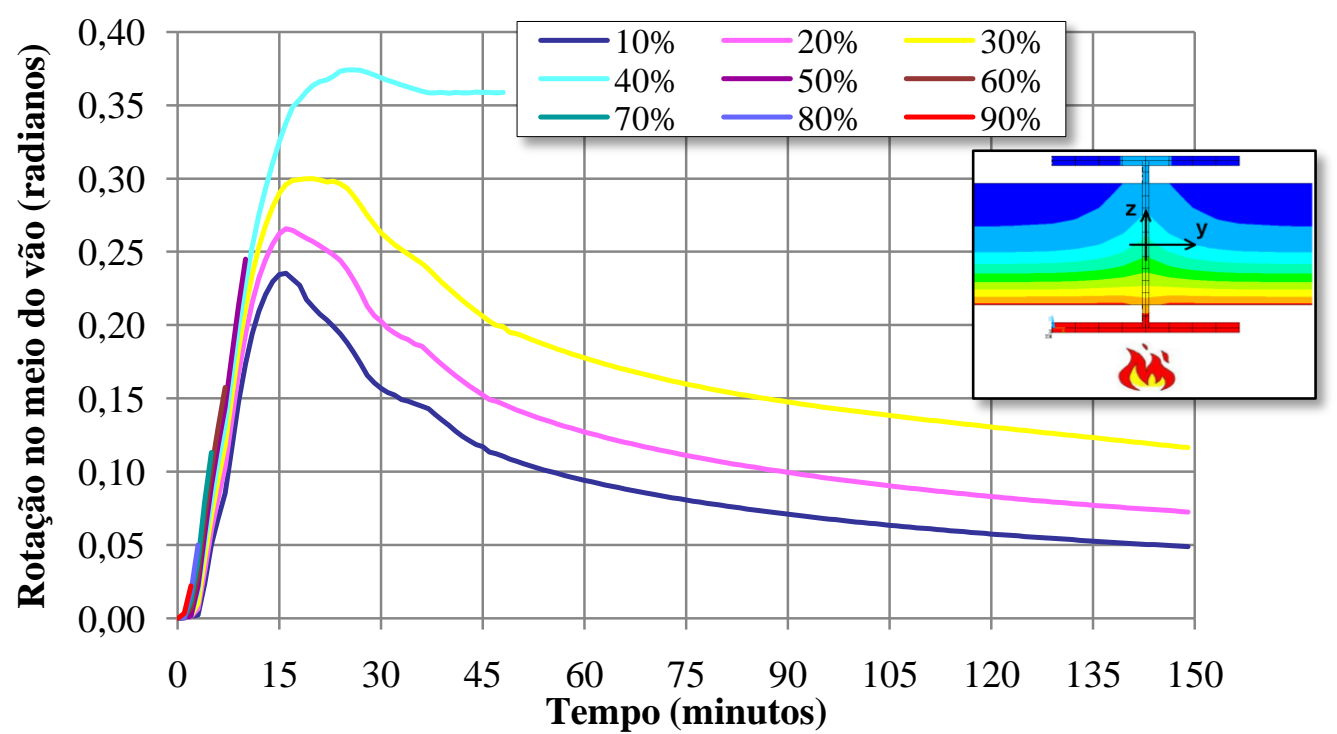

Figura 6.62 - Rotação do eixo longitudinal no meio do vão do modelo com parede na alma sem restrição axial.

Com base nos resultados numéricos apresentados, e para cargas abaixo de $40 \%$, acredita-se que essa disposição das paredes seja a mais favorável quanto ao desempenho em situação de incêndio em comparação aos modelos vistos anteriormente, no entanto, resultados experimentais devem ser analisados para melhores conclusões. Também é aquele que apresenta um comportamento mais diferenciado frente às altas temperaturas devido às orientações perpendiculares entre as direções da ação térmica e da imperfeição geométrica global. Vale lembrar ainda que as condições de vinculação no topo e na base impedem a rotação das seções transversais das extremidades na direção solicitada pelo aquecimento. 
A seguir, esse modelo de pilar com paredes na alma será apresentado com a análise que inclui a restrição axial com diferentes rigidezes e força axial inicial de $25 \%$ da carga de colapso.

\subsubsection{Pilar com paredes em contato com a alma "com" restrição axial}

Enquanto que o modelo com paredes nas mesas e com restrição axial pouco ultrapassou o tempo crítico de 15 minutos, o modelo aqui considerado facilmente venceu os 90 minutos em todos os casos analisados. Assim como esse modelo sem restrição axial, será considerada a emissividade de radiação igual a $\mathbf{0 , 7}$ e a perda de calor na face não exposta ao incêndio.

Conforme já explicado anteriormente, o modelo com paredes na alma foi analisado considerando o passo de carga a cada 60 segundos, ao invés dos 6 segundos dos modelos anteriores. Foram realizadas algumas análises comparativas com esse modelo em que ambos os valores de passo de carga foram utilizados e nenhuma diferença significativa nos resultados foi encontrada. No entanto, a diferença no tempo de processamento e capacidade de memória necessária foi bastante grande.

A força axial nesse modelo evolui conforme mostra a Figura 6.63. Para todos os graus de restrição axial existe um pico de força nos primeiros 10 minutos de ação térmica. Esse pico decresce rapidamente até um ponto de mínimo valor próximo aos 15 minutos e então inicia nova ascensão. Isso indica que o aquecimento médio da seção provoca a expansão térmica e solicita a restrição axial. No entanto, como uma das mesas é mais aquecida que a outra, rapidamente essa primeira perda sua rigidez, fazendo com que a mesa menos aquecida passe a resistir aos esforços atuantes. Posteriormente, o mesmo fenômeno inicia-se com a outra mesa e a expansão térmica de outras partes da seção supera a perda de rigidez da primeira mesa. 


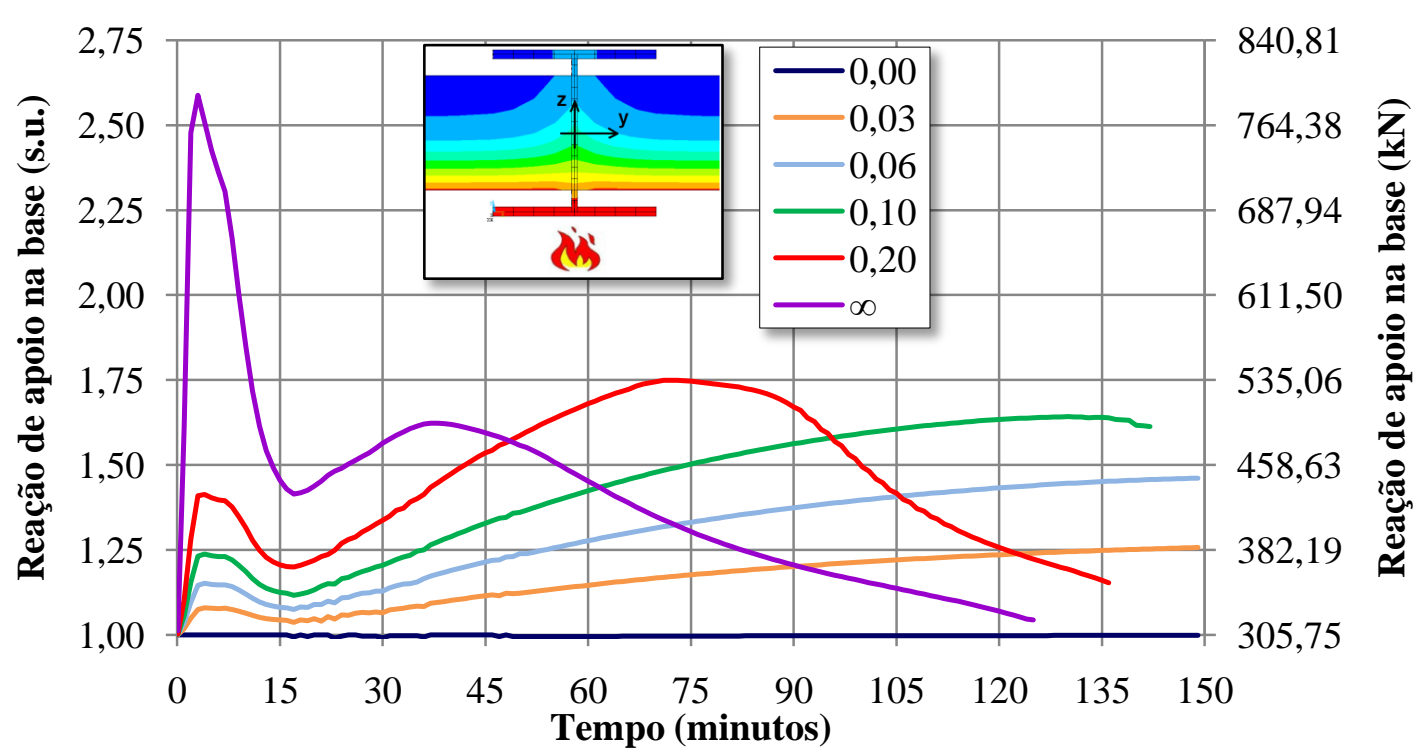

Figura 6.63 - Carregamento total aplicado para diversos níveis de restrição axial e carga estática inicial de $25 \%$ da carga de colapso em temperatura ambiente vão do modelo com parede na alma e com restrição axial.

O gráfico do deslocamento axial no topo da barra é visto na Figura 6.64, onde também é possível observar o instante em que se perde parte da rigidez da seção. Nos minutos que se seguem a expansão térmica volta a aumentar o comprimento do pilar além da deformação axial. A Figura 6.65 ilustra os deslocamentos laterais na direção da imperfeição geométrica global inicial.

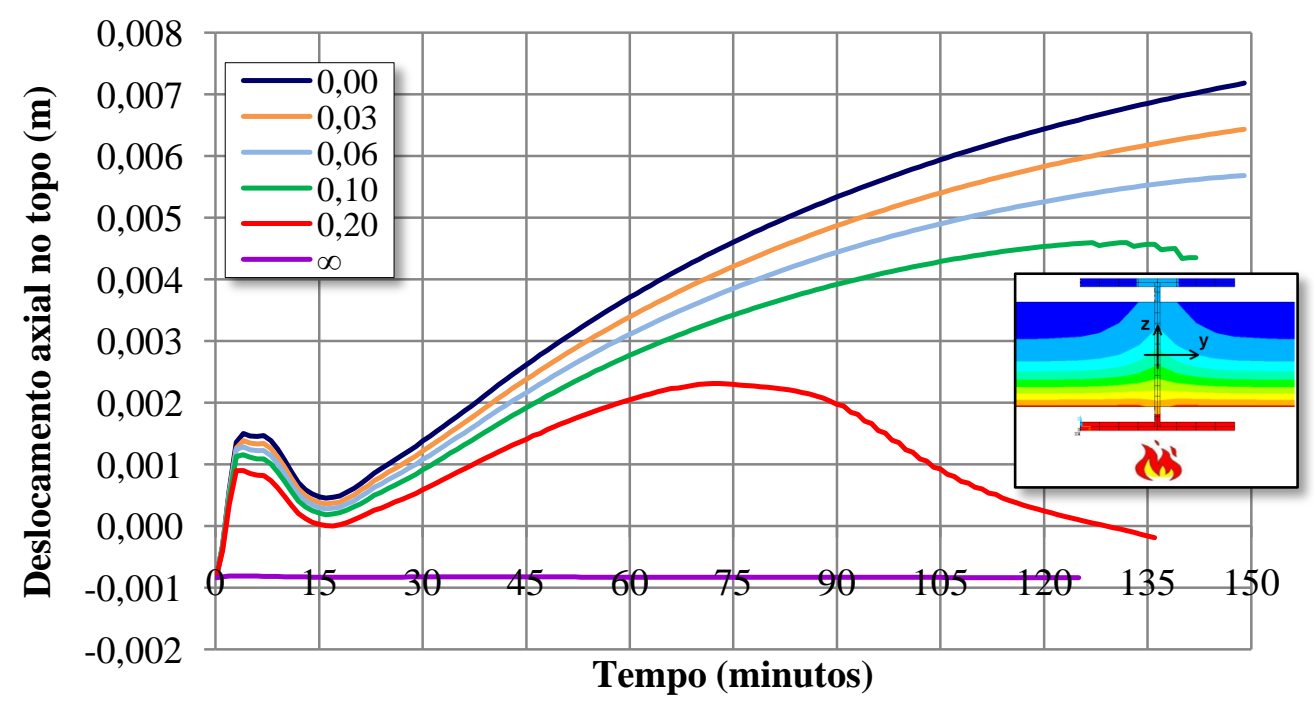

Figura 6.64 - Deslocamento axial no topo do pilar para diversos níveis de restrição axial e carga estática inicial de $25 \%$ da carga de colapso em temperatura ambiente do modelo com parede na alma e com restrição axial. 


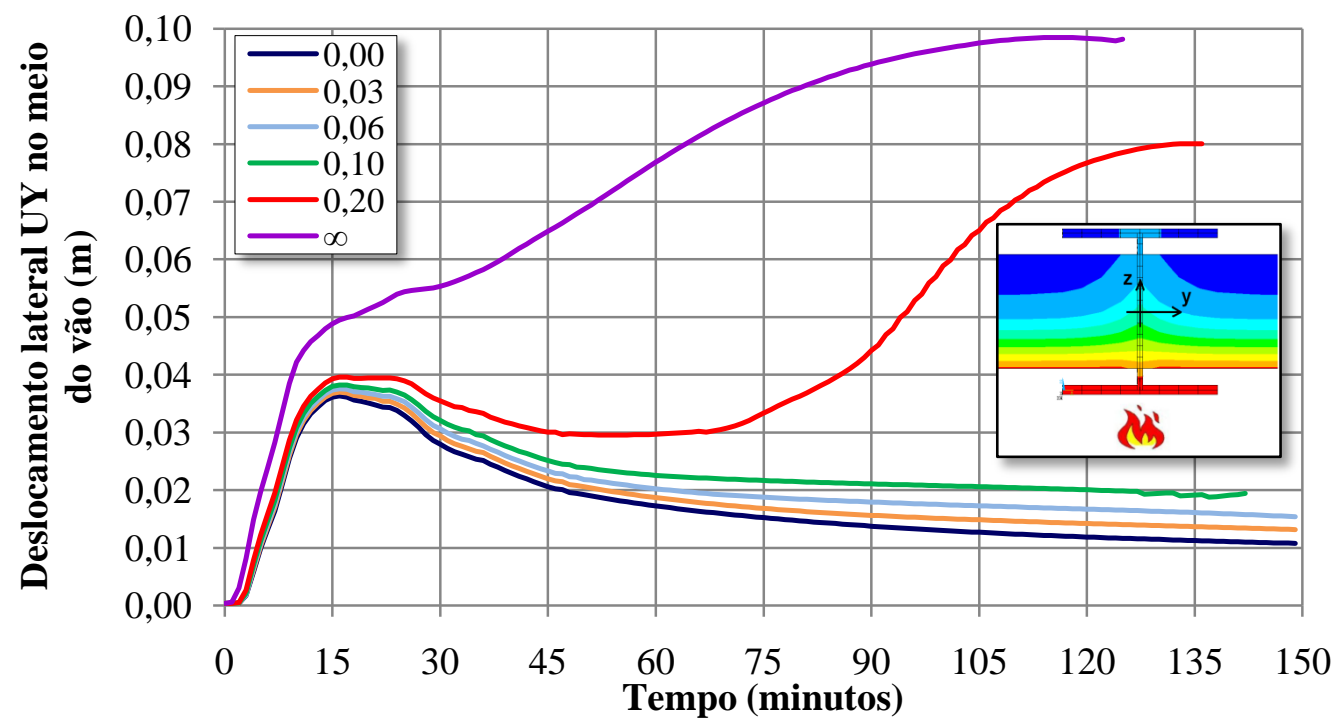

Figura 6.65 - Deslocamento lateral no meio do vão na direção UY da imperfeição inicial para diversos níveis de restrição axial e carga estática inicial de $25 \%$ da carga de colapso em temperatura ambiente do modelo com parede na alma e com restrição axial.

Uma situação interessante pode ser observada em todos os gráficos aos 15 minutos de ação de incêndio. Em especial, na Figura 6.66 que mostra o deslocamento lateral na direção perpendicular à imperfeição inicial e na Figura 6.67, que mostra a rotação do eixo longitudinal da barra. Ao se imaginar que a ação térmica deveria "atrair" a barra na sua direção, as curvas que apresentam o deslocamento em $\mathrm{Z}$ mostram uma trajetória em sentido contrário, em resposta a uma expressiva rotação da seção central da barra, que leva o nó central da alma ao lado positivo do eixo Z. Por volta de 15 minutos essa rotação diminui e inverte o sentido de giro, levando a seção no sentido da ação térmica.

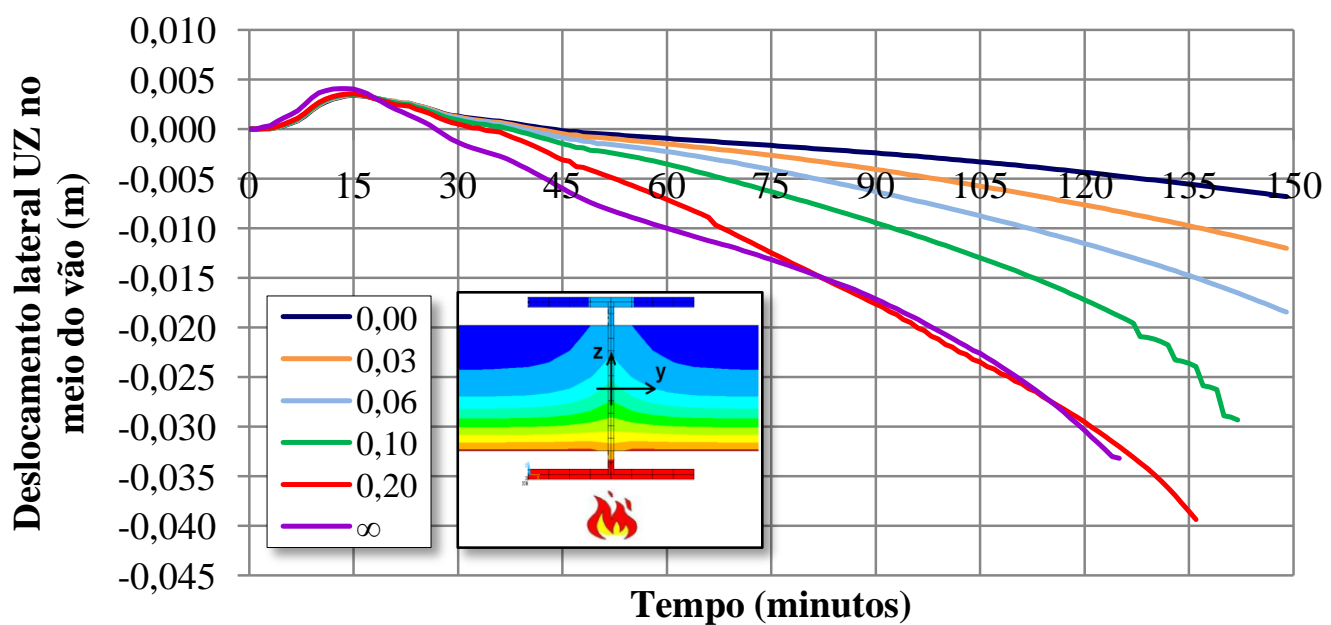

Figura 6.66 - Deslocamento lateral no meio do vão na direção perpendicular UZ à imperfeição inicial para diversos níveis de restrição axial e carga estática inicial de $25 \%$ da carga de colapso em temperatura ambiente do modelo com parede na alma e com restrição axial. 
A rotação da barra, vista na Figura 6.67, apresenta curvas de comportamento semelhante aos deslocamentos laterais na direção da imperfeição geométrica global inicial. Assim como essa mesma disposição de paredes do modelo sem restrição axial, aqui a rotação longitudinal, da seção no meio do vão, também pode alcançar valores altos como 15 e $20^{\circ}$.

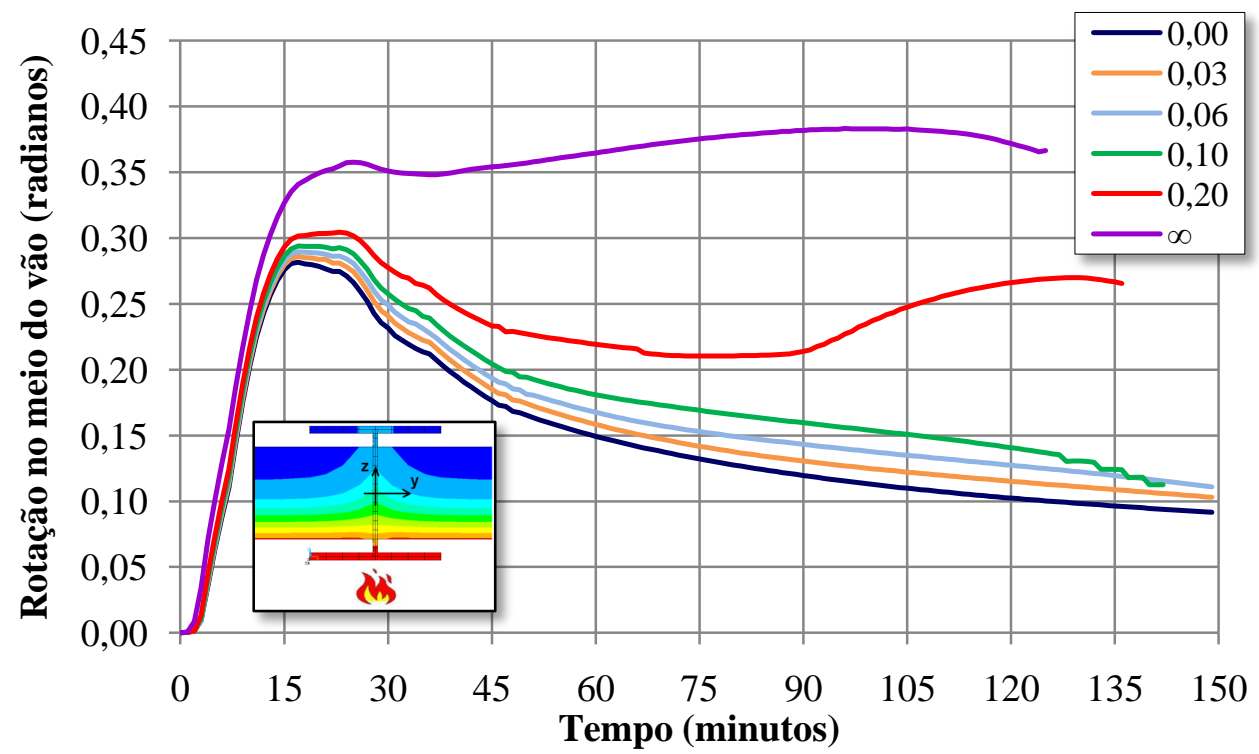

Figura 6.67 - Rotação do eixo longitudinal no meio do vão para diversos níveis de restrição axial e carga estática inicial de $25 \%$ da carga de colapso em temperatura ambiente do modelo com parede na alma e com restrição axial.

Por fim, a Figura 6.68 mostra o deslocamento do plano da seção transversal no meio do vão. Os deslocamentos nas direções perpendiculares se assemelham quanto à ordem de grandeza.

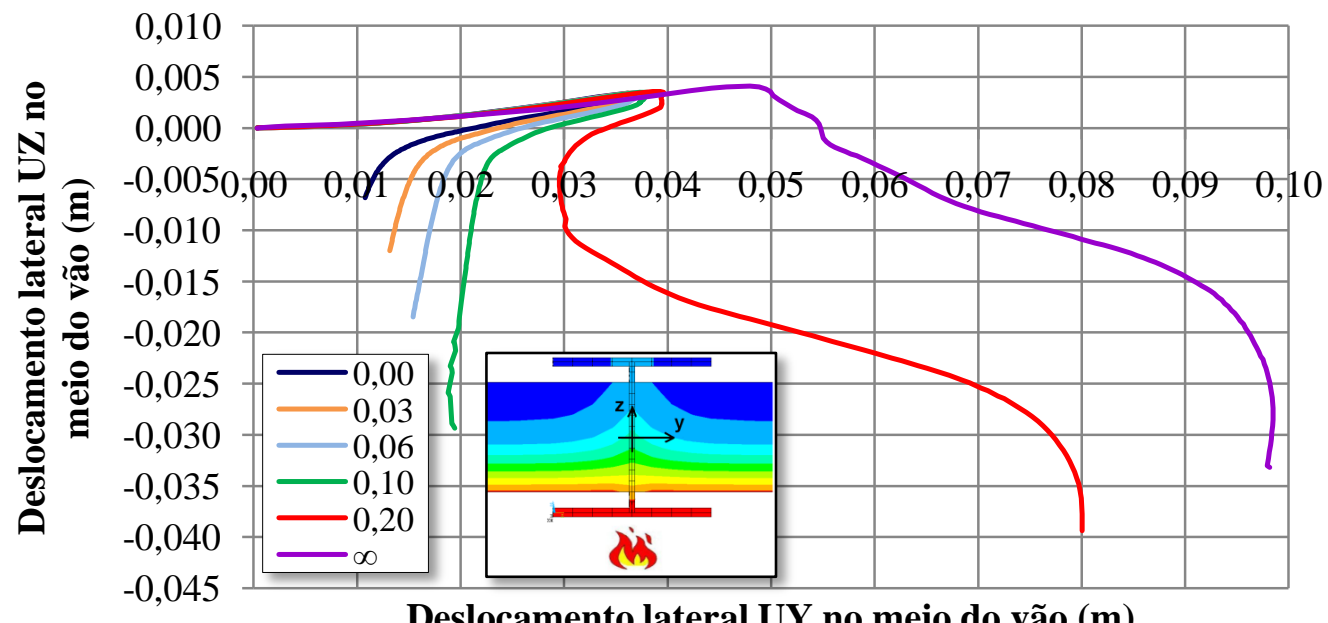

Deslocamento lateral UY no meio do vão $(\mathbf{m})$

Figura 6.68 - Deslocamento nas direções Y e Z do plano da seção para diversos níveis de restrição axial e carga estática inicial de $25 \%$ da carga de colapso em temperatura ambiente do modelo com parede na alma e com restrição axial. 
A fim de verificar se seria possível utilizar a análise simplificada proposta em Franssen (2000), analisou-se o modelo com paredes na alma sob as condições prescritas. A evolução do carregamento axial imposto pela restrição pode ser vista na Figura 6.69. A configuração da curva se assemelha àquela com restrição infinita e carregamento axial baixo (25\%). O método proposto na última referência sugere que ao traçar uma reta a partir da carga inicial, tem-se uma previsão aproximada do tempo crítico. As previsões de resultados por esse método podem ser comparadas aos valores obtidos pelas análises complexas na Tabela 6.8.

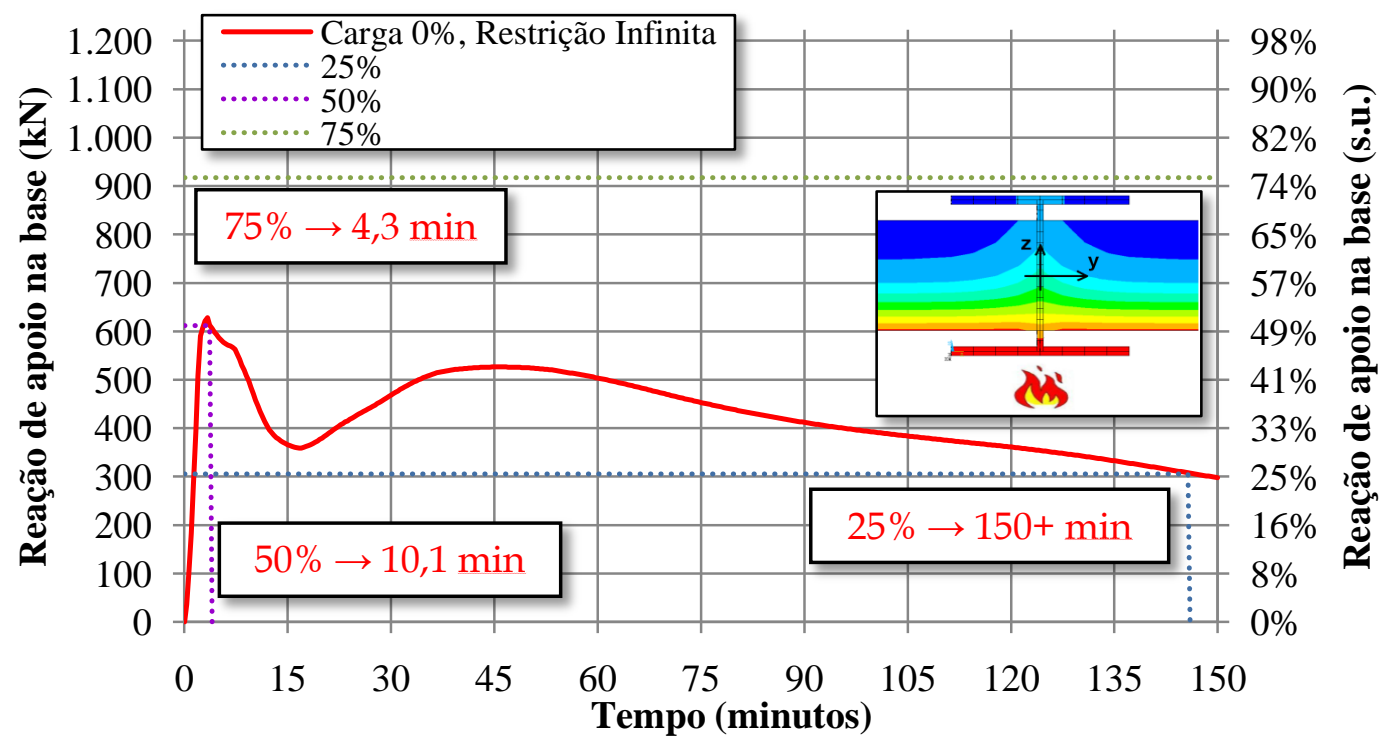

Figura 6.69 - Reação de apoio do modelo com restrição axial infinita sem carga inicial aplicada do modelo com parede na alma e com restrição axial.

Tabela 6.8 - Resultados de tempo e temperaturas críticas das análises numéricas do modelo com paredes na alma.

\begin{tabular}{|c|c|c|c|c|c|c|c|c|c|c|}
\hline \multirow{2}{*}{ Rigidez $\mathrm{k}_{\mathrm{r}}$} & \multirow{2}{*}{$\begin{array}{c}\mathrm{R} \\
(\mathrm{kN} / \mathrm{mm})\end{array}$} & \multicolumn{3}{|c|}{$\begin{array}{c}\text { Força axial inicial } \\
25 \%\end{array}$} & \multicolumn{3}{|c|}{$\begin{array}{c}\text { Força axial inicial } \\
50 \%\end{array}$} & \multicolumn{3}{|c|}{$\begin{array}{c}\text { Força axial inicial } \\
75 \% \\
\end{array}$} \\
\hline & & $\mathrm{F}_{\max (\mathrm{kN})}$ & $\begin{array}{c}\theta_{\mathrm{s}, \text { máx - crit. }} \\
\left({ }^{\circ} \mathrm{C}\right)\end{array}$ & $\mathrm{t}_{\text {crit (min.) }}$ & $\mathrm{F}_{\max (\mathrm{kN})}$ & $\theta_{\mathrm{s}, \operatorname{máx}}{ }_{\left({ }^{\circ} \mathrm{C}\right)}$ crit. & $\mathrm{t}_{\text {crit (min.) }}$ & $\mathrm{F}_{\max (\mathrm{kN})}$ & $\theta_{\mathrm{s}, \text { máx - crit. }}$ & $\mathrm{t}_{\text {crit (min.) }}$ \\
\hline 0,00 & 0,000 & 305,75 & 1078,00 & $150+$ & 611,50 & 517,44 & 10,1 & 917,25 & 226,87 & 4,3 \\
\hline 0,03 & 10,947 & 384,58 & 1078,00 & $150+$ & 629,40 & 517,44 & 10,1 & 928,52 & 226,87 & 4,3 \\
\hline 0,06 & 21,895 & 446,29 & 1078,00 & $150+$ & 645,81 & 513,91 & 10,0 & 938,89 & 226,87 & 4,3 \\
\hline 0,10 & 36,491 & 502,00 & 1070,62 & 142 & 665,44 & 513,91 & 10,0 & 951,23 & 226,87 & 4,3 \\
\hline 0,20 & 72,982 & 534,96 & 1064,00 & 136 & 705,59 & 509,90 & 9,9 & 976,43 & 226,87 & 4,3 \\
\hline 50,00 & $\infty$ & 791,20 & 1051,05 & 125 & 965,09 & 489,84 & 9,4 & 1121,63 & 221,00 & 4,2 \\
\hline $\begin{array}{c}\text { Método } \\
\text { simplificado } \\
\text { proposto por } \\
\text { Franssen }(2000)\end{array}$ & $\infty$ & - & 1075,93 & 147 & - & 191,76 & 3,7 & - & - & - \\
\hline
\end{tabular}

A grande vantagem do método simplificado reside na necessidade de apenas uma análise para conhecermos o tempo crítico de qualquer carga inicial, sem que seja necessário conhecermos o valor exato da restrição axial imposta pela estrutura circundante. Apenas para 
essa configuração de paredes foram necessárias 18 análises complexas de, em média, 6 horas de processamento cada. Foram considerados 6 graus de restrição para cada uma das 3 forças axiais iniciais consideradas.

Como mostra a Figura 6.69 e a Tabela 6.8, o tempo crítico previsto por meio do método simplificado trouxe resultados bastante próximos da análise complexa para carga inicial baixa, como $25 \%$, no entanto apresentou maiores diferenças para carga de $50 \%$ e não pôde ser aplicado para $75 \%$. Esse método simplificado foi idealizado para modelos com temperatura homogênea tanto na seção quanto longitudinalmente e mostrou melhores resultados nesse caso.

\subsection{ANÁLISE COMPARATIVA}

Os resultados de evolução da carga axial (Figura 6.70), deslocamento axial (Figura 6.71) e deslocamento lateral no meio do vão (Figura 6.72) de cada um do três modelos analisados são mostrados em um mesmo gráfico considerando carga axial de $\mathbf{7 0 \%}$ e restrição axial de $\mathbf{k}_{\mathbf{r}}=\mathbf{0 , 0 3}$. Os tempos críticos foram em todos os casos muito baixos e não passariam em nenhuma exigência normativa sem a aplicação de proteções térmicas. No entanto, a análise comparativa nos mostra que a disposição das paredes na alma é a que garante a melhor proteção ao perfil.

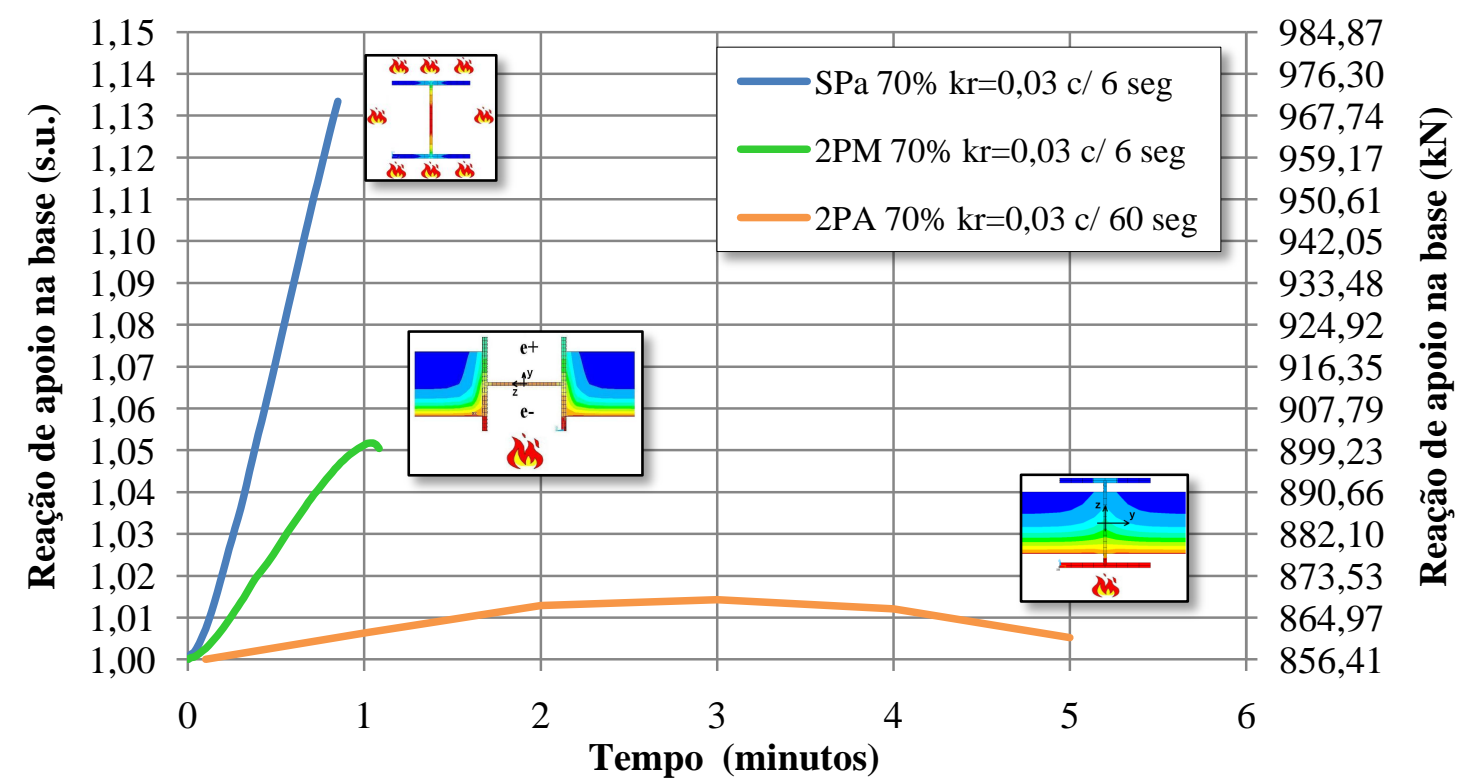

Figura 6.70 - Reação de apoio com restrição axial $k_{r}=0,03$ e carga inicial de $70 \%$ para os três modelos analisados. 


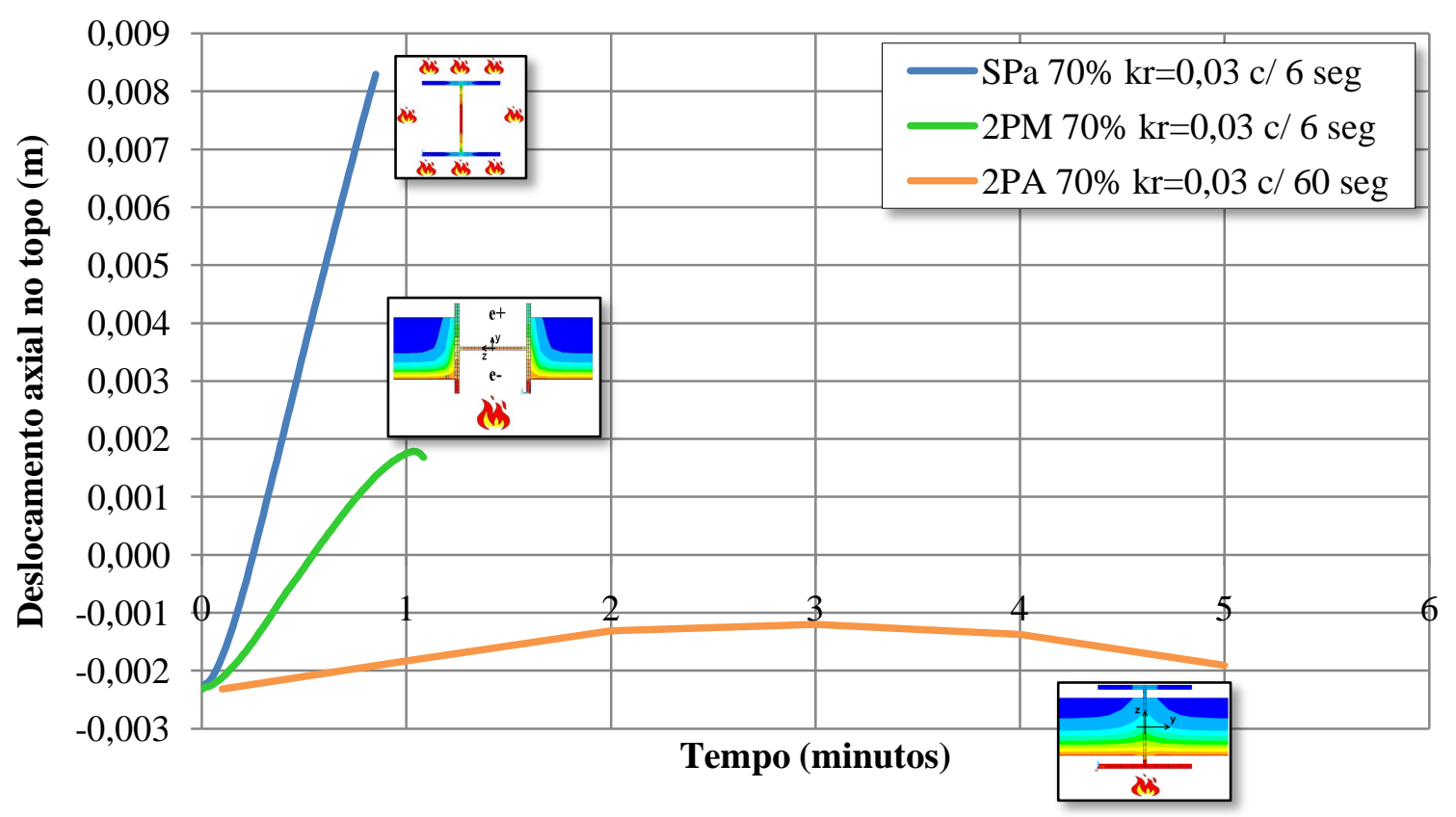

Figura 6.71 - Deslocamento axial no topo com restrição axial $\mathrm{k}_{\mathrm{r}}=0,03$ e carga inicial de $70 \%$ para os três modelos analisados.

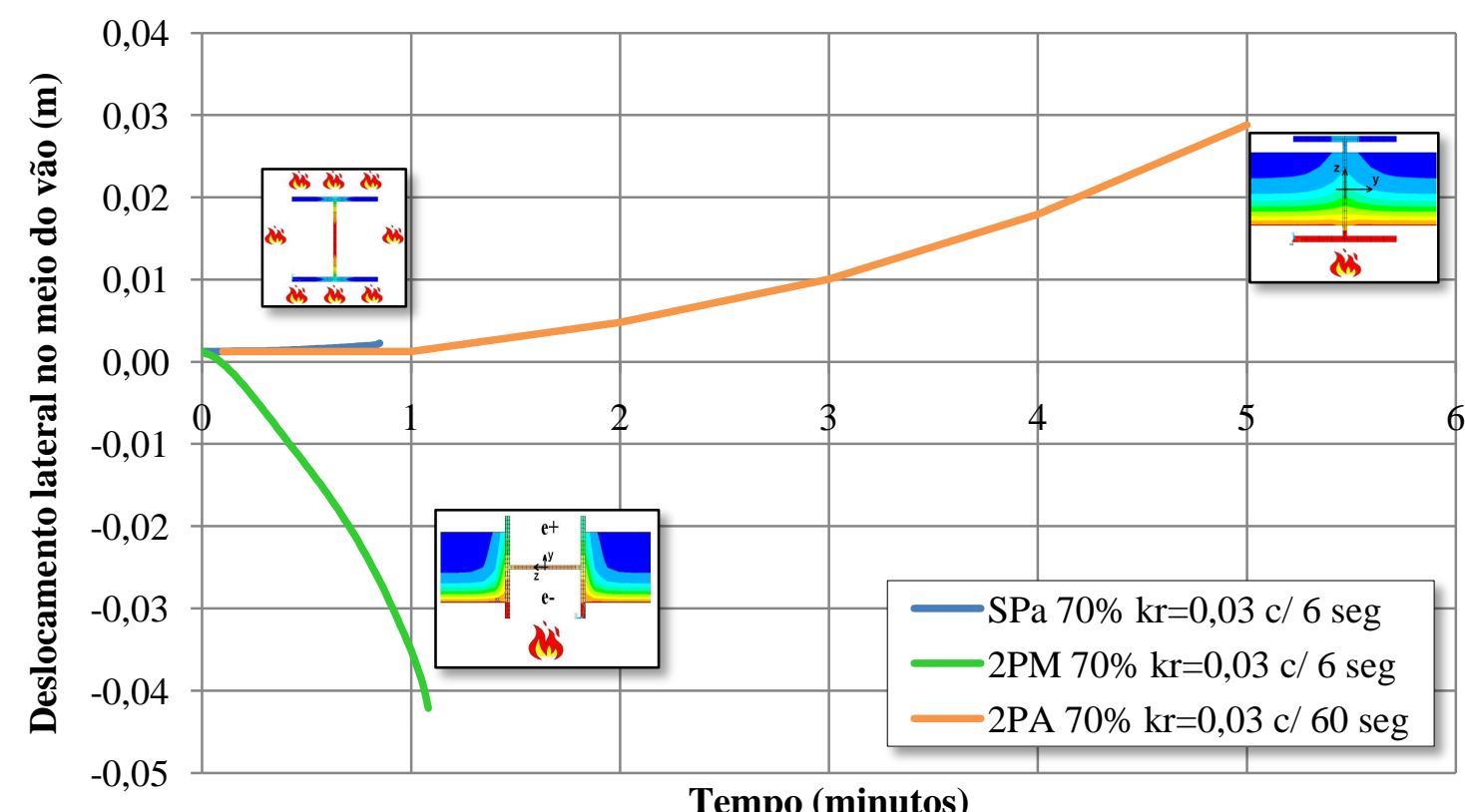

Figura 6.72 - Deslocamento lateral no meio do vão com restrição axial $k_{r}=0,03$ e carga inicial de $70 \%$ para os três modelos analisados.

Nesse capítulo foram apresentados os resultados das análises termoestruturais com e sem restrição axial dos modelos sem paredes, com paredes nas mesas e com paredes na alma. Devido ao grande volume de gráficos, apenas os resultados com restrição axial em que a carga inicial de $25 \%$ foram incluídos no corpo do texto. Os demais gráficos, com força axial inicial de 50 e $75 \%$ são apresentados no APÊNDICE E e no APÊNDICE F. 


\section{CONCLUSÕES}

\subsection{COMENTÁRIOS GERAIS}

A área de estruturas em situação de incêndio necessita maiores e contínuas investigações, recorrendo a todas as formas de pesquisa: técnicas, experimentais, computacionais e análises teóricas.

O presente trabalho é um passo no sentido de conhecer melhor o comportamento de barras de aço comprimidas sob a ação térmica, considerando a restrição axial, uma simplificação do comportamento global da estrutura, mas que representa um passo na direção do amadurecimento do conhecimento científico para elaboração e melhoria de metodologias simplificadas de projeto.

Esta pesquisa buscou analisar a viabilidade de um modelo numérico de perfil isolado, com temperatura homogênea, e também para campos térmicos diferenciados, como ocorre na presença de paredes em contato com o perfil tanto para análises térmicas quanto para análises termoestruturais.

Vale ressaltar que ambos os elementos finitos utilizados, o SOLID e o SHELL, disponibilizados na biblioteca interna do ANSYS, se mostram adequados para fins de análises térmicas, estruturais e termoestruturais, porém, foi possível notar que os elementos SHELL, dentro do contexto do presente trabalho, resultam mais eficientes quanto ao tempo de processamento global, ou seja, apresentam um menor custo computacional, de forma a possibilitar a realização das mesmas análises aqui de interesse com menor tempo de processamento. 


\subsection{QUANTO ÀS ANÁLISES TÉRMICAS}

Esse trabalho apresentou alguns exemplos de análises em campo tridimensional de temperaturas com o objetivo de validar e apresentar resultados do campo térmico por meio de comparação entre resultados obtidos em pesquisas anteriores tanto em caráter experimental quanto numérico, seja via ANSYS, seja pelo STC. Os resultados numéricos, quando comparados a pesquisas anteriores, se mostraram suficientemente satisfatórios.

Em relação à análise térmica, a transferência nodal de temperaturas, seguindo a estratégia numérica adotada, mostrou-se bastante satisfatória, mesmo na região de interface SHELL x SOLID, ou seja, na região de contato entre o perfil e a alvenaria. A metodologia aplicada no presente trabalho foi capaz de reproduzir a variação da temperatura de forma coerente com aquela obtida experimentalmente em Silva, Correia e Rodrigues (2008).

A transferência do campo térmico para o modelo termoestrutural se deu de forma correta. As respostas de temperatura do modelo térmico para um determinado nó foram comparadas aos carregamentos nodais de temperatura do modelo termoestrutural e esses apresentaram coerência.

\subsection{QUANTO ÀS ANÁLISES TERMOESTRUTURAIS}

Uma vez que a metodologia utilizada no modelo elaborado com o elemento finito SHELL foi semelhante àquela aplicada ao modelo elaborado com o elemento SOLID, pode-se afirmar que os resultados de deslocamento x tempo nas análises termoestruturais apresentam coerência, assim como o modelo em temperatura ambiente elaborado com elemento SHELL.

É possível considerar, com base nos resultados numéricos aqui obtidos e apresentados, que o elemento finito SHELL se mostra mais adequado para os fins da estratégia numérica aqui proposta, se comparado ao elemento finito SOLID. Elementos do tipo casca têm sua aplicação de forma direcionada, buscando representar satisfatoriamente elementos estruturais comprimidos, mais especificamente pilares de aço com seção transversal constituída por elementos com espessura reduzida, considerando análises a temperatura ambiente e em situação de incêndio com vistas ao contexto termoestrutural. 


\subsection{QUANTO À RESTRIÇÃO AXIAL}

A estratégia adotada para a inclusão da restrição axial com o elemento LINK10 também se mostrou bastante satisfatória. Com o elemento mencionado foi possível reproduzir os resultados apresentados em trabalhos referentes aos estudos de pilares de aço em situação de incêndio. Os resultados com restrição axial e com paredes foram coerentes com o que se esperava enquanto comportamento estrutural.

A inclusão da restrição axial visa tornar o modelo numérico mais coerente com o funcionamento mecânico das estruturas em serviço. A convergência das curvas de força axial para um mesmo tempo crítico, para uma dada carga inicial, abre precedentes para a criação de uma metodologia simplificada de dimensionamento de estruturas em situação de incêndio baseada em ábacos, fato esse que poderá ser melhor estudado em trabalhos futuros.

\subsection{SUGESTÕES PARA TRABALHOS FUTUROS}

Fica como sugestão para trabalhos futuros verificar a viabilidade da utilização do método numérico Arc-Length, disponível no ANSYS, em conjunto com o método dependente de convergência numérica Newton-Raphson.

Algumas análises piloto foram conduzidas mantendo-se o método Newton-Raphson de resolução numérica, porém reduzindo-se o passo de carga para 1 segundo de forma que foi possível em alguns casos obter o comportamento pós crítico do modelo termoestrutural. É sugerido que essa estratégia seja melhor estudada.

Também é sugerido que seja estudada a restrição rotacional nas extremidades do pilar. É conhecida sua influência no sentido de melhorar o desempenho e aumentar o tempo crítico de pilares em situação de incêndio. Dessa forma será possível conhecer com melhor coerência o tempo crítico do elemento estrutural inserido em um pórtico.

Com o presente trabalho será possível analisar outros perfis de seção tipo I de forma simples e rápida, apenas alterando o valor das dimensões do perfil nas variáveis que se encontram no cabeçalho dos scripts e seguindo a mesma hierarquia de pastas, bem como a ordem correta das análises. 
Dissertação de Mestrado

Vale lembrar que as análises numéricas desenvolvidas e apresentadas no presente trabalho representam uma fase preliminar do estudo, de modo que outras configurações de campo térmico (ou gradiente térmico) na seção transversal decorrente das paredes da compartimentação em novas posições relativas ao perfil poderão ser estudadas em trabalhos futuros propostos dentro desse mesmo contexto.

Para finalizar, é importante salientar que as análises numéricas sempre deverão ser apoiadas por análises experimentais, as quais representam uma necessidade importante para dar embasamento aos modelos numéricos. 


\section{REFERÊNCIAS}

$9-11$

RESEARCH:

OTHER

SKYSCRAPER

FIRES.

http://911research.wtc7.net/wtc/analysis/.../fires.html, (acessado em julho/2009).

ALMEIDA, S. J. C de. Análise numérica de perfis de aço formados a frio comprimidos considerando as imperfeições geométricas iniciais. São Carlos. Dissertação (Mestrado) - Escola de Engenharia de São Carlos - Universidade de São Paulo, 2007.

AMERICAN SOCIETY TESTING AND MATERIALS. ASTM E119 - Standard test methods for fire tests of building construction and materials. West Conshohohocken, 2000.

ANSYS INC. Ansys Release 9.0 - Documentation, 2004.

ASSOCIAÇÃO BRASILEIRA DE NORMAS TÉCNICAS (ABNT). NBR 8800 Projeto e execução de estruturas de aço de edifícios. Rio de Janeiro, 2008.

. NBR 14323 - Dimensionamento de estruturas de aço de edifícios em situação de incêndio - Procedimento. Rio de Janeiro, 1999.

. NBR 5628 - Componentes construtivos estruturais - Determinação da resistência ao fogo. Rio de Janeiro, 2001.

. NBR 14432 - Exigências de resistência ao fogo de elementos construtivos de edificações - Procedimento. Rio de Janeiro, 2000.

BOLEY, B.A. Theory of thermal stresses, John Wiley e Sons Inc, New York, 1985.

CLARET, A.M. Resistência ao fogo de estruturas: alternativas técnicas para a redução do custo da proteção passiva. Ouro Preto: Escola de Minas, Universidade Federal de Ouro Preto, 2000. (Relatório Interno L01/2000), 2000a.

CLARET, A.M. Resistência ao fogo de barras mistas aço-concreto modeladas pelo método dos elementos finitos. In: Jornadas Sudamericanas de Ingenieria Estructural, Punta Del Este 2000. Anais, 2000b.

COSTA, I. A. Estudo paramétrico da resistência ao fogo de barras mistas de açoconcreto. Dissertação (Mestrado) - Universidade Federal de Ouro Preto, Ouro Preto, 2001. 
DETR-PIT, Final Report of the DETR-PIT Project. Behavior of steel framed structures under fire conditions. Technical report, Universidade de Edimburgo, 2000.

DIAS, L. A. M. Estruturas de aço. Conceitos, técnicas e linguagem. São Paulo. Zigurate, 2002.

DRYSDALE, D. Special Issue on Response of Composite Steel Framed Structures to Fire. Fire Safety Journal. http://www.sciencedirect.com/science?_ob=PublicationURL\&_tockey=\%23TOC $\% 235723 \% 2$ 32001\%23999639991\%23267498\%23FLA\%23\&_cdi=5723\&_pubType=J\&view=c\&\&auth= $\mathrm{y} \& \_$acct $=\mathrm{C} 000049650 \&$ \&ersion $=1 \&$ urlVersion $=0 \&$ userid $=5674931 \& \mathrm{md} 5=\mathrm{c} 5 \mathrm{e} 32 \mathrm{~b} 7 \mathrm{fa} 100$ 5078ee531d831887cb37, 2001, p. 719-720, 2001.

DRYSDALE, D. Fire Science. In: STOLLARD, P.; JOHNSTON, L. Design against fire: An introduction to fire safety engineering design. 172p. Ed. E e FN Spon. Londres, Nova York. p. 9-20, 1994.

EUROPEAN COMMITTEE FOR STANDARDIZATION. prEN 1991-1-2: EUROCODE 1 - Basis of design and actions on structures. Part 1-2: - Actions on structures exposed to fire. European Community. Brussels, 2002.

EN 1993-1-1:2005 EUROCODE 3 - Design of steel structures. Part 1-1: General rules and rules for buildings. Stage 34 draft, Brussels, 2005.

EN 1993-1-2:2005 EUROCODE 3 - Design of Steel Structures. Part 1-2: General rules - Structural Fire Design. Brussels, 2005.

EN 1994-1-1:2005 EUROCODE 4 - Design of composite steel and concrete structures. Part 1-2: General rules - Structural Fire Design. Brussels, 2005.

EUROPEAN CONVENTION FOR CONSTRUCTIONAL STEELWORK (ECCS). Design manual on European Recommendations for the fire safety of steel structures. Brussels, ECCS, 1985.

Brussels, ECCS, 2001.

(ECCS) - Technical Committee 3 - Model Code on Fire Engineering, № 111,

FAKURY, R.H.; SILVA, V.P.; MARTINS, M.M. Temperatura Crítica de Elementos Estruturais de Aço em Situação de Incêndio. In: Jornadas Sudamericanas de Ingenieria Estructural, 29., Punta del Este, 2000. Anais, 2000.

FERREIRA, W.G., CORREIA, E.L.S., AZEVEDO, M.S. Dimensionamento de Estruturas de Aço e Mistas em Situação de Incêndio. Vitória, Grafer, 2006.

FERREIRA, F.A.; CLARET, A.M.; SANTOLIN, A. Determinação da distribuição de temperatura em perfis de aço parcialmente protegido: método simplificado. Revista Escola de Minas 60(4), Ouro Preto, 2007. p. 645-655, 2007. 
FRANSSEN, J.M. Failure temperature of a system comprising a restrained column submitted to fire. Fire Safety Journal 34. p. 191-207. Elsevier, 2000.

HUANG, Z.F.; TAN, K.H. Rankine approach for fire resistance of axially-anflexurally restrained steel columns. Journal of Constructional Steel Research 59. p. 15531571. Elsevier, 2003.

HUANG, Z.F.; TAN, K.H. Effects of external bending moments and heating schemes on the responses of thermally restrained steel columns. Engineering Structures 26. p. 769780. Elsevier, 2004.

HUANG, Z.F.; TAN, K.H.; TING, S. Heating rate and boundary restraints effects on fire resistance of steel columns with creep. Engineering Structures 28, Singapura. p. 805-817, 2006.

INTERNATIONAL ORGANIZATION FOR STANDARDIZATION. Fire-resistance tests - Elements of building construction - Part 1: General requirements. ISO 834-1:1999, 1999.

KIRCHHOF, L. D. Uma contribuição ao estudo de barras mistas aço-concreto simplesmente apoiadas em temperatura ambiente e em situação de incêndio. 141p. Dissertação (Mestrado) - Universidade de São Paulo, Escola de Engenharia de São Carlos, São Carlos, Brasil, 2004.

KIMURA, E.F.A. Análise termo-estrutural de pilares de aço em situação de incêndio. São Carlos. Dissertação (Mestrado) - Escola de Engenharia de São Carlos - Universidade de São Paulo, 2009.

LEWIS, K.R. Fire Design of Steel Members, Fire Engineering Research Report, Univesity of Canterbury, Christchurch, 2000.

LEWIS, R. W., NITHIARASU, P., SEETHARAMU, K. N. Fundamentals of the finite element method for heat and fluid flow. John Wiley e Sons, 2004.

LIENHARD IV, J. H.; LIENHARD V, J. H. A heat transfer Textbook, Phlogiston Press, Massachusetts, 2005.

MENDES, C. L. Estudo teórico sobre perfis formados a frio em situação de incêndio. Dissertação (Mestrado) - Escola de Engenharia de São Carlos, Universidade de São Paulo, São Carlos, 2004.

MITIDIERI, M.L. O comportamento dos materiais e componentes construtivos diante do fogo - reação ao fogo. In: Seito, A.I. et al. A segurança contra incêndio no Brasil. 496p. Projeto Editora. São Paulo. p. 55-75, 2008.

NEVES, I.C. The Critical Temperature of Steel Columns with Restrained Thermal Elongation, Fire Safety Journal 24 (1995) 211-227. Elsevier Science, 1995. 
ONO, R.; VENEZIA, A.G.; VALENTIN, M.V.. Arquitetura e Urbanismo. In: Seito, A.I. et al. A segurança contra incêndio no Brasil. 496p. Projeto Editora. São Paulo. p. 135$167,2008$.

REGOBELLO, R. Análise numérica de seções transversais e de elementos estruturais de aço e mistos de aço e concreto em situação de incêndio. São Carlos. Dissertação (Mestrado) - Escola de Engenharia de São Carlos - Universidade de São Paulo. 2007.

RODRIGUES, J.P.C. Fire resistance of steel columns with restrained thermal elongation. Lisboa. Dissertação (Doutorado) - Instituto Superior Técnico - Universidade Técnica de Lisboa, 2000.

ROTTER, J. M.; SANAD, A. M.; USMANI, A. S.; GILLIE, M. Structural performance of redundant structures under local fires. Proceedings of the Interflam'99, Eighth International Fire Science and Engineering Conference, Edimburgo. p. 1069-1080, 1999.

ROTTER, J. M.; USMANI, A. S. Fundamental principle of structural behavior under thermal effects. Proceedings of the First International Workshop on Structural in Fire, Copenhagen, 2000.

SEITO, A.I. Fundamentos de Fogo e Incêndio. In: Seito, A.I. et al. A segurança contra incêndio no Brasil. 496p. Projeto Editora. São Paulo. p. 35-54, 2008.

SILVA, C. J. Comportamento de estruturas metálicas e mistas em situação de incêndio - modelagem e aplicações. 191p. Dissertação (Mestrado) - Universidade Federal do Espírito Santo, Vitória, ES, Brasil, 2002.

SILVA, V.P.; PANNONI, F.D.; PINTO, E.M.; SILVA, A.A. da. Segurança das Estruturas em Situação de Incêndio. In: SEITO, A.I. et al. A segurança contra incêndio no Brasil. 496p. Projeto Editora. São Paulo. p. 135-167, 2008.

SILVA, V.P. Determination of the temperature of thermally unprotected steel members under fire situations. Considerations on the section factor. Latin American Journal of Solids and Structures 3, p. 149-161, 2006.

SILVA, V.P. Determination of the steel fire protection material thickness by an analytical process - a simple derivation. Engineering Structures 27, p. 2036-2043, 2005. 2001.

SILVA, V.P. Estruturas de Aço em Situação de Incêndio. São Paulo, Editora Zigurate,

SILVA, V.P. Ação térmica nas Estruturas: Determinação da Temperatura nos Elementos Estruturais de Aço com Proteção Térmica em Situação de Incêndio. Boletim Técnico da Escola Politécnica da USP, BT/PEF/9914, São Paulo, 2000. 
SILVA, V.P. O Comportamento de Sistemas Estruturais Básicos de Aço em Situação de Incêndio. In: Jornadas Sudamericanas de Ingenieria Estructural, 29., Punta Del Este, 2000. Anais, 1999.

SILVA, V.P.; CORREIA, A.M.; RODRIGUES, J.P. Simulação do Comportamento ao Fogo de Pilares de Aço em Contato com Alvenaria. In: Jornadas Sudamericanas de Ingenieria Estructuras, 33., Santiago 2008. Anais, 2008.

SILVA, V.P.; FAKURY, R.H. Normas Brasileiras de Estruturas de Aço em Situação de Incêndio. In: Jornadas Sudamericanas de Ingenieria Estructural, 29., Punta Del Este 2000. Anais, 2000.

SILVA, V.P.; VARGAS, M.R. Resistência ao Fogo das Estruturas de Aço. Instituto Brasileiro de Siderurgia - CBCA, Rio de Janeiro, 2003.

STAGGS, J.E.J.; PHYLAKTOU, H.N. The effects of emissivity on the performance of steel in furnace tests. Fire Safety Journal 43. p. 1-10. Elsevier Science, 2008.

STAGGS, J.E.J. Convection heat transfer in the cone calorimeter. Fire Safety Journal 44. p. 469-474. Elsevier Science, 2009.

TAKAGI, J., DEIERLEIN, G.G. Strength design criteria for steel members at elevated temperatures. Journal of Constructional Steel Research, Department of Civil and Environmental Engrg. - MC 4020, Stanford University, Stanford, p. 1036-1050, 2006.

THE STEEL CONSTRUCTION INSTITUTE. P288 Fire Safe Design: A new approach to multi-storey steel framed buildings. SCI Publication. Inglaterra, 2000.

THE TRUTH SEEKER - 9/11 AND THE WINDSOR TOWER FIRE. http://www.thetruthseeker.co.uk/article.asp?ID=2796 (acessado em julho/2009).

TOH, W.; TAN, K; FUNG, T. Rankine approach for steel columns in fire: numerical studies. Journal of Constructional Steel Research 59, Singapura. p. 315-334. Elsevier Science, 2003.

USMANI, A.S., ROTTER, J.M., LAMONT, S., SANAD, A.M., GILlIE, M. Fundamental principles of structural behaviour under thermal effects. Fire Safety Journal 36 (2001) 721-744. Elsevier Science, 2001.

VALENTE, J.C., NEVES, I.C. Fire resistance of steel columns with elastically restrained axial elongation and bending, Journal of Constructional Steel Research, Volume 52, Issue 3 (1999) 319-331. Elsevier Science, 1999.

VILA REAL, P. Incêndio em Estruturas Metálicas - Cálculo Estrutural. Edições Orion, Mafra, 2003. 
WANG, Y. C. The effects of frame continuity on the behavior of steel columns under fire conditions and fire resistant design proposals. J. Construct. Steel Res. Vol. 41, No. 1. p. 93-111. Elsevier, 1997.

WANG, Y. C. Steel and Composite Structures - Behaviour and Design for Fire Safety. Spon Press, London, 2002.

WANG, Y. C. Postbuckling behavior of axially restrained and axially loaded steel columns under fire conditions. Journal of Structural Engineering, vol. 130, n. 3. p. 371-380, 2004.

WELSH, R. 2-D Analysis of composite steel - Concrete beams in fire, A research report for the degree of Master of Engineering in Fire Engineering Department of Civil Engineering University of Canterbury, Christchurch, New Zealand, 2001.

WICKSTROM, U. Temperature calculation of insulated steel columns exposed to natural fire. Fire Safety Journal 4 (4). p. 219-225, 1982.

WICKSTROM, U. Temperature analysis of heavily-insulated steel structures exposed to fire. Fire Safety Journal 9. p. 281-285, 1985.

WONG, M. B. Modelling of axial restraints for limiting temperature calculation of steel members in fire. Journal of Construction Steel Research 61. p. 675-687, Melbourne, 2005. 


\section{APÊEDICE A - Gráficos do modelo sem paredes em contato com o perfil com $50 \%$ da carga de colapso}

Os gráficos que não foram apresentados no corpo do texto serão incluídos nesta sessão que se segue.

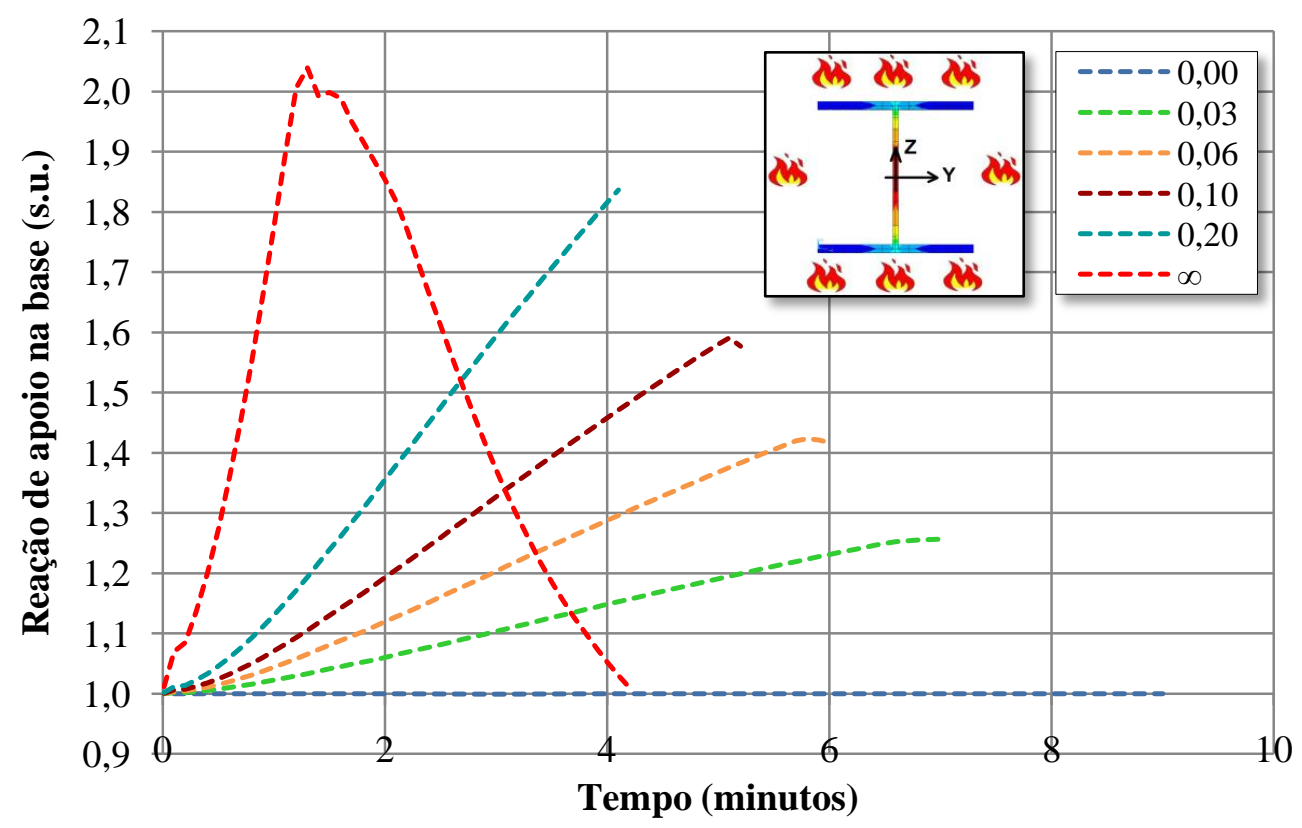

Figura A.1 - Carregamento total aplicado para diversos níveis de restrição axial e carga estática inicial de 50\% da carga de colapso em temperatura ambiente vão do modelo com parede na alma e com restrição axial. 


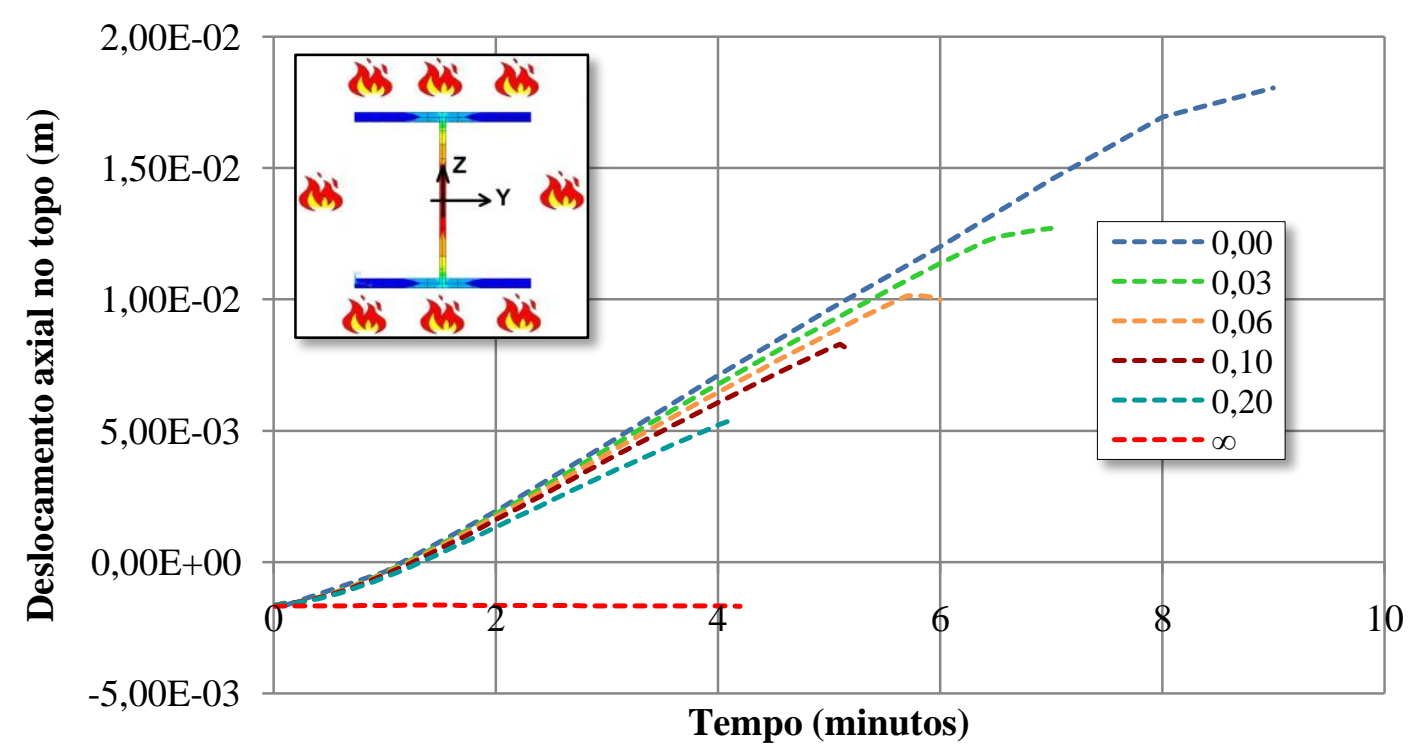

Figura A.2 - Deslocamento axial no topo do pilar para diversos níveis de restrição axial e carga estática inicial de 50\% da carga de colapso à temperatura ambiente.

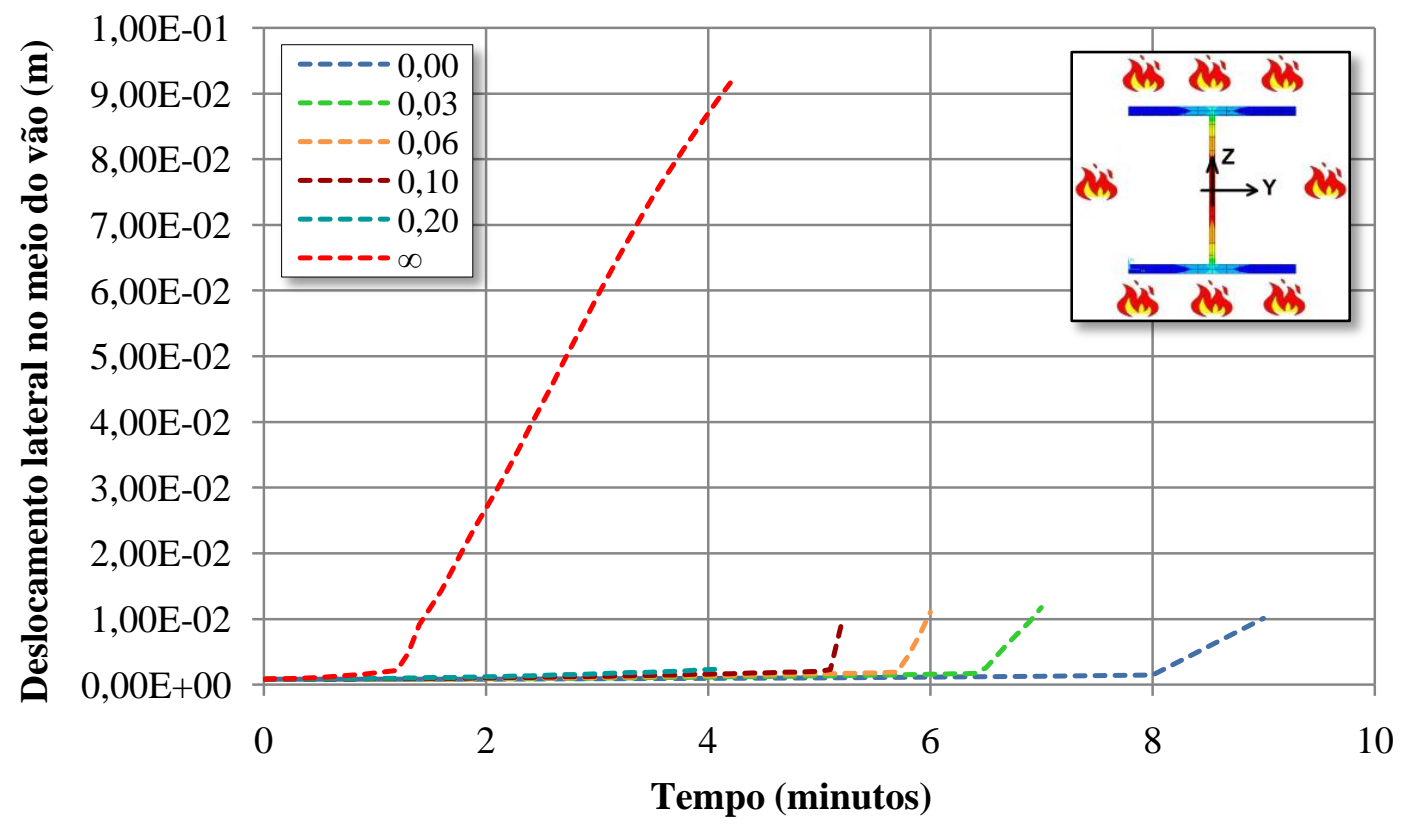

Figura A.3 - Deslocamento lateral no meio do vão na direção da imperfeição inicial para diversos níveis de restrição axial e carga estática inicial de 50\% da carga de colapso à temperatura ambiente. 


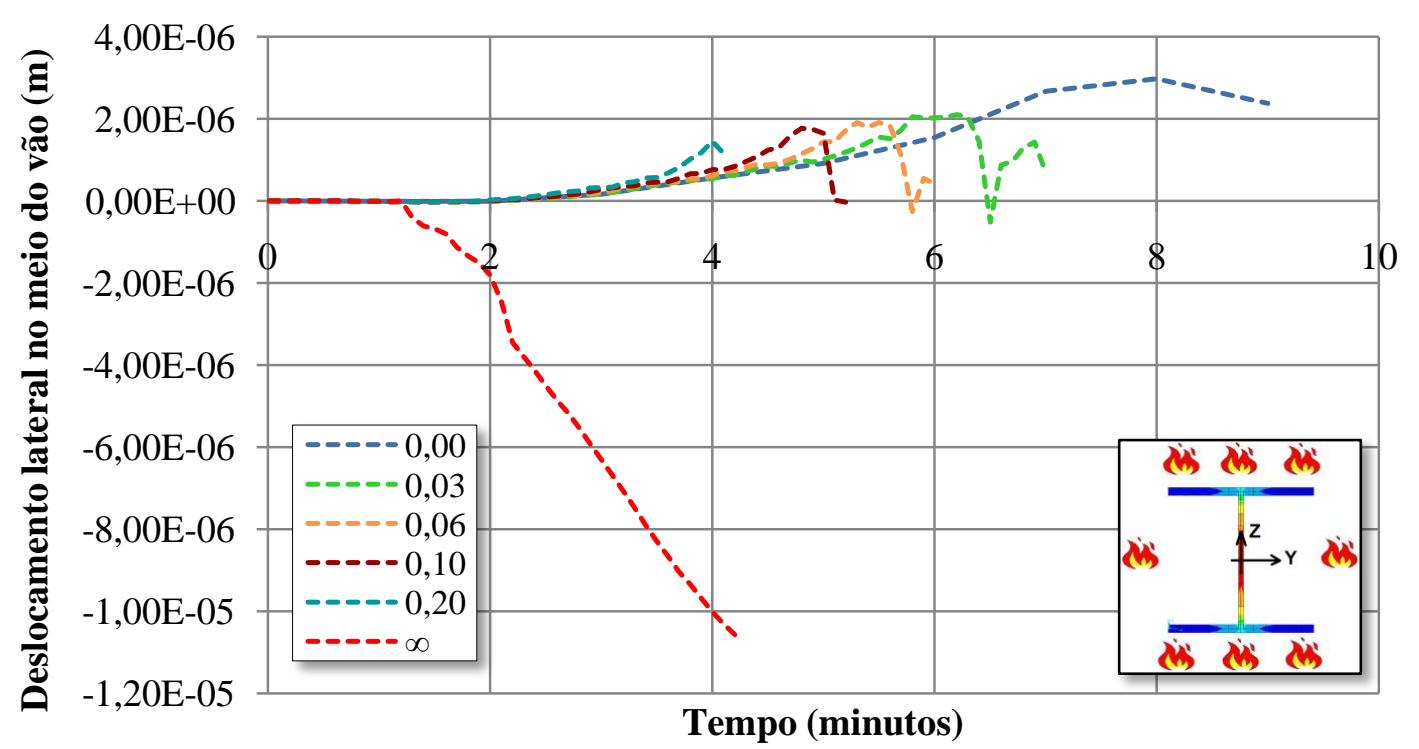

Figura A.4 - Deslocamento lateral no meio do vão na direção perpendicular à imperfeição inicial com 50\% de carga inicial.

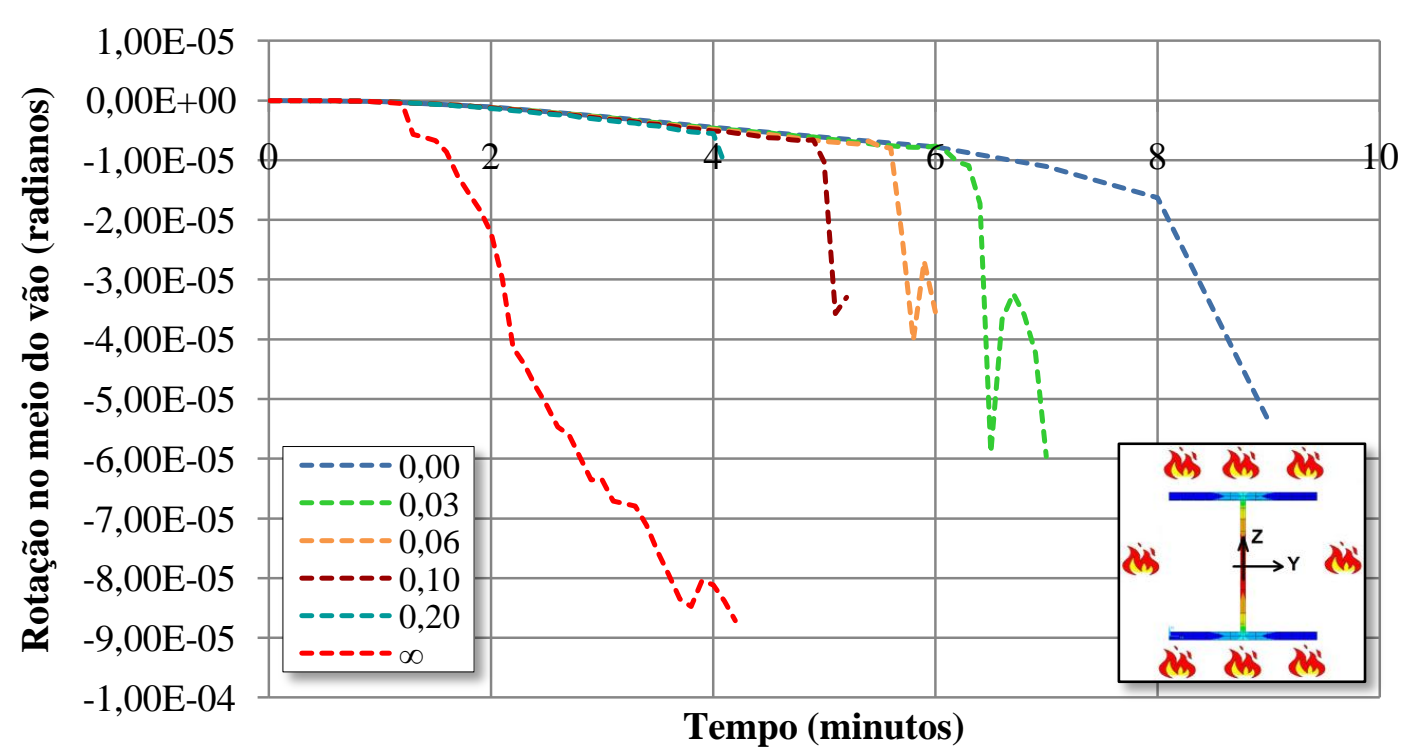

Figura A.5 - Rotação do eixo longitudinal no meio do vão com 50\% de carga inicial. 
Dissertação de Mestrado

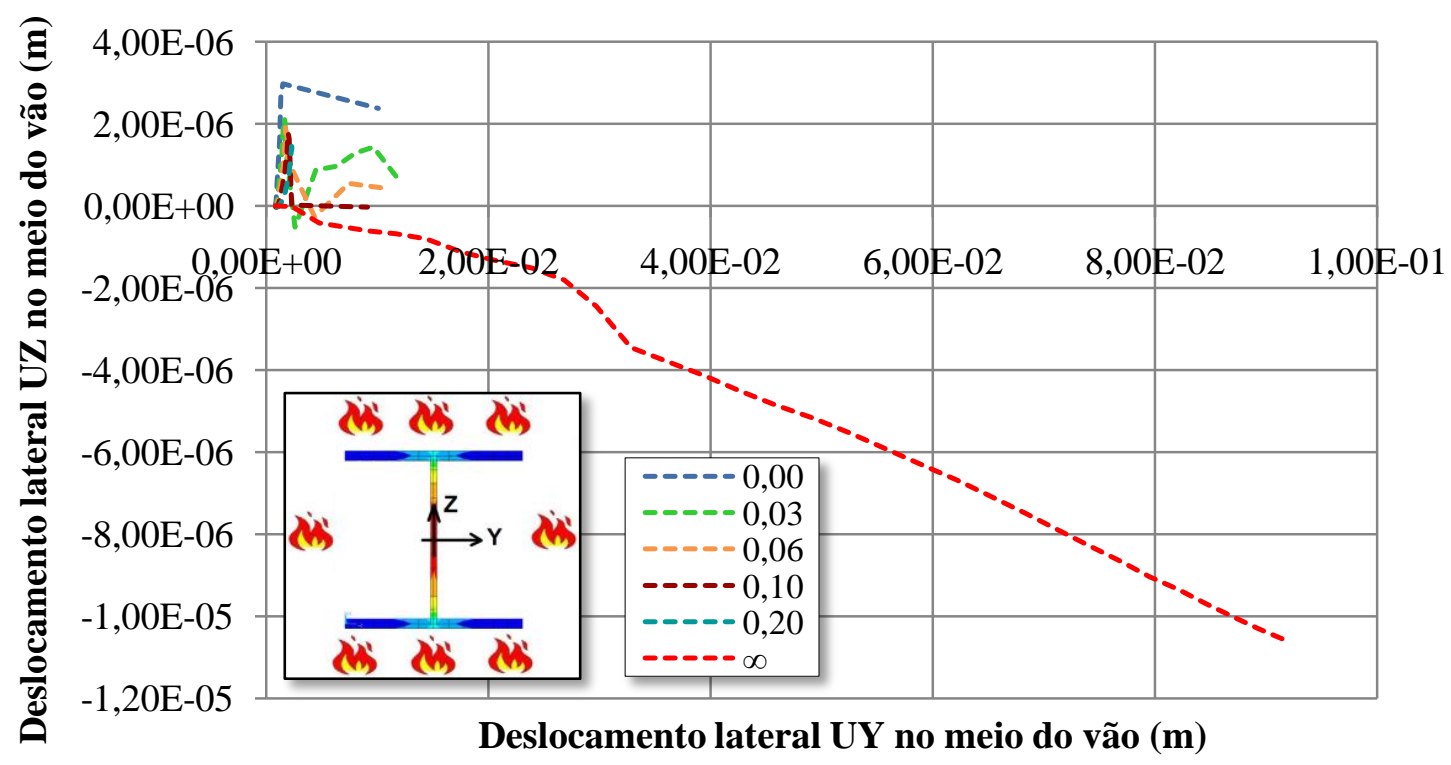

Figura A.6 - Deslocamento lateral no meio do vão nas direções Y e Z do plano da seção com $50 \%$ carga inicial. 


\section{APÊNDICE B - Gráficos do modelo sem paredes em contato com o perfil com $75 \%$ da carga de colapso}

Os gráficos que não foram apresentados no corpo do texto serão incluídos nesta sessão que se segue.

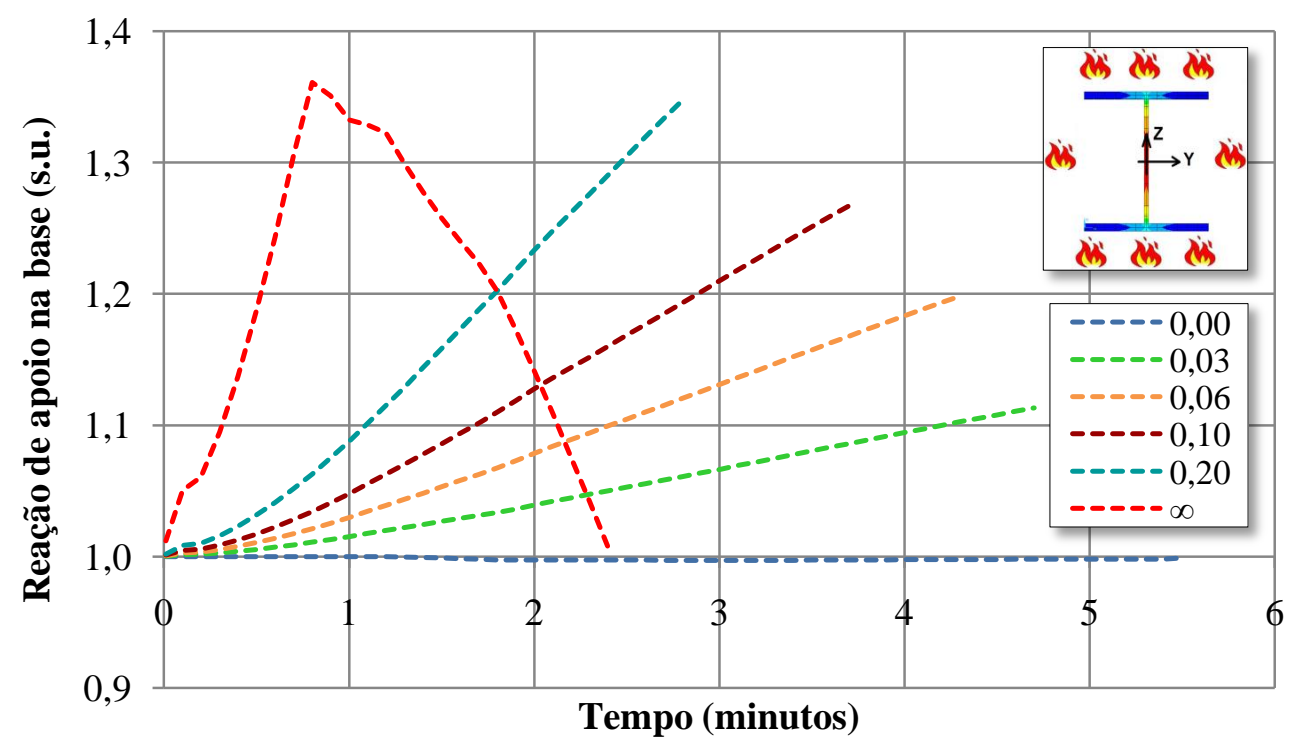

Figura B.1 - Carregamento total aplicado para diversos níveis de restrição axial e carga estática inicial de $75 \%$ da carga de colapso à temperatura ambiente. 


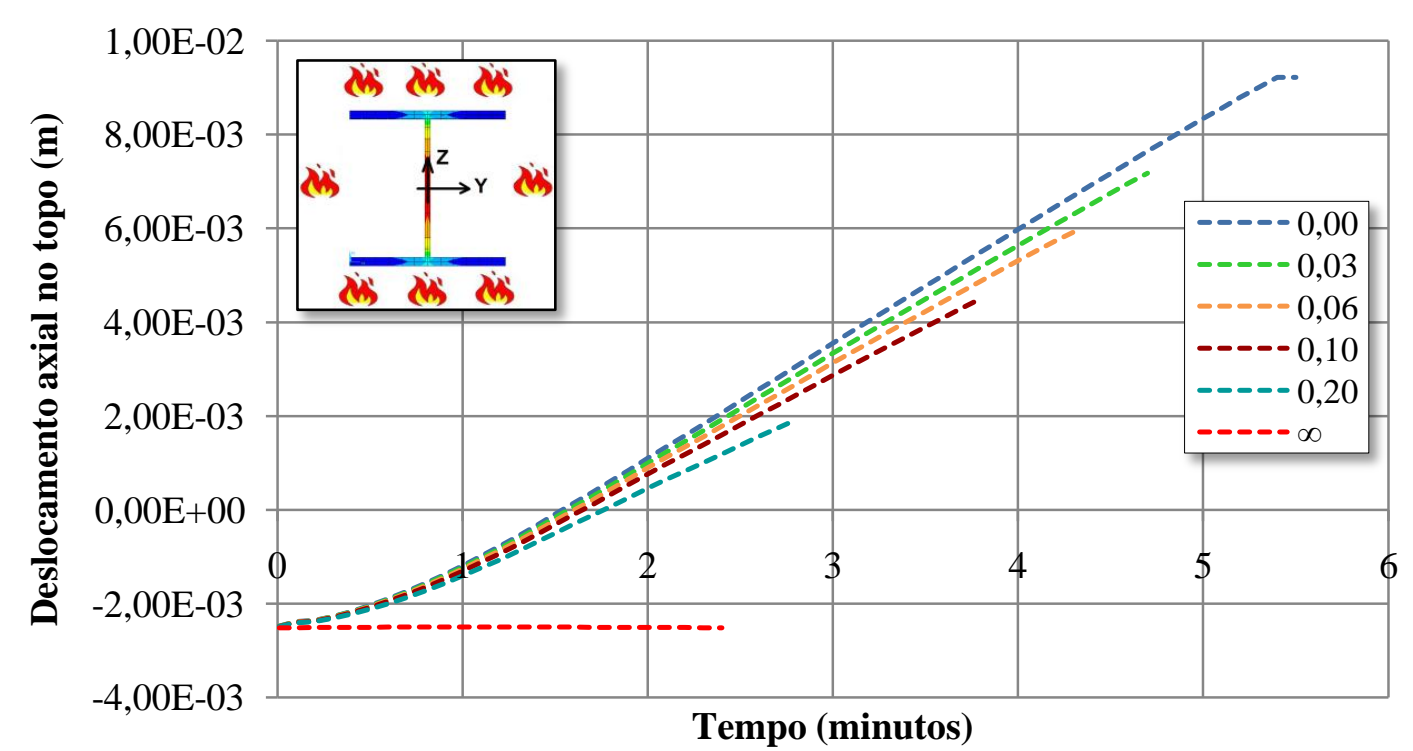

Figura B.2 - Deslocamento axial no topo do pilar para diversos níveis de restrição axial e carga estática inicial de $75 \%$ da carga de colapso à temperatura ambiente.

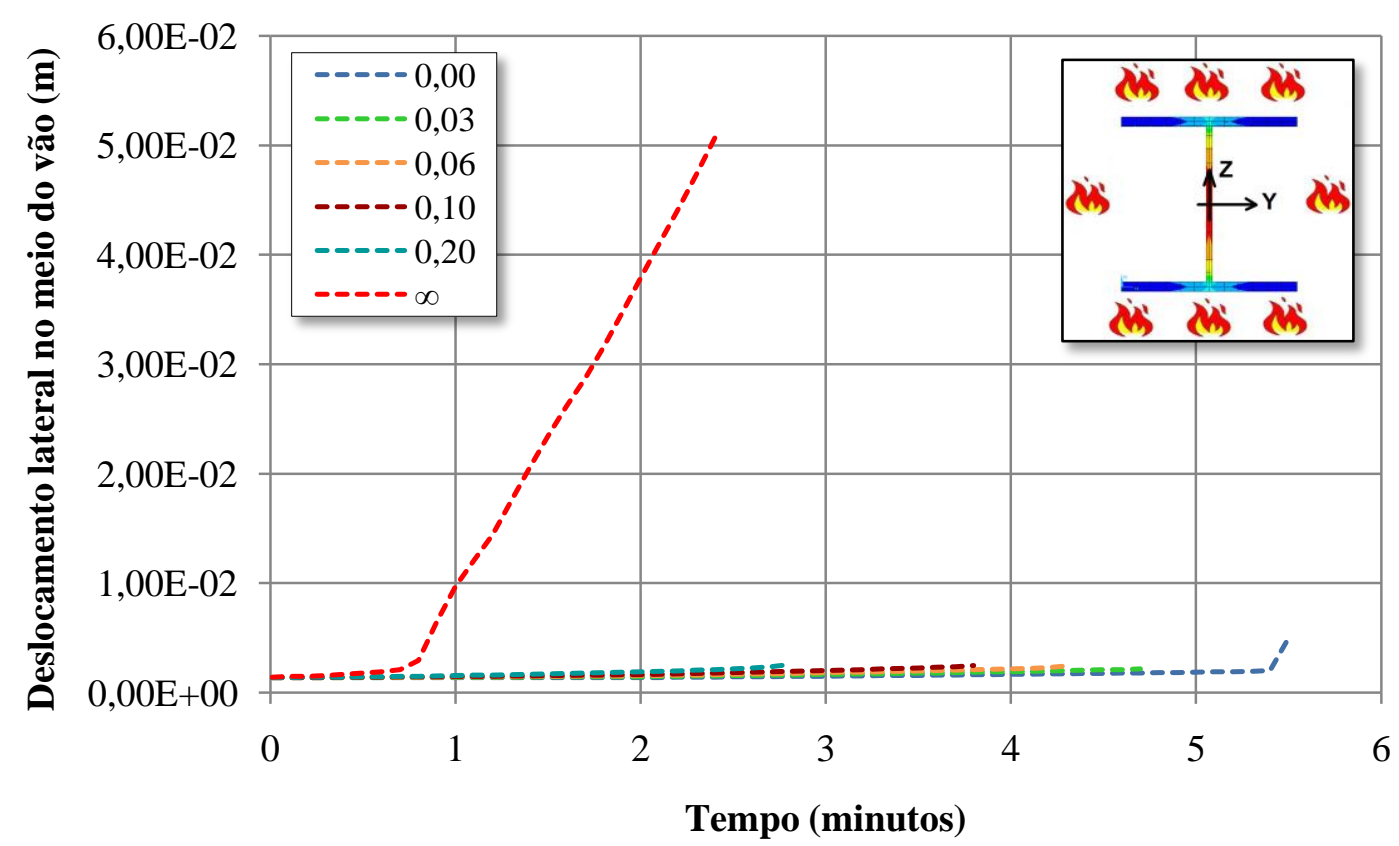

Figura B.3 - Deslocamento lateral no meio do vão na direção da imperfeição inicial para diversos níveis de restrição axial e carga estática inicial de 75\% da carga de colapso à temperatura ambiente. 


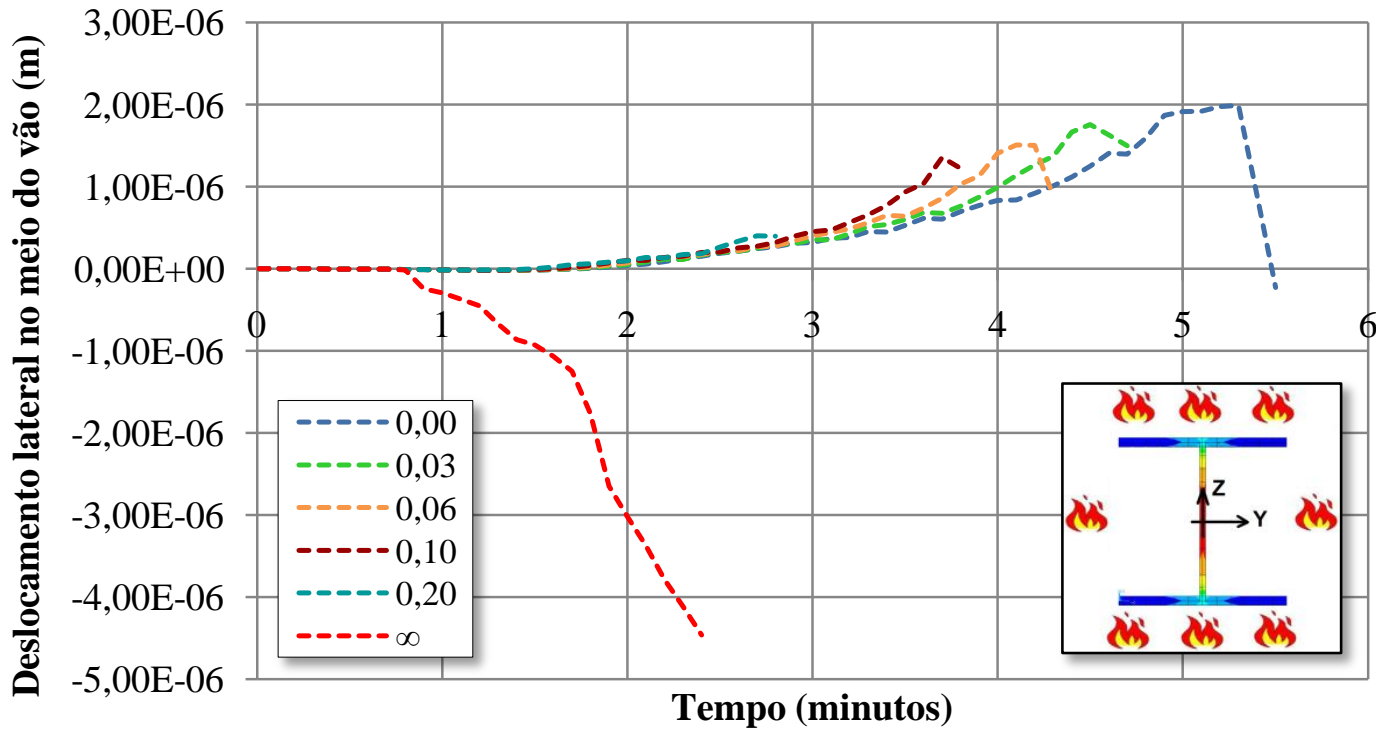

Figura B.4 - Deslocamento lateral no meio do vão na direção perpendicular à imperfeição inicial com $75 \%$ de carga inicial.

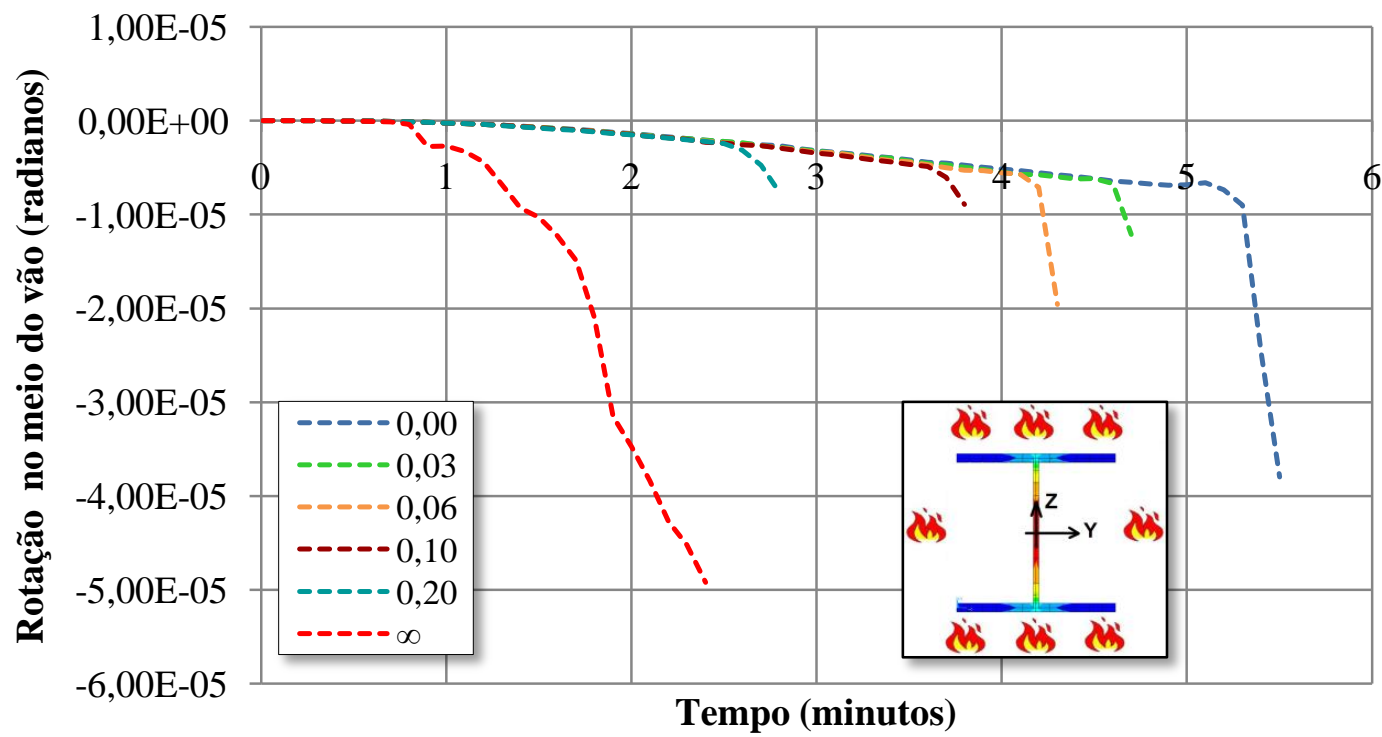

Figura B.5 - Rotação do eixo longitudinal no meio do vão com $75 \%$ de carga inicial. 


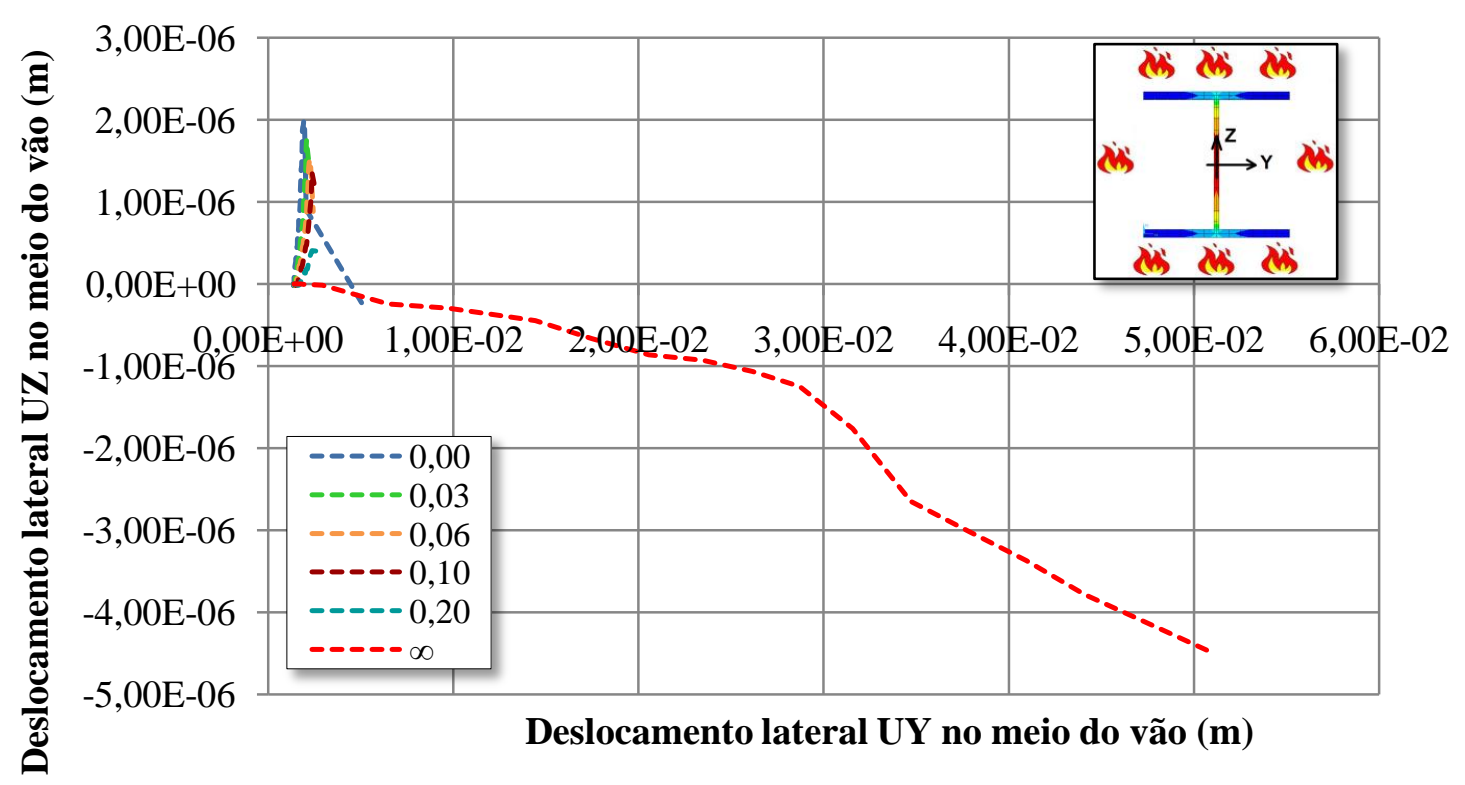

Figura B.6 - Deslocamento lateral no meio do vão nas direções Y e Z do plano da seção com $75 \%$ carga inicial. 


\section{APÊEDICE C - Gráficos do modelo com paredes nas mesas com $50 \%$ da carga de colapso}

Os gráficos que não foram apresentados no corpo do texto serão incluídos nesta sessão que se segue.

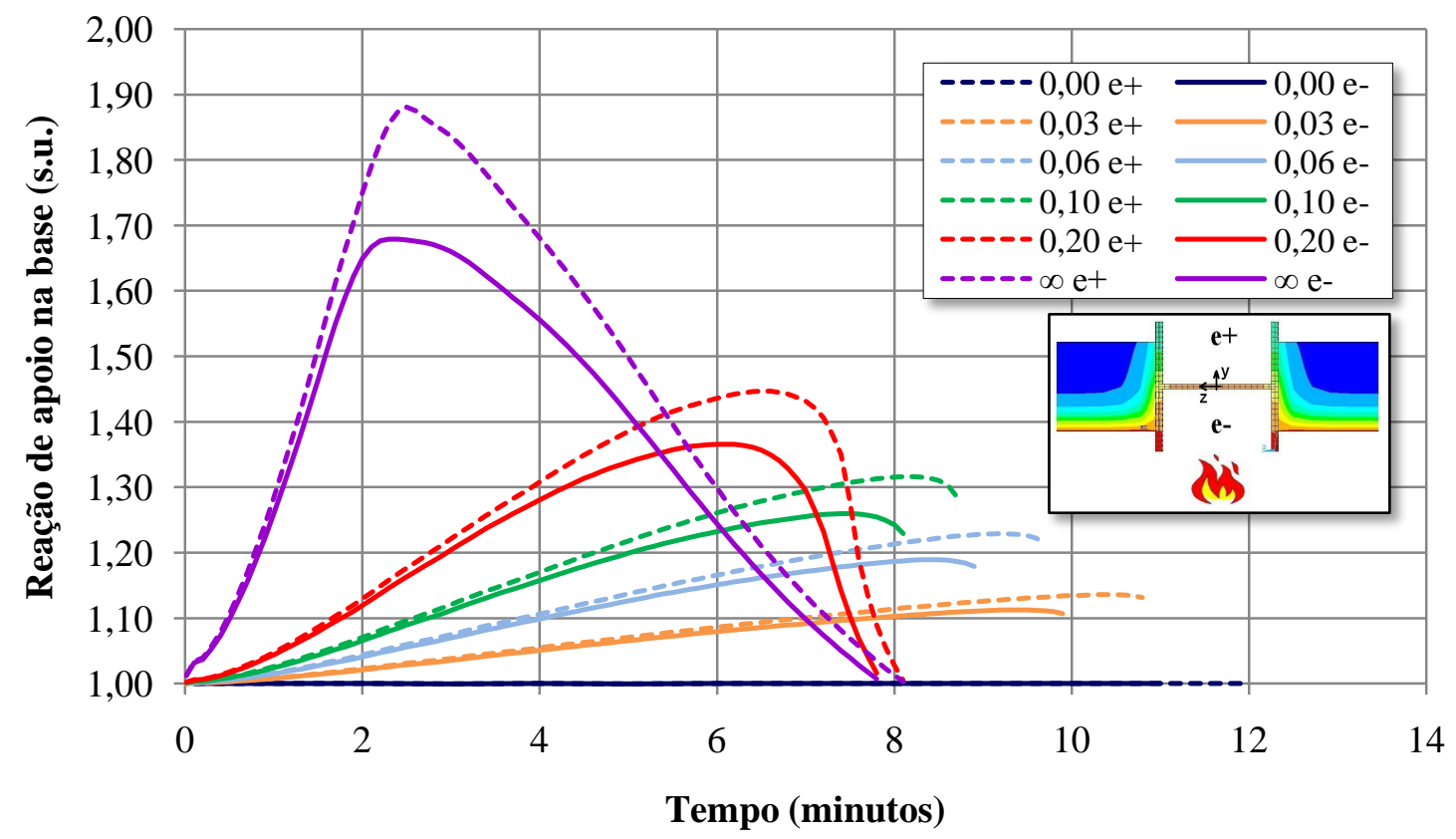

Figura C.1 - Carregamento total aplicado para diversos níveis de restrição axial e carga estática inicial de $50 \%$ da carga de colapso em temperatura ambiente. 


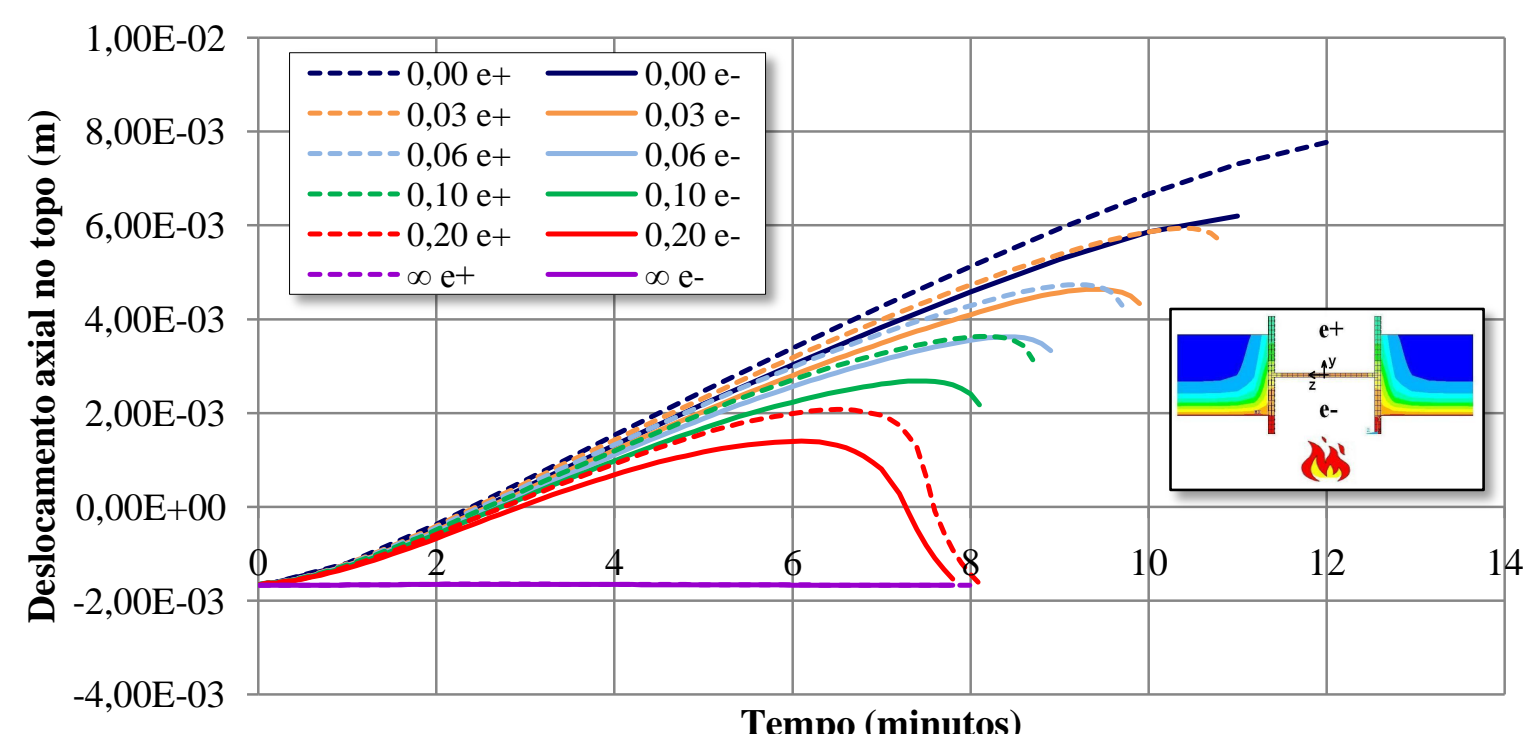

Figura C.2 - Deslocamento axial no topo do pilar para diversos níveis de restrição axial e carga estática inicial de 50\% da carga de colapso em temperatura ambiente.

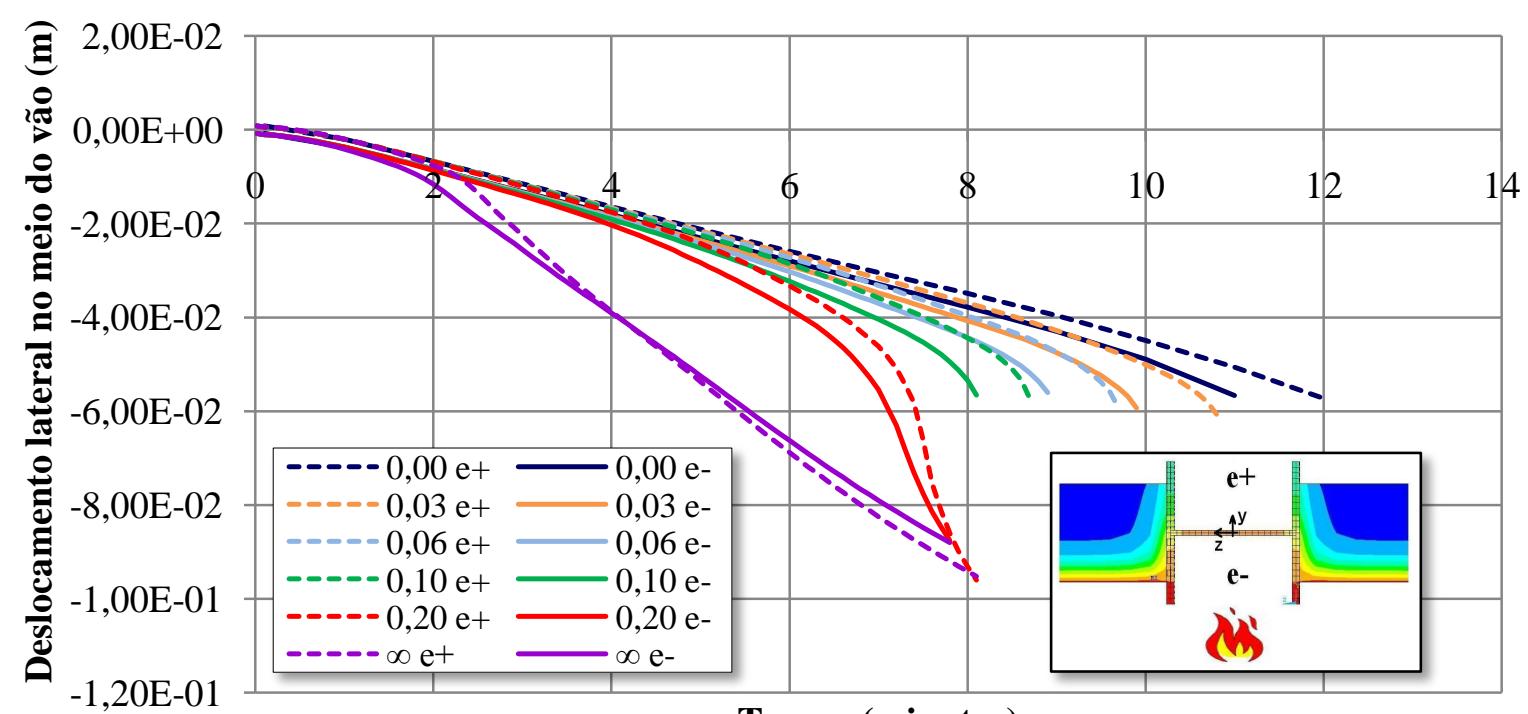

Tempo (minutos)

Figura C.3 - Deslocamento lateral no meio do vão na direção da imperfeição inicial para diversos níveis de restrição axial e carga estática inicial de 50\% da carga de colapso em temperatura ambiente. 


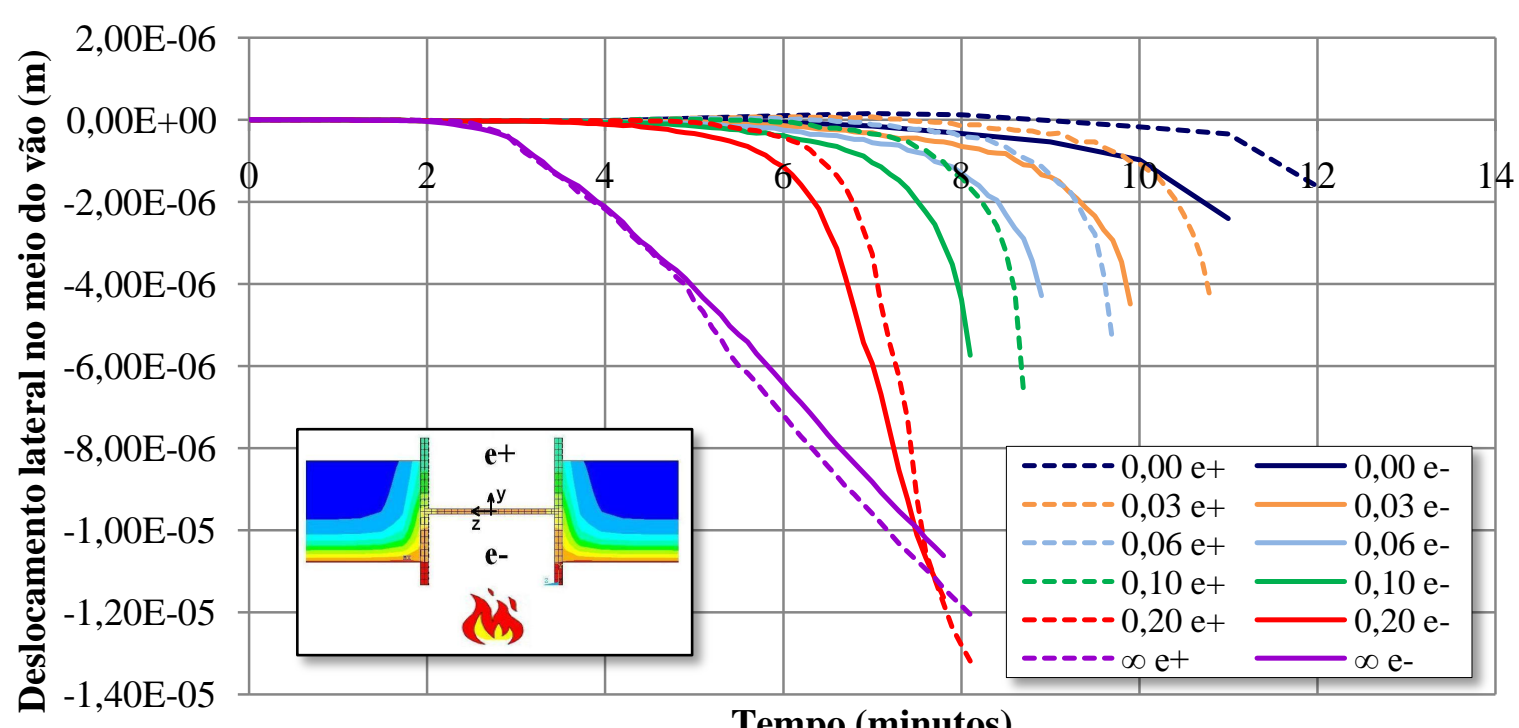

Tempo (minutos)

Figura C.4 - Deslocamento lateral no meio do vão na direção perpendicular à imperfeição inicial para diversos níveis de restrição axial e carga estática inicial de $50 \%$ da carga de colapso em temperatura ambiente.

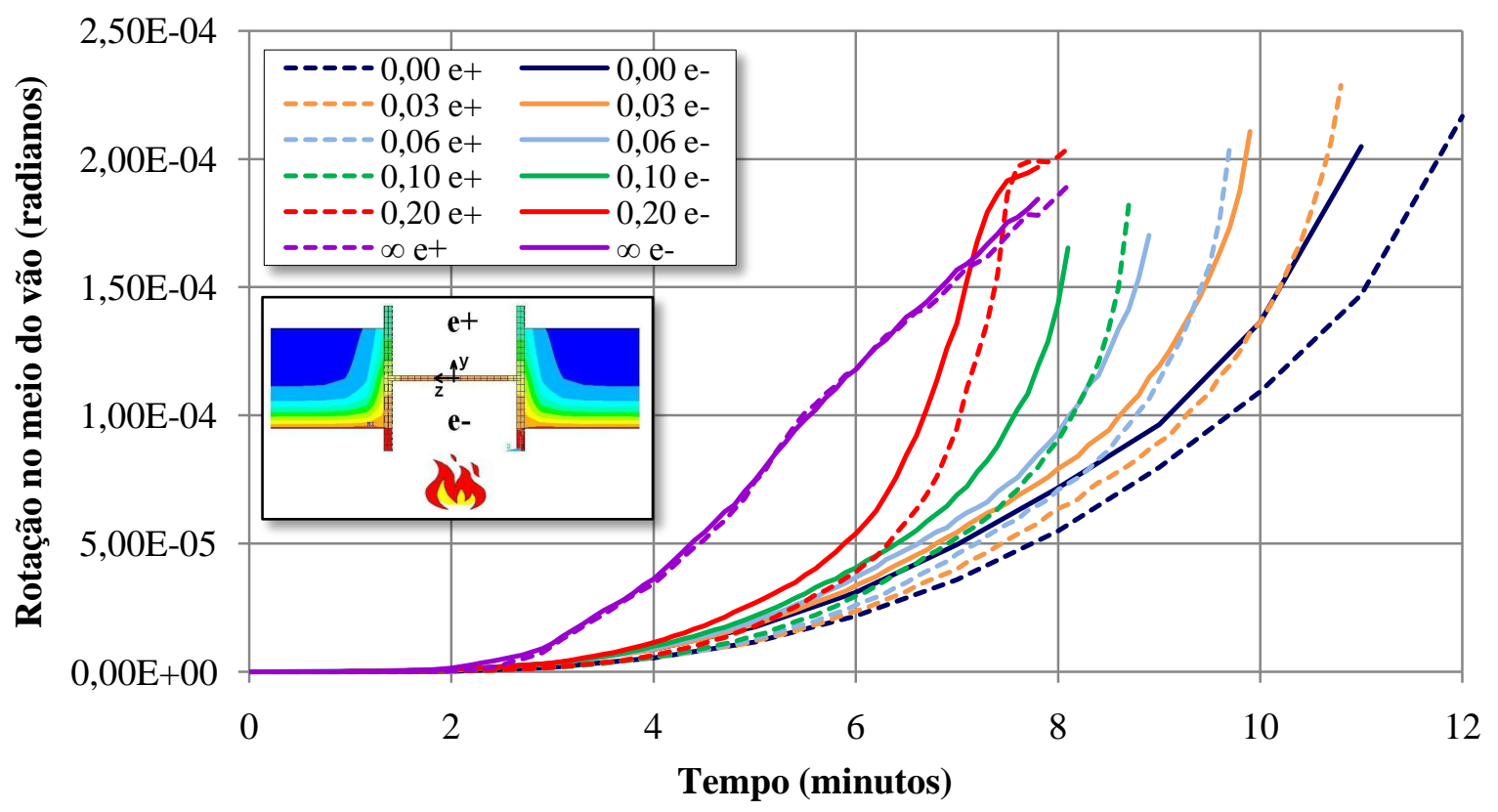

Figura C.5 - Rotação do eixo longitudinal no meio do vão para diversos níveis de restrição axial e carga estática inicial de $50 \%$ da carga de colapso em temperatura ambiente. 


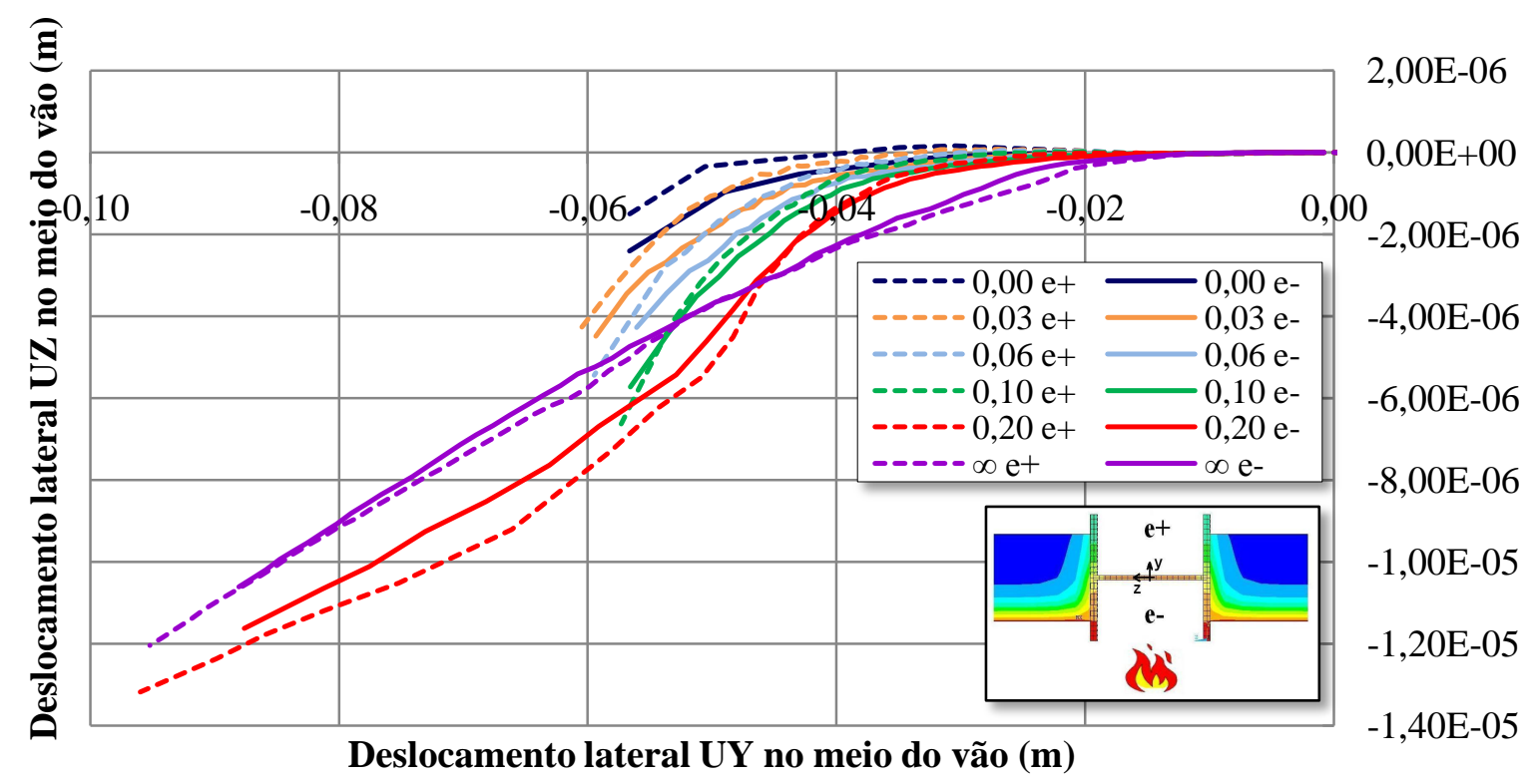

Figura C.6 - Deslocamento nas direções Y e Z do plano da seção para diversos níveis de restrição axial e carga estática inicial de $50 \%$ da carga de colapso em temperatura ambiente. 


\section{APÊEDICE D - Gráficos do modelo com paredes nas mesas com $75 \%$ da carga de colapso}

Os gráficos que não foram apresentados no corpo do texto serão incluídos nesta sessão que se segue.

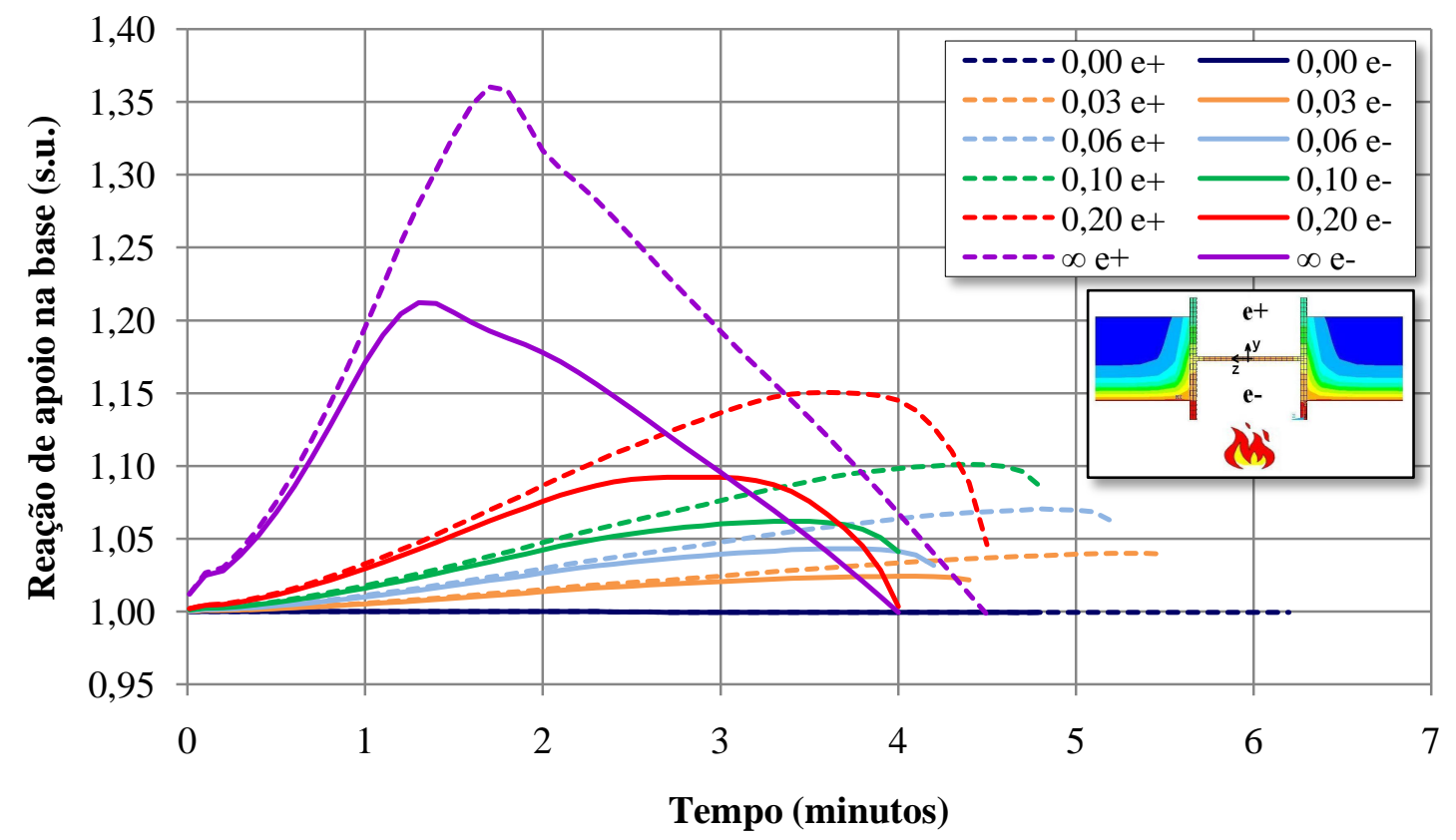

Figura D.1 - Carregamento total aplicado para diversos níveis de restrição axial e carga estática inicial de $75 \%$ da carga de colapso em temperatura ambiente. 


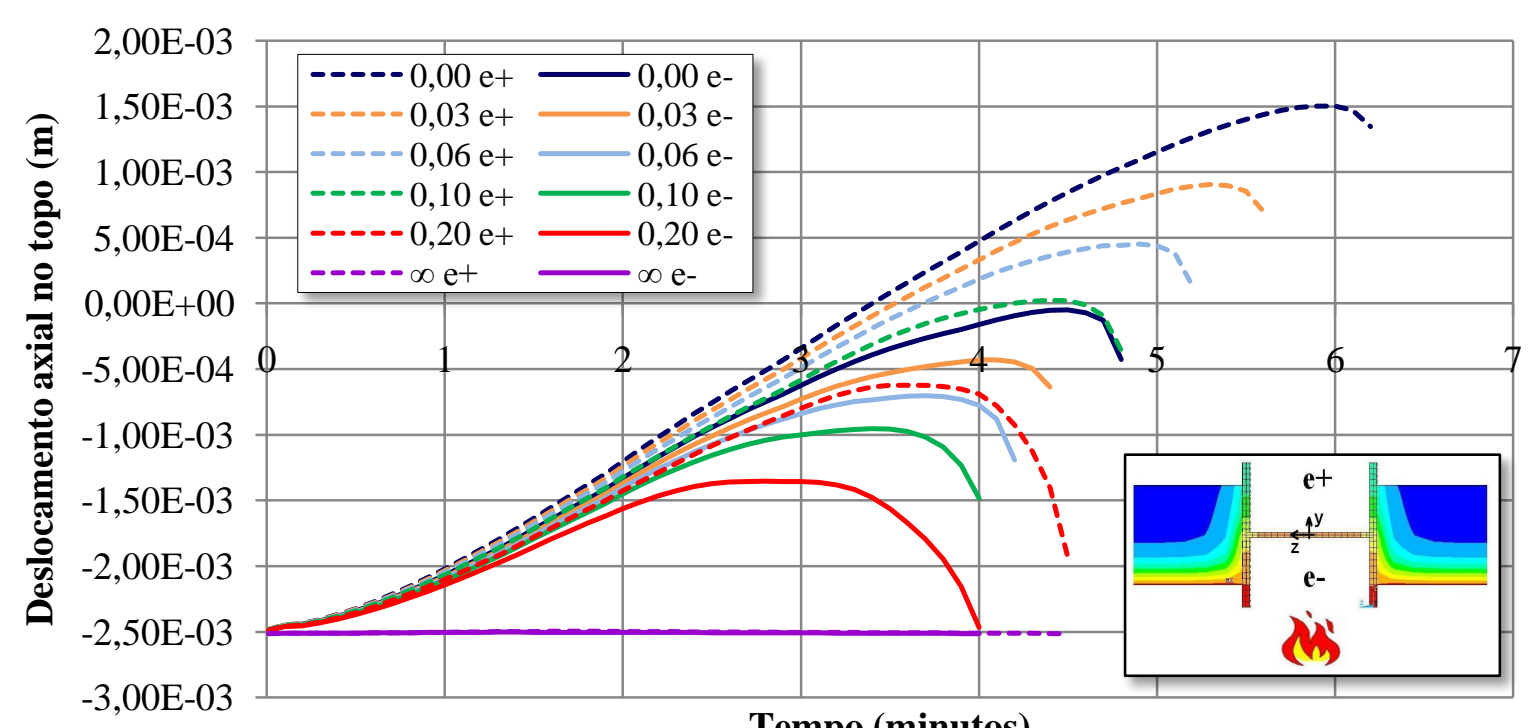

Tempo (minutos)

Figura D.2 - Deslocamento axial no topo do pilar para diversos níveis de restrição axial e carga estática inicial de $75 \%$ da carga de colapso em temperatura ambiente.

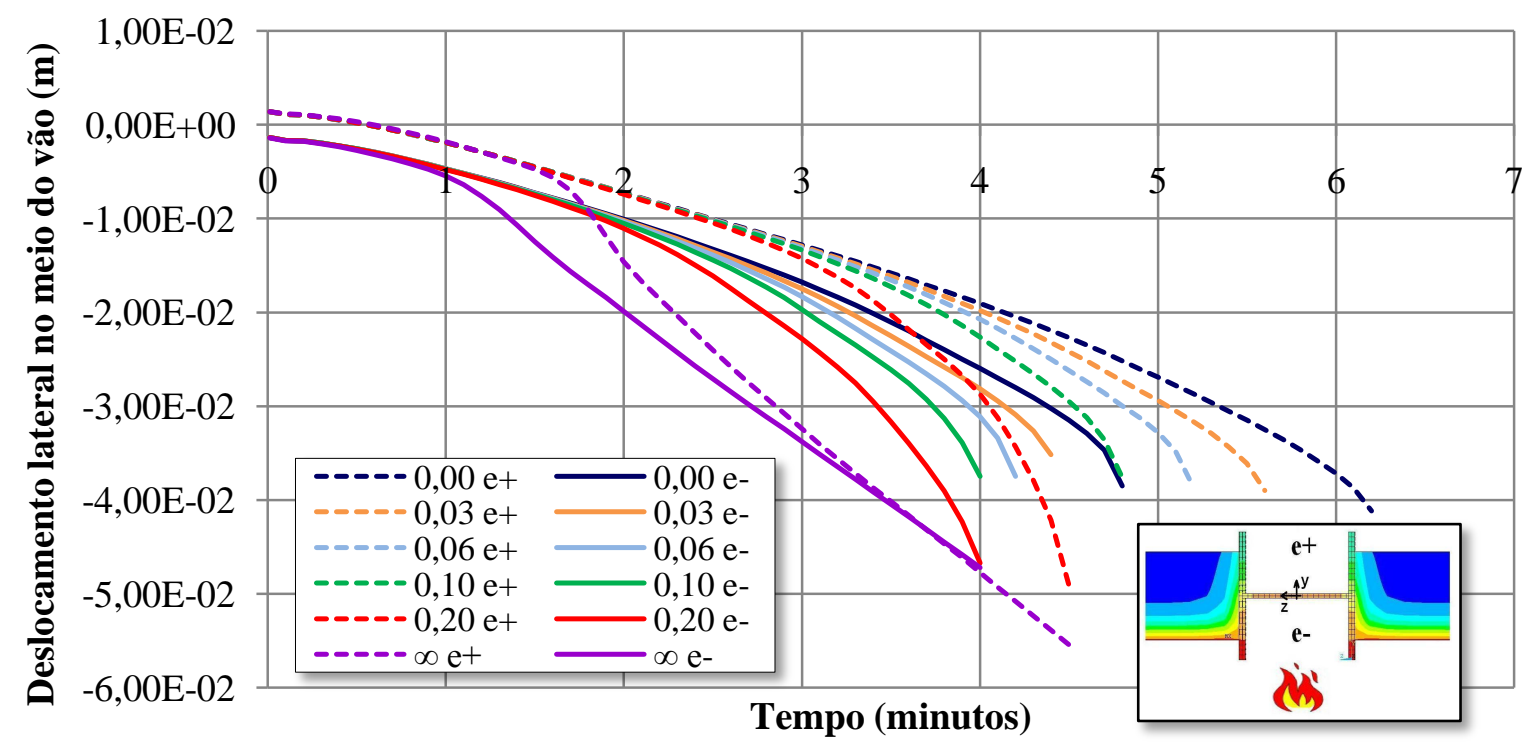

Figura D.3 - Deslocamento lateral no meio do vão na direção da imperfeição inicial para diversos níveis de restrição axial e carga estática inicial de $75 \%$ da carga de colapso em temperatura ambiente. 


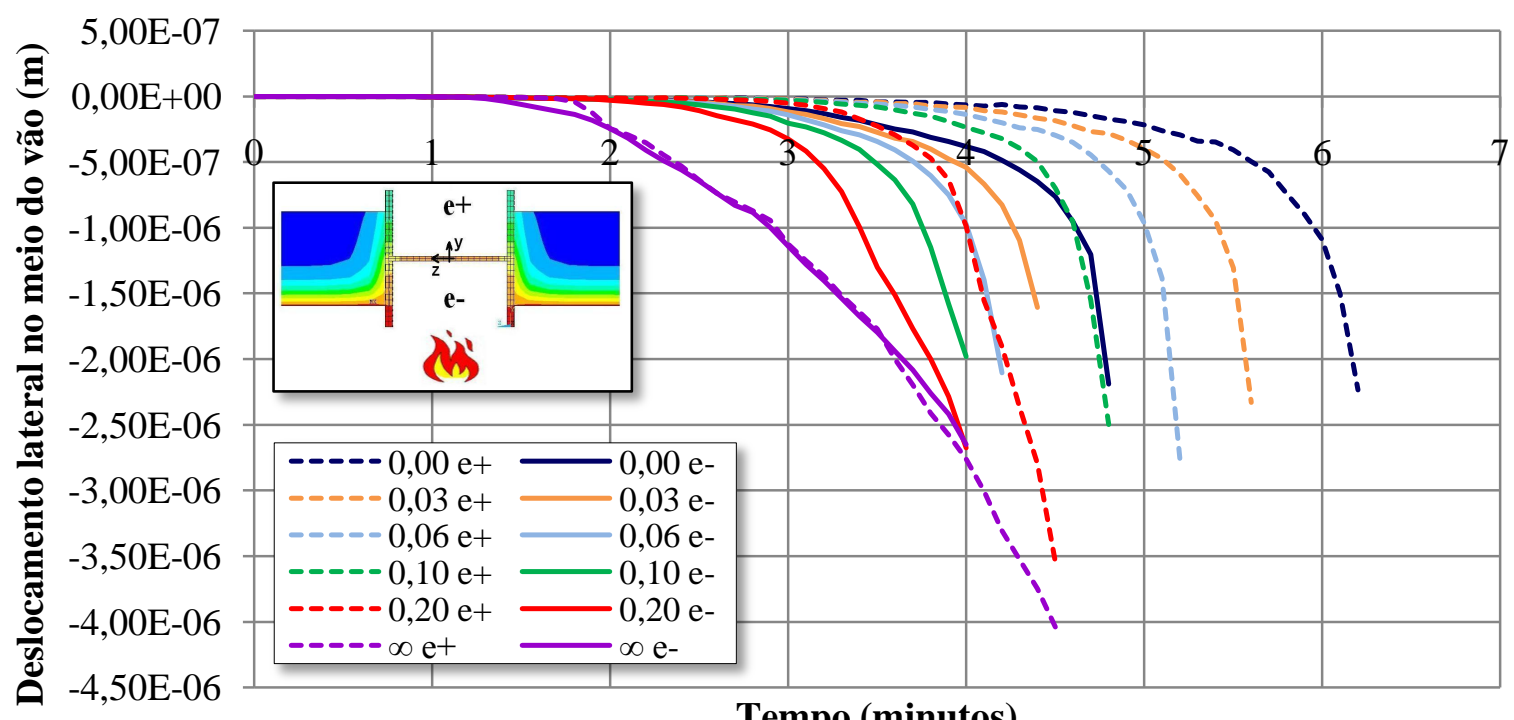

Tempo (minutos)

Figura D.4 - Deslocamento lateral no meio do vão na direção perpendicular à imperfeição inicial para diversos níveis de restrição axial e carga estática inicial de $75 \%$ da carga de colapso em temperatura ambiente.

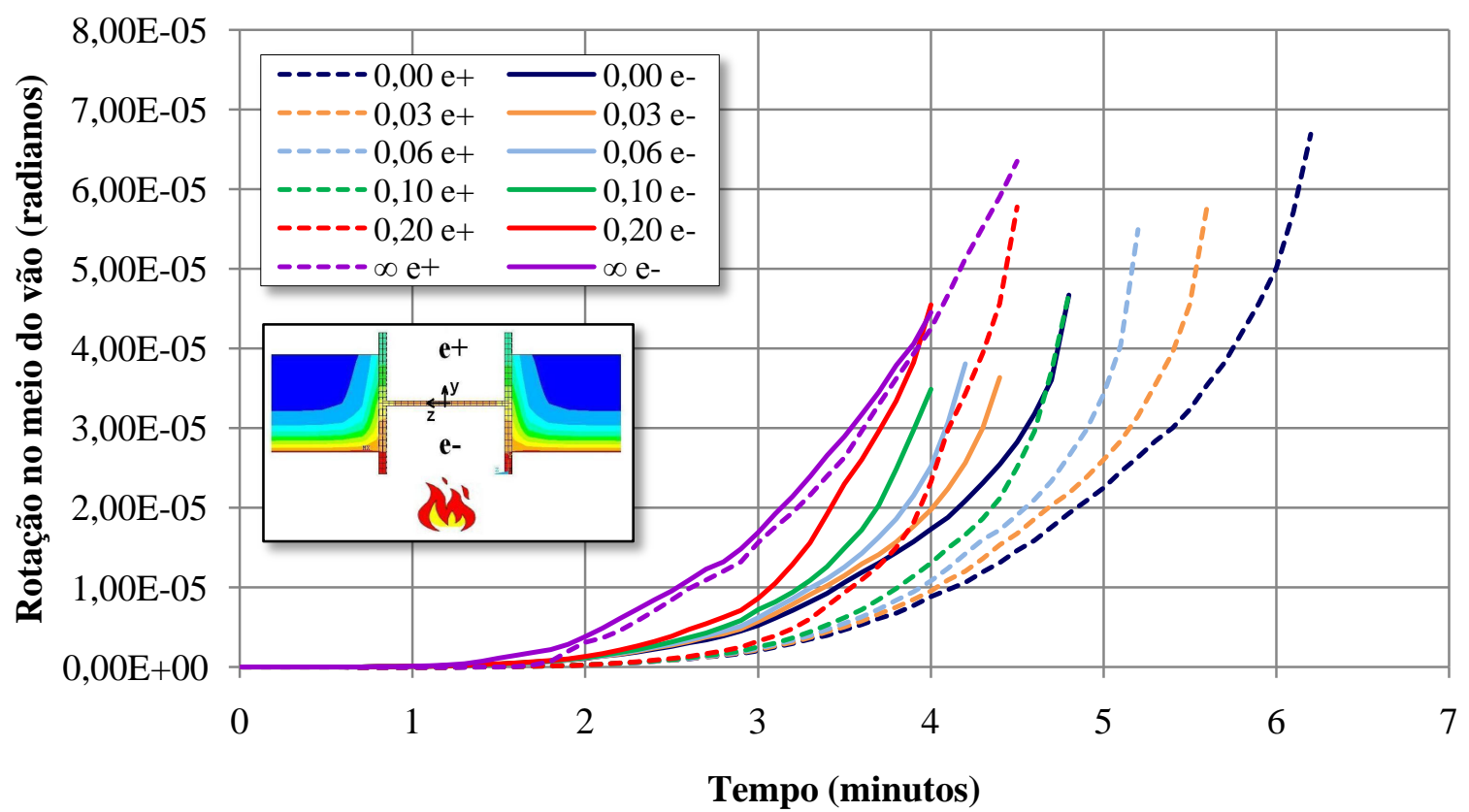

Figura D.5 - Rotação do eixo longitudinal no meio do vão para diversos níveis de restrição axial e carga estática inicial de $75 \%$ da carga de colapso em temperatura ambiente. 


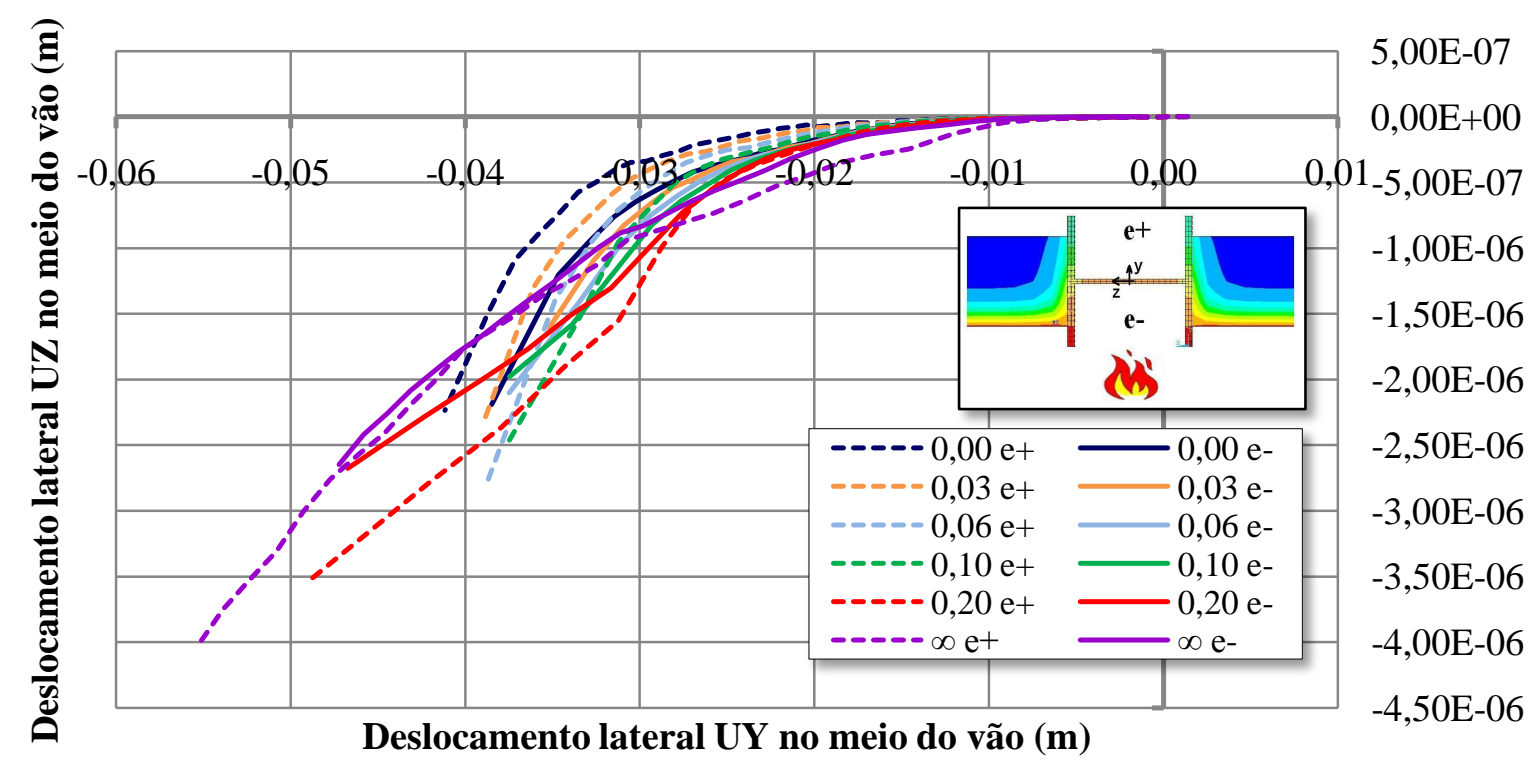

Figura D.6 - Deslocamento nas direções Y e Z do plano da seção para diversos níveis de restrição axial e carga estática inicial de $75 \%$ da carga de colapso em temperatura ambiente. 


\section{APÊEDICE E - Gráficos do modelo com paredes na alma com $50 \%$ da carga de colapso}

Os gráficos que não foram apresentados no corpo do texto serão incluídos nesta sessão que se segue.

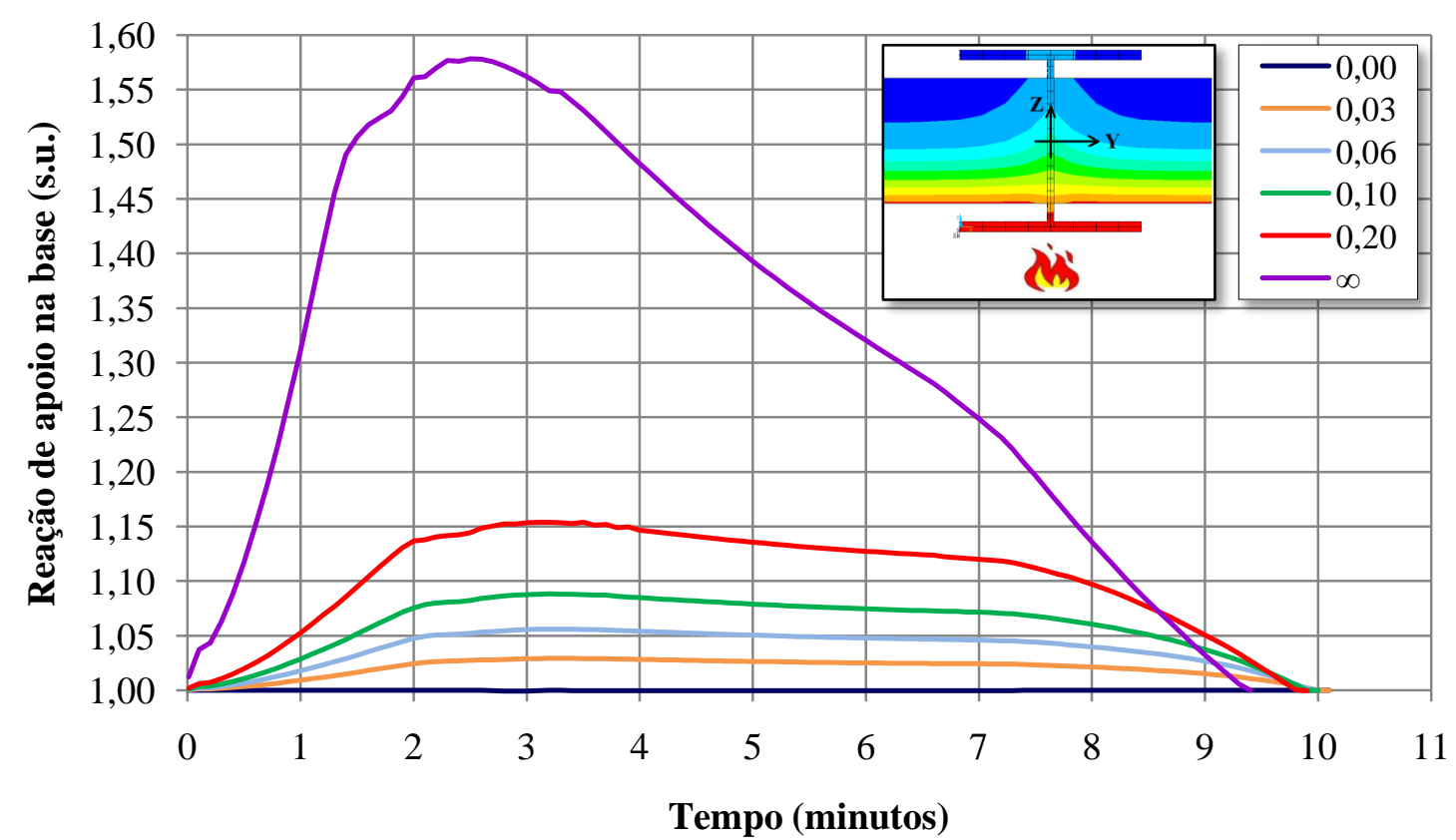

Figura E.1 - Carregamento total aplicado para diversos níveis de restrição axial e carga estática inicial de 50\% da carga de colapso em temperatura ambiente vão do modelo com parede na alma e com restrição axial. 


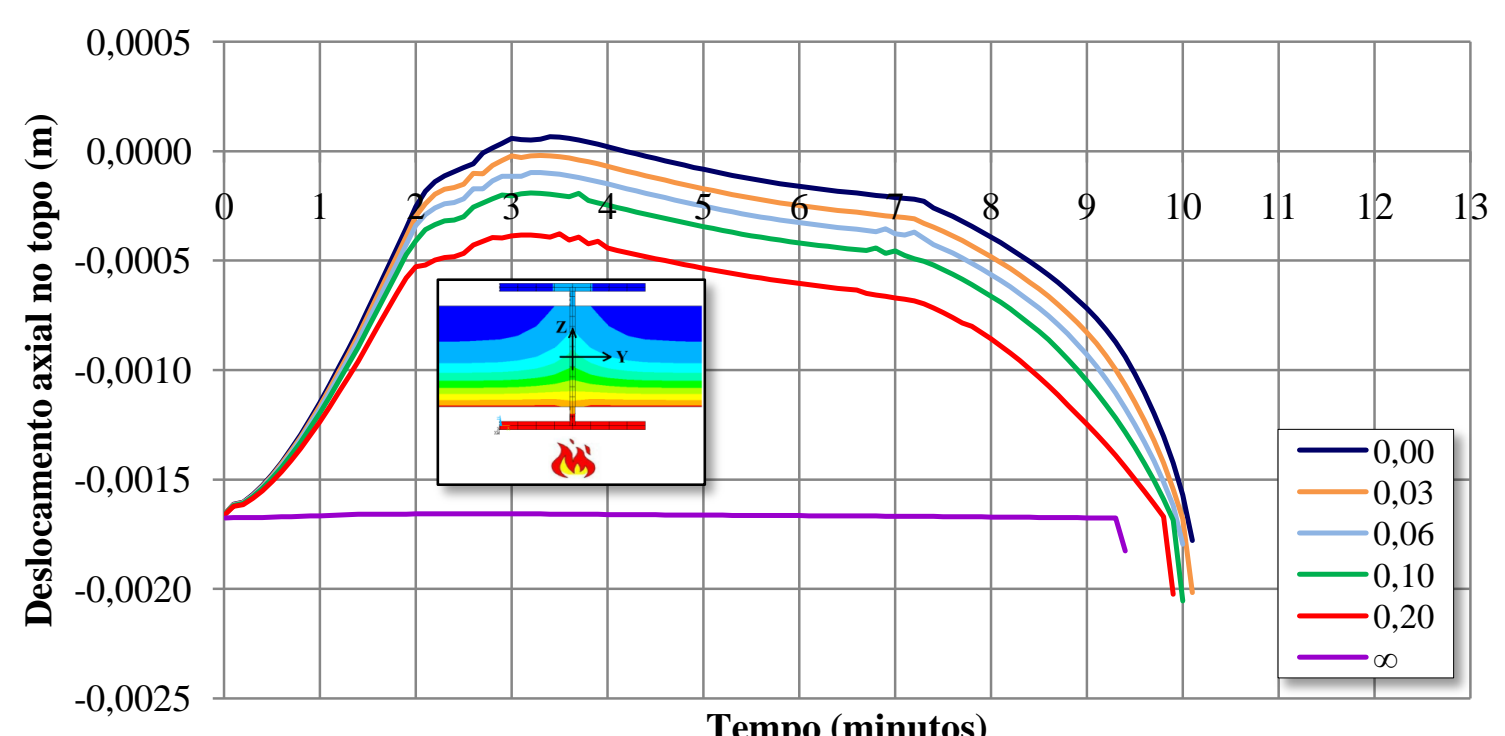

Figura E.2 - Deslocamento axial no topo do pilar para diversos níveis de restrição axial e carga estática inicial de 50\% da carga de colapso em temperatura ambiente do modelo com parede na alma e com restrição axial.

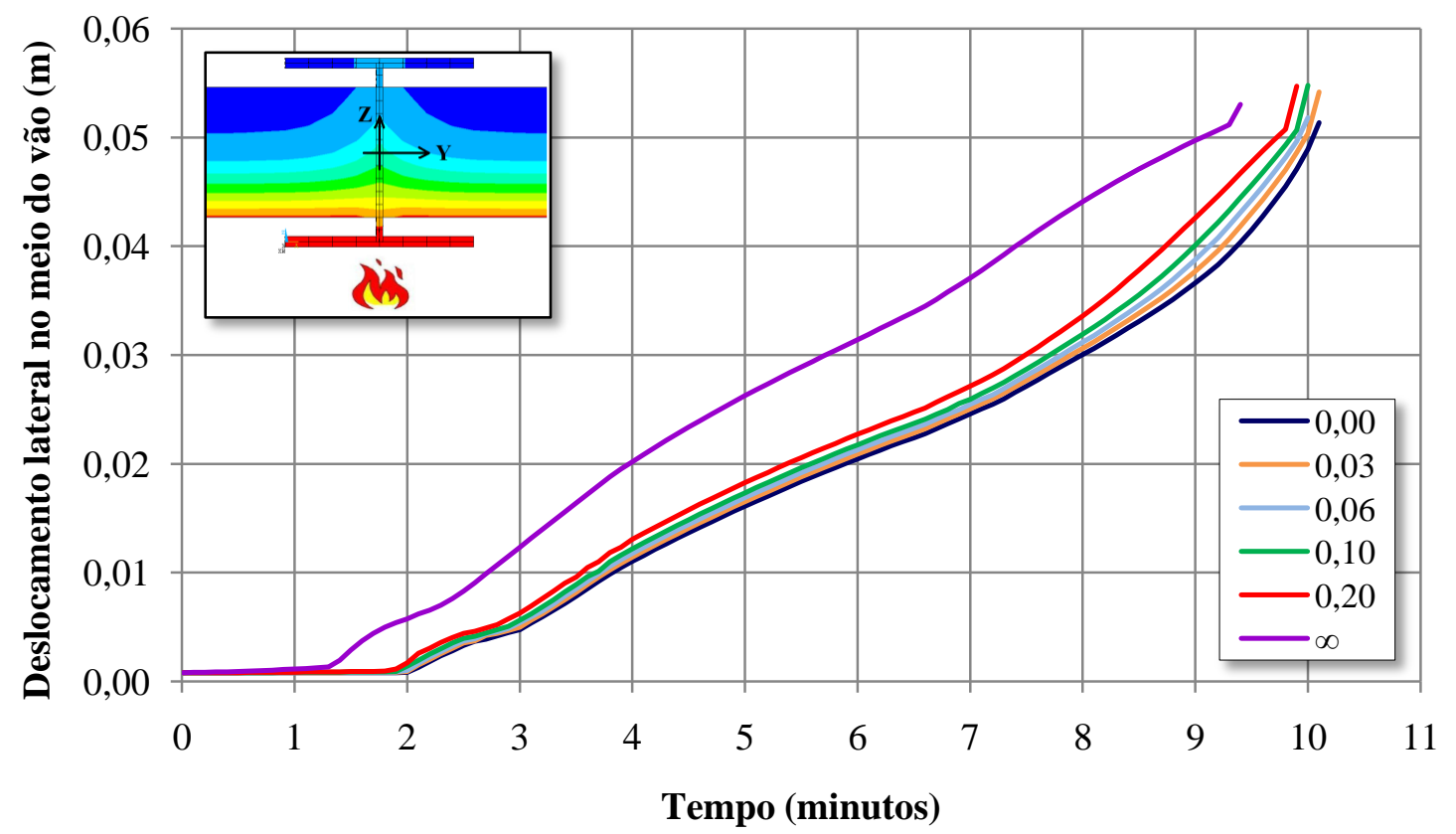

Figura E.3 - Deslocamento lateral no meio do vão na direção UY da imperfeição inicial para diversos níveis de restrição axial e carga estática inicial de 50\% da carga de colapso em temperatura ambiente do modelo com parede na alma e com restrição axial. 


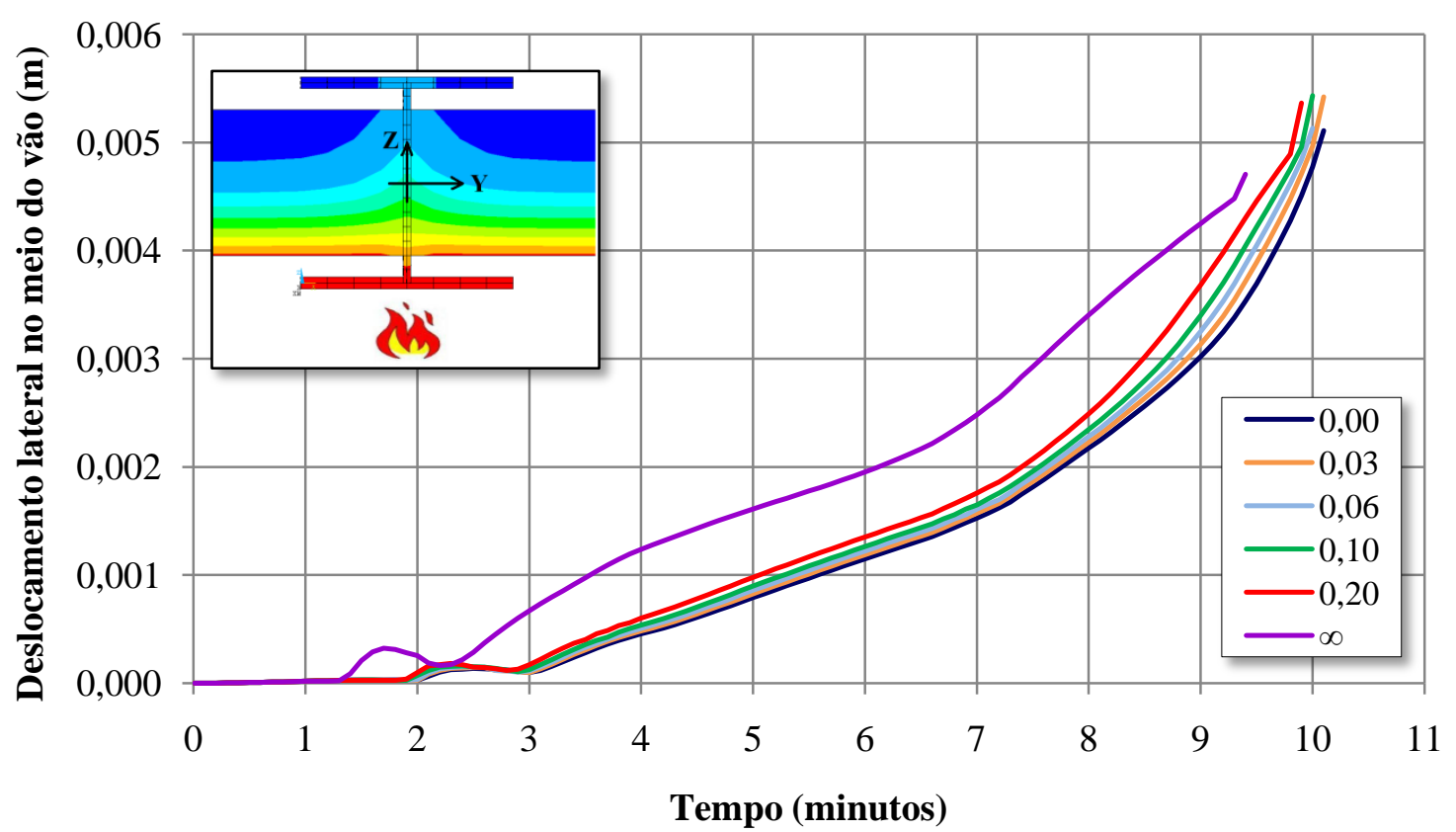

Figura E.4 - Deslocamento lateral no meio do vão na direção perpendicular UZ à imperfeição inicial para diversos níveis de restrição axial e carga estática inicial de $50 \%$ da carga de colapso em temperatura ambiente do modelo com parede na alma e com restrição axial.

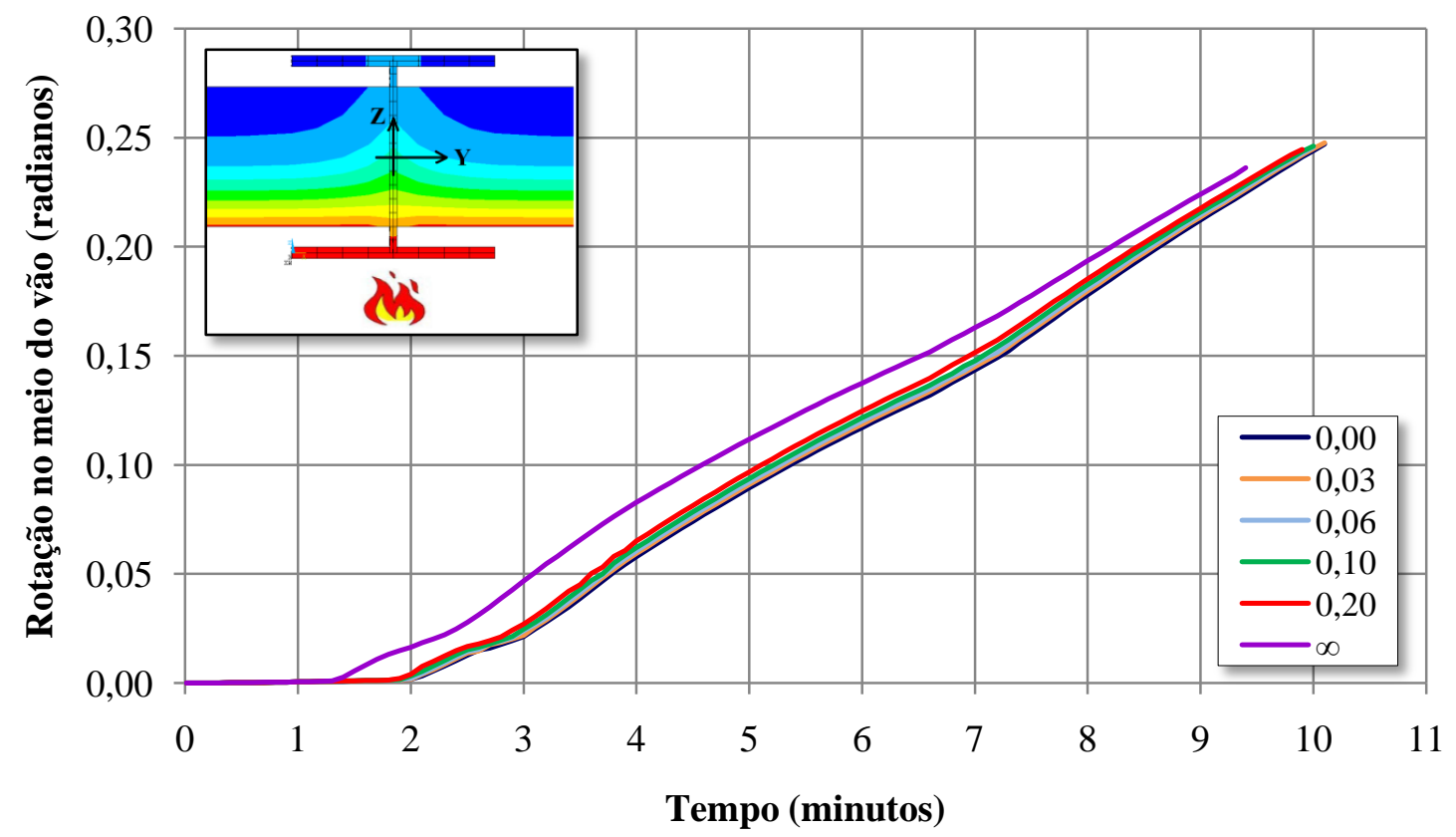

Figura E.5 - Rotação do eixo longitudinal no meio do vão para diversos níveis de restrição axial e carga estática inicial de $50 \%$ da carga de colapso em temperatura ambiente do modelo com parede na alma e com restrição axial. 


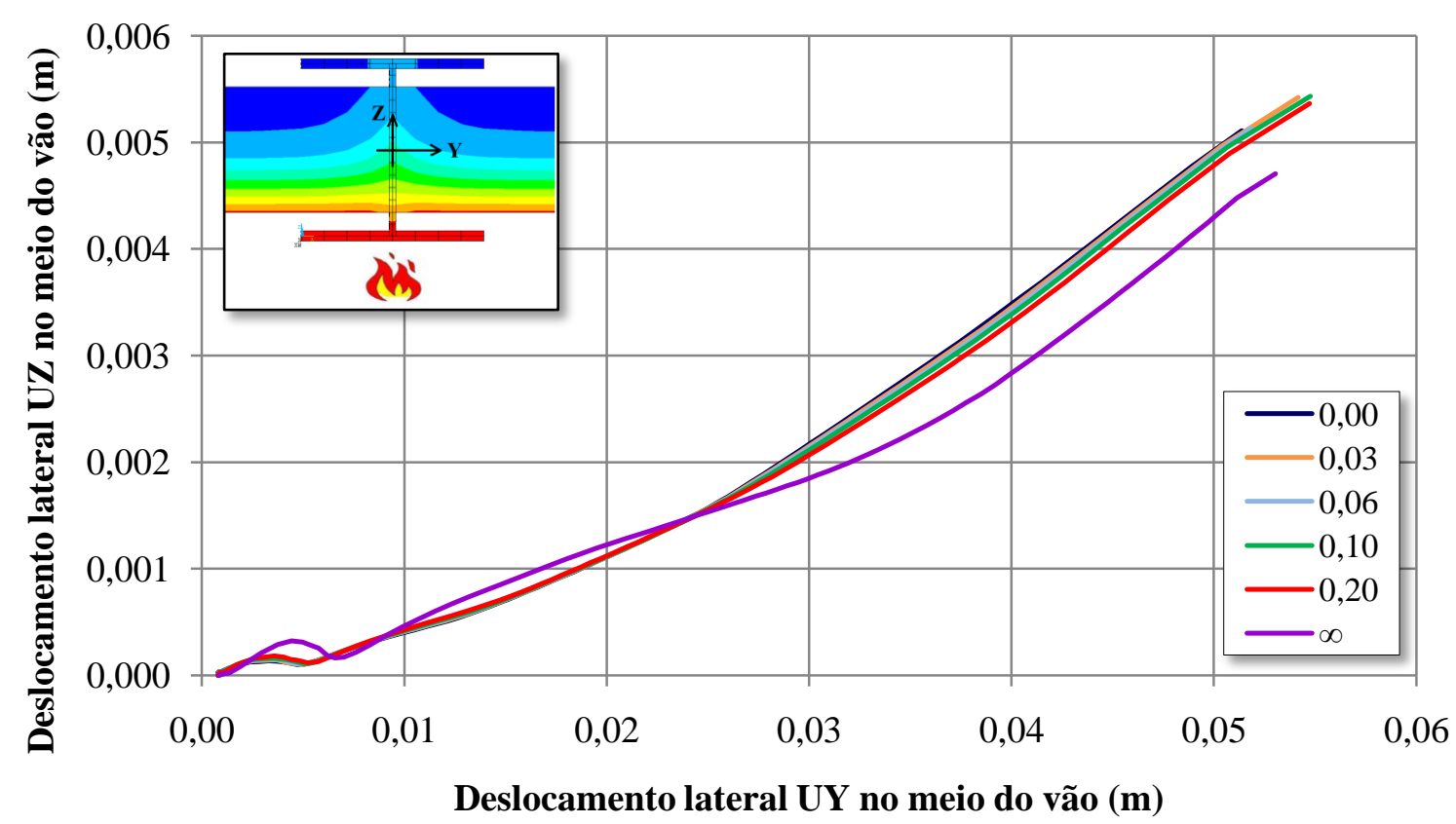

Figura E.6 - Deslocamento nas direções Y e Z do plano da seção para diversos níveis de restrição axial e carga estática inicial de $50 \%$ da carga de colapso em temperatura ambiente do modelo com parede na alma e com restrição axial. 


\section{APÊEDICE F - Gráficos do modelo com paredes na alma com $75 \%$ da carga de colapso}

Os gráficos que não foram apresentados no corpo do texto serão incluídos nesta sessão que se segue.

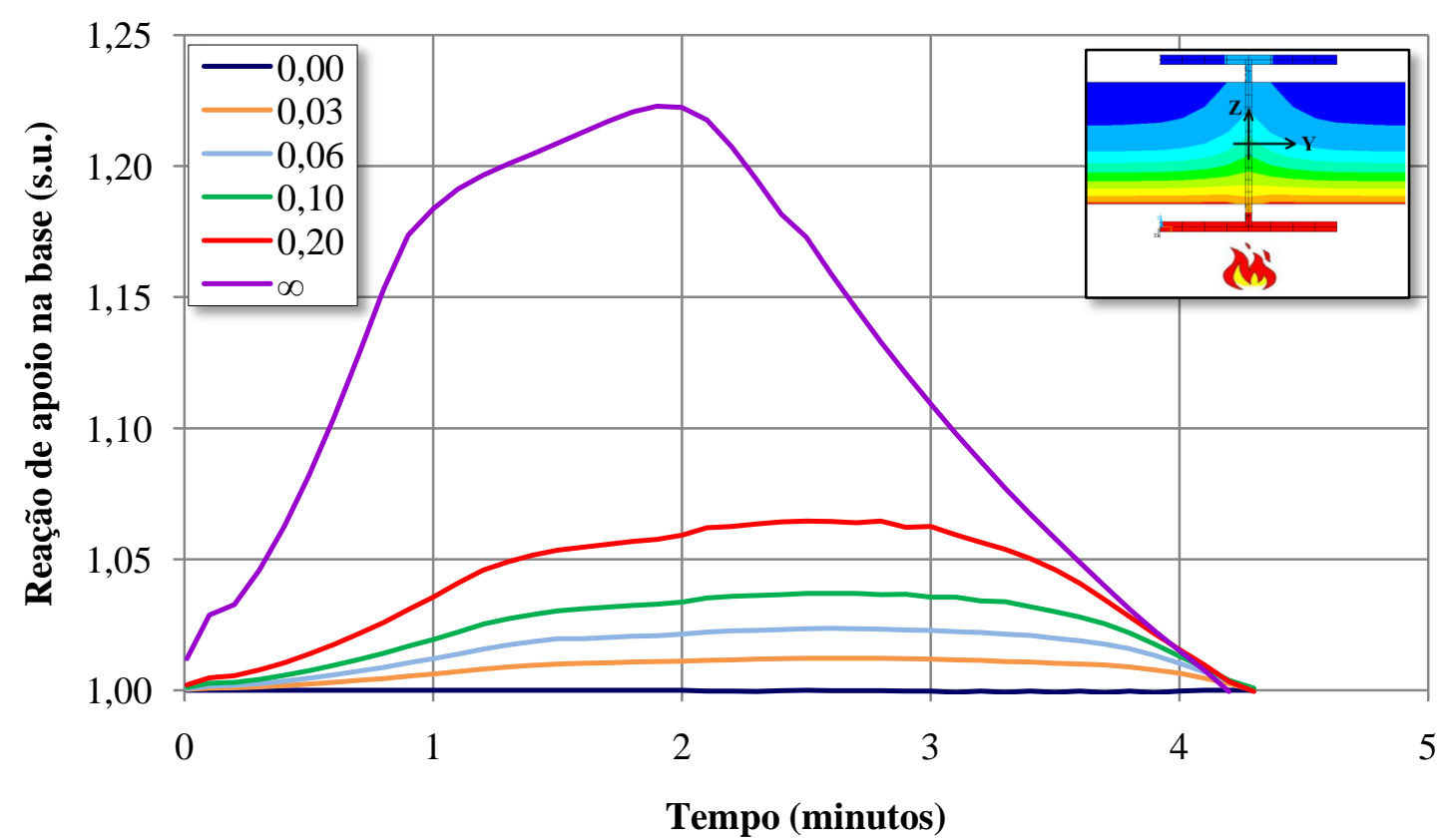

Figura F.1 - Carregamento total aplicado para diversos níveis de restrição axial e carga estática inicial de $75 \%$ da carga de colapso em temperatura ambiente vão do modelo com parede na alma e com restrição axial. 


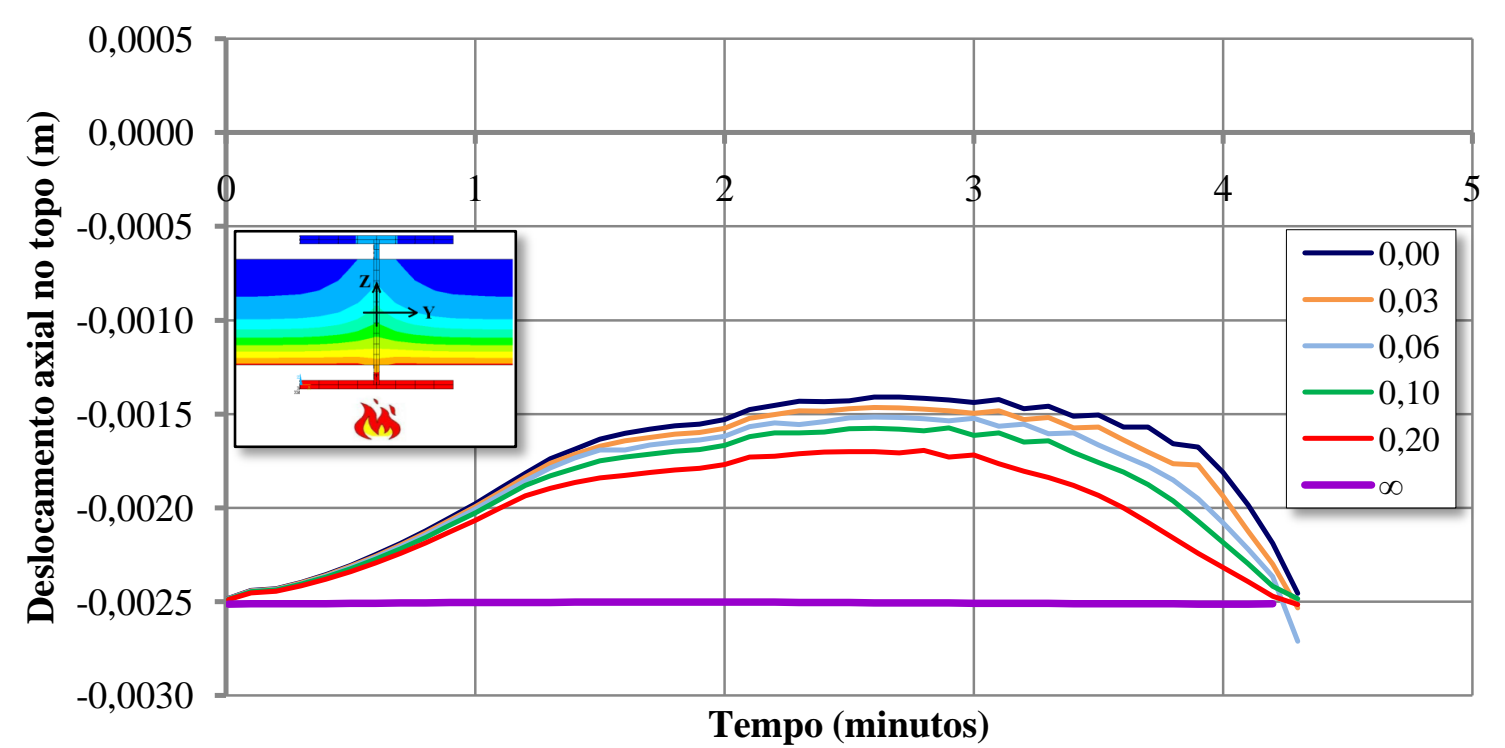

Figura F.2 - Deslocamento axial no topo do pilar para diversos níveis de restrição axial e carga estática inicial de $75 \%$ da carga de colapso em temperatura ambiente do modelo com parede na alma e com restrição axial.

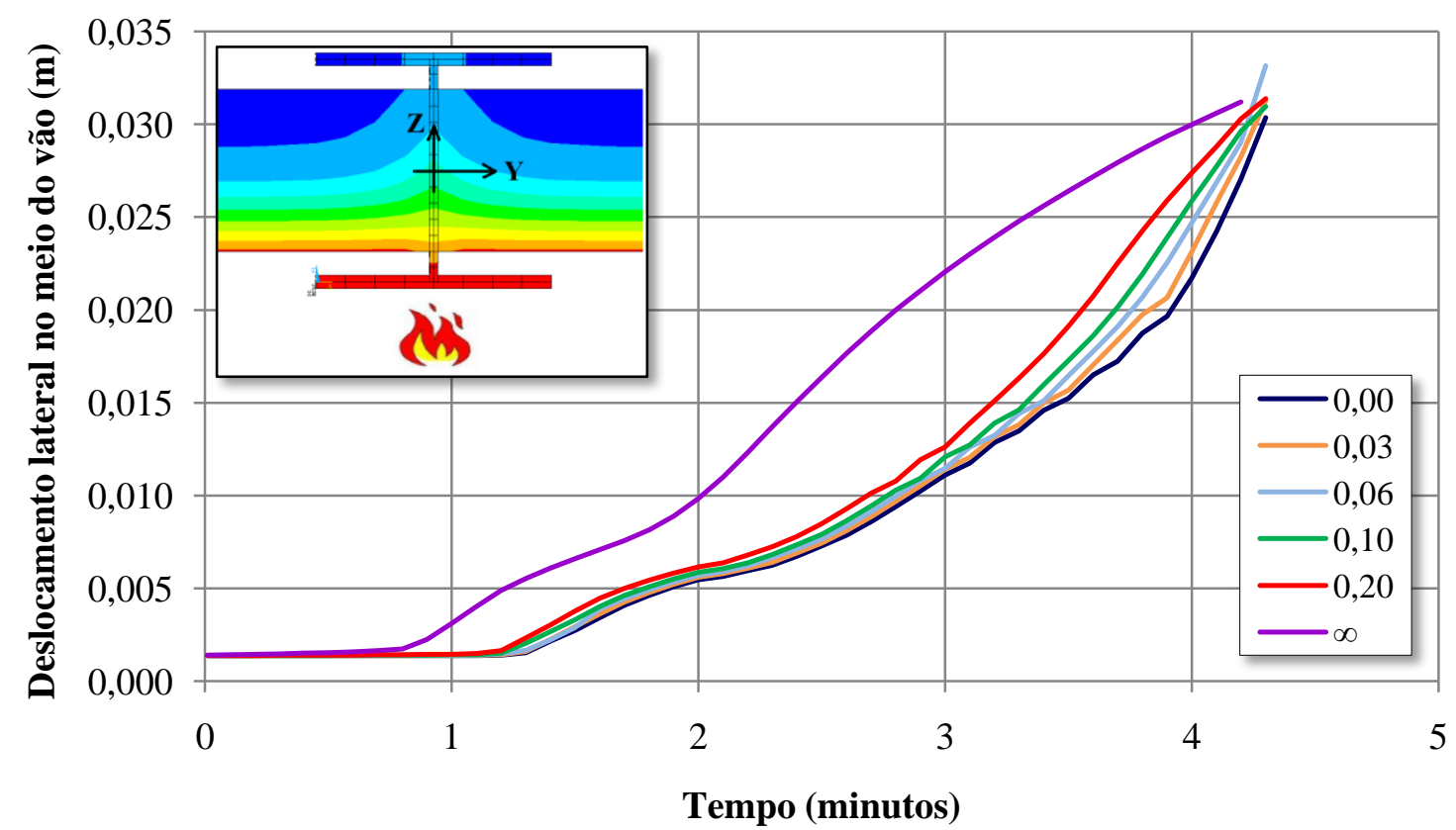

Figura F.3 - Deslocamento lateral no meio do vão na direção UY da imperfeição inicial para diversos níveis de restrição axial e carga estática inicial de $75 \%$ da carga de colapso em temperatura ambiente do modelo com parede na alma e com restrição axial. 


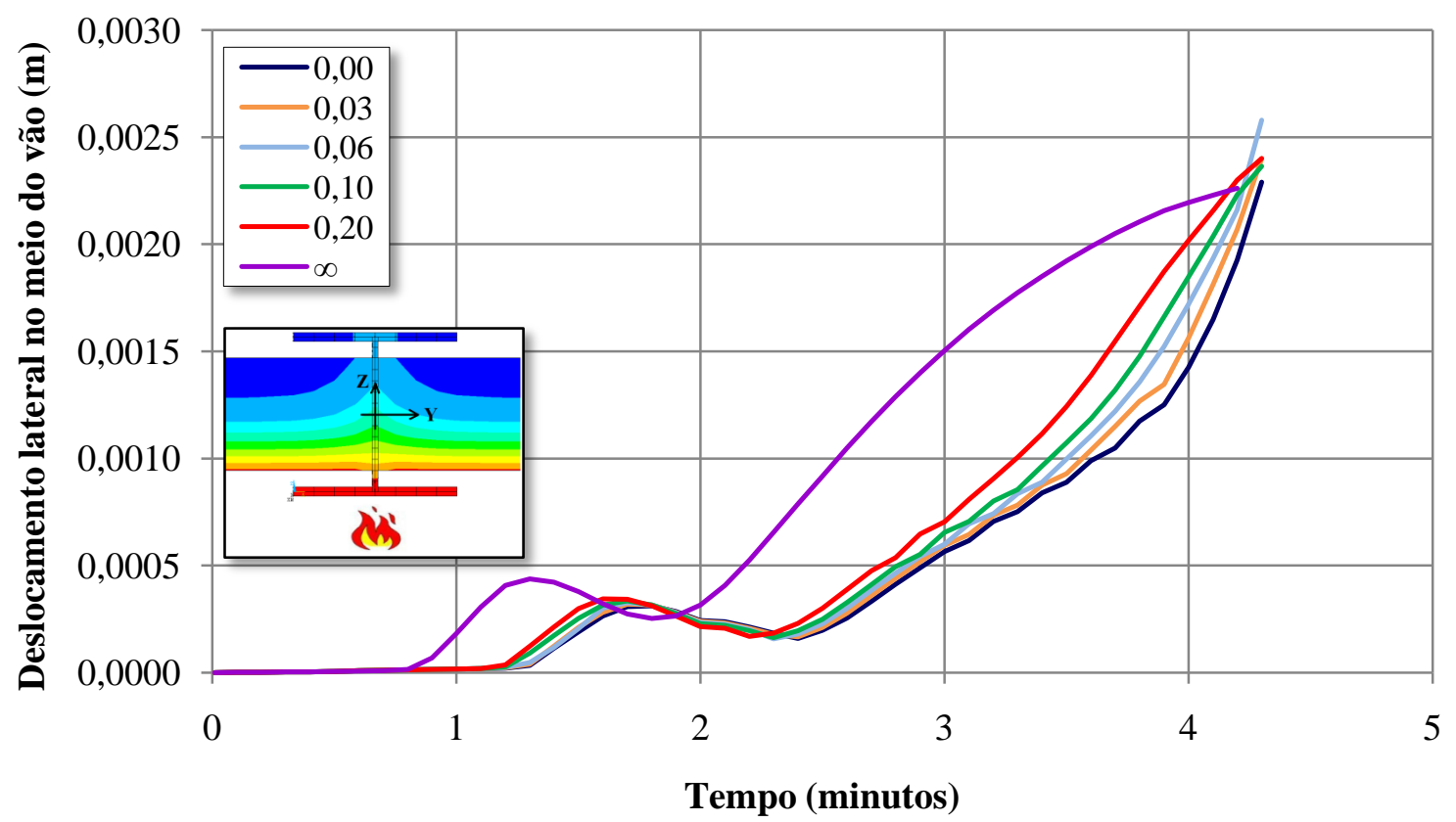

Figura F.4 - Deslocamento lateral no meio do vão na direção perpendicular UZ à imperfeição inicial para diversos níveis de restrição axial e carga estática inicial de $75 \%$ da carga de colapso em temperatura ambiente do modelo com parede na alma e com restrição axial.

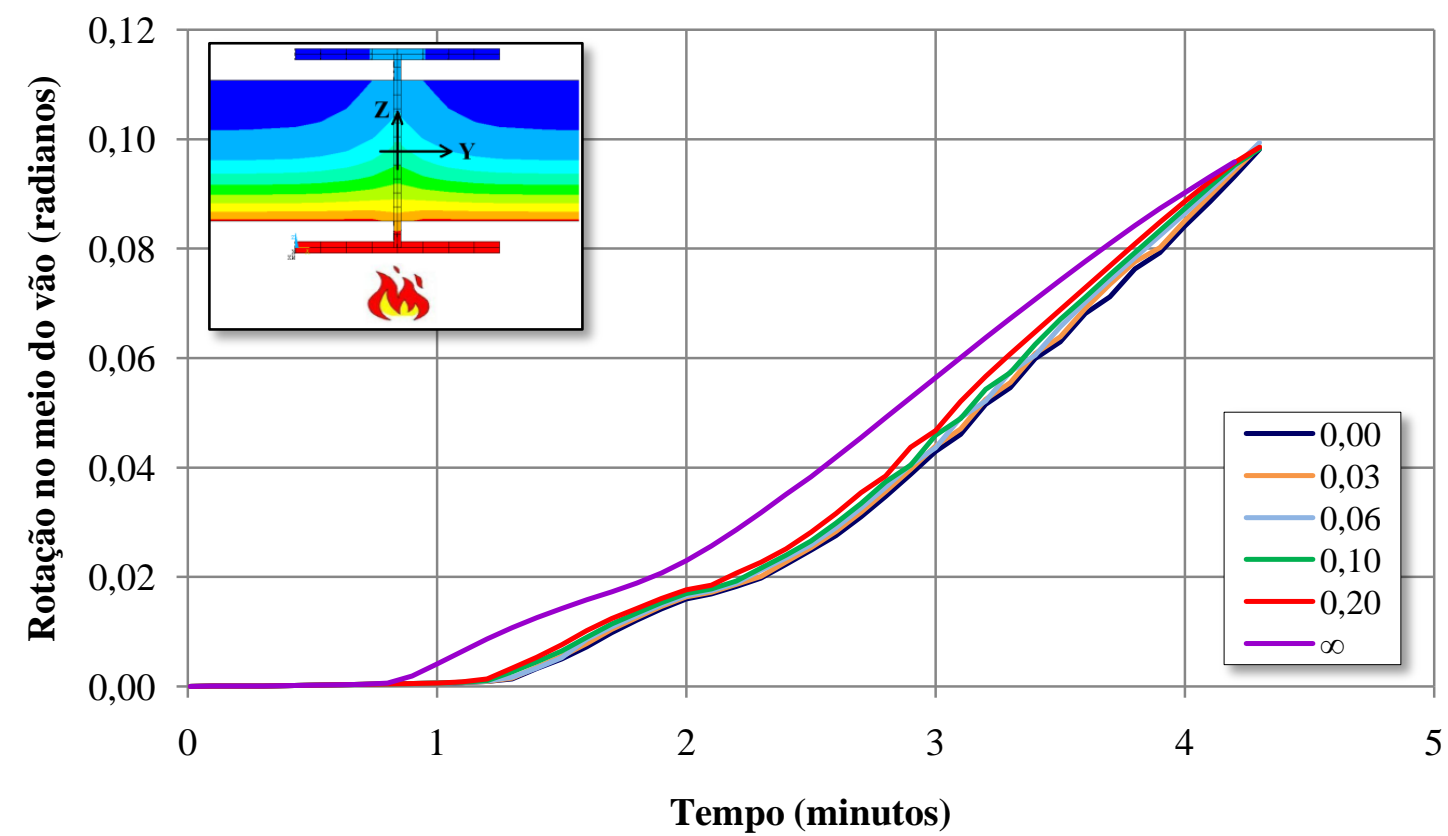

Figura F.5 - Rotação do eixo longitudinal no meio do vão para diversos níveis de restrição axial e carga estática inicial de $75 \%$ da carga de colapso em temperatura ambiente do modelo com parede na alma e com restrição axial. 


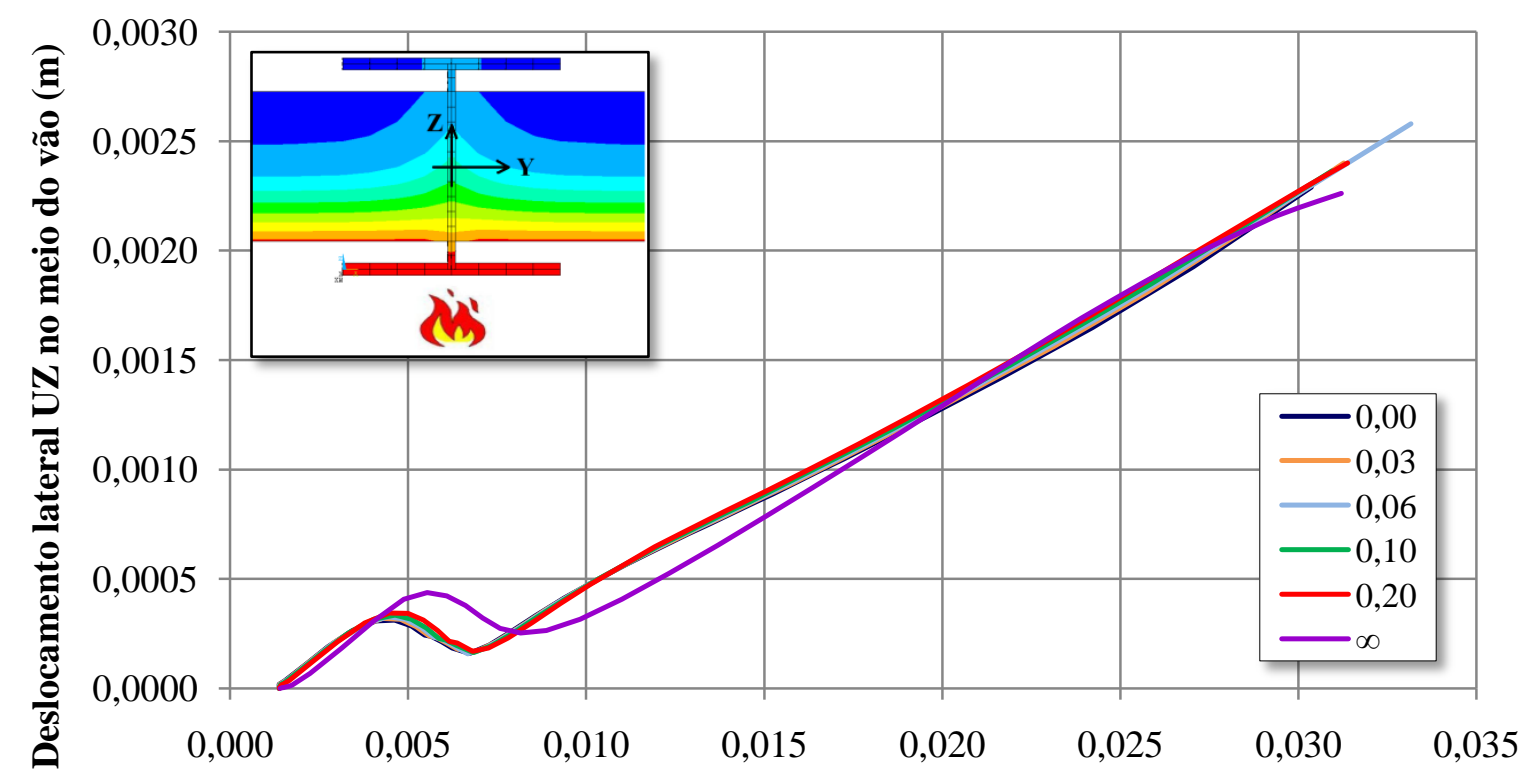

Deslocamento lateral UY no meio do vão (m)

Figura F.6 - Deslocamento nas direções Y e Z do plano da seção para diversos níveis de restrição axial e carga estática inicial de $75 \%$ da carga de colapso em temperatura ambiente do modelo com parede na alma e com restrição axial. 